Beiträge zur Technikgeschichte Band 2 Studies in the History of Technology Vol. 2

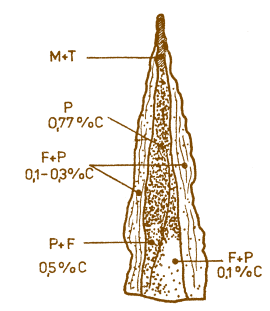

Alex R. Furger

\title{
Antike Stahlerzeugung
}

Ein Nachweis der Aufkohlung von Eisen aus Augusta Raurica
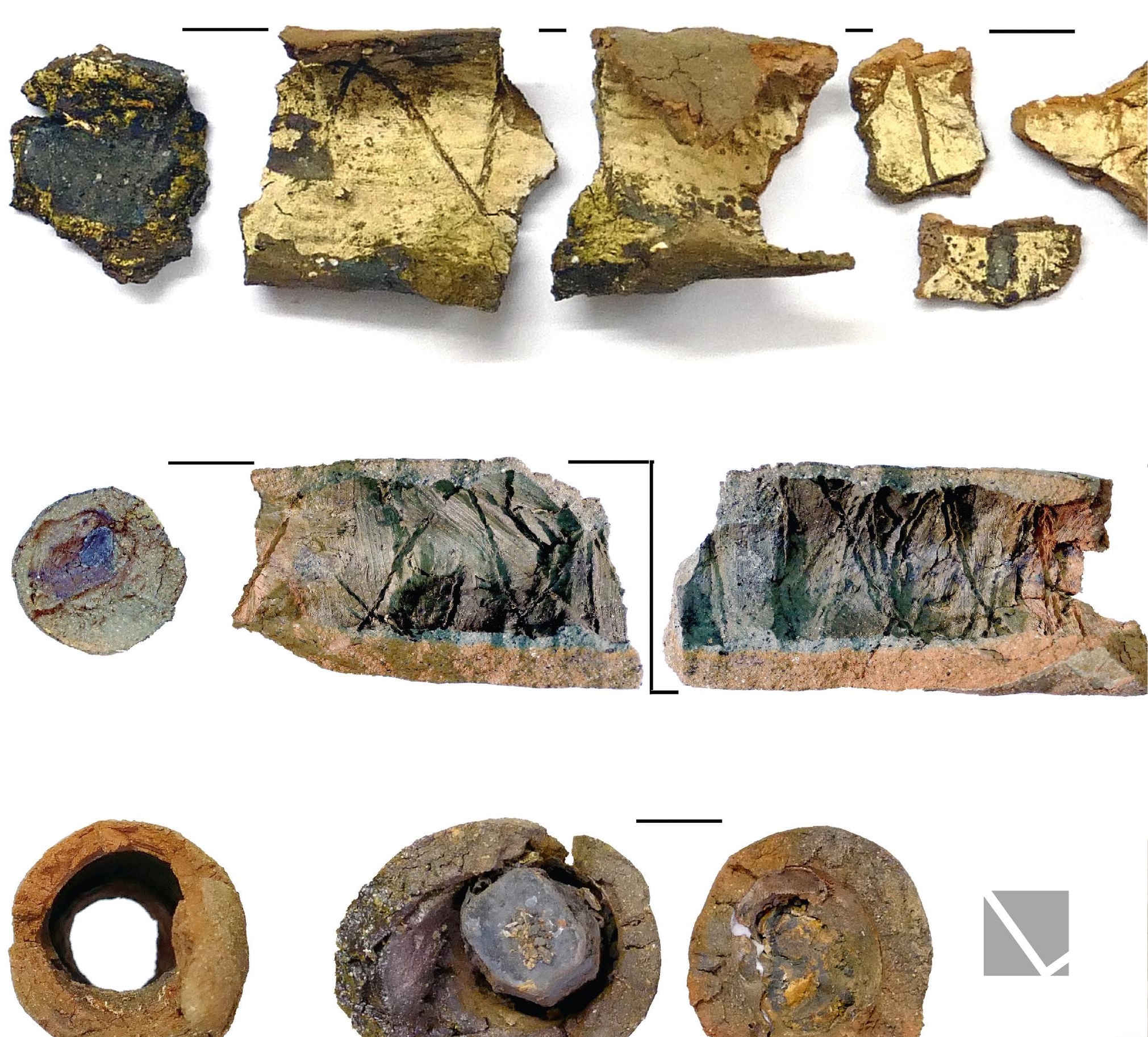
Alex R. Furger Antike Stahlerzeugung 
Herausgegeben von der Dr.h.c. Alfred Mutz-Stiftung

für alte, insbesondere antike Technologie und Technikgeschichte, Basel 
Alex R. Furger

\section{Antike Stahlerzeugung}

Ein Nachweis der Aufkohlung von Eisen aus Augusta Raurica

Ancient steelmaking. New evidence regarding the carburization of iron in Roman time Augusta Raurica (English summary: see p. 161 f.) 
(C) 2019, Alex R. Furger und LIBRUM Publishers \& Editors LLC | Basel | Frankfurt a. M. Gedruckt mit der Unterstützung der Berta Hess-Cohn Stiftung Basel.

Diese Publikation wurde auch gefördert durch:

\section{BASEL \\ LANDSCHAFT TI SWTSSLOS \\ SWIISSLOS \\ Kanton Aargau}

PRo Augusta RAurica

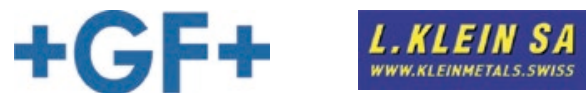

Dr. h. c. Alfred Mutz-Stiftung für alte, insbesondere antike Technologie

und Technikgeschichte, Basel

Peer-Reviewer: Albin Stücheli (Eisen-Metallurgie und -technologie),

Christoph Schneider (Antike Autoren und Quellen), Markus Helfert (Lehmstrukturen und pXRF-Analytik), Markus Peter (Numsimatik)

Deutsches Lektorat: Rainer Vollmar und Henrik Halbleib, Frankfurt a. M.

Englische Übersetzung «Summary»: Urs Werner und Richard Williams

Gestaltung und Satz: Katja von Ruville, Frankfurt a. M.

Druck: Memminger MedienCentrum, Memmingen

ISBN: 978-3-906897-28-8

DOI: $10.19218 / 3906897288$

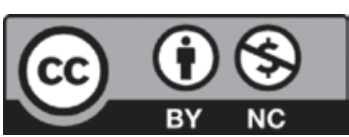

Alex R. Furger is licensed under a Creative Commons Attribution-NonCommercial 4.0 International License.

www.creativecommons.org

Open-access bei

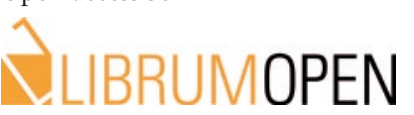

www.librumopen.com

Umschlagbild: Experimentelle Rekonstruktion der Eisen-Aufkohlung durch Umwickeln mit organischem Material und Umhüllung in Lehmmantel (Originale: S. 88 ff. Abb. 50): Aufgebrochene Umhüllungen nach dem Experiment (S. 115 ff. Abb. 77, Ausschnitt). Umschlagrückseite: Ausschnitte aus den Abbildungen 50, 71 und 115.

Stichwörter: Aufkohlung, Augusta Raurica, Einsatzhärtung (case- / box-hardening), Eisen, Eisenbarren, Experimentelle Archäologie, ferrum Noricum, Härten, Kohlenstoff, Lehme, organische Materialien, Pulad, Rennfeuer / Rennofen, Schmieden, Stahl, Tiegelstahl, Wootz, Zementation 


\section{Inhalt}

Einleitung: Stahlsorten und Überlieferung 11

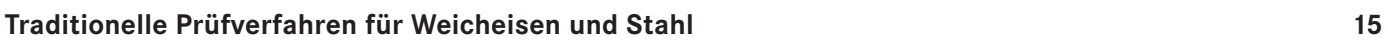

Korrosionsanfälligkeit $\quad 18$

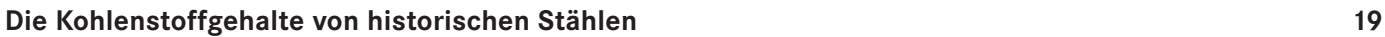

Wie machte man aus weichem Eisen härtbaren Stahl? 21

Kalthämmern $\quad 21$

Einsatzhärtung / Aufkohlung / Zementation $\quad 21$

«Rostverfahren» nach Diodor?

$\begin{array}{ll}\text { Direkte Stahlgewinnung im Eisenverhüttungsverfahren } & 24\end{array}$

$\begin{array}{lr}\text { Indirekte Stahlgewinnung durch Aufkohlungsprozesse } & 28\end{array}$

Aufkohlung im Herdfeuer $\quad 28$

$\begin{array}{ll}\text { Einsatzhärtung (Zementation) } & 28\end{array}$

Wirkungsweise und Glühdauer $\quad 28$

$\begin{array}{ll}\text { Historische Quellen } & 30\end{array}$

Archäologische Quellen 30

Von der Antike bis in die Neuzeit $\quad 34$

Frühe Zementationsindustrie $\quad 35$

Stahl bei Plinius dem Älteren (naturalis historia) 38

Frühe Spuren der Stahlerzeugung in Asien und Europa

Tiegelstahl, Wootz und andere frühe Prozesse in Asien $\quad 39$

Geschichte und Verfahren $\quad 39$

Die Tiegel 43

Das ferrum Noricum, ein Hightech-Stahl aus dem Rennofen $\quad 44$

Autoren 44

Inschriften $\quad 46$

$\begin{array}{ll}\text { Metalla-Münzprägungen } & 47\end{array}$

$\begin{array}{ll}\text { Archäologische Quellen } & 48\end{array}$

Frühe Stahlerzeugung im wikingischen Norden Europas $\quad 51$

Ethnologische Beispiele von Stahlerzeugung $\quad 54$

Ostafrika $\quad 54$

Westafrika $\quad 54$

Nepal $\quad 55$

Historische Anleitungen zur Stahlerzeugung in Lehmumhüllungen und Tiegeln 56

$\begin{array}{ll}\text { Indien } & 56\end{array}$

Theophilus Presbyter, um 1125

Johannes Kunckel, $1732 \quad 57$

Johann Andreas Cramer, 1746/1766 57

William Wallis Woodward, $1775 \quad 57$

Louis Bernard Guyton de Morveau, 1785

Johann Amos Comenius, $1832 \quad 58$

Eugène Julia de Fontenelle, 1832 
Eisenbarren sind oft Halbfabrikate $\quad 62$

Vom Rennofenprodukt zum Stahl 62

Übersicht

$\begin{array}{ll}\text { Handel mit Eisenbarren } & 67\end{array}$

$\begin{array}{lr}\text { Halbfabrikate } & 68\end{array}$

$\begin{array}{ll}\text { Doppelpyramidenförmige Spitzbarren } & 68\end{array}$

$\begin{array}{ll}\text { Archäometrie } & 69\end{array}$

$\begin{array}{ll}\text { Herstellung } & 71\end{array}$

$\begin{array}{ll}\text { Grösse und Datierung } & 71\end{array}$

$\begin{array}{ll}\text { Verbreitung } & 73\end{array}$

Flachbarren mit tüllenartigem Ende («currency bars») $\quad 74$

$\begin{array}{ll}\text { Archäometrie } & 75\end{array}$

$\begin{array}{ll}\text { Herstellung } & 76\end{array}$

$\begin{array}{ll}\text { Grösse und Datierung } & 76\end{array}$

$\begin{array}{ll}\text { Verbreitung } & 78\end{array}$

$\begin{array}{ll}\text { Stabbarren } & 78\end{array}$

$\begin{array}{ll}\text { Archäometrie } & 79\end{array}$

Grösse und Datierung $\quad 80$

Verbreitung $\quad 81$

Römische Eisenbarren $\quad 81$

Grösse und Datierung $\quad 81$

Verbreitung $\quad 81$

$\begin{array}{ll}\text { Gestempelte römische Barren } & 81\end{array}$

Frühmittelalterliche Eisenbarren $\quad 85$

$\begin{array}{ll}\text { Spatelförmige Barren («spade-shaped bars») } \quad 85 & 85\end{array}$

Dünne Stabbarren («rod-shaped bars») $\quad 85$

Sensenförmige Barren («scythe-shaped bars») 85

Axtförmige Barren («axe-shaped bars», «socketed bars») 86

«Mästermyr-Barren» $\quad 86$

Chronologie und Qualität $\quad 86$

Eine chronologisch bedingte Barrenentwicklung? 86

«Form follows quality»? $\quad 86$

Die Lehmumhüllungen aus Augusta Raurica $\quad \mathbf{8 8}$

Beschreibung $\quad 88$

$\begin{array}{ll}\text { Katalog } & 94\end{array}$

Datierung $\quad 97$

Verbreitung im Stadtareal und Befundkontext $\quad 97$

Katalognummer 4 (und evtl. 2.3) 99

Katalognummer $7 \quad 99$

$\begin{array}{lr}\text { Katalognummern 10-25 } & 99\end{array}$

Oberflächen-Röntgenfluoreszenzanalysen (pXRF) 99

Relevante Spuren im Innern der Lehmumhüllungen 99

$\begin{array}{lr}\text { Herkunft des Lehms } & 108\end{array}$

Beurteilung der Keramikstruktur $\quad 108$

$\begin{array}{ll}\text { Natürliche Magerung } & 108\end{array}$

Lehm der römischen Originale 108

Lehm der Rekonstruktionen 109 
Kohlenstoffträger: meist organische, kohlenstoffhaltige Auflagen $\quad 112$

Antike Herde und Öfen zur Aufkohlung?

Experimenteller Nachvollzug der Eisen-Aufkohlung im Lehmmantel

Ausgangsmaterial: kohlenstoffarmes «Weicheisen» 116

Die verwendeten Kohlenstoffträger $\quad 119$

Die Lehmumhüllungen $\quad 119$

Der experimentelle Prozess

der Aufkohlung im Brand $\quad 122$

$\begin{array}{lr}\text { Experiment-Konzeption } & 122\end{array}$

$\begin{array}{ll}\text { Feuerung } & 123\end{array}$

Dauer des Zementationsbrandes $\quad 123$

Die Lehmumhüllungen beim Aufschlagen $\quad 124$

$\begin{array}{ll}\text { Rissbildung durch ungeeignete Lehmmischung } & 124\end{array}$

Ergebnis des Brandes, Veränderungen und Rückstände 124

$\begin{array}{ll}\text { Abdrücke im Innern } & 126\end{array}$

Die Eisenbarren nach dem Brand $\quad 128$

$\begin{array}{ll}\text { Korrektur der Lehmrezeptur } & 130\end{array}$

Probenaufbereitung für die Analysen $\quad 130$

Aufkohlungsbefund im Mikroskop $\quad 134$

Kohlenstoffanalysen der Experimentierbarren 135

Schwefelanalysen der Experimentierbarren $\quad 135$

Mangan- und weitere Analysen der Experimentierbarren $\quad 143$

$\begin{array}{ll}\text { Methodik } & 143\end{array}$

Begleitelemente des Aufkohlungsprozesses $\quad 143$

$\begin{array}{ll}\text { Methodenvergleich Schwefelanalysen } & 143\end{array}$

Unterschiede in den drei verwendeten Weicheisenqualitäten 146

Härtemessungen an den Experimentierbarren $\quad 146$

$\begin{array}{ll}\text { Methodik } & 146\end{array}$

Die Härten des unbehandelten Experimentier-Rohmaterials 146

Die Härten des geglühten und abgeschreckten Experimentier-Rohmaterials $\quad 147$

Vergleichende Härtemessungen 147

Härtemessungen an experimentell hergestelltem «Römerstahl» 148

$\begin{array}{ll}\text { Fazit der Aufkohlungsexperimente } & 148\end{array}$

"Experiment Theophilus» $\quad 153$

$\begin{array}{lr}\text { Aufkohlung in Tiegeln } & 154\end{array}$

$\begin{array}{ll}\text { Experiment } & 154\end{array}$

Durchführung 154

Ergebnisse 154

Im Tiegel aufgekohlte römische Schuhnägel? $\quad 157$

Fazit zur antiken Stahlerzeugung und Zusammenfassung $\quad 159$

$\begin{array}{ll}\text { Conclusions to antique steelmaking, and summary } & 161\end{array}$

Glossar $\quad 163$

Quelleneditionen und Übersetzungen $\quad 164$

$\begin{array}{ll}\text { Literatur } & 165\end{array}$

$\begin{array}{ll}\text { Abbildungsnachweis } & 175\end{array}$ 



\section{Vorwort und Dank}

Die vorliegende Studie ist gewissermassen als «Nebenprodukt» des ersten Bandes dieser Reihe - «Antike Schmelztiegel. Archäologie und Archäometrie der Funde aus Augusta Raurica»- entstanden. Als ich nämlich in den Funddepots des Museums Augusta Raurica die fast 900 Schmelztiegel und deren Fragmente heraussuchte, fielen mir mehrere Dutzend Bruchstücke aus gebranntem Ton auf, die sicher keine Gebrauchskeramik und offensichtlich auch keine Tiegelkeramik darstellen. Sie sind alle oxidierend gebrannt, handgeformt und weisen innen Abdrücke von runden bis mehrkantigen, stangenförmigen Objekten auf, um die herum der Lehm geformt worden ist (Abb. 50). Die Innenflächen zeigen entweder einen «verkrusteten» rostfarbenen Belag oder sie sind im Boden wieder orange tongrundig geworden (Abb. 51, unten).

Um zu klären, ob auch diese Fragmente mit der Metallverarbeitung zu tun haben könnten, haben wir ihre Oberflächen mit der pXRF (transportables RöntgenfluoreszenzAnalysegerät) analysiert. Dass die Innenseiten manchmal tendenziell höhere Werte für Eisen ergaben als die Aussenseiten, brachte Markus Helfert zur Feststellung, «in diesen Lehmumhüllungen könnte Eisen behandelt worden sein, vermutlich bei Hitze, die auch den Lehm gebrannt hat». Spontan fielen mir alte Rezepte in der mittelalterlichen und frühneuzeitlichen Handwerksliteratur ein, wo die Herstellung von Stahl durch oberflächliches Aufkohlen unter Luftabschluss beschrieben wurde. Damit stand die Frage im Raum, ob sich eine bereits im 1.Jahrhundert n. Chr. betriebene römische Stahlproduktion anhand dieser Lehmumhüllungs-Bruchstücke nachweisen liesse. Während der Vorbereitungen zu diesem Band ist es einerseits gelungen, den Augster Funden entsprechende archäologische Zeugnisse aus dem wikingischen Norden beizusteuern, und anderseits haben unsere experimentalarchäologischen Rekonstruktionen und deren anschliessende Laboranalysen gezeigt, dass die rekonstruierten Eisenbarren durchaus aufgestählt sein können und analoge Abfallprodukte wie die römischen Fundobjekte (Fragmente von gebrannten Lehmumhüllungen) hinterlassen. Dies ist zwar kein abschliessender Beweis, zeigt aber immerhin die Machbarkeit des Prozesses mit den Endprodukten Stahl und gebrannte Lehmumhüllungen.

Dass dieser Prozess der Aufkohlung von weichem Eisen zu härtbarem Stahl nicht die einzige antike Technologie der Stahlerzeugung war, zeigt der erste Teil dieses Buches. Er gibt einen Überblick über die Geschichte der Stahlproduktion und deren vielfältige Produktionsmöglichkeiten, Qualitäten, Herstellungsgebiete und Prüfverfahren sowie der so erzielbaren unterschiedlichen Kohlenstoffgehalte.
Wieder einmal hat sich gezeigt, dass bei solchen handwerklichen Themen die interdisziplinäre Zusammenarbeit enorm fruchtbar ist. Der Historiker Guillaume Renoux forderte einerseits «la collaboration étroite entre historiens, archéologues, philologues et métallurgistes pour éviter toute erreur d'interprétation» ${ }^{1}$, und anderseits kann ich ergänzen, dass Chemiker, Handwerker und Experimentalarchäologen ebenfalls zum gemeinsamen Erkenntnisgewinn beitragen.

Mit der vorliegenden Schrift ist kein Fachbuch primär für Althistoriker oder Metallurgen entstanden. Als interdisziplinär arbeitender Archäologe kann ich nicht in allen Disziplinen kompetent sein und war daher auf spezialisierte Gutachter angewiesen (s. unten). Meine Absicht war jedoch, eine für alle verständliche Geschichte der Stahlerzeugung zu schreiben, in der die unterschiedlichsten Erkenntnisse aus Geschichtsschreibung, Archäologie, Metallurgie, Archäometrie und Experimenten gleichberechtigt zum Zuge kommen.

In diesem interdisziplinären Sinne hat der Autor mehreren Personen und Institutionen zu danken, ohne die diese Studie nicht realisierbar gewesen wäre. Im Laufe des Projektes und in folgender Reihenfolge haben mich in verdankenswerter Weise unterstützt:

- Der Kunstschmied Bernard Pivot, Basel, in dessen Werkstatt ich die Barren aus Weicheisen schmieden durfte (Abb. 61).

- Der Keramikspezialist Markus Helfert, Universität Frankfurt a. M., hat die Fragmente der römischen Tonumhüllungen aus Augusta Raurica (Augst/BL) sowie die Experimentierbarren analysiert und konnte die Tonherkunft (Abb. 50 und 51) und Spurenelemente im Eisen bestimmen (Tabelle 8). Er besorgte auch das kritische Gegenlesen der betreffenden Kapitel.

- Der Keramikspezialist Hannes Weiss, Aeugst/ZH, in dessen «römischer» Ofenrekonstruktion wir den langen Zementationsbrand zur Aufkohlung von Eisenbarren durchgeführt haben (Abb. 73).

- Der Chemiker Rudolf Kubiz von der Abteilung Metallographie \& Formstofflabor der Georg Fischer AG in Schaffhausen, der den Autor bei der Probenvorbereitung angeleitet und die Kohlenstoff- und Vickers-Härtemessungen durchgeführt hat (Abb. 111 und 112). 
- Der Giessereitechniker Dirk Lindemann, heute Leiter der Business Unit Eisenguss Europa in der Georg Fischer AG in Schaffhausen, hat diese Laboranalysen als Sponsoring des Unternehmens bewilligt.

- Die Kollegin Christine Pümpin von der Forschungsgruppe «Integrative Prähistorische und Naturwissenschaftliche Archäologie» (IPNA) der Universität Basel, die mich bei den Mikroskopaufnahmen der Anschliffe der aufgekohlten Barren-Rekonstruktionen angeleitet hat (Abb. 62-120).

- Der Kollege Christoph Schneider, Universität Basel, der die Abschnitte über antike Schriftquellen im Manuskript lektoriert und viele Anregungen eingebracht hat.

- Der Numismatiker Markus Peter, Römerstadt Augusta Raurica, mit der kritischen Manuskriptdurchsicht und Literaturangaben zum Abschnitt über die «Bergwerksprägungen» mit der Inschrift «MET(alla)|NOR(ica)».

- Der Chemiker und Werkstofftechniker Albin Stücheli, Hochschule Luzern, als Peer-Reviewer aller metallurgischen Kapitel.

- Die Metallurgen Urs Werner und Richard Williams haben die Zusammenfassung übersetzt (Summary S. $161 \mathrm{f}$.) und waren mir kompetente Diskussionspartner.

- Die Stiftungsratsmitglieder Peter-A.Schwarz (Präsident) und Christoph Schneider der «Dr. h. c. Alfred MutzStiftung für alte, insbesondere antike Technologie und Technikgeschichte», nahmen diesen Band in die Schriftenreihe «Beiträge zur Technikgeschichte» auf und unterstützten dessen Finanzierung und Produktion.

- Die Buchgestalterin Katja von Ruville, Frankfurt a. M., besorgte «gewohnt gekonnt» das Layout und den Satz.

- Den Korrektoren Rainer Vollmar und Henrik Halbleib, Frankfurt a. M., verdanke ich eine erhebliche Minimierung von Druckfehlern.

- Der Verleger Dominique Oppler des Hauses LIBRUM Publishers \& Editors in Basel schliesslich hat mit grossem Engagement die Sponsorensuche betreut, den Autor in jeder Hinsicht unterstützt und die perfekte Drucklegung verantwortet.

Bei den Recherchen und Experimenten haben die folgenden Personen mit Tipps, Ratschlägen, Materiallieferungen, Literaturangaben, Zeichnungen und experimenteller Hilfe den Autor unterstützt, denen ich ebenfalls danken möchte: Sandra Ammann (Römerstadt Augusta Raurica), Markus Binggeli (Archäotechniker, Bern), Michelle Comber (National University of Ireland, Galway / IRL), Peter Crew (Experimentalarchäologe und Schmied, Gwynedd/UK), Ludwig Eschenlohr (Porrentruy/JU), Sylvia Fünfschilling (Römerstadt Augusta Raurica, Fundkomplexdatierungen), Guntram Gassmann (Landesamt für Denkmalpflege Stuttgart/D), Franz Glaser (Landesmuseum Kärnten, Klagen-
furt/A), Paul Gleirscher (Landesmuseum für Kärnten in Klagenfurt/A, Literaturhinweise), Christoph Hinker (Österreichisches Archäologisches Institut in Wien, Literaturhinweise), Hansjörg Kilchenmann (Messerschmied, Basel), Manfred Lehner (Institut für Archäologie, Graz / A), Anders Lindahl (Department of Geology, Lund/S, SchwedischÜbersetzungshilfe), François Morier (Schmied und Experimentator, Daillens/VD), Thomy Niklaus (Schreiner, Basel), Felicitas Prescher (Zeichnerin, Basel), Christian Rico (Université Toulouse II/F), François Schluraff (Metzgerei Kuhn, Basel), Marianne Senn (Archäometerin, EMPA, Dübendorf/ZH), David Sim (Experimentalarchäologe und Schmied, University of Reading / GB), Marquita Volken (Archäologin und Schuh-Spezialistin) und Irène Vonderwahl Arnaiz (Spanischübersetzung).

Schliesslich ist es den im Impressum auf Seite 4 aufgeführten Stiftungen und Sponsoren zu verdanken, dass die Produktionskosten der Drucklegung gedeckt werden konnten. 


\section{Einleitung: Stahlsorten und Überlieferung}

«Steel-making is a highly intricate art with many steps and calling for a great deal of accuracy in the control of temperatures and mastery of quenching.»

(Congdon 1971, 27)

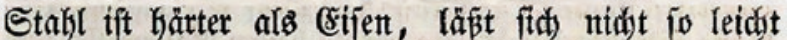 it anbere Formen bringen, als biefes; fein vorzüglid

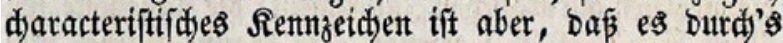

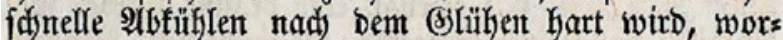 ïber wir an eintem andern Drte ausf füfrliduer reben werden. IIngebärteter Stabl werbält fth wie bas härtefte Stabeifen und mū zugleid einen hohen (Srab son 3ähigfeit beftben; gebärteter Stahl mun aber eine foldje Särte antekmen, Daf́ er yon Der beften Feíle nidjt angegriffen wirb und Slas fdneibet.}

(Hartmann 1848, 15²)

Wenn bei antiken Autoren von «Eisen bester Qualität» die Rede ist, ist in der Regel Stahl gemeint, der durch seinen erhöhten Kohlenstoffgehalt härtbar ist und daher für das Schmieden von Werkzeugen und Waffen bevorzugt wird $\left(\right.$ Abb. 1) ${ }^{3}$. Bester Stahl in der Antike wurde immer wieder mit glänzender Rüstung und unzerbrechlichem Schwert gleichgesetzt. So spricht etwa Plutarch um 100 n. Chr. von den verfeindeten Truppen im Kampf gegen die erstaunten Römer, dass die aus «marianischem Stahl verfertigten Helme und Panzer [der Parther] ... einen blendenden Schimmer von sich [gaben]» ${ }^{4}$.

Dass Eisen unter gewissen Umständen besonders hart zu machen ist, war lange Zeit eine rein empirische Erkenntnis, denn die Handwerker der Antike kannten den eigentlichen Grund des Unterschieds zwischen Eisen und Stahl nicht ${ }^{5}$, aber «it now seems clear that steel was being made intentionally ...» ${ }^{6}$. Sogar noch 1760 lieferte Johann Georg Friedrich Klein in seinem Buch über die Löttechnik eine recht nebulöse Beschreibung7: «Der Stahl ist nichts anders als ein recht compactes, festes und hartes, dabey aber schmiedbares Eisen, das weniger erdigte, und mehr metallische Theile, als das gemeine Eisen hat». Dass man auch ein Vierteljahrhundert später noch im Dunkeln tappte, mag uns heute amüsieren: «Aus den ... Versuchen über die Eigenschaften des Stahles folgt überhaupt, dass er nur eine Abart des Eisens sey, die ihren Grund in einem etwas veränderten Verhältnisse der Bestandteile haben muss ...»8 (zur späten Erkenntnis des Kohlenstoffanteils s. unten mit Anm. 85).

In der Metallurgie wird heute praktisch jedes Eisen als Stahl - also als Eisenlegierung - bezeichnet $^{9}$, da kaum mehr Reineisen benutzt wird (s. unten S. 19). Ich halte mich jedoch an die traditionellen, nicht streng naturwissen-

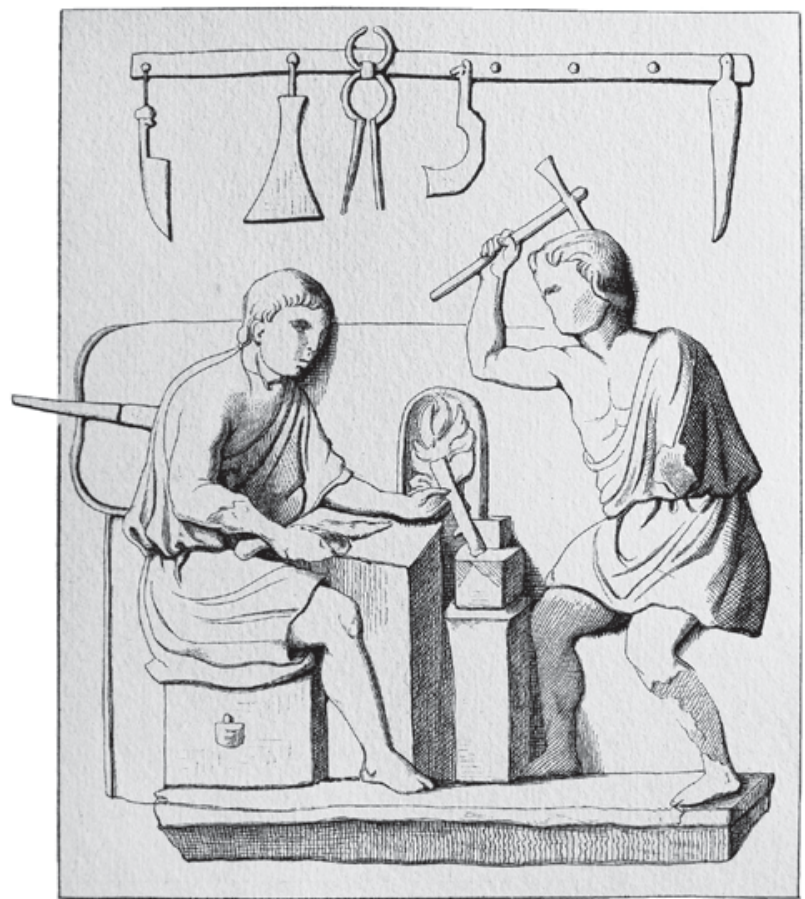

Abb. 1: Römische Schmiedeszene auf einem Marmorrelief in den Vatikanischen Museen. Es stammt von der linken Seite des Grabsteins des Messerschmieds Lucius Cornelius Atimetus. Die oben aufgehängten und auf den anderen Reliefs desselben Steines dargestellten fertigen Geräte sind vor allem Messer, aber auch Körperschaber, Wachsspatel usw. Die beiden Schmiede wussten daher sicher auch den harten Stahl zu verarbeiten und nicht nur «weiches» Schmiedeisen. 2. Hälfte 1. Jahrhundert n. Chr. Höhe des Grabaltars $133 \mathrm{~cm}$.

2 Ein halbes Jahrhundert später definiert Fridolin Reiser (1896, 1) Stahl bereits viel nüchterner: «Eisen, welches schmiedbar und härtungsfähig ist, das heisst: welches, bis zu einer bestimmten Temperatur erhitzt und sodann plötzlich abgekühlt, härter wird, nennt man Stahl. Diese Eigenschaften sind hauptsächlich durch den Kohlenstoffgehalt des Eisens bedingt.»

3 Schon im 6.Jh. v. Chr. ist aus der Zeit des Nabonidus von Babylonien (556-539 v. Chr.) von unterschiedlich teuren Eisen-Qualitäten die Rede, wobei es sich bei der teuersten Sorte wohl um Stahl handelte (2,7-mal teurer als die billigste Sorte): Neumann/Wilsdorf 1954, 78f.; Needham 1980, 507-510 Abb. 14.1 (instruktive Prozessgrafik der verschiedenen Stahlgewinnungsverfahren). - Eine sehr informative Übersicht von Stählen unterschiedlicher Kohlenstoffgehalte (0,00-1,40\% C), ihrer Bearbeitbarkeit und ihrer technischen Anwendung im frühen 20.Jahrhundert bei: Oberhoffer 1920, 107. - Kurzer Überblick zur Geschichte des Stahls: Barraclough 1981, 19-21. - Auf die antike Verwendung von Meteoreisen wird hier nicht eingegangen (dazu etwa: Siegelová 1984, 159-163). Plut. Crassus 24.1; Papakhristou / Rehren 2001, 156.

5 Beck 1884, 507.

6 Lang 2017, 7.

7 Klein 1760, 11.

8 Georgi 1785A, 281.

9 Barraclough 1981, 1-7; Presslinger/Köstler 1991, 18 Abb. 1; Galik et al. 2003, 68 Anm. 146; Sperl 2004, 961. 
schaftlich definierten Begriffe, für die sowohl die antiken Schmiede als auch die heutigen Handwerker ihre unterschiedlichen Bezeichnungen haben ${ }^{10}$ :

- Schmiedeeisen (auch «Weicheisen», «Reineisen»),

- Stahl (kohlenstoffhaltig und noch schmiedbar) und

- Roheisen («Gusseisen», spröde und nicht schmiedbar).

Die Arbeitskette vom Erz zu Eisen, Stahl und fertigem Gerät mit der entsprechenden Arbeitsteilung an verschiedenen Orten fasste Diodor von Sizilien im 1.Jahrhundert v.Chr. treffend zusammen ${ }^{11}$ : «Die Insel [Elba/I] verfügt nämlich über eine Menge Eisenerz, das die Leute dort zum Ausschmelzen und zur Aufbereitung von Eisen zerschlagen, und solches Erz besitzen sie in Masse. Denn jene, die mit den Arbeiten beschäftigt sind, zertrümmern das Gestein und brennen die so geteilten Brocken in bestimmten kunstreich angelegten Öfen. In diesen schmelzen sie dann die Steine mit Hilfe eines grossen Feuers und formen sie schliesslich in Stücke von angemessener Grösse, die in ihrem Aussehen grossen Schwämmen gleichen. Kaufleute erwerben diese entweder für Geld oder im Tausch und schaffen sie nach Dikaiarcheia [Puteoli/I] oder anderen Handelsplätzen, wo Unternehmer die Ladungen kaufen, durch Metallhandwerker, über welche sie in grosser Zahl verfügen, bearbeiten lassen und so Eisengeräte aller Art herstellen. Einige von diesen Eisenstücken schmieden sie in die Form von Waffen, andere wieder werden geschickt so zugerichtet, dass sie sich gut für zweizinkige Gabeln, für Sicheln und andere Werkzeuge eignen. Kaufleute bringen sie dann überall hin, und so haben sämtliche Teile der bewohnten Erde Anteil an dem Nutzen, der von dort entspringt.» Von einer Veredelung des Rennfeuereisens in kohlenstoffhaltigen Stahl ist in dieser Quelle allerdings nicht die Rede. Aber wir erfahren durch sie immerhin einiges über den $\mathrm{Ar}$ beitsaufwand und die Arbeitsteilung. So etwa erfolgte das Ausschmieden frischer, noch mit viel Schlacke vermengter «Ofenschwämme» (Luppen) aus den Rennöfen auf Elba mit viel anstrengender Arbeit, für die in Puteoli offenbar spezialisierte Metallhandwerker beigezogen wurden.

Diesen Prozess vom Eisenerz über die langwierige Verhüttung und das arbeitsaufwendige «Ausheizen» zum schmiedbaren Eisen - aber noch nicht zum härtbaren Stahl - fasste ein Autorenkollektiv im Zusammenhang mit Eisenbarren-Halbfabrikaten aus römischen Schiffswracks bei Saintes-Maries-de-la-Mer / F eindrücklich zusammen ${ }^{12}$ : «Dans le cadre de la réduction directe, la transformation du métal se fait à l'état pâteux. Le métal ainsi produit est souvent très hétérogène. Il peut contenir de nombreux vides, mais aussi de nombreuses inclusions de scories et de charbons de bois. La mise en forme du demi-produit consiste alors, pour partie, à compacter et à épurer cette masse de métal brut. Quand le demi-produit est fabriqué à partir de l'assemblage de feuilles de métal, le problème persiste car le fer constituant chaque feuille n'est pas nécessairement 〈propre>. De plus, la réalisation de soudures est souvent accompagnée d'ajouts - barbotine d'argile, sable, grès pilé ou mélanges plus complexes - destinés à limiter la formation d'oxydes sur les surfaces à assembler et / ou à abaisser le palier de soudabilité. Ces ajouts peuvent polluer le métal au même titre qu'un mauvais assemblage qui laisse apparaitre des vides. Dans toutes ces situations, le soin accordé au compactage et à l'épuration détermine la propreté de l'alliage. Le taux de compactage et d'épuration constitue alors le critère de qualité subsidiaire à celui du type d'alliage ferreux.» (vgl. Abb. 32).

Dass solcherart erzeugtes «gewöhnliches» Eisen für Werkzeuge, Waffen und Bauteile in der römischen Antike sehr gerne verwendet wurde und aus Gründen von Materialhärte und Preis die Buntmetalle Bronze und Messing etwas zurückgedrängt hat, ist naheliegend. Angesichts der Tatsache, dass Eisen trotz des grossen Produktionsaufwandes immer noch etwa anderthalb- bis dreimal günstiger war als Bronze und Messing ${ }^{13}$, erscheint es etwas exotisch, dass Caesar im «Gallischen Krieg» von den Völkern Britanniens berichtet: «Als Geld verwenden sie Kupfer, Goldmünzen oder Eisenstäbchen (taleis ferreis) mit geeichtem Gewicht» ${ }^{14}$. Die Umschreibung mit «Stab» (talea) ist durchaus zutreffend, da stabförmige römische Eisenbarren sehr typisch für Britannien sind und daher heute - historisch nachvollziehbar, aber inhaltlich nicht zutreffend - als «currency bars» bezeichnet werden (s. unten mit Abb. 43) ${ }^{15}$.

Es scheint, dass in Indien und im östlichen Mittelmeerraum bereits ab dem 12. oder 11.Jahrhundert v. Chr. Stähle erzeugt und gehärtet worden sind ${ }^{16}$. In einer von König Tušratta an den ägyptischen Pharao Amenophis III. (14131375 v. Chr.) gerichteten Geschenkliste wird explizit zwischen Dolchen aus Stahl (habalkinu) und solchen aus normalem Eisen unterschieden ${ }^{17}$. Auch hethitische Werkstät-

10 Prechtl 1834, 11-13; Steinbrings 1928 (Schmiedeeisen 37-42, Stahl 42-69, Roheisen 36-37); Pleiner 2006, 18.

11 Diod. 5,13,1-2; Humphrey et al. 1998, 219; Schrüfer-Kolb 2004, 30. - Im Gegensatz zur literarischen Überlieferung (s. auch unten mit Anm.256) erbrachte die Insel Elba bisher kaum archäologische Zeugnisse der angeblich bedeutenden dortigen Eisenproduktion (Corretti / Benvenuti 2001).

12 Pagès et al. 2011B, 150.

13 Furger 1995, 172.

14 Caes. Gall. 5,12,4.

15 Allen 1967, 319f.; Pleiner 1980, Abb. 11.7; Crew 1994, 346 (Interpretation «as a currency ... is clearly no longer tenable»); Pleiner 2006, 32; 34f. - Andere Übersetzungen der betreffenden CaesarStelle sind entsprechend weniger zutreffend: «Stückchen Eisen» (Übers. A.Baumstrunk [Stuttgart 1854]); «iron rings» (Transl. T. R. Holmes [London 1908]; «Eisenbarren» (Übers. M. Deissmann [Stuttgart 1980]); «eiserne Barren» (Übers. L.Möller [Wiesbaden 2013]).

16 Siehe unten mit Anm. 190. - Zum Beginn der Eisennutzung unten mit Anm. 189

17 Neumann/Wilsdorf 1954, 78f.; Yalçın 1999, 183 Anm. 34. 

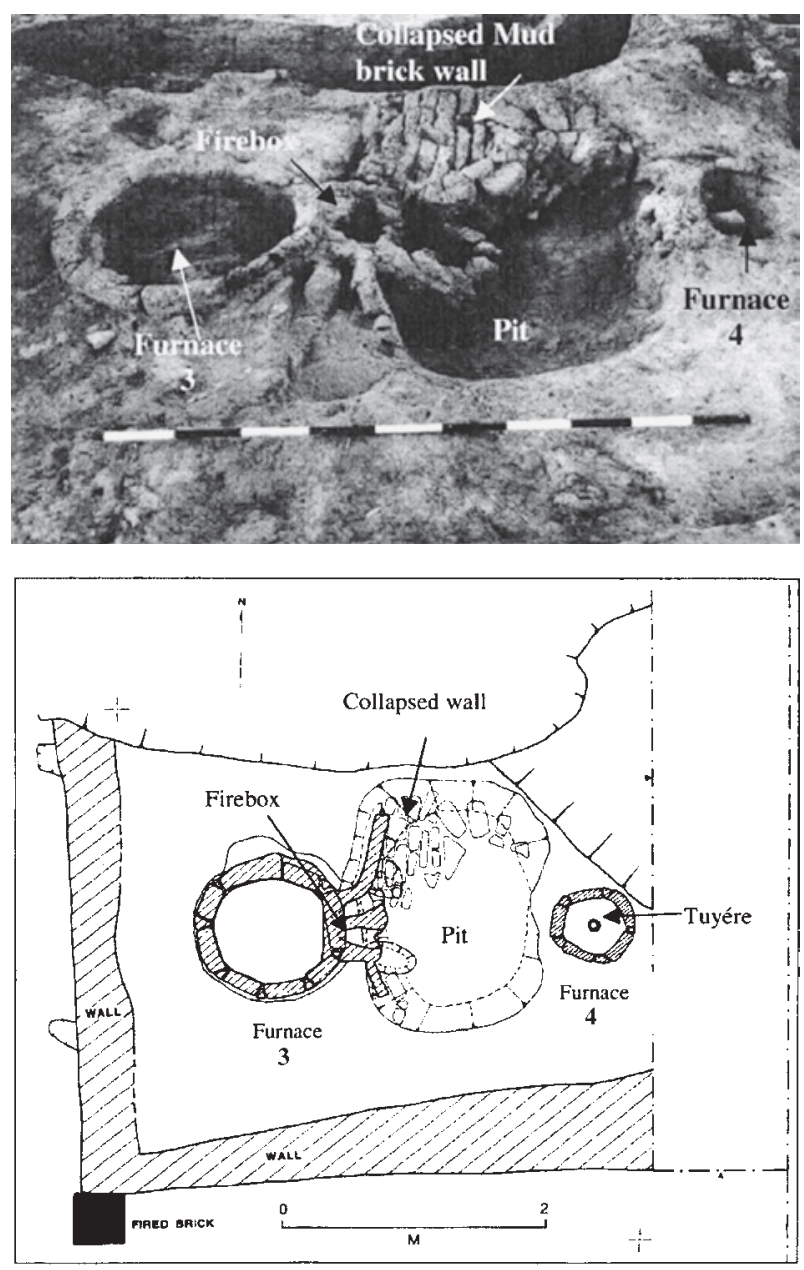

Abb. 2: Merv/TM. Oben Grundriss der Öfen 3 und 4 zur Tiegelstahlherstellung, unten Grabungsfoto (ohne M.). Im grossen Ofen 3 hatten bis zu zwanzig Tiegel Platz, im kleinen Ofen 4 bis maximal sieben Tiegel (der Form Abb.22,2). Auf Sohlenmitte von Ofen 4 mündet ein tönernes Gebläserohr («tuyère»), durch welches Luft vom Blasebalg in die Feuerkammer einströmte. In der Grube zwischen den Öfen wurde vermutlich der Blasebalg bedient.

ten scheinen bereits um 1260 v. Chr. extra "gutes Eisen» (Stahl) hergestellt zu haben ${ }^{18}$. In einer interessanten Korrespondenz von ca. 1260 v. Chr. des hethitischen Königs Hattušili III. mit einem assyrischen Regenten ist mehrfach von explizit «gutem Eisen» für Dolche und andere Waffen die Rede, welches im hethitischen Eisenindustriezentrum von Kizzuwatna (Prov. Adana, TR) hergestellt würde ${ }^{19}$. Eine andere hethitische Quelle etwa derselben Zeit betont den Unterschied zwischen «Eisen von der Feuerstelle» (aus dem Ofen) und «gutem Eisen», was nach Jana Siegelová auf einen nachträglichen separaten Prozess der Qualitätsverbesserung (durch Aufkohlung?) hinweisen könnte20.

Schon der erste abendländische Autor, Homer, erwähnt im 8. Jahrhundert v. Chr. den Stahl, konkret das Abschrecken ${ }^{21}$. Quintus Curtius Rufus berichtet in seiner Alexandergeschichte vom Geschenk resp. Tribut des besiegten Porus im 4. Jahrhundert v. Chr. an Alexander den Grossen im Umfang vieler Reiter, Wagengespanne, Leinengewänder, Waffen, gezähmter Wildtiere und rund $2 \frac{1}{2}$ Tonnen - offenbar sehr wertvollen - indischen Stahls (ferri candidi talenta $C)^{22}$. In allen späteren Quellen ist mit «weissem Eisen» stets indischer (Tiegel-)Stahl gemeint (dazu unten S. 40). In Anbetracht der aufwendigen Stahlherstellung nach indischer Technologie in Tiegeln stellen die $2 \frac{1}{2}$ Tonnen einen beachtlichen Wert dar: Vergleichen wir die in der Alexandergeschichte genannten $2 \frac{1}{2}$ Tonnen Stahl mit archäologischen Hochrechnungen, so entspricht dies der gesamten nachweisbaren Stahlproduktion von Merv in Turkmenistan (Abb. 2) resp. knapp zweieinhalb Jahresproduktionen von Akhsiket in Usbekistan ${ }^{23}$.

Für die römische Zeit nennen einige wenige Quellen - nebst Noricum in Kärnten / A (s. unten S. 44 ff.) - China ${ }^{24}$ (oder eher Indien? ${ }^{25}$ ) und das Partherreich ${ }^{26}$ (Mesopotamien und Persien) als Herkunftsländer bester Stahlqualitäten ${ }^{27}$. Cassiodor, ein spätantiker Gelehrter des 5. / 6.Jahrhunderts n. Chr. aus Süditalien, beschreibt recht detailliert den optischen Effekt der Eisen-Stahl-Verbundstoffe, die heute als Damaszenerstahl (Abb.8) resp. Wurmbuntstahl ${ }^{28}$ bezeichnet werden und im europäischen Fundgut

18 Barraclough 1981, 27-29; Siegelová 1984.

19 Zitiert nach Text in Roesch 1975, 16 f.; dazu auch Neumann/Wilsdorf 1954, 78f.; Siegelová 1984, 155 f. Anm. 9; Yalçın 1999, 183 Anm. 33; 185. - Zur hethitischen Stahlproduktion ausführlich Siegelová 1984 (Zusammenstellung der zahlreichen schriftlichen Quellen) sowie kurz auch: Reed 1934, 386; Tholander 1971, 16; Moesta 1983, 168; Presslinger / Köstler 1991, 19.

20 Siegelová 1984, $157 \mathrm{f}$.

21 Zum Beispiel Hom. Od. 9,389-394 (zitiert unten mit Anm. 193); Plut. (1./2.Jh. n. Chr.) De primo frigido, 13 («Und deshalb, was Nadeln, stählernen Schildbuckel und solche kleinen Eisen- und Stahlwaren angeht, löschen sie sie nie in Wasser ab, sondern in Öl, aus Angst, dass die zu starke Abkühlung des Wassers sie zu spröde macht.»). - Zahlreiche antike Quellen zum Abschrecken von Stahl zusammengestellt bei: Halleux 2007, 1304 Anm. 21. - Zu den zahlreichen Belegen für die Arbeit mit Eisen bei Homer: Dobesch 2000, 17-19.

22 Curt. 9,8,1 (in der etwas missverstandenen Übersetzung von F. Olef-Krafft 2014: «... hundert Talenten geläuterten Silbers»). Die Quelle wird u.a. schon von Heath 1839, 395, zitiert («... a present of steel ... about thirty pounds weight of steel ...») ohne weiterführendes Zitat; Johannsen 1953, 18; Balasubramaniam 2007; Sherby/ Wadsworth 2001, 352 Abb. 8.

23 Feuerbach 2007, 328 und 331 (mit Primärliteratur).

24 Needham 1958, 2-48; Wagner 2007, 47-54; Wagner 2007, $297 \mathrm{ff}$. (historische Belege für chinesischen «Co-fusion»-Stahl erst ab dem 6.Jh. n. Chr.); Williams 2012, 38-41.

25 Schoff 1915; Read 1934, 388; Krishnan 1954, 18-48 bes. 32-40; Wagner 1993, 55 (Originaltext des «Tribute of Yu», Vers 9, auf: http://ctext.org/shang-shu/tribute-of-yu [31.07.2017]); Biswas 2001, 101-132. - Zu den Transportwegen auch Schoff 1912, 24 (Periplus Maris Erythraei).

26 Plin. nat. 34,145 (in der Übersetzung von R. König 2008: «Die zweite Stelle [nach der ersten, von den Serern gelieferten Qualität] nimmt das parthische Eisen ein»).

27 Plin. nat. 34,145; Huntingford 1980, 22 («indisches Eisen und Stahl» im Periplus Maris Erythraei, Kap. 6); Godfrey/van Nie 2004, 1118.

28 Zum sog. pattern-welding: Williams 2012, 62-84 Abb. 1. 


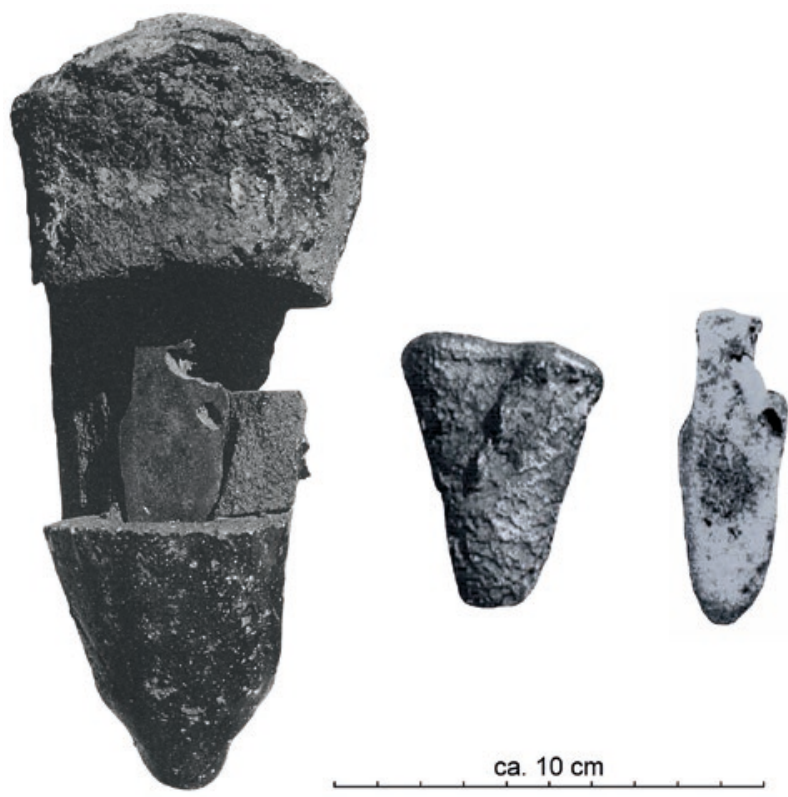

Abb. 3: «Crucible steel»: Links ein kleiner Stahltiegel aus Gattihosahalli in Südindien (vgl. Abb.22,6) mit oben aufgeklebtem Deckel, in der Mitte aufgeschnitten, um den noch darin steckenden Regulus, d. h. den Stahlbarren, sichtbar zu machen. Mitte: ein ähnlicher Barren aus einem Tiegel. Rechts: ein anderer kleiner, längs aufgeschnittener Tiegelstahl-Barren.

derselben Zeit auch vielfach nachgewiesen sind. Cassiodor schreibt im Namen Theoderichs: «... hat Eure Brüderlichkeit Schwerter für uns ausgewählt, die sogar im Stande sind, Rüstungen zu durchschneiden, noch kostbarer wegen ihres Eisens als wegen des teuren Goldes. So glänzend ist ihre polierte Klarheit, dass sie mit genauer Deutlichkeit die Gesichter derjenigen widerspiegeln, die auf sie schauen ... Das Mittelstück ihrer Klingen, geschickt ausgehöhlt, erscheint wie mit kleinem Wurmwerk gekräuselt, und hier spielen so mannigfaltige Schatten, dass man fast glauben möchte, das glänzende Metall sei mit vielen Farben verwoben. Dieses Metall wird sorgfältig auf Eurem Schleifstein geschliffen und mit Eurem höchst glänzenden Pulver so kräftig poliert, bis sein stählerner Glanz ein Spiegel für Männer ist.» ${ }^{29}$

Die lange Tradition der Stahlherstellung in Indien zeigt sich auch in der Vielfalt der Eisen- und Stahl-Qualitäten, zwischen denen man im Mittelalter konkret zu unterscheiden wusste. So werden im Rasaratna Samuchaya («Alchemie Indiens») des Autors Vagabhata aus dem 13. oder 14. Jahrhundert $n$. Chr. sechs verschiedene Begriffe für Stahl verwendet und Gusseisen, leicht hämmerbares und glänzendes Eisen, zäher Stahl ohne grosse Deformationseigenschaften, spröder und brüchiger Stahl etc. in ihren Vorzügen und Unterschieden beschrieben ${ }^{30}$.

Die Antike hat Stähle sehr unterschiedlicher Qualität gekannt ${ }^{31}$. Dies lag nicht allein an den verschiedenen Erzeugungsverfahren, sondern auch am Ausgangsmaterial («Verunreinigungen» im Weicheisen) und womöglich vor allem an den Fähigkeiten und Erfahrungen der griechischen und römischen Stahlerzeuger. Robert Halleux fasste die antiken Quellen zusammen und übersetzt einen Dai-
machos-Text aus dem 3. Jahrhundert v. Chr. mit einer interessanten Auflistung antiker Stähle und deren werkzeugspezifischen Eigenschaften ${ }^{32}$ : «Celui [jener Stahl] de Sinope et le chalybe sont utiles aux outils de charpentier, le lacédémonien pour les limes, les forets à fer, les ciseaux à graver et les outils pour travailler la pierre, l'acier lydien pour les limes également, pour les coutelas, les rasoirs, les racloirs». Trotz der relativ zahlreichen Nennung bei antiken Autoren muss Stahl - im Gegensatz zum allgegenwärtigen Eisen - damals ein rares, geschätztes und teures Material gewesen sein: «In the quality of the products, therefore, is reflected the fact that as a rule there was a shortage of good steel.» ${ }^{33}$

Aufgrund solcher Spezialstähle und unserer Erfahrungen kann man daher nicht so weit wie John F. Healy gehen, der ausschliesslich dem asiatischen Wootz-Stahl (Abb.3; 23) die nötige Qualität zugesteht ${ }^{34}$ : «Such crucible processes for converting iron into steel were probably the only practicable way of obtaining good steel in Antiquity.»

Die Erforschung von antikem Stahl anhand von Fundobjekten, Werkstatteinrichtungen und analytischen Befunden steht aber immer noch am Anfang: «La technique de production de l'acier par les Grecs anciens est un problème qui n'était pas jusqu'à ce jour résolu.» ${ }^{35}$

Cassiod. var. 5,1; Hodgkin 1886, 264 f. - Eine japanische Schwertklinge des 2.Jh. n. Chr., gefertigt in Damaszenertechnik, trägt sogar eine Inschrift, wonach ihre Klinge in China «durch hundertfaches Veredeln» (Falten? Aufkohlen?) gefertigt worden sei (Wagner 1993, 283 Anm. 23). - Archäometrische Zusammenstellung verschiedener römischer Schwerttechnologien bei Lang 2017, 3.

30 Rasaratna Samuchaya, Buch V, Verse 71-72; Biswas 2001, 102; $120 \mathrm{f}$

31 Pleiner 1968, 313; Healy 1978, 215; Dobesch 2000.

32 Halleux 2007, 1303. - Eine Übersicht zu griechischen Quellen über Eisen und Stahl: Pleiner 1969B, 9-10; 20-28.

33 Pleiner 1968, 313.

34 Healy 1978, 215

35 Conophagos/Papadimitriou 1986, 135. 


\section{Traditionelle Prüfverfahren für Weicheisen und Stahl}

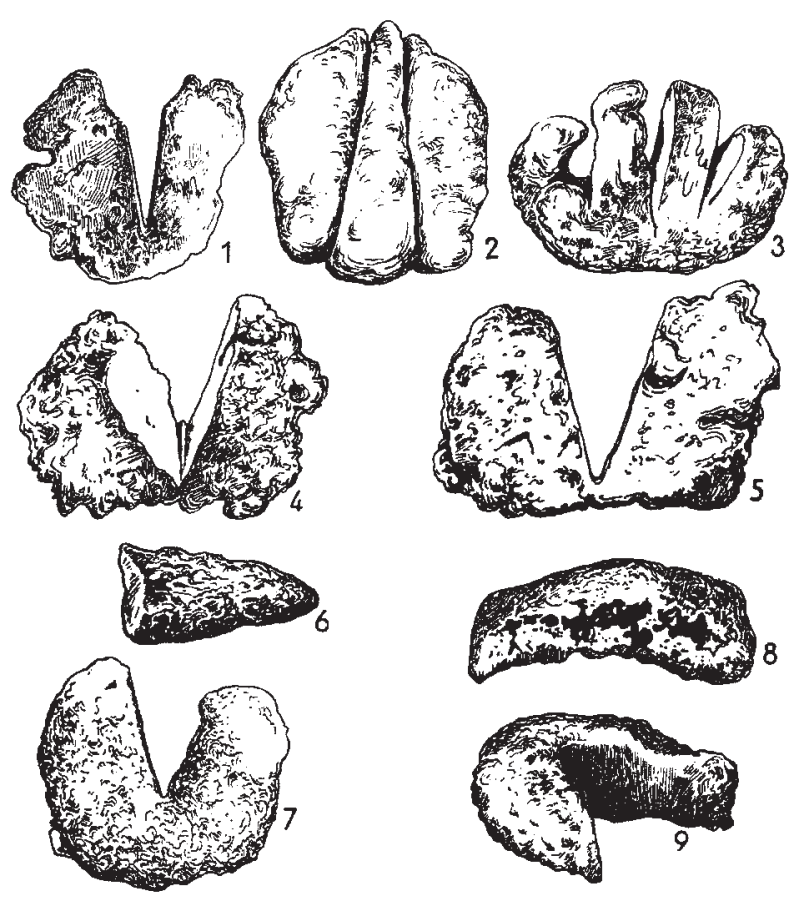

Abb. 4: Roheisenluppen von slawischen und skandinavischen Fundorten mit grossen Einkerbungen, die beim Prüfen der Qualität mit Hilfe eines ins glühende Eisen eingeschlagenen Meissels oder Keils entstanden sind. Frühmittelalterlich. Ohne M.

Schon immer konnten die Schmiede weiches, kohlenstoffarmes Verhüttungseisen von kohlenstoffangereichertem Stahl unterscheiden, auch wenn man weder die metallurgischen Unterschiede im Detail kannte noch über die Analyse- und Härtemessungsverfahren von heute verfügte. Mehrere einfache «Tests» lassen Stähle leicht erkennen und von Weicheisen unterscheiden ${ }^{36}$ :

1. Den ältesten «Stahltest» überliefert Philon von Byzanz (3./2.Jh. v. Chr.). Bei seiner Beschreibung von Stahlschienen für Geschütze im «Handbuch der Mechanik» beschreibt er einen Qualitätstest für «sogenannt keltische und spanische Schwerter»: «Will man nämlich diese prüfen, ob sie brauchbar sind, so fasst man mit der rechten Hand das Schwert, legt es horizontal über den Kopf und zieht es auf beiden Seiten herunter, bis man die Schultern berührt. Hierauf lässt man rasch beide Hände seitwärts los, das Schwert aber losgelassen wird wieder gerade und kehrt so in seine frühere Gestalt zurück, so dass es keinen Gedanken von einer Krümmung hat; und so oft man dies auch thun mag, die Schwerter bleiben gerade.» Das Eisen für solche Schwerter müsse im Feuer optimal bearbeitet werden und «ausserordentlich rein» sein, damit es «weder zu spröde noch zu weich ist». Die Elastizität komme davon, dass «die Schwerter kalt kräftig geschlagen sind ${ }^{37}$. Über eine Vorbehandlung zur Aufkohlung des Eisens erfahren wir von Philon leider nichts.

2. Ein ebenfalls bereits für die Antike belegtes Prüfverfahren «für eine Beurteilung der Rohluppenqualität» war «das einfache Anspalten» der glühenden Eisenklötze. Dies konnte «besonders bei grossen Stücken nur einen ersten Anhaltspunkt liefern. In mehreren, an ein und derselben Rohluppe vorgenommenen Einhieben konnte die Beschaffenheit der Bruchfläche mehr oder weniger identisch, aber auch verschieden ausfallen. Darauf deuten die jeweils ein oder mehr Einhiebe an zahlreichen Rohluppen aus Nord-, Mittel- und Osteu-

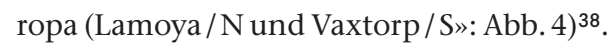

3. Der bis heute häufigste und einfachste Test für die Härte von Stahl resp. die «Weichheit» von Eisen besteht in wenigen Hammerschlägen auf dem Amboss: «Les forgerons [des Dogon, Mali] reconnaissent dès les premiers coups de marteau s'ils ont à travailler un acier 〈mou〉 ou un acier «dur〉.»39 Von diesem einfachen Prüftest scheinen mehrere eisenzeitliche und römische Spitzbarren zu zeugen, bei denen man die eine Spitze etwas flachgehämmert hat (Abb.5) ${ }^{40}$. Stahl schmiedet sich bei mittlerer Glut auf dem Amboss viel härter und zäher als das weiche Schmiedeeisen ${ }^{41}$, und bei hoher Glut «verbrennt» Stahl früher als Weicheisen.

4. Spröder, d. h. heiss in Wasser abgeschreckter Stahl lässt sich leicht brechen, während kohlenstoffarmes Weicheisen sich leicht biegen lässt, ohne zu brechen.

5. Jeder Stahl zeigt - im Vergleich mit normalem Eisen eine spezifische Bruchfläche mit sehr typischem Korn-

Ausführliche Listen verschiedener simpler Stahl-Prüfverfahren: Poppe 1820, 21-23 (Tests 1-14); Riley 2011, 21-25.

37 Philon, Belopoiika 4,46f.; Beck 1884, 449f.; Livadefs 1956, 51 Anm. s. - Zur Erstedition in den Mathematici veteres von 1693 (p. 71) siehe Livadefs 1956, 51 Anm. 8.

38 Pleiner 1997, 254 Abb. 3 (weitere Beispiele aus Europa und Asien); Mäder 2003, 166 (Zitat) Abb. 45 (= unsere Abb.4); Pleiner 2003, Abb. 30.1-30.4; Pleiner 2006, 51 Abb. 21,5.6 (15./ 16.Jh.).

39 Soulignac 2017, 83.

40 Giot 1964, Abb.1; Kleemann1966, 122 Abb. 3 (= unsere Abb. 5); Berranger / Fluzin 2012, 678 f. Abb. 4, BLD1; Berranger et al. 2017B, Abb. 6, oben.

41 Georgi 1785B, 278; Duhamel 1786, 462 («... l'acier cémenté est beaucoup plus dur que le fer, \& chaque percussion du marteau n'y fait pas grande impression ...»). 

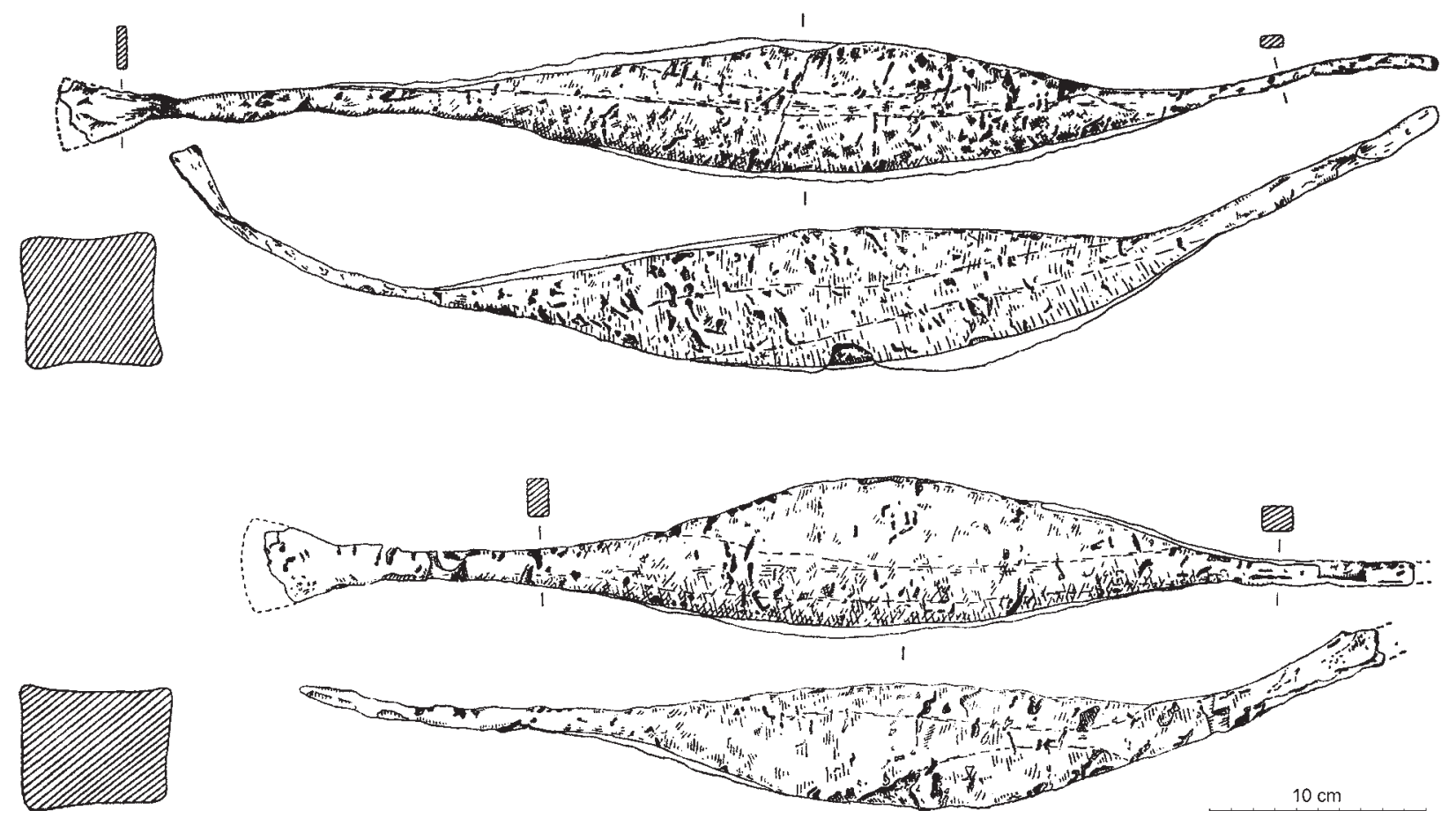

Abb. 5: Zwei doppelkonische Spitzbarren (vgl. Abb. 36-40) mitje einem leicht ausgeschmiedeten Ende. Mit wenigen Hammerschlägen konnte ein erfahrener Schmied an der Härte und am Glühverhalten beurteilen, wie gut die Qualität des Eisens ist und ob es sich eher um Eisen oder um Stahl handelt. Aus dem Spitzbarren-Depot von Bad Königshofen/D-Aubstadt. M. 1:4, Gewicht 5,17 resp. 3,97 kg.

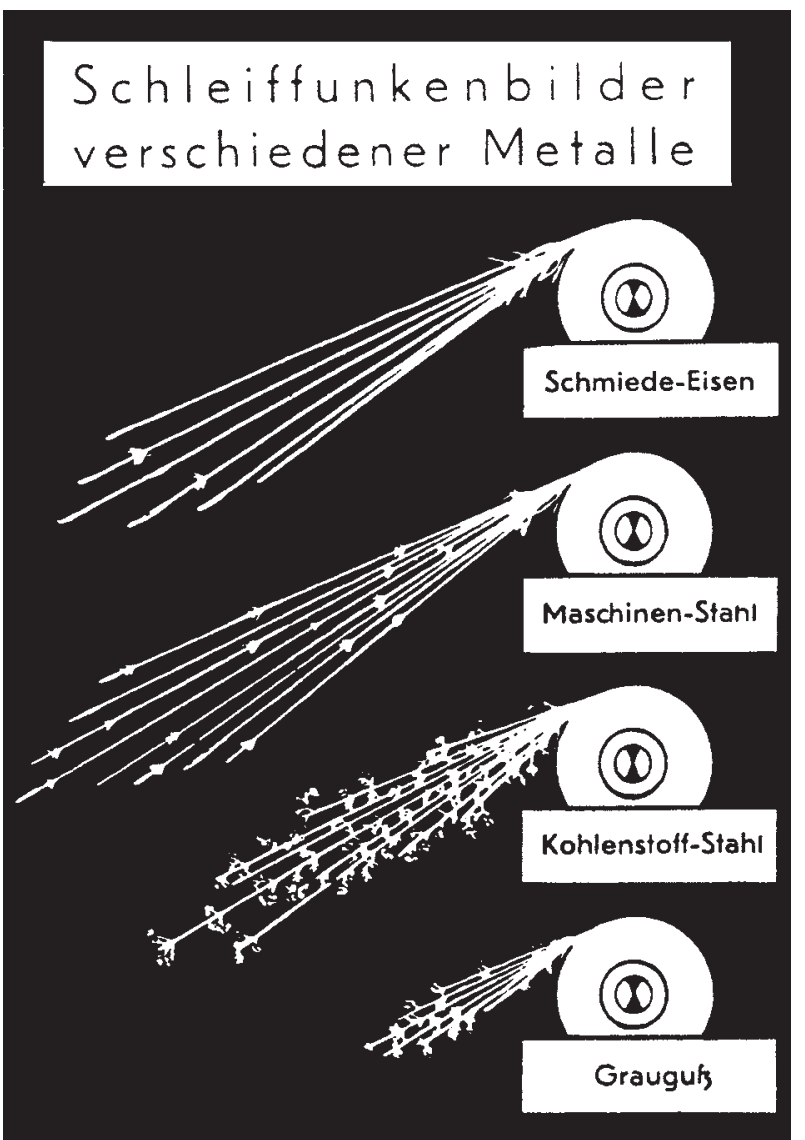

Abb. 6: Im Erscheinungsbild des Funkenwurfs auf dem rotierenden Schleifstein prüft der Schmied auch heute noch, ob er es mit Schmiedeeisen oder Stahl zu tun hat. Dasselbe Phänomen eines im Halbdunklen sichtbaren Funkenwurfs tritt in Erscheinung, wenn mit einem «Feuerstahl» auf einen Feuerstein geschlagen wird. 


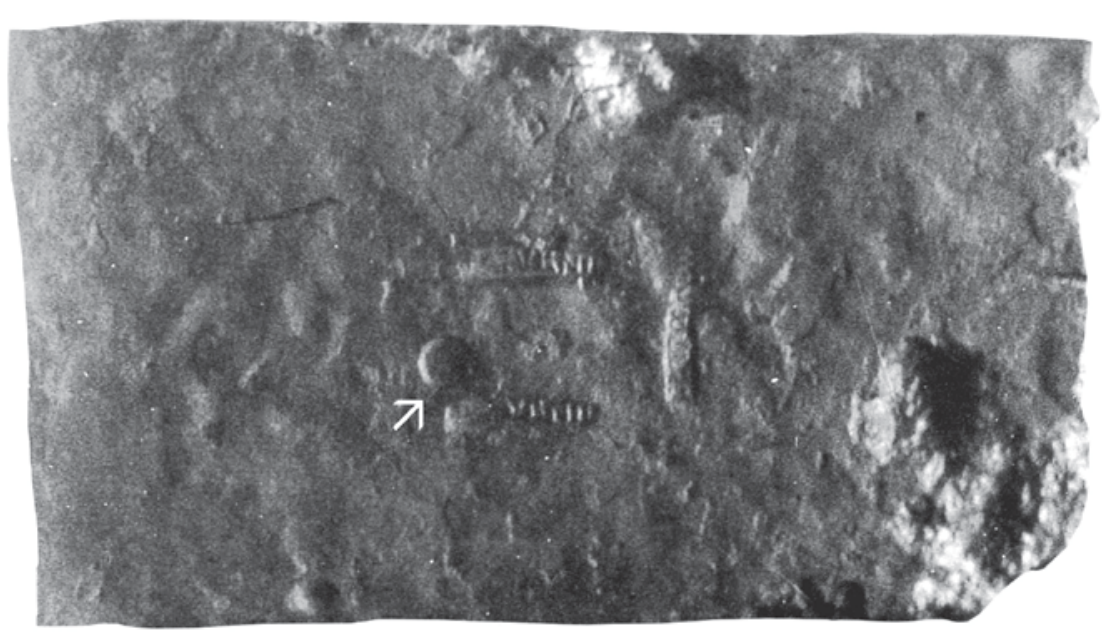

$10 \mathrm{~cm}$
Abb. 7: Zeugnis eines antiken «Schnelltests»? Flachrechteckiger römischer Stahlbarren (ca. 0,9-1,0\% C) aus einem Schiffswrack bei Bonifacio / F vor Korsika. Mit dem kräftigen Einschlagen einer runden Punze (Pfeil) konnte schnell festgestellt werden, wie hart das Metall ist: weiches Schmiedeeisen oder harter Stahl? Die beiden Fabrikantenstempel nennen einen SATVRIN[VS]. Objektgrösse $30 \times 125 \times 230 \mathrm{~mm} ;$ M. 1:2. gefüge; ein guter Stahl zeigt in der Bruchfläche «un grain très-fin, d'un gris-blanc, non brillant» ${ }^{42}$.

6. «Wenn Stahl fein polirt ist, so erscheint er mit weisslich grauem Glanze. Das polierte Eisen hingegen fällt ins Bläuliche. Je härter der Stahl, desto bessere Politur nimmt er an.» ${ }^{43}$

7. Auf der modernen rotierenden Schleifmaschine bildet Stahl bündelförmige und stark leuchtende Funken, während Normaleisen nur schwache längliche Einzelfünkchen erzeugt (Abb.6). Dieser «Schnelltest» ist in jeder heutigen Schmiedewerkstatt der gängige Weg, wenn der Meister rasch die Qualität eines Rohstücks prüfen will ${ }^{44}$ ! Diese Beobachtung «rekonstruierte» Otto Schaaber für die antiken Schmiede so, dass auch mit den schon immer omnipräsenten Schleifsteinen bei «rasch laufendem, trockenen Stein» die Unterschiede im Funkenwurf wahrnehmbar waren ${ }^{45}$.

8. Einen weiteren, sehr geläufigen «Test» zur Unterscheidung von Eisen und Stahl hat man wohl auch schon in der Antike mit der Feile durchgeführt: «Eine gehärtete Feile fasst bei weichem Stahl, bei gehärtetem, harten Stahl gleitet sie $a b .{ }^{46}$

9. Statt den Abrieb auf Stahl mit einer Feile zu prüfen, empfiehlt eine andere alte Methode, einen gut gehärteten Meissel auf die zu prüfende Eisenunterlage zu schlagen: «Staucht sich hierbei die Schneide ..., so besitzt der Stahl geringe Härte und Härtungsfähigkeit; springen Stückchen aus der Schneide aus, so ist der Stahl spröde und wenigstens für Werkzeuge mit schärferen Schneiden nicht geeignet.» ${ }^{47}$

Auf die effektive Anwendung eines ganz simplen Stahl-Härtetests lässt ein runder Punzeneinschlag auf einem stempelsignierten römischen Stahlbarren aus einem Schiffswrack vor Korsika schliessen (Abb. 7): Der von Saturninus gestempelte Barren besteht aus Stahl mit 0,9 bis 1,0\% Kohlenstoff und trägt neben drei Namensstempeln zwei Ein- drücke einer Kugelpunze. Damit liess sich leicht die Härte feststellen und zwischen Weicheisen sowie ungehärtetem respektive gehärtetem Stahl unterscheiden ${ }^{48}$ (zum Stempel siehe Abb. 48,4).

42 Duhamel 1786, 435 (Zitat); 461; Poppe 1820, 21, Test 2; Prechtl 1834, 10 («... hackiges oder zackiges Gefüge, d.h. die Bruchflächen erscheinen mit spitzigen Hervorragungen bedeckt»); Hartmann 1848, 15 («graulichweisse, ins Weisse übergehende Farbe ... seine Textur ist zackigförmig. Je dichter und gleichartiger das Korn, desto besser ist der Stahl. ... körniges Gefüge, blaues, weisschimmerndes Korn ...»); Reiser 1896, 8f.; Ledebur 1903, 781 («Das Aussehen der Bruchfläche giebt ein weiteres Merkmal für die Beschaffenheit» [des Stahles]); 1080; Dobesch 2000, 14 («Bruchprobe»); Berranger / Fluzin 2012, 674. - Klein 1760, 117, beschrieb dies damals so: «Die äusserlichen Kennzeichen eines guten Stahls sind diese, dass er, wenn man ihn zerschläget, kurz abspringe und auf den Bruch ganz gleich und weisblaulich sey und sich seine Schiefern und zähe Adern darunter zeigen. Je zarter und egaler also das Korn auf dem Bruch, desto feiner und besser ist der Stahl»; Ledebur 1903, 780f. (mit einer Anleitung zur «Vorprüfung» von Stählen).

43 Poppe 1820, 21, Test 1.

44 Diesen Hinweis verdanke ich Bernard Pivot, Kunstschmied in Basel/CH. - Vgl. dazu Steinbrings 1928, 49 (Beschreibung der «Funkenprobe», mit der sich fünf verschiedene Eisen- und Stahlsorten unterscheiden lassen) sowie den instruktiven Kurzfilm «Metal ID - Spark Testing» auf: https: // www.youtube.com/watch?v=D094e Ba4S7c\#t=561.3759174 (12.05.2016).

45 Schaaber 1963, 204 (Zitat); Schaaber 1977, 267.

46 Klein 1760, 120; Poppe 1820, 22, Test 13; Reiser 1896, 42 und 45; Ledebur 1903, 780 und 781; Brearley 1914, 95 f. (ausführlich zum Stahl-Test mit Feile); Steinbrings 1928, 49 f.; Schaaber 1963, 203 f. (Zitat) Abb. 150; Schaaber 1977, 267.

47 Ledebur 1903, 781.

48 Zwicker 1996, bes. Taf. 8,2. 


\section{Korrosionsanfälligkeit}

Eisen und Stahl unterliegen auch unterschiedlicher Korrosion. Es fiel mir im Museumsdepot immer wieder auf, dass vor allem dünne Eisenteile entweder relativ gut erhalten sind oder aber äusserst schlecht. Gut und wenig korrodiert haben ganz gewöhnliche Eisenbleche wie etwa Scharnierbänder, Beschlagbleche und dergleichen die Bodenlagerungen überstanden. Solche Stücke haben meist noch einen metallischen Kern und sind sogar etwas elastisch. Die anderen, schlecht erhaltenen dünnen Eisenteile finden sich in Klappmessergriffen oder an Skalpellgriffen ${ }^{49}$. Sie sind meist nur noch in den schützenden Kerben der Bronzehalterungen zu beobachten. Die Konsistenz solcher Klingen ist meist schwarz korrodiert, brüchig und sehr spröde - ein metallischer Kern ist nicht mehr vorhanden. Dieser markante Unterschied im Oxidationsverhalten ist auf die bei langer Lagerung viel grössere Korrosionsanfälligkeit von Stahl gegenüber Eisen in vielen Böden zurückzuführen ${ }^{50}$.

In der Stahl- und Handwerkerliteratur wird aber oft das Gegenteil beobachtet: «Stahl wird weniger von feuchter Luft angezogen und ist nicht so geneigt zum Rosten, als Eisen.» ${ }^{51}$ Ich vermute den Grund dieser Diskrepanz der Beobachtungen in der Zeitdauer: Bei kurzer Lagerung in der Werkstatt oder bei den Händlern bildet sich schnell und gerne Flugrost, vor allem auf rohen Eisenoberflächen, also auf Gebrauchsgerät. Objekte aus Stahl hingegen sind oft fein geschliffen oder gar poliert und daher weniger anfällig auf Rostbildung an der Luft. Im Gegensatz dazu waren Bodenfunde sehr lange einem salzhaltigen Milieu ${ }^{52}$ ausgesetzt, welches offenbar die kohlenstoffreichen Stahlklingen schneller zum Oxidieren brachte als normale Eisenbleche. korrosionsanfälligen Klingen leider nur Reste in den Einlasskerben erhalten geblieben ...»).

50 Duhamel 1786, 442 («L'acier poli se colore plus promptement que le fer poli ...»); Amborn 1976, 46 und 240 (Korrosionsanfälligkeit von Stahl); Salter 1997, 102 («... the high carbon content of the metal promotes corrosion»); Bauvais 2008, 3 («Plus l'acier est chargé en carbone, plus il est soumis à une corrosion bien plus intense que le fer.»).

51 Georgi 1785B, 278 (Zitat); 365; Poppe 1820, 21, Absatz 5; Beck 1884, 264 und 652; Healy 1978, 236; Moesta 1983, 170 (nach Wegrosten der «weniger kohligen Teile» blieben die «besseren Stücke übrig»); Soulignac 2017, 103 («L'oxydation des aciers à faible taux de carbone $[0.45 \% \mathrm{C}]$ est normalement plus faible que celle du fer pur»).

52 Zur Korrosionsförderung von Bodensäuren an archäologischen Objekten: Gruber et al. 2011 


\section{Die Kohlenstoffgehalte von historischen Stählen}

In der modernen metalltechnisch-historischen Literatur werden die Eisen- resp. Stahlqualitäten mit sehr verschiedenen Grenzwerten und Begriffen beschrieben resp. definiert. So nennt Fridolin Reiser 1896 einmal zwölf verschiedene Stahlsorten mit zwölf optimalen Kohlenstoffgehalten und einmal elf Sorten - je nach Werkzeugart, Aufgabe und Anwendung53. Die Werte entsprechen einerseits dem technisch notwendigen Kohlenstoffgehalt, andererseits sind sie auch archäometrisch an antiken Originalobjekten nachgewiesen. Die folgende Übersicht soll die Grenzsetzungen veranschaulichen:

\begin{tabular}{|c|c|}
\hline$<0,1 \% \mathrm{C}:$ & Reineisen $^{54}$ \\
\hline 0,1-0,5\% C: & Schmiedeeisen ${ }^{55}$ \\
\hline $0,1-1,5 \%$ C: & Definition von «usual carbon steel» ${ }^{56}$ \\
\hline 0,2\% C: & $\begin{array}{l}\text { Minimaler Kohlenstoffgehalt in römi- } \\
\text { schem Halbzeug vom Magdalens- } \\
\text { berg / } \text { A }^{57}\end{array}$ \\
\hline 0,3\% C: & $\begin{array}{l}\text { Untere Kohlenstoffgrenze von (härtba- } \\
\text { rem) Stahl, «low carbon steel» } 58\end{array}$ \\
\hline 0,3-0,6\% C: & $\begin{array}{l}\text { Höherfeste Baustähle resp. «medium- } \\
\text { carbon steel»; wenig auf Verschleiss be- } \\
\text { anspruchte Werkzeugstähle }{ }^{59}\end{array}$ \\
\hline $0,4-0,9 \% \mathrm{C}:$ & Für die römischen Exportstähle vom \\
\hline & $\begin{array}{l}\text { Magdalensberg «definierter Kohlenstoff- } \\
\text { gehalt» } 60\end{array}$ \\
\hline$>0,45 \% \mathrm{C}:$ & Moderne Definition von Stahl ${ }^{61}$ \\
\hline$>0,6 \% \mathrm{C}:$ & $\begin{array}{l}\text { Definition von «high carbon steel» (oder } \\
\text { eutektischer / eutektoider Stahl }{ }^{62} \text { ) }\end{array}$ \\
\hline$>0,8 \% \mathrm{C}:$ & Hypereutektoidischer Stahl $1^{63}$ \\
\hline 0,8-1,2\% C: & Werkzeugstähle ${ }^{64}$ \\
\hline 0,9-1,8\% C: & $\begin{array}{l}\text { Höchster in römischen Fundobjekten } \\
\text { (Halbzeug und Gerät) vom Magdalens- } \\
\text { berg nachgewiesener Kohlenstoffge- } \\
\text { halt } 65\end{array}$ \\
\hline$>1,3 \% \mathrm{C}:$ & Stähle «mit hohem \\
\hline & Verschleisswiderstand»66 \\
\hline 1,5-2,1\% C: & Definition von ultrahigh carbon steel ${ }^{67}$ \\
\hline 1,7\% C: & Obergrenze von schmiedbarem Stahl ${ }^{68}$ \\
\hline
\end{tabular}

53 Reiser 1896, Tabellen auf Seiten 35 und 36.

54 Schaaber 1963, 133 (<0,1\% C); Amborn 1976, 15 (<0,008\% C); Epprecht/Schaller 1981, 33 (Vickers-Härte weichgeglüht: HV 70100; kaltverformt: bis um HV 200 und mehr); Godfrey/van Nie 2004, 1121 («iron that has not been carburised»: HV 100-180); Pagès et al. 2011B, $149 \mathrm{f}$. $(\leq 0,02 \% \mathrm{C}=$ «ferrite»); Lang 2017, 1 .

55 Bersch 1899, 734 (0,04-0,6\% C); Schaaber 1963, 133 («Weiche Stähle ... unterhalb etwa $0,2 \%$ bis $0,3 \%$ [C]»); Schaaber 1977, 221 Anm. ** («unter 0,1\% C, auf alle Fälle unter 0,3\%»); Rehder 1989, 27 (Grenze zwischen schmiedbarem Eisen und Stahl bei etwa 0,20,5\% C); Hollemann / Wiberg 2007, 1640 ( $<0,4 \%$ C: «nicht härtbar», «Baustahl»); Halleux 2007, 1301 (0,05\% C: «acier doux»); Wagner 2007, $290(0,1-0,3 \% \mathrm{C}=$ «mild steel»).

56 Godfrey / van Nie 2004, 1121 (0,1-1,5\% C); Pagès et al. 2011B, 150 (acier $=0,02-1,8 \%$ C); Sim 2012, $129(0,1-2 \%$ C).

57 Vetters 1966, 173; Soulignac 2017, 32f. Tab.8. - Obergrenze für wenig anspruchsvolle Maschinenteile und Werkzeuge: Schiefer / Grün 1927, 185 («Wird eine mittlere Festigkeit verlangt ..., so genügt durchwegs ein weicher, zäher kohlenstoffarmer Stahl von höchstens $0,2 \mathrm{vH}[\%]$ Kohlenstoffgehalt ...»).

58 Bersch 1899, 736 (0,2\% C, «weicher Stahl»); Rommel 1929, 2127 (0,5\% C); Schaaber 1963, 1133 (0,2-0,3\% C); Schaaber 1977, 2221 Anm. **; Epprecht/Schaller 1981, 30 («werden bei der [langsamen] Abkühlung unter $723^{\circ} \mathrm{C}$ hart»); 33 (Vickers-Härte 240; abgeschreckt und nicht angelassen bis $630 \mathrm{HV}$ ); Moesta 1983, 163 (etwa 0,3\% C); 167 (0,2\% C); Straube 1986, 26; Brady/Clauser 1991, 804; Godfrey / van Nie 2004, 1121 (medium to high carbon steel: HV >800); Cech 2010, 198 (0,1\% C); Lang 2017, 1 («0,25\% C»). Eine gut gehärtete spätantike Stahlpunze aus Heerten / NL gehört mit HV 326-409 in diese Kategorie: Godfrey/van Nie 2004, 1120.

59 Ledebur 1903, 730 (0,5-0,7\% C, «für Tischmesser, gewöhnliche Hämmer»; Anlassfarbe blau); Schaaber 1963, 134 (Vergütungsstähle 0,25 bis etwa 0,5\% C); Brady/Clauser 1991, 804; Straube 1996, 26 (den Literaturhinweis verdanke ich Marianne Senn); Soulignac 2017, 32f. Tab. 8.

60 Sperl 2002B, 151

61 Definition von Otto Schaaber, zitiert nach Vetters 1966, 175.

62 Ledebur 1903, 730 (0,7-0,8\% C, «für Prägestempel»; Anlassfarbe gelb); Kucypera / Hošek 2014, 31 («around 0,8\% C»); Birch 2017, 146 (0,83\% C); Soulignac 2017, 32 f. Tab. 8.

63 Ledebur 1903, 730 (0,9-1,0\% C, «für Feilen, harte Steinbohrer, Fräser»; Anlassfarbe rot); Wagner 1993, 273; Kucypera/Hošek 2014, 31; Birch 2017, 147 (0,83-2,06\% C); Lang 2017, 1.

64 Ledebur 1903, 730 (1,0-1,2\% C, «für harte Dreh- und Hobelstähle»; Anlassfarbe dunkelgelb bis purpurrot); Steinbrings 1928, $44 \mathrm{f}$. (0,5-1,7\% C); Schaaber 1963, 134; Espelund 1996, 50 («... Eisen mit 1,2\% C als unschmiedbar angesehen ...»); Halleux 2007, 1301 (bis 1,2\% C: «acier dur», «acier extra dur doux»); Hollemann / Wiberg 2007, 1640 (0,4-1,7\% C: härtbarer Bereich); Wagner 2007, $290(0,5-1 \%$ C $=$ «tool steel»).

65 Vetters 1966, 173 (Halbzeug: max. 1,42\% C); 174 (Werkzeuge: max. 1,8\% C); Straube 1996, 28 (0,9\% C). - Geschmiedeter Barren resp. «bloom» aus Cranbrook/GB «... showed quench products and areas of high carbon steel of up to 1,5\%» (Lang 2017, 5).

66 Ledebur 1903, 730 (1,2-1,4\% C, «für Rasiermesser und sehr harte Werkzeuge»; Anlassfarbe braunrot); Straube 1996, 26.

67 Godfrey / van Nie 2004, 1118; 1121.

68 Reiser 1896, 1 (2,3\% C); Rommel 1929, 2127 (1,6\% C); Schaaber 1963, 133 (1,5\% C); Amborn 1976, 15 (1,7\% C); Moesta 1983, 163 (1,5\% C); Hollemann / Wiberg 2007, 1637 (1,7\% C). 


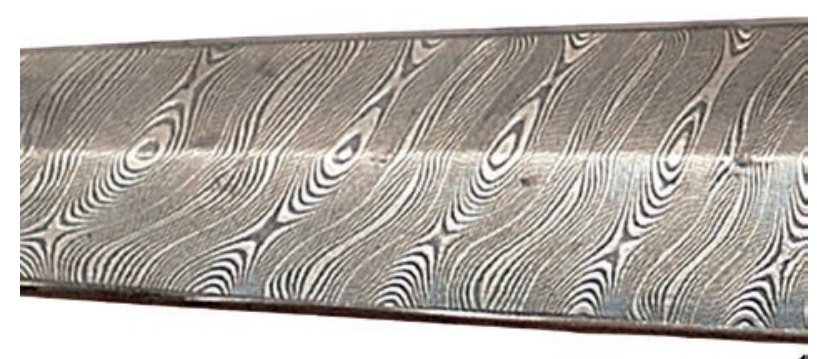

1

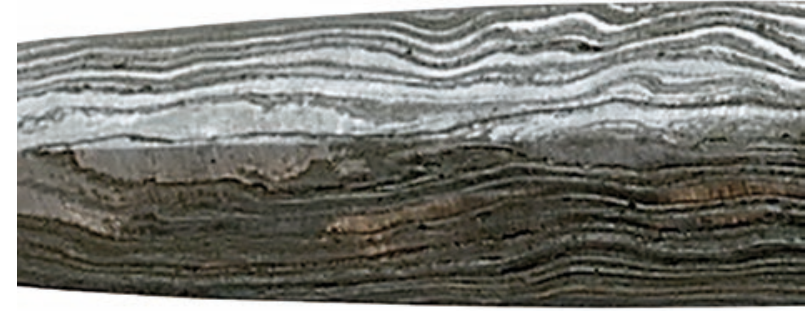

2
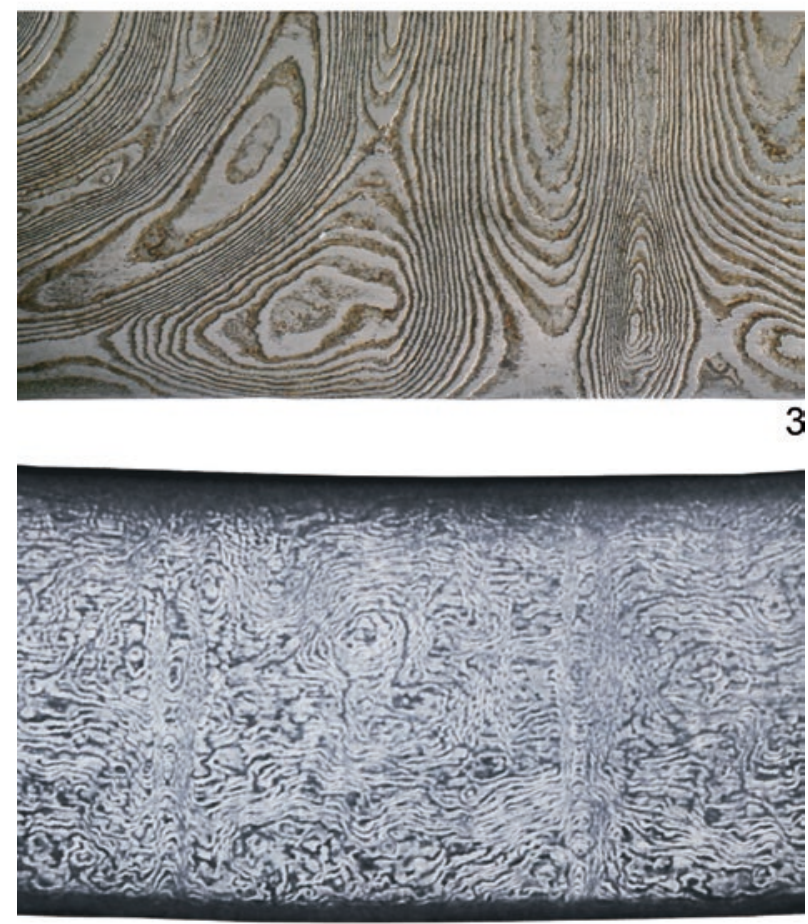

4

Abb. 8: Polierte Schwert- und Messerklingen aus Damaszenerstahl: 1 Streifendamast Europa (20.Jh.), 2 Streifendamast Indien (20. Jh.), 3 Wellendamast, 4 Stufendamast. Ohne Massstab.
$1,8 \%$ C:

$\leq 2 \%$ C:

\section{$2,1-4,3 \% \mathrm{C}$ :}

Obere Kohlenstoffgrenze von (härtbarem) Stahl 69

Obergrenze der Kohlenstoffaufnahme durch Aufkohlung70

Kohlenstoffgehalt von Gusseisen («Roheisen»), «extrem spröde»71.

Die hier aufgeführten Weicheisen- und Stahl-«Sorten ${ }^{72}$ liegen im archäologischen Fundstoff praktisch nie homogen vor. Ausnahme sind die durch Verflüssigung entstandenen asiatischen Tiegelstähle (39ff.). Diese weisen auch die höchsten Kohlenstoffgehalte antiker Stähle auf. «It was eventually found that ‘wootz〉 was a high-carbon steel with over 1\% C, a novelty in Europe where high-carbon steels were not previously known.» ${ }^{73}$

Allein schon durch das Ausheizen, Entschlacken und Zusammenschmieden der «Eisenschwämme» aus dem Rennfeuer werden Zonen sehr unterschiedlichen Kohlenstoffgehaltes zu heterogenem «Eisen» verdichtet (s. unten mit Anm.112). Durch das sekundäre ganze oder partielle Aufkohlen, das Aufschweissen von Stahlschneiden, das Zusammenschweissen zu Verbundstoffen oder im Extremfall das Damaszieren (Abb. 8) werden die Werkstoffe und Geräte noch heterogener und verraten ihre Struktur nur bei einer entsprechenden archäometrischen Untersuchung74. Auf die erwähnten Verarbeitungen wird im Folgenden näher eingegangen.

69 Bersch 1899, 736 (<1,8\% C); Straube 1986, 26; Cech 2010, 198 $(<2,06 \% \mathrm{C}))$.

70 Godfrey/van Nie 2004, 1122.

71 Bersch 1899, 734 (2,3-5,0\% C); Read 1934, 388f. (2,2\% C); Schaaber 1963, 133 (2-4,3\% C) und 134 ( >2\% C); Amborn 1976, 15 («Über 1,7\% C ist es [das Eisen] leicht giessbar, aber nicht mehr schmiedbar»); Rehder 1989, 32 («about four percent carbon»); Galik et al. 2003, 68 Anm. 146 (3-5\% C); Godfrey/van Nie 2004, 1121; Halleux 2007, 1301 (>2,5\% C: «fontes»); Hollemann / Wiberg 2007, 1637 («durchschnittlich 4\%C»); Cech 2010, 198 (1,5-5\% C); Pagès et al. 2011B, 150 (1,8-6,7\% C); Birch 2017, 146 (2,06-4,3\% C).

72 Zu neuzeitlichen verwendungsspezifischen Werkzeugstählen mit optimalen Kohlenstoffgehalten: Schiefer / Grün 1927, 30 ff. Tabellen 2-7.

73 Srinivasan 2017, 909.

74 Zum Beispiel: Schwarzlose 1886, 127-158 (S. 140: «Aufschweissung von Stahl an den Schneidestellen»); Rommel 1929, $2131 \mathrm{f}$. und 2133; Pleiner 1970, bes. 133; Vetters 1966; Epprecht/Schaller 1981; Biborski et al. 1982 (82 Abb. 7,a mit einem Schwert aus Augusta Raurica, das in Schichten geschmiedet und mit einem Stahlkern mit 0,5\% C versehen ist [hier Abb. 31]); M. Mehofer in Daim et al. 2005, 206-210 Abb. 6-10; Pagès at al. 2006, 112 Abb. 6 und 7; 115; Presslinger et al. 2007, 232-234. 


\section{Wie machte man aus weichem Eisen härtbaren Stahl?}

\section{Kalthämmern}

Die einfachste Technik ${ }^{75}$, ein weiches Schmiedeeisen oder ein Eisen mit etwas Kohlenstoff zu härten, ist die Kaltbearbeitung durch intensives, langes Hämmern relativ flacher Bleche, Bänder und Federn ${ }^{76}$. Dabei kam dem Handwerker eine ähnliche Verdichtung und Verhärtung des Materials entgegen wie beim Kaltschmieden von Kupferlegierungen. Das Kaltschmieden von Schwertklingen wird schon im 3.Jahrhundert v. Chr. ausführlich und eindrücklich von Philon von Byzanz in seiner Abhandlung über den Geschützbau beschrieben ${ }^{77}$. Konrad von Megenberg umschrieb im 14.Jahrhundert den Prozess folgendermassen: «Stahel kümt von eisen und wirt hert von vil smitslegen und widersprechen.» ${ }^{78}$

Die zunehmende Härte ist sogar am Klang der Hammerschläge zu hören ${ }^{79}$. Möglicherweise spricht sogar Plinius der Ältere von diesem Prozess, wenn er meint, «das im Feuer glühend gemachte Eisen verdirbt, wenn es nicht durch Schläge gehärtet wird $»^{80}$. Je nach Interpretation dieses Pliniustextes meint der antike Autor jedoch etwas ganz anderes $^{81}$. Von Stahl, d. h. Eisen mit legiertem Kohlenstoff, ist hier aber nicht die Rede!

Von dieser einfachsten Art des Härtens durch Verdichtung des Eisens unter dem Schmiedehammer berichtet, wie erwähnt, auch Philon von Byzanz (3./2.Jh.). Bei seiner Beschreibung von (Stahl?-)Schienen für Geschütze im «Handbuch der Mechanik» schreibt er u. a., dass das Werkstück «kalt kräftig geschlagen» werden solle, «denn das gebe die Elasticität», und weiter unten wird er konkreter: «Wir schlagen nun die Schienen auf beiden Seiten kalt, und so werden ihre Oberflächen hart, die Mitte aber bleibt weich, weil der Schlag, da er leicht ist, nicht ins Innere dringt; wie sie nun aus drei Lagen bestehn, zwei harten und einer weicheren, der mittleren, darum besitzen sie auch Elasticität, wie ich eben gezeigt habe.»82

\section{Einsatzhärtung / Aufkohlung / Zementation}

Eine oft eingesetzte und vielfach variierte Methode einer einfachen Stahlerzeugung ist das «sogenannte Einbrennen durch Aufstreuen kohlehaltiger Substanzen auf das glühende Eisen und die Einsatzhärtung durch Glühen des zu härtenden Werkzeugs» ${ }^{83}$. Dies kann auch unabsichtlich durch längeres sanftes Glühen in der Holzkohle erfolgen. Das Prinzip der oberflächlichen Kohlenstoffan- reicherung im Eisen wird allgemein als «Aufkohlen» resp. «arburization» bezeichnet ${ }^{84}$.

Die frühneuzeitlichen Metallurgen hatten die seit der Antike entwickelten empirischen Aufkohlungsmethoden und -materialien immer noch angewandt, ohne die chemischen Prozesse zu verstehen. Sie fassten die Kohlenstoffträger (Holzkohlenstaub usw.) als «brennliches Wesen» zusammen und nannten sie als Wirkstoff das «Phlogiston» - eine mysteriöse, hypothetische Substanz, die sich in der Luft anreichert ${ }^{85}$. In einem zweibändigen Eisen-Handbuch des 18.Jahrhunderts wird diese Vorstellung - in unseren Augen sehr umständlich - wie folgt beschrieben: «Das Eisen muss dadurch sehr ausgedehnet, und dessen Zwischen-

75 Kurze Übersicht über die unterschiedlichen Methoden zur Stahlerzeugung: Barraclough 1981, 16-18.

76 Rinman 1814, 150; Prechtl 1834, 10; Reiser 1896, 19 (ausführlich); Ledebur 1903, 747 («Je feinkörniger das Gefüge bei der Bearbeitung wird, desto mehr nimmt die Festigkeit ... zu, während die Zähigkeit ... in der Regel abnimmt.»); Epprecht/Schaller 1981, 31; Maddin et al. 1991, 5; Wagner 1993, 280 f.; Pleiner 2006, 66; Presslinger et al. 2007, 150; Balasubramaniam 2008, 229 (Indien).

77 Philon, Belopoiika, 4. Buch, Abschnitt 47 (Köchly/Rüstow 1853, 298/299).

78 Pfeiffer 1861, 479

79 Wagner 1993, 280 («... but European Smiths of the past few centuries seem not to have used this hardening technique to any significant extent.»).

80 Plin. nat. 34,149; Humphrey et al. 1998, 219; Halleux 2007, 1305 f. - Die Stelle in den Oden von Horaz (Hor. carm. 1,35,37-40), wonach das Schwert - weil es stumpf geworden ist - auf neuem Amboss umzuschmieden sei, beschreibt den gewöhnlichen Vorgang des Nachschmiedens und wird von Renoux (2012) wahrscheinlich überinterpretiert.

81 Plin. nat. 34,149 (übersetzt in der interdisziplinären Ausgabe von Rottländer 2000, 149: «... Wenn Eisen im Feuer glühend gemacht wird, verdirbt es, wenn es nicht durch Schmieden verfestigt wird. ...»).

82 Philon, Belopoiika 4,47; Diels / Schramm 1919, 52 f.; Livadefs 1956, 51 Anm. r.

83 Evenstad 1790, 64; Giolitti 1915, XX (Prinzip der Zementation); Steinbrings 1928, 67-69; Johannsen 1953, 153 (Zitat); Healy 1978, 232 und 236; Cleere 1981, 178; Henseling 1981, 22; Brunhuber 1991, 228 (Einsatzhärten); Maddin et al. 1991, 16 («surface carburizing»); 19 («case carburization»); Presslinger et al. 2007, 234; Cech 2010, 198; Craddock 2010, 252 f.; Craddock 2013, 16; Lang 2017, 6, Absatz 2. - Kritisch zu diesem einfachen Verfahren: Rehder 1989, $27 ; 31 ; 36$.

84 Den Prozess der einfachen Aufkohlung im Herdfeuer bei Weissglut beschrieben z. B. Sven Rinman 1782 und Ole Evenstad 1790, zitiert bei Wagner 1990, 111 und 112-115.

85 Zum Beispiel: Perret 1780, 85 f.; 129; 132; Halle 1783, 5 f.; 20; 37; Georgi 1785B, 307; 324f.; 333; 346; 364; 367; Giolitti 1915, XXV; Rinman 1815, 343. - Zur Geschichte des «Phlogiston»: Barraclough 1981, 11. 


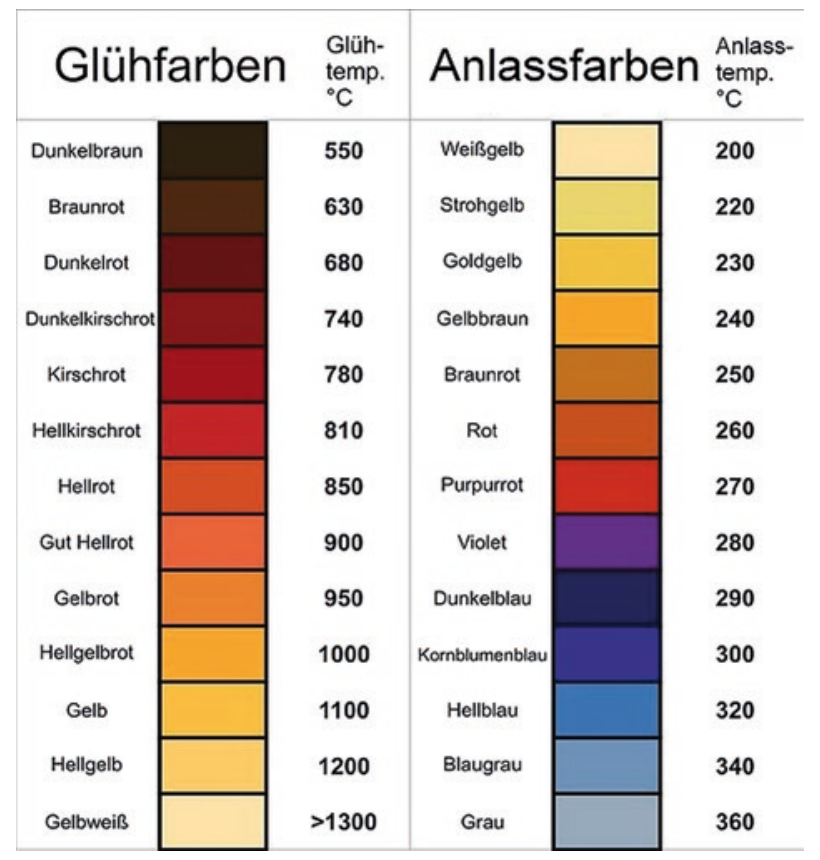

Abb. 9: Das Härten von Stahl geschieht oft in zwei Stufen: Zuerst wird scharf geglüht, meist bis auf Rotglut (Farbskala links), dann möglichst rasch in Wasser oder Öl abgeschreckt. Das ganze Objekt oder auch nur seine Arbeitskante wird anschliessend erneut erwärmt, aber nur bis zur «Anlassfarbe» (rechts). Damit diese auf dem blanken Metall sichtbar ist, muss eine Fläche blank gefeilt oder angeschliffen werden. Erneut wird in Wasser rasch abgekühlt. Diese Behandlung verändert die Härte und Elastizität des Stahls. In Kenntnis der gewünschten optimalen Eigenschaften und mit viel Erfahrung weiss der Schmied genau, auf welcher Stufe er sein Objekt glühen und abschrecken und danach «anlassen» muss.

räumchen so geöffnet werden, dass das von der Hitze in Bewegung gesetzte, und in einem Menstruum [Lösungsmittel] aufgelöste brennbare Wesen, in dieselben eingesogen werden kann. Dieses kann doch nicht schnell gehen, sondern erfordert einige Zeit, die zum Grade der Hitze, der Dicke des Eisens, der Lebhaftigkeit des Phlogistons, und der eigenen grösseren oder geringeren Neigung oder Anlage, dieses Brennliche um zu Stahl zu werden, aufzunehmen verhältnismässig ist.» ${ }^{86}$ Es war also lange Zeit nicht bekannt, dass der Kohlenstoff zur Stahlerzeugung ausschlaggebend ist ${ }^{87}$; er wird in diesem Zusammenhang erst ab dem frühen 19. Jahrhundert genannt. Der Pionier David Mushet erkannte in seinen Versuchen: «... crude iron and steel only differ from each other in the proportions of the carbon they contain.» ${ }^{88}$

In der Praxis wurde das «Einbrennen» von Kohlenstoff in vorindustrieller Zeit auf sehr unterschiedliche Weise erreicht (dazu unten S.28) und führte zu Stählen mit sehr heterogener Kohlenstoffverteilung (unten mit Anm. 112). Durch Aufkohlung wird «a hard surface ... produced on a softer and tougher core, because the carbon makes its way into the metal from the outside» ${ }^{89}$.

Nur mit einem Kohlenstoffgehalt von rund 0,3 bis maximal 2,0\% C lässt sich Eisen überhaupt härten: durch abruptes
Abschrecken aus der hellroten Glut zuerst und nachherigem Anlassen (Abb. 9, rechts) ${ }^{90}$, durch leichtes Wiederaufwärmen auf braune bis gelbe Farbe und nochmaliges Abschrecken. Schon Johann Samuel Halle brachte es 1783 auf den Punkt: «... was den Stahl am schnellsten abkühlt, das härtet ihn am besten.»91 Das erste Abschrecken würde den Werkstoff für Werkzeuge oder Waffen jedoch allzu hart und spröde (brüchig!) machen ${ }^{92}$. Deshalb soll durch das folgende Anlassen ein Teil der Elastizität des Roheisens zurückerlangt werden: Dermassen zweistufig behandelt, ist der Stahl hart genug als Arbeitskante und Schneide und elastisch genug, um bei der Arbeit nicht zu brechen. Allerdings: «Das nachherige Anlassen zur Milderung der Sprödigkeit findet sich bei antiken Schriftstellern nirgends erwähnt ...» ${ }^{93}$ Die archäometrischen Untersuchungen am Gefüge antiker Stähle belegen aber mehrfach die Kenntnis auch dieses Verfahrens!

Ziel der Stahlherstellung ist es also, einen optimalen Kohlenstoffgehalt von etwa 0,3 bis max. 1,5\% C in das Eisen zu bringen, damit es ganz oder teilweise gehärtet werden kann. Im Rennfeuer-Ofen verhüttetes Eisen weist normalerweise sehr niedrige Kohlenstoffgehalte auf (ca. 0-0,3\% C); es muss also mit Kohlenstoff angereichert resp. «aufgekohlt» werden. Dieser Prozess wird auch Zementation genannt. Die Aufkohlung von Eisen zu Stahl («blister steel» ${ }^{94}$ ) durch Zementation ist nach Harry Brearley «not only of great antiquity, but has always been of great importance, and was the direct incentive and predecessor of the comparatively modern art of making cast streel» (vgl. auch unten mit Abb. 19) ${ }^{95}$.

Das erst viel später erzeugte Gusseisen ${ }^{96}$ hingegen weist sehr hohe Kohlenstoffgehalte auf (ca. 2,1-4,3\% C), ist gar nicht mehr schmiedbar und muss dementspre-

86 Georgi 1785B, 345.

87 Cech 2010, 198 («... sondern man nahm an, dass Feuer Eisen «reinigt> oder auf andere Weise verändert»).

88 Mushet 1840, 33; 501-530 (Zitat: S. 526)

89 Reed 1934, 386.

90 Duhamel 1786, 434; Landrin 1835, 179-181; Reiser 1896, 24-33 (Abschrecken / Härten) und 68-76 (Anlassen); Ledebur 1903, 725 731; Steinbrings 1928, 59-65; Krishnan 1954, 41-44; Neumann/Wilsdorf 1954, 55-57; Epprecht/Schaller 1981, 31; Presslinger 2007. - Zum Ausglühen, Abschrecken, Härten und Anlassen in antiken Schriftquellen: Renoux 2004.

91 Halle 1783, 30. - Zu den alten, phantasievollen bis esoterischen Empfehlungen für Härtewasser-Zusätze siehe unten mit Anm. 183.

92 Halle 1783, 32f. («Da das Wasserhärten Stücke wider unsre Absicht bisweilen zu sehr erhärtet, und brüchig macht, so hat man das Anlassen erfunden ...»).

93 Rommel 1929, 2130.

94 Dazu zum Beispiel: Barraclough 1981, 70-78.

95 Brearley 1914, 2 (Zitat); Rehder 1989, 35.

96 In China ab etwa 400 v. Chr. (Needham 1958, 9-14; Da 1965, 68) resp. 200 n. Chr. (Read 1934, 388), in Europa ab dem 15.Jh. n. Chr. (hierzu auch Duhamel 1786, 452-457). 
chend mit geeigneten Verfahren teilweise entkohlt werden $\left(«\right.$ Frischen $\left.{ }^{97}\right)$.

Versuche haben aber auch gezeigt, dass im Rennfeuer - entgegen einer lange Zeit vertretenen Auffassung - beim Verhütten des Eisenerzes nebst kohlenstoffarmem punktuell auch kohlenstoffreiches Eisen entstehen kann (s. unten).

Zusammenfassend lasse ich Karolin Kastowski und Mitautoren zu Wort kommen, die den Arbeitsprozess des Aufkohlens und Verschweissens stählener Werkstoffe für die Latènezeit folgendermassen beschreiben ${ }^{98}$ : «Das Aufkohlen von dickeren Schichten nimmt viel Zeit in Anspruch und die Verstählung ergreift bloss die Oberfläche. Die Gefahr der Abschleifung droht nach einer kurzen Benutzung. Einige dieser Nachteile können durch Flächenaufkohlung und Zusammenschweissen von dünneren Eisenbändern beseitigt werden. ... In diesem Falle ist kaum eine andere Lösung als das Verschweissen von den im Voraus aufgekohlten Elementen zu einem Ausgangsstück für das geplante Werkzeug anzunehmen. Das oben erwähnte Verfahren war bereits ziemlich anspruchsvoll. Der heutigen Praxis gemäss werden die Eisenteile bei höheren Temperaturen von 1200 bis $1300^{\circ} \mathrm{C}$ (Weissglut) geschweisst, denn unter diesen Bedingungen wird das austenitische Metall genügend plastisch; die Stähle, bei denen die Entkohlungsgefahr unter höheren Temperaturen droht, schweisst man dagegen nur bei etwas niedrigeren Temperaturen, also kaum den kritischen Temperaturbereich überschreitend.»

\section{«Rostverfahren» nach Diodor?}

Der Vollständigkeit halber sei hier noch ein antikes «Veredelungsverfahren» für Eisen erwähnt, welches das Schmieden von Waffen ermöglichen sollte, die «alles zerhauen, was sie treffen» und nicht vor «Schild noch Helm, noch Knochen» haltmachen:

Das von Diodor aus dem 1.Jahrhundert v. Chr. überlieferte Rezept muss unvollständig sein, denn das Oxidieren normalen Eisens allein kann noch zu keiner Qualitätsverbesserung führen. Diodor schreibt: «Auf eine eigene Art werden die Schutz- und Angriffswaffen bei ihnen [den Celtiberern] verfertigt. Sie vergraben Eisenplatten in die Erde und lassen sie liegen, bis der Rost nach und nach die schwächeren Theile des Eisens völlig verzehrt hat, so dass nur die festesten noch übrig sind. Hieraus machen sie nun treffliche Schwerter und die übrigen Werkzeuge für den Krieg.»99 clough 1981, 361-388; 394-402; Henseling 1981, 42 Abb. 20; 86 f. Abb. 58; Rostoker/Bronson 1990, 139-152; Michel 2011, 368-371 («oroshi»-Technik in Japan); Sim 2012, 133 f.; Lang 2017, 6, Absatz 3 (Frischen in der Antike?).

98 Kastowsky et al. 2011, 515.

99 Diod. 5,33 (nach der Übersetzung von Wurm/Klawes 2014, 355); Poppe 1820, 16; Rommel 1929, 2130; Ploss 1957, 112; Livadefs 1956, 51 Anm. q; Moesta 1983, 170. 


\section{Direkte Stahlgewinnung im Eisenverhüttungsverfahren}

Bei der Verhüttung von Eisenerz im Schacht- resp. Rennfeuer-Ofen entsteht nicht nur, wie lange geglaubt, kohlenstoffarmes Weicheisen ${ }^{100}$. Dieses ist zwar gut zu schmieden und eignet sich ausgezeichnet zur Feuerverschweissung. Härten durch Abschrecken und Anlassen kann man es aber nicht, denn dazu benötigt es einen Kohlenstoffgehalt von mindestens $0,3 \% \mathrm{C}$.

Experimente in nachgebauten antiken Rennöfen haben -spätestens seit 1964 - wiederholt gezeigt, dass in gewissen Milieus innerhalb des Ofens, bei einer Temperatur um $1200^{\circ} \mathrm{C}$ und je nach Mischungsverhältnis von Holzkohle und Erz, aber auch mit Kohlenstoff angereicherte Eisenflitter, Plättchen und auch grössere «Eisenschwämme» entstehen können ${ }^{101}$, denn: «Im Schachtofen wird zunächst ... kohlenstoffarmer Stahl erzeugt, der später im Schachtofen bei Kohlenstoffüberschuss in einem weiteren Prozessschritt in Roheisen umgewandelt wird (Mehrstufenprozess).»102 Die Anwesenheit von Mangan begünstigt diesen Prozess, und Phosphor erschwert ihn, denn «stark manganhaltiges Eisen kann besonders viel Kohlenstoff aufnehmen» ${ }^{103}$. Neuere Forschungen und Experimente haben gezeigt, dass mit norischen und anderen Erzen durchaus Stahl durch direkte Reduktion erzeugt werden kann ${ }^{104}$. Jüngere Beobachtungen in Afrika bestätigen diese Vermutung. Von dort wird berichtet, wie im Rennofen «unsorted cast iron, steel and low carbon pellets, lumps and fragments» entstehen können, die dann sorgfältig ausgelesen und entweder zusammengeschweisst oder in einem Tiegel mit Lehm zusammengebacken und homogenisiert werden müssen (s. S. 54) ${ }^{105}$. Das kohlenstoffreiche Produkt, das im sog. «Bloomery-Prozess» ${ }^{106}$ direkt aus dem Rennofen gewonnen wird, wird auch als Rohstahl bezeichnet ${ }^{107}$. Ole Evenstad berichtet im 18. Jahrhundert ausführlich von direkter Stahlerzeugung in norwegischen Rennöfen ${ }^{108}$.

Offenbar herrschen in der Ofenmitte die besten Bedingungen zur Kohlenstoffanreicherung im reduzierten Eisen ${ }^{109}$. Es ist zu vermuten, dass die römischen Berg- und Hüttenleute in Noricum (Kärnten / A) Ofenkonstruktionen kannten und eine Prozessführung beherrschten, die es ihnen erlaubte, direkt aus dem Verhüttungsprozess KohlenstoffStahl («bloomery steel») zu gewinnen ohne den Umweg über langwierige und energieintensive Aufkohlungsprozesse (wie z.B.in Augusta Raurica). Auf diese Weise sollen Stähle mit rund $1 \%$ Kohlenstoff und bisweilen sogar mit bis zu 2\% C direkt durch Reduktion im Verhüttungsofen gewonnen werden können ${ }^{110}$.

Lokal und in enger Nähe zu den Blasebalgdüsen können sich auch kleine Partikel aus Gusseisen im Verhüttungsofen bilden. Durch starke Luftzufuhr über die Ge- bläse werden diese kohlenstoffreichen Teile jedoch schnell wieder oxidiert und entkohlt ${ }^{111}$. Diese unterschiedlichen lokalen Prozessbedingungen führen schlussendlich zu einem heterogenen Eisen-Stahl-Gefüge ${ }^{112}$. «Durch mehrfaches Umschmieden, später «Gärben` genannt, konnte ein homogenes, weitgehend schlackenarmes Eisen (unter 1 Vol-\% Schlackeneinschlüsse) erzeugt werden.» ${ }^{113}$ Im alten Indien und im frühindustriellen England ${ }^{114}$ war durch das «Co-smelting» in Tiegeln eine optimale Durchmischung möglich (s. Seite 41).

100 Straube 1986, 21 und 26

101 Rommel 1929, 2127 f.; Pleiner 2000, 190-193; Straube et al. 1964 (S. 28: Analyse aus grossen Versuchsöfen: 2,95\% C; S. 32: aus kleinen Versuchsöfen: um 0,5\% C); Pleiner 1968, bes. 313 und 316; Pleiner 1969A, bes. 486 f.; Schaaber 1977, 221; Straube 1973, 480 491 Abb.1-18; Rehder 1989, 27 f.; Rostoker/Bronson 1990, 121 und 135 f.; Straube 1996, 28f.; 33-39; Tab.2; 59-114 Abb.28-31; 40; Salter 1997; Juleff 1998, 221 f.; Sperl 2002A, 61-63 Anm. 9-15 (mit älterer Lit.); Galik et al. 2003, 71; Navasaitis / Selskienė2007A, 390f. Abb. 4 (0,2-0,8\% C in Eisenluppe aus Virbaliūnai /LT, 4. / 5. Jh.); Sim 2012, 133; Truffaut 2014, 290; Lang 2017, 7. - Zu den Beobachtungen und Feststellungen dieser Autoren kritisch: Espelund 1996, 48. - Über die Heterogenität von Stahl und Eisen in Rennfeuerluppen war man sich in historischer Zeit bewusst und homogenisierte die Masse durch Umschmieden: Duhamel 1786, 421 (zitiert nach R. A. F. de Réaumur)

102 Presslinger et al. 2016.

103 Hollemann/Wiberg 2007, 1639

104 Presslinger/Köstler 1991, 23f. Abb. 6 (Noricum); Truffaut 2008 (vertritt auf S.262 die Meinung, dass das Mangan in norischen Erzen die Stahlproduktion wesentlich begünstigt hat); Navasaitis/Selskienė 2007A, 390f. (Baltikum, um 500 n. Chr.). - Zum Mangan in norischen Eisenerzen siehe auch unten mit Anm. 128.

105 David et al. 1989, 184; 196 und 199 (Zitat). - Schilderung dieses aufwendigen Prozesses in einem Tiegel: Celis 1991, 163-167 Abb. 134-137 (Westafrika).

106 Barraclough 1981, 23-26.

107 Presslinger/Köstler 1991, 18.

108 Evenstad 1790, $64 \mathrm{f}$.

109 Radomir Pleiner $(1968,313)$ rechnet mit einer Prozesstemperatur von rund $1200^{\circ} \mathrm{C}$

110 Neumann/Wilsdorf 1954, 55; Schaaber 1963, 203; Pleiner 1980, 397; Presslinger 2008.

111 Pleiner 1968, 316 und 318

112 Beispiele von Stahlobjekten und -barren mit sehr heterogener Verteilung von kohlenstoffarmen und -reichen Zonen: Godfrey/van Nie 2004, 1120 (gehärtete spätantike Stahlpunze, HV 326-409); Pagès at al. 2006, 114f. Abb. 8 und 9 (kohlenstoffreiches Halbzeug); Birch 2017, 149 (kohlenstoffreiche Roheisenklumpen).

113 Sperl 2002A, 63 (Zitat); Sperl 2002B, 151. - Beispiel eines Plattenbarrens bester Stahlqualität aus dem römischen Chur/GRWelschdörfli mit gut homogenisiertem Gefüge $(0,97 \%$ C): Epprecht/Schaller 1986, 188 (hier Abb. 33, 46).

114 Barraclough 1981, 388-393. 
Das «Geheimnnis» eines guten Stahlofens mag eine innen angebrachte Senke oder Nische sein, in welche die Stahlteilchen absinken und unter glühender Holzkohle ihren Kohlenstoffgehalt bewahren. Erst 1987 wurden in einem bisher wenig bekannten Eisenverhüttungsgebiet Noricums, im Görtschitztal/A (Abb.27,5), mindestens zwei Öfen freigelegt (Abb. 10), die drei resp. vier Luftkanäle aufwiesen, welche von den Blasebälgen ins Ofeninnere führten (Abb. 11,4; 12,3). Unter den Mündungslöchern der Luftzufuhr war je eine Nische ausgespart (Abb. 11,5; 12,2), die wahrscheinlich zur Aufnahme der kohlenstoffreichen Luppen bestimmt war, wo unter schützenden Holzkohlen eine reduzierende Atmosphäre herrschte ${ }^{115}$.

Man hatte offenbar solche einzelnen eisen- resp. stahlhaltigen Luppen und Eisenschwammbrocken aus dem Ofen herausgelesen und auf ihre Härte geprüft: So konnte man die spröden Stahlstücke von den weicheren Eisenstücken trennen und separat zusammenschweissen ${ }^{116}$. Die Beschickung der Öfen mit Erz, die optimale Menge der Holzkohle ${ }^{117}$ und allfällige Zuschlagstoffe, die Feuerführung und die Bauweise der Öfen müssen genauso entscheidend für ein gutes Resultat gewesen sein wie die Erfahrung der Stahlmacher: «The problem is evidently more complex, and it seems that the old smelters after all succeeded only sometimes in producing steel in the furnance.» ${ }^{118}$

Der in den letzten Jahren an den raffinierten Verhüttungsöfen im Görtschitztal in Noricum (Abb.10; 12) erschlossene Arbeitsprozess muss äusserst effizient gewesen sein! Gerhard Sperl fasst ihn - gestützt auch auf Experimente mit Nachbauten - folgendermassen zusammen: «Aus den Ofenmassen, der Konstruktion und den Nutzungsspuren, insbesondere den Auswaschungen unter dem Windeintritt, wurde angenommen, dass vor jeder Düse (Abb. 11,4.5; 12,1.3) eine Luppe von etwa $20 \mathrm{~kg}$ Gewicht nach jeweils 6 Stunden Blasarbeit entstand, die aus dem Ofen gezogen wurde, ohne dass der gesamte Prozess unterbrochen werden musste. Vorteil war eine gewaltige Brennstoffersparnis (50 bis 70 Prozent) und eine gleichmässige Ausbeute und Qualität, die Grundlage einer geordneten Wirtschaft um die Ofenanlagen.» ${ }^{119}$ Dass diese Technologie des «direkten Verfahrens» zur Stahlgewinnung im Rennofen so lange Zeit und in erstaunlich gleichbleibender Produktqualität hatte angewendet werden können, zeugt von einer grossen Erfahrung und straffen Organisation, die man als «amtliche Qualitätssicherung» bezeichnen könnte: «Der Ferrum-Noricum-Prozess ist damit als Meisterleistung der keltisch-römischen Hüttenleute und ihrer Verwaltung zu sehen.»120

Vermutlich beschrieb Aristoteles bereits im 4.Jahrhundert v. Chr. in seinen Meteorologika just dieses Vorgehen ${ }^{121}$ : «Auch Schmiedeeisen lässt sich schmelzen, so dass es flüssig und wieder fest wird. Entsprechend macht man es bei der Stahlbereitung: hier bildet die Eisenschlacke einen Bodensatz, der von unten weggeräumt wird; hat das Eisen diesen Prozess mehrmals durchlaufen, so ist es durch diese Reinigung zu Stahl geworden. Oft lässt man aber diesen Reinigungsprozess nicht stattfinden, denn der Verlust an Material und an Gewicht ist dabei gross. Je weniger man es reinigen muss, desto besser ist das Eisen.» Es erstaunt nicht, dass diese wenig klare Textstelle zu mancherlei kontroversen Theorien und Experimenten anregte ${ }^{122}$.

Wie wir gesehen haben, belegen neuere Experimente die Möglichkeit, im Rennfeuer nebst Weicheisen auch Stahl herzustellen. Nicht nur das: Lokal findet offenbar eine partielle Verflüssigung statt, die Stahlpartikel mit bis zu 3,65\% Kohlenstoff hervorbringt! Von diesen bisher erst selten archäometrisch erkannten antiken «Gusseisen-Zwischenprodukten» seien einige Roheisenstücke aus dem antiken Teurnia bei Lendorf-St. Peter in Holz / A erwähnt. Sie enthalten sogar über 4,3\% Kohlenstoff und sind sehr porös, was «auf die Gasentwicklung bei der Abkühlung der flüssigen Metallschmelze und bei der Erstarrung im Zweiphasengebiet - flüssig / fest - zurückzuführen» ist ${ }^{123}$.

Bedingung für die direkte Stahlerzeugung im Rennofen sind aber grosse Erfahrung und ein eingeübter Prozessablauf, «controlled by a skilled smelter» ${ }^{124}$. Trotz vieler Experimente mit verschiedenen Erzen ${ }^{125}$, Öfen, Befeuerungen und Prozessführungen ist es erst selten gelungen, die Technik der Direktgewinnung von «Norischem Stahl» nachzuvollziehen ${ }^{126}$. Immerhin haben die Experimente gezeigt,

115 Glaser 1995; Glaser 2000. - Bei den Verhüttungsversuchen Harald Straubes von 1964 wurde noch mit einer Düse pro Ofen belüftet, was leider zu keinen repräsentativen Ergebnissen führen konnte (Straube et al. 1964, 17-36 Abb. 4-6; 43).

116 Sim 2012, 133; Lang 2017, 6, Absätze 1 und 5; Navasaitis / Selskienẻ 2007B, $167 \mathrm{f}$.

117 Pleiner 1968, 313 («... a greater quantity of charcoal in proportion to the ore in the individual charges»).

118 Pleiner 1968, 313.

119 Sperl 2002B, 152.

120 Zur norischen Bergbau- und Verhüttungsverwaltung siehe auch unten mit Abb. 24 und 26. - Malzacher 1963, 53; Galik et al. 2003, 73 (Zitat); Sperl 2004, 961.

121 Aristot. meteor. 4,6 (383a-b); Beck 1884, 459f.; Neumann/Wilsdorf 1954, $81 \mathrm{f}$.; Livadefs 1956, $64 \mathrm{f}$; Healy 1978, 232 Anm. 44; Humphrey et al. 1998, $219 \mathrm{f}$.

122 Pleiner 1969, 25 f.; Sauder 2013; Kucypera / Hošek 2014, 37 Abb. 5.

123 Presslinger et al. 2016, 139 Abb. 2. - Ähnliche Befunde aus dem angelsächsischen England (8. /9.Jh.): Mack et al. 2000; aus Nordeuropa (4.-7.Jh.): Navasaitis/Selskienė 2007B (S. 167 mit weiteren Beispielen und Lit.).

124 Wrona 2013, bes. 10 (Zitat) Tab. 2; Kucypera / Hošek 2014, 35.

125 «Stahlerze» und «Stahlgruben» erwähnt bei Johannsen 1953, 153. - Ob die ortsspezifischen Mangan- und Phosphor-Gehalte der Erze bei der Stahlerzeugung eine entscheidende Rolle spielten, wird kontrovers diskutiert. Heute vermutet man eher, dass der Ofenbau und die Prozessführung im Rennofen ausschlaggebend für partiell hohe Kohlenstoffwerte sind.

126 Für diesbezügliche Auskünfte danke ich Guntram Gassmann, Landesamt für Denkmalpflege Stuttgart / D (Januar 2016). 

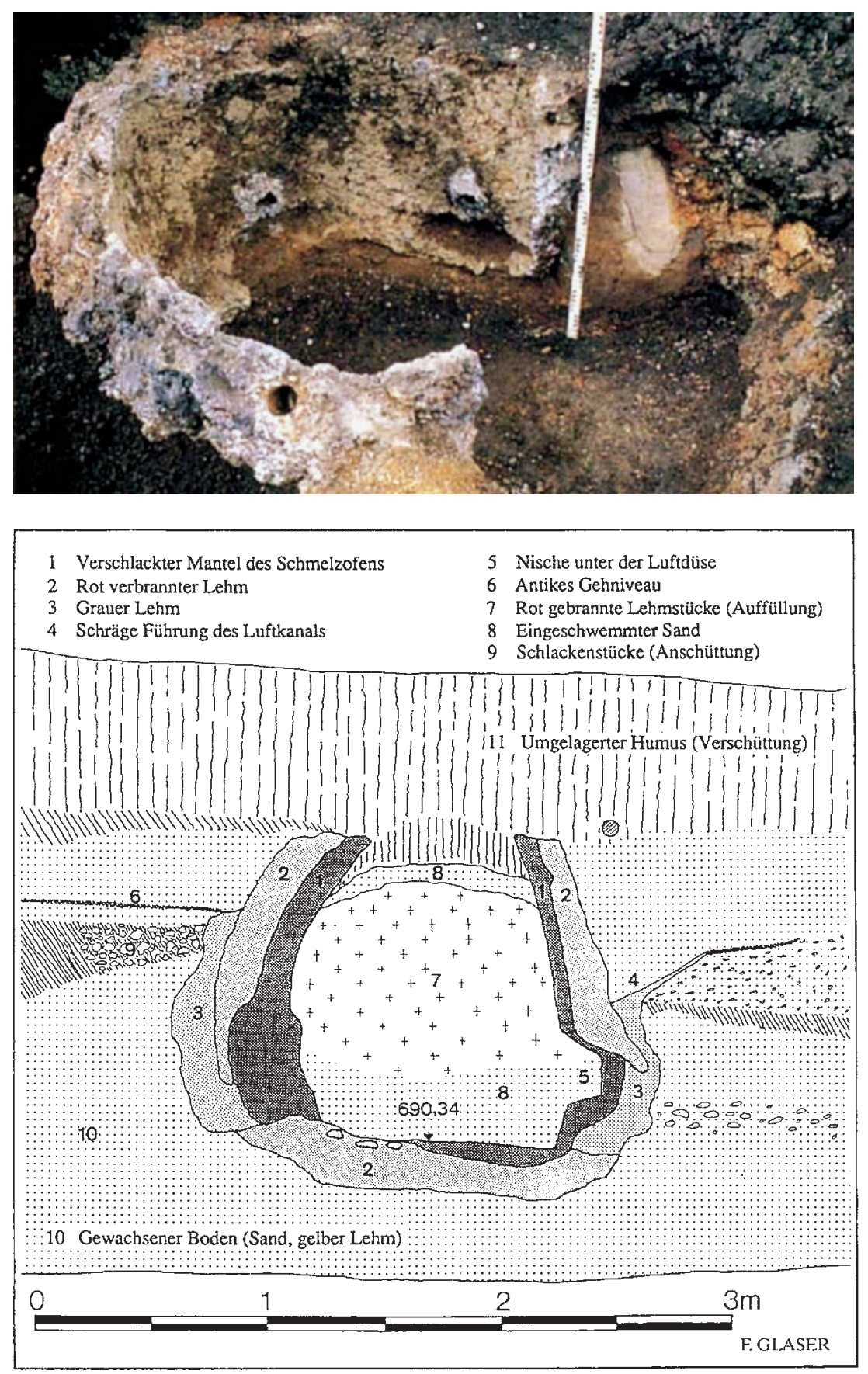

Abb. 10: Rennofen 9 aus Kitschdorf / $A$ in Noricum, etwa einen Meter hoch erhalten, Innendurchmesser ca. 1 Meter (Grundriss: Abb. 12). Mit dicker Verschlackung bis an die Unterkanten von vier Nischen, die sich unter den vier Luftöffnungen (für vier Gebläse) befinden (analog Abb. 11,5).
Abb. 11: Rennfeuerofen aus Möselhof/A in Noricum, Querschnitt. Man beachte, dass mehrere Belüftungsdüsen ( «Tuyère») von den Gebläsen in den Ofenraum führen (4) und jeweils darunter eine Nische (5) angebracht ist (Abb. 10; 12).

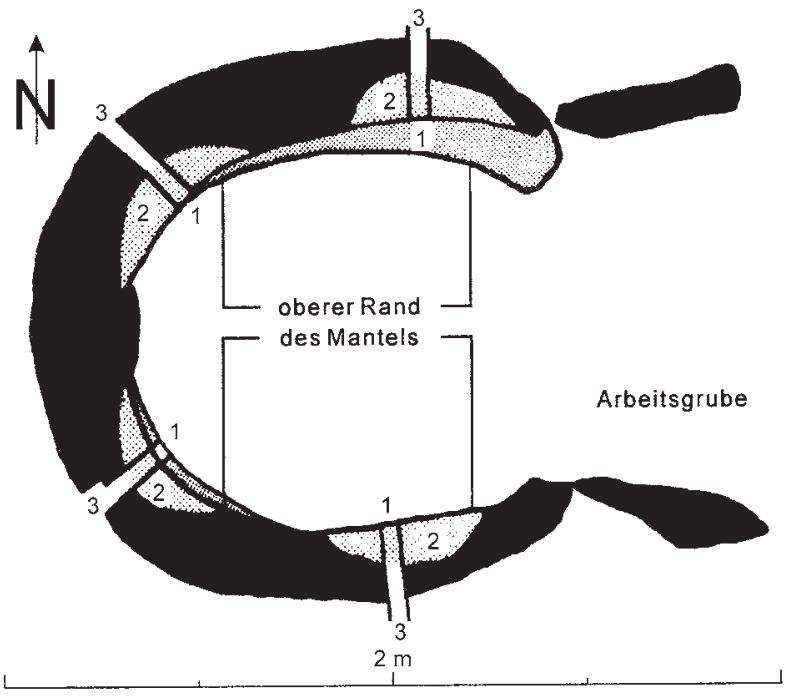

Abb. 12: Rennofen 8 aus Kitschdorf/A in Noricum (Foto: Abb. 10), mit mehreren Nischen wie im Ofen aus dem nahen Möselhof/ A (Abb. 11,5). Bildbreite $2 \mathrm{~m}$. 
dass mit einem «high fuel to ore ratio and a tall furnance» die Bildung von Stahl unterstützt werden kann ${ }^{127}$.

Man hat immer wieder den hohen Mangangehalt steirischer (und anderer) Eisenerze als Ursache für die Möglichkeit der Direktgewinnung guter Stahlqualitäten aus den Verhüttungsöfen ins Feld geführt ${ }^{128}$. Seit es aber gelungen ist, auch mit phosphorreichen, aber praktisch manganfreien Erzen partiell Kohlenstoff-Stahl zu erzeugen, muss nicht allein der Chemismus der Erze, sondern auch die Technologie für die Herstellung von Stahl entscheidend gewesen $\operatorname{sein}^{129}$. Harald Straube hielt 1986 fest, dass «sowohl in Europa als auch in Kleinasien kohlenstoffhaltiger Stahl bei der Erzreduktion im Schachtofen angefallen war und vieles dafür spricht, dass schon die Schmiede jener Zeit verstanden, den härteren Werkstoff vom weichen, praktisch kohlenstofffreien Eisen zu unterscheiden ...». Er glaubte dabei an eine zentrale Rolle, die Noricum in der Eisenveredelung und Geräteherstellung innegehabt hätte: «Bezüglich dieser Technik [des Härtens durch Abschrecken] gibt es keine Indizien dafür, dass sie - von uncharakteristischen Einzelfällen abgesehen - andernorts zu gleicher Zeit wie in Noricum oder gar früher beherrscht und in grösserem Umfang absichtlich angewendet wurde.» ${ }^{130}$ Für den Althistoriker Gerhard Dobesch gibt es - im Lichte der antiken Quellen - drei besonders hervorzuhebende Eisen- resp. Stahlqualitäten: als bestes das Eisen der Chalyber ${ }^{131}$, gefolgt von jenem aus Bilbilis in Spanien und als «drittbestes» jenes der Noriker ${ }^{132}$.

Inzwischen haben sich die «Einzelfälle» jedoch gemehrt, und wir müssen vermuten, dass sowohl kohlenstoffhaltiges Eisen im Rennofen dezentral erzeugt als auch Verbundstoffe mit Eisen und Stahl hergestellt und die so geschmiedeten Werkzeuge und Waffen vielerorts gehärtet wurden ${ }^{133}$. Für manche Eisenverarbeitungszentren im Mittelmeerraum ist aufgrund der neueren Forschungen anzunehmen, dass die Stahlproduktion direkt im Rennfeuer die Regel war und die Aufkohlung (Zementation) von Schmiedeeisen zu Stahl eher die Ausnahme. Ümit Güder, Marie-Henriette Gates and Ünsal Yalçın fassen die Resultate im Fall des eisenzeitlichen Verhüttungsplatzes von Kinet Höyük/TR (Mitte 8. bis Mitte 7.Jh. v. Chr.) beispielhaft zusammen ${ }^{134}$ : «The current study supports the consensus on Iron Age metallurgy in the eastern Mediterranean and Near East that carburizing was realized during the smelting process, without any evidence for quenching. It especially provides new data and insights on local workshop practice during this period of developing iron technology. The research conducted here demonstrates that Kinet's metal workers appreciated the heterogeneous nature of their materials and achieved success with it by adapting thermo-mechanical treatments. They knew to select the medium- and high-carbon steel, which is harder than pure iron, for improved tool production. They could apply effective heat treatments by stabilizing the temperatures in their smithing hearths. They were also aware of refractory materials, and the advantages they offered in furnace construction or as fluxes. Kinet's ironsmiths thus belonged to a broad community of contemporary craftsmen with shared technological knowledge.»

Das Wissen um Abschrecken und Anlassen der stählernen Arbeitskanten von Werkzeugen war allgemein bekannt ${ }^{135}$ !

Es stellt sich die Frage, wie man die weichen von den harten (kohlenstoffhaltigen) Eisenpartikeln aus dem Verhüttungsofen trennte. Es wurde vermutet, dies sei durch Auslese und Härteprüfung erfolgt (s. oben mit Anm. 116).

127 Dungworth 2011, 240 (Zitat) und 241.

128 Malzacher 1963, 51; Pleiner 1968, 313; Truffaut 2008 (mit älterer Lit.); Kucypera / Hošek 2014, 35; Truffaut 2014, bes. 290 f.

129 Zur Bearbeitbarkeit von phosphorhaltigem Eisen und dem Einfluss des Phosphors auf die Qualität (z. B. Sprödigkeit): Vega et al. 2003.

130 Straube 1986; Straube 1996, 29 (Zitat). - Der Prozess der direkten Stahlgewinnung im Rennfeuer wird ähnlich auch von Evenstad 1801, 59-64, beschrieben («Von der Methode den gerösteten Eisenstein im Blaseofen zu Stahl zu verblasen»).

131 Siehe dazu auch unten mit Anm. 186.

132 Dobesch 2000, 12-13 und Anm. 15.

133 Kucypera / Hošek 2014, 38. - Zu ausgereiften Eisen-Stahl-Verbundstoffen und deren Härtung durch Abschrecken und Anlassen im römischen Vindonissa (Windisch/AG): Epprecht/Schaller 1981; in den Kleinkastellen Zugmantel und Feldberg: Maddin et al. 1991, 8-16 Abb. 1-3.

134 Güder et al. 2017, $62 \mathrm{f}$.

135 Plin. nat. 34,146; Rommel 1926, 2128-2130 (mit weiteren antiken Quellen zum Abschrecken). - Ebenfalls beschrieben im Rasaratna Samuchaya («Alchemie Indiens») des indischen Autors Vagabhata aus dem 13. oder 14. Jahrhundert n. Chr. (zitiert bei Prakash 2011, 401 Abb.17) oder von Thephilus Presbyter (um 1125), Buch 3, Kap.18-21, nach der praxisnahen Übersetzung Brepohls 1987, 80-83. - Zur Technik des Anlassens und den Anlassfarben: Perret 1780, 118f.; Pleiner 2006, 69 Tab. 2. 


\section{Indirekte Stahlgewinnung durch Aufkohlungsprozesse}

\section{Aufkohlung im Herdfeuer}

Nebst den beiden direkten Technologien zur Stahlherstellung - Verhüttung mit selektiver Auslese resp. Frischen von Gusseisen - ist es am einfachsten und naheliegendsten, stark kohlenstoffhaltige Stoffe durch langes Einwirkenlassen auf der Eisenoberfläche zur Diffusion in das Metall zu bringen. Bei der Stahlerzeugung ist der «Härtegrad vom Kohlenstoffgehalt abhängig; dadurch erklärt sich die immense Wichtigkeit der Aufkohlung in der Metallurgie» ${ }^{136}$.

Dass diese Methode der Herstellung «von Stahl durch Glühen des zuvor entkohlten Eisens mit Holzkohle» zwar «umständlicher und kostspieliger» war «als die unmittelbare Erzeugung aus Roheisen im Frischfeuer ...», betonte vor über hundert Jahren Adolf Ledebur. Die Aufkohlungsmethode würde sogar «vorläufig auch noch eine gewisse Bedeutung sich bewahren» (Abb.17). Er sah die Vorteile im Zementationsverfahren u.a. darin, dass auf diese Weise weniger Fremdkörper in den Stahl gelangen können als im Verhüttungsofen, dass hierdurch reinere Stähle zu erzeugen seien und dass sich aufgekohlter Stahl (Abb.13), trotz höherer Herstellungskosten, gut für «die Herstellung feinerer Werkzeuge, Feilen und dergleichen» eigne $^{137}$.

\section{Einsatzhärtung (Zementation)}

\section{Wirkungsweise und Glühdauer}

Die Aufkohlung von Eisen, auch Einsatzhärtung, box/case hardening oder Zementation genannt, erfolgt durch «ein langdauerndes Glühen von Eisenstücken niedrigen Kohlenstoffgehalts in einem Tiegel oder Kasten aus gebranntem Ton oder Eisen, der mit Holzkohlepulver dicht gestopft und luftdicht verschlossen wurde» (Abb. 17; 18) ${ }^{138}$. Damit das Eisen überhaupt Kohlenstoff aufnehmen kann, bedarf es einer Prozesstemperatur von mindestens $723^{\circ} \mathrm{C}^{139}$ und einer sehr langen Feuerungszeit: «Die Zementhärtung ... ist nur ein langsames Verfahren, so in einer Stunde kaum die Dicke eines Pergamentblattes verbessert [aufgekohlt], welche im Putzen [Schleifen, Polieren] wieder verlohren geht.»140 Um eine Kohlenstoffanreicherung durch Einsatzhärtung auch in der Tiefe zu erreichen, ist eine Zementationsdauer von vielen Stunden erforderlich (Abb. 13).

Zur genügend intensiven Aufkohlung im abgedeckten Glühkasten, im verschlossenen Tiegel oder in einer Lehmumhüllung sind lange Einwirkungszeiten und sehr hohe Temperaturen erforderlich, wie alle Autoren darlegen, so zum

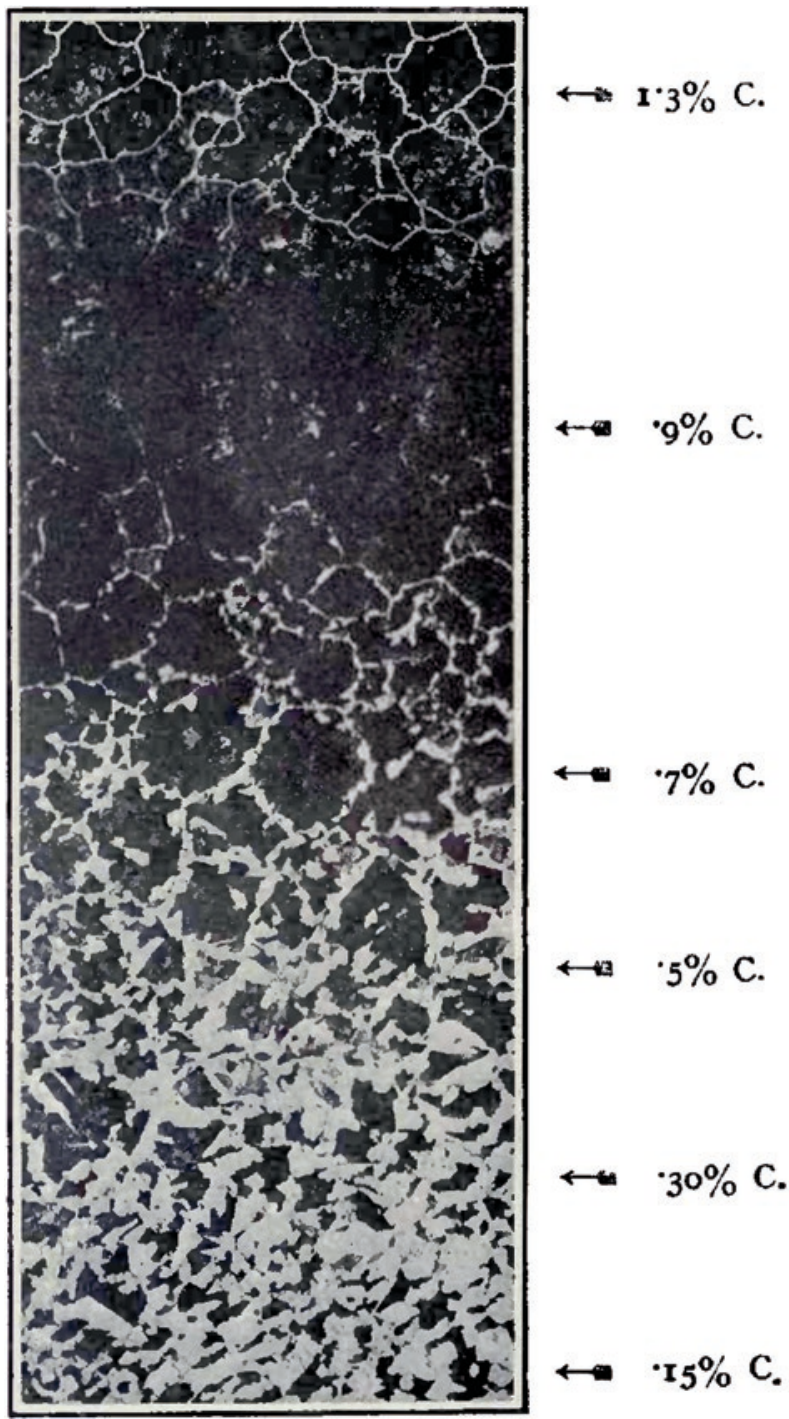

Abb. 13: Polierter Querschnitt durch ein während acht Stunden bei $1000^{\circ} \mathrm{C}$ aufgekohltes Eisenstück. Der nach innen abnehmende, durch die Zementation eingebrachte Kohlenstoff ist dunkel, die Eisenkörner (Ferrit) sind hell. Von aussen (oben im Bild) nach innen nimmt der Kohlenstoffgehalt von 1,3\% C bis 0,15\% C kontinuierlich ab und zeigt die zeit- und temperaturabhängige Eindringtiefe und die beschränkten Möglichkeiten dieses Verfahrens (vgl. Abb. $107 f f$.). Nur durch tagelanges Glühen bei rund $1000^{\circ} \mathrm{C}$ von nur wenige Zentimeter dünnen Eisenstangen ist eine gute Durchdringung des Eisens mit Kohlenstoff resp. ein homogener Stahl zu erreichen. 


\begin{tabular}{|c|c|c|c|}
\hline Quelle & Prozess-Temperatur & Verweildauer & Eindringtiefe (Ergebnis) \\
\hline Epprecht / Schaller 1981, 30: & $>700^{\circ} \mathrm{C}$ & «lange» & $?$ \\
\hline Pleiner 2006, 67: & $780-770^{\circ} \mathrm{C}$ & $?$ & (ca. $0,8 \% \mathrm{C}$ ) \\
\hline Pleiner 2006, 67: & $815^{\circ} \mathrm{C}$ & $?$ & (ca. $0,6 \% \mathrm{C}$ ) \\
\hline Pleiner 2006, 67: & $830^{\circ} \mathrm{C}$ & $?$ & (ca. $0,5 \% \mathrm{C}$ ) \\
\hline Rostoker / Bronson 1990, 124: & ca. $850^{\circ} \mathrm{C}$ & $24 \mathrm{~h}$ & $3 \mathrm{~mm}$ \\
\hline Pleiner 2006, 67; 200: & $900^{\circ} \mathrm{C}$ & «a period of hours» & $1 \mathrm{~mm}($ ca. $0,4 \% \mathrm{C})$ \\
\hline Amborn 1976, 44: & $>900^{\circ} \mathrm{C}$ & $?$ & $?$ \\
\hline Pleiner 2006, 66: & $900-950^{\circ} \mathrm{C}$ & $12 \mathrm{~h}$ & $2 \mathrm{~mm}$ \\
\hline Maddin u. a. 1991, 5 f.: & $900-1000^{\circ} \mathrm{C}$ & $\sim 8 \mathrm{~h}$ & $1,5 \mathrm{~mm}$ \\
\hline Krishnan 1954, $32 \mathrm{f}$. & $950-1000^{\circ} \mathrm{C}$ & «long enough» & $?$ \\
\hline Brearley 1914, 38 (nach Portevin / Beriot): & $1000^{\circ} \mathrm{C}$ & $8 \mathrm{~h}$ & $0,9-1,1 \mathrm{~mm}( \pm 0,9 \% \mathrm{C})$ \\
\hline Craddock 2010, 253 (nach Barraclough): & $1050-1100^{\circ} \mathrm{C}$ & seven days & $(0,6-2,0 \% C)$ \\
\hline Buchanan 1807, I, 174 ff.; II, 19 f. & $?$ & 4 resp. $6 \mathrm{~h}$ & $?$ \\
\hline Godfrey / van Nie 2004, 1122 Anm. 16 & $926^{\circ} \mathrm{C}$ & $50 \mathrm{~h}$ & $4 \mathrm{~mm}$ \\
\hline Tylecote 1987, 271: & $900{ }^{\circ} \mathrm{C}$ & $6 \mathrm{~h}$ & $2 \mathrm{~mm}$ \\
\hline
\end{tabular}

Tabelle 1: Zusammenstellung der für Aufkohlungsprozesse von Eisen mit Hilfe organischer, kohlenstoffreicher Hilfsmaterialien in den Quellen empfohlenen Prozesstemperaturen und Einwirkungszeiten sowie der dadurch erzeugten Eindringtiefe des Kohlenstoffs und dessen prozentualer Anteil am Stahl.

Beispiel auch Wilfried Epprecht und Eduard Schaller: «Je heisser das Eisen ist, umso mehr $\mathrm{C}$ kann es lösen, insbesondere oberhalb von etwa $740^{\circ} \mathrm{C}$ bei Gelb- und Weiss-Glut (Abb.9, links). Der aus der Holzkohle stammende Kohlenstoff wird von der Eisenoberfläche aufgenommen und diffundiert ins Innere der Stücke. Je länger man auf diese Weise glüht, umso tiefer dringt er ein, und umso höher wird der C-Gehalt» ${ }^{141}$. Die Abhängigkeit von Temperatur, Glühdauer und Eindringtiefe des Kohlenstoffs im Eisen veranschaulicht J.E. Rehder mit einem Vergleich ${ }^{142}$ : «For example, a <case depth requiring two hours at $950^{\circ} \mathrm{C}$ will take seven hours at $850^{\circ} \mathrm{C}$ and 30 hours at $750^{\circ} \mathrm{C}$; doubling case depth will require four times as long. It is therefore a relatively slow process; today, carburizing temperatures above about $850^{\circ} \mathrm{C}$ are used to obtain useful case depth in reasonable time.» Eine lange Glühdauer führt dadurch auch zu einer Homogenisierung des Kohlenstoffs im Eisen ${ }^{143}$.

Für unsere Experimente (s. unten) ist es interessant zu sehen, welche Temperaturen und Einwirkungszeiten für die Aufkohlung von Eisenoberflächen mit Hilfe organischer, kohlestoffreicher Hilfsmaterialien von anderen Autoren genannt werden (Tabelle 1) ${ }^{144}$.

Die Aufkohlung von weichem Eisen mit Kohlenstoff zu Stahl war Voraussetzung, das Eisen überhaupt härten zu können. Das Einbringen von Kohlenstoff in Eisen kann dabei

- $\quad$ sowohl integral an Rohmaterial - etwa am Barren oder Flacheisen - zur anschliessenden Weiterverarbeitung erfolgen (z. B. flache Streifen)
136 Oberhoffer 1920, 313-327; Amborn 1976, 44 (Zitat); Pleiner 2006, 66 f.; 200 f.; Sim 2012, $132 \mathrm{f}$.

137 Ledebur 1903, 1075 (Zitat) und 1081.

138 Perret 1780, 129; Perret 1780, 133 («in Büchsen von Eisenblech»); 132; Halle 1783, 37; Georgi 1785B, 307; 333; 347 f.; 381 f.; Poppe 1820, 8-13; Karsten 1821, 298 F. («Kasten aus Sandstein»); Reiser 1896, 103-107; Brearley 1914, 52f.; Rinman 1815, 555 («in verklebten Tiegeln oder in Thonkisten»); 601 («Stahlbrennen», «Brennstahl»); 635 (Anleitung); 667 (Anleitung); Healy 1978, 236; Barraclough 1981, 55-57; Henseling 1981; Moesta 1983, $167 \mathrm{f}$. (Zitat); Rehder 1989, 32. - Siehe auch unten mit Anm.335; Craddock 2010, 253 («... carefully arranged in great sandstone chests ...»).

139 Rostoker / Bronson 1990, 122; Wagner 1993, $271 \mathrm{f}$.

140 Halle 1783, 37 (Zitat); Perret 1780, 129 («... denn eine Stunde Hitze härtet nicht über die Dicke eines Pergament-Blattes»); Georgi 1785B, 381 (nach 1-2 Stunden eine «Stahlhaut von Pergamentsdicke»).

141 Ledebur 1903, 1083 (Aufkohlung findet erst ab $750^{\circ} \mathrm{C}$ statt); Brearley 1914, 3 Abb. 1 (Eindringtiefe 10-20 mm); 38f. Abb. 31; Oberhoffer 1920, 315 (maximale Aufkohlungstemperatur: $1184^{\circ} \mathrm{C}$ ); Krishnan 1954, 32f. («Each bar of iron was surrounded with charcoal and the bars heated to a temperature of $950^{\circ}$ to $1,000^{\circ} \mathrm{C}$ and kept at that temperature long enough for absorbing the requisite amount of carbon»); Epprecht/Schaller 1981, 30 (Zitat); Rehder 1989, 28 (Kohlenstoffaufnahme ab $727^{\circ}$ resp. bei rund $740^{\circ} \mathrm{C}$ ); Sim 2012, 132 Abb. 82 («The depth to which the carbon is absorbed is a function of the temperature and duration of heating»).

142 Leo 1902, 439 Tab. 1,1 (Eindringtiefen in einer $445 \mathrm{~mm}$ starken Eisenplatte nach 12 Tagen bei $1000-1200^{\circ} \mathrm{C}$ : Oberfläche: $1,00 \% \mathrm{C}$; $12 \mathrm{~mm}$ tief: $0,70 \% \mathrm{C} ; 24,5 \mathrm{~mm}$ tief: $0,40 \% \mathrm{C} ; 31 \mathrm{~mm}$ tief: $0,27 \%$ C; $37 \mathrm{~mm}$ tief: 0,25\% C; $43 \mathrm{~mm}$ tief: 0,25\% C); Tab.1,2.3 (ähnliche Werte nach 30- resp. 40-stündigem Glühen); Rehder 1989, 28 (Zitat).

143 Moesta 1983, 167. - Ich danke an dieser Stelle dem Messerschmied Hansjörg Kilchenmann in Basel für interessante Diskussionen zu diesem Thema.

144 Ledebur 1903, Tabelle S. 1084 (Zusammenhang zwischen Verweildauer, Eindringtiefe und Kohlenstoffgehalt beim «box-hardening» in einem grossen Zementierofen); Giolitti 1915, 72-74 (Verhältnis von Temperatur, Glühzeit und Eindringtiefe des Kohlenstoffes beim Stahl-Zementieren). - Für die Zubereitung von Tiegelstahl waren bedeutend höhere Temperaturen erforderlich. 
- oder direkt an der Schneide resp. Arbeitsfläche der fertig geschmiedeten Geräte und Waffen (Messer, Feilen, Schwerter, Panzer usw.) ${ }^{145}$.

Aufgrund früher Eisenfunde, an denen sich durch einfache Härtemessungen ein Abschreck- und Anlassprozess nachweisen lässt, kann auch die historische Verbreitung dieser Innovation rekonstruiert werden (s. oben mit Anm. 16-27).

\section{Historische Quellen}

Über Stahl, die Regionen seiner Produktion und seine Verarbeitung sind viele griechische und lateinische Quellen überliefert, so etwa zum ferrum Noricum (Seiten 44 ff.) oder die Informationen von Plinius dem Älteren (Seite 38). Aber: «Sur la cémentation, les témoinages sont rares.» ${ }^{146}$ Ausserhalb Europas und des Mittelmeerraums scheint die Aufkohlungstechnik früher gar nicht bekannt gewesen zu sein $^{147}$. Die wenigen von Robert Halleux zusammengetragenen antiken Textstellen zur Stahlerzeugung durch Zementation (Aufkohlung) sind spärliche, zum Teil auch recht vage Hinweise:

Julius Pollux schreibt in seinem onomasticon, dass entweder nach Aristoteles oder nach Theophrast (4./3. Jh. v. Chr.) «das Gefäss, in welchem man das Eisen mischt, pe-

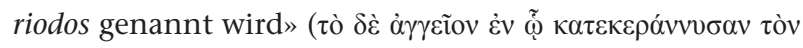

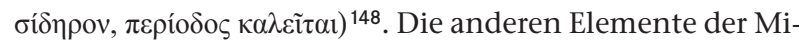
schung werden nicht genannt; es muss sich um Holzkohle und weitere Reaktionsmittel handeln.

Hesychios von Alexandria (4./5. Jh. n.Chr.) ${ }^{149}$ nennt den «kalathos ... ein Gefäss, in dem man Eisen schmelzt»

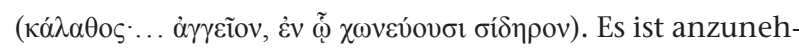
men, dass es sich bei dem Gefäss nicht um einen Tiegel im Sinne des indischen Tiegelstahls handelt, sondern um einen Zementationstiegel. Über dessen Namen erschliesst sich die zylindrische Gefässform mit ausladender Mündung.

Plinius der Ältere (23-79): «Auf andere Weise verarbeitet, dient er [der Ofen] zur [Oberflächen-]Verdichtung der Ambosse und der Pinnen der Hämmer.» ${ }^{150}$ Das erinnert an die bis in die Neuzeit angewandte Aufkohlung von besonders beanspruchten Werkzeugkanten, Hammer- und Ambossoberflächen und dergleichen.

Eine eigentliche und eindeutige Beschreibung des Oberflächen-Aufkohlungs- resp. Zementationsprozesses von weichem Eisen zu härtbarem Stahl findet sich im antiken Schrifttum nicht.

\section{Archäologische Quellen}

Die Form der aus den Augster Lehmumhüllungen erschlossenen Barren (Abb.50) allein lässt nicht auf eine Umhüllung und anschliessende Zementation zur Stahlerzeugung schliessen. Es sind durchaus ganz ähnliche und in der Grösse vergleichbare Eisenbarren gefunden worden, die vermutlich nie aufgekohlt worden sind. Zu nennen ist etwa ein frühes Stück aus dem 6.Jahrhundert v. Chr., das im Apolloheiligtum von Nea Mesimvria-Zone/GR zum Vorschein kam und dieselbe, an den Enden sich verjüngende Form aufweist (Abb. 14) wie die aus Augusta Raurica erschlossenen Stücke. Das Stück aus Nordostgriechenland ist archäometrisch untersucht und weist «a uniform distribution of large, amorphous ferrite grains with a lot of slag inclusions but no welding lines» auf, «indicating that the bar was forged from a single bloom». Das Stück ist also nicht aufgekohlt. Chemische Analysen ergaben einen erhöhten Wert von 2,09\% Manganoxid, was typischerweise auf die lokalen Erze zurückzuführen sei. Maria Kostoglu bezeichnet den $26 \mathrm{~cm}$ langen und $616 \mathrm{~g}$ schweren Barren als «unique find» resp. als «currency bar ... found with the iron spearheads and the spits in the sanctuary of Apollo» ${ }^{151}$.

Der Vorstellung, im archäologischen Material einfache, allein durch Aufkohlen erzeugte Stähle vorzufinden, wird von manchen Autoren mit Skepsis begegnet: «Auch eine Glühung unter Holzkohle bei künstlicher Luftzufuhr wäre dafür geeignet gewesen, die allerdings allein schon wegen der erforderlichen langen Dauer als sehr wenig wahrscheinlich zu beurteilen ist ...» ${ }^{152}$.

Spuren von Aufkohlungsprozessen: Diese Skepsis kann neuerdings ausgeräumt werden, denn im Oppidum von Entremont/F fand sich in einer Eisenwerkstatt des 2.1. Jahrhunderts v. Chr. eine $1 \mathrm{~cm}$ dicke Eisenplatte mit einem eindeutigen Aufkohlungsbefund: Sie weist aussen eine nur 0,5-2,5 mm dünne Zone mit 0,7-1,0\% Kohlenstoff auf. Auf einer Objektseite folgt darunter eine $2-3 \mathrm{~mm}$ in die Tiefe gehende Übergangszone mit 0,1-0,6\% C, und im Kern ist das Reineisen (Ferrit) unverändert geblieben (Abb. 15) ${ }^{153}$.

Noch näher an die Befunde aus Augusta Raurica kommt ein wahrscheinlich aufgekohlter Eisenbarren mit quadratischem Querschnitt aus der römischen Schmiede

145 Beispiel bei Presslinger 2007, 60 Abb. 2 (eisenzeitliche Messerklinge). - Zum Verfahren bei Feilen: Buxbaum 1932, 29-31.

146 Halleux 2007, 1304.

147 Needham 1958, 10 (China, Indien); 47 («Cementation [in China, 12.-3.Jh. v. Chr.] ... had left no traces, textual or archaeological, so far discoverable»).

148 Poll. 7,99,6; Livadefs 1956, 64; Halleux 2007, 1304. Anm. 26.

149 Hesychius, Lexicon, kappa 393; Halleux 2007, 1305 Anm. 27.

150 Plin. nat. 34,144 (hier zitiert in der Übersetzung Hermann Vetters 1966, 180 f.); Halleux 2007, 1305 f. - Nüchterner und etwas vager übersetzt die interdisziplinäre Projektgruppe Plinius (Rottländer 2000, 39): «... auf andere Weise, um Ambosse oder Hammerfinnen zu verstärken».

151 Kostoglou 2008, 37 Abb. 14,b; 63 f. Abb. 30.

152 Straube 1996, 124.

153 Berranger/Fluzin 2007, 14 Tab. 4 und 16 Abb. 5 (auf Seite 14 wird von «traitements de cémentation volontaires, observés pour un objet sur une épaisseur de plus de $20 \mathrm{~mm}$...» gesprochen, in der Bildlegende Seite 16 jedoch von «soudure d'une feuille d'acier trempée et d'une feuille de ferrite»). 


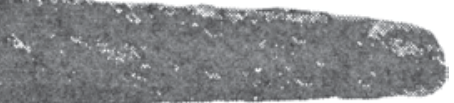

Abb. 14: Eisenbarren aus dem Apolloheiligtum von Nea MesimvriaZone/GR, 6. Jh. v. Chr. Das Stück ist in Form geschmiedet, aber nicht aufgekohlt worden. M. 1:3.

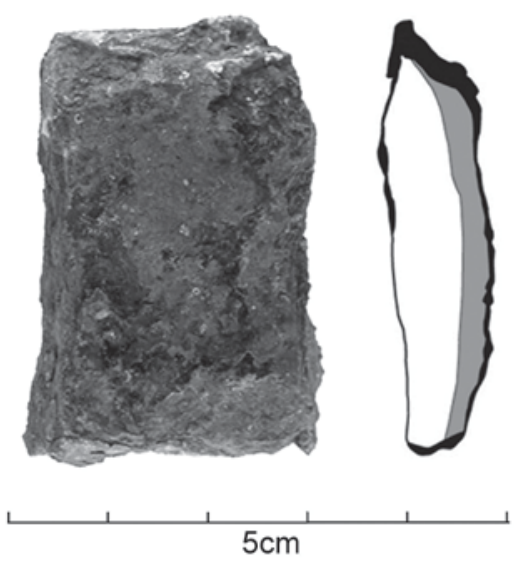
$\begin{gathered}\text { Fer doux } \\ \text { (ferrite) }\end{gathered} \quad \begin{gathered}\text { Acier peu carburé } \\ (0,1 / 0,6 \% \mathrm{C})\end{gathered}$
Acier très carburé
$(0,7 / 1 \% \mathrm{C})$

$(0,1 / 0,6 \% \mathrm{C})$

$(0,7 / 1 \% \mathrm{C})$

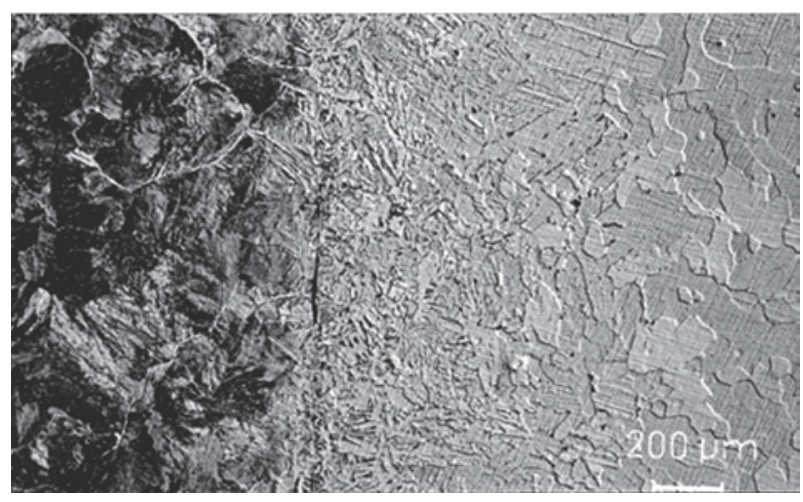

Abb. 15: Entremont/F, Oppidum. Eisenplatte aus einer Schmiedewerkstatt, Ansicht und Schnitte. Oben: Die Zonen an der Objektoberfläche mit hohem Kohlenstoffgehalt lassen auf eine Zementation resp. Aufkohlung schliessen. M. 1:1. - Unten: Übergangszone Ferrit-Stahl. Ausschnitt 2,15 mm breit.
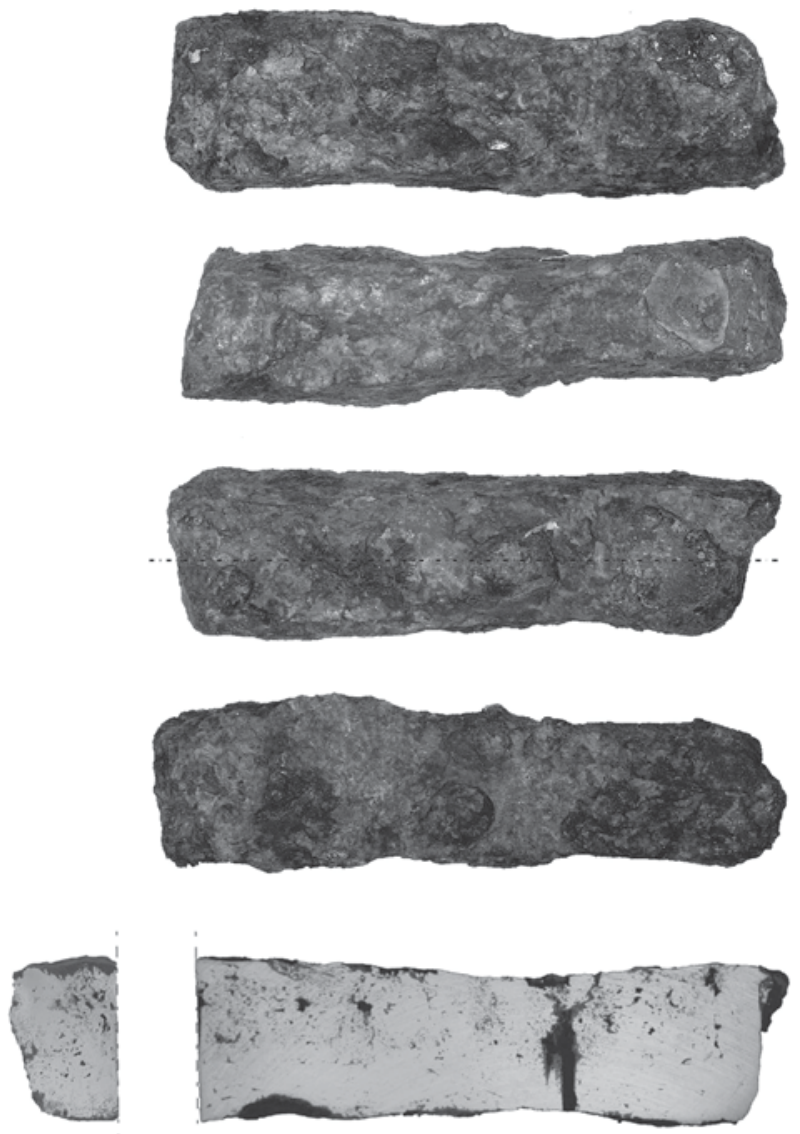

$10 \mathrm{~cm}$

Acier de 0,1 à $0,3 \% C$ Acier à $0,4 \% \mathrm{C}$

Acier à

Acier a localement $0,8 \% \mathrm{C}$
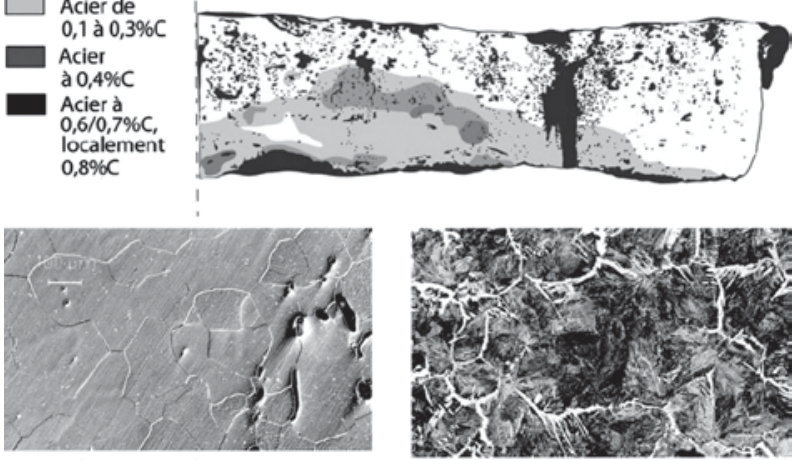

Ferrite équiaxe non écrouie.

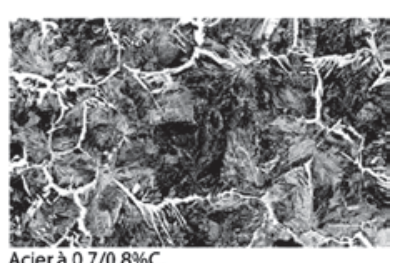

Acier à $0,7 / 0,8 \%$ C.

Abb. 16: Touffréville / F. Eisenbarren mit deutlichen Spuren einer oberflächlichen Aufkohlung (Fotos und Schnitte mit Angaben der Kohlenstoffgehalte). 1. Hälfte 1. Jh. n. Chr. M. 1:3. Details unten, ohne M. 


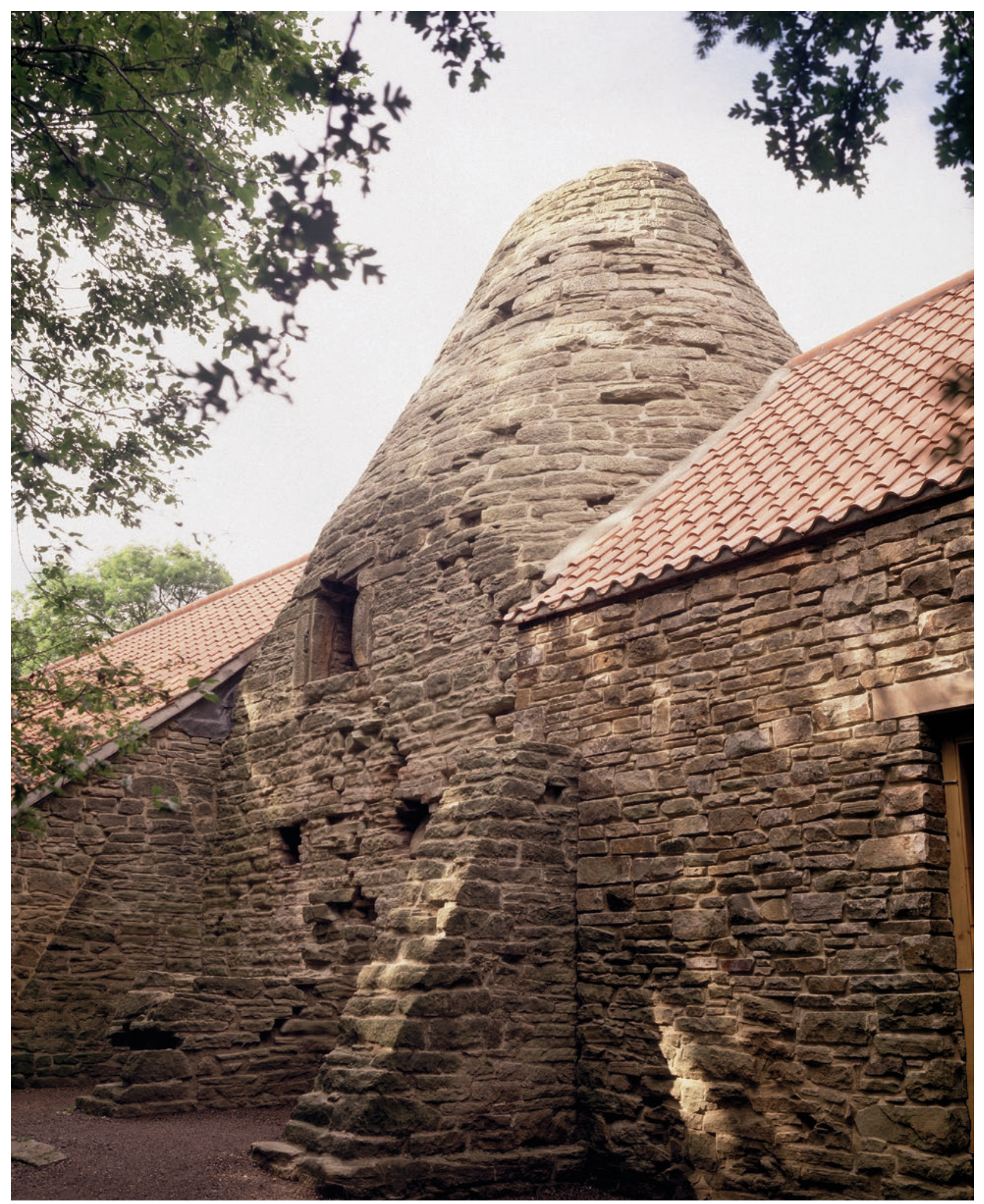

Abb. 17 (Doppelseite): Ein Beispiel der grossmassstäblichen Zementationsindustrie zur Erzeugung frühindustrieller Stähle: der «Derwentcote Steel Furnace» in Durham / GB (erbaut um 1730). In den grossen Brennkammern (Bild rechts) fand der Zementationsprozess in hermetisch verschliessbaren Metallkästen, Steintrögen oder gemauerten Kammern statt. Hier wurden während über 150 Jahren (bis 1891) schwedische, leicht phosphorhaltige Eisenbarren zusammen mit Holzkohlen in versiegelten Kisten tagelang bei grosser Hitze zementiert. Dies führte am Ende zu einem «Blister Steel», den zum Beispiel Messerschmieden weiter verarbeiteten. Das Bild oben zeigt den zentralen Ofentrakt des einzigen erhaltenen und seit 1985 unter Denkmalschutz stehenden Baukomplexes (restauriert 1990). Im Nachbartrakt befand sich eine Mühle für Holzkohle; eine einst ebenfalls vorhandene, wasserbetriebene Hammerschmiede ist nicht erhalten. 


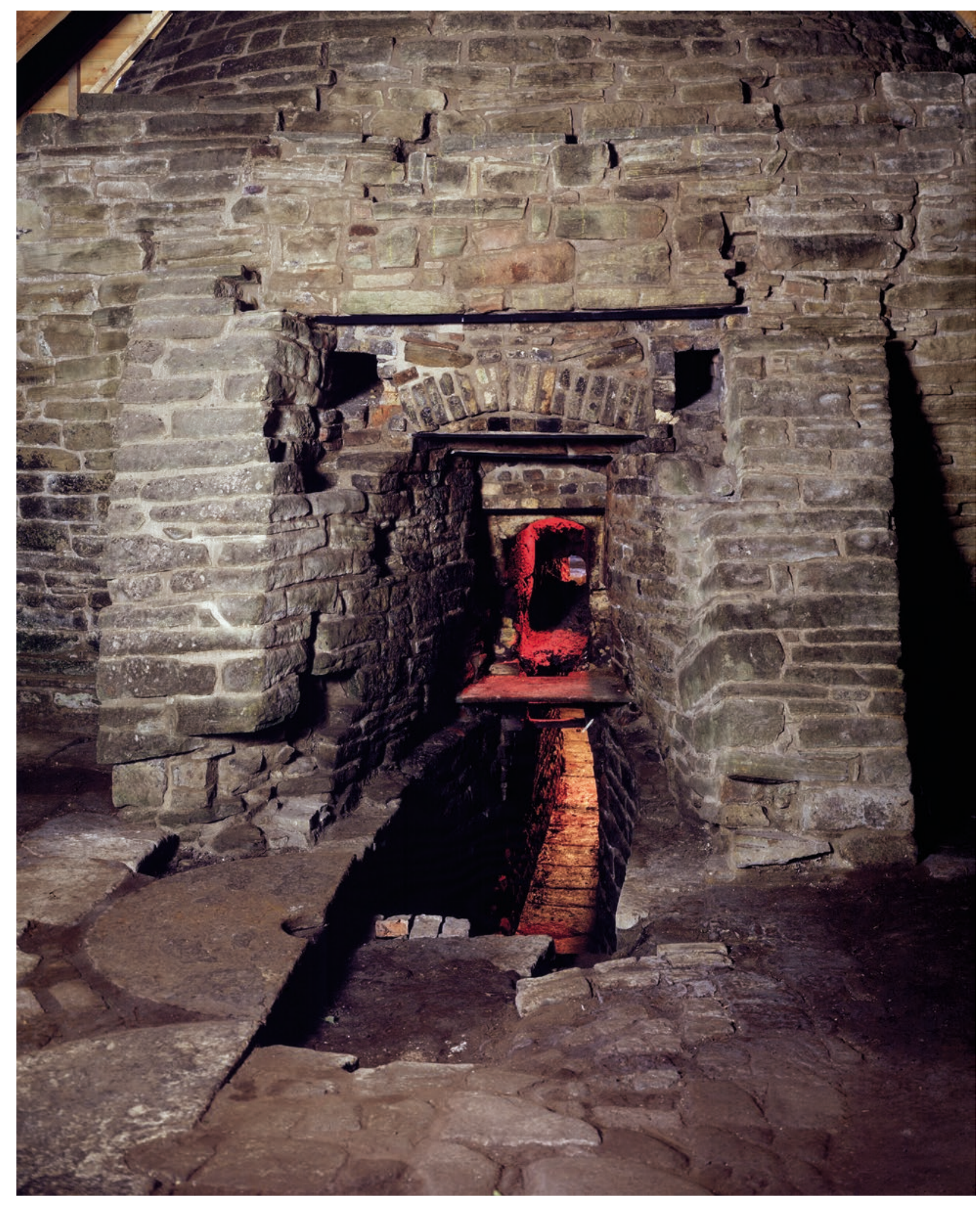


von Touffréville/F heran ${ }^{154}$. Er hat quadratischen Querschnitt, ist ca. $19 \mathrm{~cm}$ lang und wiegt 2,5 kg (Abb.16), ist also noch etwas schwerer als unsere rekonstruierten Barren der B-Serie («Buttereisen», Abb. 61, oben links; Tabelle 3). Er weist im Innern zwar zahlreiche kleine Stahlzonen mit Kohlenstoffgehalten von über 0,6\% C auf, was auf ein heterogenes Grundmaterial zurückzuführen ist. Eine lagenweise Verteilung von möglicherweise absichtlich eingearbeiteten kohlenstoffreicheren Partien ist jedoch nicht zu erkennen. Nur in den Randzonen, d.h. auf den Barrenoberflächen, sind kompakte aufgestählte Zonen im Schnittbild erkennbar (Abb.16, zweitunterstes Bild). Der Barren aus Touffréville unterscheidet sich jedoch von unseren Experimentierbarren (Beispiel Abb.107-110) in heterogener verteilten Kohlenstoffanreicherungen.

Belege für aufgekohlte (zementierte) Stähle und Barren: Andere archäometrische Befunde an Fertigprodukten und Barren zeigen dieselben Strukturen einer erfolgreichen Aufkohlung wie unsere Experimentierbarren (z.B.Abb.98; 107). Aus zahlreichen Beispielen von der griechischen Antike bis ins Frühmittelalter seien erwähnt:

- Speerspitze aus Gorszewice (Bez. Szamotuly)/PL (7.-6.Jh. v. Chr.) ${ }^{155}$,

- Lanzenspitzen aus Mesimvria-Zone/GR (spätes 6.Jh. v. Chr.) ${ }^{156}$,

- Axtklingen mit partieller Oberflächenaufkohlung aus Fiskerton/GB (5. / 4.Jh. v. Chr.) ${ }^{157}$,

- zwei Tüllenbarren aus Estrées Saint Denis / F ${ }^{158}$ und Sait Maur / F-Les Catlets ${ }^{159}$ (beide eisenzeitlich; Abb. 41),

- mehrere Werkzeuge aus dem Oppidum von Manching / D (3.-1.Jh. v. Chr.) ${ }^{160}$,

- Messerklingen aus Kayla-Kastro/GR (2./3.Jh. n. Chr.) ${ }^{161}$,

- Barrenbruchstück und Ahle aus Gurina / A (römisch) ${ }^{162}$,

- Pilumspitze aus Windisch / AG-Vindonissa (1.Jh. n. Chr.) ${ }^{163}$

- Schuppenpanzer aus Carlisle / GB (1.-3.Jh.) ${ }^{164}$

- kleine Eisenbarren aus Helgö/S («Migration period» [um 400-550]) ${ }^{165}$

- Axtklinge aus Baardorf / A (um 700 n. Chr.) $)^{166}$

- $\quad$ oder Schwert aus Lutomir/ P (11.Jh. n. Chr.) ${ }^{167}$.

Beim heutigen Forschungsstand scheint es, dass zementierter Stahl nur in Ausnahmefällen auch als Halbfabrikat, d. h. in Barrenform, verhandelt worden ist (sog. «socket bars»). Es handelt sich um die eisenzeitlichen Stabbarren vom Typ BAD1: kleine, dünne Stäbe mit Tülle, die 0,7-1,0\% Kohlenstoff enthalten können ${ }^{168}$. In Frankreich treten sie auffallend gehäuft im Norden (Pariser Becken, Normandie) auf ${ }^{169}$. «The BAD1 «socket bar» variant is significant because it contains a non-negligible proportion of steel, coming from a peripheral cementation process, which could have given this variant good mechanical characteristics. The carbon enrichment of a surface increases its hardness.»170

\section{Von der Antike bis in die Neuzeit}

Die Aufkohlung von Weicheisen zu Stahl war - wie es unsere wenigen Beispiele oben zeigen - seit der Antike bekannt. Es wurde schon vermutet, die Technologie sei von den Römern erfunden worden ${ }^{171}$. Wir haben jedoch einige konkrete Beispiele von Eisenfunden mit typischen Strukturen der Aufkohlung ihrer Oberflächen aufgelistet, deren früheste in das 6.Jahrhundert v. Chr. zurückreichen (Beispiel aus Polen). Die ebenfalls oben aufgeführten spärlichen schriftlichen Quellen, die vermutlich über diesen Prozess Zeugnis ablegen, gehen ins 4./3.Jahrhundert v. Chr. zurück. Stahl beiderlei Herkunft - d. h. durch Zementation als auch durch direkte Verhüttung gewonnen - muss demzufolge bereits während der fortgeschrittenen Hallstattzeit respektive in der klassischen Zeit Griechenlands in spezialisierten Betrieben erzeugt worden sein. Noch frühere Quellen, etwa jene von Homer (s. oben mit Anm. 21), bezeugen die Existenz von härtbarem Stahl bereits in der griechischen Archaik, ohne dass wir aber wüssten, wie dieser hergestellt worden ist.

Die Einsatzhärtung resp. das Zementieren wurde nicht nur bis ins 18. / 19. Jahrhundert praktiziert (s. unten S. $35 \mathrm{f}$. und Anm.340-348, Abb.30), sondern entwickelte sich in der Frühen Neuzeit durch einen Technologiewandel zum industriellen Massenprodukt, etwa zur Produktion von Messerstahl ${ }^{172}$.

154 Berranger et al. 2014, 192ff. Abb. 9. - Zu den Eisen- und Stahlbarren s. unten mit Abb. 32 bis 49

155 Piaskowski 1961, 268f. Abb. 13 («a cemented spearhead»).

156 Kostoglou 2008, 155 oben und unten.

157 Fell/Salter 1998, 2f. Tab. 1 Abb. 2-4.

158 Berranger 2014, Taf. 13, ESD Fe 13.

159 Fluzin et al. 2012A, 201 Abb.5; Berranger et al. 2017B, Abb. 16, rechts (Barrentyp BAD1).

160 Schwab 2002, 13-15 Abb. 12-18.

161 Kostoglou 2008, 72f.; 197 (mit weiteren Beispielen).

162 Giumlia-Mair 2015, 441 Abb. 183k (Kat.-Nr. 58); 1831 (Kat.-Nr. 61); 494 (Tabelle). Aufkohlungsbefund nach geätzten Anschliffen (im Text anders interpretiert).

163 Epprecht/Schaller 1981, 49 Abb. 10.

164 Fulford et al. 2004, 212 und 219, No. 13, Tab. 1, Abb. 13,3.4.

165 Modin / Lagerquist 1978, 114 f. (Rod 4; Rod 5).

166 Eichert/Mehofer 2014, 23-32 Abb. 10-14.

167 Williams 2012, 261 Abb. 56-57 Anm. 30 (nach J. Piaskowski); ebda. weitere Beispiele mit aufgekohlten Klingen, z.B.263 Abb.61-62 (Schwert, 13.Jh. [?], im Landesmuseum Zürich / H, Inv. IN7006).

168 Berranger / Fluzin 2012, 674 f. Abb. 1, unten rechts (Schliffbild mit Aufkohlungsstruktur), Tab. $1 ; 680$.

169 Berranger et al. 2017B, 323 Abb. 15 (Kreuzsignaturen).

170 Berranger/Fluzin 2012, 677 (Zitat); Fluzin et al. 2012A, 201 Abb. 52.

171 Congdon 1971, 26.

172 Wagner 2007, 291. 

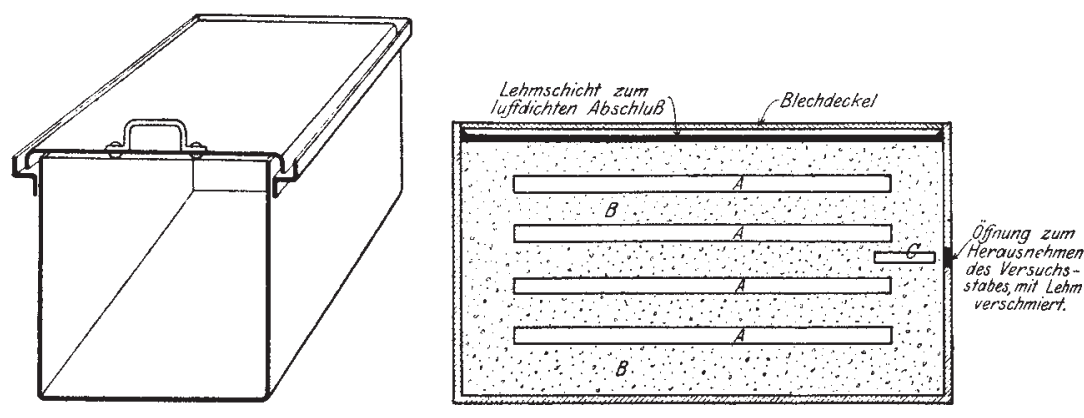

Abb. 18: Industrieller Einsatzkasten «nach Schuchardt\&Schütte» (Berlin, später Köln) zum Zementieren von Eisenstangen (1927). Solche Kästen fanden in verschiedenen Grössen Verwendung. Links Querschnitt durch den Härtungskasten aus Eisenblech; rechts vertikaler Längsschnitt. A: flache Eisenstangen ( Werkzeug- oder Schnellstahl», "10 bis $20 \mathrm{~mm}$ dick, 50-100 mm breit»); B: «klein gestossene Holzkohle mit feingesiebten Ascheresten vermengt» als Härtungspulver; C: «Probier-oder Versuchsbolzen» für Zwischenkontrollen während des Zementationsprozesses.

\section{Frühe Zementationsindustrie}

Aus einer antiken «Kleinindustrie» mit der Aufkohlung kleiner Eisenbarren (unten mit Abb. 50) ist im Laufe der Jahrhunderte eine grossmassstäbliche Industrie geworden (Abb. 17) ${ }^{173}$. Die frühe Industrie war - vor der Erfindung rationellerer, besser steuerbarer und Energie sparender Methoden zur Stahlerzeugung - auf Zementationsprozesse durch äusserliche Aufkohlung angewiesen. Diese erfolgten in hermetisch verschliessbaren grossen Tiegeln, Metallkästen (Abb. 18), Steintrögen oder gemauerten Ofenkammern (Abb. 17, Bild rechts). Die aufgekohlten Produkte werden in der Literatur des 18. und 19. Jahrhunderts «Zementstahl» genannt (Abb.13), die Härtemittel «Zementierpulver» und die Werkplätze «Zementierhütten» ${ }^{174}$.

Aus den zahlreichen alten Arbeitsanleitungen sei hier die kurze Beschreibung von Johann Schiefer und Ernst Grün wiedergegeben: «Flache Schweissstähle, 10 bis $20 \mathrm{~mm}$ dick, $50-100 \mathrm{~mm}$ breit, packt man in grosse, bis 8 oder $12 \mathrm{t}$ Eisen fassende, gemauerte Kisten zwischen zerkleinerte Holzkohle und glüht das Ganze bei etwa $1000^{\circ} \mathrm{C}$ 7-12 Tage lang, worauf man die Kisten während 5-7 Tagen langsam abkühlen lässt. Dabei wandert der Kohlenstoff in das Eisen bis in das Innerste der Stäbe. Die Menge des aufgenommenen Kohlenstoffes ist von der Höhe der Temperatur, der Dauer des Glühens und der Dicke der zu zementierenden Stücke abhängig. Das Erzeugnis hat einen Kohlenstoffgehalt von 0,8-1,5 vH [\%] und ist auf dem Bruche grau und grobblättrig ... Zementstahl enthält noch Schlackeneinschlüsse, auch ist der Kohlenstoffgehalt nicht in allen Teilen gleichmässig hoch, erfordert also einen Ausgleich. Beides kann erreicht werden, entweder a) durch Zusammenschweissen mehrerer Rohstäbe oder b) durch Umschmelzen. Ersteres, das ältere Verfahren, heisst Gärben ...» ${ }^{175}$

Zum Beschicken eines kleineren Zementierkastens wie auf unserer Abbildung 18 (links) schreiben dieselben Autoren: «Da das Einsetzen [der Stangen oder fertig geformten Werkzeugteile] in Blech- oder gusseisernen Kästen geschieht, halte man die gangbarsten Grössen stets bereit. Es ist zu beachten, dass der einzusetzende Maschinenteil von den Seitenwandungen und dem Boden mindestens 20 bis $30 \mathrm{~mm}$ absteht. Der Boden des Kastens wird mit einer Aschenschicht von etwa $30 \mathrm{~mm}$ Höhe bedeckt, hier- auf wird Einsatzpulver gestreut, der Gegenstand eingebettet und ringsum reichlich in Einsatzzpulver eingepackt. Der übrige Teil des Kastens wird mit Asche gefüllt, darauf kommt eine Schicht, bestehend aus dem Brei aus in Wasser angerührtem Lehm vermengt mit Asche. In diese Lehmdecke drückt man nun den Deckel des Einsatzkastens und verschmiert die Ränder und Ecken des Deckels sorgfältig mit Lehm. Auf diese Weise erreicht man einen guten luftdichten Abschluss des Kasteninhaltes, die Hauptsache für den Erfolg beim Einsetzen. Vorsichtshalber umwickelt man den Kasten noch kreuz und quer mit Bindedraht. ... Die Feuerbehandlung richtet sich nach Grösse und Umfang des Einsatzstückes; in der Regel genügen 6 bis 8 Stunden bei etwa 850 bis $900^{\circ} \mathrm{C} . » 176$

Die erwähnten Kasten aus Stein, Eisenblech oder Gusseisen sind eine Weiterentwicklung der kleineren Zementationstiegel (Experiment: Abb. 115). Sie werden bis heute, im modernen Fachbedarf, als «Glühkasten» resp. «Härtekasten» angeboten und bestehen heute aus einer Wanne aus Spezialstahl mit abgedichtetem Deckel (Abb. 19) ${ }^{177}$.

173 Siehe auch oben mit Anm. 138. - Zur Anlage von Abbildung 17: Cranstone 1997; Andrews et al. 2017 (archäologische Untersuchung).

174 Perret 1780, 129-157; Halle 1783, 20-31; Georgi 1785A, 306-363; Rinman 1815, 555-666; Comenius 1842, 536f. Taf. 311; Hartmann 1848, 713-751; Reiser 1896, 104; Leo 1902; Ledebur 1903, $1074-$ 1086; Giolitti 1915, XXIII-XXVIII Abb.4-6; 207-212 Abb.73-78 (frühindustrielle Zementieröfen; siehe auch unten mit Anm. 347); Oberhoffer 1920, 313-327; Schiefer/Grün 1927, 16f.; 184-190 Abb. 154-159; Barraclough 1981, 55-204; 349-360.

175 Schiefer/Grün 1927, $16 \mathrm{f}$.

176 Reiser 1896, 104 f.; Schiefer / Grün 1927, 186 und 188 (Zitate).

177 Rostoker/Bronson 1990, 124. - Erhältlich z.B.bei Nabertherm Schweiz AG, Hägendorf/CH, www.nabertherm.ch («Härtekästen»), oder bei Schröder Industrieöfen, Flörsheim am Main/D, www.schroeder-industrieoefen.de (24.11.2015). - Zu grossen Zementieröfen, in denen 8-14 Tonnen Eisenartikel in einem 7-9 Tage langen Einfeuerungsprozess aufgekohlt werden können: Leo 1902; Ledebur 1903, 1075-1081 Abb. 366-370. 


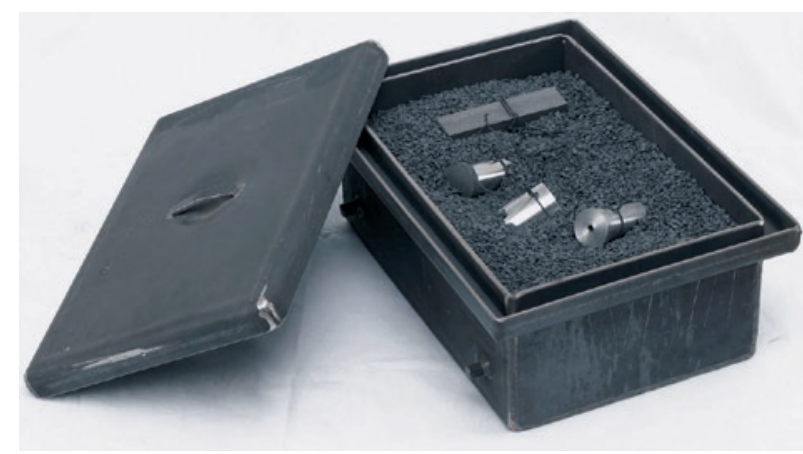

Abb. 19: «Nachkomme» traditioneller Zementationstiegel zur Aufkohlung von Eisen (Abb. 115): moderner Glühkasten (hardening box) zur Aufkohlung im Glühofen, Beispiel der Firma Nabertherm. Auszug aus dem Firmenprospekt: «Härtekästen sind aus wärmebeständigem Werkstoff 1.4841 (DIN) gefertigt und verfügen über einen Deckel zur Beschickung von oben. In das umlaufende Dichtungsprofil am oberen Rand des Kastens ist zur Abdichtung eine keramische Faser eingelegt. ... Die Kästen können ... mit entsprechendem Granulat zum Aufkohlen (auch Einsatzhärten oder Zementieren genannt) ... eingesetzt werden. Hierzu werden die Werkstücke mit Aufkohlungsgranulat ... in den Kasten gelegt.»

Der gute Verschluss der «Glühkästen» sorgt dafür, dass die Holzkohle im Aufkohlungsgefäss auch bei langem Glühen «ne se réduit point en cendres ..., même à la chaleur la plus violente \& la plus long-temps continuée» ${ }^{178}$. Sven Rinman warnte vor mangelnder Sorgfalt beim Einsatzhärten in Boxen: «Eine Eisenhaut entsteht auf dem Stahl, wenn der Stahlbrenner einen Fehler begangen und das Cementpulver nicht dicht genug um die [Eisen-]Stäbe gepackt hat, wenn die Stahlkisten kleine unmerkliche Ritzen, wodurch ein Luftzug bewirkt wird, erhalten haben ...»179 Ein luftdichter Verschluss der Holzkohleoberfläche als Schutz vor dem Verbrennen kann auch durch eine Lehmschicht erfolgen ${ }^{180}$.

Erst mit bedeutenden technologischen Neuerungen ab der Mitte des 19. Jahrhunderts verlor das «case hardening», das grossmassstäbliche Aufkohlen resp. Einsatzhärten in Spezialbetrieben, relativ rasch an Bedeutung.
178 Duhamel 1786, 462 .

179 Rinman 1815, 636.

180 Leo 1902, 438 («... mit Thon oder einem anderen feuerfesten Material bedeckt»); 439 («Auf die fertige Beschickung [mit Eisenwaren und Holzkohlepulver] kommt eine etwa $50 \mathrm{~mm}$ starke Thonschicht»).

181 Stephens 1884, 142-146; Becker 1973, 77-80 Abb.1 (mit älterer Lit.).

182 Biringuccio 1540, 79 (zitiert nach Johannsen 1925: «... Ich glaube diesem Bericht [über die Heiden und ihre Stahlerzeugung aus Eisenfeilspänen aus dem Vogelmist] nicht recht ...»); Woodward 1795, 28-34; Beck 1884, 690-696 und 836f.; Erichsen 1924, 130 133 (Thidrek von Bern, 13.Jh.); Validi 1936, 23 f. (nach al-Bīrūnī, 10. /11.Jh., sowie deutsch-norwegischen Sagen, 13.Jh.); Johannsen 1953, 68; Ploss 1957; Salin 1957, 96 Anm. 1 (Rezept von alBīrūn̄̄, 11.Jh.); 103 Anm.4-5 (Wieland-Sage); Thouvenin 1984, 369 Anm. 4; Said 1989, 214 f. («... These [iron] fragments or grains they add to flour which they feed to ducks ...", nach al-Bīrūnī, 10. / 11.Jh.); Gilmour 2007, 76.

183 Healy 1978, 233 (« ... water, urine, he-goat's blood, oil, and vinegar»); Moesta 1983, 166. - Zum Härten ausführlich: Reiser 1896, 24-33; Ploss 1957, 112; 118 ff.; Schaaber 1963, 139-143; Schaaber 1977, 267 (partielles Härten); Pleiner 2006, 68 f.; Presslinger 2007. - Zu legendenhaften Rezepten für Abschreckwässer: Theophilus Presbyter (um 1125), Buch 3, Kap. 21 (nach der praxisnahen Übersetzung von Brepohl 1987, 83); Kunckel 1732, 316-333 (lange Liste mit vielen Rezepten: «Schellkraut-Safft», «Seyffen», «Unschlitt», «[Männer-]Harn», «Bocksblut», «Hauswurz», altes «gebrannt Schuh-Leder», aber auch bewährte Mittel wie «Leinöl» und viele mehr); Halle 1783, 31 («1 Quart Morgenurin ...»); Woodward 1795, 28-30 («spurge», «wild horse-radish», «red-haired child's water», «nettle's juice», «bullock's gall» etc.); Darmstädter 1927 (Zwiebel- und Rettichsaft, Harn, Bocksblut, Flüssigkeit aus Würmern und viele andere pflanzliche Ingredienzen); Hils 1985, 62 (Harn, Leinöl, Bocksblut [«wen der Bok czu bruensten get»], Rübenrettich, Meerrettich, Regenwürmer, Engerlinge [Quelle von 1389]); 68 (gemäss der Sinaturenlehre: Eisenkraut, Steinwurz, Drachenschwanz, Schwertlilie usw.); 69 (Talg vom Schafsbock u.a.); Rostoker/Bronson 1990, 14 Anm. 3 (Blut, Urin, Tauwasser vom Monat Mai, Quecksilber); Presslinger 2007, 63 f. (Eisenkraut, Ochsenzungenkraut, Urin, Drachenkraut, Senf mit Essig usw.; «Das Ablöschen in Urin ist im Vergleich zu reinem Wasser von Vorteil, weil die darin enthaltenen Substanzen den Abkühlungsprozess etwas verlangsamen und damit die inneren Spannungen beim Härten vermindern»). - Die von Gansum 2004 postulierten intensiven rituellen und kultischen Bezüge zur frühgeschichtlichen Eisen- und Stahlbearbeitung sind ohne grosse historische Evidenz und überbewertet.

184 Halle 1783, 30. 


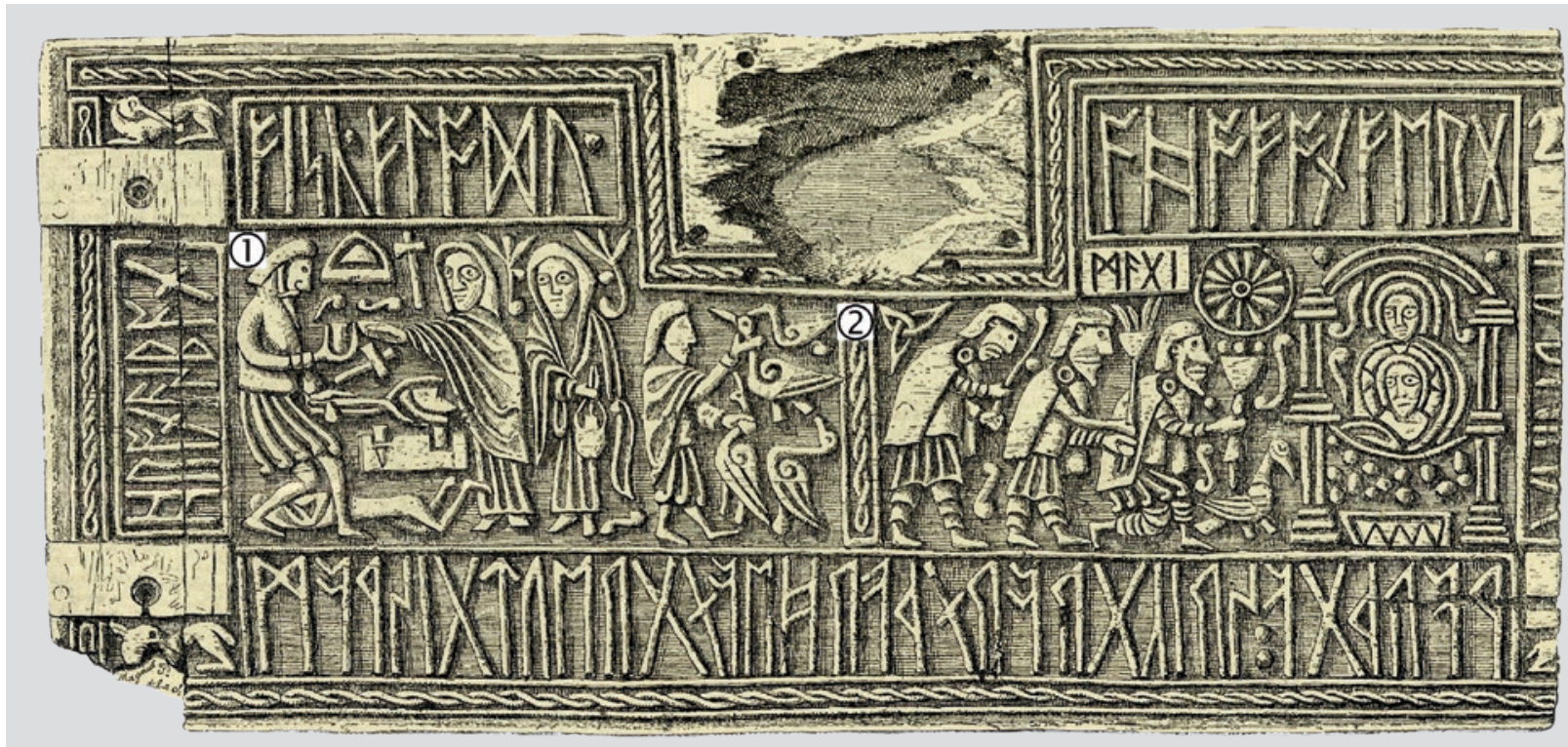

Abb. 20: Runenkästchen von Auzon /F, sog. "Franks Casket», aus Walknochen (heute im British Museum). Relief auf der Vorderseite mit Szene der Wieland-Sage (links). (1) Wieland in seiner Schmiede am Amboss; (2) entweder Wielands Bruder Egil beim Sammeln von Vogelfedern oder ein Gehilfe beim Stopfen der Vögel mit «Eisen-Körnern». Anfang 8. Jahrhundert n. Chr. Breite $23 \mathrm{~cm}$.

"Stahlbereitung durch Darmpassage» eine vielzitierte Legende

In mehreren arabischen, russischen und skandinavischen Quellen wird erzählt, wie ein raffinierter Schmied kleinste Eisenkrümel - zum Beispiel Feilspäne - eingepackt in einem Teig aus Mehl und Milch seinen Hühnern verfüttert (Abb. 20181). Aus dem Kot werden die Teilchen wieder herausgelesen und erneut verfüttert. Nach mehreren solchen Darmpassagen werden die Partikel gereinigt, im Herdfeuer erhitzt und auf dem Amboss zu einem kompakten Eisenstück zusammengeschweisst. Daraus fertigt der Meister in der «Wieland-Sage» das Schwert «Mimung» an, dessen Schärfe und Stabilität unerreicht sei. In anderen Quellen werden auch «hungrige» Enten, Gänse und sogar Strausse genannt ${ }^{182}$.
Die relativ grosse Oberfläche der kleinen Eisenstückchen bewirkt offenbar, dass im Darm der Vögel genügend Stickstoff und Kohlenstoff in das Eisen diffundiert, um am Schluss einen guten, härtbaren Stahl zu haben.

Genauso von Legenden umrankt resp. esoterisch anmutend, sind die vielen in alten Schriften empfohlenen Flüssigkeiten und Zusätze, in denen der glühende Stahl zum Härten abgeschreckt werden soll ${ }^{183}$. Auch damals gab es allerdings schon nüchterne kritische Stimmen in Zusammenhang mit Abschreckwasser: «Kein Knoblauch, Rettig, Schlangen u. d.[dergleichen] helfen ...»184. 


\section{Stahl bei Plinius dem Älteren (naturalis historia)}

Plinius ist der erste antike Schriftsteller, der etwas ausführlicher auf die Eisengewinnung und Stahlerzeugung eingeht (s. auch oben Seite 30). Die «klassischen» Übersetzungen haben jedoch aus Unkenntnis metallurgischer Prozesse wenig Sinnhaftigkeit ergeben. Erst als sich Metallurgen, Experimentalarchäologen und Altphilologen zu einer interdisziplinären Übersetzung der Plinius-Texte zusammengetan haben, sind die Aussagen klarer geworden ${ }^{185}$.

Plinius unterscheidet in nat. 34,143-144 zwischen Weicheisen, sprödem Eisen, Eisen aus sehr kleinteiligen Luppen (für Schuhnägel), rasch rostendem Eisen und dem aus der Luppe zusammengeschweissten Roheisen (strictura). Er nennt auch den Begriff acies für Stahl ${ }^{186}$ und beschreibt das Härten: «Der Hauptunterschied liegt aber im Wasser, in welches es gleich darauf glühend getaucht wird.» Nebst Wasser sei, vor allem bei «feineren Eisenwaren», das Ölbad zum Abschrecken vorzuziehen, «damit sie nicht durch das Wasser zu spröde werden» ${ }^{187}$.

Was Plinius zur Stahlerzeugung sagt, blieb infolge von Interpretationen und Übersetzungen, die sich linguistisch, aber nicht technologisch orientierten, lange Zeit unklar. Mit der Übersetzung von Hermann Vetters von Plin. nat. 34,142 ff. wird vieles klar ${ }^{188}:$ «... auch bei den Öfen gibt es grosse Unterschiede; in ihnen wird eine Art Kern des Eisens ausgeschmolzen, der zur Erhärtung der Schneide (oder Spitze) dient. Auf andere Weise verarbeitet, dient er zur (Oberflächen-)Verdichtung der Ambosse und der Pinnen der Hämmer ...» Es darf also durchaus von römischem «Ofenstahl» gesprochen werden.
185 Schaaber 1976/77; Schaaber 1977, 223-267 Anm. 12-30; Knoll et al. 1980; Straube 1996, 115-121 (auf Grundlage von H. Vetters) und vor allem Rottländer 2000, 36-68.

186 Plin. nat. 34,143-144; Schaaber 1976/77, 98f.; Humphrey et al. 1998, 218. - Zu den antiken Begriffen für Stahl: Rommel 1929,

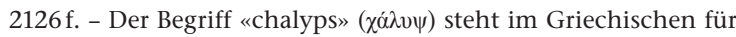
Stahl; dessen Erfindung soll auf das Volk der Chalyber an der südöstlichen Schwarzmeerküste zurückgehen: Lykophr. 1109 («... hingestreckt, vom Eisenschwerte, vom chalybischen ...» [in der Übersetzung von C. von Holzinger 1895]); Strab. 12,3,19 und 23; Amm. 22,8,21 («Diesen Gegenden benachbart sind die ... Chalyben, die zum erstenmal Eisen gefördert und bearbeitet haben»); Xen. an. 5,5 («... die meisten von ihnen [den Chalybern] verschafften sich durch Eisenbergbau ihren Lebensunterhalt»); Eur. Alc. 980 f. («Auch das Eisen der Chalyber bezwingst du durch deine Gewalt»); Beck 1884, 262 («Die Chalyber galten den Griechen als die Erfinder des Stahls»); 263-265 (mit zahlreichen Quellen); $425 \mathrm{f}$. (chalybischer und lakonischer Stahl); $453 \mathrm{f}$. (lydischer Stahl); Rommel 1929, 2132; Johannsen 1953, 45; Livadefs 1956, 49; Bianchi 1997 (mit älterer Lit.); Yalçın 1999, 185; Rottländer 2000, 53 f.; Pierre Flobert in Maréchal 2002, 254 («le mot chalybs désigne l'acier chez les poètes (Virgile, Properce, Lucian, Silius, etc.) ... au grec, comme adamas, qui désigne aussi parfois l'acier chez les poètes (Virgile, Properce, Martial, etc.)»); Halleux 2007, 1302f. Anm. 14; Facella 2013. - Zu Martial, der den Stahl der Chalyber und Noriker in einem Zug nennt, unten mit Anm. 252. - Zu Aristoteles und seiner Beschreibung der Stahlerzeugung durch die Chalyber: Healy 1978, 235 Anm. 75.

187 Plin. nat. 34,146; Ploss 1957, 118; Vetters 1966, 179-185; Straube 1973, 491 f.; Übers. H. Vetters in Straube 1996, 116-119 (117 zur Wortbedeutung von acies und strictura). - Das Abschrecken, Härten und Anlassen von Stahlschwertern, insbesondere mit Öl, ist in einigen antiken Quellen bezeugt (zitiert bei Halleux 2007, 1304 Anm. 22-25; 1317) und vielfach beschrieben von al-Kindī (9. Jh.): Hoyland/Gilmour 2006, z. B. S. 58.

188 Straube 1973, 492 (hier zitiert in der Übersetzung von H. Vetters); Knoll et al. 1980; Straube 1996, 115-121 (mit der Übersetzung von Vetters 1966). 


\section{Frühe Spuren der Stahlerzeugung in Asien und Europa}

Über den Beginn bewusster Stahlerzeugung und die Kenntnis des Härtens durch Abschrecken und Anlassen (vgl. Abb.9) besteht nach wie vor eine gewisse Unklarheit. Sicher ist nur, dass die Veredelung des Eisens durch Anreichern von Kohlenstoff erst lange nach dem Beginn der Eisennutzung - in Anatolien und Mesopotamien im 3. Jahrtausend v. Chr. - erfolgte ${ }^{189}$. Die verschiedenen Autoren nennen als Beginn der Stahlerzeugung Zeiten um 12001000 v. Chr. für Ägypten und den Nahen Osten ${ }^{190}$, später im alten Griechenland ${ }^{191}$ und um $200-100$ v. Chr. für Mitteleuropa ${ }^{192}$. Die Erwähnung im 8. oder 7.Jahrhundert v. Chr. des Stahlhärtens im kalten Wasser in Homers Odyssee lässt erkennen, dass damals die Stahlverwendung in Griechenland bereits geläufig war: «Wie wenn ein Mann, ein Schmied, eine grosse Axt oder ein Dechsel | Glühend in kühles Wasser, das mächtig zischende, eintaucht, | Um es zu härten - denn das bewirkt die Stärke des Eisens $\mid \ldots{ }^{193}$

\section{Tiegelstahl, Wootz und andere frühe Prozesse in Asien}

\section{Geschichte und Verfahren}

Mit Wootz- resp. Pulad-Stahl (Abb. 3 und 23) ${ }^{194}$ ist nicht nur ein kohlenstoffreiches Eisen gemeint, sondern auch im Gegensatz zu den zähen, schlackenreichen Luppen aus dem Rennfeuerprozess - ein in der Schmelze erzeugtes Produkt. Das Wissen um diese Technologie hat sich bis in die Frühe Neuzeit erhalten ${ }^{195}$.

Die Erzeugung dieser Art von schwach kohlenstoffhaltigem Gusseisen ist nach Auffassung einiger Autoren in Mittelasien - vor allem in Indien - um 700 v. Chr. viel früher belegt als in Westasien (2./3.Jh. n. Chr.), und in Europa gelang die Herstellung von Gusseisen im Hochofen noch viel später (ca. 15. Jh. n. Chr.) ${ }^{196}$. Eine geographische Ausnahme bildet al-Andalus, das südspanische Andalusien unter maurischer Herrschaft, wo im 10. bis 14. Jahrhundert Tiegelstahl nicht nur verarbeitet, sondern auch hergestellt wurde ${ }^{197}$.

Während archäometrische Belege, welche die Herstellung von Tiegelstahl glaubhaft machen, ab dem 4.Jahrhundert v. Chr. zu finden sind, sind historische Quellen jedoch viel jüngeren Datums ${ }^{198}$. Das älteste bekannte Rezept wird vom griechischen Alchemisten Zosimos aus Panopolis (Oberägypten) überliefert, der um 300 n. Chr. in Alexandria lehrte ${ }^{199}$. Sein Wissen geht wahrscheinlich aber auf viel ältere Quellen zurück. Etwas häufiger berichten
189 Müller-Karpe 1994, 14 («Eisen war ... im frühen 2.Jahrtausend v. Chr. zur Zeit der altassyrischen Handelskolonien ... ein überaus kostbares Material»).

190 Tholander 1971 (mit älterer Lit.); Snodgrass 1980, 366; Tylecote 1987, 271; Maddin et al. 1991, 5 (Palästina, Westanatolien); Biswas 2001, 101 (Indien; mit weiterer Lit.); Pleiner 2006, 66 und 198 (17./ 16. Jh. v. Chr.); Prakash 2011, 381 und 401 (Indien: ab ca. 700 v. Chr.).

191 Halleux 2007, 1301 ff. - Ausführlich: Beck 1884, 405-466; Sanidas et al. 2016, 281-298. - Analyse eines Schwerts aus einem Grab des 10. Jh. v. Chr. aus Lefkandi / GR aus «mild steel» mit hohem PerlitAnteil: Golfomitsou et al. 2017, 204-207 Abb. 14.1-14.6.

192 Tylecote 1987, 272 (La Tène). - Für früheres Einsetzen der Kenntnis des Aufkohlens: Snodgrass 1980, 367 Anm. 52 («Alpine Central Europe ... 7th to 4 th centuries...»).

193 Hom. Od. 9,389-394 (zitiert in Anlehnung an die Übersetzung von R. Hampe 2009). - Dazu vor allem Beck 1884, 406 (Homer-Zitat); Neumann/Wilsdorf 1954, 80; Mitsche 1961, 460 f.; Pleiner 1969B, 9f.; Healy 1978, 233 Anm. 48; Snodgrass 1980, 366; Humphrey et al. 1998, 220.

194 Von der sehr umfassenden Spezialliteratur zum asiatischen Tiegelresp. Wootz-Stahl seien hier nur wenige Titel zitiert (mit jeweils älterer Literatur): Schoff 1915, 234-239 (Indien); Krishnan 1954; Kuppuram 1989, 325-341; Said 1989, 216 («... This is called faulād. Herat is celebrated for its faulād»; nach al-Bīrūnī, 10./11.Jh.); Craddock 1998, 41-45; Biswas 2001, 121-125; Feuerbach 2002; Craddock 2003; Feuerbach et al. 2003; Rehren/Papachristou 2003; Feuerbach 2006, 12f.; Feuerbach 2007; Balasubramaniam 2008, 213-257; Craddock 2010, 275-283 Abb. 7.20-7.21; Prakash 2011, 400-408 Abb. 17; Le Coze 2012; Sim 2012, 134 f.; Williams 2012, 25-37; Alipour / Rehren 2014; Juleff 2015; Lang 2017, 6, Absatz 4. - Zur (Tiegel-)Stahlproduktion in China: Needham 1958, 14-15; 26-31; 44-46; Needham 1980, 511-524 bes. 520; Wagner 1993, 289 (Eisenschmelzen in Tiegeln in der Han-Periode [um 200 v. Chr. bis 200 n. Chr.] umstritten); Feuerbach 2002, 175; Wagner 2008, 261-264 Abb. 112 (Schmelze mit Vorbehalten); Desai 2018, 934-938. - Besonders gute Übersichten geben Feuerbach 2006 und Wagner 2007, 303-305.

195 Buchanan 1807, vol.I, 174-177; vol.II, 19-23 Abb.41; Rinman 1814, 455-459; 465-468; Voysey 1832; Heath 1839; Mushet 1840, 650-678; Beck 1884, 241-246; Bersch 1899, 754; Juleff 1998, 115119 Abb. 62; Srinivasan 2007 (673-677: Forschungsgeschichte).

196 Über den Beginn der Tiegelstahlherstellung gehen jedoch die Meinungen auseinander: Craddock 1998, 46-48; Prakash 2011, 383 («early 2nd millennium BC»); 402 (« 700 BC»); Feuerbach 2007, 319 («The first definitive evidence for the trade in crucible steel come from the 3rd century AD, in a text written by the Alexandrian alchemist, Zosimos of Panopolis»); 321 (Tiegelstahlherstellung erst in Turkmenistan und Usbekistan, erst später in Indien und Sri Lanka); Balasubramaniam 2008, 230 (Wootz-Stahlherstellung in Südindien spätestens ab dem 3.Jh. v. Chr.; mit älterer Lit.).

197 Dinnez 2001

198 Übersicht historischer Tiegelstahlrezepte bei Feuerbach 2002, 159 Tab. 27.

199 Craddock 1998, 47 (englische Übersetzung); Gilmour 2015, 193f.; 197. - Siehe auch das interessante Zeugnis von Cassiodor (oben mit Anm. 29). 
wenige Jahrhunderte später arabische Gelehrte über diese Technik zur Herstellung unerreicht guter Stähle. Dazu gehören Dschaābir (Jabir) ibn Hayyān «Geber» (ca. 721$800 / 815)^{200}$, Ya'cūb al-Kindī (um 800-870) ${ }^{201}$, Muhammad ibn Zakariyya al-Razi (860-925)202 und Muhammad ibn Ahmad al-Bīrūnī (um 975-1050) ${ }^{203}$. Im 18. und 19.Jahrhundert schliesslich haben einige westliche Reisende in Indien den Prozess der Tiegelstahlgewinnung noch beobachtet und beschrieben ${ }^{204}$. Die Begeisterung im Westen für den Wootz- resp. Pulad-Stahl Asiens und das Bewusstsein um seinen hohen materiellen Wert fanden auch in einem Gedicht von Alexander Sergejewitsch Puschkin im Jahr 1830 ihren Niederschlag205:

\begin{tabular}{|l|l|}
\hline «Mein ist alles!, sprach das Gold; & "All is mine, said gold \\
Mein ist alles!, sprach der Stahl. & All is mine, said bulat \\
Ich kauf' alles!, sprach das Gold; & All I can buy, said gold \\
Ich nehm' alles!, sprach der Stahl.» & All I will take, said bulat.» \\
\hline
\end{tabular}

Wootz-Stahl wird üblicherweise auch als Tiegelstahl bezeichnet, der in hitzebeständigen Tonzylindern, gefüllt mit Eisenstücken ${ }^{206}$ und organischen, kohlenstoffhaltigen Materialien, während langer und scharfer Befeuerung in speziellen Öfen (Abb. 21) zum Schmelzen gebracht wurde. Eine Bedienungsgrube mit zwei Hochtemperatur-Öfen aus dem 9. / 10. Jahrhundert hat sich in Merv (Turkmenistan) relativ gut erhalten (Abb. 2) ${ }^{207}$.

Die in die Tiegel gegebenen Kohlenstoffträger (siehe unten S.43) und ihre Mischung waren wahrscheinlich wohl gehütete Fabrikationsgeheimnisse. In einer andalusisch-islamischen Quelle des 13.Jahrhunderts wird sogar angeführt, dass - im Text nicht spezifizierte - «Medikamente» vor dem Schmelzen in die Tiegel gegeben werden, durch welche der Stahl «so hart würde, dass er andere Eisen schneidet» 208 .

Die Angaben in der Literatur über die Temperaturen, die zur Tiegelstahl-Herstellung (durch Schmelzen des Eisens in den Tiegeln!) notwendig sind, und vor allem über die Verweildauer der Wootz-Tiegel im Feuer schwanken extrem: 2,5 h im Feuer ${ }^{209}$; ungefähr 4 Stunden $^{210}$; ca. $6 \mathrm{~h}$ (bei $\left.1450-1550^{\circ} \mathrm{C}\right)^{211} ; 8-9 \mathrm{~h}$ (bei $\left.900-1500^{\circ} \mathrm{C}\right)^{212} ; 10-12 \mathrm{~h}$ (bei $\left.\sim 1200^{\circ} \mathrm{C}\right)^{213} ; 14-24 \mathrm{~h}$ (bei $\left.\leq 1200^{\circ} \mathrm{C}\right)^{214}$ und sogar $24 \mathrm{~h}$ Brenndauer (bei $\left.1150-1250^{\circ} \mathrm{C}\right)^{215}$.

Das Erreichen des Schmelzpunktes ist bei der Tiegelstahl-Produktion nicht in erster Linie die Folge besonders hoher Prozesstemperaturen, sondern des Umstandes, dass als Folge kontinuierlicher Kohlenstoffaufnahme im geschlossenen System des versiegelten Tiegels der Schmelzpunkt des Eisens $\left(1536^{\circ} \mathrm{C}\right.$ für Reineisen) sinkt: auf $1493^{\circ} \mathrm{C}$ bei $0,5 \% \mathrm{C}$, etwa $1470^{\circ} \mathrm{C}$ bei $0,8 \% \mathrm{C}$ und noch tiefer $\left(1400^{\circ} \mathrm{C}\right.$ ) bei rund $2 \% \mathrm{C}$ und schliesslich auf $1130^{\circ} \mathrm{C}$ bei $4,3 \% \mathrm{C}^{216}$.

Die so erzeugten Stahlbarren weisen die im Tiegel erstarrte zylindrische Form auf - entsprechend der inneren Wand im unteren Bereich der Tiegel (Abb. 22,6; 23). Diese Rundbarren waren rund 2-4,5 kg schwer ${ }^{217}$.
Mit der Wootz-, Pulad- resp. Tiegeltechnik können drei unterschiedliche Verfahren durchgeführt werden:

1. Aufkohlen von Schmiedeeisen zu Wootz-Stahl (sog. südindischer oder Mysore-Prozess): Roheisenstücke werden vermischt mit Holzschnipseln, Pflanzenteilen (z.B.Rinden, Kirschpflaumen, Granatapfelschalen), Reisspelzen oder Austernschalen (resp. Perlmuttpulver) in einen schlanken Tiegel gefüllt, dieser mit Lehm dicht verschlossen. Nach dem Trocknen werden die Tiegel im Holzkohleofen (z. B. Abb. 21) etwa 6-7 Stunden lang erhitzt, bis das Eisen viel Kohlenstoff aufgenommen hat und schmilzt ${ }^{218}$.

2. Schmelzen zu Pulad-Stahl (sog. Ferghana-Prozess) nach der Verhüttung: Die untere Hälfte des schlanken Tiegels ist mit einer etwa 4,5 kg schweren Rennofen-Luppe

200 Williams 2012, 96-98 (mit älterer Lit.).

201 Hoyland/Gilmour 2006; Gilmour 2015, 193; 195 f. - Al-Kindīs Verdienste schmälernd: Said 1989, 219.

202 Williams 2012, 98-100 (mit älterer Lit).

203 Al Hassan/Hill 1986, 251-254; Dinnez 2001, 75; Hoyland/Gilmour 2006, 52; Gilmour 2015, 195. - Neben dem Tiegelstahlverfahren berichtet al-Bīrūn̄̄ u.a. auch über das Verfüttern von in Mehl verpackten Eisenfeilspänen an Strausse, um diese nach der Darmpassage weiterzuverarbeiten: Salin 1957, 96 Anm. 1.

204 Buchanan 1807; Voysey 1832; Holland 1892, 146-149.

205 A. C. Puschkin: Udozestvennia Literaturea, Moskau, I (1978), 229; Englisches Zitat nach Sherby/ Wadsworth 2001, 352.

206 Voysey 1832, 246f., erwähnt zwei verschiedene Sorten von Eisen, die im Verhältnis 3:2 in die Tiegel kommen.

207 Feuerbach 2002, 60-105 Abb. 23-31 Map 7.

208 Dinnez 2001, 77 (Zitat englisch).

209 Heath 1839, 392.

210 Beck 1884, 242.

211 Balasubramaniam 2008, 239; 244 («Another significant variation in the process is the time duration»).

212 Prakash 2011, 403.

213 J.D. Verhoeven, zitiert nach Prakash 2011, 403.

214 Srinivasan 2007, 676 Anm. 14.

215 Voysey 1832, 247 (ohne Temperaturangabe); Kuppuram 1989, 335 (ohne Temperaturangabe; erstes Glühen während $24 \mathrm{~h}$, dann noch drei weitere Glühphasen in Lehmpackungen während je 12-16 h); Lowe et al. 1991, 627; Sim 2012, 134 (1-24 h bei $\left.1400^{\circ} \mathrm{C}\right)$.

216 David et al. 1989, 184 (Zahlen leicht abweichend); Rehren/Papakhristou 2000, Abb. 10; Biswas 2001, 124; Truffaut 2008, Tab. 1 (Zahlen leicht abweichend); Le Coze 2012, 345.

217 Papakhristou / Rehren 2001, 151 f. Abb. 1,2; 2; Feuerbach 2007, 328 und 331.

218 Heath 1839, 392 (Eisenstückchen vermischt mit trockenem Holzhäcksel in Tiegel, zugedeckt mit zwei grünen Blättern, Tiegelmündung mit gemagertem Lehm zugestopft und getrocknet. 20-24 Tiegel zusammen in einem kleinen Ofen während nur $2 \frac{1}{2} 2$ Stunden im Feuer belüftet. Frischen der Reguli im Düsenbereich eines Ofens knapp unter dem Schmelzpunkt während mehreren Stunden); Holland 1892, 147; Al Hassan/Hill 1986, 253 f. (nach alBīrūnī, 10./ 11.Jh.); Said 1989, 219; Craddock 1998, 44 und 55 f.; Juleff 1998, 117 f.; Rehren / Papakhristou 2000, 65 und 68; Biswas 2001, 122-124; Balasubramaniam 2008, 238-242 (mit älterer Lit.); Le Coze 2012, 344-347; 351; Gilmour 2015, 196; Srinivasan 2017, 910. - Ein analoger Prozess, als «trempe du fer Indien» in einer Quelle des 11.Jh. n. Chr. beschrieben: Berthelot 1888, 347 (Text); 332 (französische Übersetzung). 

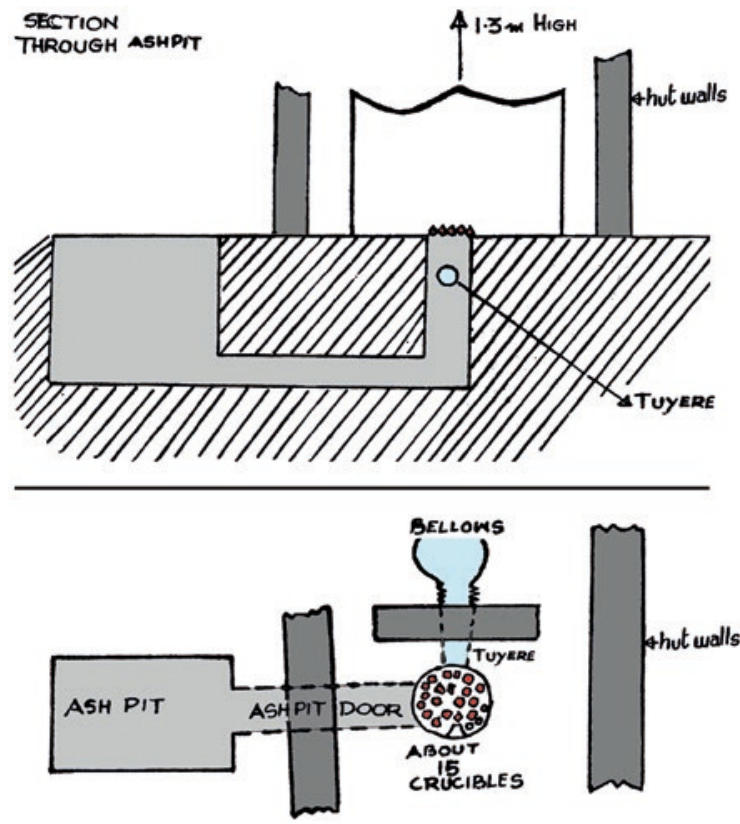

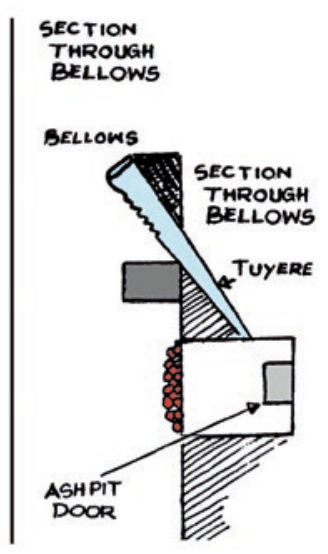

Im Tiegelstahlprozess können mit diesen Verfahvon rund 1-2\% Kohlenstoffgehalt gefüllt, der Tiegeldeckel mit Lehm aufgesetzt. Im wenig verdichteten Material sind auch Schlackenteile und Holzkohlestücke verteilt. Bei etwa $1400^{\circ} \mathrm{C}$ wird das Eisen reduziert; es verflüssigt sich und nimmt gleichzeitig in der reduzierenden Tiegelatmosphäre Kohlenstoff auf ${ }^{219}$. Dieses «Gusseisen» weist entweder ideale Kohlenstoffgehalte auf oder es muss, wenn sie zu hoch sind, anschliessend noch mehrfach gefrischt werden 220 .

3. Ein Prozess, welcher das Frischen ersetzt («co-fusion»; sog. Persischer-, Hyderabad- oder Dekkan-Prozess): Enthält nämlich ein (geschmolzener) Stahl zu viel Kohlenstoff, so dass er weder geschmiedet noch für schneidende Werkzeuge oder Waffen verwendbar ist, werden kleinstückige Teile von kohlenstoffarmem Schmiedeeisen und kohlenstoffreichem Roheisen im richtigen Verhältnis gemischt, in einen Tiegel gebracht und unter der nötigen Hitze zusammengeschmolzen ${ }^{221}$. Der aus dieser «Co-fusion» gewonnene Stahl wird, gegenüber dem kostengünstigen Zementationsstahl, als Luxusstahl bezeichnet, «requiring highly skilled labor» ${ }^{222}$.

Diese Vielfalt der Tiegelstahlherstellung mag erstaunen, aber alle Verfahren und Tiegelkonstruktionen führen zum selben Ziel, wie Gill Juleff prägnant formulierte: «What can be interpreted is that all the forms known are effective and that crucible steel is a resilient technology able to tolerate a high degree of variation. This implies a high degree of technological competence and knowhow ...»223. Paul T. Craddock führte die Vorlieben für das eine oder andere Verfahren auf geographische und ethnische Unterschiede zurück: «It maybe significant that the smiths practising the co-fusion Hyderabad process were traditionally Muslim whereas the smiths practising the carburizing Mysore process were Hindi.»224
Abb. 21: Südindien. Schema eines traditionellen Ofens zur Herstellung von Tiegelstahl. Unten links Grundriss, darüber Längsschnitt durch den Aschegraben, rechts Querschnitt durch die Gebläse-Einrichtung mit Blasebalg und Luftdüse ( Tuyère», hellblau). Die ca. 15 Stahltiegel (rot) liegen dicht beisammen im runden, $\mathrm{ca}$. $1,3 \mathrm{~m}$ hohen Ofen. Ohne Mst. ren ausgezeichnete Stähle mit 1 bis $2 \%$ Kohlenstoff erzeugt werden ${ }^{225}$, die nach dem Härten und Anlassen und allenfalls dem Damaszieren (Abb. 8) ${ }^{226}$ ausgezeichnete Eigenschaften punkto Schärfe, Härte und Elastizität aufwei-

219 Rehren/Papakhristou 2000; Hoyland/Gilmour 2006, 51 f.; zum selben Prozess auch: Heath 1839, 392.

220 Voysey 1832, 247; Heath 1839, 393; Wagner 1993, 351.

221 Massalski 1841, 297-301 (zusammengefasst in Wagner 2007, $311 \mathrm{f}$. Abb. 10); Needham 1958, 26-31; 47 (China, vor allem ab dem 5. Jh. n. Chr.); Al Hassan/Hill 1986, 253 (nach al-Bīrūnī, 10./11.Jh.); Said 1989, 216 (nach al-Bīrūnī, 10./ 11.Jh.); Craddock 1998, 44 und 53 f.; Rehren / Papakhristou 2000, 65 und 68; Biswas 2001, 124 f.; Hoyland/Gilmour 2006, 52; 128; Feuerbach 2007, 332f.; Wagner 2007, 295-301 (China); Balasubramaniam 2008, 242-245 (mit älterer Lit.); Le Coze 2012, 352; Gilmour 2015, 196; Srinivasan 2017, 910. - Zu diesem Prinzip auch: Rehder 1989, 33 und 35.

222 Wagner 2007, 296.

223 Juleff 2015, 85.

224 Craddock 1998, 59.

225 Prakash 2011, 402 ( 1,5\% C); 403 (1,2-1,9\% C); Balasubramaniam 2008, 225 (1,0-1,8\% C).

226 Die Herstellung von Damaszenerstahl erfolgt - je nach Definition - allein durch Verschmelzen von Eisen mit Kohlenstoff im Tiegel (Tiegelstahl) oder durch lagenweises Verschweissen von weichem Eisen und (indischem Tiegel-)Stahl. Feuerbach 2006, 12, unterscheidet sogar vier unterschiedlich hergestellte DamaszenerStahlsorten («... only recently are we beginning to understand the scientific principles behind the formation of the characteristic pattern»). - Zum Damaststahl in der Antike, im Mittelalter und in der Frühen Neuzeit: Schwarzlose 1886, 127-158; Landrin 1835, 159f.; Rommel 1929, 2130-2132; Sachse 1989; Feuerbach 2002, 181-215; Wagner 2007, 298 (historische Quelle des 11.Jh. n. Chr. aus China zu damastähnlichem Verbundstahl); 301. - In einigen Quellen ist auch davon die Rede, dass die Klingen am Schluss kalt geschmiedet werden. Dazu und zu den daraus gefertigten Produkten gibt es eine unüberschaubar grosse Literatur von der detaillierten Fachuntersuchung bis zum Handbuch für Sammler. 

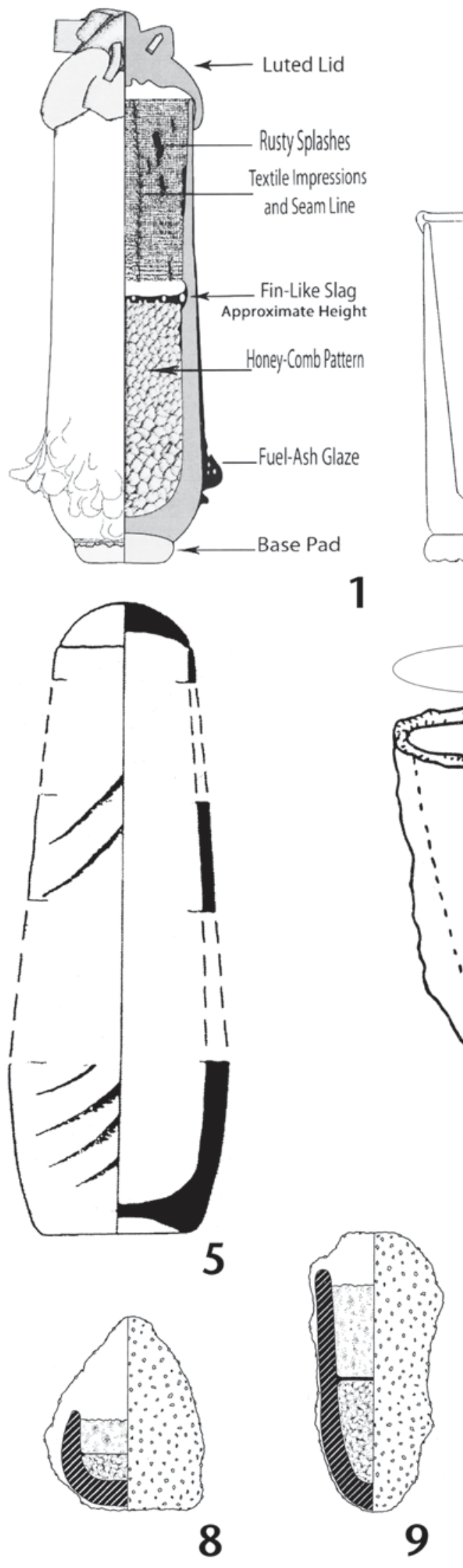
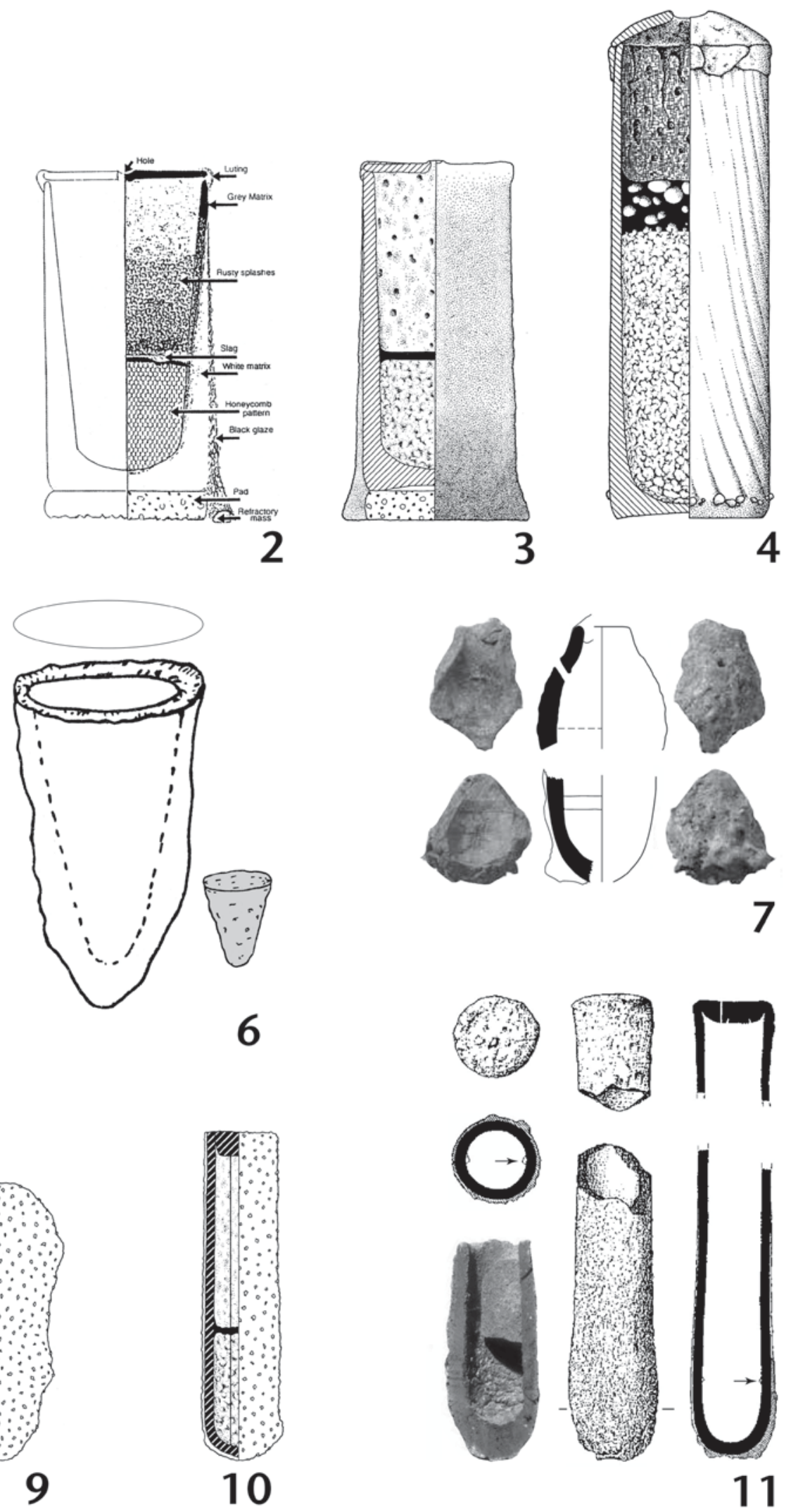

Abb. 22: Zusammenstellung von Stahltiegeln resp. Rekonstruktionen von verschiedenen Fund- und Produktionsplätzen in Iran (1: Chähak), Turkmenistan (2-3: Merv), Usbekistan (4-5: Akhsiket), Indien (6: Fundort unbekannt [Oval: Deckel schematisch; grau: Stahlbarren]; 8: Konasamudram; 9: Gattihosahalli) und Sri Lanka (7: Hattota Amune Wallewala; 10: Mawalgaha; 11: Samanalawewa). Mst. 1:4. 
sen. Sie sind wegen des sehr hohen Kohlenstoffgehalts jedoch viel schwieriger zu schmieden als herkömmliche Stähle, da sie bei allzu hoher Hitze rasch zerbrechen. Dies beklagte zum Beispiel der bekannte französische Forscher René-Antoine Ferchault de Réaumur, denn er habe um 1720 in Paris niemanden gefunden, der imstande war, indischen, in Kairo gekauften Wootz-Stahl zu schmieden ${ }^{227}$. In modernen archäologischen Experimenten ist die Produktion von Tiegelstahl auch in Europa erfolgreich nachvollzogen worden 228 . Es würde aber zu weit führen, hier auf diese viel beschriebene Technik ausführlich einzugehen 229 .

Nur die Stahltiegel interessieren uns - im Vergleich zu den Tonumhüllungen von Augusta Raurica - näher:

\section{Die Tiegel}

Das erforderliche Tonmaterial und die Mischung für die Stahltiegel beschreibt Bhanu Prakash kurz und treffend: «The crucible used for making Wootz steel was made from locally available aluminous clay (Kaoline) mixed with some magnetite dust and rice husk or straw. During firing and heating rice husk got charred and deposited in the crucible providing it excellent refractory property.» ${ }^{230}$ Der verwendete kaolinitische Ton musste mit seiner siliziumund kohlenstoffreichen Matrix hoch refraktär sein ${ }^{231}$. In anderen Untersuchungen werden auch Quarzfragmente, Holzkohle und Schamotte aus zerschlagenen Ofenwänden und Tiegeln als Zusatz zum Tiegelton erwähnt ${ }^{232}$, ebenso auch Strohhäcksel, Reisspreu und Graphit ${ }^{233}$. Das nach dem Stahlerzeugungsprozess zerschlagene Tiegelmaterial ist oft stark verschlackt, schwarz, porös und relativ leicht und hart gebrannt. Wo erwähnt, seien die Stahltiegel vor ihrem Einsatz mit Eisen und Holzkohle nicht vorgebrannt worden $^{234}$. Sie waren immer nur zum einmaligen Einsatz bestimmt und nicht wiederverwendbar ${ }^{235}$. An die 12-25 Tiegel kamen auf jeweils eine Ofencharge ${ }^{236}$.

Die Tiegel zur Erzeugung von Tiegelstahl sind immer schlank und hoch, teils scheibengedreht, teils handgeformt und teils über einen zylindrischen Kern geformt. Die Umrisse sind immer zylindrisch und weichen im Einzelfall etwas konisch oder birnenförmig ab (Abb.22). Ihre Höhe schwankt zwischen 20 und $40 \mathrm{~cm}$, die Durchmesser $4-10 \mathrm{~cm}$. Zur Gewährleistung eines reduzierenden Milieus im Tiegelinnern sorgte immer ein mit Lehm aufgeklebter Deckel. Durch das lange und intensive Aussetzen in der Ofenhitze finden sich aussen und vor allem im unteren Bereich oft starke Verschlackungen. Beim Erreichen der Stahlschmelze bildete sich durch das flüssige Metall in der unteren Tiegelhälfte an der Tiegelinnenwand ein Belag mit bienenwabenförmiger Struktur; der Spiegel des flüssigen Stahls hinterliess eine gratförmige horizontale Schlackenbraue. Die obere Tiegelhälfte, wo sich die Gase der verglühten kohlenstoffhaltigen Zusätze sammelten, zeigt innen meist russige Partikel.
Am Schluss des Prozesses und nach dem Abkühlen²37 wurden die Tiegel zerschlagen, damit die Reguli resp. «cakes» (Abb. 22,6; 23) entnommen und verkauft werden konnten. An den Produktionsstätten blieben mit der Zeit auf diese Weise Unmengen von Tiegelscherben zurück ${ }^{238}$.

Vom regen Handel mit asiatischem Tiegelstahl ins Römische Reich berichtet der «Periplus Maris Erythraei» (Küstenbefahrung des Roten Meeres) aus dem 1.Jahrhundert n. Chr. Offenbar wurde indischer (und andernorts hergestellter?) Stahl über den Wasserweg in arabische Häfen verschifft und von dort ins Imperium weiterverhandelt, wo er als wertvolles Qualitätsprodukt einen ausgezeichneten Ruf besass $^{239}$. Wenn Plinius schreibt, «Aber unter allen Sorten fällt die Siegespalme dem serischen Eisen zu» ${ }^{240}$, so sind mit den Serern vermutlich Inder und ihr Tiegelstahl gemeint.

227 Zitiert von Bréant 1823, 224. - Zur Bedeutung von R. A. F. de Réaumur für die Stahltechnologie: Barraclough 1981, 535-543.

228 Erstmals wohl um 1800 durch David Mushet in England: Mushet 1840, 650-678; Heath 1839, 396. - Zusammenfassend Giolitti 1915, XXIII (Tiegelstahlerzeugung in England); Barraclough 1981, 205-344 und 494-521 (ausführlich); Evans 2008; Craddock et al. 2017. - Weitere Experimente: Balasubramaniam 2008, 240f. (mit älterer Lit.); Kucypera / Hošek 2014, 32 ff. Abb. 1 und 2 (zitiert nach Fabiánek et al. 2003). - Weitere Versuche: http: / /apmt-online. de/ wootz.html (12.04.2016).

229 Knapp zusammenfassend und mit älterer Literatur: Bersch 1899, 754; Prakash 2011, 402-408. - Siehe unter vielen anderen Arbeiten auch: Schoff 1915, 234-239 (Indien); Kuppuram 1989, 325-341 Abb. S. 329 (= hier Abb.21); Juleff 1998 (Sri Lanka, bis in die Neuzeit); Biswas 2001, 121-125; Craddock 2010, 275-283 Abb. 7.207.21; Prakash 2011, 400-408 Abb. 17. - Zu römerzeitlichen Schwertern aus Eisen, Stahl, verschiedenen Verbundstoffen und Damaszenerstahl: Biborski et al. 1982.

230 Prakash 2011, 404 (Zitat). - Zur Herstellung von Tiegeln zur Stahlerzeugung auch: Voysey 1832, 246; Heath 1839, 392; Lowe et al. 1991; Bhardway/Sharma 1997, 11 f. Taf. 2,35-37; Craddock 1998, 50f. Abb. 4-6; Feuerbach 2002, 108-111 Abb. 15; Feuerbach 2006, 13; Papachristou / Rehren 2008; Le Coze 2012, 346; 361 f.; Srinivasan 2017, 912.

231 Papakhristou / Rehren 2001, 149 f., Tab. S. 151 (nur 1\% FeO); Srinivasan 2017, 913.

232 Voysey 1832, 246; Feuerbach 2007, 329 (hohe Schamottanteile in der Tiegelkeramik in Merv [Turkmenistan] zur Streckung des lokal nicht vorhandenen hitzebeständigen Tiegeltones); Srinivasan 2017, 913 («quartz fragments», «pieces of charcoal»).

233 Rostoker/Bronson 1990, 60 (Holzkohle- und Koks-Pulver, Graphit); Le Coze 2012, 346 (Strohhäcksel, Reisspreu, Graphit).

234 Lowe et al. 1991, $627 \mathrm{f}$.

235 Le Coze 2012, 346.

236 Prakash 2011, $402 \mathrm{f}$.

237 Srinivasan 2017, 914 («the ingot was slow cooled»).

238 Balasubramaniam 2008, 240 Abb. 4.10 (Querschnitt durch einen Stahl-Regulus).

239 Huntingford 1980, 22. - Dazu auch Schoff 1915, bes. 234-239; Schoff 1912, 24; $70 \mathrm{f}$.

240 Plin. nat. 34,145 (in der Übersetzung der interdisziplinären Projektgruppe Plinius: Rottländer 2000, 41 und 57 f. Anm. 35); Healy 1978, 215; Halleux 2007, 1303 («fer Sérique [chinois]»); 1396f. (ferrum Indicum); Balasubramaniam 2008, 230; Lang 2017, 1 («It has been suggested that Seric iron came from China or possibly Sri Lanka»). 


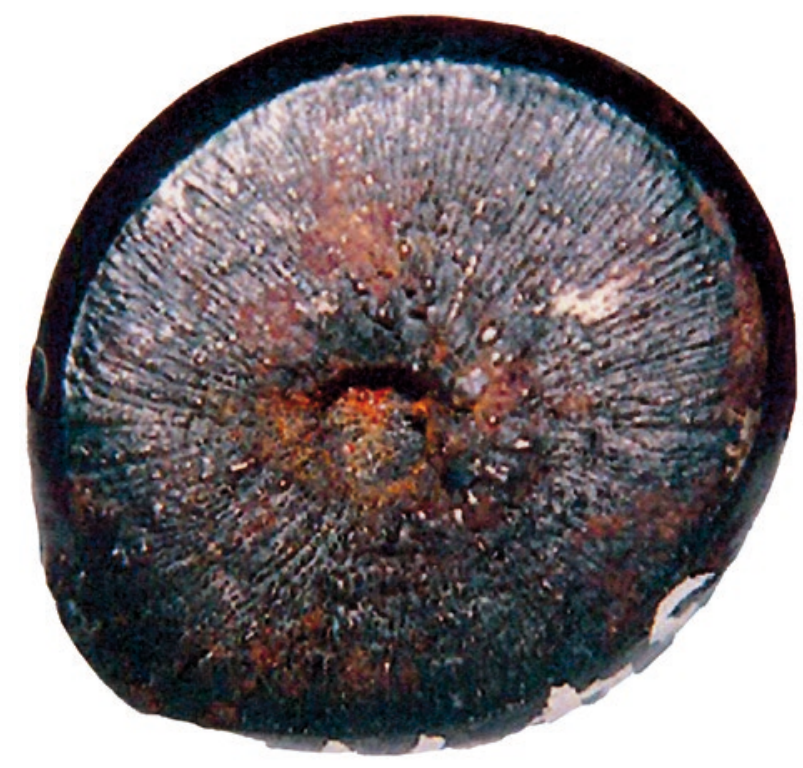

Abb. 23: Zylinderförmiger Barren aus dem indisch-asiatischen Tiegelstahlprozess im Science Museum, London/GB. Die Eisen-Kohlenstoff-Schmelze in hohen röhrenförmigen Tiegeln (Abb. 22) führte zu einem homogenen Stahlbarren, und beim langsamen Abkühlen und Erstarren bildeten sich auf dessen Oberfläche radiale Erstarrungsstrukturen. Ohne Massstab.

Die im Prinzip analoge Stahlerzeugung in einer Schmelze mit viel Kohle, jedoch nicht in Tiegeln, sondern in frühindustriellen Prozessen in Europa, beschreiben im 16. Jahrhundert Vannoccio Biringuccio und Georg Agricola ${ }^{241}$.

\section{Das ferrum Noricum, ein Hightech-Stahl aus dem Rennofen}

Das ferrum Noricum war in der römischen Antike der Inbegriff des guten Messerstahls. Hier, im heutigen Kärnten / A, wurde schon früh Eisenerz verhüttet und Stahl erzeugt (Abb.27), der schon lange vor der Einverleibung in das Römische Reich im Jahr 16 n. Chr. im Süden berühmt war $^{242}$. Administrativ lag der Stahlhandel in den Händen von conductores (Grosspächter), die als Zwischenglied zwischen den Betrieben in Noricum, den Materialdepots und Werkstätten in Aquileia / I und der kaiserlichen Verwaltung in Rom amteten ${ }^{243}$. Von ihnen erfahren wir in einigen Inschriften (s. unten mit Abb. 24).

Nebst produktionstechnischen und administrativen Aspekten der norischen Stahlproduktion soll uns zuerst interessieren, welch guten Ruf das begehrte Rohmaterial in der Antike hatte. Norischer Stahl wird in diesem Zusammenhang mehrfach von Zeitzeugen genannt, weshalb ich alle bekannten Äusserungen hier in den entscheidenden Zitaten aufliste (in chronologischer Reihenfolge) ${ }^{244}$ :

\section{Autoren}

Quintus Horatius Flaccus (65-8 v.Chr.) in den «Epoden»: «Bald wirst du ... deine Brust mit einem norischen Schwert durchbohren ...»245

Quintus Horatius Flaccus in den «Oden»: «Ihn schrecket kein norisches Schwert zurück ...»246

Publius Ovidius Naso (43 v. - 17 n. Chr.), in den «Metamorphosen»: «... härter als Eisen, das in Noricum in der Esse geschmolzen wird.» ${ }^{247}$

Strabon (um 63 v. Chr. - nach 23 n. Chr.) in seiner grossen «Geographie»: Von Aquileia folgt man einem Fluss über 1200 Stadien aufwärts «bis zu der Stadt Noreia [Hauptstadt von Noricum] ... Dieser Ort hat ergiebige Goldwäschereien und Eisenwerke.»248

Titus Petronius Arbiter (um 14-66 n. Chr.) im «Gastmahl des Trimalchio»: «... habe ich ihm aus Rom als Geschenk Messer aus Norischem Eisen [Stahl] mitgebracht. ... Dann gab er uns die Erlaubnis, die Schärfe der Schneiden an unseren Wangen zu prüfen.»249

241 Biringuccio 1540, $77 \mathrm{f}$. (in deutscher Übersetzung: Johannsen 1925, 76-79); Agricola 1557, 368.

242 Zur Geschichte Noricums: Alföldy 1974; kurzer historischer Abriss: Malzacher 1963, 49f. - Zu den technischen Aspekten der Herstellung und Endprodukte aus ferrum Noricum zusammenfassend: Sperl 2002A (mit älterer Lit.).

243 Winkler 1969, 163 f.; Alföldy 1974, 113-117; Kaus 1981, 74; Grassl 1988 (Bedeutung von Aquileia als Umschlagplatz für das ferrum Noricum, insbes. für die Ausrüstung der römischen Armee); Gostenčnik 2005, 99.

244 Zusammenstellung in der RE XXXIII (1936) 1043 s.v. Noricum (W. Ruge); Schaaber 1963, 129; Piccottini 1981, 70f. (Zusammenstellung der griechischen und lateinischen Zitate); Grassl 1988, 87 f.; Gostenčnik 2005, 99f.; Lang 2017, 4; 6. - Noricum resp. die Steiermark als Eisenproduktionslandschaft in der Frühen Neuzeit: Klein 1760, 115.

245 Hor. epod. 17,71 («ense pectus Norico recludere»); Beck 1884, 510; Dobesch 2000, 11; Hofeneder 2017, 1-3.

246 Hor. carm. 1,16,9 («neque Noricus deterret ensis ...»); Beck 1884, 510; Dobesch 2000, 11; Hofeneder 2017, 1-3.

247 Ov. met. 14,712 («durior et ferro, quod Noricus excoquit ignis»); Dobesch 2000, 11; Hofeneder 2017, 3-4 («... der in norischem Feuer geschmolzen wird, und härter als der Fels ...»). - E. Rösch, Publius Ovidius Naso. Metamorphosen (München $1992^{13}$ ), übersetzt: «... härter als Eisen, wie das norische Feuer es auskocht»; Beck 1884, 510.

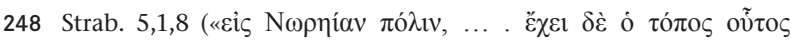

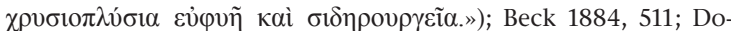
besch 2000, 14f.; Hofeneder 2017, 4-5.

249 Petron. 70,1-3 («attuli illi Roma munus cultros Norico ferro .. etiam nobis potestatem fecit, ut mucronem ad buccam probaremus.»); Dobesch 2000, 12; Hofeneder 2017, 5-6. - W.Ehlers/ K. Müller et al., Das Gastmahl des Trimalchio (Düsseldorf 2014), übersetzen: «... habe ich ihm aus Rom steirische Stahlmesser mitgebracht. ... Auch uns gab er Gelegenheit, die Schneide an der Backe zu prüfen.» 
Gaius Plinius Secundus (der Ältere; 23/24-79 n. Chr.) in der «Naturkunde»: «In unserem Herrschaftsbereiche gibt es Orte mit Erzlagerstätten, die durch ihre Güte hervorragen, wie etwa bei den Norikern ...» ${ }^{250}$

Marcus Valerius Martialis (40-104 n.Chr.) im liber spectaculorum («Buch der Schauspiele»): «Wie sicher war der Stoss, mit dem norische Speere lenkte / die tapfere Hand des noch so jungen Carpophorus!»251

Martial in den «Epigrammen» (geschrieben um 85-103 n. Chr.): «Bilbilis, ausgezeichnet durch das grausame Metall, | das Chalyber und Noriker übertrifft, und das von seinem Eisen dröhnende Platea, | das mit schwacher, aber unruhiger Strömung | der Salo - dazu bestimmt, die Waffen zu härten - umflutet ...»252

Galenos von Pergamon (um 129 - um 216 n.Chr.) in den «Anatomischen Verfahren»: «Es [das Skalpell] soll aus dem feinsten Stahl sein, wie es der Norische ist, damit es nicht stumpf wird, sich verbiegt oder bricht.»253

Titus Flavius Clemens von Alexandria (um 140/150-220 n. Chr.) in den auf Griechisch verfassten Stromateis («Die Teppiche»): «Die Noroper (es ist eine Paeonische Völkerschaft, jetzt nennt man sie norisch) verfertigten Erz und reinigten zuerst das Eisen.» 254

Eusebios von Caesarea (um 260-339 n. Chr.) übernahm in seiner Praeparatio evangelica (»Vorbereitung auf das Evangelium «) wortwörtlich den Text des Clemens von Alexandria. ${ }^{255}$

Rutilius Claudius Namatianus (1.Hälfte 5.Jh.) im Gedicht De reditu suo («Über seine Rückkehr»): «Kein reicheres Erz hat die norische Scholle ans Licht gebracht ...» (im Vergleich mit anderen guten Erzen, explizit jenes von den Biturigen [in Aquitanien / F] resp. aus Elba / I oder Sardinien / I) ${ }^{256}$.

Stephanos von Byzanz (6.Jh. n. Chr.) in den Ethnika: «Norakos, Stadt in Pannonien. Der Bürger heisst Norakier. Wie Epaphroditos in den Homerika erklärt, heisst die Stadt deshalb Norakos, weil es in Pannonien ein Eisen gibt, welches, mit dem Wetzstein poliert, sehr hell glänzt. Davon abgeleitet ist auch der Ausdruck funkelndes Erz〉.» ${ }^{257}$ Nach Stephanus verknüpft der Grammatiker Epaphroditos aus Chaironeia (1.Jh. n. Chr.) also die Wortbedeutung des homerischen Epithe-

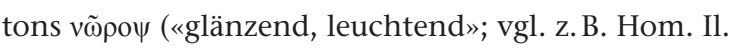
2,578; 11,16,) mit der Stadt Norakos in Pannonien. ${ }^{258}$ Die Aussage von Epaphroditos findet sich auch in der byzantinisch-griechischen Enzyklopädie Suda / Suida (10.Jh.), welche die Ethnika des Stephanus zitiert. ${ }^{259}$

Annolied (spätes 11.Jh.): Sogar noch im 11.Jahrhundert klingt der gute Ruf des Norischen Stahls nach: «... bekannt aus heidnischen Büchern. Dort liest man: «Noricus ensis, das heisst: ein bayerisches Schwert, denn sie glaubten zu wissen, dass keine [anderen Schwerter] besser bissen: Oft durchschlug man die Helme damit.» 260
Aus einigen dieser Zitate ${ }^{261}$ geht hervor, dass Norisches Eisen gerne - und auch ausserhalb eines handwerklichen oder kommerziellen Kontextes - einfach als Sinnbild einer guten Stahlqualität zitiert worden ist.

250 Plin. nat. 34,145 («... vena bonitatem hanc praestat, ut in Noricis...», in der Übersetzung von Vetters 1966, 181); Beck 1884, 510; Straube 1996, 117 [ebda. zitiert]); Dobesch 2000, 12-14 (ausführlich zu den Begriffen vena und excoquere; Norisches Eisen als exportiertes Halbfabrikat); Rottländer 2000, 41 Anm. 39; Hofeneder 2017, 6-9 («... wird diese Güte an einigen Orten durch die Erzader gewährleistet, wie bei den Norikern ...»).

251 Mart. Spect. 26 (23) («Norica quam certo venabula derigit ictu | fortis adhuc teneri dextera Carpophori»); auf http:// lateinoase. de/autoren/martial/martial.html (29.04.2018): «Mit so sicherem Wurf lenkt die Rechte des kräftigen und immer noch jungen Carpophorus Jagdspiesse aus Noricum.»; Dobesch 2000, $11 \mathrm{f}$; Coleman 2006, 186; $189 \mathrm{f}$.

252 Mart. 4,55,12; («saevo Bilbilin optimam metallo, | quae vincit Chalybasque Noricosque, | et ferro Plateam suo sonantem, | quam fluctu tenui sed inquieto | armorum Salo temperator ambit ...»); Dobesch 2000, 11 f.; Hofeneder 2017, 9-11 (ebda. 9 zu Mart. Spect. $26[22+23]$ [«norische Jagdspiesse»]). - Zum Eisen und Stahl der Chalyber siehe Anm. 186.

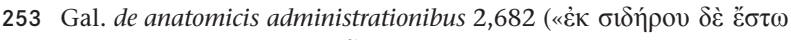

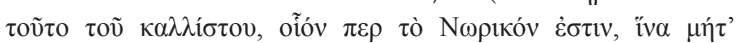

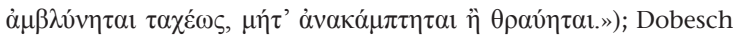
2000, 12; Hofeneder 2017, 11 f. - Die Übersetzung stammt von Christoph Schneider.

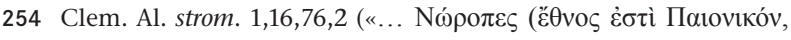

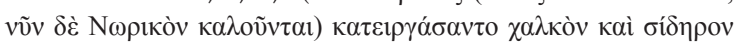

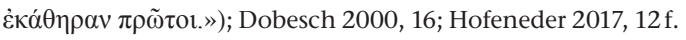

255 Eus. Pr. Ev. 10,6,9; Dobesch 2000, 16: «Es liegt auf der Hand, dass Eusebius aus Clemens abschrieb ...».

256 Rut. Nam. 1,352 («... nihil uberius Norica glaeba tulit ...»); Beck 1884, 510; Dobesch 2000, 15; Hofeneder 2017, $13 \mathrm{f}$.

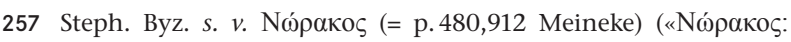

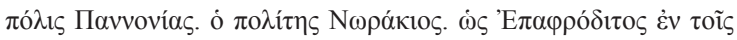

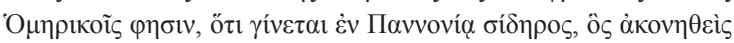

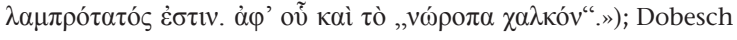
2000, 15 f. Anm. 22-23; Hofeneder 2017, $14 \mathrm{f}$.

258 Billerbeck 2014, 401 Anm. 149.

259 Suda (früher als Suida zitiert) N 561 Adler; Dobesch 2000, 16 («Das Wissen der Suda [stammt] aus Stephanos»).

260 Annolied, 20, 8-13. - Beck 1884, 718; Nellmann 2005, 26 f.; 93.

261 Hier nicht aufgeführt wird Sidonius Apollinaris (um 431 - um 487 n. Chr.), carmina 5,51. Bei der Erwähnung, dass «die norischen Länder sich durch Eisen» auszeichnen würden, handelt es sich nach Andreas Hofeneder (2017, 17-18 Anm. 110-116 [mit älterer Lit.]) um ein «Falsum», nach Gerhard Dobesch $(2000,15)$ gar um einen «seltsamen Blindgänger», welcher von Dobesch $(2000,15)$ auf falsch zugeschriebene Verse eines Humanisten des 16.Jh. zurückgeführt wird. 
$\mathrm{I} \cdot \mathrm{O} \cdot \mathrm{M}$

M. TREBVS

M FIL PALAT

ALFVS - EQVO

P P PRAEF $\cdot I \cdot D$

AQVIL $\cdot C \cdot F \cdot \bar{N}$.

$\mathrm{V} \cdot \mathrm{S} \cdot \mathrm{L} \cdot \mathrm{M}$.
ISIDI · NOREI

$\mathrm{V} \cdot \mathrm{S} \cdot \mathrm{L} \cdot \mathrm{M}$

PR Ó - SA L V́ T E

Q S EP TVEI .

C L É M E N T I S

$\mathrm{CON} \cdot \mathrm{FER} \cdot \mathrm{N} \cdot \mathrm{P} \cdot \mathrm{D}$

ET $\cdot$ TI $\cdot \mathrm{CL} \cdot$ HÉRACLE

$\mathrm{ET} \cdot \mathrm{CN} \cdot \mathrm{OCT}^{\mathrm{A}} \cdot \mathrm{SECVNDI}$

PRO - FER - Q - SEPTEI

VALÉNS - PRO - FERR

CIL III 4809
TERMVNIBVS · AVC

SACR - $Q \cdot$ CALPVRNIVS

PHOEBIANVS $\cdot \mathrm{C} \cdot \mathrm{F} \cdot \mathrm{N} \cdot \mathrm{ET}$

QVINTVS - CALPVRNIVS

PHOEBIANVS $\cdot$ IVNIOR $\cdot$ E

CHARITONIANVS • FILI

RESTITVERVNT $\cdot$ CVRANTE

C - IVL - HERMETE - PROC

CIL III 5036

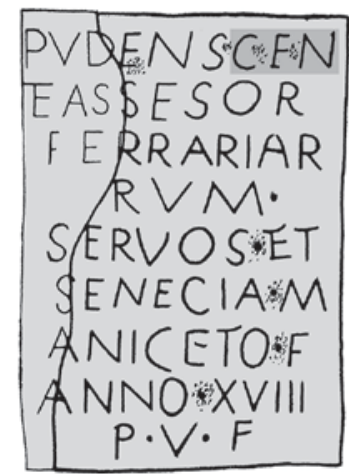

Alföldy 1969,33

Abb. 24: Inschriften aus Kärnten in Österreich (Teil von Noricum) mit der Nennung von conductores ferrariarum Noricarum. Ohne Massstab (Höhen der Inschriftsteine siehe Text).

\section{Inschriften}

Mehrere in der Eisenproduktion beschäftigte Pächter resp. Beamte aus Noricum ${ }^{262}$ finden sich auf Weih- und Grabinschriften aus Kärnten / A (Abb. 24; Fundorte Abb. 27) ${ }^{263}$ :

Grabinschrift des Pudens[?] aus Tiffen/A (Abb.24, rechts): Die ergänzte Inschrift nennt mit Pudens wohl einen Sklaven, obwohl direkt auf den Namen C(onductoris) F(errariarum) N(oricarum) [et ass]ES(s)ORI(s) [fe]RRARIARUM [s]ERVOS folgt. Nach Géza Alföldy gehört der Grabstein aufgrund des Namens zu einem Sklaven, «der in der Verwaltung der norischen Eisenbergwerke Aufgaben hatte. ... So wird man im Sklaven Pudens keinen Assessor, sondern den Sklaven eines norischen Bergassessors erblicken dürfen ... und zugleich den Beauftragten des conductor [Grosspächter, Verwalter] der norischen Eisenbergwerke.» ${ }^{264}$ Höhe noch $115 \mathrm{~cm}$.

Weihinschrift CIL III 4788 aus Tiffen/ A (Abb. 24, links): Weihung an Iupiter IOM durch Marcus Trebius Alfius, einen praefectus iure dicundo (mit der Rechtsprechung beauftragter Präfekt) aus Aquileia, Pächter von norischen Eisenverarbeitungsbetrieben (C.F.N. = conductor ferrariarum Noricarum) ${ }^{265}$. Höhe $109 \mathrm{~cm}$.

Weihinschrift CIL III 4809 aus Pulst-Hohenstein/A (Abb.24): Weihung des Conductors Quintus Septueius Verus (oder Clemens) und seiner drei Privatprocuratoren (Pächter) an die in Noricum oft verehrte Göttin Noreia («Isidi Noreiae»). Hier steht statt C.F.N. das ausführlichere Kürzel CON.FER·N. respektive con(ductor) fer(rariarum) N(oricarum), unten gefolgt von pro(curatorum) fer(rariarum) ${ }^{266}$. 2.Jh. n. Chr.; Höhe $56 \mathrm{~cm}$.

Votivaltar aus Zollfeld/A-Virunum (auf Abb.27 nicht kartiert): Ein fragmentierter und sekundär verbauter $\mathrm{Al}$ tar nennt denselben Conductor ferrariarum Noricarum Quintus Septueius Clemens. Sein Sklave Thallus hat aufgrund eines Gelübdes den Stein gestiftet und wird wohl ebenfalls im Eisenbergbauwesen beschäftigt gewesen $\operatorname{sein}^{267}$.
Weihinschrift CIL III 5036 aus Friesach/A (Abb. 24): Weihung des Quintus Calpurnius Phoebianus und seiner beiden Söhne an die Termunes (Grenzgottheiten) für die Wiederherstellung deren Heiligtums unter der Bauleitung des Procurators Caius Julius Hermes. Die Funktion des weihenden Phoebianus ist wiederum mit dem Kürzel C.F.N. (c[onductor] flerrariarum] N[oricarum]) versehen, jene des Bauleiters mit PROC[uratore $]^{268}$. 1.Jh. n. Chr.; Höhe $66 \mathrm{~cm}$.

262 Piccottini 1981, 73 f.; Hirt 2010, 53-56 Anm. 29 Abb. 14.

263 Weitere Belege $(5 \times$ conductores [Verwalter], $4 \times$ procuratores [Pächter] und $2 \times$ servi, auf insgesamt fünf Inschriften) bei Winkler 1969, 164 ff. (mit Abb. S. 167; mit weiterer Lit.). - Ferner: Weihung an Jupiter des Fortunatus CONDUCT[oris] FERRAR[iarum] aus Wieting/ A: Leber 1967, 524-526 Abb. 7; Piccottini 1981, 72 Nr. 2. - Bauinschrift für ein Mithrasheiligtum aus Aquileia / I des Tiberius Claudius Macro, CON[ductoris] FER[rariarum] NOR[icarum]: Piccottini 1981, 72 Nr. 5. - Grabstein von Crescens Gentianus(?), [as]SES[s]OR [Procuratoris fe]RRARIAR[um Norica]RUM, für seinen 18-jährigen Sohn Anicetus aus Tiffen/A: Piccottini 1981, 73 Anm. 6 (mit älterer Lit.).

264 Alföldy 1969, 24 f. Kat.-Nr. 33 (Zitat); Alföldy 1970, 176; N. Schindel, in Cech et al. 2017, 357. - Foto auf http://lupa.at/1958 (01.05.2018)

265 Schmid 1932, 197f. Abb. 20; Malzacher 1963, 52 Abb. 3, links (Fundort: «Schloss Lang bei Feldkirchen»); Winkler 1969, 164f., Zeugnis 1; Alföldy 1970, 176; Alföldy 1974, 115; Piccottini 1981, 71 f.; Galik et al. 2003, 69 Abb. 19 (Fundortangabe: Feldkirchen / ASchloss Lang). - Foto auf http: / / lupa.at / 4913 (01.05.2018).

266 Schmid 1932, 193; 196-198 Abb. 19; Malzacher 1963, 52 Abb. 3 , rechts; Alföldy 1970, 176; Alföldy 1974, 115 f. Taf.17; Piccottini 1981, 72 Nr.3; Piccottini 2002, 110f. - Foto auf http://lupa. at / 5764 (01.05.2018)

267 Piccottini 1985, bes. 467.

268 Schmid 1932, 195 f. Abb. 18; Malzacher 1963, 52 Abb.3, Mitte; Winkler 1969, 164f., Zeugnis 3; Alföldy 1970, 177; Alföldy 1974, 116 Taf.26; Piccottini 1981, 72 Nr. 4; N.Schindel, in Cech et al. 2017, 357. - Fotos auf http: / / lupa.at / 4912 (01.05.2018) 


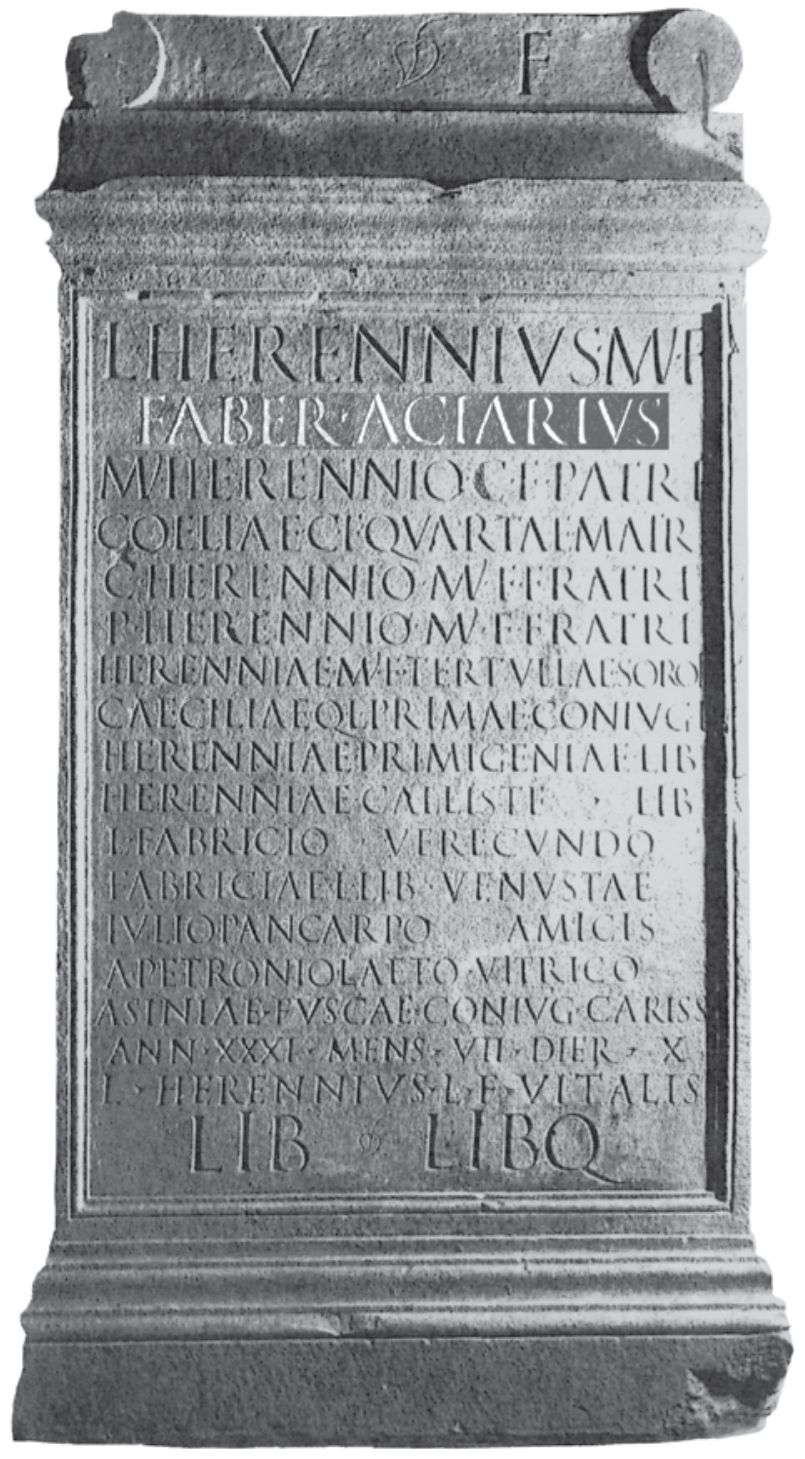

Abb. 25: Grabaltar des Lucius Herennius (s. erste Zeile), aus Aquileia/I. Wichtig hier ist die Nennung seines Berufes: faber aciarius (Stahlschmied; hier hervorgehoben). Höhe $177 \mathrm{~cm}$.

Die fünf hier vorgestellten Inschriften ${ }^{269}$ fanden sich in engerem Umkreis des Magdalensberges: Jene von Friesach $26 \mathrm{~km}$ im Norden, die beiden von Tiffen $28 \mathrm{~km}$ im Westen und die von Puls dazwischen (Abb.27,8-11). Der Hüttenberger «Erzberg» und der benachbarte «Eisner» bei Semlach $^{270}$, wo das Eisenerz abgebaut worden ist (Abb. 27,3.6), liegen rund $25 \mathrm{~km}$ nördlich vom Magdalensberg und nur $10 \mathrm{~km}$ östlich von Friesach. Die in den Inschriften genannten conductores ferrariarum Noricarum müssen also alle im selben Grossrevier gearbeitet haben.

Grabaltar des Stahlschmieds (faber aciarius) Lucius Herennius (Abb.25) aus Aquileia/I. Die lange Inschrift nennt zahlreiche Verwandte - Mitweihende und Verstorbene. Wichtig ist der hier erstmals erwähnte Beruf des Herennius: faber aciarius. - 1. Hälfte 1.Jh. n. Chr. ${ }^{271}$.

Römische Ziehklinge mit HERENNI-Stempel, aus Eisen, gefunden auf dem Dealul Grădiștii bei Orăștie / RO (770 km östlich von Aquileia resp. $670 \mathrm{~km}$ südöstlich des norischen Eisenverarbeitungszentrums). Die Vermutung, der Stahlschmied Lucius Herennius aus Aquileia (oben) hätte dieses Stück gefertigt und mit seinem Herstellerstempel versehen, ist sehr verlockend und schon verschiedentlich geäussert worden 272 .

\section{Metalla-Münzprägungen}

Eine besondere Quellengattung sind Inschriften auf Kleinmünzen. Unter den Prägungen des Hadrian (76-138, regiert 117-138) und Antoninus Pius (86-161, regierte 138161) interessiert uns eine Untergruppe - relativ seltener - Semisses und Quadrantes mit der rückseitigen Inschrift MET(alla)·|NOR(ica) (Abb. 26) ${ }^{273}$. «Dass MET prinzipiell das Wort metalla meint, steht ausser Frage, wobei dieses Wort «Bergwerk» meint. ... Auch die Auflösung NOR als Norica kann als gesichert gelten.» 274

Diese sog. «Bergwerksprägungen» sind im zweiten Viertel des 2.Jahrhunderts in Rom entstanden und nennen auch andere Bergwerksreviere (metalla) wie zum Beispiel metalli Ulpiani, metal Aurelianis oder metal Pannonicis. Es handelt sich um Kleinstnominale, deren geringer Wert etwa für Lohnzahlungen (wie ursprünglich vermutet wurde) nicht geeignet war. Sind diese Prägungen in der Absicht Roms zu verstehen, die «fortlaufende wirtschaftliche Bedeutung des Bergbaus in der Region deutlich» herauszustreichen ${ }^{275}$ ?

Nur in wenigen Fällen ist von diesem Münztyp der Fundort bekannt (Abb.27,12-14): zweimal Lauriacum (Enns/A-Lorch, $135 \mathrm{~km}$ nördlich der norischen Eisenerzvorkommen ${ }^{276}$ und einmal St. Peter in Holz/A (85 km westlich; Abb. 26,5) 277 . Weitere Fundorte von METNOR-Prägungen in Noricum selbst sind Enns / A und St. Va-

269 Und die in Anm. 263 erwähnten. Siehe auch: Alföldy 1970, 168; N. Schindel, in Cech et al. 2017, $357 \mathrm{f}$. (mit einigen weiteren Belegen).

270 Zu den montanarchäologischen Grabungsbefunden siehe Cech et al. 2017, bes. Abb. S. 58

271 Editionen: Brusin 1991, 319 Kat.-Nr. 703; Hope 2001, 114 Kat.-Nr. IA 700; Lettich 2003, 138f. Kat-Nr. 172. - Die Inschrift ist u. a. auch erwähnt in: Malzacher 1963, 58 Abb. 10; Straube 1996, 142; Dexheimer 1998, 112 Kat.-Nr. 93.

272 Daicoviciu et al. 1953, 182 (kurze Objektbeschreibung); Malzacher 1963, 58; Glodariu 1968, 363; 367 (kurze Objektbeschreibung); Straube 1996, 142.

273 RIC II, 474/1011 Taf. 16,330; BMCRE III 533/1850-1852 Taf. 98,3-

274 N. Schindel, in Cech et al. 2017, 357 (Zitat); 365 Abb. 2,LA

275 Woytek 2004, bes. 40 und 61 Kat.-Nr. I-II / 2 (mit älterer Lit.) (den Literaturhinweis inklusive Nachtrag verdanke ich Markus Peter, Museum Augusta Raurica); Gostenčnik 2005, 102 (Zitat).

276 Dembski 1983.

277 Glaser 2005, 66 Abb. 4. 

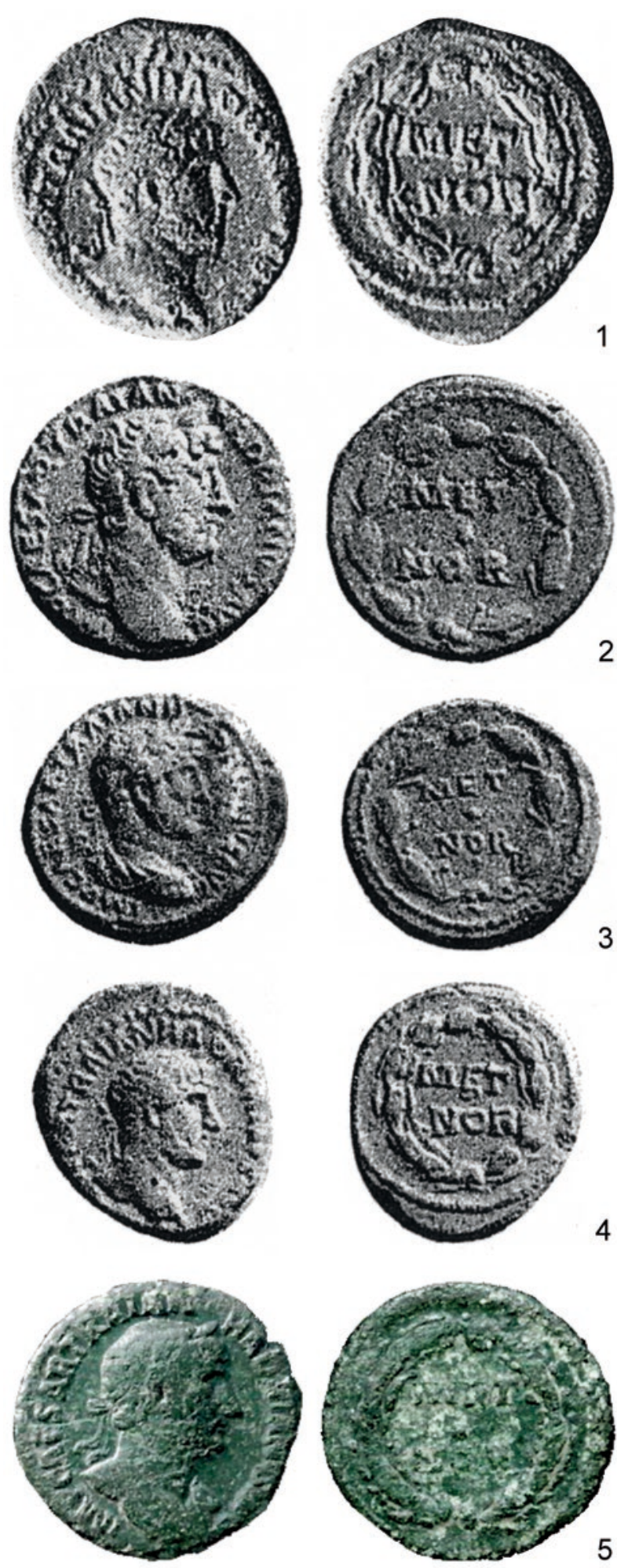

Abb. 26: Semisses und Quandrantes des Hadrian mit der Revers-Inschrift MET(alla)·NOR(ica), geprägt 128-129 n. Chr. Ohne Massstab. lentin / $\mathrm{A}^{278}$. Dies zeigt, dass deren Umlauf einerseits regional begrenzt auf die «Eisenprovinz» Noricum war, andererseits auch andernorts verstreut Einzelstücke auftreten können.

In der numismatischen Forschung wird daher die Funktion der nummi metallorum und insbesondere der MET-NOR-Prägungen sehr unterschiedlich interpretiert $^{279}$ : Johann van Heesch vermutet, dass die Münzen zwar reguläres Zahlungsmittel waren, aber aus Anlass einer norischen Eisenbergwerkseröffnung resp. -wiedereröffnung ausgegeben worden sind ${ }^{280}$. Anders interpretiert Bernhard Woytek aufgrund seiner umfassenden Sammlung solcher Metalla-Prägungen deren Funktion folgendermassen: «Insgesamt bleibt festzuhalten, dass Einzelstücke der seltenen Metalla-Serien gelegentlich in den römischen Donauprovinzen Noricum, Pannonia und Moesia Superior gefunden werden und somit zweifelsfrei dort umliefen doch sicherlich nicht exklusiv in diesen Gebieten. Auch aus dem Kernland des Reichs gibt es nämlich Fundbelege bzw. Provenienzen oder zumindest fundierte einschlägige Vermutungen. ... Wir dürfen nach allem Gesagten davon ausgehen, dass es sich bei den nummi metallorum um gewöhnliches, in Rom geprägtes Reichskleingeld handelt, das sich von anderen Kleinbronzen in der Wertstufe des Semis oder des Quadrans lediglich durch die besondere Typologie ... unterscheidet.» ${ }^{281}$ Dennoch könnte das Prägen solcher «Bergwerks»-Münzen Teil einer breit angelegten «Marketing-Strategie» sein, wie sie für Gewinnung, Verarbeitung und Vertrieb des Norischen Eisens von Gerhard Sperl vermutet wird $^{282}$.

\section{Archäologische Quellen}

Im Laufe der langen Erforschung der Eisenvorkommen und der antiken Verhüttungsplätze kristallisierten sich sieben Bergbau- resp. Verhüttungsareale - verschiedener Zeitstellungen - im Areal des Regnum Noricum resp. der heutigen Steiermark heraus (Abb. 28) ${ }^{283}$, worauf u. a. auch Peter Trebsche hingewiesen hat: «Es scheint also nicht ausgeschlossen, dass der römische Bedarf an Eisen in mehreren Produktionsgebieten Noricums gedeckt wurde.» ${ }^{284}$ Nicht berück-

278 Gemäss der Zusammenstellung in: Woytek 2004, 52 Anm. 100 (mit der entsprechenden Primärliteratur). MET-NOR-Prägungen sind jedoch auch aus Rom und Curium/CY bekannt (Woytek 2004, 53; 54 Anm. 111).

279 Markus Peter schreibt dazu in einer E-Mail vom 23.05.2018 u.a.: «...generell geht es wohl eher um die Bedeutung der Bergwerke in militärischem Zusammenhang (Dakerfeldzüge Traians) und danach um die wiederkehrende Nennung kaiserlicher Bergwerke.»

280 van Heesch 1969, 182; 192, Hadrianus 13a-14c (5 Belege).

281 Woytek 2004, 53 und 56.

282 So Sperl 2004, 961.

283 Nach Malzacher 1963, 50 (noch ohne Feldkirchen und Görtschitztal)

284 Trebsche 2012, 150. 


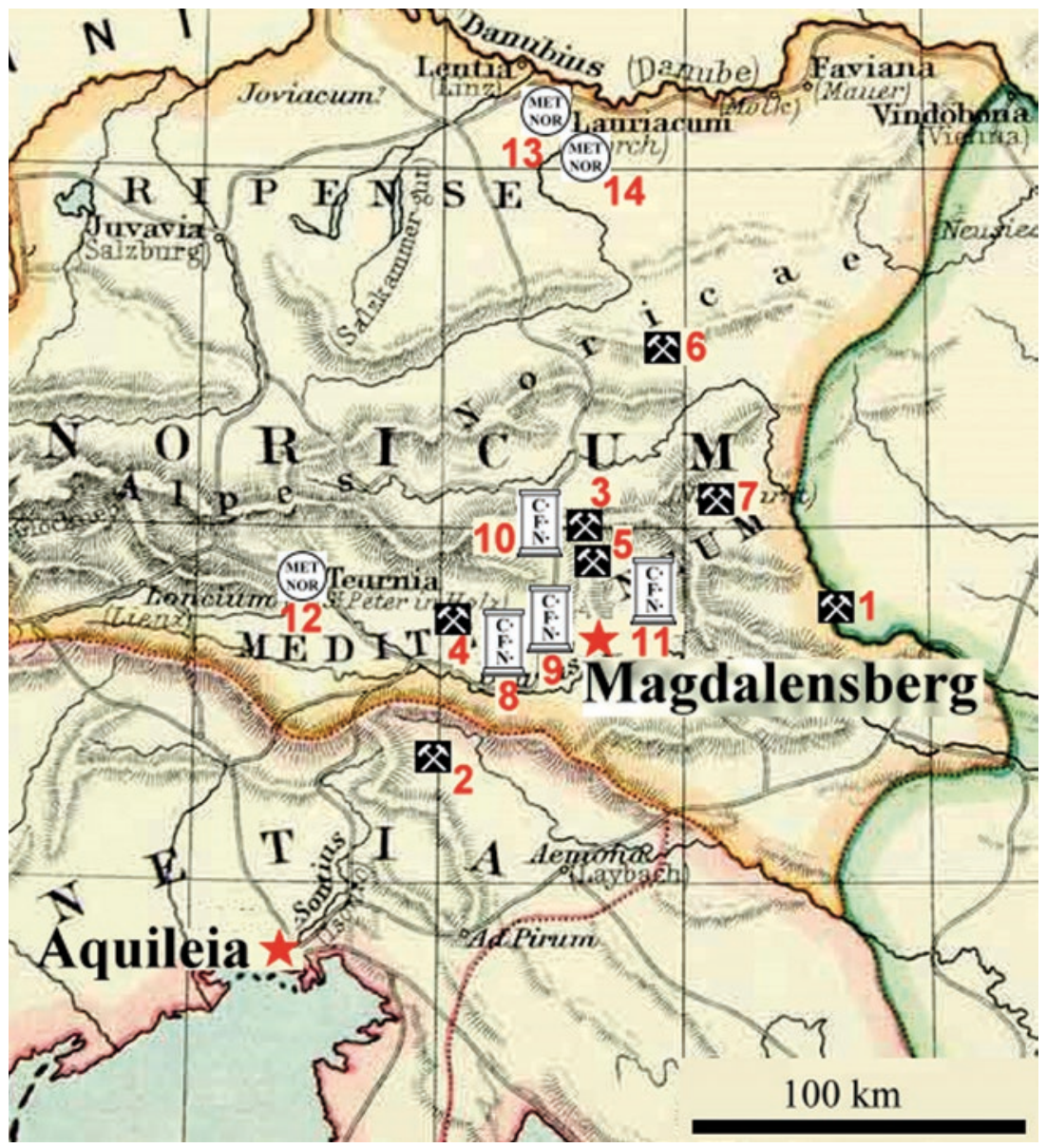

Abb. 27: Karte von Noricum mit Abbau- und Verhüttungsstellen des «norischen» Eisenerzes (1-7), Fundstellen von Inschriften (8-11) und Münzfunden (12-13) in Zusammenhang mit dem «ferrum Noricum» sowie die Städte auf dem Magdalensberg und Aquileia (siehe Text).

\section{Verhüttungsreviere:}

1 Tillmitsch bei Leibnitz / A;

2 Wochein/Oberkrain (Bohinj/SLO);

3 Hüttenberg/ A und Semlach-Eisner / A,

4 Feldkirchen / A;

5 Görtschitztal/ A (mit Möselhof, Raffelsdorf,

Kitschdorf);

$6 \mathrm{Erzberg} / \mathrm{A}$;

7 Köflach/A-Pichling.

Inschriften:

8 Tiffen / A;

9 Pulst-Hohenstein / A,

10 Friesach / A;

11 Wieting/A (Zollfeld/A-Lauriacum

nicht kartiert).

Münzen «MET NOR»;

12 St. Peter in Holz / A;

13 Enns / A-Lorch-Lauriacum;

14 St. Valentin / A. sichtigt sind hier Belege weiterer Eisenerzgewinnung und -verhüttung im Mittleren Burgenland (z. B. Oberpullendorfer Bucht $)^{285}$, rund $150 \mathrm{~km}$ östlich des norischen Eisen- und Stahlzentrums.

1. (Abb. 27,1) Tillmitsch bei Leibnitz/A (80 km nördlich des Magdalensbergs), 8.-6.Jh. v. Chr.

2. (Abb. 27,2) Wochein (Bohinj / SLO), Oberkrain (60 km südwestlich des Magdalensbergs), Mittel- bis Spätlatènezeit, 4.-1.Jh. v. Chr.

3. (Abb. 27,3) Hüttenberg / A und Semlach-Eisner / A, das römische Candalice? (Abb. 28; 26 km nordnordöstlich des Magdalensbergs), 1.Jh. v. Chr. bis 1.Jh. n. Chr. ${ }^{286}$

4. (Abb. 27,4) Feldkirchen / A (26 km westlich des Magdalensbergs), 1.Jh. n. Chr. ${ }^{287}$

5. (Abb. 27,5) Görtschitztal / A (Abb. 10-12; mit Möselhof, Raffelsdorf und Kitschdorf; 7-10 km südlich Hüttenberg / Semlach), Ende 1.Jh. v. Chr. bis 5. / 6.Jh. ${ }^{288}$

6. (Abb. 27,6) Erzberg / A (Steiermark, 96 km nordnordwestlich des Magdalensbergs), römerzeitlicher (2.Jh. n. Chr.) Abbau ungewiss und umstritten 289

7. (Abb. 27,7) Köflach / A-Pichling (61 km nordnordöstlich des Magdalensbergs)? ${ }^{290}$

Das Zentrum der Eisenveredelung und des Exports des ferrum Noricum in den beiden ersten vor- und nachchristlichen Jahrhunderten muss die grosse römische Siedlung auf dem Magdalensberg / A gewesen sein, wie zahlreiche Befunde, Fundobjekte und deren archäometrische Untersuchung zeigen ${ }^{291}$. Es fällt im Vergleich auf, dass die Eisenfunde, Werkzeuge und Geräte - ja sogar einfachste Nägel

285 Kaus 1981, 76-84; 87 («Ein guter Teil des in der Antike so gerühmten norischen Eisens dürfte aus den Produktionsstätten des mittleren und südlichen Burgenlandes stammen.»); Trebsche 2012, 150 Abb. 1,24-26 (mit älterer Lit.)

286 H. Haberfelner et al. 1928 (Geologie); Vetters 1966, 177 Abb. 11 (Schachtofen von Lölling/A); Kaus 1981, 75 f. (Schachtofen von Lölling/A ist «eher ins späte Mittelalter als in das Altertum zu stellen»); Cech 2008; Presslinger 2008; Cech 2012; Birch 2017; Cech et al. 2017; Walach et al. 2017. - Zum antiken Namen: Itin. Ant. 276, 6.

287 Galik et al. 2003, bes. 68-80; Gostenčnik 2005, 100.

288 Glaser 1995; Glaser 2000; Sperl 2004, 970 Abb. 7a (Beschreibung der Betriebsweise); Gostenčnik 2005, 100.

289 Kritisch: Kaus 1981, 76; Sperl 2004, 972 («Für die Steiermark gibt es keinen Beweis für römisches Eisenwesen am Erzberg»).

290 Gostenčnik 2005, 100.

291 Mitsche 1961; Malzacher 1963, 57; Schaaber 1963; Vetters 1966; Straube 1996, 26-32; Straube/ Dolenz 1996; Piccottini 2002, 103105 Abb. 1 und 2; Sperl 2002A, 63 («Es ist zu vermuten, dass die Qualitätssicherung [Veredelung der Luppen und Roheisenstücke] erstmals auf dem Magdalensberg in den Reihen von Schmiedeherden [unter dem späteren Tempel] geschah ...»); Cech 2008; Presslinger 2008; Gostenčnik 2010, 291-294 Abb. 2-7. - Zur dem ferrum Noricum zugrunde liegenden Rennfeuertechnik s. oben. 
- vom Magdalensberg viel häufiger aus gutem, d.h. kohlenstoffreichem Stahl hergestellt sind als vergleichbare Objekte an anderen Fundstellen ${ }^{292}$ :

\begin{tabular}{|l|r|r|r|r|}
\hline & $\begin{array}{l}\text { Mag- } \\
\text { dalens- } \\
\text { berg / A } 293\end{array}$ & $\begin{array}{l}\text { Neuss / } \\
\mathrm{D}^{294}\end{array}$ & $\begin{array}{l}\text { Heiligen- } \\
\text { kreuz / A295 }\end{array}$ & Polen296 \\
\hline $\begin{array}{l}\text { Weicheisen } \\
(<0,3 \% \text { C): }\end{array}$ & $21 \%$ & $83 \%$ & $73 \%$ & $74 \%$ \\
\hline $\begin{array}{l}\text { Stahl (0,3- } \\
1,8 \% \text { C): }\end{array}$ & $68 \%$ & $17 \%$ & $27 \%$ & $26 \%$ \\
\hline $\begin{array}{l}\text { Roheisen }> \\
1,8 \% \text { C): }\end{array}$ & $11 \%$ & $0 \%$ & $0 \%$ & $0 \%$ \\
\hline Stückzahl: & $(62)$ & $(38)$ & $(138)$ & $(267)$ \\
\hline
\end{tabular}

Vom Magdalensberg sind so viele Eisenobjekte und auch Halbzeug (Kanteisen und Barren) bekannt, dass daraus «weniger auf eine ausschliessliche Nutzung zur Deckung des örtlichen Eigenbedarfs zu schliessen [ist] als vielmehr auf die Verwendung als Handelsgut» ${ }^{297}$. Die Stadt auf dem Magdalensberg - vermutlich Strabons Noreia ${ }^{298}$ - dürfte «eine Kontrollfunktion für den Warenhandel, nicht nur nach der Menge, sondern auch nach der Qualität, gehabt haben. Besonders deutlich wird dies, wenn man die für die Frühphase nachgewiesenen Schmiedeherde betrachtet, die wohl nicht nur für den örtlichen Bedarf an Eisen, sondern auch für die Qualität des von dort weithin verhandelten Stahles wichtig gewesen sein dürften», wie Gerhard Sperl die gängige Meinung zusammenfasst und den Magdalensberg denn auch als «frühestes Werkstoff-Prüfzentrum» charakterisiert ${ }^{299}$.

Für eine so wichtige wirtschaftliche Funktion stand der Magdalensberg zu seiner Frühzeit «noch relativ isoliert da». Die fast im Zentrum der Eisenerzvorkommen und Verhüttungsplätze gelegene (Abb. 27) Stadt der Wertschöpfung und des Handels wurde auch schon als «Emporium italisch-römischer Händler» bezeichnet ${ }^{300}$.

Über die möglichen Absatzgebiete dieses Norischen Eisens geben allein schon die verschiedenen historischen Berichte einen Hinweis: Das «Norische Eisen» war im Römischen Reich bekannt als Qualitätsprodukt von sprichwörtlicher Härte. Es muss weit verbreitet und daher auch intensiv verhandelt worden sein. Just von diesen intensiven und weitläufigen Handelsbeziehungen zeugen einige Wandgraffiti auf den Mauern von Handelshäusern auf dem Magdalensberg ${ }^{301}$. Sie belegen einerseits den Umschlag von grossen Eisenmengen: Halbzeug wie Ringe, Haken oder Platten, die zu Hunderten exportiert wurden. Andererseits zeigen auch die lokal gefertigten Fertigprodukte ein «mediterranes Formenrepertoire», was ebenfalls auf eine exportorientierte Produktion auf dem Magdalensberg schliessen lässt ${ }^{302}$. Die Wandinschriften berichten von zahlreichen Händlern, die weither aus den Südprovinzen zum Wareneinkauf nach Kärnten kamen. Oft wurden 500 und mehr anuli (Ringe) oder unci (Haken) in einer über
1000 kg schweren Ladung an einen Händler im Süden geliefert $^{303}$. In späterer Zeit, vielleicht am Ende des 1.Jahrhunderts n.Chr., scheint sich die Drehscheibe der norischen Eisenwertschöpfung und -aufbereitung - zu Barren und Halbzeug etwa - vom Magdalensberg ins 5,5 km südwestlich gelegene Zollfeld / A verlagert zu haben. Vermutlich galt der Stadtname Virunum - überliefert zwar nur für Zollfeld - auch bereits für die Anlage auf dem Magdalensberg $^{304}$.

Die Untersuchungen und Analysen an Verhüttungsöfen und Eisenfunden zeigen, wie wir schon oben gesehen haben, dass insbesondere der Stahl «auf direktem Wege durch Reduktion aus Norischem Eisen erzeugt» wurde [gemeint ist wohl «aus Norischem Erz»]. Es handelt sich bei der Stahlerzeugung auf dem Magdalensberg «also nicht um einen zweiten Arbeitsvorgang, in welchem durch Zementation in festen organischen Substanzen (Holzkohle etc.) Stahl aus C-armen Rennfeuerprodukten hergestellt wurde» 305 .

Die manganhaltigen Eisenerze aus dem Gebiet um Kärnten, dem ehemaligen Noricum, wurden und werden bis in die Gegenwart abgebaut und verhüttet. Das Hauptabbaugebiet der Frühen Neuzeit lag weiterhin am Hüttenberg in Kärnten (eingestellt im 20.Jh.), aber auch auf dem Erzberg in der Steiermark (Abb. 27,3.6) ${ }^{306}$, wo das Eisenerz in einen grossem Tagebau bis heute ausgebeutet wird. Bis in die Neuzeit waren diese Vorkommen wichtig: «Zur letzteren

292 Generell Straube 1996, 27 f. (mit weiterer Lit.).

293 Römische Stadt: Schaaber 1976/77, 97 Tab. 2; Straube 1986, 26.

294 Legionärslager: Schaaber 1976/77, 97 Tab. 2; Schaaber 1977, $221 \mathrm{f}$. Tab. 1.

295 Hallstatt- und frühe Latènezeit: Schaaber 1976/77, 97 Tab. 2 (nach J. Piaskowski); Schaaber 1977, 221 f. Tab. 1.

296 Hallstatt- und frühe Latènezeit: Schaaber 1976/77, 97 Tab. 2 (nach J. Piaskowski); Schaaber 1977, 221 f. Tab. 1; Barraclough 1981, 32. Pleiner $(1968,315)$ nennt für Polen im 1.-4.Jh. n. Chr. zwar wenig einheitliche, aber dennoch relativ hohe C-Gehalte von 0,5-0,7\% C in Eisenobjekten.

297 Straube 1996, 26f. (Zitat); 130 .

298 Siehe oben mit Anm. 248.

299 Sperl 2002B, 151.

300 Gostenčnik 2005, 97.

301 Egger 1961, bes. 28-37; Gostenčnik 2010, 294 Abb. 7.

302 Gostenčnik 2005, 97 f. (Zitat); 100 («ein Vorherrrschen der mediterranen Formen unter den Werkzeug- und Geräteformen; bodenständige Komponenten sind eher die Ausnahmen ...»). - Gegenteiliger Meinung ist Heimo Dolenz (1998, 247 f.): «Einschränkend gilt es jedoch zu beachten, dass es sich gerade bei einfachen Werkzeugtypen um optimierte Zweckformen handelt, die sowohl im römischen als auch im latènezeitlichen Handwerk gleiche Formen besitzen konnten. ... ist eine Trennung in römisches und latènezeitliches Werkzeug ... grösstenteils nicht möglich.»

303 So etwa Grassl 1988, 88; Gostenčnik 2005, 101 (mit Mengenangaben).

304 Malzacher 1963; Piccottini 2002, 103.

305 Vetters 1966, 175 (Zitat); 179; Presslinger 2008, 245; Truffaut 2008, 262.

306 Kossmat 1910, $455 \mathrm{f}$. 

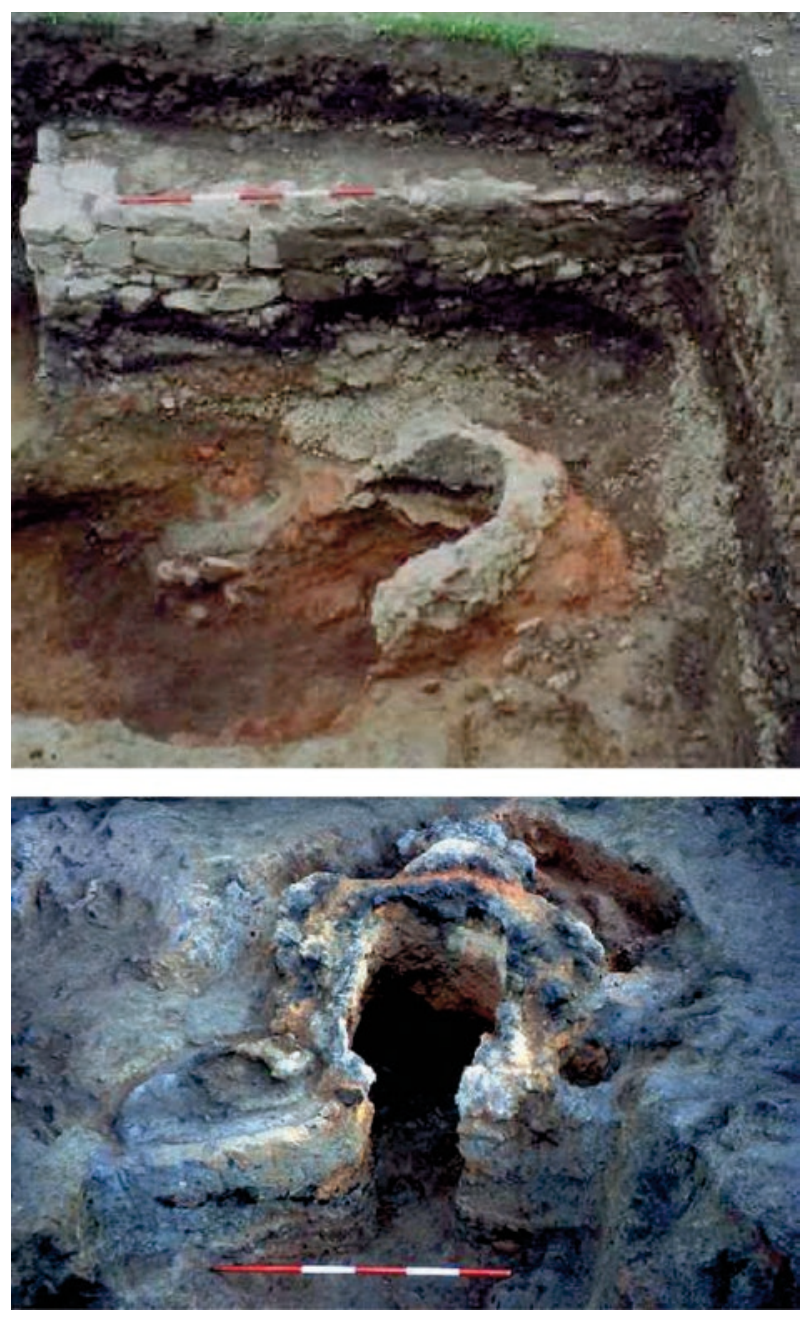

Abb. 28: Hüttenberg / A, Erzberg. Römische Rennfeueröfen 3 und 6. In solchen Verhüttungsöfen in der Nähe verschiedener Erzvorkommen in Noricum wurde durch ein speziell gesteuertes Verfahren ein kohlenstoffhaltiges Eisen gewonnen. Die besten Stahlteile sind anschliessend zu Barren und Halbzeug weiterverarbeitet worden. Als Produktionsstätten für diese Veredelungsverfahren werden der nahe Magdalensberg / A und die $135 \mathrm{~km}$ südwestlich liegende Hafen- und Handelsstadt Aquileia/I diskutiert.

Gruppe zählt das Grossvorkommen des steirischen Erzberges mit durchschnittlich nur unter 3 Gew.\% MnO im frischen Siderit. Am Hüttenberger Erzberg dagegen, in dessen Bereich eine ganze Reihe von kleinen, derartigen Mn-Vorkommen vorhanden sind, sind über 4 Gew.\% MnO regelmässig im frischen Eisenspat enthalten.» ${ }^{307}$ Die Bedeutung dieser manganreichen Eisenvorkommen brachte der Metallurge Richard Williams so auf den Punkt ${ }^{308}$ : Kärnten und die Steiermark «were famous steel making areas and it is no coincidence that the ores at Erzberg for example were high in manganese.... My own suspicion is that manganese was very significant and that a lot of the unique processes that were used in these areas were developed....». Wegen sich verringernder Ergiebigkeit, ungünstigem Erzchemismus und schwerer Zugänglichkeit wurde der Eisenerzabbau auf dem Hüttenberg schliesslich eingestellt.
Sicher wurde die Stahlerzeugung auch andernorts in manchen keltischen und römischen Verhüttungsorten und Siedlungen beherrscht ${ }^{309}$, zumindest in kleinmassstäblichem Rahmen wie in Augusta Raurica (s. unten, Abb. 50 und 55). Dass aber gerade rund um den Magdalensberg in Kärnten in grossem Umfang Stahl hergestellt wurde und nicht anderswo, liegt also nicht allein an den dort verhütteten Erzen, wie lange vermutet wurde, sondern an der gleichbleibend hohen Qualität des Norischen Stahls. Harald Straube nennt den Workflow, den spezifischen Ofenbau, die Kenntnis der optimalen Einsatzstoffe und die Beherrschung der Erz- und Feuerführung als ausschlaggebend für den Erfolg der norischen Eisenindustrie vor 2000 Jahren ${ }^{310}$.

\section{Frühe Stahlerzeugung im wikingischen Norden Europas}

Nebst der antiken Stahlproduktion durch Tiegelschmelzen in Asien und durch geschickte Verhüttungstechnik im Römischen Reich (Noricum!) ist in den letzten Jahren von skandinavischen Archäologen eine ganz andere Technik der Stahlerzeugung erkannt worden: die Aufkohlung von kleinen Schmiedeeisen-Barren in Lehmumhüllungen (Abb.29). Die «clay packages» bestehen aus gebranntem Lehm, sind zylinderförmig, aber fragmentiert, tragen aussen grobe, unebene Spuren der Formung mit den Fingern, und ihre Hohlräume weisen quadratische, runde und komplexere Querschnitte auf. Die Innendurchmesser schwanken von 7 bis $24 \mathrm{~mm}$. Trapezförmige und sechseckige Querschnitte wie in Augusta Raurica (Abb. 50,2.5.10.11.18) lassen sich an den nordischen Funden bisher nicht beobachten.

Hin und wieder, wenn die Innenseiten der Lehmfragmente einsehbar sind, geben sich Negativabdrücke von Schnüren oder Pflanzenstreifen zu erkennen (Abb.29,1.9.13.14), was Sigmund Jakobsen und Anders Söderberg anhand des Materials von Ribe / DK resp. Helgö / S zur folgenden Interpretation führte ${ }^{311}$ : Man wollte aus kleinen Stangen von Weicheisen (Schmiedeeisen) durch Aufkohlung Stahl erzeugen. Die Metallteile wurden hierfür mit organischem, viel Kohlenstoff enthaltendem Material

307 Clar/Meixner 1953, 145.

308 E-Mail vom 23.07.2018. Ich danke an dieser Stelle Richard Williams für seine Diskussionsbeiträge und Unterstützung.

309 Es ist zu vermuten, dass solche Belege sich häufen werden, sobald von mehr Fundstellen mit Belegen für Eisenverarbeitung auch Werkstoffanalysen an den dort hergestellten Produkten durchgeführt sind (zum Beispiel Pagès et al. 2006, 115f. Abb. 8 und 9; Epprecht/Schaller 1986).

310 Straube 1996, 111.

311 Söderberg 2008, $6 \mathrm{f}$. 

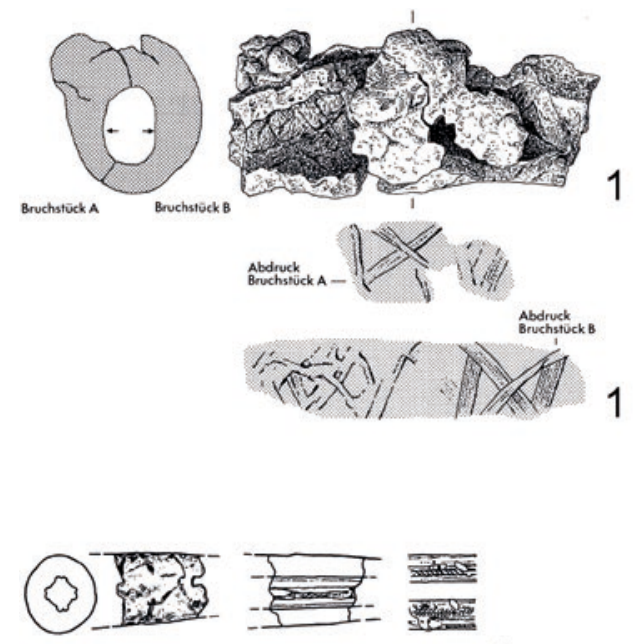

9

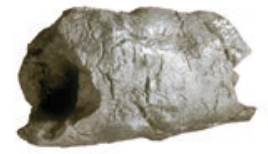

11
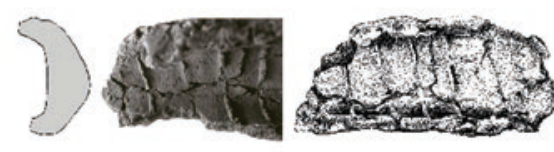

13

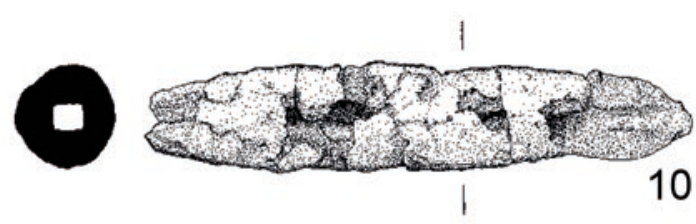

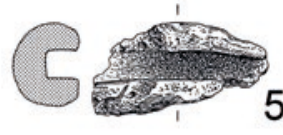

$3=$

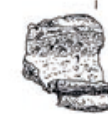

6

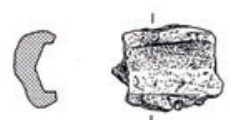

7

$8 b$

$8 a$

(2)

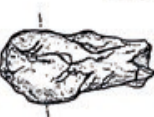

12

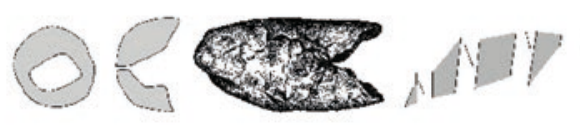

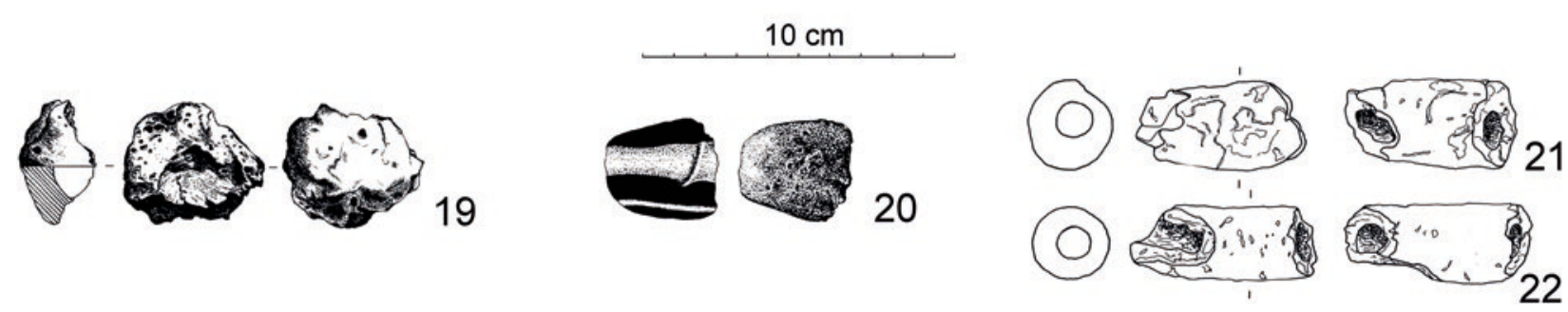

Abb. 29: Beispiele römischer und frühmittelalterlicher Lehmumhüllungen aus Europa. Es ist zu vermuten, aber nicht in jedem Fall nachweisbar, dass in diesen Umhüllungen ebenfalls (wie in Augusta Raurica; Abb. 50) auch Eisen zu Stahl aufgekohlt worden ist. 1-8 Bosau/D; 9 Haithabu-Hedeby/D; 10 Bastubacken/S; 11-18 Helgö/S; 19 Sigtuna/S; 20 Brough of Birsay/GB, Orkney; 21-22 Zürich-Üetliberg. M. 1:3.

umwickelt (dazu unten S.119f.). Wo nötig, wurde es mit Schnüren oder (Bast?-)Streifen um die Eisenstangen festgebunden. Darum herum knetete man eine 6-15 mm dicke Lehmschicht, liess diese trocknen und brachte das Ganze ins Feuer. Die Einwirkungszeit und vor allem die erzeugte Temperatur ist bisher archäometrisch nicht ermittelt worden, und auch von den darin aufgestählten Eisenstangen wurde bisher keine einzige gefunden.

Der Aufkohlungsprozess zur Stahlerzeugung durch Diffusion von «Kohlenstoff aus dem organischen Material in das Eisen» wird erst nach mehrstündigem Befeuern abgeschlossen gewesen sein (s. S. 29). Die oft grünlichgrauen Fragmente (Helgö/S) weisen aussen oft Risse und glasurartige Versinterungen auf und lagen offenbar in einer reduzierenden Atmosphäre. Die dichte Umhüllung mit Lehm sorgte im Innern - auf der Eisenoberfläche - für eine reduzierende, kohlenstoffreiche Atmosphäre. Am Ende wurden die Lehmgebilde abgekühlt und zerschlagen: Die aufgekohlten «Stahlstangen» konnten herausgenommen und zu schneidenden Geräten oder zu Waffen verarbeitet werden. Oder man setzte seinen Stahl sparsam ein und verschweisste ihn mit Schmiedeeisen zu Verbundstoffen mit den Arbeitskanten aus Stahl (sog. «Anstählen»). Die Deutung der Lehmumhüllungen wird durch den Umstand erhärtet, dass in Helgö viele davon im Kontext mit Schmiedewerkzeugen gefunden wurden.

Solche Lehmumhüllungen sind über fast das gesamte wikingische Einflussgebiet verteilt (Auswahl in Abb.29). Belege aus dem 6. bis 11.Jahrhundert n. Chr. fanden sich nach der Zusammenstellung von A. Söderberg ${ }^{312}$ in:

- Bosau/D (Abb. 29,1-8), 9. Jahrhundert ${ }^{313}$

- Haithabu-Hedeby/D (Abb. 29,9) ${ }^{314}$, wikingerzeitlich

312 Söderberg 2008, 1 und 6.

313 Gebers 1981, Taf. 21,16; 22,8-16 («Gussformen»); Drescher 1983, 183f. Abb. 4,1 (angeblich zur Messingbearbeitung).

314 Drescher 1983, 183f. Abb. 4,2. 
- $\quad$ Ribe/DK, wikingerzeitlich, um 260-450315

- Bastubacken /S (Abb. 29,10), wikingerzeitlich bis mittelalterlich ${ }^{316}$

- $\quad$ Birka/S, wikingerzeitlich ${ }^{317}$

- Helgö/S, Gebäudegruppe 3 (Abb. 29,11-18), «Migration period» (um 400-550) $)^{318}$

- $\quad$ Fröjel/S, wikingerzeitlich, 10./11.Jh. ${ }^{319}$

- $\quad$ Sigtuna/S (Abb. 29,19), 11./ 12.Jh. ${ }^{320}$

Sowie ausserhalb Skandinaviens:

- Brough of Birsay, Orkney, Scotland / GB (Abb. 29,20), 8. Jh. ${ }^{321}$

- Gradišče/SLO? ${ }^{322}$

- Zürich-Üetliberg (Abb. 29,21.22), möglicherweise römisch. $\varnothing 25-30 \mathrm{~mm}$; Negativ im Querschnitt rund mit $\varnothing 11 \mathrm{~mm}$; Ton orange-beige, innen schwarz (als «Gussformfragmente», möglicherweise für Halsringe, bezeichnet) ${ }^{323}$.

315 Söderberg 2008, 1.

316 Reisborg 1996, 241 f. Abb. 174.

317 Söderberg 2008, 1 .

318 Söderberg 2008, 1 .

319 Gustafsson/Söderberg 2005, 17 Abb. 4 (Aufkohlungs-Lehmhülle?) und 6 .

320 Söderberg/Gustafsson 2007, 26f. Abb. 14 (für einen dünnen Draht mit rechteckigem Querschnitt; in der Dimension ähnlich unserer Abb. 50,20; 51,20*). Ich danke Markus Helfert für die Vermittlung und Anders Lindahl für einige Übersetzungen aus dem Artikel.

321 Curle 1982, 42 Abb. 406.

322 Forbes 1964, 208 («In Gradišče [Carinthia] many fragments of crucibles impregnated with iron have been found. But these are probably crucibles used for the production of steel by the cementation process, during which iron may have occasionally absorbed excessive carbon and liquified.»). Da keine Quelle für diese Äusserungen zitiert wird, ist der Hinweis nicht zu verifizieren. Bei der Suche halfen mir verdankenswerterweise Paul Gleirscher, Christoph Hinker und Manfred Lehner.

323 Weidmann 1991,50 Taf. 117,1920.1921; 236. 


\section{Ethnologische Beispiele von Stahlerzeugung}

\section{Ostafrika}

Erst vor wenigen Jahren nahm man zur Kenntnis, dass in Ostafrika, am Westufer des Victoriasees, seit Jahrhunderten Stahl erzeugt wurde. Die Tradition wurde vom Volk der Haya überliefert, ist heute aber praktisch in Vergessenheit geraten, denn sie betreiben heute ausschliesslich Ackerbau und Viehzucht.

Das Eisenerz wird geröstet und zusammen mit Holzkohle in einen Rennofen gegeben. Bezeichnenderweise ist dieser nicht nur mit ein bis zwei Gebläsedüsen (tuyères) versehen wie in anderen Gegenden Afrikas, sondern mit deren fünf bis sieben, ähnlich wie im römischen Noricum (Abb.12)! Hinzu kommt, dass die vorgefertigten Tonröhren tief in den Brennraum des Ofens hineinragen, so dass die Luft zwischen Blasebälgen und Feuer gut vorgewärmt wird. Dies führt zu einer optimalen Belüftung und entsprechend hoher Verhüttungstemperatur. Das von den Haya einst produzierte Eisen enthält bis zu 2,4\% Kohlenstoff und muss daher als Stahl bezeichnet werden ${ }^{324}$.

Das «Geheimnis» des Kohlenstoffgehalts in diesem frühen afrikanischen Stahl ist vermutlich einerseits das vorgängige Rösten der Eisenerzknollen in einer Grube dichtbepackt mit viel nassem Holz, dann das Vorwärmen der Gebläseluft in den langen Tonröhren und schliesslich die dicke Lage von verkohlten Sumpfgräsern in der Vertiefung unten im Verhüttungsofen, denn hier hinein tropft das zähflüssige Eisen nach genügend langer Befeuerung. Was unlängst mit dem Wissen alter Männer rekonstruiert werden konnte, erweist sich aufgrund archäologisch nachgewiesener Verhüttungsöfen ${ }^{325}$ als eine 2000 Jahre alte Fertigkeit in Ostafrika.

\section{Westafrika}

In der Mitte des 20.Jahrhunderts waren noch letzte «Eisenkocher» in Westafrika zu beobachten, die aus selbst gegrabenen Erzen in kleinen Rennöfen Eisen erzeugten, die Luppen ausschmiedeten und Werkzeuge daraus herstellten ${ }^{326}$. René Gardi beschrieb einerseits seine Beobachtungen zum Zusammenschweissen der Ofenluppe unter reduzierender Atmosphäre im Norden Kameruns: «Die Eisenplättchen, die so entstanden sind [durch die Reduktion des Erzes im Rennfeuer], werden in einem kaffeetassengrossen Tontiegel gesammelt, in die glühende Holzkohle der Esse gestellt und zu einem Klumpen zusammengeschweisst, der allmählich nach mehrmaligem neuem Erhitzen zu einem
Barren ausgeschlagen wird. Es ist zu erwähnen, dass die kalt gehämmerten Plättchen im Tiegel zum Schutze gegen neuerliches Oxidieren mit einem Lehmbrei zugedeckt werden. Ferner wird oft zum gleichen Zwecke über den Eisenklumpen, der in der Glut der Esse erhitzt wird, Asche oder trockener, zerriebener Lehm gestreut.» ${ }^{327}$ Andererseits beobachtete er eine simple Methode der Aufkohlung: «... Die fertigen Geräte werden in der Regel in einer Lehmbrühe, niemals in reinem Wasser, abgeschreckt und dadurch gehärtet. Durch reines Wasser wird das Eisen zu hart und spröde, eine Tatsache, welche meinen urweltlichen Metallurgen wohlbekannt ist. Wir haben auch beobachtet, dass das glühende Eisen in der Esse mit pulverisierter Akazienrinde bestreut wurde, offenbar um den Stahl etwas aufzukohlen und also zu härten.» ${ }^{328}$

Eine ähnliche Technik der Aufbereitung wurde auch in Ghana und Togo beobachtet: Das frisch verhüttete Eisen, in Form der noch heissen Luppe, wurde in Ghana auf einem Amboss aufgeschlagen «to remove the worst impurities; the remaining nodules are packed together in a ball of clay, heated in a forge, and hammered together. The consolidated bloom is then immediately forged into an implement» ${ }^{329}$. Es ist zu vermuten, dass der Tiegel zugedeckt wurde und sich in ihm auch Holzkohle befand, die zu einem Aufkohlungsprozess der Eisenkörner geführt hat.

Dies wird an einem anderen Beispiel aus Togo explizit bestätigt: Bei den Bandjéli-Leuten im Norden von Togo wurde um 1900 folgender Prozess beobachtet: «Die erste Arbeit des Schmiedens ist das Reinigen der vom Schmelz-

324 Schmidt/Avery 1978 (mit älterer Lit.); Van der Merve 1980, 494 496; Schmidt / Avery 1983, 422; Shore 1986 (Zusammenfassung); Rostoker/Bronson 1990, 137. - Archäometrisch konnte auch an anderen Orten in Ostafrika eine Produktion von kohlenstoffreichem Eisen im Direktverfahren nachgewiesen werden: Lyaya et al. 2012, 204.

325 Schmidt / Avery 1983, Abb. 1-10.

326 Gardi 1954; Gardi 1969, 14-45; Henseling 1981, 21 f. Abb. 10; David et al. 1989; Celis 1991.

327 Gardi 1954, 20. - Heterogenes Eisengefüge nach Verhüttung mit rund 0,2-2\% Kohlenstoff, jedoch ohne Anzeichen einer bewussten sekundären Aufkohlung: I. Gräf in Hahn 1993, 167-170 Abb. 1-4.

328 Gardi 1954, 21. - Siehe auch Roesch / Kühn 1976, 7 (etwas missverständlich: «Eine ... «Einsatzhärtung〉 beobachtete auch R. Gardi bei der Weiterverarbeitung von Luppenteilen zu Ackergeräten bei den Matakam im Bergland von Kamerun. Hierbei wurden die kleinen Luppenteile in Tontiegeln mit Holzkohle luftdicht eingepackt und mehrere Stunden erhitzt, um daraus Messer und $\mathrm{Si}$ cheln mit höherer Festigkeit herzustellen.»).

329 Van der Merve 1980, 493. 
feuer erstandenen Eisenluppe. Zu dem Zwecke wird diese mit Stein auf Stein ganz zerklopft und dabei das Eisen herausgeklaubt. Die kleinen Eisenstückchen werden dann in eine aus trockenem Gras und nassem Lehm bestehende Hülle fest eingeschlagen zu einer etwas faustgrossen Kugel und diese mehrere Stunden ins Schmiedefeuer gebracht. Die im Schweissstadium befindliche Eisenmasse wird dann ausgeschmiedet ...» ${ }^{330}$ Durch das verkohlende Gras in der Lehmkugel, die grosse Oberfläche der darin liegenden «Eisenstückchen» und die mehrstündige Verweildauer «im Schweissstadium» ergibt sich logischerweise eine Aufkohlung zu Stahl.

\section{Nepal}

Die Kāmi in Nepal, Angehörige der niedrigen Schmiedekaste, verfügen zwar nur über einfachste Einrichtungen und Werkzeuge, jedoch über ein grosses Spektrum von Fertigkeiten wie Schmieden, Treiben, Löten usw. Wenn ihre Feilen, für die ein besonders harter Stahl bevorzugt wird, stumpf sind, werden sie nachgeschärft und neu aufgekohlt. So kann man sie wieder «scharf» härten, damit sie möglichst lange weiterverwendet werden können.

Zuerst werden die alten stumpfen Feilen geglüht und so wieder weich gemacht. Darauf werden die «Hiebe» mit einem scharfen Meissel nachgeschlagen, d.h., die Feile wird wieder «scharf» gemacht. Anschliessend unterziehen die Kāmi ihre nachgeschärften Feilen einem erneuten Aufkohlungsprozess, d. h. einer Einsatzhärtung («case hardening»): Als Kohlenstoffträger wird ein Gemisch aus der Asche von Hühnerfedern und dem Saft von zerquetschten Sauerklee-Blättern genommen, der Brei wird auf die Feile aufgetragen und das Ganze verpackt (hierzu fehlen leider Detailangaben) und geglüht ${ }^{331}$.
330 Anonymus 1900, 351; Hahn 1993, 70-74 Abb. 25-27. - Dieser sekundären Aufkohlung widerspricht aber Hahn $(1993,133)$ : «Die Herstellung der Lehm-Eisenkugel [in Bandjéli] beeinflusst also in keiner Weise den Kohlenstoffgehalt des Stahls.» Der Autor meint (S. 155): «Nur in Afrika entstand dabei eine Technologie, die direkt im Rennofen einen hoch inkohlten Stahl hervorbringt.» - Ein weiterer Beleg zu dieser Technik der Stahlerzeugung in Lehmtiegeln an der Elfenbeinküste: Celis 1991, 160-166 Abb. 124 und 135. 331 Höfer 1972, $55 \mathrm{f}$. 


\section{Historische Anleitungen zur Stahlerzeugung in Lehmumhüllungen und Tiegeln}

Es sind verschiedene Anleitungen und Beschreibungen aus historischer Zeit überliefert, welche den Aufbau des aufzukohlenden Eisens mit organischen (kohlenstoffreichen) Substanzen und einer Lehmumhüllung schildern. Einige Beispiele ${ }^{332}$ :

\section{Indien}

Aus Indien berichtet Arun Kumar Biswas, dass konische Tiegel mit 250-550 Gramm weichem Renneisen, Holzschnipseln, Blättern und Pflanzenranken, Reisspelzen usw. gefüllt und anschliessend mit Lehm verschlossen worden sind. Nach dem Trocknen kamen sie für 5-6 Stunden in einen Ofen ins Holzkohlefeuer. Im Ofen hatten 14 Tiegel nebeneinander und ein weiterer daraufgestellt Platz; dazwischen und darüber kam viel Holzkohle, die immer wieder nachgefüllt werden musste. Nach der Glühzeit wurden die Tiegel noch im Ofen zum Abkühlen mit Wasser besprengt. Die aus den Tiegeln herausgenommenen konischen Stahlblöcke weisen an der Oberfläche einen Kohlenstoffgehalt von $0,8 \% \mathrm{C}$ auf, der gegen den Kern abnimmt ${ }^{333}$. - Neben zahlreichen antiken und frühneuzeitlichen Zeugnissen der Gewinnung von Tiegelstahl in Indien und anderen asiatischen Ländern (s. oben S. 39-44, Abb. 22) muss es offenbar auch spezielle Eisenverhüttungsöfen gegeben haben, in denen sich direkt kohlenstoffreicher Stahl erzeugen liess ${ }^{334}$.

\section{Theophilus Presbyter, um 1125}

Theophilus Presbyter empfiehlt in seiner Diversarum Artium Schedula, die er um 1100-1120 erarbeitet hatte, für kleine, aus Stahl geschmiedete und gehauene Feilen: «Nachdem der Hieb mit dem Hammer, mit dem Meissel oder mit dem Messer eingehauen worden ist, schmiere [die Feilen] mit altem Schweineschmalz ein, umwickle sie mit Streifchen, die aus Bockleder geschnitten sind, und binde darum Leinenfaden. Danach umhülle sie einzeln mit durchgeknetetem Ton, die Angel lasse aber unbedeckt. Nachdem sie getrocknet sind, stecke sie ins Feuer und blase kräftig, bis das Leder verbrennt. Ziehe sie schnell aus dem Ton und lösche sie gleichmässig in Wasser ab, nimm sie heraus und trockne sie am Feuer» (experimentelle Rekonstruktion: Abb. 114) ${ }^{335}$. Über die Verweildauer im Feuer macht Presbyter keine Angaben.
Die von Marcelin Berthelot vorgelegten, wenig älteren «traités techniques» nennen ebenfalls ein partielles Aufkohlungsverfahren, auch Nitridierungs- oder Carbonitrierhärten genannt: Bereite einen Brei aus gebranntem Ziegenhorn, Salz und Wasser, bestreiche damit eine Schwertklinge (nur die Schneiden?), glühe sie und schrecke sie in Wasser $\mathrm{ab}^{336}$. Das Eindringen des im Horn enthaltenen Stickstoffs in die Eisenoberfläche führt zu einer dünnen Schicht mit Nitriden, die dem Objekt eine hohe Oberflächenhärte verleihen ${ }^{337}$. Ein identisches Rezept wurde noch im 20.Jahrhundert von Schmieden in Westafrika zur Härtung von Feilen verwendet: «Das Horn eines Hammels wird im Holzkohlefeuer leicht angebrannt und ... mit einem Messer abgeschabt. Dieses Hornpulver ${ }^{338}$, mit Kochsalz vermischt, ergibt ein stickstoffreiches, härtendes Mittel zur Nitridierung. Es wird auf die glühende Feile aufgestreut und im Ofen abgedampft. Zunächst wird das Werkstück im Wasser, nach Wiederholung des Glühvorgangs in Öl und nach dem dritten Glühen wieder in Wasser abgeschreckt.»339

332 Hier nicht aufgeführt ist das ausführliche Tiegelstahl-Rezept von Marcianus Graecus (Anfang 11.Jh.): Halleux 2007, 1309f. Anm. 41.

333 Biswas 2001, 123 f. (mit älterer Lit.). - Zeitgenössische Beschreibung des Prozesses und der Öfen: Buchanan 1807, vol. I, 174-177 (6 Stunden Glühdauer); vol.II, 19-23 Abb.41 (4 Stunden Glühdauer).

334 Juleff 1996 (Samanalawewa / Sri Lanka).

335 Presbyter Buch 3, Kap. 19; zitiert nach der praxisnahen Übersetzung Brepohl 1987, 81; Beck 1884, 984. - Ein ähnliches Verfahren wird auch für spätkeltisch-römische Eisenerzeugnisse postuliert: Presslinger/Mayr 2001, 289. - Verfahren mit einem Härtepulverbrei resp. einer «Härtemasse» (statt Schweineschmalz) zur Feilenhärtung: Rinman 1815, 677; Buxbaum 1932, 29 (Bestandteile: Holzkohlestaub, Weizen- und Roggenmehl, Zyankali, Blutlaugensalz, Glaspulver u. a.). - Zum Abdecken nicht aufzukohlender Partien mit Lehm auch: Schiefer/Grün 1927, 188; Rehder 1989, 28 und 32 .

336 Berthelot 1888, 342 (Text); 328 (französische Übersetzung).

337 Zum Einbringen von stickstoffhaltigen Härtungsmitteln (sowie Phosphor) auch Bergmann 1920, 166; Kastowsky et al. 2011, 516 (Nitrieren).

338 «Härtepulver» aus «gebrannten Klauen», ebenfalls zur Härtung von Feilen, auch bei: Karsten 1821, 299; sinngemäss auch: Rinman 1815, 676 ( «So wie die Feilen aus dem Feuer kommen, werden sie mit einem Stück Horn berieben ...); Buxbaum 1932, 29 («Klauenmehl»). - Zu Horn-Zusätzen in Aufkohlungspulvern siehe unten bei Anm. 535.

339 Armbruster 1995, 121. 
Johannes Kunckel, 1732

J. Kunckel beschreibt 600 Jahre nach Theophilus (1732) «aus Eisen Stahl zu machen» den auch in anderen Quellen beschriebenen Prozess einer Aufkohlung von dünnen Eisenstangen in einem geschlossenen Tongefäss: Man solle 14-15 Pfund «kleine Stänglein» aus Eisen lagenweise in eine Tonröhre schichten, abwechslungsweise mit jeweils einer fingerdicken Lage fein gestossener Buchen-Holzkohlen belegen, und solle anschliessend auf die Rohre «die Deckel mit einem guten Luto ... darauf verlutieren». Die Gefässe seien dann «bey 24 Stunden wohl Feuer» auszusetzen. Kunckel beschreibt die Kriterien der so erlangten Stahlqualität so: «So nun der Stahl oben auf viel Blätterlein krieget, ist es ein gutes Anzeigen, eines guten Stahls, die doch alle in der Arbeit vergehen. Die eiserne Stänglein müssen wohl, eben, glatt und gleicher Dicke seyn, nicht rissig oder sprissig. ... Je dünner nun die eisernen Stäbe sind, je besserer Stahl daraus wird, wenn nur die Dicke als ein doppelter Thaler [ca. $5 \mathrm{~mm}$ ] ist ...»340

\section{Johann Andreas Cramer, 1746/1766}

Wenige Jahre nach Johannes Kunckel beschreibt Johann Andreas Cramer im zweiten Teil seiner «Anfangsgründe der Probierkunst» das Aufkohlen von Eisenstäben in einem Tiegel besonders ausführlich ${ }^{341}$ :

«1. Suche nicht allzu dicke Stäbe aus von den fremden Sachen befreyten und reinen Eisen, von welchem das beste Kennzeichen dieses ist, dass es sich eben so wohl in der Wärme als Kälte geschmeidig erweiset. Mache ein Cement von solchen Sachen, welche im Feuer ein häufiges brennliches Wesen, so aber ganz und gar kein mineralisches Schwefelsaures bey sich hat, von sich stossen: dergleichen alle erstickte Kohlen sind, mit einem Worte, alle und jede Theile von den Thieren und Gewächsen, welche ein etwas feuerbeständiges brennliches Wesen in sich haben; unter welchen doch diejenigen die übrigen übertreffen, welche, nachdem sie ein starkes Feuer ausgehalten haben, eine rückständige fette Kohle zurücke lassen...

Nimm von mässig zerkleinertem Kohlengestübe 1 . Th. [Teil] [,] Holzasche $1 / 2$ Th. mische es unter einander. Nimm Kohlengestübe 2 Th. von Beinen, Hörnern, Leder, Haaren, die man in einem gelinden Feuer in verschlossenem Gefässe schwarz gebrannt, und zu Pulver gestoßen hat 1 Th. ... [,] Holzasche $1 / 2$ Th. vermische es miteinander.

Uebrigens hat man befunden, dass die Theile von den Thieren wegen des häufigern und zartern brennlichen Wesens geschwinder wirken, als die übrigen.

2. Man lasse ein irdenes Gefässe dessen cylindrische Gestalt die beste ist, verfertigen, welches zwey oder drey Zoll höher seyn soll, als die Stäbe) lang sind: auf dessen Boden streue den auf vorbemeldte Art zubereiteten Cement, dass er, wenn er etwas zusammen gedrucket ist, den Boden anderthalb Zoll hoch bedecke. Alsdenn setze die Stäbe aufrecht in einer solchen Ordnung hinein, dass sie von den Seiten des Gefässes und von einander, ohngefehr einen Zoll weit abstehen: die leeren Zwischenräumgen fülle mit eben dem Cemente an, und beschütte auch damit die Stäbe, dass das ganze Gefässe voll werde; dieses bedecke hernach mit einer Stürze [Deckel], und verschmiere die Fugen mit dünnem Leimen. Anstatt des irdenen Gefässes kann man auch eines, das von Eisenblech gemacht ist, darzu gebrauchen; welches man aber von aussen mit Leimen beschlagen muss, damit es nicht geschwinde verbrenne.

3. Alsdenn setze es, wenn es dergestalt vorgerichtet ist, in einen Ofen, wo man viele Stunden lang ein gleichförmiges Feuer halten kann, oder in den Boden des Thurns, oder in den ersten Nebenofen des faulen Heinzen. Gieb ein so starkes Feuer, dass das Gefässe sechs oder zehen Stunden lang mässig glüe: wenn diese Zeit verflossen ist, so nimm es heraus und lösche die glüenden Stäbe in kaltem Wasser ab. Alsdenn werden sie spröde, und in Stahl verwandelt seyn, es wird auch von aussen keine Schlacke zu sehen seyn, noch das Gewichte abgenommen haben, wenn man nur die Regierung des Feuers gehörig veranstaltet hat.

4. Dieses sind aber die Zeichen, dass das Eisen in Stahl verwandelt worden, wenn es, nachdem man es glüend in kaltem Wasser abgelöschet hat, sehr harte wird, sich unter den Hammer nicht treiben lässet, sondern zerbrechlich ist, wenn man stark drauf schlägt, und wenn es von der härtesten Feile nicht angegriffen wird: wenn es aber nach und nach, langsam und stufenweise erkaltet, so lässet es sich einigermassen feilen, und mit dem Hammer ausdehnen, eines mehr, das andere weniger.»

Es erstaunt für die technikhistorisch rege Zeit des 18. Jahrhunderts nicht, dass Johann Georg Friedrich Klein in seiner «Beschreibung der Metalllothe und Lötungen» Cramers Text praktisch wörtlich zitiert ${ }^{342}$.

Dieses Rezept lag unserem Aufkohlungsversuch in einem Tiegel (Abb. 115) zugrunde.

\section{William Wallis Woodward, 1775}

Recht ähnlich und für die Erzeugung relativ grosser Stahlmengen geeignet ist das zweite Rezept von William Wallis Woodward in seinen gesammelten «Valuable Secrets». Es werden ebenfalls hermetisch verschlossene Tiegel verwendet, die jedoch mit mehreren Eisenbarren schichtweise

340 Kunckel 1732, 314f. - Ganz ähnlich Réaumur 1722, 8 und 66-69; Brearley 1914, 2 f. - Abdecken der nicht aufzukohlenen Stellen mit Ton auch bei: Rehder 1989, 28.

341 Cramer 1766 (Erstauflage 1746), 554-556.

342 Klein 1760, 117-120. 


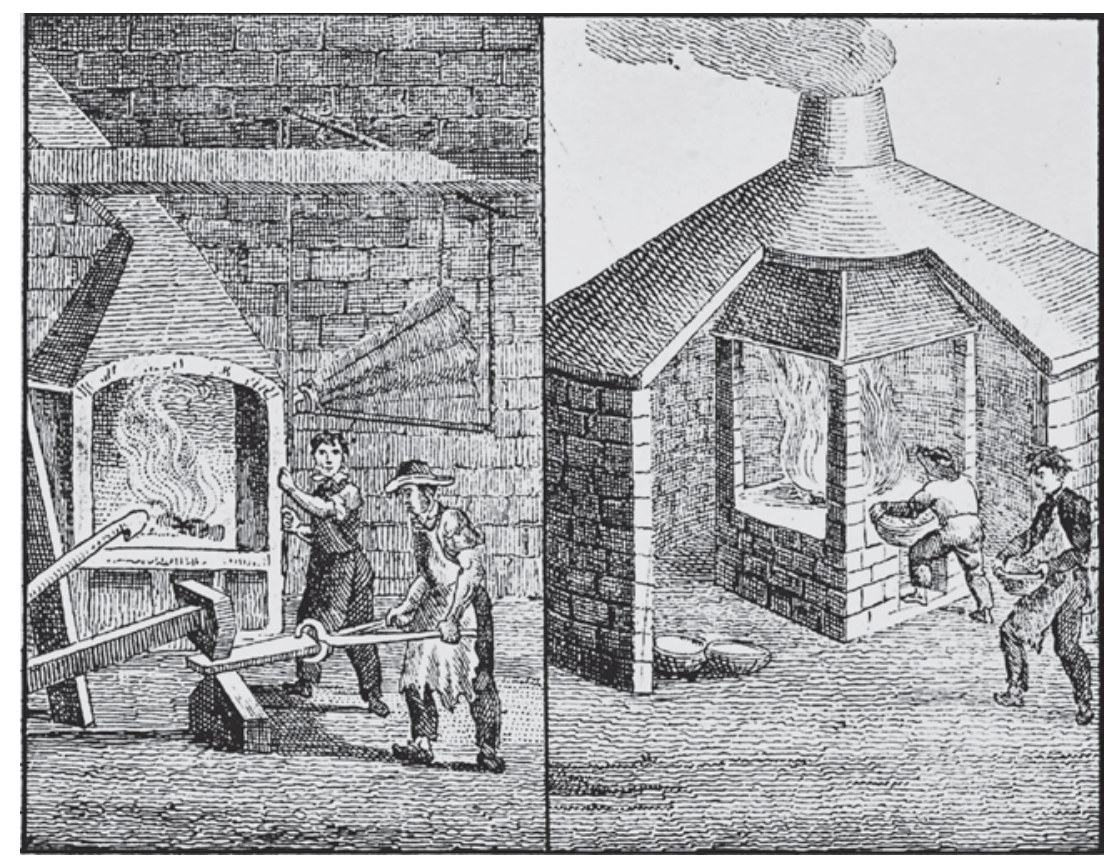

Abb. 30: Die Stahlerzeugung durch Aufkohlung zuerst in Lehmumhüllungen, später auch in Tiegeln - fand ihre frühindustrielle Fortsetzung in einem Glühprozess in grossen Aufkohlöfen. Die Lithographie aus dem Werk von Johan Amos Comenius aus dem Jahr 1832 resp. 1842 zeigt rechts den Ofen beim Beschicken mit Holzkohle. Links werden die Eisenbänder - vor oder nach dem Aufkohlen? - unter dem Hammerwerk ausgeschmiedet. zwischen Holzkohlepulver eingepackt sind ${ }^{343}:$ «1. Take one bushel of beech coals pulverised and sifted; alder's coals, ... vine ashes ..., both well pulverised and sifted, equal parts, half a peck. Mix well these powders, and stratify your iron bars with them in a crucible well luted; then give a good fire for twenty-four hours. ... 2. If you want to have your steel white, you must add to all the above powders one peck of juniper-wood allies. 3. If you want it purple, you must make a lexiviation of vine and shoes ashes, foot and garlick, well pounded equal parts; and a sufficient quantity of water to make the said bullitorium, in which you will steep, cold, your iron bars before you cement them. 4 ... 5. The stratum super stratum ought to be made one, or, one and a half, inch thick of powder to each bed. - The bars ought to be ranged cross-way one over another; and large crucibles are to be preferred to small ones. - You must take care to have them so well luted, as not to allow the least air to find its way in ...»

An anderer Stelle in seinen «Valuable Secrets» beschreibt William Wallis Woodward ein anderes Aufkohlungsverfahren mit Eichenasche, Knoblauchpulver und Holzkohle, in einen eisernen Topf schichtweise mit Lehm eingepackt und dreimal 24 Stunden erhitzt ${ }^{344}$.

\section{Louis Bernard Guyton de Morveau, 1785}

L. B. Guyton de Morveau berichtet in seiner lexikalischen Abhandlung über die Erzeugung von Stahl 1885 in den «Nouveaux Mémoires de l'Académie de Dijon», und ein Jahr später erscheint der Beitrag im Band «Chimie 1» der mehrbändigen «Encyclopédie Méthodique» ${ }^{345}$ : «On prend des barreaux de fer, on les met dans un creuset cylindrique, de manière qu'ils soient environnés de toute part de charbon pulvérisé, \& même que la poussière de charbon venant à se tasser, ils en restent cependant couverts: on a attention que les barreaux ne se touchent pas, \& qu'ils soient éloignés des parois du creuset d'à peu près un pouce. Ayant lutté le couvercle, on place le creuset dans le fourneau, où on entretient un feu capable de le porter au rouge-blanc pendant sept à huit heures. Le-fourneau étant refroidi, on trouve le charbon aussi noir \& présentant les mêmes apparences que lorsqu'on l'a introduit dans le creuset, ... mais l'état du fer a bien changé. Si on le découvre à la lime, par laquelle il se laisse encore entamer. ... De ductile qu'il étoit, il est devenu aigre \& cassant ... Après l'avoir chauffé au rouge, on le refroidit subitement dans l'eau, il acquiert une dureté dont il n'étoit pas susceptible avant cette opération, il a donc été converti en acier.»

\section{Johann Amos Comenius, 1832}

Im Werk «Neuer Orbis Pictus für die Jugend ...» findet sich unter vielen anderen Handwerksdarstellungen auch ein Kapitel über «Die Hammerwerke, das Eisengiessen und die Zubereitung des Stahls». Letztere wird folgendermassen beschrieben ${ }^{346}$ : «Man erhält den künstlichen Stahl, in-

\footnotetext{
343 Woodward 1795, $25 \mathrm{f}$

344 Woodward 1795, 11.

345 Guyton de Morveau 1785, 415 f.; Guyton de Morveau 1786, 422.

346 Comenius 1842 (Erstpublikation 1832), 772-774 (mit lithographierter Tafel 315 [= unsere Abb. 30]). Diesen Literaturhinweis verdanke ich Alfred Mutz† und Olga Bender, Basel.
} 
dem man viele dünne Stäbe in einem Ofen aufschichtet, in welchem sich eine Mischung von Kohlen und Asche oder zerstossenem Glas befindet. Man unterhält ein starkes Feuer (Abb. 30, rechts), und nach 5 bis 6 Tagen ist das Eisen in Stahl verwandelt. Wenn es herausgenommen und kalt geworden ist, wird es gehämmert» (Abb.30, links). Diese Technologie ist die frühindustrielle Weiterentwicklung der Stahlerzeugung durch Aufkohlung im Tiegel, wie wir sie aus älteren Quellen kennen (Beispiele oben). Die deutlich längere Glühzeit ist der Menge Eisen im Ofen und der angestrebten völligen Durchdringung der «dünnen Stäbe» mit Kohlenstoff geschuldet.

In Coalbrookdale bei Shrewsbury in England standen die frühesten solcher industriell betriebenen Zementationsöfen zur Stahlherstellung. Sie waren im frühen 17.Jahrhundert in Betrieb und sind 2001/2005 sogar archäologisch untersucht und im Detail beschrieben worden (vgl. auch S. 35 Abb. 17) ${ }^{347}$.

\section{Eugène Julia de Fontenelle, 1832}

Im «Manuel complet» der Schmuckhersteller schildert Eugène Julia de Fontenelle die Aufkohlung von Eisen zu Stahl folgendermassen ${ }^{348}$ : «Acier de cémentation. On prend le fer malléable le plus pur qu'on place dans un creuset, ou mieux dans des caisses en tôle, en fer de fonte, en grès, en brique, etc., dans lesquelles on place une couche de cément composé de suie 0,4 à 0,8 [parts], charbon de bois 0,4 , cendres de 0,3 à 0,8 , sel marin 0,3 . Le charbon animal passe pour être le meilleur. On y met alors les barres de fer par couches au milieu d'un lit de charbon en poudre; on entretient à une forte chaleur rouge égale à environ 80 à $90^{\circ}$ du pyromètre de Wedgwood ${ }^{349}$ pendant cinq à six jours. La couche supérieure des barres on laisse passer l'extrémité de quelques-uns au-dehors de la caisse afin de servir d'épreuve. Cette couche de fer est couverte de sable ou d'argile en pâte. Quand on pense que l'opération est terminée, on tire les barres éprouvettes pour essayer si la conversion en acier est parfaite jusqu'au centre. Dans le cas négatif, on continue de chauffer; dans le cas positif, on laisse refroidir le fourneau, l'on retire les barres qui sont boursoufflées, on les casse par leurs extrémités et l'on met de côté celles qui ne sont pas bien aciérées ...» Auch hier im «Manuel complet» wird, wie im «Neuen Orbis Pictus für die Jugend» aus demselben Jahr, eine mehrtägige Glühzeit von fünf bis sechs Tagen empfohlen. Ebenfalls nicht neu ist die Zugabe von etwas Salz. Der Hinweis, dass tierischer Kohlenstoff besser als pflanzlicher sei, ist aus heutiger Sicht schwer zu begründen. Es könnte aber sein, dass Knochen- oder ganz speziell Hornteile im Zementierungsmittel mit ihrem hohen Stickstoffgehalt das Eisen nicht nur aufkohlen, sondern auch «nitridieren» 350 .
Neu ist die Beschreibung des Glühkastens aus Eisenblech, Gusseisen, Sandstein oder Ziegelsteinen. Wir erfahren auch von der Möglichkeit, einige aus dem Glühkasten herausragende Eisenstäbe zur Vorprüfung zu entnehmen ${ }^{351}$.
347 Barraclough 1981, 89-91; Belfort/ Ross 2007.

348 de Fontenelle 1832, 209f. (210: Tiegelstahlherstellung).

349 Der Versuch einer Umrechnung in ${ }^{\circ} \mathrm{C}$ führte zu sicher falschen, irrelevanten Temperaturangaben. $90^{\circ}$ Wedgwood soll der «schwächsten Schweisshitze des Eisens» entsprechen.

350 Zur Nitridierung des Stahl s. oben mit Anm. 336 und 339.

351 So auch bei Georgi 1785B, $348 \mathrm{f}$. 


\section{Der Umgang mit Stahl in der römischen Werkzeugtechnologie}
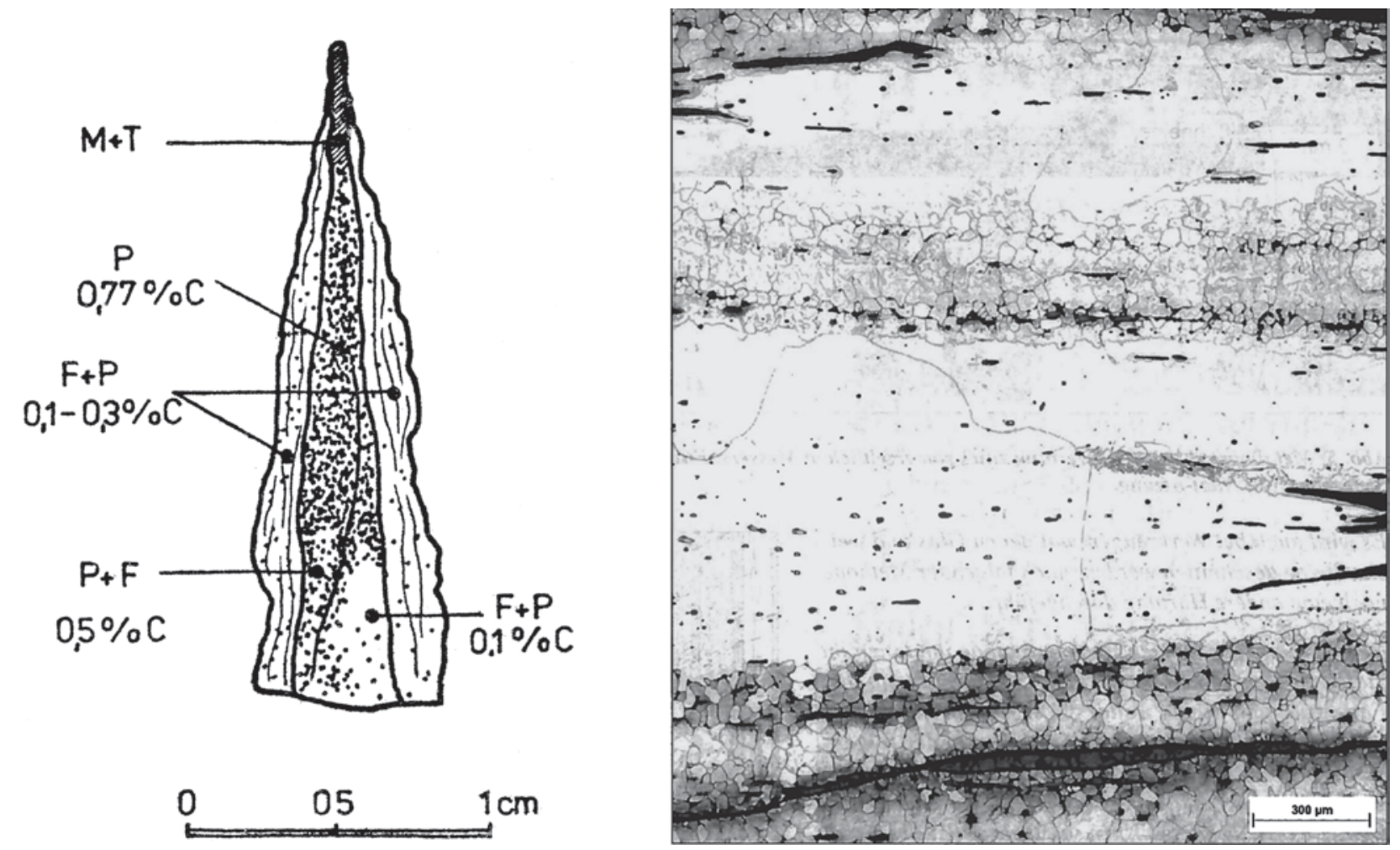

Abb. 31: Verbundstoff-Beispiele. - Links Weicheisen mit eingesetzter Klinge aus härtbarem Stahl, Querschnitt durch eine Schwertschneide aus Augst/BL (Augusta Raurica). Dreiplattige Struktur mit einem perlitischen Kern und ferritisch-perlitischen Oberflächen der Klinge. Die Schwertschneide ist warm bearbeitet (nach Biborski et al. 1982, 83 Abb. 7.a). C = Kohlenstoffgehalt (\%); $F=$ Eisen $/$ Ferrit; $M=$ Martensit; $P=$ Perlit-Stahl; $P+F=$ Perlit-Ferrit-Stahl; $T=$ Troostit. - Rechts: keltisches Tüllenbeil mit verschiedenen Ferritausbildungen bzw. Anordnungen infolge Verschmiedens von Stahlstäben, aus LinzGründberg/A; Nital-Ätzung (nach Presslinger 2007, Abb. 3). Unterschiedliche Massstäbe.

Stahl wurde in der Antike teils zentral produziert und verhandelt, teils bei den Verbrauchern in den Siedlungen in kleinen Mengen durch Aufkohlung gewonnen (wie z. B.in Augusta Raurica). In den letzten Jahren konnte in Einzelfällen sogar nachgewiesen werden, dass schwere, sehr kohlenstoffreiche Roheisenbrocken aus besonders befeuerten Verhüttungsöfen verhandelt und erst vor Ort «von Schmieden gefrischt», d.h. auf einen schmiedbaren Kohlenstoffgehalt hinuntergebracht wurden. Die Rohstücke waren viel zu kohlenstoffreich und spröde und hätten nicht geschmiedet werden können. Man hat sie daher «durch langzeitiges Glühen soweit abgekohlt, bis sie zu schmiedbarem Stahl wurden» ${ }^{352}$. Vermutlich war dieses Vorgehehen jedoch eher die Ausnahme: Die vielen Schiffsfunde aus der Bucht von Saintes-Maries-de-la-Mer / F mit unzähligen Eisenbarren verschiedenster Grösse und Kohlenstoffgehalte liessen in den letzten Jahren erahnen, dass für den Grossund Fernhandel verschiedener Eisen- und Stahlsorten viele Qualitäten in möglicherweise «genormten» Barrenformaten im Umlauf waren: «À chaque type morphologique de barre correspond un alliage ferreux particulier.» ${ }^{353}$
Das Schmieden von Stahl stellt besondere Anforderungen an den Handwerker: Er ist infolge seines Kohlenstoffgehaltes und seiner Härte viel mühsamer zu hämmern als Schmiedeeisen, darf nicht allzu hoch erhitzt werden und verliert im offenen Schmiedefeuer rasch seinen Kohlenstoff. David Sim vermutet daher, dass die «Schmiedehäuschen» auf vielen römischen Darstellungen teilweise verschlossene Essen sind. Er konnte mit eigenen Versuchen nachweisen, dass solche Umfassungen die Hitze besser zusammenhalten, Brennstoff sparen helfen und vor allem die Entkohlung stark verringern ${ }^{354}$.

Wertvoller Stahl wurde in der Antike «sparsam» verwendet. Nur am Erzeugungsort, zum Beispiel auf dem Magdalensberg in Noricum, konnte man es sich leisten, ganze

352 Presslinger et al. 2016, 141 (mit mehreren Belegen).

353 Pagès et al. 2011B (mit älterer Lit.), 158: Grössenvariation der südfranzösischen Barren: 20-200 cm, 1,5-33 kg); 174 (Zitat).

354 Sim 2012, 136f. Tab. 9, Abb. 6 und Farbtaf. 3. 
Messer, Meissel ${ }^{355}$, Sicheln, zierliche Gürtelhaken ${ }^{356}$ und dergleichen aus Stahl zu schmieden. Aber auch dort hat man Verbundstoffe aus weichem Eisen und angeschweissten, härtbaren Stahlschneiden hergestellt ${ }^{357}$. Plinius nannte dieses «Zusammengeschweisste» stricturae ${ }^{358}$. Wegen solcher kleiner Stahl-Einsätze in massiven Eisenwerkzeugen wurde sogar behauptet, dass in der Antike gar nicht so viel Stahl wie von vielen Autoren vermutet benötigt worden sei ${ }^{359}$.

Archäometrische Untersuchungen an antiken Eisenobjekten konnten wiederholt den Nachweis erbringen, dass die Schneiden und Arbeitskanten römischer Werkzeuge und Waffen aus Stahl bestehen. Der übrige Teil des Geräts besteht jedoch aus normalem Schmiedeeisen. Robert Maddin et al. sprechen von aufgekohlten Stahlstreifen («sheets»), die durch Hämmern mit normalem Eisen bündelweise aufgeschweisst werden ${ }^{360}$. Auch bei der Untersuchung römischer Werkzeuge und Messer vom Magdalensberg / A, «bei denen die jeweiligen Arbeitsflächen bzw. Messerschneiden aus höherkohlenstoffhaltigem (und meist gehärtetem) Stahl bestehen», stellte Otto Schaaber fest, dass «für die weniger beanspruchten Teile, also den Schaft eines Meissels oder den Rücken eines Messers, weicher 〈billiger〉 Stahl (Eisen) verwendet wurde» ${ }^{361}$.

An der betreffenden Stelle sind die Stahlstücke in das Weicheisen durch Feuerverschweissung eingesetzt und dann nur noch wenig in die endgültige Form überschmiedet worden. Dabei «wurde Stahl sehr zweckmässig (und sparsam) immer dort eingeschmiedet, wo er wegen seiner Härte notwendig war» ${ }^{362}$. Die Grenzlinien zwischen Stahl und Weicheisen sind in den angeätzten Schliffbildern gut zu sehen (Abb. 31 ${ }^{363}$ ), und Härtemessungen liefern den Nachweis, dass nicht nur unterschiedliche Werkstoffe nebeneinander vorliegen, sondern dass die Arbeitskanten dieser Geräte auch gezielt durch Abschrecken und Anlassen gehärtet worden sind ${ }^{364}$.
355 Mitsche 1961.

356 Presslinger/Rupprechtsberger 2016.

$357 \mathrm{Zu}$ Verbundstoffen (mit angeschweisster Stahlkante) auch oben mit Anm. 133. - Beck 1884, 544-455; Pleiner 1970; Schaaber 1977, 221 und 267; Schaaber 1976/77, 98 Abb.8; Epprecht/Schaller 1981; Conophagos / Papadimitriou 1986, 137Abb. 14-16; Presslinger / Köstler 1991, 25 f. Abb. 9 Tab. 2 (Messerrücken: 0,02\% C; angestählte resp. «angelötete» [«arsenhaltige Eisenverbindung als Lot»] Schneide: 1,30\% C); Pleiner 2006, 202; Presslinger/Mayr 2001, 289; Presslinger 2008, 242f. Tab. 6-7; Sim 2012, 129 Abb. 70.

358 Plin. nat. 34,143 (siehe oben mit Anm. 186); Rottländer 2000, 38 f. und $53 \mathrm{f}$. Anm. 26.

359 Espelund 1996, 48-50 («Das Verhältnis Weicheisen/Stahl in Gegenständen lag vielleicht bei 20/1»).

360 Maddin et al. 1991, 5; 16.

361 Schaaber 1963, 200.

362 Epprecht/Schaller 1981, 42 (Zitat). - Zur Existenz von Verbundstoffen (Eisengeräte mit Schneiden aus Stahl) generell Straube 1973, 479.

363 Leider ist nicht klar, um welches Objekt es sich konkret handelt. Biborski et al. haben um 1980 drei römische Schwerter im Museum Augusta Raurica durch grobe Sägeschnitte und Entnahme grosser Teilproben «behandelt», lieferten jedoch nie eine Entnahmedokumentation (freundliche Mitteilung von Max Martin $\dagger$, 1982/83). Bei den drei beprobten Objekten handelt es sich um Inv. 1961.4401; 1961.1568 und unbekannte Inv.-Nr. (siehe auch Biborski et al. 1986).

364 Neumann 1954, 51-54 Abb. 30-34; 58f. Abb. 35; Vetters 1966, 174 Abb. 9; 10 (Magdalensberg/A); Epprecht/Schaller 1981 (Windisch/CH). - Zur frühmittelalterlichen Stahltechnologie: M. Mehofer in Daim et al. 2005, 206-210 Abb. 6-10. 


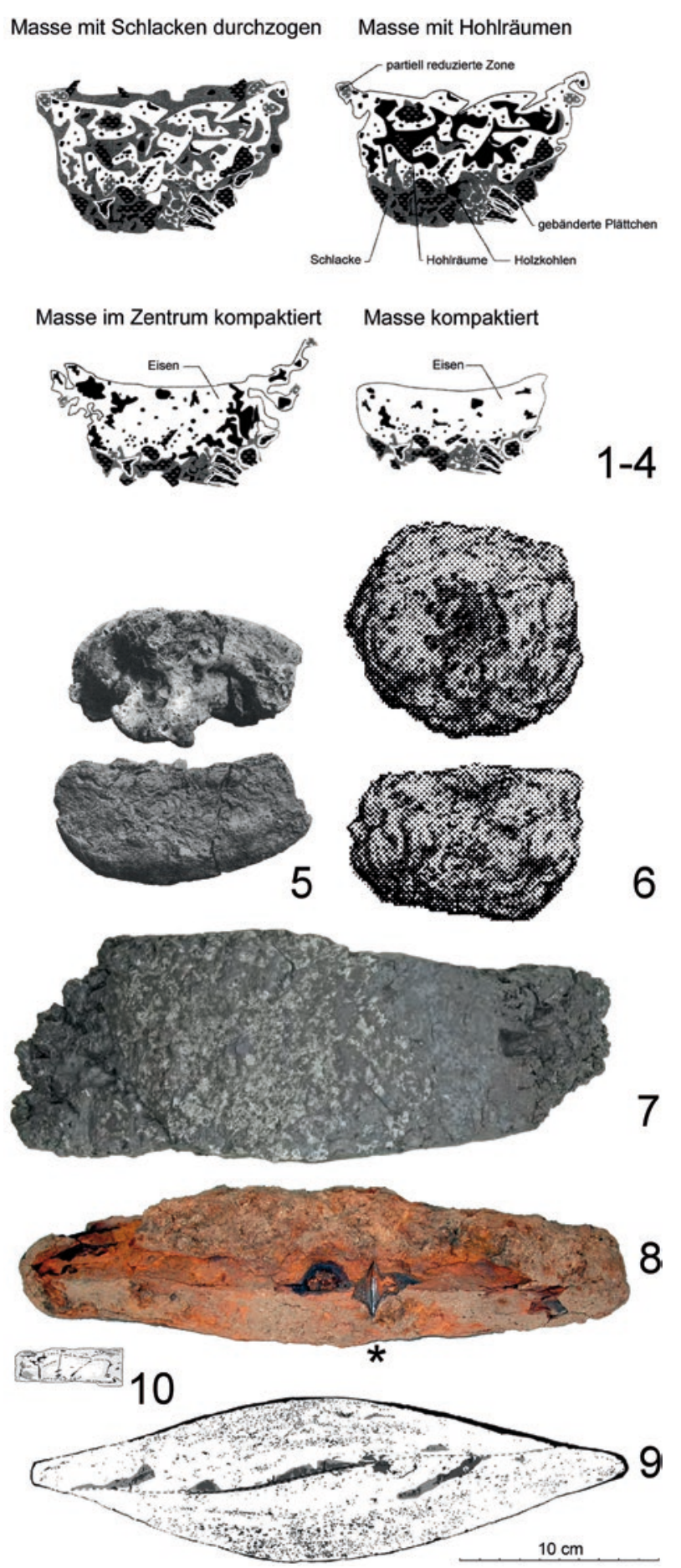

Abb. 32: Vom Ofenschwamm (Luppe) bis zur Handelsware: Mit zunehmender Bearbeitung in der Esse und auf dem Amboss unter dem Hammer entweichen die Schlacken-, Asche- und Holzkohleteile aus der heterogenen Eisenmasse, wie sie im Rennofen entsteht (oben), und sie wird je länger je mehr zu einem gereinigten, homogenisierten Eisen, das in Barrenform als Halbfabrikate in den Handel gelangt (unten). Fundorte: 1-4: Frankreich; 5: Zurzach /AG; 6: Somogyfajsz / H; 7: Alésia / F; 8: Westhawk Farm, Kent/GB; 9: Durrenentzen/F; 10: Chur/GR. M. 1:4 (1-4 ohne M.).
Unsere Kenntnis von den Handelsformen, in denen Eisen und Stahl transportiert, verkauft, zwischengelagert und gar versteckt worden sind, ist sehr ungleich über die Epochen verteilt. Am meisten ist über eisenzeitliche und frühmittelalterliche Eisenbarren geforscht und publiziert worden, manchmal jedoch auf wenige Fundräume beschränkt (z. B. Grossbritannien, Südfrankreich, Skandinavien, Nordosteuropa). Aus der Römerzeit kennen wir zwar unzählige Barren, doch mangels eindeutiger Barren-Formtypen und Barren-Hortfunden muss man die Stücke fast einzeln in Fundberichten zusammensuchen. Noch schlechter ist die Fundsituation (Forschungsstand oder effektive Präsenz?) im Mittelmeerraum, wie Maria Kostoglou festgehalten hat ${ }^{365}$ : «Although iron and steel currency bars, as a standardized form for storing and trading iron, are often found in Central and North Europe, they are not a common find in Greek and Mediterranean excavations.»

\section{Eisenbarren sind oft Halbfabrikate}

\section{Vom Rennofenprodukt zum Stahl}

Im Rennofen entsteht beim Verhütten von Eisenerz ein heterogener «Ofenschwamm» (raw bloom) mit vielen Hohlräumen, Holzkohle- und Aschepartikeln und Schlackenteilen (Abb.32,1.2). Im Laufe des sorgfältigen, langwierigen «Ausheizens» des fast weissglühenden Schwammes werden die ursprünglich isolierten Zonen reinen Eisens zu einem Ganzen zusammgeschweisst (Abb. 32,3.4) ${ }^{366}$. Holzkohlerreste und flüssige Schlacke entweichen dabei unter dem grossen Hammer, der besonders sanft geführt werden muss, solange der Eisenschwamm noch porös und sehr brüchig ist. Oft bleibt im Ofen ein «Schlackenkonglomerat» zurück (Abb. 32,5).

Diesen Ausheizungsprozesse charakterisieren Paul Merluzzo und Mitautoren wie folgt ${ }^{367}$ : «Au fur et à mesure que l'on s'éloigne du bord le plus épais, la scorie disparaît et le nombre d'inclusions et de vacuoles diminue, jusqu'à de-

365 Kostoglou 2003, 66f.

366 Fluzin 2002, 62-70, Fotos 1-36; Merluzzo et al. 2014, 241-250 Abb.3-7. - Die Aufbereitungsschritte kurz zusammengefasst auch in: France-Lanord 1963, 174; Crew 1991, 28-32 (experimentelle Barrenherstellung); Crew 1994, 345; Crew 1995, 277; Fluzin et al. 2012A, 197-199 Abb. 2.

367 Merluzzo et al. 2014, 245. 
venir rare dans la partie où le métal est plus compact. Cette zone, surtout dans la partie la plus centrale, contient de nombreuses cavités plus ou moins refermées, ainsi que des reliques d'anciennes cavités sous forme de liserés noirs.»

Beim Ausheizen entstandene Roheisenstücke (Abb.32,6 [1,6 kg] und Abb.32,7 [12,5 kg]) enthalten noch viele Schlacken- und Holzkohleeinschlüsse (smithed bloom). Manchmal sind an ihnen noch Eindrücke des Hammers oder der Zange zu beobachten ${ }^{368}$, und einige wurden glühend mit einem schweren Keil aufgeschlagen, um die Qaulität zu prüfen (Abb. 4) ${ }^{369}$. Bisweilen werden bereits solche Primärprodukte zum Schmieden in Umlauf gebracht («iron billet», Abb.32,8 [4,46 kg]), wenn sie nämlich «une homogénéité suffisante pour en faire un produit utilisable par les forgerons» erreicht haben ${ }^{370}$.

Je nach weiterer Behandlung, durch mehrfaches Ausschmieden (Entfernen weiterer Schlacken- und Holzkohleteile) und allenfalls auch Zusammenschweissen, entsteht ein Halbfabrikat, das in unterschiedlich grossen viereckigen Klötzen oder in Barren verschiedener Form in den Handel kommt $(9 ; 10[0,49 \mathrm{~kg}])$. Je nach Qualität enthält solches antikes «Handelseisen» entweder noch ziemlich viele Schlackeneinschlüsse und kleine Holzkohlepartikel (die man heute sogar ${ }^{14} \mathrm{C}$-datieren $\mathrm{kann}^{371}$ ), oder es liegt ein fast reines Eisen vor. Diese sind «des éléments commercialisables et directement utilisables par le forgeron ${ }^{372}$. Im direkten Verfahren erzeugter Stahl kann dieselben Eigenheiten aufweisen.

\section{Übersicht}

Die Geschichte und formale Entwicklung von Eisenund Stahlbarren in Europa, wie ich sie hier kurz skizziere (Abb.32-49), sind wohl am ausführlichsten von Radomír Pleiner vorgelegt und mit zahlreichen Funden illustriert worden ${ }^{373}$. Von der grossen Zahl von Barren, die mengenmässig durch grosse Hortfunde dominiert wird, ist bisher nur wenig archäometrisch untersucht worden. Mit anderen Worten: Bei den allermeisten Barren handelt es sich um Schmiedeeisen, bezüglich Reinigungsgrad, Kompaktierung und Homogenisierung jedoch von unterschiedlicher Qualität. Es ist immer noch unklar, ob sich in manchen Barren Stahlqualitäten verstecken und ob man Stahlbarren an der Barrenform erkennen konnte.

Wie erwähnt, weisen Eisenbarren in der Regel mikroskopische Hohlräume und viele Verunreinigungen auf, vor allem von eingeschlossenen Schlacken und Holzkohlen, weil der «Ofenschwamm» nicht «vollständig» ausgeheizt worden ist. Dies zeugt von einem «rapid refining process» ${ }^{374}$, also einem nur oberflächlich erfolgten Ausheizen des Ofenschwamms aus dem Rennofen. Solch wenig gereinigtes Eisen kam natürlich ebenfalls in Umlauf und wurde direkt zum Schmieden wenig anspruchsvoller Geräte verwendet. Diese schlechte Qualität war in Form normierter Barren (doppelkonische Spitzbarren und «currency bars») natürlich verpönt. Diese bestehen in aller Regel aus einem besser gereinigten Eisen ${ }^{375}$, das - im Falle der «currency bars» - oft auch in mehreren Lagen durch Zusammenschweissen weiter homogenisiert wurde (s. unten). Es scheint, dass in römischer Zeit die seit 500 Jahren bekannten doppelkonischen Spitzbarren (Abb.49, links) allmählich durch eine Vielzahl unterschiedlich proportionierter, relativ kleiner Rechteckbarren ersetzt wurden (s. unten) ${ }^{376}$.

Die relativ wenigen naturwissenschaftlichen Untersuchungen von antiken Eisenbarren lassen heute drei Gruppen erkennen:

1. Es dominieren durchschnittlich gut ausgeheizte, d.h. schlacken- und holzkohlearme Eisen, die oft aus mehreren Teilen zusammengeschweisst sind (Beispiele in Abb. 37 und 45). Diesen Barren gemeinsam ist die typische heterogene innere Verteilung von kohlenstoffarmen Bereichen und kohlenstoffreicheren Zonen.

2. Andere Barren bestehen aus einem wenig anspruchsvollen Eisen. Es sind schlecht aufbereitete Luppeneisen von hoher Porosität mit vielen Einschlüssen von Holzkohlepartikeln und Schlacke (Beispiel Abb. 39).

3. Ganz wenige der archäometrisch untersuchten Barren bestehen aus Stahl. Die hier abgebildeten Beispiele sind in Abbildung 33 mit einem Stern (*) versehen. Für Stahl typische Barrenformen lassen sich zurzeit noch nicht erkennen, mit Ausnahme vielleicht der latènezeitlichen kleinen «barres à douille» (BAD) (Abb. 33,15-17) 377 .

$\mathrm{Zu}$ jeder Zeit waren unterschiedliche Barrenformen (und -qualitäten?) im Umlauf. Dies bezeugen einerseits Schiffsladungen aus Wracks (Abb. 45; 46) oder einige wenige Horte mit zwei verschiedenen Barrentypen ${ }^{378}$. Die oft zitierte Grabstele eines römischen Eisenhändlers aus Augst/BLAugusta Raurica scheint - bei näherer Betrachtung - ebenfalls zwei verschiedene Barren zu zeigen: lange Rechteckbarren auf der Waage und dem grossen Stapel im Hintergrund sowie zwei massige Spitzbarren am Boden zwischen den beiden Waagschalen (Abb. 34) ${ }^{379}$.

\footnotetext{
368 Merluzzo et al. 2014, 243 Abb. 3; 249 Abb. 6 und 7.

369 Pleiner 2003, Abb. 33.2-33.5

370 France-Lanord 1963, 174.

371 Leroy et al. 2012; Berranger et al. 2017A.

372 Thouvenin 1984, 368.

373 Pleiner 2006, 23-52 Abb. 4-21.

374 Berranger / Fluzin 2012, 668.

$375 \mathrm{Zu}$ den Einschlüssen in wenig ausgeschmiedetem Eisen und deren Potential zur Herkunftsbestimmung: Leroy et al. 2014, Abb.5.1; 5.3; 5.4 .

376 Berranger / Fluzin 2012, 681.

377 Berranger 2014, Taf. 13.

378 Allen 1967; Pleiner 2006.

379 Bossert-Radtke 1992, 95-97 Kat.-Nr. 64 Taf. 48-51; Pagès 2014, 59 Tab. 2 (kartiert in Abb. 10 als Fundpunkt 35).
} 


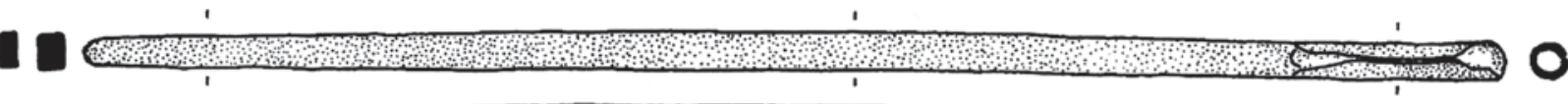
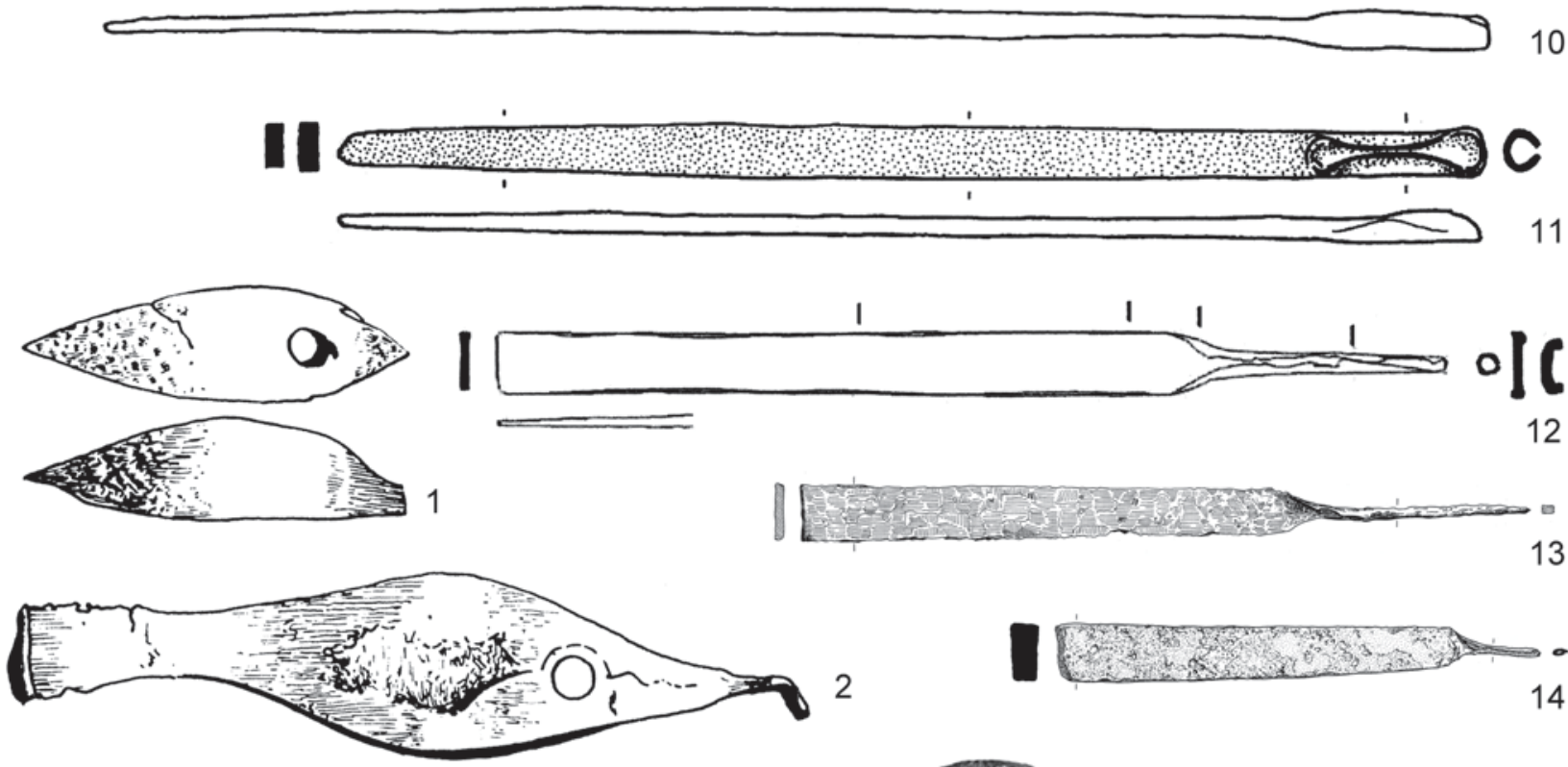

$20 \mathrm{~cm}$
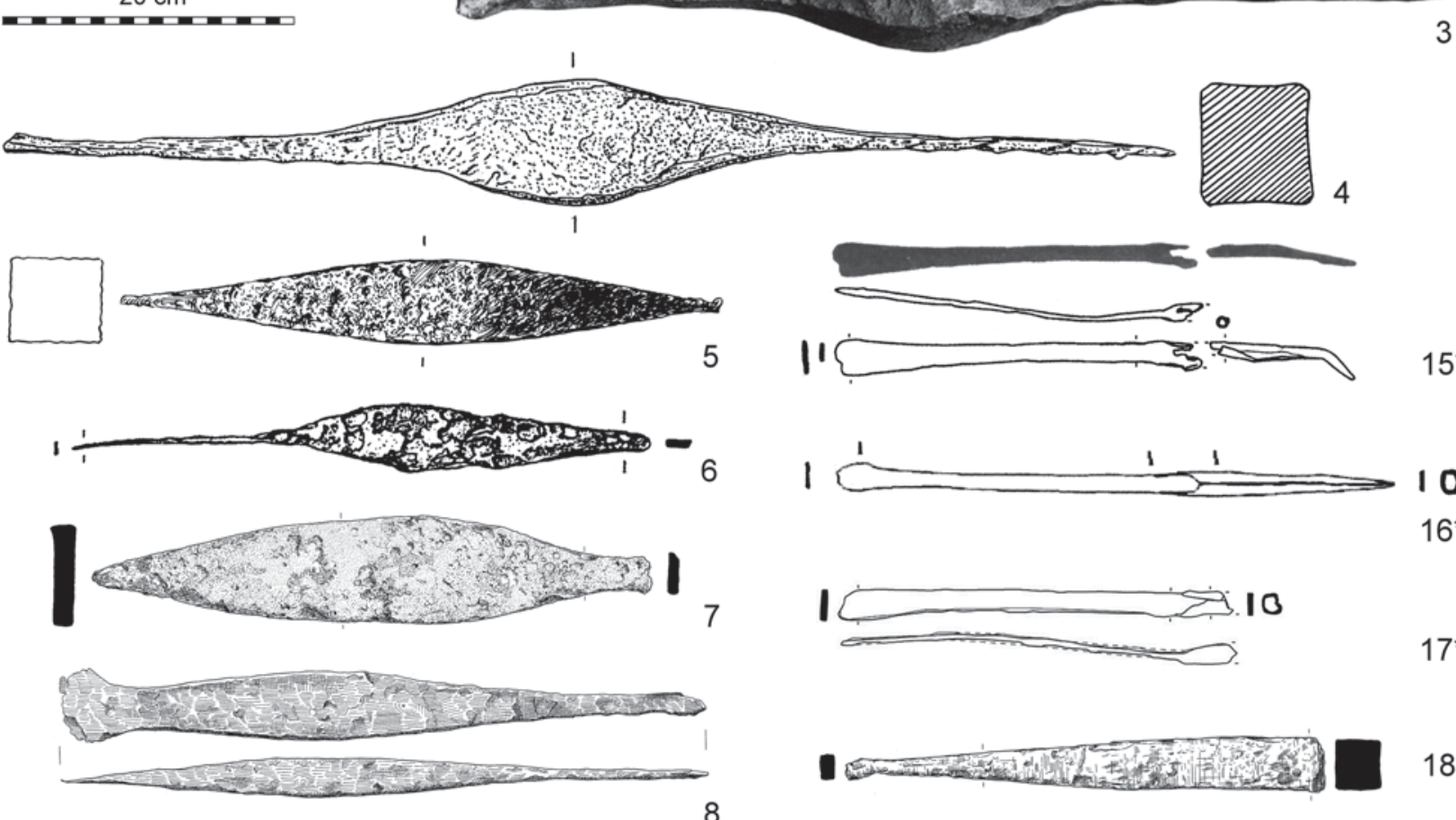

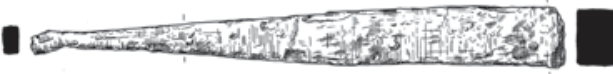

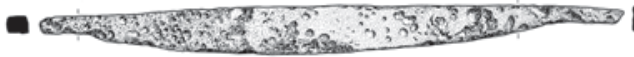

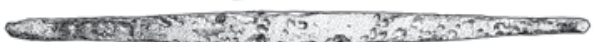
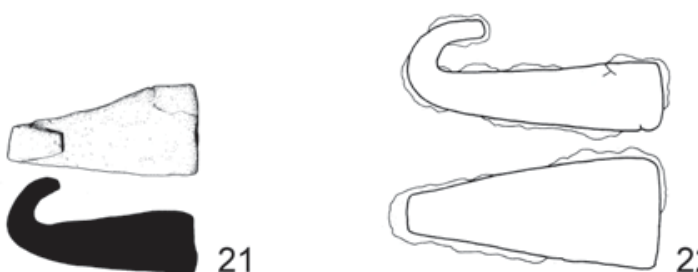
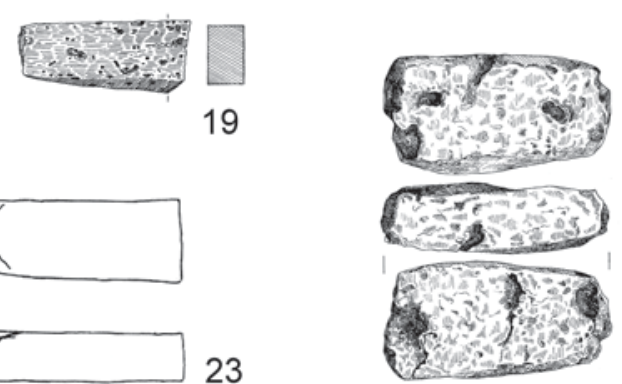

20

Abb. 33, Teil 1: Typenvarianten mediterraner und eisenzeitlicher Eisenbarren. Barren, die nachweislich aus Stahl bestehen, sind mit einem Stern (*) versehen. M. 1:6. Fundorte: 1.2 Khorsabad/IRQ-Dur Scharrukin; 3 Splügenpass/GR; 4 Saint-Connan/F; 5 Homburg/D-Sanddorf; 6 Frankreich (ohne Fundort); 7.9.14.18 Bern/BE, Massenfund Tiefenau; 8.13.19.20 Manching/D (8: «Typ Manching»), Oppidum; 10.11 Montan/F; 12 Pouilly-sur-Saône/F; 15 Beauvais /F; 16.17 St. Maur/F; 21 Gussage all Saints / GB; 22 Laleham/GB; 23 Mailhac/F, niveau Cayla III. Quellen siehe Abbildungsnachweise. 


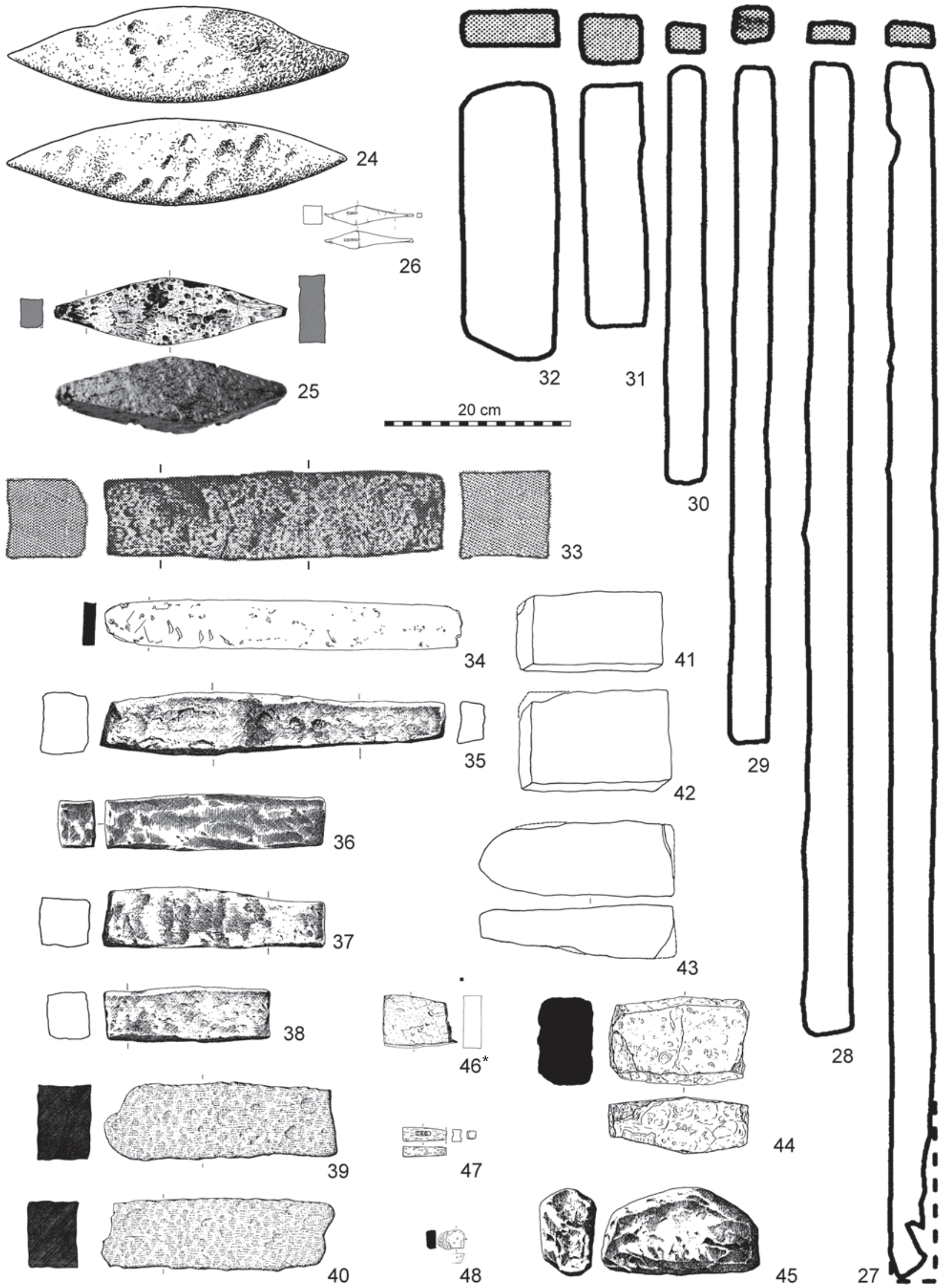

Abb. 33, Teil 2: Typenvarianten römischer Eisenbarren. Barren, die nachweislich aus Stahl bestehen, sind mit einem Stern (*) versehen. M. 1:6.

Fundorte: 24 Augst/BL (Altfund 1912); 25 Kaiseraugst/AG-Schmidmatt; 26 Andernach/D-Martinsberg; 27-32 Saintes-Maries-de-la-Mer/F, verschiedene Schiffswracks; 33 Kapospula/HU oder Heténypuszta/HU; 34.44 Magdalensberg/A; 35.37.38.45 Sisak/HR, «Mint site»; 36 Hrvatska Dubica/HR; 39.40 Cáceres-el-Viejo /E; 41-43 Gruissan/F, Schiffswrack «Mateille A»; 46 Chur/GR-Areal Dosch; 47 Oberwinterthur/ZH-Unteres Bühl; 48 Neftenbach/ZH. Quellen siehe Abbildungsnachweise. 

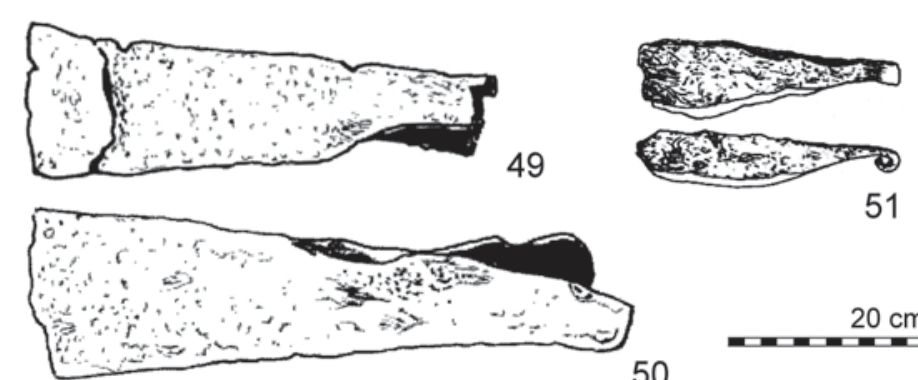

50

\section{$20 \mathrm{~cm}$}
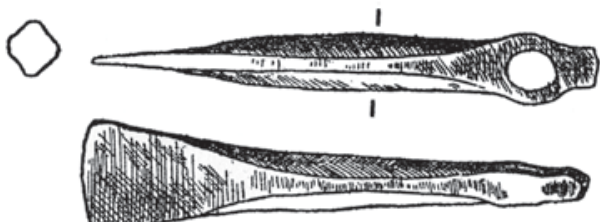

0 - 1 1. 1
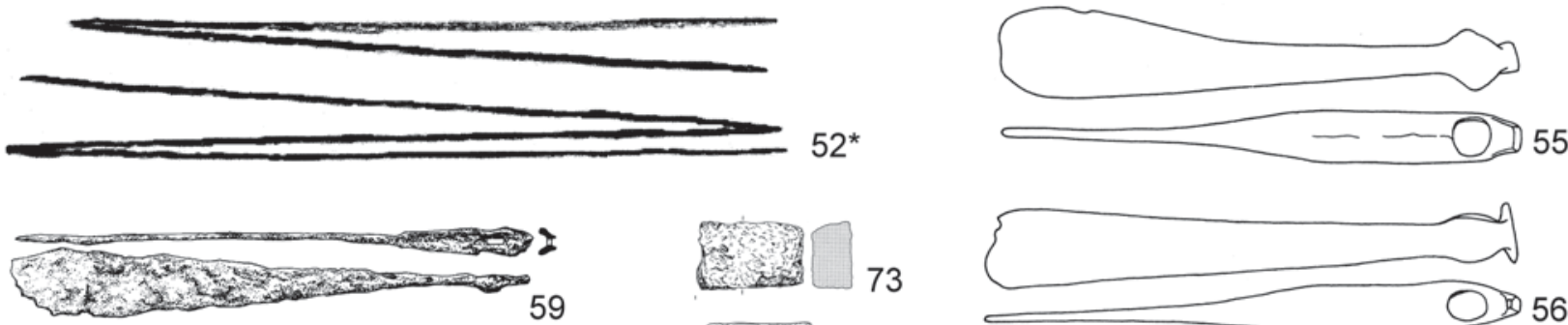

-
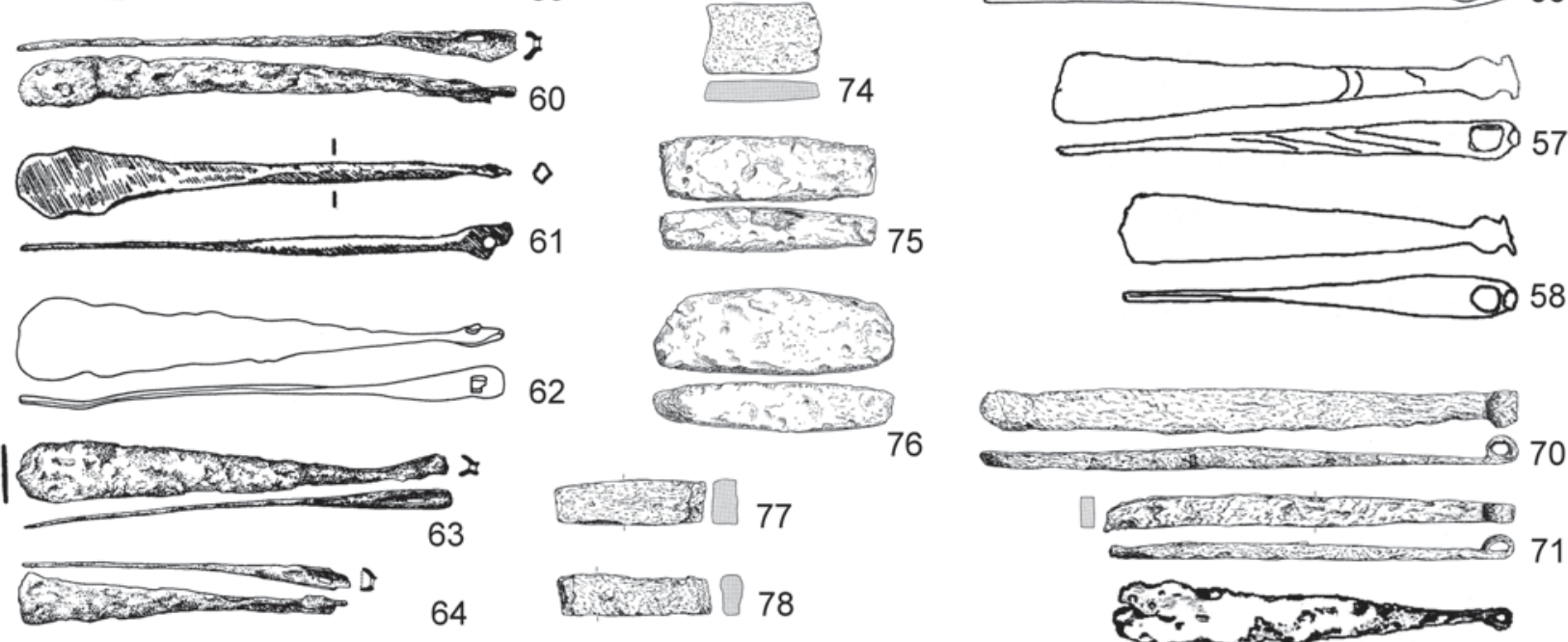

2.

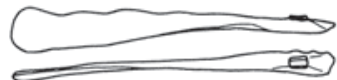

65
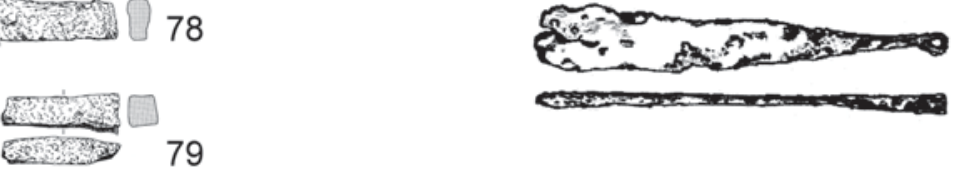

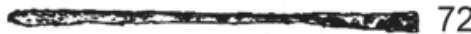

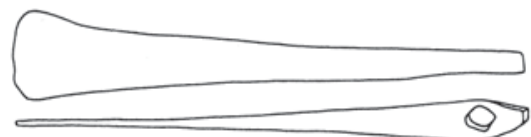

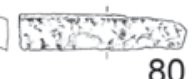

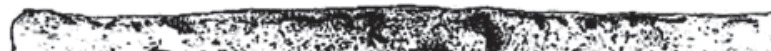

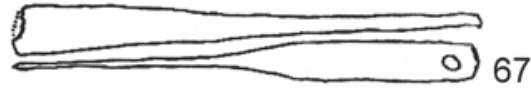

$66 \square\left[\begin{array}{ll}3+3 \\ 61\end{array}\right.$

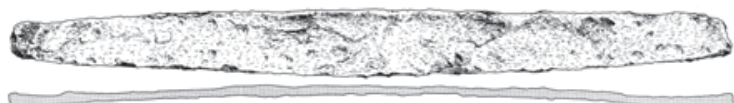

82

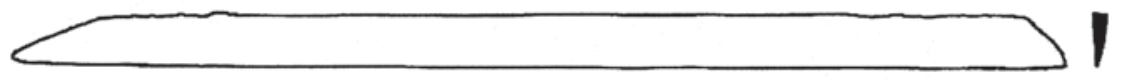

Abb. 33, Teil 3: Typenvariatnen frühmittelalterlicher Eisenbarren. M. 1:6.

Fundorte: $49.50 \mathrm{Helgö/S;} 51$ Ardal/S; 52 Skedstad/S; 53.54 .61 Norwegen (verschiedene Fundorte; 53: Beil oder Barren?); 55-58.62.65-68 Kraków/PLKanonyczastrasse; 59.60.63.64 Břeclav-Pohansko/CZ; 69 Přerov-Prerau/CZ; 70.71.73.74.75.76.77.78.79.84.86.87 Haithabu/D-Hedeby; 72 Vel'ký Kližz, Slowakei; 80-83 Helgö/S; 85 Mästermyr/S; 88 Olsborg/D; 89 Fagerhult/S. Quellen siehe Abbildungsnachweise. 


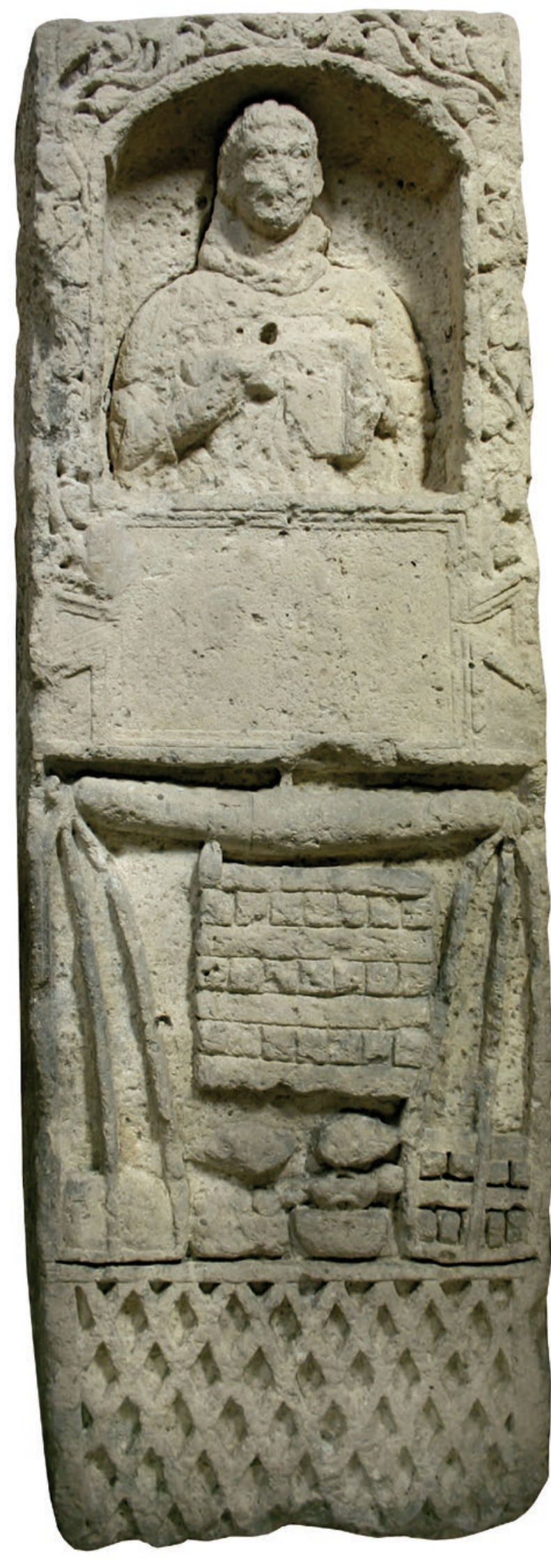

Abb. 34: Augst/BL, Augusta Raurica. Grabstele eines Eisenhändlers mit Waage und Eisenbarren (das Inschriftfeld in der Mitte ist nicht beschriftet). Zwischen den beiden Waagschalen unten liegen eindeutige doppelpyramidenförmige Spitzbarren. Die anderen, auf der Waagschale rechts und im Stapel im Hintergrund dargestellten Barren sind vermutlich lange Stabbarren (analog Abb. 46). Höhe 2,22 m.
Eine Eigenart mancher Barrentypen ist, dass sie - zu verschiedenen Zeiten! - in Form stilisierter Geräte oder Waffen hergestellt wurden. Typische Beispiele hierfür sind etwa die unten angeführten eisenzeitlichen «currency bars» mit tüllenartigem Ende (Abb.33,10-14) oder die frühmittelalterlichen «Axtbarren» (Abb.33,53-69). Die Hintergründe dieses Phänomens sind bis jetzt ungeklärt, doch Radomír Pleiner machte sich seine Gedanken darüber ${ }^{380}$ : «The circulation of blanks in the form of stylized implements is a remarkable phenomenon in the economy of materials. It signalizes a transitional period at the dawn of the largescale production of iron in different times and areas during which the role of these intermediate products appeared to swing between a starting material for smiths and object of trade up to a means of exchange and even premonetary currency.»

Auf die bis jetzt einzigen bekannten, durch Zementation erzeugten Stahlbarren, die schlanken sog. «barres à douille» (BAD1; Abb.33,15-17), ist schon oben eingegangen worden (mit Anm. 169).

\section{Handel mit Eisenbarren ${ }^{381}$}

Eine eindrückliche ikonographische Bildquelle ist ein Mosaik aus der Mitte des 3.Jahrhunderts n.Chr. aus Sousse / TUN (Abb. 35) ${ }^{382}$. Es zeigt ein Schiff am Hafen, von dem rechts zwei fast nackte Träger - offensichtlich ziemlich schwere - Stangen löschen und an Land tragen. Links im Bild stehen zwei ordentlich gekleidete Männer an einer grossen Waage und wiegen die Schiffsfracht. Die langen schlanken, im Mosaik braungelb dargestellten Stangen sind aufgrund ihrer Grösse und des zu vermutenden Gewichtes Metallbarren. Dargestellt sind eher Eisenbarren als ursprünglich vermutet Bleibarren, denn die wären gedrungener, grau und fast zu schwer für einen Träger alleine. Das Mosaik aus Tunesien illustriert sehr schön den Fernhandel mit Eisenbarren - am ehesten des Typs von SaintesMaries-de-la-Mer/F (Abb. 46) - auf dem Wasserweg. Zahlreiche uniforme Serien von Eisenbarren - sie können 16 bis 4200 Exemplare enthalten - fanden sich in eisenzeitlichen wie auch in römischen Depotfunden. Meist liegen sie ausserhalb von Siedlungen und Schmiedewerkstätten, was die Forschung entweder als Handelsware oder als Ritualdeponierung interpretierte. Jedenfalls zeugen solche Depots ebenfalls von weiträumigen Handelsbewegungen mit Rohmaterial resp. Halbfabrikaten für die Eisenverarbeitung.

380 Pleiner 2006, 50 .

381 Zum Eisenhandel generell: Feugère/Serneels 1998. - Siehe auch die Verbreitungkarten unten Abb. 40, 42 und 44 mit den Hinweisen auf ältere Verbreitungskarten in den Anmerkungen.

382 Zum Mosaik von Sousse: Dunbabin 1978, 270 Taf. 58,121 («... men carrying bars of lead off ship»); Fantar 1994, Farbtafel Seiten 115118 (= unsere Abb. 35); Feugère/Serneels 1998, 257 Abb. 7 («barres longues d'environ une mètre ...»). 


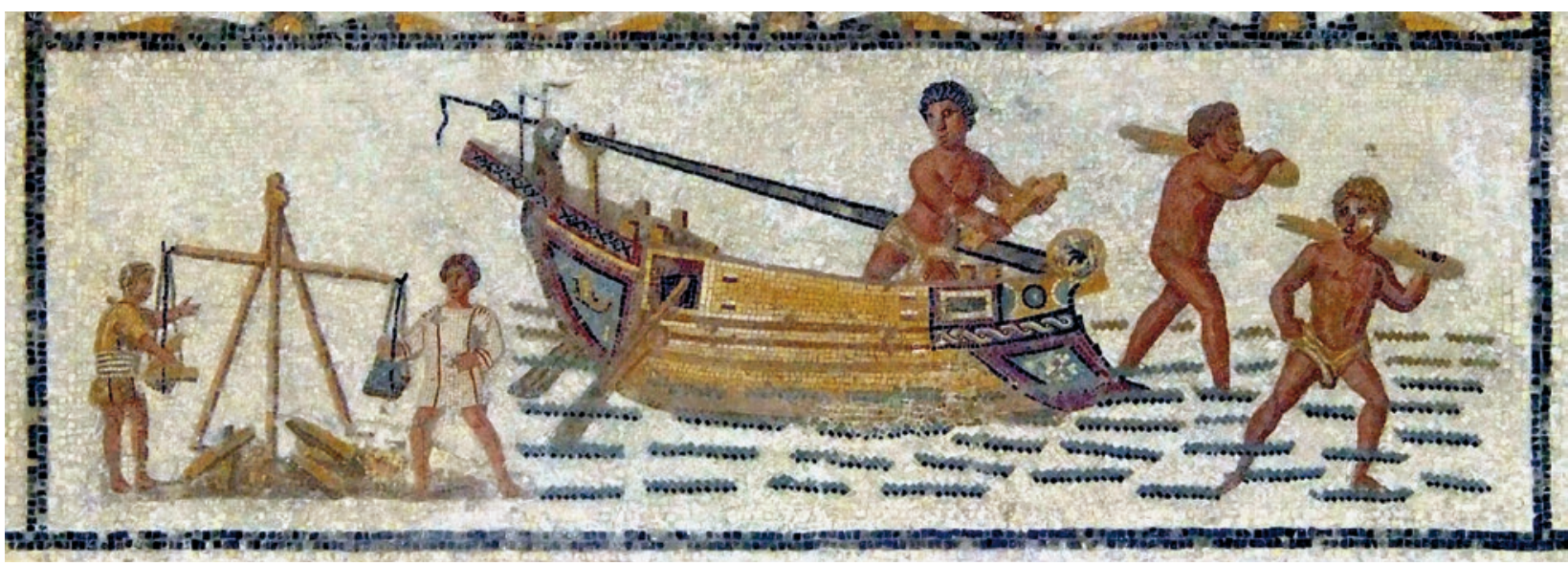

Abb. 35: Sousse / TUN-Hadrumetum. Mosaik mit Darstellung eines römischen Transportschiffes beim Entladen der Fracht im Hafen. Zwei Männer tragen rechts schwere Stangen an Land, und links werden die Stücke gewogen (ähnlich wie auf Abb. 34). Die etwa beinlangen Stangen wurden schon als Bleibarren interpretiert, was bei vorherrschenden Gewichten um 70-90 kg schwer vorstellbar ist. Die dargestellte gelöschte Ladung könnte daher auch aus eisernen Stangenbarren bestehen. Grösse $90 \times 230 \mathrm{~cm}$, Mitte 3. Jahrhundert.

\section{Halbfabrikate}

Lange beschränkte sich die «Eisenbarrenforschung» auf Typologie und Chronologie, «since they have often been discovered outside of datable contexts, or because their discovery is old and poorly documented ${ }^{383}$. Die erst in den letzten Jahren erkannten inneren Gefüge und heterogen verteilten Kohlenstoffgehalte all dieser Eisenbarren zeigen, dass wir es damit nicht mit «normalem» Roheisen direkt ab Verhüttungsplatz zu tun haben, sondern mit eigentlichen Halbfabrikaten ${ }^{384}$ : «Il s'agit toutefois d'une forme d'échange du fer très peu attestée, en raison de l'absence quasi-générale de masses brutes de réduction conservées pour cette période. La diversité des signatures chimiques constatée au sein du lot étudié indiquerait que les artisans acquéraient leur matière première brute auprès de réseaux d'échanges variés. La mise en forme finale de ces produits aurait alors pu être effectuée au sein d'un atelier ou d'un ensemble d'ateliers de forgeage. ... La formation de certains demi-produits à partir de plusieurs masses de métal différenciées permet également d'envisager l'acquisition de portions de métal de volume variable, transformées ultérieurement de façon à se conformer à un standard métrologique.»

\section{Doppelpyramidenförmige Spitzbarren}

Die bekannteste antike Barrenform ist der doppelkonische Spitzbarren (Abb.36; s. auch Abb.5). Sie gehören zu den schwersten Eisenbarren überhaupt ${ }^{385}$. Ihre Grösse ist durch Zusammenschweissen mehrerer ausgeheizter Luppenteile entstanden. Je nach Erhaltung und Korrosion sind bei einigen Funden entsprechende Schweissnähte von Auge gut zu erkennen. Aimé Thouvenin hat sich ausführlich mit dem Grobschmieden solcher Spitzbarren beschäftigt und schreibt zu diesem Vorgehen ${ }^{386}$ : «Lorsque les éléments ferreux sont rassemblés et que l'on homogénise, avant de former le lingot final.»

Die auffallende Form der Spitzbarren, die ein bequemes Stapeln auf den ersten Blick kaum zulässt ${ }^{387}$, hat offenbar einen schmiedetechnischen Grund, der bei allen anderen Barrenformen keine Rolle für die äussere Barrenform mehr gespielt hat. Heinrich Hanemann beschreibt die Grundlagen und praktischen Erfahrungen, die zur Spitzbarrenform geführt haben, treffend ${ }^{388}$ : «Der Befund [an einem Barren von Rheinhausen /D] zeigt zweifellos, dass damals eine gute Schmiedbarkeit, die wichtigste technische Eigenschaft, noch nicht ohne weiteres als selbstverständlich von jedem Barren erwartet werden konnte. Dies gibt einen Fingerzeig zur Erklärung der eigentümlichen zugespitzten Form. Wenn eine Luppe zu einer Spitze ausgeschmiedet ist, so liegt hierin der unmittelbare Beweis für ihre Schmiedbarkeit und somit für die Güte der Ware. Dazu kommt noch eine andere in der Art der Verarbeitung liegende Ursache für die Form. Wenn man einen Barren ausschmiedet, muss man ihn fest mit der Zange halten. Das geht am besten,

383 Berranger / Fluzin 2012, 677

384 Berranger et al. 2017A, $62 \mathrm{f}$.

385 Allen 1967, 314f.; 317 f. Taf. 33,E; Jacobi 1974, 249; Drescher 1976, 67 f. Abb. 19; 20,a-d; von Kaenel 1981, Abb. 5; Senn Bischofberger 2005, 15-17; Pleiner 2006, 30; Berranger / Fluzin 2012, 668 («At a microscopic scale, they show deep cracks»).

386 Thouvenin 1984, Abb. 1-4 (S. 371: Zitat).

387 Mutz 1981, Abb. 1-2 («Die gebündelten [16] Barren sind mit einem 8 Meter langen Seil zu einem festen Block zusammengezogen.» Dies ist allerdings nur mit «in die Lücken eingeschobenen Holzleisten» zu erreichen). - Mit der Bündelung und Schnürung doppelkonischer Spitzbarren für den Transport (z.B.auf Tierrücken) hat sich schon früh Christian Mehlis auseinandergesetzt: Mehlis 1915,118 .

388 Hanemann 1930, 273f. 


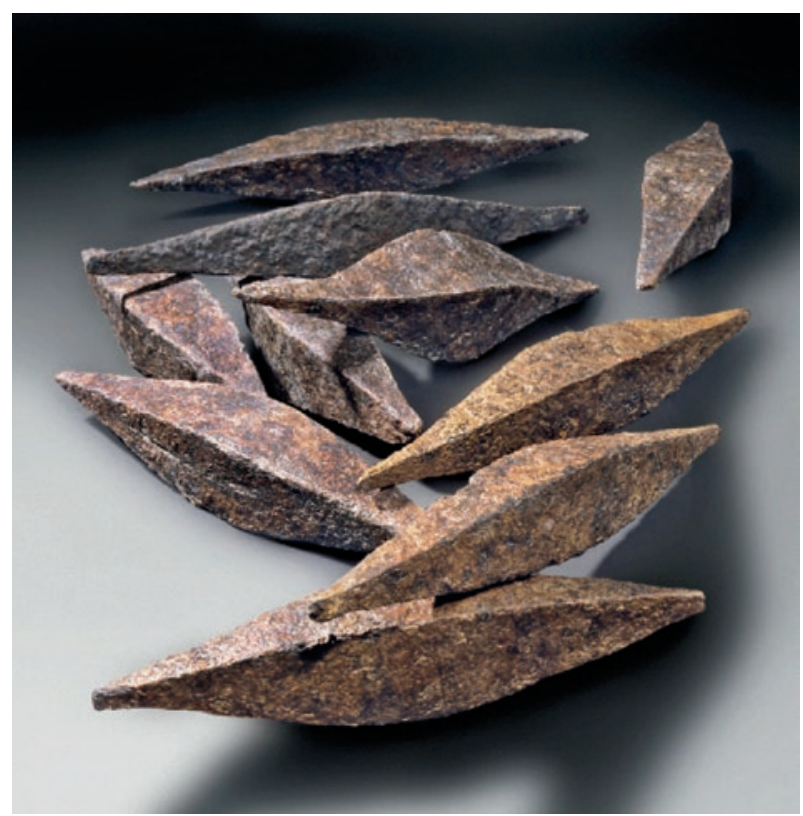

Abb. 36: Ensemble verschiedener keltischer Spitzbarren aus Eisen, gefunden in Pleidelsheim $/ D$, oberhalb des rechten Neckarufers. Jeder Barren wiegt ca. 4,5 bis $5 \mathrm{~kg}$.

wenn man den Barren an einer Stelle zu einer Spitze verjüngt hat. Man fasst die Spitze mit der Zange an und kann den übrigen Teil nach Belieben bearbeiten. Wenn dabei Gegenstände wie Messer, Speerspitzen, Nadeln und dergleichen hergestellt werden sollen, wird man zunächst so viel von dem Barren, wie für die Herstellung dieser Gegenstände nötig ist, auf entsprechend kleineren Querschnitt ausschmieden und dann abtrennen. Das Ausschmieden geschieht an dem Ende des Barrens, das der mit der Zange gefassten Spitze entgegengesetzt ist, und geht so vor sich, dass auch hier der Barren zunächst zu einer Spitze verjüngt und dann in der Nähe der Spitze zu gleichmässigem Querschnitt ausgeschmiedet wird. Wenn dann das ausgeschmiedete Teil abgetrennt wird, so hat das Ende des Barrens, von dem abgeschmiedet ist, eine zugespitzte Form, sodass nunmehr der Typus eines Spitzbarrens mit zwei sich gegenüberstehenden Spitzen entstanden ist.»

\section{Archäometrie}

Diese praktischen Überlegungen decken sich mit den archäometrischen Befunden. So hat ein Spitzbarren aus Ay bei Neu-Ulm/D eine besonders gut ausgeschmiedete Eisenqualität in seinen extrem lang ausgeschmiedeten Enden, während er im dicken Kern zerklüftet wie die meisten anderen Spitzbarren ist: «Die Barren enthalten besonders in dem dickeren Teil viele grosse Hohlräume und Einschlüsse, die zum Teil aus Schlacken, zum Teil aus nicht vollständig reduzierten Erzstücken bestehen mögen. Nur in den stärker ausgeschmiedeten Enden ... ist das Eisen einigermassen dicht geworden.» 389

Interessante archäometrische Befunde an Spitzbarren konnten in jüngster Zeit durch Marion Beranger und Mit- autoren/-innen dokumentiert werden ${ }^{390}$, ganz ähnlich wie an den Barren aus den südfranzösischen Schiffswracks (Abb. 45 und 46): Die untersuchten Barren aus Durrenentzen/F weisen sehr heterogene Strukturen auf (Abb.37), ähnlich der dünnen Stangenbarren aus Saintes-Maries-dela-Mer (Abb. 45). Andere doppelkonische Spitzbarren sind bisher erst in Einzelfällen archäometrisch untersucht ${ }^{391}$. Auch die Durrenentzen-Barren sind aus kohlenstoffarmen und -reicheren Teilstücken zusammengeschweisst und alles andere als homogene Eisen- oder Stahlbarren. Durch das Zusammenschweissen unterschiedlicher Einzelteile lassen sich im selben Barren Zonen von 0,2\% C von anderen Bereichen mit 0,2-0,6\% C oder gar 0,7-0,8\% C unterscheiden (Abb. 37).

Spitzbarren weisen in der Regel mikroskopische Hohlräume und viele Verunreinigungen auf, vor allem von eingeschlossenen Schlacken und Holzkohlen (vgl. Abb. 32) 392 $^{2}$ Bereits Albert France-Lanord konnte das deutlich aufzeigen und hatte mit seinen Analysen eines eisenzeitlichen Spitzbarrens von 5,2 kg Gewicht vom Mont Lassois/F (Abb.38) erkannt, dass «le métal a été fortement surchauffée et refroidi lentement». Das von ihm untersuchte Exemplar zeigte zwar keine Schweissnähte, doch die Heterogenität des Gefüges interpretierte er so, dass diese Barren «avaient pu être formés de l'assemblage de masses de fer brut, récoltées dans plusieurs fourneaux et réunies» ${ }^{393}$. Die Heterogenität zeigte sich sowohl in den besonders häufigen Schlackeneinschlüssen als auch durch die an verschiedenen Stellen gemessenen Härten des Mont-Lassois-Barrens $^{394}$ : Sie schwanken sehr stark (Abb.38), was auf sehr ungleich verteilten Kohlenstoff zurückzuführen ist. Mit durchschnittlich 0,15\% Kohlenstoff und 0,66\% Phosphor liegt die Zusammensetzung nahe bei den «currency bars» (s. unten). Der zweite von A. France-Lanord untersuchte Spitzbarren, 6,45 kg schwer und gefunden in Strassburg / F, enthält kaum Kohlenstoff und Phosphor, besteht aus noch stärker zerklüftetem Material mit einer «extrème abondance de scories» ${ }^{395}$ und gehört damit zu einer noch minderen Qualität.

Radomír Pleiner fasst die inzwischen durchgeführten Untersuchungen wie folgt zusammen ${ }^{396}$ : «Metallographic

389 Rädeker / Naumann 1961, 588 Abb. 2; 6-9 (mit Schnittbildern).

390 Berranger et al. 2017A, bes. 60; Berranger et al. 2017B, Abb. 6; Bauvais et al. 2018.

391 Hanemann 1930; Fry 1952; Rädeker/Naumann 1961; France-Lanord 1963; Zwicker 1967; Delamare et al. 1982.

392 Fry 1952, 50; Berranger / Fluzin 2012, 668.

393 Rädeker/Naumann 1961, 593; France-Lanord 1963, 168-171 Abb. 1-9 (Zitat S. 170). - Pleiner 2002, 28, erwähnt, dass die beiden Barren vom Mont Lassois / F und aus Strassburg / F «heterogenously carburized» waren.

394 So auch Rädeker / Naumann 1961, 592.

395 France-Lanord 1963, 171-173 Abb. 10-13; 22.

396 Pleiner 2006, 30. 

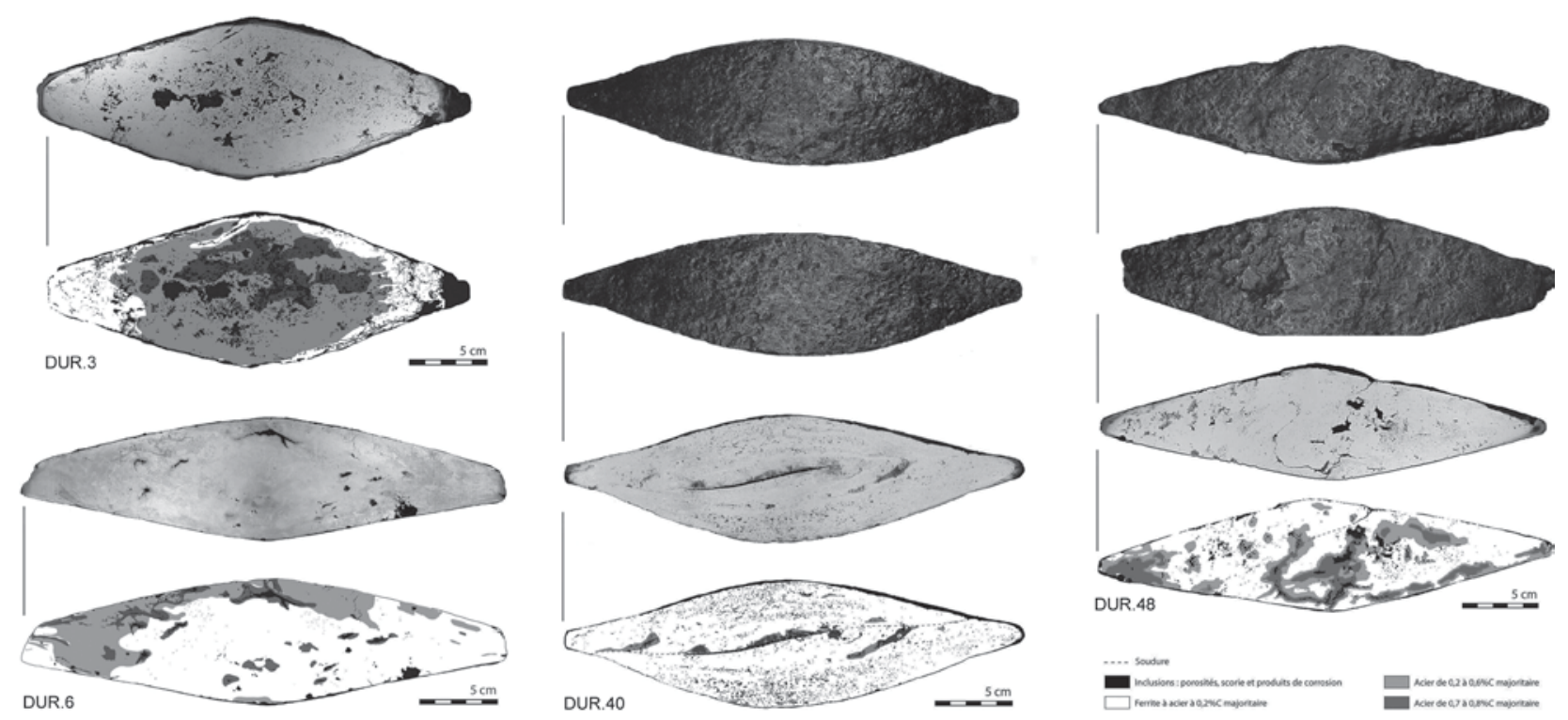

Abb. 37: Vier (von insgesamt 51) Spitzbarren aus dem eisenzeitlichen Depotfund von Durrenentzen/F. M. 1:6.

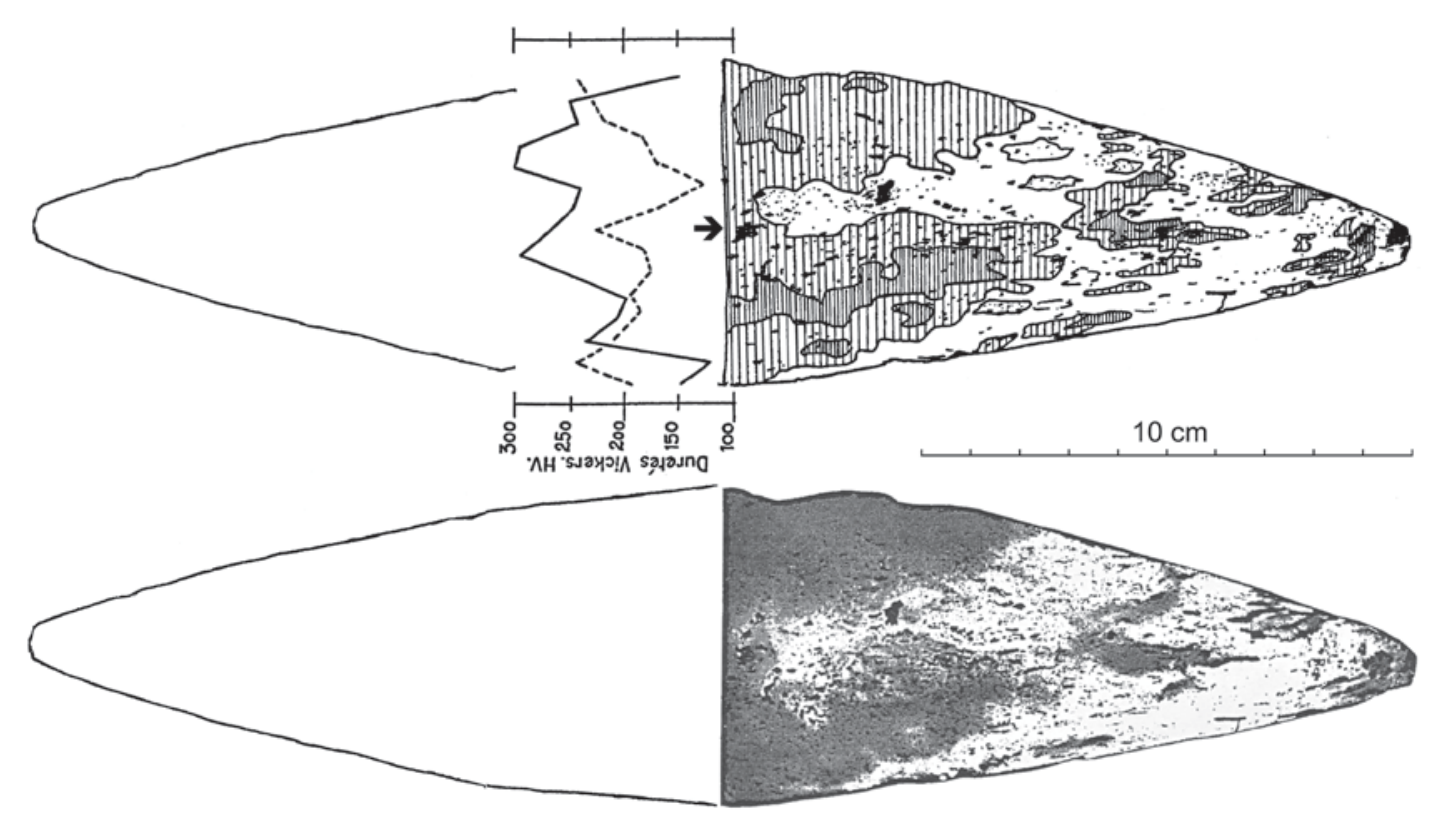

Abb. 38: Der doppelkonische Spitzbarren vom Mont Lassois / F im Schnitt. Oben rechts Interpretation, unten rechts geätzter Längsschnitt, oben Mitte der Verlauf der Vickers-Härte quer durch den Barren: Die gestrichelte Linie zeigt den Härteverlauf in der Barrenmitte, die durchgezogene Linie entlang der Peripherie mit besonders grossen Härten in der Nähe der vielen Schlackeneinschlüsse. M. 1:2. 
analyses of bars from Renningen, Kaisheim, Ay, Steinburg and Touffreville show not only that the metal was heterogeneously carburized during the bloomery process $(0,05 \%$ up to $0,5 \%$, and even up to $1,3 \% \mathrm{C}$ ) but also that the bars were each welded together from several blooms - some of the welding seams even appear on the ingot surface, others on polished sections where considerable segregation of phosphorus may be observed.»

Zusammenfassend ist festzustellen, dass die «innere» Materialbeschaffenheit der formal so homogen erscheinenden Doppelspitzbarren äusserst unterschiedlich sein kann! Die Form gibt demzufolge keine Hinweise auf die Eisenqualität dieser Spitzbarren ${ }^{397}$. Ich möchte die Aufbereitungsqualität dieser schweren Barren in drei Kategorien unterteilen:

1. Nur wenig aufbereiteter Ofenschwamm, der zwar zu einem metallischen Barren von schlechter Qualität ausgeschmiedet ist, jedoch noch viele Schlackeneinschlüsse und vor allem offene Poren und Hohlräume aufweist. Sehr heterogen im Gefüge. Beispiel: Einzelfund aus Frankreich (Abb.39), Barren aus Strassburg / F ${ }^{398}$ und Stahlbarren aus Rheinhausen / D 399 .

2. Ein etwas intensiver ausgeheizter Werkstoff, der jedoch immer noch in «grösseren und kleineren Nestern gelagerte Schlacken» sowie Löcher enthält, weil er ebenfalls «nur unvollkommen durchgeschmiedet wurde». Diese Barrenqualität kann aus Bereichen mit stellenweise $0,1-0,8 \%$ Kohlenstoff bestehen, also eine gewisse Stahlqualität aufweisen, auch wenn das heterogene Material noch weiter homogenisiert werden müsste. Beispiel: Einzelfund vom Mont Lassois / F (Abb. 38) (00 $^{40}$ und die Barrenhorte von Sauggart/ $\mathrm{D}^{401}$ und Renningen $/ \mathrm{D}^{402}$.

3. Sehr sorgfältig ausgeheizt und dadurch nur wenige Schlacken- und Holzkohleeinschlüsse, bisweilen aus Einzelstücken zusammengeschweisst, aber dann durch gutes Ausschmieden relativ homogenisiert. Die Kohlenstoffverteilung kann dennoch sehr heterogen sein; von Stahl kann jedoch nicht gesprochen werden. Beispiel: der Barrenhort von Durrenentzen/F (Abb. 37).

\section{Herstellung}

Untersuchungen an einem anderen Spitzbarren aus Frankreich ergaben einen aufschlussreichen Befund bezüglich seiner Herstellung (Abb.39). Die zahlreichen Schlackeneinschlüsse und vor allem die offenen Poren und Hohlräume des wenig ausgeheizten Rohlings finden sich vor allem im Zentrum; die äusseren, Ferrit-dominierten Zonen sind viel reiner: «Les extrémités subissent, elles, une très forte déformation: les trous sont refermés et les scories presque totalement éliminées vers la surface.» Die Autoren interpretieren dies einleuchtend damit, dass beim Ausschmieden des Barrens der Hammer vor allem in den ober- flächennahen Zonen eine Kompaktierung des Eisens bewirkte, während Schlackeneinschlüsse und Hohlräume im Kern des Barrens kaum die Chance hatten, ausgequetscht zu werden ${ }^{403}$. Um ein besseres, reineres Resultat zu erhalten, hätten dünnere Rohlinge ausgeheizt werden müssen und danach zu massiven Barren zusammengeschweisst werden müssen (Abb. 37,DUR40.DUR48).

Die erwähnten Schweissnähte ${ }^{404}$ zeigen, dass viele Spitzbarren aus mehreren Teilen zusammengesetzt sind. Kürzlich ist es sogar gelungen, archäometrisch nachzuweisen, dass einige Barren aus Teilen unterschiedlicher Erzvorkommen zusammengesetzt sind ${ }^{405}$. Das unerwartete, erstaunliche Resultat interpretieren die Autoren dahingehend, dass «many actors were involved at different stages of the chaîne-opératoire creating a complex network of exchange. Indeed, some of the semi-products are constituted of two parts of the same origin ... On the contrary, [other] semi-products ... were made from two parts of different origins welded together. This latter observation implies a segmentation of the chaine-opératoire with intermediary centres where crude masses of iron or raw intermediary products are assembled to form the bipyramidal semi-products.»

\section{Grösse und Datierung}

Die 51 doppelkonischen Spitzbarren aus Durrenentzen im Elsass wiegen 5,5-6,9 kg, sind 21,5-33,1 cm lang und gehören auf Grund der ${ }^{14} \mathrm{C}$-Analysen ihrer Kohlenstoffspuren in die eisenzeitliche Phase Hallstatt D / Latène A (um 630-400 v. Chr.; Abb. 37) ${ }^{406}$. Letztere kommen aber auch noch viel später, bis in römische Zeit ${ }^{407}$, vor und sind wohl die häu-

397 Drescher 1976, 67 («Äussere Merkmale, die auf die Art des Materials schliessen lassen, gibt es nicht»).

398 Siehe oben mit Anm. 395

399 Hanemann 1930 (der Barren besteht zwar aus Stahl mit 0,44\% C, ist aber «ausserordentlich schwefelrein» und sein «Phosphorgehalt ... niedrig», weshalb er überhaupt einigermassen bearbeitet werden kann. Beim experimentellen Schmieden des «antiken» Stahls in mehrere Messerklingen erwies er sich als schlecht verformbares Material, in dem sich grosse und tiefe Schmiederisse bildeten und «grosse Schlackeneinschlüsse» gut zu erkennen waren.).

400 Siehe oben mit Anm. 393.

401 Fry 1952. - Zum Fund des Hortes mit 24 (28?) Doppelspitzbarren und zu den Barrengrössen: Paret 1935 (Längen meist 30-50 cm; Gewicht $\varnothing 6,44 \mathrm{~kg})$.

402 Zwicker 1967 (17 Doppelspitzbarren, 1 Stück metallurgisch untersucht).

403 Delamare et al. 1982, 103 Abb. 2-4 (= unsere Abb. 39).

404 Siehe oben mit Anm. 386 und unten mit Anm. 416.

405 Dillmann et al. 2017, 117-120 (Zitat: S. 120).

406 Berranger et al. 2017A, 47 f. Abb. 2 und 3; 59f. Abb. 11 Tab. 3.

407 Kleemann 1966, 128 f.; Jacobi 1974, 250 Anm. 1123; von Kaenel 1981, 19 Anm. 11-13 («Die Datierung ist im einzelnen noch wenig erforscht und vielfach Ermessenssache.»). - Die Schiffsladung von der Carmelküste / IL, cargo a, mit 49 schlanken Spitzbarren $(\varnothing 2 \mathrm{~kg}$ schwer) ist im 12.Jh. n. Chr. gesunken: Galili et al. 2015, Abb.3-4. 

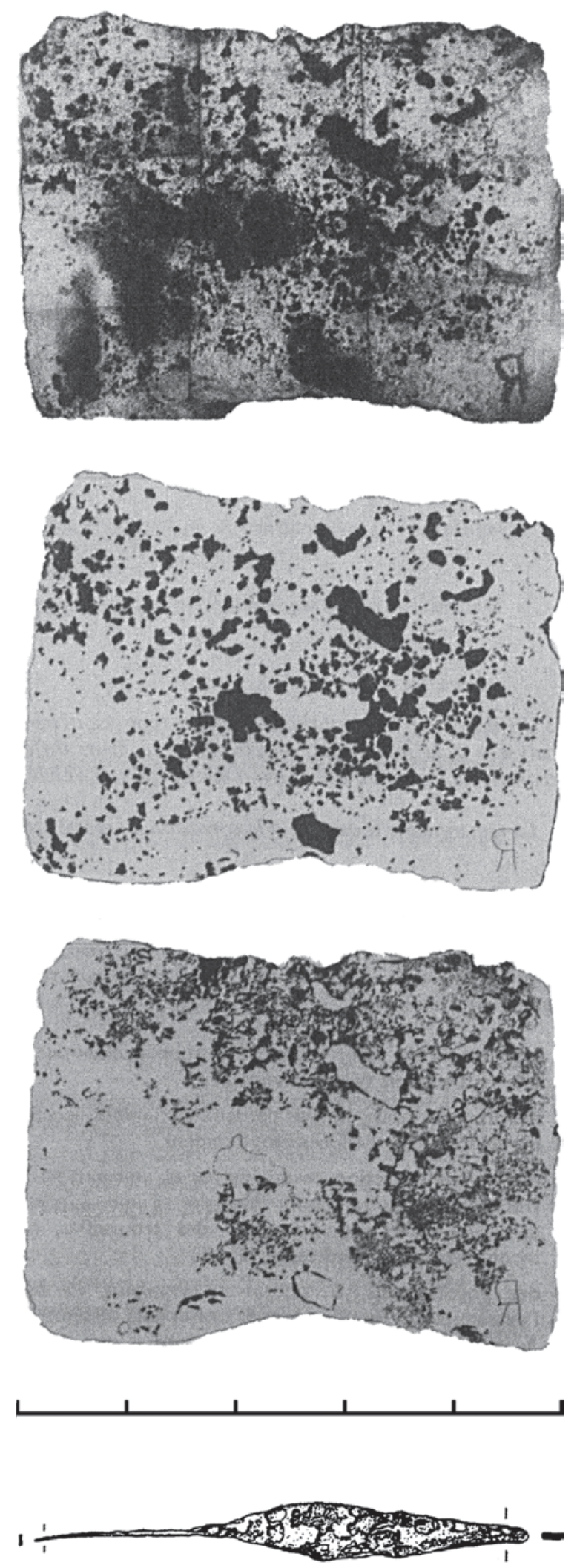

Abb. 39: Die Querschnitte durch einen schlanken Spitzbarren (Abb. 33,6) aus Frankreich (ohne Fundortsangabe) im metallurgischen Schliffbild zeigen deutlich den heterogenen, wenig gereinigten («ausgeheizten») Werkstoff: oben: nach Nitalätzung; helle Zonen = Ferrit/Eisen); Mitte: Hervorhebung der Poren und Löcher in Schwarz; unten: Hervorhebung der Schlackeneinschlüsse in Dunkel. M. 3:2 (Gesamtansicht unten: Länge 397 mm). figsten antiken Eisenbarren überhaupt. Bevor es möglich war, solche Barren über die geringen ${ }^{14} \mathrm{C}$-Einschlüsse naturwissenschaftlich zu datieren, war man auf gute Befunde und Vergesellschaftungen der Barren angewiesen. Weil Eisenbarren generell zumeist einzeln oder in isolierten Horten gefunden werden, sind «Befunddatierungen» selten zu erschliessen. Ein schon früh gewürdigtes Beispiel sind die rund 50 Spitzbarren aus Saint-Connan in der Bretagne/F. Die rund 300 Kilogramm Eisen waren in einer keramikdatierten Siedlung der Latènezeit, möglicherweise als «stock d'un artisan forgeron», vergraben ${ }^{408}$.

Die Formen solcher Spitzbarren variieren nach metallurgischen Kriterien; sie sind sicher nicht chronologisch im Sinne einer typologischen Abfolge zu gliedern ${ }^{409}$. Der einzige chronologische Trend, der an diesen Barren beobachtet werden kann, ist schon 1966 von Otto Kleemann erkannt worden ${ }^{410}$ : «Für viele römerzeitliche Barren ist eine besonders ausgeprägte Form typisch mit geraden, planen Flächen, scharfen Kanten, kurzen Enden ... mit sauber überarbeiteter, fast glatter Oberfläche».

Die Form geht möglicherweise auf bipyramidale Barren des 8. / 7. Jahrhunderts v. Chr. von rund 5-9 kg Gewicht zurück, die aus dem Nahen Osten, zum Beispiel im 160-Tonnen-Hortfund im Palast des Sargon in Khorsabad / IRQ-Dur Scharrukin, bekannt sind (Abb. 33,1.2) ${ }^{411}$. Es gibt am anderen Ende der Zeitachse sogar ikonographische Hinweise, dass sehr grosse doppelpyramidenförmige Barren noch resp. erneut im 17. Jahrhundert hergestellt worden sind ${ }^{412}$.

Nach Marion Berranger und Philippe Fluzin machen die doppelpyramidenförmigen Spitzbarren in der Eisenzeit 99\% der bekannten Barrenfunde aus; über 6800 Exemplare sind gefunden worden. Sie wiegen meist 3-71/2 Kilogramm, können jedoch bis $12,7 \mathrm{~kg}$ erreichen ${ }^{413}$. Ihre Länge beträgt in der Regel $30-86 \mathrm{~cm}$. Sie kann aber bis zu $140 \mathrm{~cm}$ erreichen, wenn ihre Spitzen extrem lang ausgeschmiedet sind (analog Abb. 5; 33,3.4) $)^{414}$.

408 Giot 1964, 52-56 Abb. 2

409 Drescher 1976, 67 («Die Formen zeitlich einzuordnen, ist nicht gelungen»).

410 Kleemann 1966, 130.

411 Forbes 1950, 447 f. Abb. 97; Kleemann 1966, 131; Drescher 1976, 67; Pleiner 2006, 23 f. Abb. 5 und 13. - Ein ähnlicher, $20 \times 6,5 \times 4 \mathrm{~cm}$ messender, $1,77 \mathrm{~kg}$ schwerer und im Zentrum gelochter Doppelspitzbarren aus Karthago/TUN aus dem 4.-3.Jh. v. Chr. bei: Fluzin 2002, 72 Abb. 23 und 26.

412 Forrer 1932, 103 Abb. 1 (Darstellung des Agricola von 1661); von Kaenel 1981, 19.

413 Aus dem äusserst reichen Schrifttum zu den antiken doppelkonischen Spitzbarren beziehe ich mich konkret auf: Jacobi 1974, 248 250 Abb. 57 Taf.76; von Kaenel 1981; Doswald 1994A; Berranger / Fluzin 2012, 668 (Gewichtsspektrum 1-8 kg, im Ausnahmefall 10,6 kg); 680f. Abb. 9; Bofinger/Schmid 2012, 133 Abb. 3 (= unsere Abb. 36).

414 Pleiner 2006, 28. 


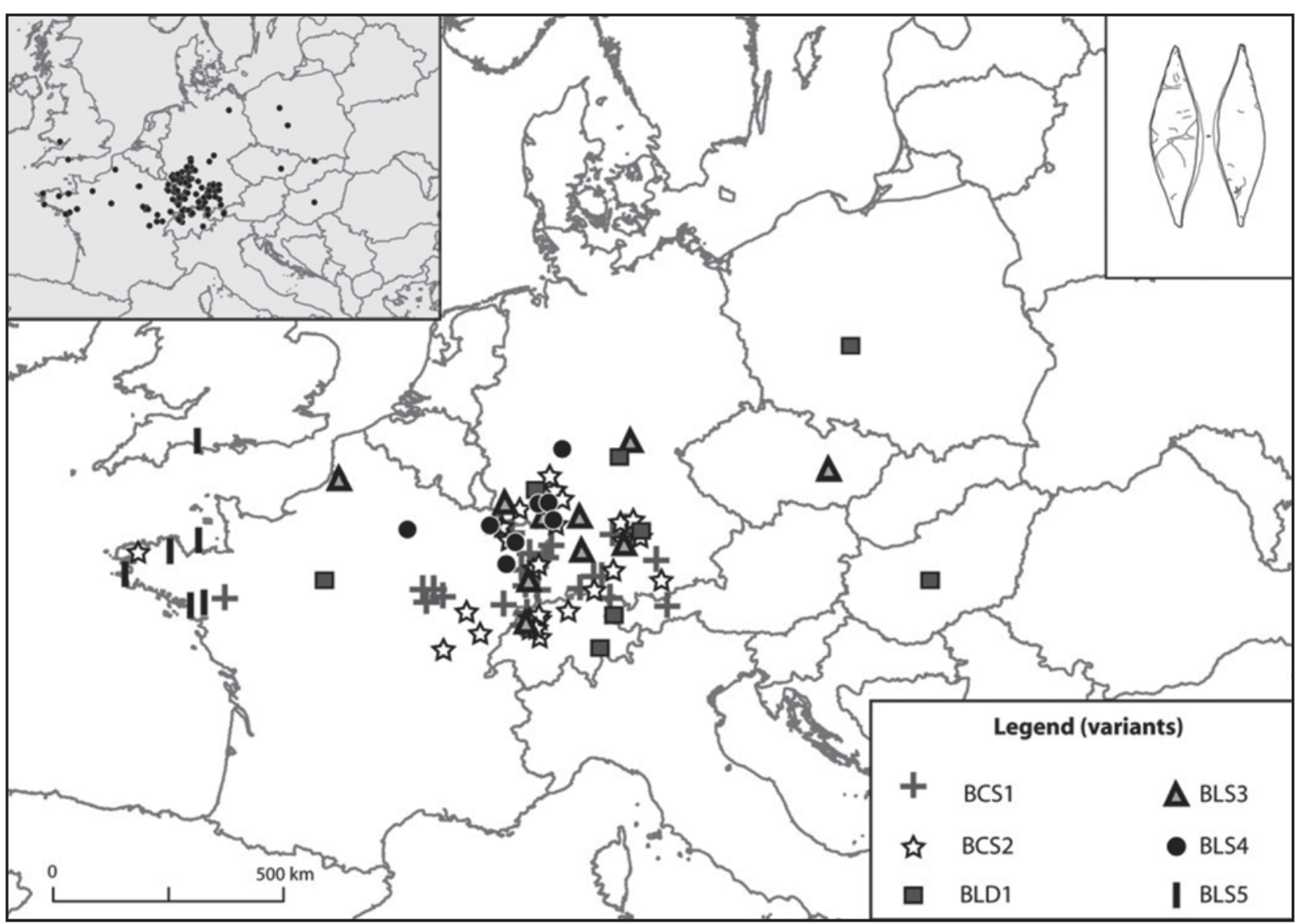

Abb. 40: Verbreitung der doppelkonischen Spitzbarren.

Die beachtlichen Gewichte der «grossen» doppelkonischen Spitzbarren $(\varnothing$ ca. $6 \mathrm{~kg}$ ) weisen eine grosse Streuung auf und richten sich nicht nach antiken «Normgewichten». Albert France-Lanord spekulierte, die grossen Barren seien jeweils das Produkt eines Rennfeuervorganges in einem der kleinen damaligen Verhüttungsöfen ${ }^{415}$. Dies würde die grossen Schwankungen der Barrengewichte erklären. Dem steht jedoch, mit Blick auf die oft erkennbaren Schweissnähte an den Spitzbarren, gegenüber, dass «mehrere Luppen zusammengeschmiedet wurden, da nicht wenige Barren schon äusserlich an langen Fugen erkennen lassen, dass sie aus grossen Teilstücken bestehen» ${ }^{416}$.

Die Frage, wie weit und in welcher Ausgestaltung diese Barren noch in die römische Zeit hinein gebräuchlich waren, hat die Forschung viel beschäftigt. Zur Zeit der Pionierarbeit von Derek Allen war das Problem noch kaum lösbar" ${ }^{417}:$ «... although they are generally believed to be of La Tène date, and in some cases are thought to have Roman associations, their archaeological context has not been finally established».

\section{Verbreitung}

Das Verbreitungsgebiet der doppelkonischen Spitzbarren konzentriert sich auf Mitteleuropa mit wenigen Ausreissern in Osteuropa, Palästina, am Atlantik und in England
(Abb. 40) ${ }^{418}$. Innerhalb Frankreichs fällt auf, dass lange, sehr spitz auslaufende Barren nur im Westen, d.h. in der Bretagne, der Normandie und im Pariser Becken vorkommen, die gedrungenen Spitzbarrenformen jedoch vor allem in Ostfrankreich, in Lothringen, im Elsass und der Franche-Comté419.

Philippe Dillmann und Mitautoren haben zahlreiche hallstattzeitliche Spitzbarren und Eisenlagerstätten im Zentrum des Verbreitungsgebiets, d. h. in Lothringen, im Elsass und in Baden-Württemberg (Abb.40), analysiert. Durch die Kombination von chemischen Spurenanalysen und Osmium-Isotopenanalysen ist es ihnen erstmals gelungen, die Eisenvorkommen zu bestimmen, welche bei der Herstellung ausgewählter Spitzbarren genutzt worden sind. Mehr

415 France-Lanord 1963, 175.

416 Kleemann 1961, 582 (Zitat); Rädeker/Naumann 1961, 595. - Zu den Schweissnähten resp. Teilstücken siehe auch oben mit Anm. 405.

417 Allen 1967, 317

418 Weitere Verbreitungkarten: Kleemann 1961, Abb.1; Giot 1964, Abb. 3; Jacobi 1974, Abb. 57 (Signatur: liegende Rhomben); von Kaenel 1981, 19 Abb.9 (nach Kleemann 1966); Pleiner 1980, Abb. 11.7 (Signaturen 1 und 8); Doswald 1994A, Abb. 4; Berranger et al. 2017B, Abb. 5 .

419 Berranger et al. 2017B, Abb. 5. 


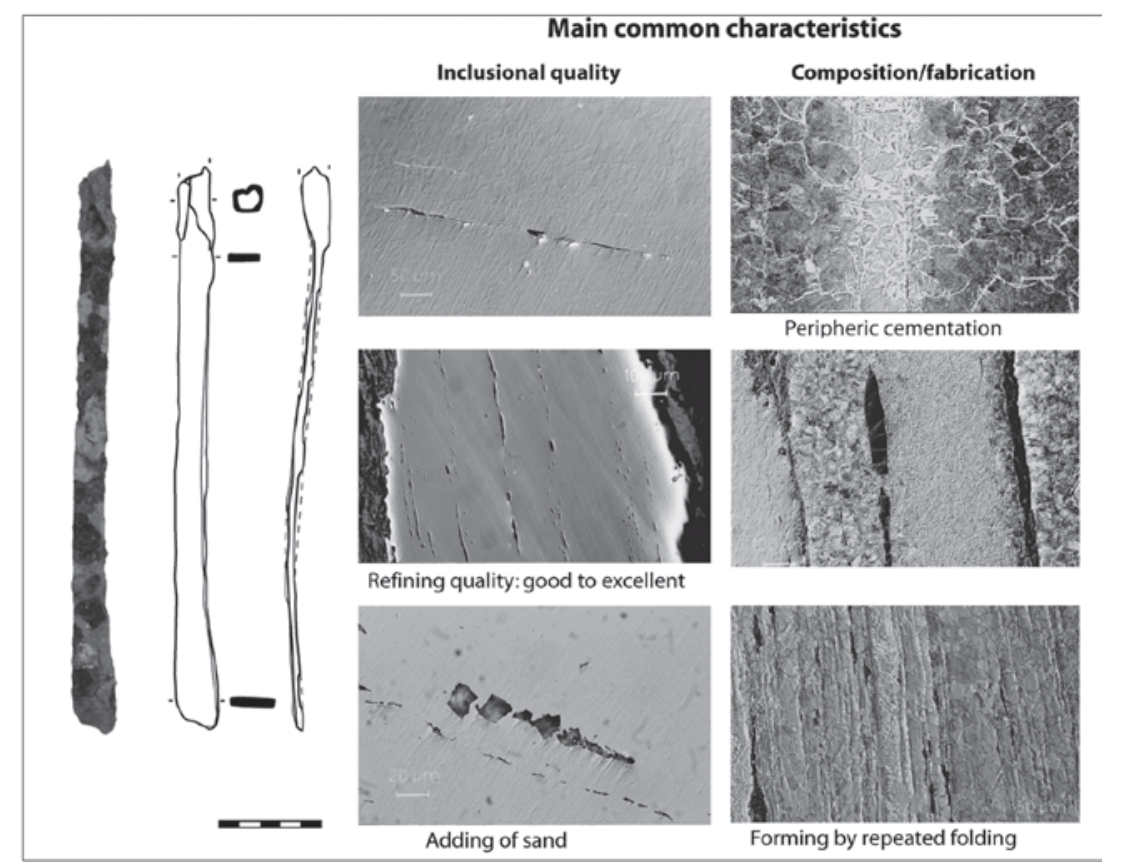

Abb. 41: Ein schlanker «socket bar» aus aufgekohltem Stahl (s. rechts oben), mehrschichtig verschweisst und gut ausgeschmiedet. Beispiel aus St. Maur/F; 2. Jh. v. Chr. Barrenlänge ca. $30 \mathrm{~cm}$. noch: Die Produktionszonen und die dichtesten Fundkonzentrationen der Spitzbarren scheinen mit einer Häufung von «Fürstengräbern» (Wagengräbern) in Zusammenhang zu stehen, auch wenn die Autoren kulturgeschichtlich nicht näher auf dieses Phänomen eingehen ${ }^{420}$.

Wie bei anderen Barrentypen, die bisweilen in Horten deponiert worden sind, ist umstritten, ob es sich bei den schweren doppelkonischen Spitzbarren um Handelsware oder Kultgut handelt (Abb. 36). Hans Drescher vertritt hierzu eine klare Interpretation ${ }^{421}$ : «Die Depots als «Händlerversteck zu deuten, wie es in der älteren Literatur häufig geschieht, ist falsch, da die Niederlegung in sumpfigem oder schwer zugänglichem Gelände gegen den Wunsch, die Stücke wieder zu heben, spricht. Sie werden eher als Opfer (für einen Schmiedegott?) zu betrachten sein ...» Doch schon zuvor hatte Otto Kleemann präziser differenziert ${ }^{422}$ : Die grossen Horte an schlecht zugänglichen Orten seien eher als Weihegaben zu sehen, die Einzelfunde hingegen eher «als kleinen Besitz ..., bei dem man aber eine baldige Zuführung zu einer Werkstatt gut vermuten kann».

\section{Flachbarren mit tüllenartigem Ende ("currency bars»)}

Eine andere Form wird als schmale Stangenbarren, auch als «Schwertbarren» und oft als «currency bars» bezeichnet (resp. «saumons d'épée») ${ }^{423}$. Dies ist jedoch aus heutiger Sicht irreführend ${ }^{424}$; man würde sie heute neutraler als Flacheisen mit einem dünnen, tüllenartigen Ende («pinched socket») bezeichnen. Es wurde wiederholt vermutet, aus solchen Barren seien direkt Schwerter geschmiedet worden ${ }^{425}$. Das wäre allerdings nur mit den phosphor- armen «currency bars» sinnvoll, da die Legierung ansonsten zu spröde wäre ${ }^{426}$.

Diese ganz spezielle Barrenform wurde wiederholt in Untertypen aufgeteilt ${ }^{427}$, jedoch ohne nennenswerte handelsgeschichtliche oder materialkundliche Ergebnisse. Zwei der bekannteren Untergruppen bilden die sog. spiessförmigen («spit-shaped bars») und die pflugscharförmigen Langbarren («plough-share bars») ${ }^{428}$.

420 Dillmann et al. 2017, 109-120 Abb. 2 und 3.

421 Drescher 1976, 67.

422 Kleemann 1966, 132.

423 Zur reichen Literatur über «currency bars» zum Beispiel: FranceLanord 1963, 175-177 Abb. 24-26 (Barren aus La Tène); Allen 1967, 308-310; 315f.; 316f. («saumons d'épée»); 318-335; Jacobi 1974, 251-253 Anm. 1130 Taf.77,1505.1506; Drescher 1976, $68 \mathrm{f}$. Abb. 20,e-h; Hingley 1990 (94: forschungsgeschichtlicher Überblick); Crew/Salter 1993; Crew 1994 (345: forschungsgeschichtlicher Überblick); Crew 1995, 278f.; Martin/Ruffat 1998; Feugère 2000 (mit weiterführender Lit.); Orengo 2003, 185-190 Abb. 5658; Pleiner 2006, 32-37 Abb. 14,6.7; 15; Berranger/Fluzin 2012, 680f. Abb. 9. - Weitere Verbreitungskarten bei: Jacobi 1974, $252 \mathrm{f}$. Abb. 57 (Rechteck- und Kreissignaturen); Pleiner 1980, Abb.11.7 (Signaturen 5-7).

424 Crew 1994, $345 \mathrm{f}$.

425 Berranger / Fluzin 2012, 676

426 Hingley 1990, 93.

427 Zusammengestellt von Pleiner 2006, 33-37 («saumons d'épée», «Wérimont type», «Schwurschwerter» etc.). - Ferner: Feugère 2000; Dieudonné-Glad et al. 2001, 67 f. Abb. 2 («Saône type», «Tiefenau type», «Bearwood type»).

428 Allen 1963, 12 Abb. 2 (Verbreitungskarte England), 310-314 Taf. 31-34 («spit-shaped bars ... extremely narrow and pointed»; «plough-share bars ... long and flat, tapering to a point of sorts»); Cunliffe 2005, Abb.18.10, unten (Verbreitungskarte). - Zu den griechischen «spit-shaped bars» des 9.-5.Jh. v.Chr. (z.T. aus Stahl): Kostoglou 2003, 66f. Abb. 3,a.b. 
Als eine Sonderform der «currency bars» könnte man die leichten, dünnen Streifenbarren mit Tülle («socket bars») bezeichnen. Wir sind bereits oben (mit Anm.168-170) kurz auf sie eingegangen. Sie sind um die $30-40 \mathrm{~cm}$ lang (Abb.33,15-17), treten - allerdings nicht gerade häufig im nördlichen Frankreich auf (Pariser Becken, Normandie) und gehören in die Latènezeit (2.Jh. v. Chr.). Typisch für diese «socket bars» ist, dass sie sekundär aufgekohlt sind, an ihrer Oberfläche also Kohlenstoff angereichert haben und als Stahlbarren zu bezeichnen sind (Abb.41). Philippe Fluzin und Mitautoren charakterisieren diesen Barrentyp wie folgt ${ }^{429}$ : «A new type of semi-product (300 specimens already studied), with the same morphology as the currency bars, but with a lower mass, was also evidenced: socket bars. They are small flat iron pieces with a socket (... average weight: about $100 \mathrm{~g}$ ).» Ihre archäometrische Untersuchung ergab eine ausgezeichnete Reinheit bezüglich Schlackenund anderen Einschlüssen (Abb.41, oben Mitte), eine fein geschichtete Struktur gut verschweisster und ausgehämmerter Lagen (Abb.41, unten rechts) und eine systematische Zementation mit deutlicher Aufkohlung der Oberfläche (Abb.41, oben rechts). Dies mag der Grund sein, dass diese Barren zur optimalen Aufkohlung sehr dünn ausgeschmiedet worden sind.

\section{Archäometrie}

Metallurgische Untersuchungen von «currency bars» wurden erst in jüngerer Zeit durchgeführt ${ }^{430}$. Auch wenn Peter Crew bereits 1994 schreibt, die Analysenergebnisse von «currency bars» «... indicate a strong correlation between the shape of the bars and their metal type» ${ }^{431}$, ist bis heute nicht klar geworden, wie Phosphorgehalt, Kohlenstoffgehalt (Stahl!) und Ausschmiedequalität die Form und Grösse dieser zahlreichen «currency bars» beeinflusst hätten. Typisch für diese Barrenform ist jedoch immer die ausgezeichnete Aufbereitung des Materials zu einem homogenen Eisen mit nur wenig Klüften, Schlacken- und Holzkohleeinschlüssen - also geeignet, um direkt daraus Produkte bester Qualität zu schmieden ${ }^{432}$.

Nebst den Qualitätsmerkmalen dieses in Stabform kursierenden Eisens hat sich die archäometrische Forschung besonders auch auf die Möglichkeiten der Herkunftsbestimmung des Rohmaterials (Erze) konzentriert. Der Schlüssel zur Beantwortung dieser Fragen steckt in den in den «currency bars» eingeschlossenen geringen Schlacken und ihren Spurenelementen ${ }^{433}$. Hierzu sind von der künftigen Forschung mit verbesserten Methoden der Probenentnahmen und Nachweisgrenzen noch spannende Resultate zu erwarten (s. auch Anm. 602).

Kaum typendefinierend ist der Kohlenstoffgehalt der meisten «currency bars». Wie stark sie aufgestählt sind, scheint in der Regel nicht in der Absicht zu liegen, gute Stahlbarren herzustellen, sondern liegt anscheinend in der unterschiedlichen Beschaffenheit des Verhüttungsproduk- tes und des Schmiedeverfahrens: «In short, there was a clear variation of carbon content between the bars and within each bar which depended on the carbon content of the bloom and on the smithing conditions. A given carbon content, that is to say a certain quality of the iron, cannot have been one of the commercial characteristics of these bars.» 434

Offenbar bestehen viele «currency bars» aus phosphorhaltigem Eisen ${ }^{435}$. Die Barren aus dem Hort von Beckford / GB bestehen demgegenüber - ausnahmsweise! - aus Stahl und sind sehr gut ausgeschmiedet ${ }^{436}$. Hier scheint sich eine Korrelation abzuzeichnen zwischen den schwertförmigen «currency bars» mit hohem Phosphorgehalt und den «spit-shaped» Barren mit wenig Phosphor ${ }^{437}$ : «The currency bars were undoubtedly iron stock produced in a size and shape identifiable to the blacksmithing community. The fact that Allen's sword-shaped currency bars are phosphoritic, while the spit-shaped currency bars are low in phosphorus content would suggest that the shape of the bars were varied according to the source from which the iron was smelted. ... Iron Age blacksmiths could then differentiate between the iron of different sources, and perhaps, select a particular iron stock depending on the tool to be manufactured.»

Im Gegensatz zu den doppelkonischen Spitzbarren oder den Hakenbarren sind die «currency bars» so gut ausgeschmiedet («ausgeheizt»), dass sie weder grosse Einschlüsse noch Risse noch Schweissspuren von Auge erkennen las$\operatorname{sen}^{438}$. Als Faustregel bei solchen dünnen Flachbarren kann die Feststellung von Marion Berranger und Philippe Fluzin gelten $^{439}$ : «The flatter the product, the better is the quality of refining.» Solche «currency bars» weisen in der Regel zwar weniger als 0,5\% Kohlenstoff auf, bestehen also nicht aus hochqualitativem Stahl ${ }^{440}$, sie sind aber dank eines gut

429 Fluzin et al. 2012A, 201 Abb. 5 (= unsere Abb. 41).

430 Crew/Salter 1993; Dieudonné-Glad et al. 2001; Paynter 2002; Berranger/Fluzin 2012, 668-675 (an Funden aus Frankreich); Berranger et al. 2017B, Abb. 16.

431 Crew/Salter 1993, 11 («Over twelve types of currency bar are now known from Britain and their different shapes are probably an indication of the metal type and its qualities.»); Crew 1994, 346 (Zitat).

432 France-Lanord 1963, 176 («un produit parfaitement pur et élaboré ... destinés au commerce et à la fabrication de petits outils»).

433 Pionierhaft in der Methodik: Hedges / Salter 1979.

434 Dieudonné-Glad et al. 2001, 71.

435 Hingley 1990, 93; Crew 1994, 346. - Phosphorarme Beispiele: Dieudonné-Glad et al. 2001.

436 Hedges/Salter 1979; Paynter 2002, 17; Crew 1994, 346 und 348.

437 Ehrenreich 1985, 78.

438 France-Lanord 1963, 176; Paynter 2002, 17 («the metal has been worked considerably»); Berranger/Fluzin 2012, 668f. - Ausnahmen mit vielen Schlackeneinschlüssen: Dieudonné-Glad et al. 2001, 69.

439 Berranger/Fluzin 2012, 672.

440 Berranger / Fluzin 2012, 671; 676. 

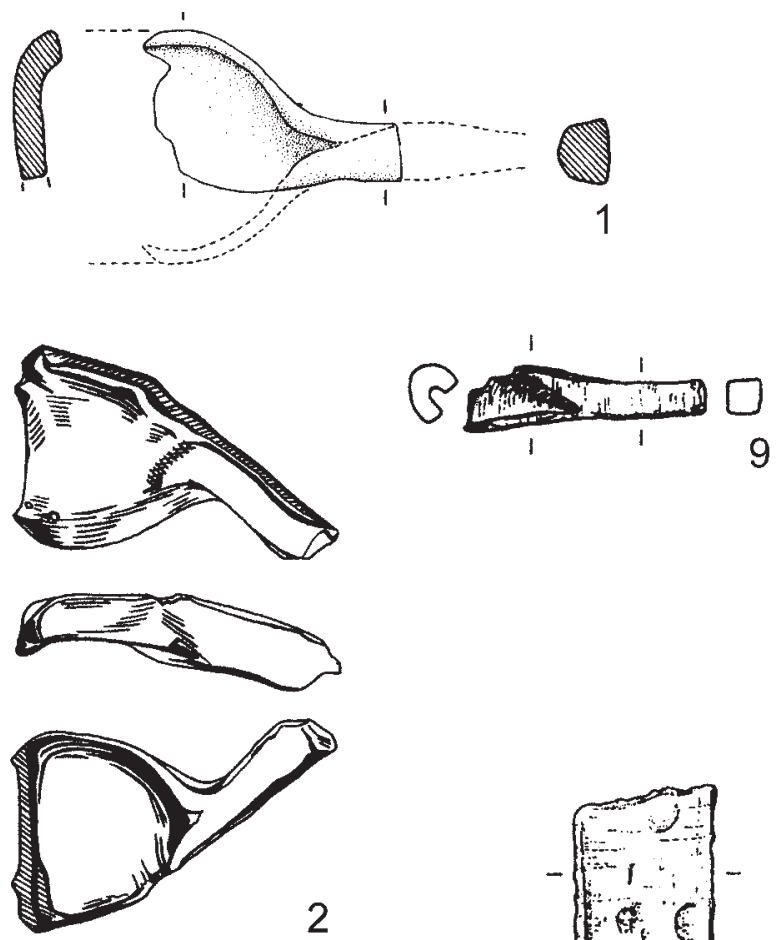

2
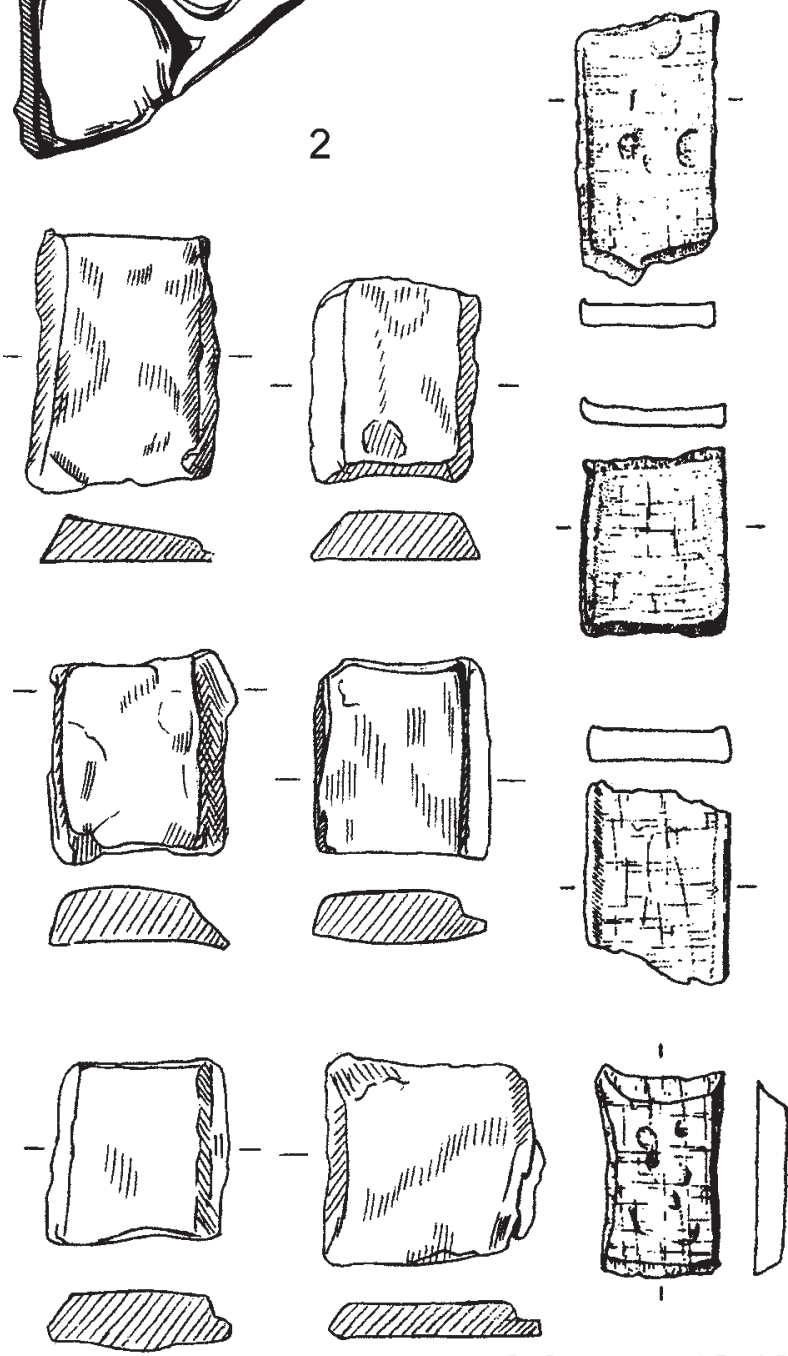

3-8

$10-13$

$10 \mathrm{~cm}$

Abb. 42: Abgeschrotete Segmente von Stabbarren (1-2; «currency bars»), zerlegt zur Weiterverarbeitung in Schmiedewerkstätten. Die rechteckigen Segmente 3-8 weisen zwar ebenfalls Schrotspuren eines Meissels auf, sie sind jedoch nicht eindeutig als Teile von Stabbarren zu erkennen. 1: Aigueperse /F; 2-8: Zurzach/AG; 9-13: Berching/D-Pollanten. M. 1:2. aufbereiteten Eisens ein «first-class material for the fabrication of objects requiring high mechanical properties - weapons and various blades, or tools, the production of which may also have taken place in the same workshops» ${ }^{441}$.

\section{Herstellung}

Mit der Herstellung resp. Rekonstruktion eines «currency bar» hat sich Peter Crew, unterstützt durch den erfahrenen Schmied Heinz Denig, intensiv auseinandergesetzt: von der Erzverhüttung über das Ausheizen der Luppe bis zum Schmieden des Barrens ${ }^{442}$. Das sorgfältige Ausschmieden erforderte etwa 40 «Hitzen», und ab Stadium Luppenverdichtung wurden rund $33 \mathrm{~kg}$ Holzkohle benötigt, für das Schmieden des «fertigen» Eisens allein $15 \mathrm{~kg}$. Das Endprodukt entspricht exakt den originalen Barrenfunden mit Tülle aus England, ist $583 \mathrm{~mm}$ lang und wiegt 0,516 kg.

Peter Crew und Chris Salter kommen andernorts zum Schluss ${ }^{443}$ : «The quantification of these experiments suggests that prehistoric iron was a more expensive commodity than previously appreciated. For each kilogram of finished bar iron about $100 \mathrm{~kg}$ of charcoal and about 25 mandays work were required.» Die Experimente belegen sehr schön: «Qualität hat ihren Preis» resp. erfordert einen grossen Zeitaufwand. Es erstaunt in Kenntnis des Herstellungsaufwandes für Eisenbarren bester Qualität umso mehr, welche riesige Wertschöpfung und welche soziale Leistung in den zahlreichen Weihe- und Verwahrhorten thesauriert worden ist.

\section{Grösse und Datierung}

Die Form und Grösse der «currency bars» schwanken in geringerem Umfang als bei anderen Barrentypen: Sie wiegen üblicherweise $0,4-2,2 \mathrm{~kg}$ und sind $23-85 \mathrm{~cm}$ lang - bei flach-rechteckigem Querschnitt von $4-5 \times 32-45 \mathrm{~mm}$. Es scheint, dass die Typen aus Stahl im Gewicht relativ einheitlich, d.h. ca. 0,6-0,9 kg schwer sind und eine besser definierte Untergruppe darstellen ${ }^{444}$. Dennoch kann man die «currency bars» nicht als «standardized closely by weight» bezeichnen ${ }^{45}$, sondern eher mit Sarah Paynter folgern ${ }^{446}$ : «It is unlikely that the weight was regulated intentionally but rather that it was determined by the smelting and smithing practices of the producer. The dimensions and weights of the bars are therefore likely to be characteristic of the producer.»

441 Crew 1995, 277; Berranger / Fluzin 2012, 677 (Zitat).

442 Crew 1991, 28-35 bes. Abb. 4, unten.

443 Crew/Salter 1993 (Zitat: S. 11).

444 Crew 1994, Abb. 3 («currency bars» in Stahlqualität, Gruppen B Beckford type, C Gretton type und K Coffinswell type).

445 Ehrenreich 1985, 78; Hingley 1990, 94; Dieudonné-Glad et al. 2001, 71 («... can we consider a weight standard for these ingots? It has still to be proven»).

446 Drescher 1976, 68; Paynter 2002, 16 (Zitat). 


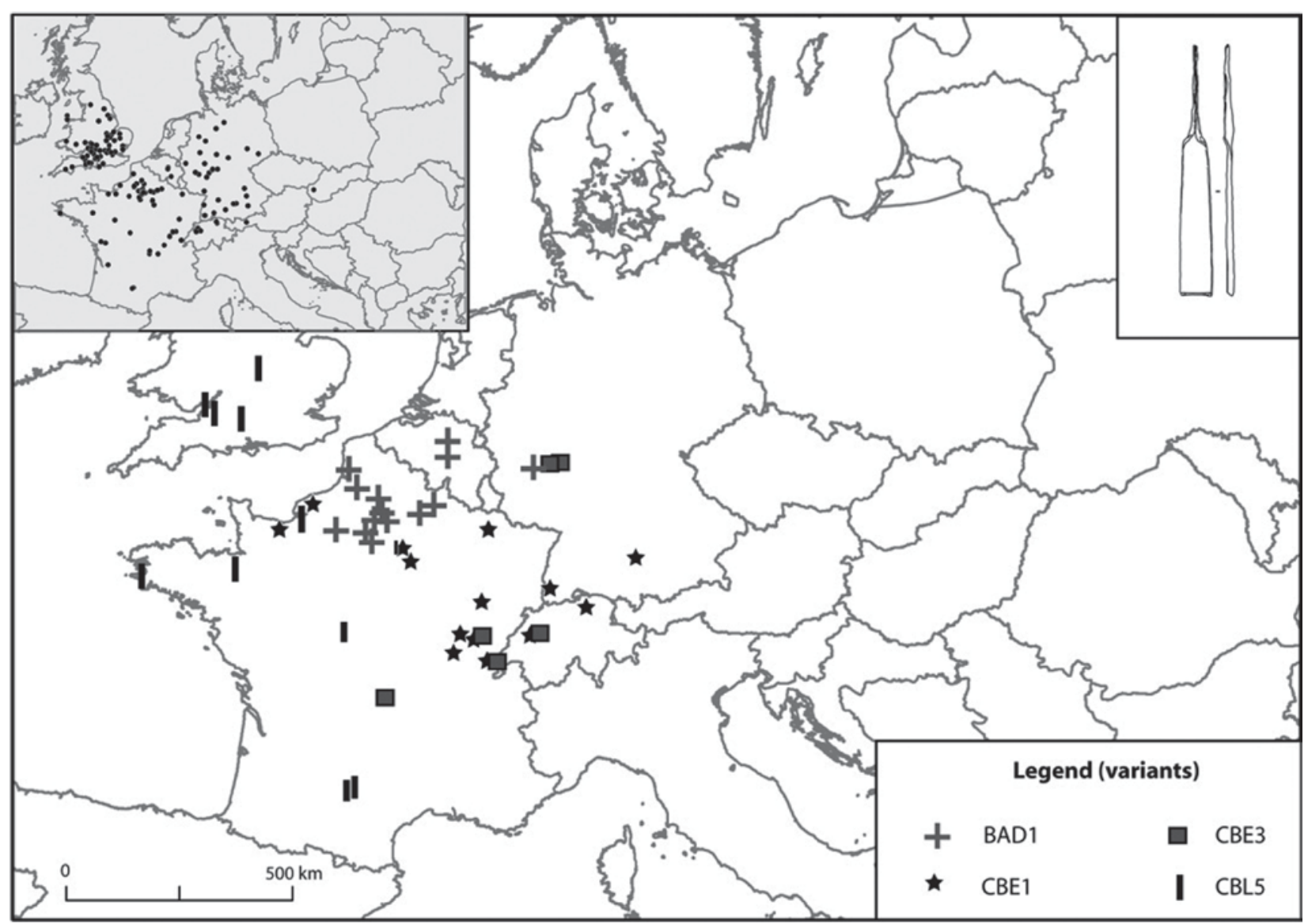

Abb. 43: Verbreitung der geraden Stangenbarren mit tüllenartigen Enden (sog. «currency bars»).

Allein aus England sind heute über 1500 Fundstücke bekannt. Fast 90\% davon stammen nach Peter Crew aus Hortfunden ${ }^{447}$. Der grösste Fundkomplex umfasst 394 Barren und wurde 1824 in Meon Hill bei St. Quentin/GB gefunden ${ }^{448}$. Besonders die grossen Horte wurden, wie oben beschrieben, wegen der Äusserung Caesars (Anm. 14) von vielen Forschern als «Ritualhorte» 449 und weniger als normale Händlerdepots gedeutet. Radomír Pleiner sieht in dieser Hinsicht mit seinem markigen Statement ein grosses wirtschaftliches Problem ${ }^{450}$ : «And why were tons of valuable iron taken out of circulation and use is a question which has little chance of being solved. Ritual reasons cannot be excluded in a world so heavily tainted with cults and superstitions. Possibly, these moments might have lead to economical collapse of a technically prospering society.»

«Currency bars» liegen nicht nur aus vielen Hortfunden vor, sondern sie können durchaus in Siedlungen vorkommen. In Danebury/ GB machten sie sogar ganze 32\% der Eisenfunde aus der Siedlung aus ${ }^{451}$ ! Dass die «currency bars» genannten Barren oft nicht in Depots «verschwunden» sind, sondern in Schmiedewerkstätten gebraucht, mit dem Meissel zerlegt und in kleinere Endprodukte des täglichen Bedarfs umgeschmiedet worden sind, belegen manche mehr oder weniger eindeutige Barrenabschnitte, zum Beispiel aus Zurzach/AG-Tenedo, Berching-Pollanten/D und Aigueperse/F (Abb. 42) ${ }^{452}$. Von den zahlreichen eng- lischen Vorkommen erbrachten 14 Fundorte solche Fragmente von «currency bars», «some of them with chisel-cut ends, clearly a result of bars being used as stock for manufacturing other objects» ${ }^{453}$.

Die Datierung der «currency bars» ist etwas eindeutiger als jene der doppelkonischen Spitzbarren. Schon 1967 legte Derek Allen die damals bekannten Befunddatierungen der englischen Funde vor und kam zum Schluss, dass «the context of the sword-shaped bars is essentially pre-Belgic [vorrömisch] and of the 1st century B.C., perhaps in some cases the earlier part of that century». Diese Barren waren - soweit die datierten Stücke heutzutage belegen vom 2.Jh. v. Chr. bis ins 1.Jh. n. Chr. - also vor allem in der Spätlatènezeit - im Umlauf (zum Caesar-Zitat siehe oben mit Anm. 14 und 15).

\footnotetext{
447 Crew 1994, 345.

448 Allen 1967, $330 \mathrm{f}$

449 Hingley 1990, 91; $94 \mathrm{f}$.

450 Pleiner 2006, 30.

451 Crew 1995, Tab. 62.

452 Danebury/GB: Crew 1995, Abb. 145. - Zurzach/AG: Doswald 1994B, 294 Abb.212m, E439 (= unsere Abb.42,2-8). - BerchingPollanten / D: Schäfer 2002, Abb. 13,2-8 (= unsere Abb. 42,9-13). Aigueperse/F: Orengo 2003, Taf. 36,10 (= Abb. 42,1).
}

453 Crew 1994, 345. 


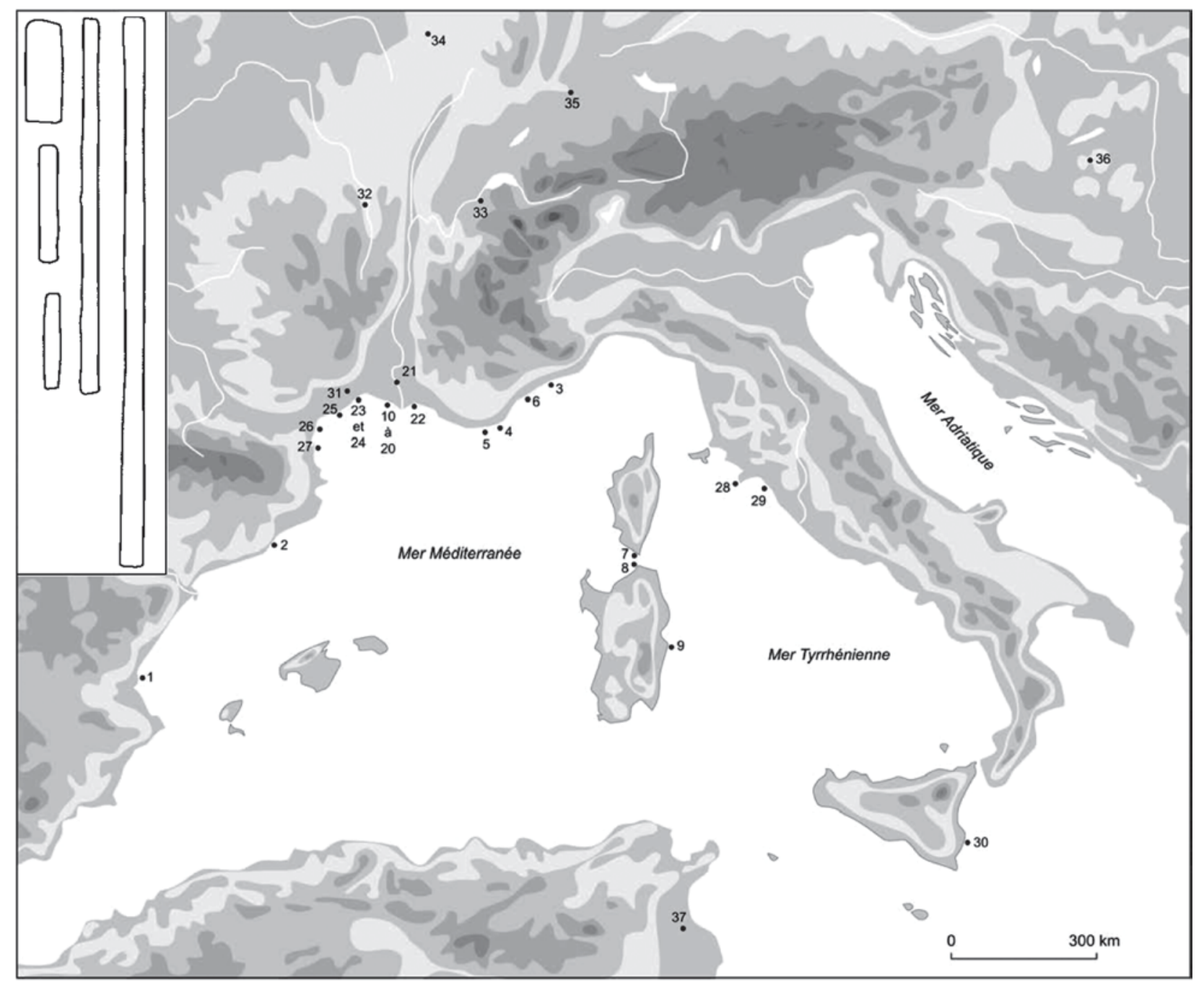

Abb. 44: Verbreitung der geraden Stabbarren des Typs «Saintes-Maries-de-la-Mer».

\section{Verbreitung}

Das Verbreitungsgebiet der «currency bars» (Abb.43) liegt schwerpunktmässig westlicher als die Verbreitung der Doppelspitzbarren (Abb. 40). Sie sind vor allem in England gefunden worden (Abb. 43, oben links), streuen aber auf dem Kontinent vom Atlantik bis ins heutige Rumänien ${ }^{454}$. Beide Formen (oder Eisentypen?) sind mindestens während der Spätlatènezeit gleichzeitig erzeugt und verhandelt worden.

\section{Stabbarren}

Einfache, rechteckige Barren oder Stangen mit rechteckigem bis quadratischem Querschnitt finden sich in praktisch allen grösseren Siedlungen mit vorhandener Eisenverarbeitung (Beispiel oben mit Abb. 16), aber auch in Depotfunden oder als Handelsgut in Schiffswracks ${ }^{455}$. Die eisernen «Stäbe» können lang und kantig sein wie etwa in den vor Saintes-Maries-de-la-Mer / F gesunkenen Handelsschiffen (Abb. 46) ${ }^{456}$, gedrungen und quaderförmig-massiv wie bei vielen römischen Stücken (Abb.33,33-40457 und 45) oder lanzettförmig sich verjüngende Enden aufweisen (Abb. 14; 33,9). Zu den letzteren gehören die ganz wenigen bekannten Barren aus dem antiken Griechenland ${ }^{458}$ und einige Beispiele aus der Frühzeit von Alésia / F ${ }^{459}$.

454 Weitere Verbreitungskarten: Allen 1967, Abb. 1 (Grossbritannien) Doswald 1994, Abb. 5 (Mitteleuropa); Crew 1995, Abb. 148 (Grossbritannien); Martin/Ruffat 1998, Abb. 4 (Mitteleuropa); Cunliffe 2005, Abb.18.10, oben; Berranger et al. 2017B, Abb. 15 (Frankreich).

455 Zum Beispiel: Solier 1981, 176-223 Abb. 81-82 (Schiffsfund von Mateille / F A, 2. Hälfte 4.Jh.).

456 Pagès 2010, $201 \mathrm{ff}$. Abb. 169-194.

457 Zusammengestellt in Anm. 470.

458 Kostoglou 2003, 64-66 Abb. 2,a.b (Messemvria / GR, Apolloheiligtum, spätes 6.Jh. v. Chr.).

459 Pleiner et al. 2003, 98-107 Abb. 6 und 19 (lingots 1 und 3); 129; Mangin / Fluzin 2006, 146 Abb. 15. 


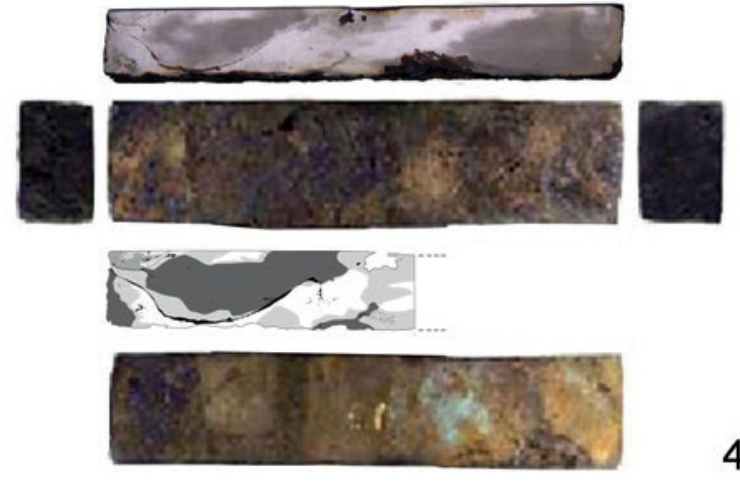

4C
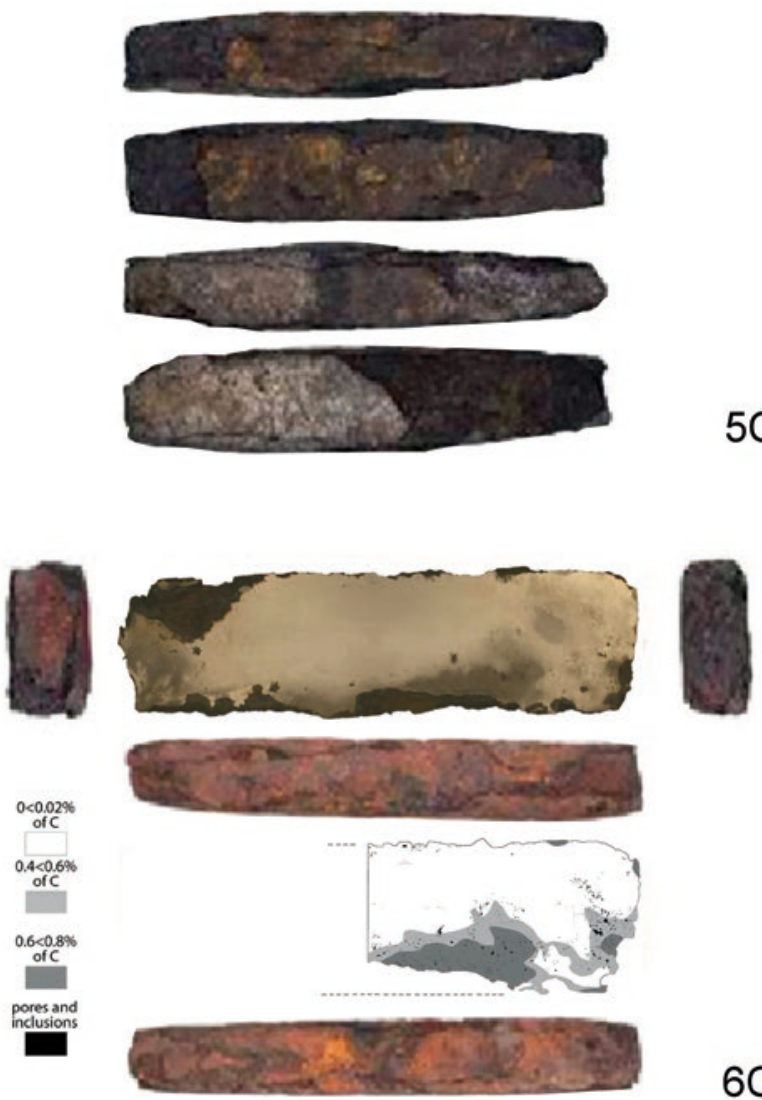

$10 \mathrm{~cm}$

Abb. 45: Saintes-Maries-de-la-Mer/F.Drei (kurze) Beispiele zahlreicher Eisenbarren aus römischen Schiffswracks (Fotos und Schnitte mit Angaben der Kohlenstoffgehalte). Sie weisen im Innern zwar kohlenstoffreichere Zonen auf, sind aber nicht durch Zementation oberflächlich aufgekohlt. Beispiele der langen Varianten siehe Abb. 46. M. 1:6.

Formal ähnliche, sowohl kurze als auch lange römische Stab- oder Flachbarren fanden sich in beachtlicher Zahl in den Schiffswracks bei Saintes-Maries-de-la-Mer / F (Abb. 44-46) ${ }^{460}$, im Schiffswrack «Saint-Gervais 2» bei Fossur-Mer / F ${ }^{461}$ oder bei Risan-Rhizon / MNE (Abb. 47) ${ }^{462}$. Einige Barren von Saintes-Maries-de-la-Mer sind allerdings fast doppelt so gross wie das oben vorgestellte Stück aus Touffréville (Abb. 16), und andere dieser bemerkenswerten Schiffsfunde sind noch bedeutend länger (Abb. 46).
Als eine Sonderform der Stabbarren könnte man die gedrungenen, kurzen Hakenbarren ( «hooked blocks») bezeichnen. Es sind Vierkantstäbe mit einem sich verjüngenden, in Hakenform umgebogenen Ende (Abb. 33,21-23) ${ }^{463}$. Ihre Längen schwanken um 12-22 cm, ihr Gewicht beträgt 0,9$2,9 \mathrm{~kg}$. In England fanden sich solche Hakenbarren in Siedlungen (nicht Horten!) des 5.-1. Jahrhunderts v. Chr. («preRoman iron Age»; s. auch Abb.49, grob gepunktete Signatur). Sie können sowohl sorgfältig und glatt geschmiedet als auch nur oberflächlich überhämmert sein und Schweissnähte zeigen. Archäometrische Untersuchungen an zwei Hakenbarren weisen auf «forged ... impure iron containing much smelting slag which had not been expelled during preliminary smithing» hin, manchmal mit erhöhten Phosphorwerten. Das Gefüge ist sehr heterogen, und Aufkohlung war nur in «small amounts» festzustellen. Diese Befunde interpretierten Peter Crew und Vanessa Fell als Rohprodukte in einem frühen Stadium des Ausheizungsprozesses (Abb. 32), «shaped as a result of their use as a trade iron. By drawing down one end of the block of iron and bending it round to form a hook, the smith was able to demonstrate the quality of the iron ...».

\section{Archäometrie}

Die Stabbarren vom Typus Saintes-Maries-de-la-Mer zeigen in den archäometrischen Schnitten keinerlei Anzeichen einer sekundären Aufkohlung. Im Gegenteil: Die unregelmässige Verteilung kohlenstoffreicherer Partien im Weicheisen-Gefüge spricht eher für teils zusammengeschweisste - teils kohlenstoffarme, teils kohlenstoffreichere - Produkte aus einem Rennofen. "Cette hétérogénéité en carbone qui se retrouverait partout dans le même lingot ne modifierait pas les associations d'impuretés. ... Les résultats d'analyse chimique donnent un pourcentage moyen de carbone de ... 0,02 à 0,8\%, qui est précisément la limite à partir de laquelle se forment des carbures appelés perlite. ... Et pourtant il s'agirait d'acier ...» ${ }^{464}$ Die Tatsache, dass die Ladungen der einzelnen vor Saintes-Maries-de-laMer gekenterten Schiffe sowohl Eisen- als auch Stahlbarren enthielten, bedeutet, dass die Frachten sich aus Halbfabrikaten unterschiedlicher Kohlenstoffgehalte zusammensetzten. Die ebenfalls feststellbaren Unterschiede in den

460 Long et al. 2002, bes. 179-187 Abb. 4 und 11 (Barrenstempel); Maréchal 2002, 245-254 Abb.3-6; Coustures et al. 2006, Abb. 4,3C.4C.5C.6C; Pagès et al. 2011A, Abb. 2,4C.5C.6C; 4; 9.

461 Monguilan/Tivolle 1987.

462 Lang 2017, 6 Abb. 4. - Vgl. den ganz ähnlichen römischen Barren aus der «Mint site» in Sisak/ HR: Durman 2002, Abb. 7,3.

463 Ehrenreich 1985, Abb.2.7; Crew 1995, 277; Fell 2003 (S. 131 und 132: Zitate; mit Nachweisen zu 13 britischen Objekten in Tab. 22, mit älterer Lit.).

464 Maréchal 2002, 246f. (zitiert nach Robert Glain); 248 Abb. 3-6. 

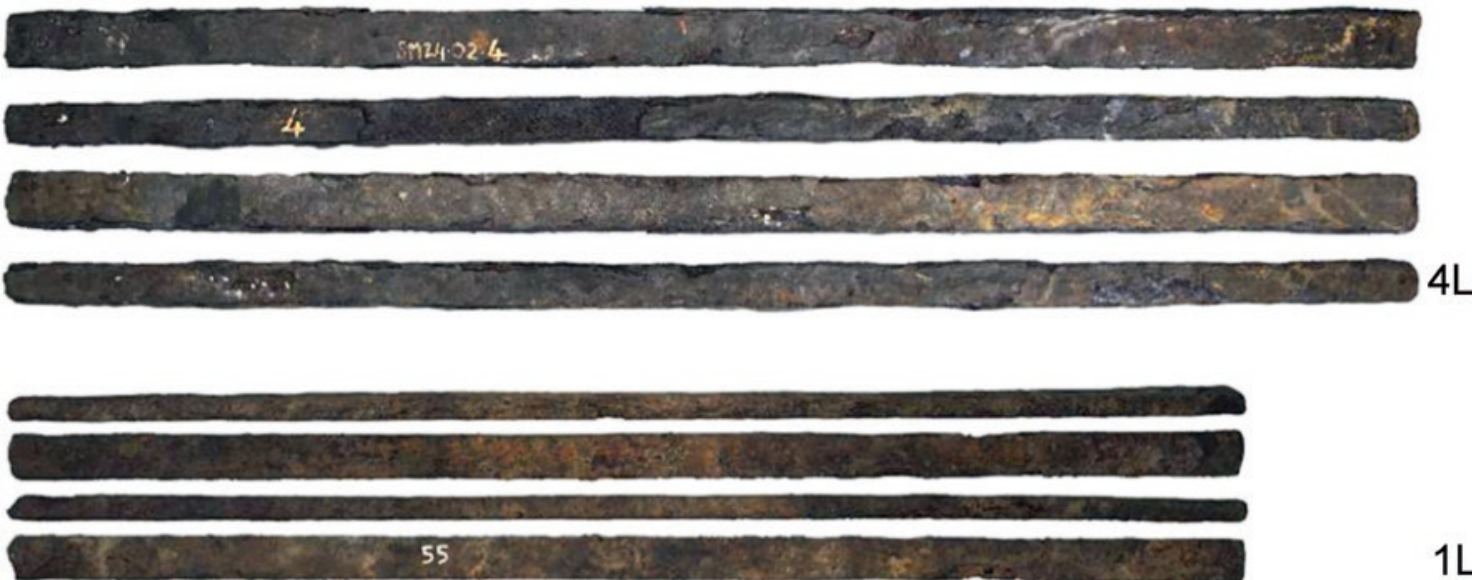

$1 \mathrm{~L}$

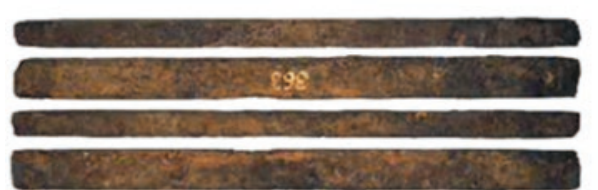

$1 \mathrm{M}$

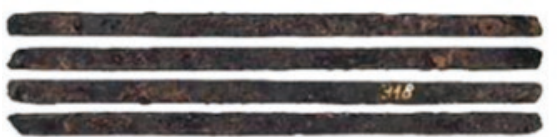

$2 \mathrm{M}$

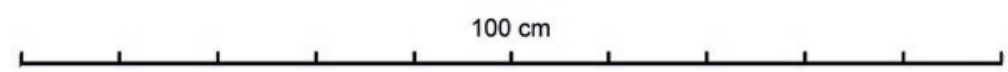

Abb. 46: Saintes-Maries-de-la-Mer/F. Je zwei mittellange und zwei lange Beispiele zahlreicher Eisenbarren aus römischen Schiffswracks (kleine Auswahl). Beispiele der kurzen Varianten siehe Abb. 45 (und Abb. 33, 27-32). M. 1:10.
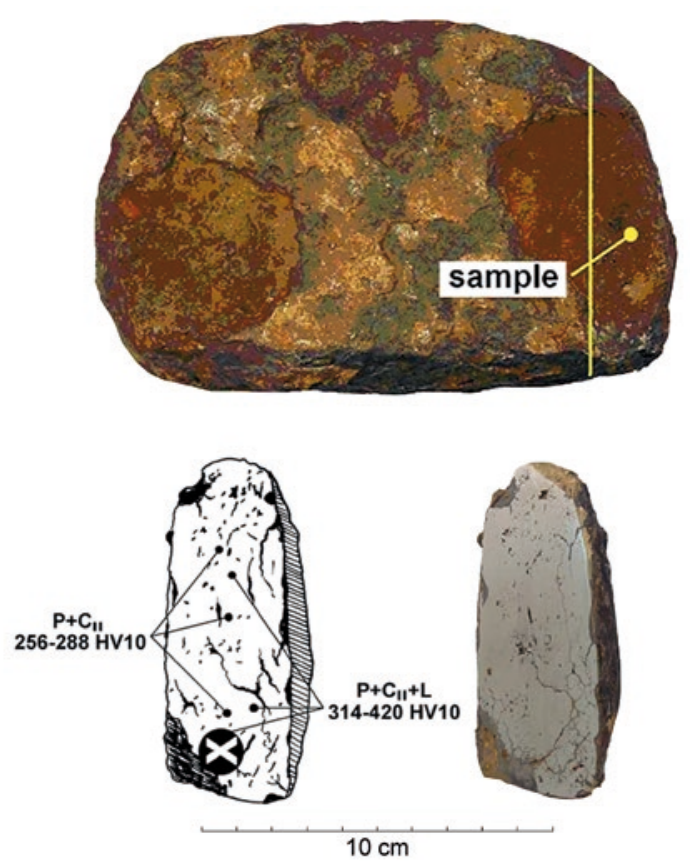

Abb. 47: Etwa handflächengrosser Eisenbarren aus einem römischen Schiffswrack bei Risan-Rhizon/MNE. Das heterogene Gefüge ist vermutlich das Resultat vom Austreiben der Schlacke und Zusammenschweissen einer Eisenluppe mit kohlenstoffarmen und kohlenstoffreicheren Bestandteilen. M. 1:3.
Phosphor- und Mangangehalten könnten auf die den Barren zugrundeliegenden Erze zurückzuführen $\operatorname{sein}^{465}$.

Etwas eindeutiger und möglicherweise weniger heterogen zusammengesetzt scheint die jüngere Fracht auf dem um 140 n. Chr. gesunkenen Schiff «Saint-Gervais 2» bei Fos-sur-Mer / F gewesen zu sein ${ }^{466}$. Die Ladung bestand u. a. aus Stabbarren von $550 \times 31 \times 28$ mm Grösse und ursprünglich je rund $4 \mathrm{~kg}$ Gewicht. Zwar sind nur wenige Analysen an Einzelstücken vorgenommen worden, doch die sprechen für ein sehr gut ausgeheiztes und kompaktiertes Material, das aus mehreren Schichten zusammengeschweisst wurde. Es entstand ein «acier extra-doux ... pris en sandwich entre deux bandes d'acier plus carburé». Der Längsschliff zeigt eine oberflächennahe «structure ferrito perlitique», wonach die Barren nach dem Schmieden oberflächlich aufgekohlt worden sind.

\section{Grösse und Datierung}

Die Stabbarren aus den elf südfranzösischen Schiffswracks sind 1,5 bis $33 \mathrm{~kg}$ schwer (Gesamtgewicht etwa 500 Tonnen!), 25 bis $190 \mathrm{~cm}$ lang und datieren rund in die Zeit zwi-

465 Maréchal 2002, 252.

466 Monguilan/Tivolle 1987. 
schen dem 2.Jahrhundert v. Chr. und dem Ende des 1.Jh. n. Chr. ${ }^{467}$ Aber sogar innerhalb der Formgruppen (Abb. 45; 46) schwanken die Masse und Gewichte beträchlich ${ }^{468}$ : «Mais ces lingots en dimensions souvent différentes ont des poids qui varient trop à l'intérieur même de leurs catégories définies par leur formes et dimensions ...»

\section{Verbreitung}

Diese geraden Stangenbarren unterschiedlichster Grösse streuen über einen relativ kleinen Raum im westlichen Mittelmeergebiet (Abb. 44) ${ }^{469}$. Zum Verbreitungsgebiet der Barren selbst passt auch deren Darstellung auf einem Mosaik aus Sousse an der tunesischen Ostküste (Abb. 35).

\section{Römische Eisenbarren}

Das Erscheinungsbild römischer Eisenbarren ist viel individueller als in der Eisenzeit. Nebst den klein gewordenen rhombischen Doppelspitzbarren (Abb.33,25-26; Abb.48,1-2) fallen nun überall klotz- und quaderförmige Barren in grosser Zahl auf, die keinen formalen Normie-

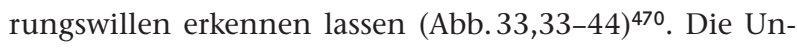
einheitlichkeit römischer Eisenbarren «do not involve any stylized implements and were of a very different quality: wrought iron, hard carbon steel often affixed with punchmarks of the producers.... The bulk of the other Roman ingots are, of course, brick-shaped heavy blocks.» ${ }^{471}$ Die wenigen metallurgisch untersuchten römischen Quaderbarren sind, wie die meisten anderen antiken Eisenbarren, mehrlagig zusammengeschweisste Verbundmaterialien mit variierenden Kohlenstoffgehalten im selben Stück ${ }^{472}$.

\section{Grösse und Datierung}

Ihre Grösse schwankt beachtlich, erreicht aber nicht mehr die Gewichte von bis zu 12,7 kg der eisenzeitlichen Spitzbarren ${ }^{473}$ oder gar die bis zu $33 \mathrm{~kg}$ wiegenden längsten Stabbarren aus den südfranzösischen Schiffswracks. Nicht einmal das nach 400 n. Chr. vor Gruissan / F gesunkene Schiff «Mateille A» hatte schwere Eisenfracht geladen; die Barren aus der dortigen Ladung wiegen nur 1,97,4 kg (Abb. 33,41-43) 474! Die mehr oder weniger deutliche Quaderform römerzeitlicher Barren lässt keinen speziellen Formgebungswillen mehr erkennen wie gewisse eisenzeitliche (Abb.33,7-9.15-17.20-23) und frühmittelalterliche (Abb. 33,51.84-89) «Spezialbarren».

\section{Verbreitung}

Das Verbreitungsgebiet römischer quaderförmiger Barren unterschiedlichster Grösse - ist sehr uneinheitlich und wegen des schlechten Forschungsstandes sehr unvollständig.
Meines Wissens hat erst Cornel Doswald einen Versuch einer Verbreitungskarte gewagt, allerdings beschränkt auf England, den Alpenraum und Osteuropa ${ }^{475}$.

\section{Gestempelte römische Barren}

In - eher seltenen - Ausnahmefällen können römische Eisenbarren gestempelt sein. Möglich ist auch, dass einige einst vorhandene Stempel wegen der Korrosion nicht mehr erkannt worden sind. Was der Grund zur Stempelung der Barren war, ist nicht eindeutig, denn Stempel finden sich sowohl auf Eisen- als auch auf Stahlbarren. Direkter Ausdruck eines Qualitätsversprechens sind sie also nicht. Die Stempel enthalten kaum je Symbole ${ }^{476}$, sondern in der Regel kurze Texte. Es kommen sowohl Abkürzungen vor als auch Personennamen. Diese sind in der Regel im Genitiv und bezeichnen entweder den Produzenten oder den Vertreiber der Barren. Stempel kommen auf grossen und kleinen Barren vor und finden sich auf den unterschiedlichsten Barrentypen (Abb. 48). Es fällt auf, dass gerade die meistverbreiteten Gruppen wie etwa die grossen doppelkonischen Spitzbarren oder die schwertförmigen «currency bars» meines Wissens nie gestempelt sind.

Von den archäometrisch untersuchten gestempelten Barren bestehen - im Gegensatz zu den ungestempelten Stücken - überdurchschnittlich viele aus Stahl (s. Katalog). Dies zeigt, dass offenbar vor allem die qualitätvollen «gestählten» Eisenbarren mit einem Stempel des Fabrikanten versehen wurden, was bei den «normalen» Weicheisenbarren weniger oft der Fall war.

Leider sind die Barrenfunde aus Schiffswracks wegen des Meerwassers meist sehr stark korrodiert, weshalb einst vorhandene Stempel kaum mehr zu erkennen und zu lesen sind. Dies trifft besonders auf die Aberhunderte von Stangenbarren aus den vielen Schiffswracks vor Saintes-Mariesde-la-Mer / F zu (s. Abb. 48,5-8.11.13.14) ${ }^{477}$.

467 Pagès et al. 2011, 1234-1237 Abb. 2 Tab. 1 und 2; Pagès 2014, 57.

468 Maréchal 2002, 246.

469 Pagès 2014, 57-59. - Weitere Verbreitungkarten ähnlicher Barren: Doswald 1994A, Abb. 6 («lingots en barre carré»); Pagès 2010, Abb. 163; Bauvais et al. 2018, Abb. 1 .

470 Solier 1981, Abb. 81; Ulbert 1984, Taf. 29,264.265; Gömöri 2000, Abb. 43; Durman 2002, Abb. 3; 6; 7; Pleiner 2006, Abb. 17,6-8; Pagès 2010, Abb.103.1. - Frühmittelalterliche Beispiele: Hallinder / Tomtlund 1978, Abb. 2-4; Westphalen 2002, Taf. 39,5-8.

471 Pleiner 2006, 39-43 Abb. 17 (S. 39f.: Zitat).

472 Zum Beispiel Pagès 2010, 122 f. Abb. 103/1; Pagès et al. 2011, Abb. 2 (= unsere Abb. 45); Berranger et al. 2014, Abb. 9 (= unsere Abb. 16).

473 Pleiner 2006, 39 («Compared with the heavy Celtic bipyramidal ingots the Roman pieces are relatively rare and represent what can be called a miniaturized version.»).

474 Solier 1981, 206 Abb. 81 (s. unsere Abb. 33,41-43).

475 Doswald 1994, Abb. 6.

476 Ausnahme: Long et al. 2002, Abb. 4, unten (Anker).

477 Long et al. 2002, 179-182; Maréchal 2002, 245 f. 

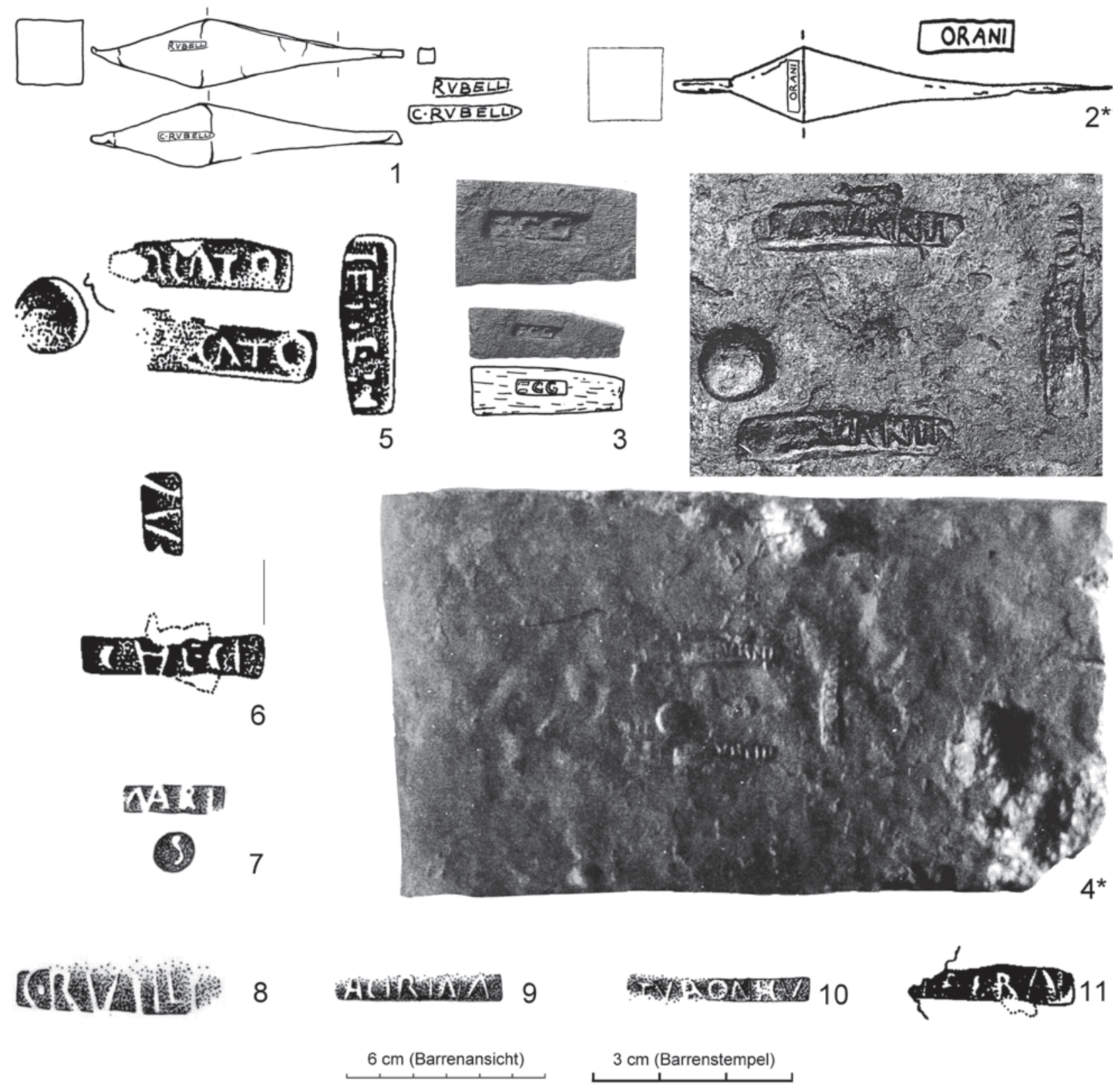

Abb. 48, Teil 1: Gestempelte römische Eisen- und Stahlbarren: Stempel auf kleinen Barren und ohne bekannte Gesamtform. Barren, die nachweislich aus Stahl bestehen, sind mit einem Stern (*) versehen. Barren ganz M. 1:2; Stempel M 1:1.

Fundorte: 1 Andernach/D-Martinsberg; 2 Magdalensberg / A; 3 Oberwinterthur / ZH-Vitudurum; 4 Bonifacio, Korsika / F (=Abb. 7); 5 Saintes-Maries-de-laMer/F, Wrack SM 10; 6 Saintes-Maries-de-la-Mer/F, Wrack SM9; 7 Saintes-Maries-de-la-Mer/F, Wrack SM3; 8 Saintes-Maries-de-la-Mer/F, Wrack SM6; 9.10 Arles / F-Trinquetaille; 11 Saintes-Maries-de-la-Mer/F, Wrack SM9.

Fortsetzung Seite rechts (grosse Barren): 12 Palavas-les-Flots /F; 13 Saintes-Maries-de-la-Mer/F, Wrack SM9; 14 Saintes-Maries-de-la-Mer/F, Wrack SM2; 15 Almazora /E-Ben-Afelí. Quellen siehe Abbildungsnachweise. 


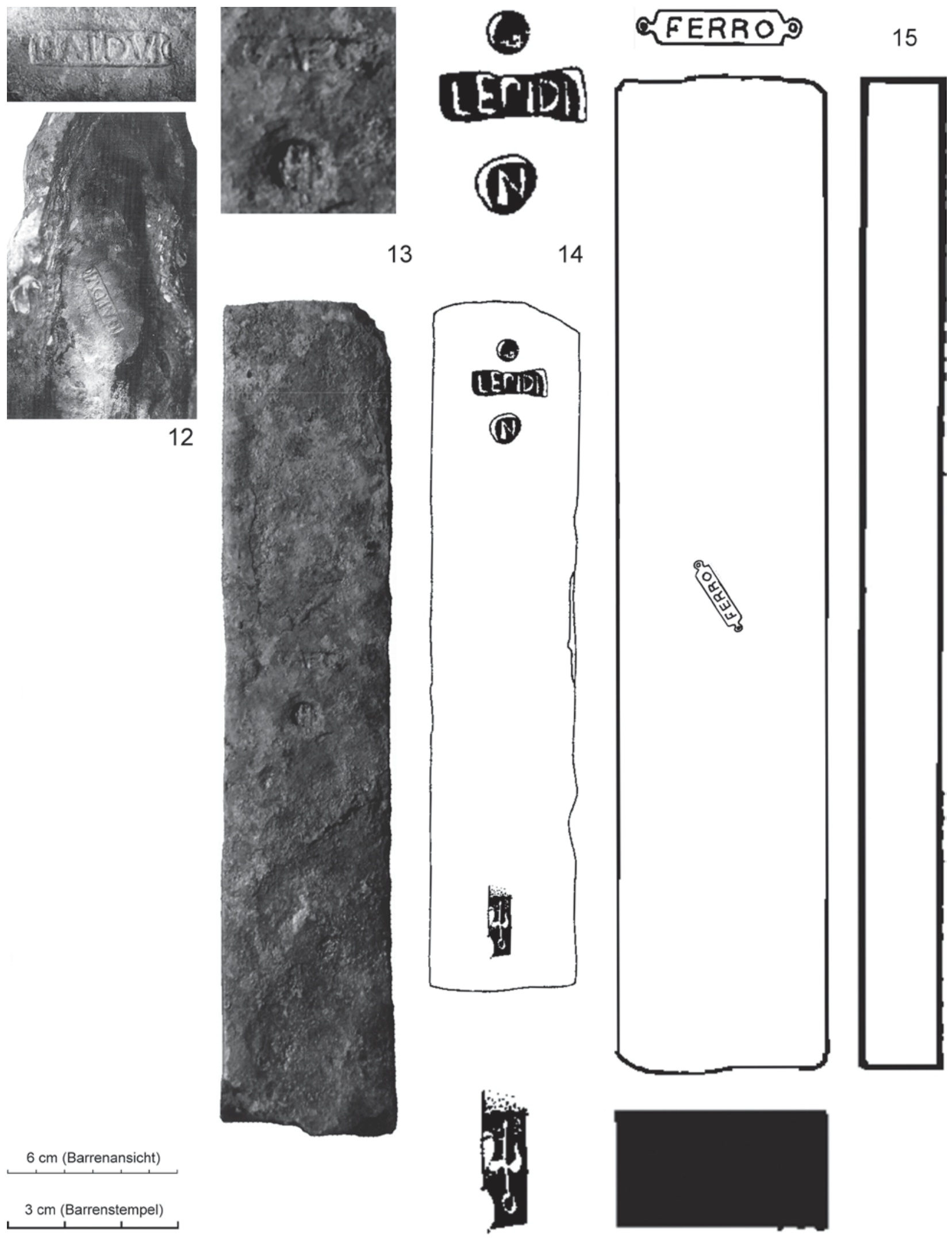

Abb. 48, Teil 2: Gestempelte römische Eisen- und Stahlbarren: Stempel aufgrossen Barren. Fundorte siehe Legende links. Barren, die nachweislich aus Stahl bestehen, sind mit einem Stern (*) versehen. Barren ganz M. 1:2; Stempel M. 1:1. 
Stempelanbringung: Stempel sind auf manchen Barren aus den Schiffwracks vor Saintes-Maries-de-la-Mer/F angebracht, jeweils am Ende einer flachen Seite der Stücke. Zur Anbringung der Stempel - glühend oder kalt - stellen sich Marie-Pierre Coustures und Mitautoren die Frage478: «Sont-ils été apposés à froid ou à chaud? La question n'est pas secondaire, tant la réponse qu'on y apportera conditionnera leur interprétation», und kommen zum Schluss, die Stempel seien bereits von den Fabrikanten - und nicht erst von den Händlern - in das weiche, glühende Eisen eingeschlagen worden: «La régularité de l'estampillage, la forme des timbres et le fait que ceux-ci sont toujours imprimés avec soin, tout conduit à voir dans ces estampilles les marques des fabricants.» Davon ist auch Jean-Marie Maréchal überzeugt ${ }^{479}$ : Die Saintes-Maries-de-la-Mer-Barren seien «été estampillés dans le métal encore chaud, sans doute grâce à un poinçon ou un tasseau en acier constituant la matrice dans laquelle l'inscription devait être marquée en creux». Von kalt angebrachten Graffiti sind gar keine Spuren erkennbar ${ }^{480}$.

\section{Katalog}

Abb. 48,1:

Abb. 48,2: Magdalensberg/A (Siedlungsfund), in der Form und Grösse eines Pfriems resp. «Doppelstachels», Grösse $133 \times 21 \times 20 \mathrm{~mm}$, Gewicht $0,094 \mathrm{~kg}$, mit Stempel .ORANI $(28 \times 6 \mathrm{~mm})$, tiberisch (um 15-40 n.Chr.). Es «wurde die Idee geäussert, dass es sich [bei den «Doppelstachel-Pfriemen`] nicht um Werkzeuge, sondern eine Art von Barren handelte, deren lange Spitzen eine gute Schmiedbarkeit anzeigen sollten» ${ }^{482}$. Archäometrie: nicht untersucht, vermutlich aber Stahl (in Anlehnung an ungestempelte «Doppelstachel» derselben Form und Grösse mit 0,36-1,43\% C) ${ }^{483}$.

Abb.48,3: Oberwinterthur/ZH-Vitudurum, aus einer Auffüllschicht (zusammen mit Eisenschlacken; Siedlungsfund), Barrengrösse $47 \times 10,0-10,5 \times 7,0-10,2 \mathrm{~mm}$, Gewicht $0,055 \mathrm{~kg}$, beide Enden sind leicht schräg abgeschrotet, mit Stempel [T]GC $(5 \times 16 \mathrm{~mm}), 1$.Jh. n. Chr. Archäometrie: «Der Barren wurde verhältnismässig sorgfältig aus weichem Schweisseisen geschmiedet», «... not of steel but of relatively pure, in general ferritic iron with low $\mathrm{Mn}$ and $\mathrm{P}$ contents». «Apparently such material was produced by renowned workshops and wanted by customers for making small objects of desired quality» 484

Abb. 48,4: Bonifacio, Korsika / F (Schiffswrack, s. auch Abb. 7), Barrengrösse $230 \times 125 \times 30 \mathrm{~mm}$ (keine Gewichtsangabe), $3 \times$ gestempelt SATVRIN(VS) $(33 \times 5-7 \mathrm{~mm})$, römisch. Archäometrie: Stahl (etwa 0,9-1,0\% C) ${ }^{485}$.

Abb. 48,5: Saintes-Maries-de-la-Mer / F (Schiffswrack SM 10), Form 1L, Barrengrösse ca. 740-1385 mm, Gewicht ca. 9-12 kg (Form 1L generell), mit Stempel Q CATO//Q CATO//TEREN (ca. $27 \times 7 \mathrm{~mm}$ resp. $27 \times 8 \mathrm{~mm}$ ), römisch, 1.Jh. n. Chr. ${ }^{486}$.

Abb. 48,6: Saintes-Maries-de-la-Mer / F (Schiffswrack SM 9), Form 4C, Barrenlänge $<400 \mathrm{~mm}$, Gewicht ca. $2-7 \mathrm{~kg}$ (Form $4 \mathrm{C}$ generell), mit Stempel FAL[?] / CAECI $(26 \times 5 \mathrm{~mm})$, römisch, 2. Viertel 1.Jh. n. Chr ${ }^{487}$.
Abb. 48,7:

Saintes-Maries-de-la-Mer/F (Schiffswrack SM 3), Form 1 oder 2, Barrengrösse?, Gewicht?, mit Stempel MARI / S (ca. $15 \times 4,5 \mathrm{~mm}$ resp. $\varnothing$ ca. $7 \mathrm{~mm}$ ), römisch, um 1-60 n. Chr. ${ }^{488}$.

Abb. 48,8: $\quad$ Saintes-Maries-de-la-Mer/F (Schiffswrack SM 6), Form 2M, Barrenlänge ca. 40-70 mm, Gewicht ca. 1,5-5 kg (Form 2M generell), mit Stempel C.RVTILI (ca. $31 \times 6-8 \mathrm{~mm}$ ), römisch, 2. Hälfte 1. Jh. v. Chr. ${ }^{489}$.

Abb. 48,9: Arles/F-Trinquetaille (Schiffswrack), Barrengrösse ?, Gewicht?, mit Stempel ACIRINA (ca. $25 \times 4 \mathrm{~mm}$ ), rö$\operatorname{misch}^{490}$.

Abb. 48,10: Arles/F-Trinquetaille (Schiffswrack), Barrengrösse ?, Gewicht ?, mit Stempel TVRONICV $(28 \times 4 \mathrm{~mm})$, römisch $^{491}$

Abb. 48,11: Saintes-Maries-de-la-Mer / F (Schiffswrack SM 9), Form 4C, Barrenlänge $<400 \mathrm{~mm}$, Gewicht ca. 2-7 kg (Form 4C generell), mit Stempel T.AFRAN $(>25 \times 5 \mathrm{~mm})$, römisch, 2. Viertel 1.Jh. n. $\mathrm{Chr}^{492}$.

Abb. 48,12: Palavas-les-Flots / F (Schiffswrack), Barrengrösse $380 \times 45 \times 42 \mathrm{~mm}$, Gewicht ca. $4 \mathrm{~kg}$ (stark korrodiert), mit schräg zur Barrenlängsachse angebrachtem Stempel HAEDVI («von den Haeduern», aus dem Burgund[?]) $(25 \times 7 \mathrm{~mm})$, 1.Jh. v. Chr.-1.Jh. n. Chr. Archäometrie: nicht untersucht ${ }^{493}$.

Abb. 48,13: $\quad$ Saintes-Maries-de-la-Mer / F (Schiffswrack SM 9), Form 4C, Barrenlänge < 400 mm, Gewicht ca. 2-7 kg (Form 4C generell), mit Stempel CAECI/ / H $(25 \times 7 \mathrm{~mm}$ resp. $\varnothing$ $14 \mathrm{~mm})$, römisch, 2. Viertel 1.Jh. n. Chr ${ }^{494}$.

Abb. 48,14: Saintes-Maries-de-la-Mer/F (Schiffswracks SM 2), Form 4, Barrengrösse ?, Gewicht ?, mit Stempel S/ / LEPIDI / / N $(26,5 \times 8 \mathrm{~mm}$ resp. $\varnothing 8 \mathrm{~mm}$ resp. $\varnothing$ $11 \mathrm{~mm}$ ), römisch, 1. Viertel 1.Jh. n. Chr. ${ }^{495}$.

Abb. 48,15: Almazora/E-Ben-Afelí (Schiffswrack), Barrengrösse $352 \times 71 \times 28 \mathrm{~mm}$, Gewicht ca. $5,5 \mathrm{~kg}$ (rekonstruiert),

478 Coustures et al. 2006, 249-252 Abb. 5-6 Tab. II (S. 250: Zitat).

479 Maréchal 2002, $241 \mathrm{f}$.

480 Coustures et al. 2006, 250.

481 Gaitzsch 1978, 15 Abb. 14; Pleiner 2006, 39f. Abb. 17,1.17.

482 Pleiner 1996, 224

483 Dolenz 1998, 219-222 Abb. 48,W367 Taf. 79,W364-W368; Naumann 1964, 501 f. Abb. 13 und 14; Schaaber 1964, 504 f. Abb. 5; Pleiner 2006, 39 f. Abb. 17,2.

484 Pleiner 1996; Schaltenbrand Obrecht 1996, 195 f. Kat.-Nr. E1170 Abb. 184 Taf. 69,1170; Pleiner 2006, 40 Abb. 17,18.

485 Zwicker 1996, Taf. 7,1; 8,1; Long et al. 2002, 179 Anm. 17; Pleiner 2006, 41.

486 Long et al. 2002, 180-182 Abb. 11,3 Tab. 1; Coustures et al. 2006, $249 \mathrm{f}$; $251 \mathrm{f}$. Tab. II,7b.

487 Long et al. 2002, 180-182 Abb.11,1 Tab. 1; Coustures et al. 2006, 249f. Abb. 6; 251 Tab. II, 4.

488 Long et al. 2002, 182 Tab. 1; Coustures et al. 2006, 249f. Abb. 5,4 Tab. II,5.

489 Long et al. 2002, 182 Tab. 1; Coustures et al. 2006, 249f. Abb. 5,3 Tab. II,1.

490 Coustures et al. 2006, 249f. Abb. 5,1.

491 Coustures et al. 2006, 249f. Abb. 5,2.

492 Long et al. 2002, 180-182 Abb. 11,2 Tab. 1; Coustures et al. 2006, 249f. Abb. 5,4; 251 Tab. II,5.

493 Long et al. 2002, 179 Anm. 18; Maréchal 2002, 240-245 Abb. 1-2; 245 .

494 Long et al. 2002, 182 Tab. 1; Coustures et al. 2006, 249f. Abb. 6 Tab. II,5.

495 Long et al. 2002, 164f. Abb. 4; 181f. Tab. 1; Maréchal 2002, 245 f.; Coustures et al. 2006, 249f. Tab. II,10. 
mit schräg zur Barrenlängsachse angebrachtem Stempel FERRO (ca. $23 \times 5 \mathrm{~mm}$ ), um 85-95 n. Chr. Archäometrie: nicht untersucht ${ }^{496}$

(nicht abgeb.): Saintes-Maries-de-la-Mer / F (Schiffswracks SM 2, 9 und 24), Form 1, Barrengrösse?, Gewicht?, mit Stempel ILV (IVLIVS ?), kombiniert mit EROTIS, um 100 v. Chr. bis 75 n. Chr. (alle drei Schiffe). Archäometrie: nicht untersucht ${ }^{497}$

(nicht abgeb.): Saintes-Maries-de-la-Mer / F (Schiffswrack SM 10), Form 1L, Barrenlänge ca. 740-1385 mm, Gewicht ca. 9-12 kg (Form 1L generell), mit Stempel MAXIMI//MAXIMI / / [---], römisch, 1.Jh. n. Chr. Archäometrie: nicht untersucht ${ }^{498}$

(nicht abgeb.): Saintes-Maries-de-la-Mer/F (Schiffswrack SM 9), Form 4C, Barrenlänge $<400 \mathrm{~mm}$, Gewicht ca. 2-7 kg (Form 4C generell), mit Stempel T.COR, römisch, 2. Viertel 1.Jh. n. Chr. Archäometrie: nicht untersucht ${ }^{499}$.

(nicht abgeb.): Saintes-Maries-de-la-Mer/F (Schiffswrack SM 9), Form 4C, Barrenlänge $<400 \mathrm{~mm}$, Gewicht ca. 2-7 kg (Form 4C generell), mit Stempel CAVLI, römisch, 2. Viertel 1.Jh. n. Chr. Archäometrie: nicht untersucht ${ }^{500}$.

(nicht abgeb.): Saintes-Maries-de-la-Mer / F (Schiffswrack SM 10), Form 4C, Barrenlänge $<400 \mathrm{~mm}$, Gewicht ca. 2-7 kg (Form 4C generell), mit Stempel FVLVIOR/ / FVLVIOR, römisch, 1.Jh. n. Chr. Archäometrie: nicht untersucht ${ }^{501}$

(nicht abgeb.): Saintes-Maries-de-la-Mer / F (Schiffswrack SM 24), Form $4 \mathrm{~L}$, Barrenlänge $>720 \mathrm{~mm}$, Gewicht ca. $22 \mathrm{~kg}$, mit Stempel MANI [?] / / MANI [?], um 120 v. Chr. bis 75 n. Chr. Archäometrie: nicht untersucht ${ }^{502}$

\section{Frühmittelalterliche Eisenbarren}

Es würde zu weit führen, hier auch noch die zahlreichen Barrenformen des frühen Mittelalters im Detail aufzuführen ${ }^{503}$. Im Einflussgebiet der Merowinger sind Barrenfunde äusserst selten, so dass sich die bisherige Forschung auf die fundreicheren Gebiete Skandinaviens (Wikinger) und Nordosteuropas (Slawen) konzentrierte. Die aus römischen Kontexten bereits bekannten quaderförmigen Barren (Abb.33,33-46) finden sich naheliegenderweise auch im Frühmittelalter (Abb.33,73-84), stammen in der Regel ebenfalls aus Siedlungen resp. Werkstätten (und nicht aus Horten) und müssen hier nicht extra behandelt werden.

\section{Spatelförmige Barren («spade-shaped bars»)}

Spatel- resp. spatenförmige Barren (Abb. 33,1.2) ${ }^{504}$ weisen, ähnlich den viel älteren Vorgängern «currency bars», am einen Ende eine Tülle auf. Sie sind jedoch leichter als jene, und ihre Form ist gedrungener, die Tülle relativ weit und der Barrenschaft spatenförmig in rhombische Form dünn ausgeschmiedet. Sie gehören in die Vendel- und Wikingerzeit (rund 300-600 n. Chr., evtl. sogar bis um 900), sind $20-34 \mathrm{~cm}$ lang und haben eine grosse Gewichtsvariation von $0,154-1,65 \mathrm{~kg}$. Nach Radomír Pleiner sind zwei Grössenklassen unterscheidbar. Nach Marta Lindeberg streut der Typus relativ eng in Mittelschweden ${ }^{505}$. Pär Hallinder konnte anhand vieler Horte mit «spade-shaped bars» nachweisen, dass nicht die Barren generell, sondern je nach einzelnem Hort relativ einheitliche Masse und Gewichte erkennbar sind ${ }^{506}$. Die Funktion dieser Barren ist umstritten: «The spade-shaped currency bars have previously been interpreted as trade iron and the hoards have therefore been seen as temporary stores or hiding places where bars were deposited for various reasons in transit from producer to consumer.» Heute ist wieder eher von Ritualhorten die Rede, ähnlich wie 500 Jahre zuvor bei den britannischen «currency bars»: «... the sheer number of hoards that have been left in the ground and by the regularity of the find contexts, which strongly indicate that the intention was to bury the bars permanently. There are also circumstances that suggest that the burial of currency bars did not take place in secrecy and that the places where hoards had been buried were known.» ${ }^{507}$

\section{Dünne Stabbarren («rod-shaped bars»)}

Dünne Stabbarren (Abb. 33,52) ${ }^{508}$ sind oft gefaltet. «Four different groups ranging from thicker square-sectioned to slender and often round-sectioned were presented; the latter were usually of hard steel (pearlite, pearlite-and-cementite up to $0,8-1,2 \%$ C). However, the carbon content was heterogeneous. Various kinds of material were obviously used for making different sorts of artefacts.» ${ }^{509}$

\section{Sensenförmige Barren ("scythe-shaped bars»)}

Sensenförmige Barren (Abb. 33,89) ${ }^{510}$, «... so-called rodshaped bars which are thinner (square-sectioned) and, according to Kerstin Haglund, have slanting tips like the scythe-shaped pieces» ${ }^{511}$. In der Länge variieren sie stark

496 Izquierdo 1980, 182 Abb. 11,7; Ramos et al. 1984, 128-130 Abb. 3,d; Long et al. 2002, 179 Anm. 16.

497 Long et al. 2002, 166; 182 Tab. 1; Maréchal 2002, 245 f.; Coustures et al. 2006, 249f.; 251 Tab. II,9.

498 Long et al. 2002, 182 Tab.1; Coustures et al. 2006, 249f.; 251 Tab. II,7a.

499 Coustures et al. 2006, 249f. Abb. 5,4; 251 Tab. II,5

500 Coustures et al. 2006, 249f. Tab. II,1.

501 Long et al. 2002, 182 Tab. 1; Coustures et al. 2006, 249f.; 251 Tab. II,8.

502 Coustures et al. 2006, 249 f.; 251 Tab. II,8.

503 Einen guten Überblick gibt Pleiner 2006, 43-50 Abb. 18-20. - Zum Barrenhandel in Skandinavien: Westphalen 2004, 31 (mit weiterführender Lit.).

504 Hallinder/Haglund 1978; Pleiner 2006, 43 f. Abb. 18,1.2; Lindeberg 2010 (mit älterer Lit.).

505 Lindeberg 2010, 205 Abb. 1-2. - Weitere Verbreitungkarte: Hallinder / Haglund 1978, Abb.3.

506 Hallinder / Haglund 1978, 34-37 Diagr. 1-4.

507 Lindeberg 2010, 206.

508 Haglund 1978, Abb. 6-14; Hallinder/Tomtlund 1978, 65-76 Abb. 5; Pleiner 2006, 43 Abb. 18,3.4.

509 Pleiner 2006, 454.

510 Haglund 1978, Abb. 4-5; Pleiner 2006, 44 f. Abb. 18,5.

511 Pleiner 2006, $44 \mathrm{f}$. 
um 52-72 cm, in den Extremen können sie 47-79 cm lang sein und 0,15-0,6 kg schwer. Archäometrie $e^{512}$ : «The metallography of one of the bars from Fagerhult showed it had been welded together from $2-3$ bands $(0,1$ to $0,8 \% \mathrm{C})$ with prevailing low carbon steel.» Datierung: 5.-7.Jh.

\section{Axtförmige Barren («axe-shaped bars», «socketed bars»)}

Axtförmige Barren (Abb.33,53-69)513: Die relativ dünnen, wenig massiven Barren sind ein Phänomen: Sie dominieren das frühmittelalterliche Barrenspektrum sowohl im skandinavischen als auch im slawischen Raum und kommen in zahlreichen, zum Teil sehr grossen Horten vor. Sie weisen - wenig erstaunlich - erhebliche Grössenunterschiede auf: in Skandinavien um 16-30 cm Länge, im slawischen Raum um 6-47 cm. Ihr Gewicht schwankt um 0,12-16 kg (skandinavisch) resp. meist 0,06-2,2 kg (slawisch). In diese Kategorie gehört ein riesiger Depotfund aus Krakau/PLKanonyczastrasse mit 4212 axtförmigen Barren und einem Gesamtgewicht von 3,63 Tonnen! Sie sind dort mit 32$37 \mathrm{~cm}$ Länge und 0,4-1,7 kg Gewicht relativ einheitlich und bestehen aus leicht kohlenstoffhaltigem Stahl (0,2-0,3\% C).

Sie gehören in beiden Fundgebieten ins 6.-9. Jahrhundert. In Skandinavien scheinen sie jedoch etwas früher möglicherweise schon ab etwa 200 - aufzutreten. In der Forschung wurden diese Barrentypen einerseits als «vormonetäre Zahlungsmittel» bezeichnet, andererseits und besonders oft - kultische Gründe zur Deponierung angeführt. Beim grossen Fundstoff von zahlreichen Fundorten wurden naheliegenderweise auch manche typologische Unterteilungsversuche angestellt (s. Abb. 33,53-69) ${ }^{514}$.

Archäometrischen Untersuchungen zufolge sind diese Barren schlackenarm, weisen Schweissnähte auf und enthalten unterschiedlich grosse Kohlenstoffanteile $(0,02$ 0,7\% C). «Anhand chemischer Untersuchungen und technischer Details ergab sich, dass Barren von verschiedenen Herstellungsorten, von unterschiedlichem Gewicht und mit unterschiedlichen Abmessungen (auch Barrenbruchstücke) gemeinsam in einem Hort vorkommen können.»515

\section{«Mästermyr-Barren»}

Eine letzte Gruppe frühmittelalterlicher Barren, ebenfalls vornehmlich aus dem skandinavischen Raum, wird als «Mästermyr-Typ» bezeichnet (Abb. 33,85-87) ${ }^{516}$. Die wenig häufigen Stücke gehören ins 9. Jahrhundert.

\section{Chronologie und Qualität}

\section{Eine chronologisch bedingte Barrenentwicklung?}

Es gibt durchaus eine «Barrenentwicklung» in dem Sinne, dass gewisse Barrentypen zu bestimmten Zeiten in Umlauf waren und andere zu anderen Zeiten. Dies zeigt sich im allmählichen Wechsel von den grossen doppelkonischen Spitzbarren nach der Hallstattzeit zu den viel schlankeren «currency bars», die die Latènezeit dominierten (Abb. 49). An diesem Bild haften jedoch Unklarheiten, solange die Bedeutung der Spitzbarren in römischer Zeit nicht geklärt ist. Das Problem liegt nach wie vor daran, dass viele Eisenbarren Einzelfunde sind oder aus isolierten Hortfunden stammen, die nicht datierbar sind. Eine formale Entwicklung der römischen Eisenbarren ist heute noch nicht erkennbar, und für das Frühmittelalter liessen sich die grossen Gruppen (z. B. die axtförmigen Barren) bisher nicht in eine typologische oder gar feinchronologisch abgesicherte Entwicklungsreihe bringen.

\section{«Form follows quality»?}

«Form follows function» ist sicher ein wichtiger Grund, dass die meisten Barrentypen eine jeweilige «Idealform» haben, die für den Schmied an der Esse ideal war und keine Entwicklung im Sinne einer formalen Verbesserung mehr zuliess - zum Leidwesen der Archäologinnen und Archäologen.

Und: Sowohl die geraden Stabbarren als auch die doppelpyramidenförmigen Spitzbarren lassen keine normierten Eisen- oder Stahltypen erkennen; die Barrenform allein erlaubte demzufolge keinen Hinweis auf den Kohlenstoffgehalt. Die Formen der Barren scheinen einerseits von der Herkunft dieser Rohstoffe resp. Halbfabrikate abzuhängen (Abb. 40; 43 und 44), andererseits sind sie beeinflusst von der Aufbereitungstechnik vom Ofenschwamm bis zum Barreneisen und - wie oben erwähnt - von der «idealen» Handels- und Ausgangsform für die Weiterverarbeitung zu Endprodukten in den Werkstätten.
512 Hallinder/Haglund 1978, 39 Abb.4-5; 43-45; 53f.; 57; Pleiner 2006, 44.

513 Ohlhaver 1939 (zur Deutung als Barren); Zaitz 1988, Abb. 7 (Verbreitungskarte Kleinpolen); Bialeková 2000, Abb. 146 (Verbreitungskarte slawischer Raum); Zagórska-Telega/Bochnak 2001; Pleiner 2006, 45-48 Abb. 19,3-19; 20, oben; Lindeberg 2010, 214 216 Abb. 4; Szmoniewski 2010 (mit älterer Lit.).

514 Zum Beispiel Zaitz 1988, 264-274.

515 Bialeková 2000, 202.

516 Hallinder 1978, Abb. 15; Pleiner 2006, 50 Abb. 21,1-4. 


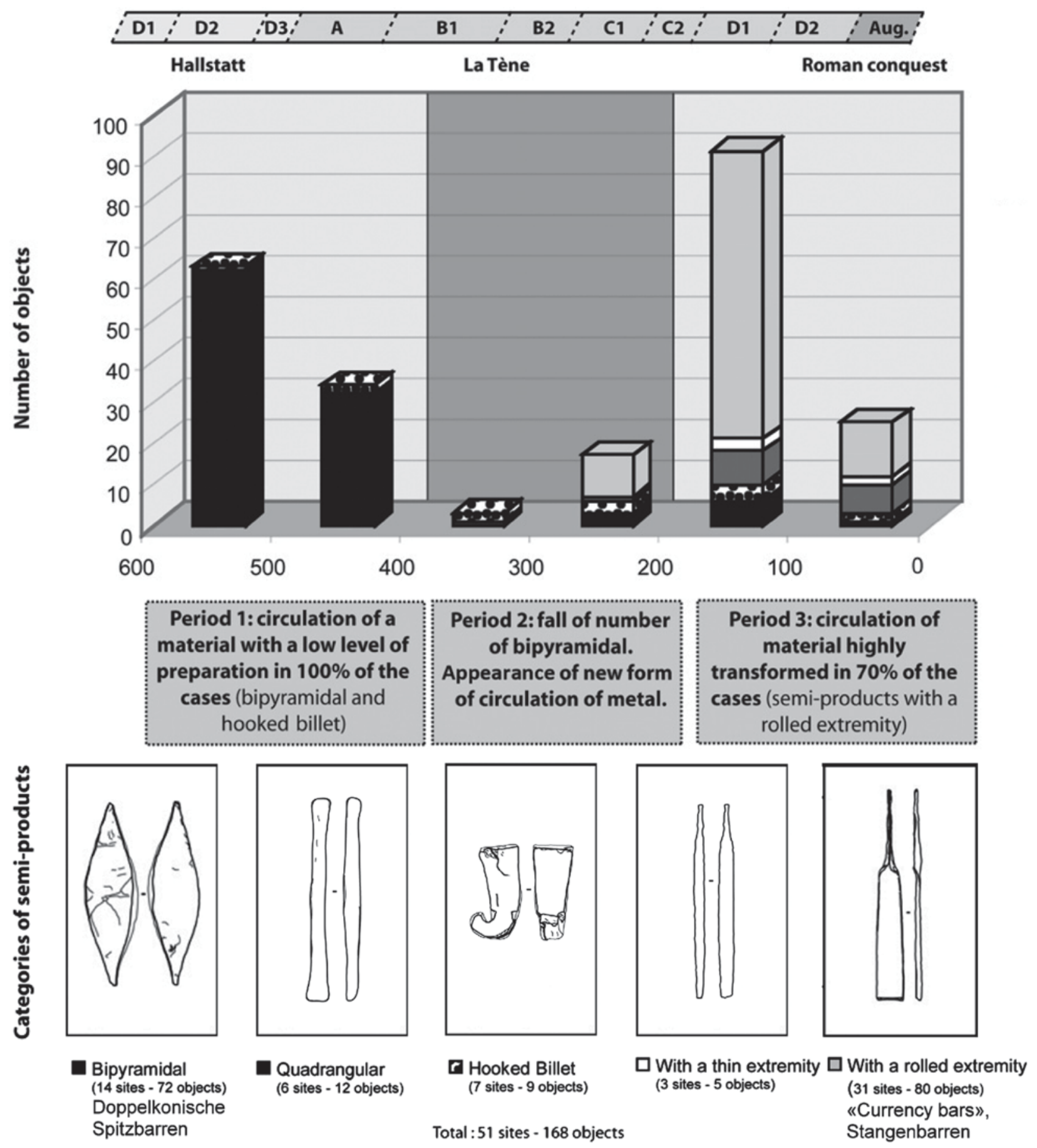

Abb. 49: Zeitliche und anteilmässige Entwicklung der doppelkonischen Spitzbarren, der geraden Stangenbarren mit tüllenartigen Enden (sog. "currency bars») und einiger seltenerer Typen in Frankreich. 


\section{Die Lehmumhüllungen aus Augusta Raurica}

Zusammenfassend zum oben Gesagten dürfen wir feststellen, dass dank vieler archäometrischer und mikroskopischer Untersuchungen von Geräten aus Eisen deren Herstellung durch Zusammenschweissen von weichem Eisen und härtbarem Stahl zu Verbundstoffen heute bestätigt werden kann. Über die Methoden, wie Stahl selbst erzeugt worden ist, wie also der Kohlenstoff in das Eisen gelangte, weiss man allerdings erst wenig. Eine der möglichen Methoden legte Paul T. Craddock ganz generell folgendermassen dar ${ }^{517}$ : «Even so it seems probable that in most instances early steels were made either from natural steel blooms or were deliberately carburised. This would have been carried out by heating the iron at red heat packed in charcoal dust in a sealed clay container for many hours.» Und John E. Rehder postulierte gar518: «The enclosure [of an ancient carburizing process] would be of a material like clay which should leave archaeological traces.»

Wie wir schon oben gesehen haben, waren in der Antike sicher mindestens zwei Wege bekannt, nämlich die Aufkohlung von Weicheisen einerseits und die gezielte Verhüttung und Auslese von Stahlpartikeln aus dem Rennofen andererseits. Aber: «We do not know what recipes were adopted by the Roman blacksmiths ...» ${ }^{519}$

Aufgrund des aktuellen Stands der Befunde und Untersuchungen gehe ich von der These aus, es handle sich bei den Lehmumhüllungen aus Augusta Raurica um Abfallprodukte von Aufkohlungprozessen und nicht um Reste anderer Technologien ${ }^{520}$. Mit den im Folgenden vorgestellten Funden aus Augusta Raurica, ihrer Analyse und den daraus abgeleiteten Experimenten kommen wir den effektiven «Rezepten» etwas näher:

\section{Beschreibung}

Die Fragmente aus Augusta Raurica (Abb.50) sind äusserst einheitlich bezüglich Tonstruktur, Farbe und Aufbau. Lediglich die Grössen und die Formen der inneren Querschnitte (Negativabdrücke) variieren. Allen Objekten gemeinsam sind folgende Charakteristika:

Die Umhüllungen sind grob von Hand geformt und aussen etwas geglättet, jedoch nur selten sorgfältig (Abb. 50,23). Ihre Wandstärken messen meist um die $8 \mathrm{~mm}$, variierend in den Extremen von 4 bis $10 \mathrm{~mm}$. Mehrere Umhüllungen sind zweischichtig aufgebaut (Kat.-Nr. 5-7, 11-13 und evtl. 27). Beim besonders grossen Exemplar 22 zeugt ein deutlicher Aussenwulst von einem mehrstufigen Aufbau. Zuerst wurde das Mittelstück des dicken
Barrens umhüllt, dann das Endstück darüber geformt (Abb. 50,22).

Die Gesamtform dieser Lehmumhüllungen wäre wegen der starken Fragmentierung schwierig zu rekonstruieren. Zum Glück liegen von einem Stück (Abb. 50,2) genügend, zum Teil anpassende Bruchstücke vor, um zu erkennen, dass es sich ursprünglich um röhrenförmige Gebilde mit beidseitig sich verjüngenden Enden handelt. Die Grössen dieser Lehmumhüllungen schwanken relativ stark. Ihre äusseren Durchmesser betragen in der Mehrzahl der Fälle um die $4-5 \mathrm{~cm}$, aber einige besonders grosse Stücke bringen es auf $6-9 \mathrm{~cm}$.

Die Innenquerschnitte sind oft kantig, aber es kommen auch annähernd kreisrunde Querschnitte vor (Abb. 50,7). In den meisten Fällen jedoch hatten die Stangen, welche einst in den Lehmumhüllungen steckten, einen vier-, fünf- oder sechseckigen Querschnitt (Abb. 50,2.1012.18d.19.22). Typisch sind nicht unbedingt gleichseitige Formen, sondern eher trapezoidale Querschnitte. Ein besonders grosses Stück hat ausnahmsweise einen ovalen Querschnitt (Abb. 50,6).

Der Ton ist sehr porös, relativ weich und sandet leicht ab. Eine Brenntemperatur lässt sich von Auge nicht abschätzen. Die im Binokular erkennbaren leichten Versinterungen (Abb. 57) lassen jedoch auf die Einwirkung hoher Temperaturen während langer Zeit schliessen (dazu unten S. 108).

An den äusseren Oberflächen fallen viele kleine und kleinste Vertiefungen im Lehm auf. Diese sind in wenigen Fällen noch mit Holzkohleflitterchen gefüllt, meist aber ausgebrannt und «leer»(Abb.51, oben). Es scheint, dass die mit Lehm umhüllten «Pakete» noch weich und feucht ins Holzkohlefeuer gelegt und allmählich getrocknet, dann gebrannt und schliesslich geglüht worden sind. In einem Fall ist ein enges Loch mit 3-4 mm Durchmesser durchgehend (Abb. 50,18a), als wäre ein dünnes Ästchen in den Lehm geraten und im Feuer ausgebrannt.

Die Tonfarbe ist ebenfalls sehr einheitlich: Die Stücke sind orangebeige bis rötlich-ockerfarben. Spuren von sehr starker Hitzeeinwirkung, wie Versinterungen oder «Glasu-

\footnotetext{
517 Craddock 2010, 252.

518 Rehder 1989, 36.

519 Maddin et al. 1991, 19

520 Guntram Gassmann schreibt freundlicherweise dazu: «Eventuell handelt es sich bei der Verpackung [aus Augusta Raurica] um Schutzhüllen, die beim Feuerverschweissen angelegt wurden, um Verzunderungen zu vermeiden.» (E-Mail vom 14.01.2016).
} 
(2) $10(0)$

(a) 10

OLI. $\theta_{3}$

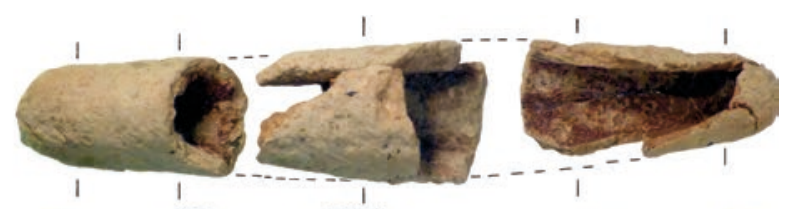

(0) (0) (1) 30
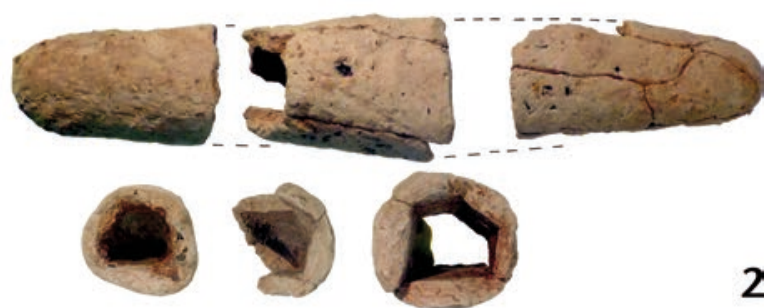

2
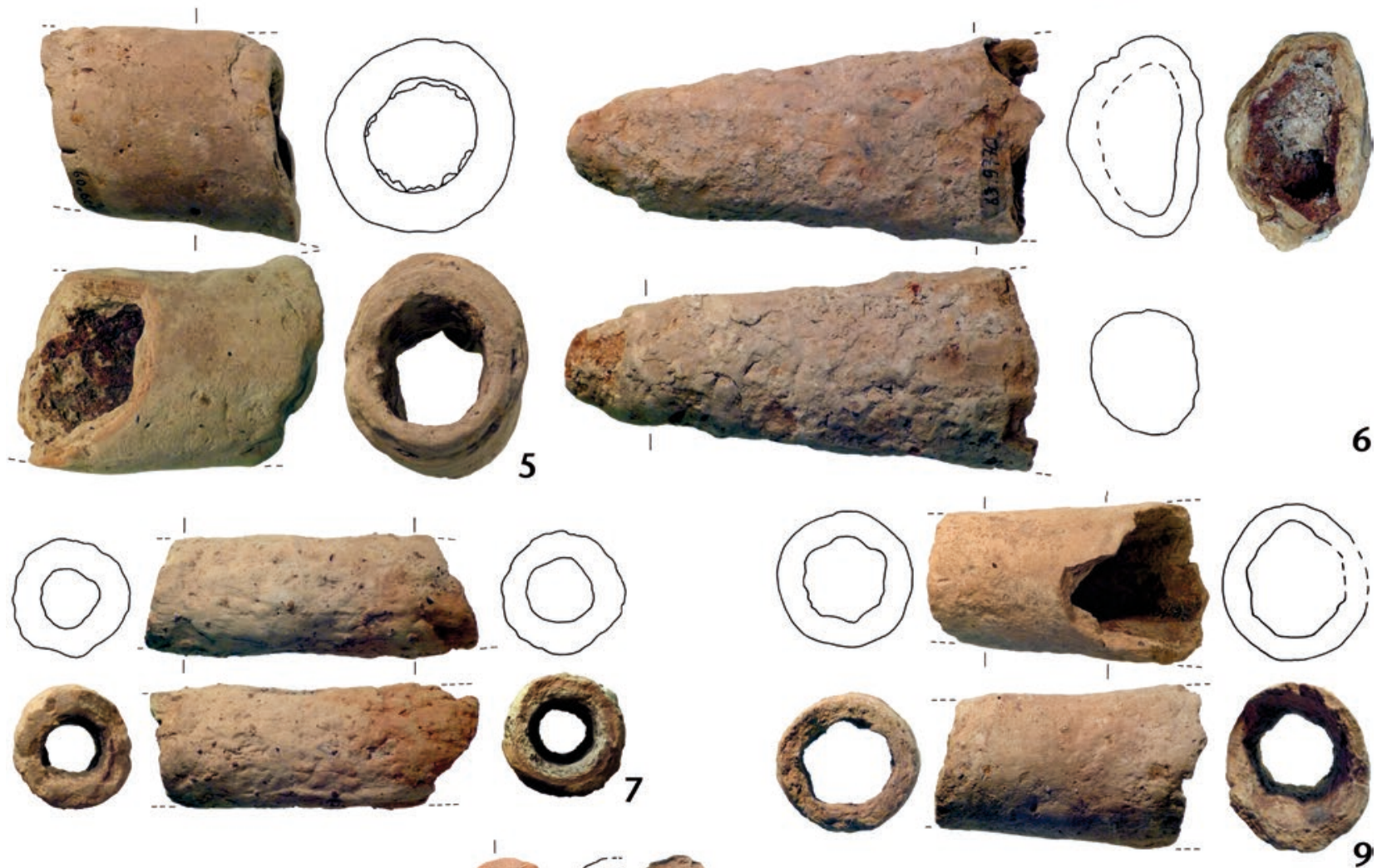

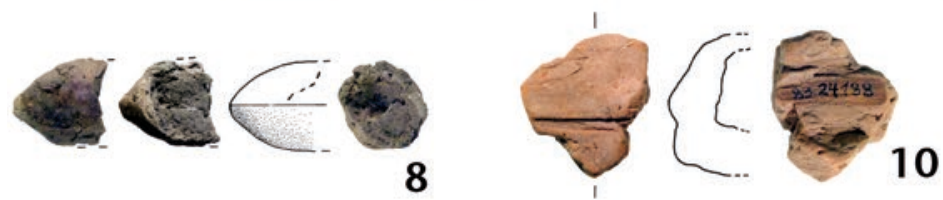
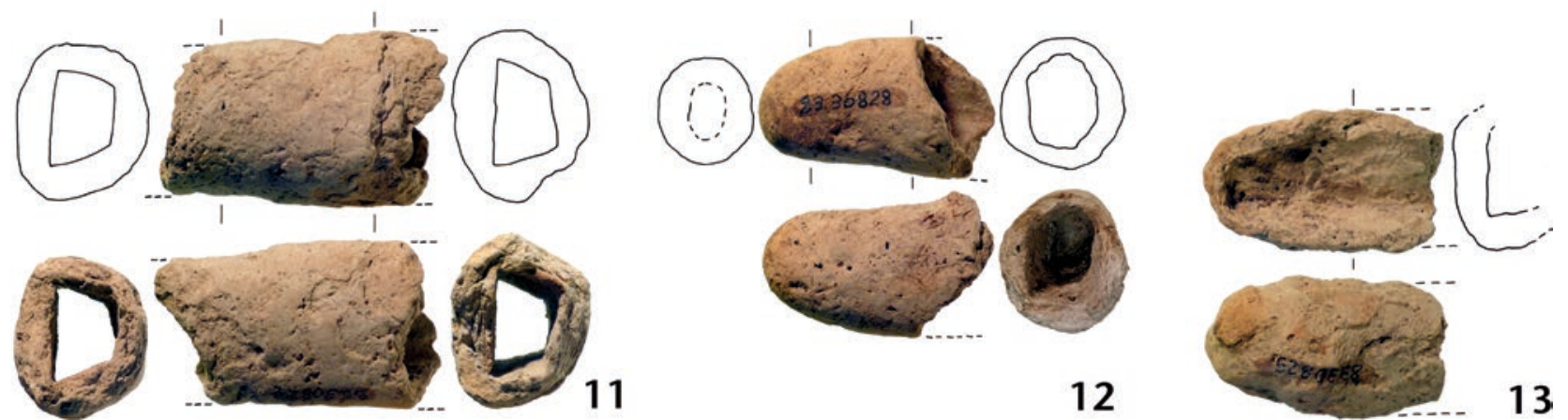

Abb. 50, Teil 1: Augst/BL, Augusta Raurica. Lehmumhüllungen 1-13 aus verschiedenen Stadtteilen (Abb. 55; siehe Katalog). M. 1:3. 

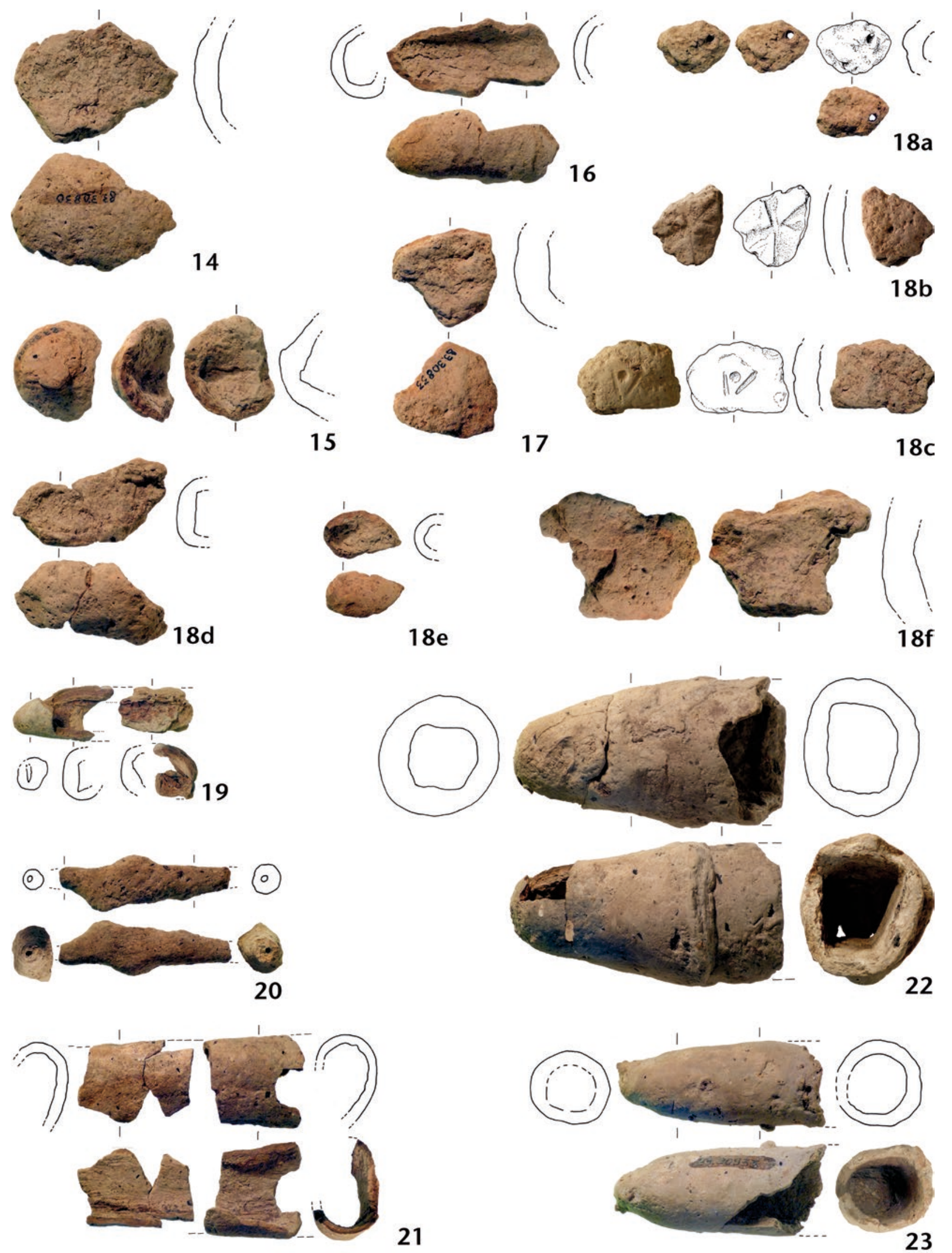

Abb. 50, Teil 2: Augst/BL, Augusta Raurica. Lehmumhüllungen 14-23 aus verschiedenen Stadtteilen (Abb. 55; siehe Katalog). M. 1:3. 

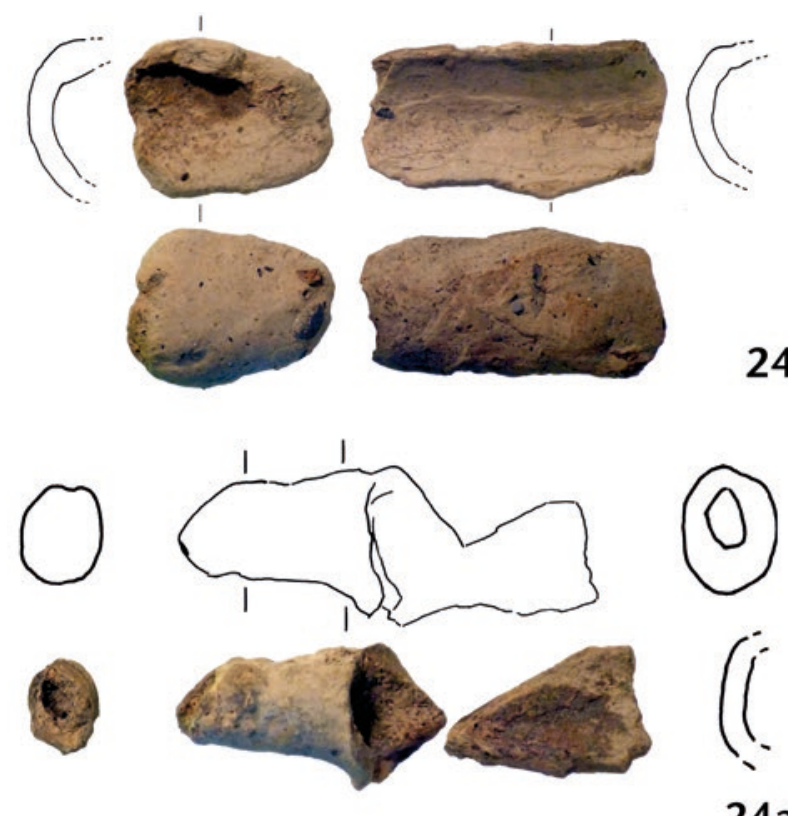

$24 a$
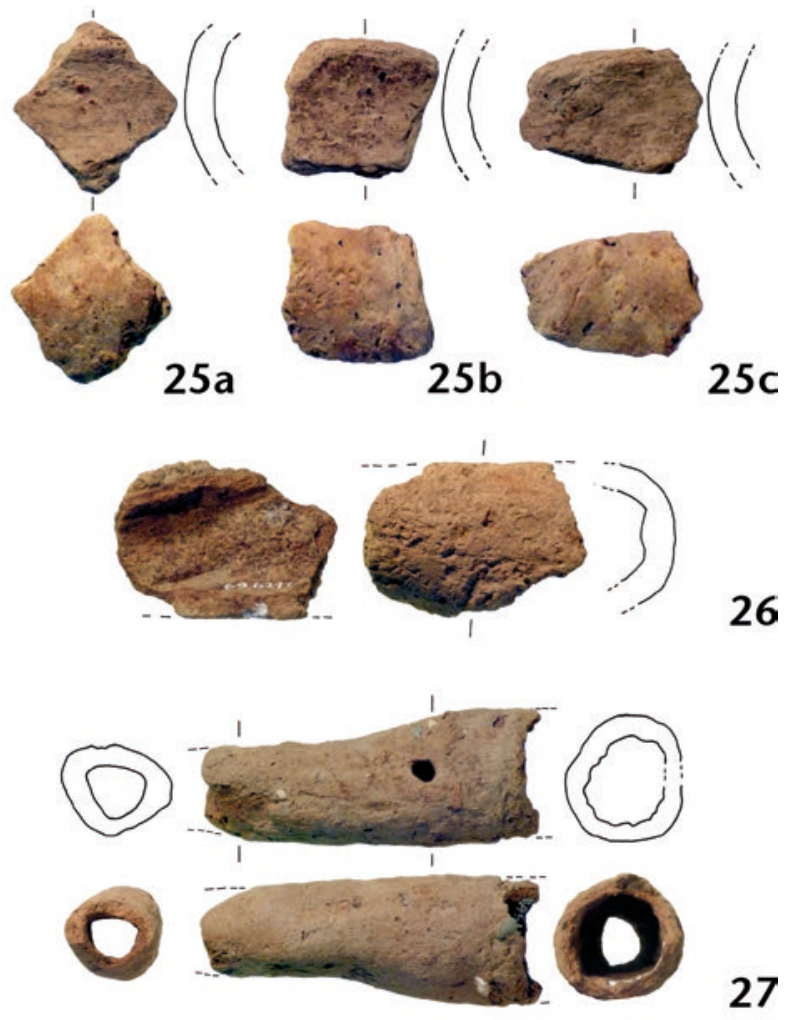

Abb. 50, Teil 3: Augst/BL, Augusta Raurica. Lehmumhüllungen 24-27 aus verschiedenen Stadtteilen (Abb. 55; siehe Katalog). M. 1:3. 

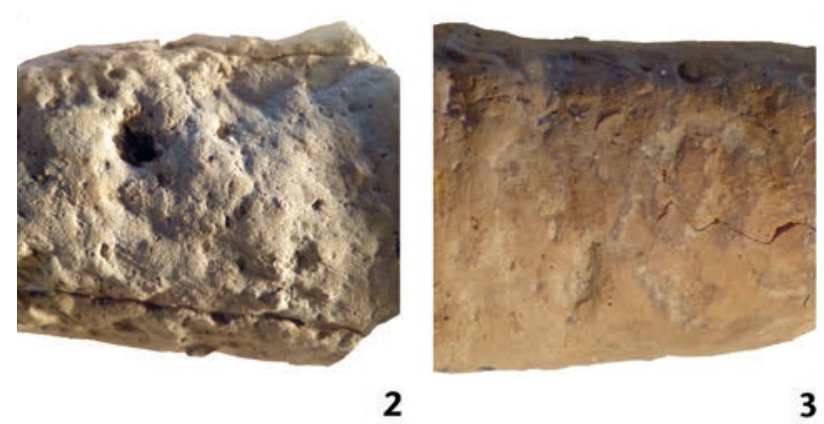

2
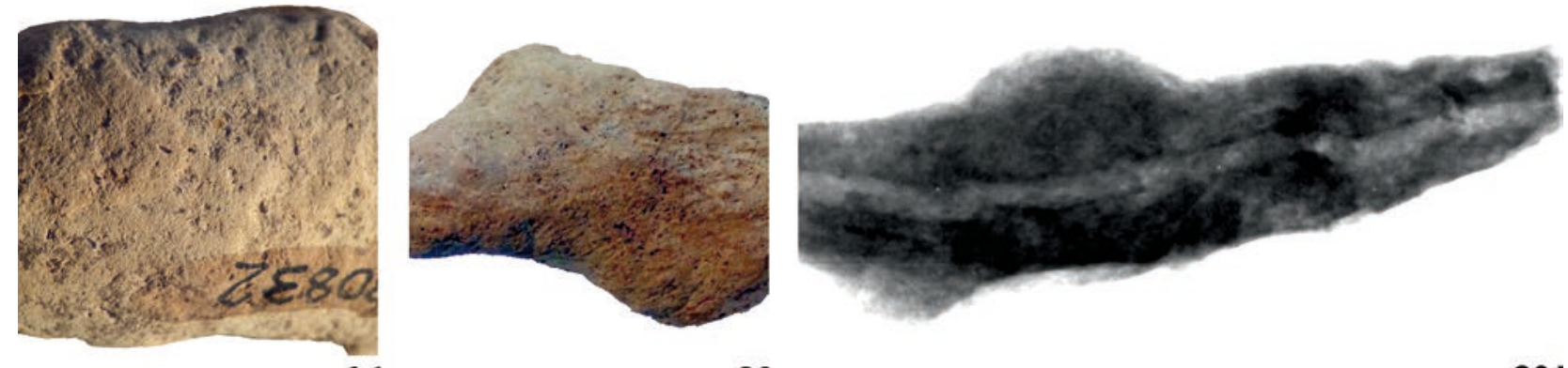

20
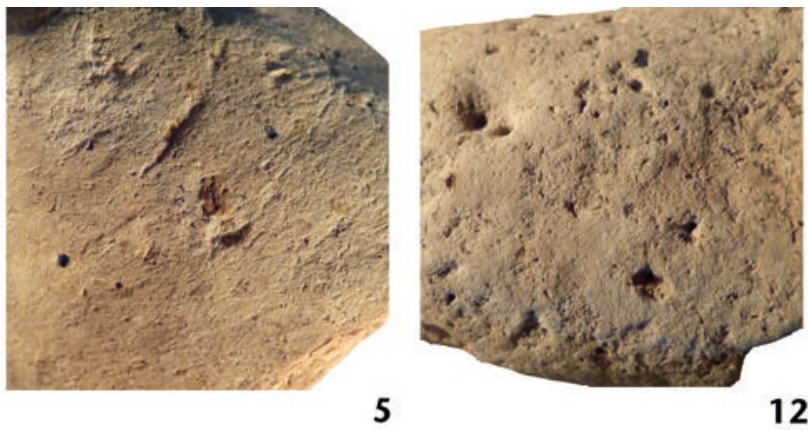

12

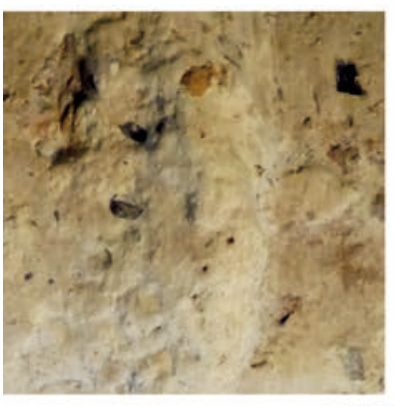

22

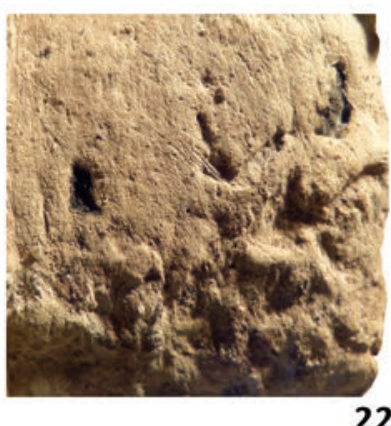

22
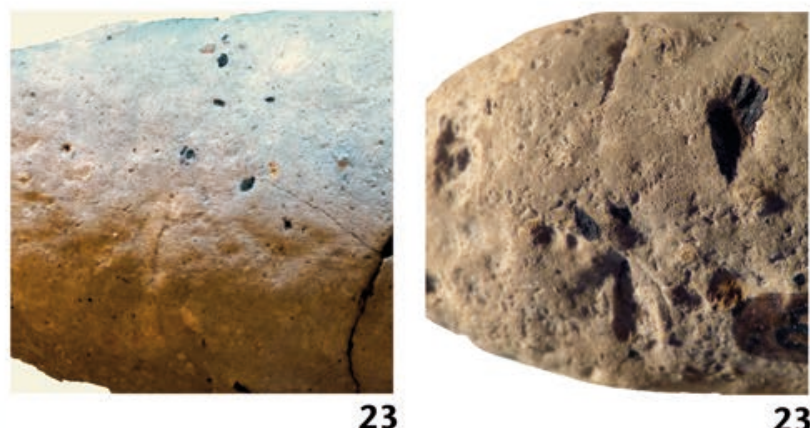
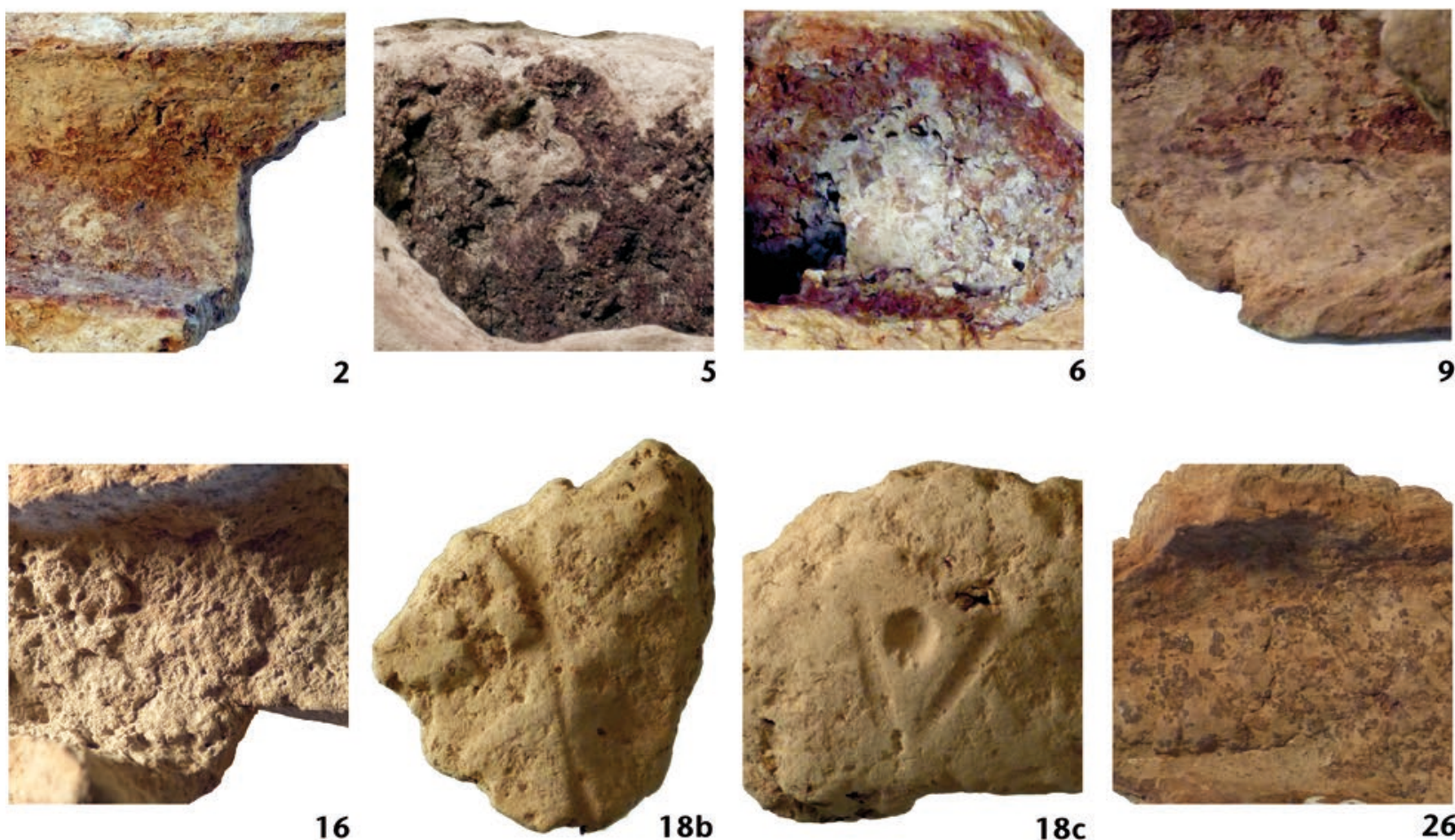
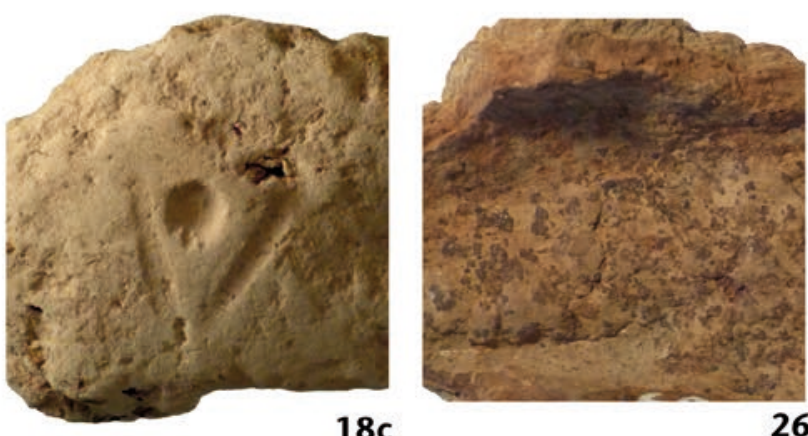

Abb. 51: Augst/BL, Augusta Raurica. Ausgewählte Details von Lehmumhüllungen (Katalognummern wie Abb. 50). Obere drei Reihen: Aussenseiten (20* Computer-Tomographie); untere zwei Reihen: Innenseiten. M. 1:1. 

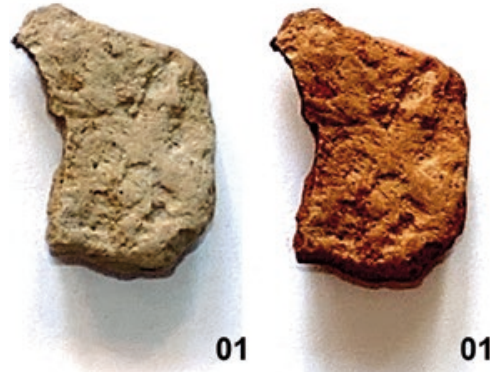

01
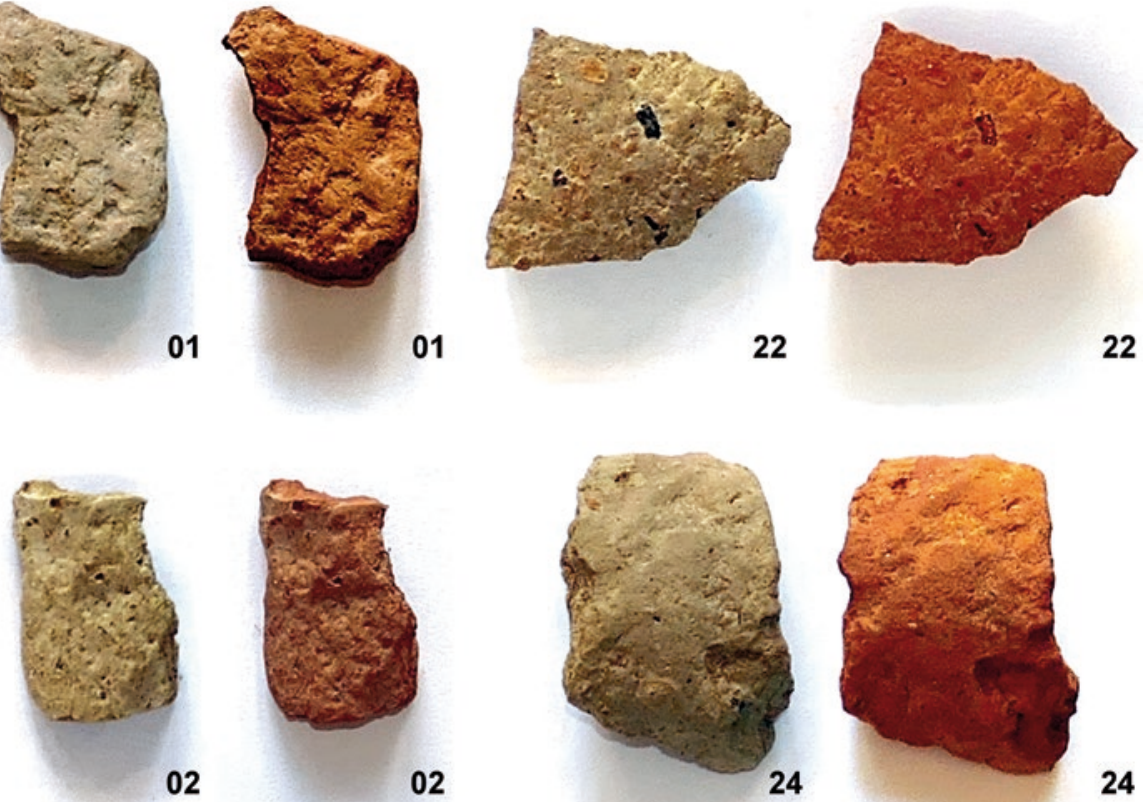

02

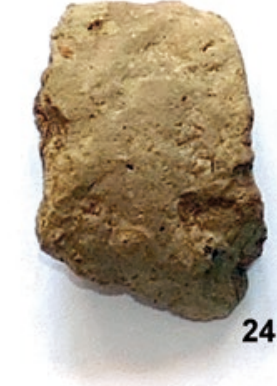

$10 \mathrm{~cm}$

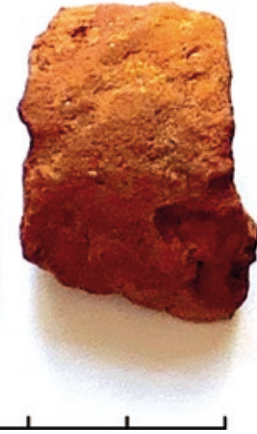

22

Abb. 52: Augst/BL, Augusta

24 Rachica. Nachände von Kleinfragmenten der Katalognummern 01, 02, 22 und 24; links jeweils im Fundzustand und rechts nach dem Nachbrand. M. 1:1. ren», finden sich auf keiner Oberfläche der Objekte. Wo die Oberfläche innen besser erhalten ist, ist sie bräunlich bis rostfarben gefleckt (Eisenoxidflecken?). Diese innere Braunfärbung kann ganz dünn sein (z.B.ca. 0,5 mm auf Abb. 50,2; 51,2) oder mit 3-4 mm sich bis etwa zur Mitte der Wanddicke ausgewirkt haben (Beispiele Abb. 50,19.26; 51,26). Eine künstliche Magerung ist - selbst an frischen Brüchen - von Auge nicht erkennbar (zur natürlichen, äusserst feinen «Magerung» des Tones, erkennbar unter dem Binokular, siehe unten mit Abb. 57).

Es sollte abgeklärt werden, ob die orangebeigen bis rötlich-ockerfarbenen Oberflächen der Funde dem ursprünglichen Zustand entsprechen und wieso sie nicht genauso rot wie Teile der Rekonstruktionen (Abb. 76) erhalten sind. Um dies abzuklären, wurde ein Nachbrand einiger kleiner Fragmente in oxidierender Atmosphäre durchgeführt (Abb.52). Der Keramikspezialist Markus Helfert schreibt dazu: «Durch die Bodenlagerung kann eine solche Farbänderung nicht passieren. Meines Erachtens sehen wir hier den Einfluss der (leicht) reduzierenden Atmosphäre bei der Aufkohlung des Eisens im Ofen. Durch den Nachbrand wurde vor allem das Eisenoxid im Ton $\mathrm{zu} \mathrm{Fe}_{2} \mathrm{O}_{3}$ oxidiert, was zu der roten Farbe führt (Abb.52, jeweils rechts). Die noch vorhandenen Holzkohleflitter (z.B.Abb. 51,22.23) sind ein gutes Indiz für das reduzierende Milieu bei der Herstellung.»521 Die stärker ins Rötliche oxidierten Rekonstruktionen (Abb. 76 und 77) zeugen von einer grösseren Sauerstoffzufuhr, als sie offenbar im antiken Zementationsofen herrschte.
Zwei Fragmente aus demselben Fundkomplex zeigen innen vage Negativabdrücke von Umwicklungen (Abb. 50,18b.18c; 51,18b.18c), die ich aufgrund ähnlicher Stücke aus dem frühmittelalterlichen Skandinavien mit besserer Erhaltung (Abb. 29,1.9.14) ${ }^{522}$ als Schnur- und Knotenabdrücke interpretiere. Leider sind die Oberflächen zu sandig und verwischt, um Details erkennen zu können. Kleine Negativwülste an einigen Innenkanten anderer Stücke (z. B. Abb. 50,26) und Verbreiterungen innen in manchen Endstücken der Lehmumhüllungen (z. B. Abb. 50,13) lassen erkennen, dass die Inhalte einst mit einem weichen Material umwickelt waren. Dies führte zu kleinen Wülsten an den Längskanten und zu leicht verdickten Enden bei einigen der umhüllten Stangen.
521 Auf die Möglichkeit eines Nachbrandes hat mich Markus Helfert (Universität Frankfurt a. M. / D) hingewiesen, der auch das Ergebnis kommentiert hat (E-Mail vom 28.06.2018). Der Brand erfolgte in einem einfachen Emailofen bei rund $700^{\circ} \mathrm{C}$ während $40 \mathrm{Minu}$ ten (zuzüglich Aufheizzeit).

522 Söderberg 2008, 3f. Abb. 8-17 (= hier Abb. 29,11-18). 


\section{Katalog}

1 (Nachbrand: Abb. 52,01) Inv. 1995.060.D02750.7. Drei Fragmente vom Endstück einer Lehmumhüllung. Ton hellbraun bis ockerfarben, innen leicht bräunlichbeige. Oberflächen stark abgewittert. Querschnitt innen und aussen oval. Masse: L. noch $37 \mathrm{~mm}$, Wanddicke noch 4-6 mm, Dm. aussen max. ca. $42 \mathrm{~mm}$, innen max. ca. $35 \mathrm{~mm}$. Analyse: Probe 1995_060_D02750_7_a (innen: Tabelle 2); Literatur: Sütterlin 1996 (Grabung generell); Fundkomplex D02750, Grabung 1995.060, Grabungsname: Elektro-Leitung Steinler, Region: Insula 19. Sediment: grauer siltiger Lehm mit Holzkohle; Fundkomplexdatierung: um 1 bis 50; Datierungsgüte: wenig Material.

2 (Nachbrand: Abb. 52,02) Inv. 1980.33753. 2 Endstücke und Mittelteil einer Lehmumhüllung, zusammengesetzt aus 11 Fragmenten. Querschnitt aussen rundlich, innen fünfkantig (hausdachförmig). Die beiden sich verjüngenden, geschlossenen Endstücke zeigen ähnliche Innenformen. Ton ockergelb, weich (Abb. 51,2); innen ockergrauer unregelmässiger Belag (Abb. 51,2). Masse: L. 63, 65 und $75 \mathrm{~mm}$; L. rekonstruiert ca. $250 \mathrm{~mm}$. Dm. max. $44 \mathrm{~mm}$, Wanddicke 5-8 mm. Analyse: Probe 1980_33753_a (aussen) und Probe 1980_33753_b (innen; Tabelle 2); Literatur: Tomasevic-Buck 1985, 247-253 (Grabung generell); Fundkomplex B06071, Grabung 1980.051, Grabungsname: W. Stutz Parz. 815, Region: Insula 22. Abtragsdicke $0,39 \mathrm{~cm}$. Sediment: Kanal[verfüllung] vor Profil 15 und Profil 16; Fundkomplexdatierung: nicht möglich (keine Begleitfunde).

3 Inv. 1980.34900. Mittelstück von einer Lehmumhüllung, innen mit verrundet-sechskantigem Querschnitt, aussen rundlich. Ton aussen ockerbraun, weich (Abb. 51,3); innen dunkelbrauner unregelmässiger Belag. Masse: L. noch $68 \mathrm{~mm}$; Wanddicke $5 \mathrm{~mm}$. Dm. aussen 27-34 mm, innen 16-21 mm; Literatur: wie Kat.-Nr. 2; Fundkomplex B06174, Grabung 1980.051, Region: Insula 22. Abtragsdicke $0,24 \mathrm{~cm}$. Fundkomplexdatierung: Tendenz «früh»; Datierungsgüte: kaum Material.

4 Inv. 1988.051.C05038.18. Endstück (3 kleine anpassende Fragmente) einer Lehmumhüllung. Querschnitt aussen rundlich, innen kantig. Ton ockergelb, weich; innen brauner Belag. Masse: L. noch $22 \mathrm{~mm}$, Wanddicke 6-7 mm. Dm. mind. $35 \mathrm{~mm}$, innen $14 \times 20 \mathrm{~mm}$. Analyse: Probe 1988_051_C05038_a (innen: Tabelle 2); Literatur: Hänggi 1989, 50 f. Abb. 32 (= hier Abb. 53); 33; 57; 65; Fundkomplex C05038, Grabung 1988.051, Grabungsname: Vögtlin, Region: Insula 22. Sediment: diverse geschichtete Gehhorizonte, mit verziegeltem Material von Herdstellen vermischt; rot verbrannt, gelb-ocker und schwarz-braun geschichtet. Fundkontext: mehrere Schmiedebefunde in Bauperioden 1 und 2 (1. Hälfte 1.Jh.). Fundkomplexdatierung: um 10 bis 100; Datierungsgüte: wenig Material.

5 Inv. 1960.6081. Zylindersegment, leicht konisch. Die beiden (Bruch-)Enden sind sekundär angeschliffen und zeigen konzentrische Strukturen von mindestens zwei Lehmschichten. Oberfläche aussen ockerfarben und geglättet (Abb.51,5), innen mit stellenweise brauner Kruste (Abb. 51,5). Querschnitt aussen oval, innen oval bis kantig. Masse: L. noch $76 \mathrm{~mm}$, Wanddicke $11-16 \mathrm{~mm}$. Dm. $64 \times 72 \mathrm{~mm}$, innen $38 \times 46 \mathrm{~mm}$; Literatur: Steiger et al. 1977 (Grabung generell); Fundkomplex V04120, Grabung 1960.054, Grabungsname: Steinler Insula 31, Region: Insula 31. Abtragsdicke $0,24 \mathrm{~cm}$. Fundkomplexdatierung: um 20 bis 50; Datierungsgüte: wenig Material.

6 Inv. 1963.9770. Spitz zulaufende, geschlossene Röhre. Im Bruch Struktur von mindestens zwei Lehmschichten. Oberfläche aussen ockerfarben und uneben-«narbig», innen mit brauner Kruste
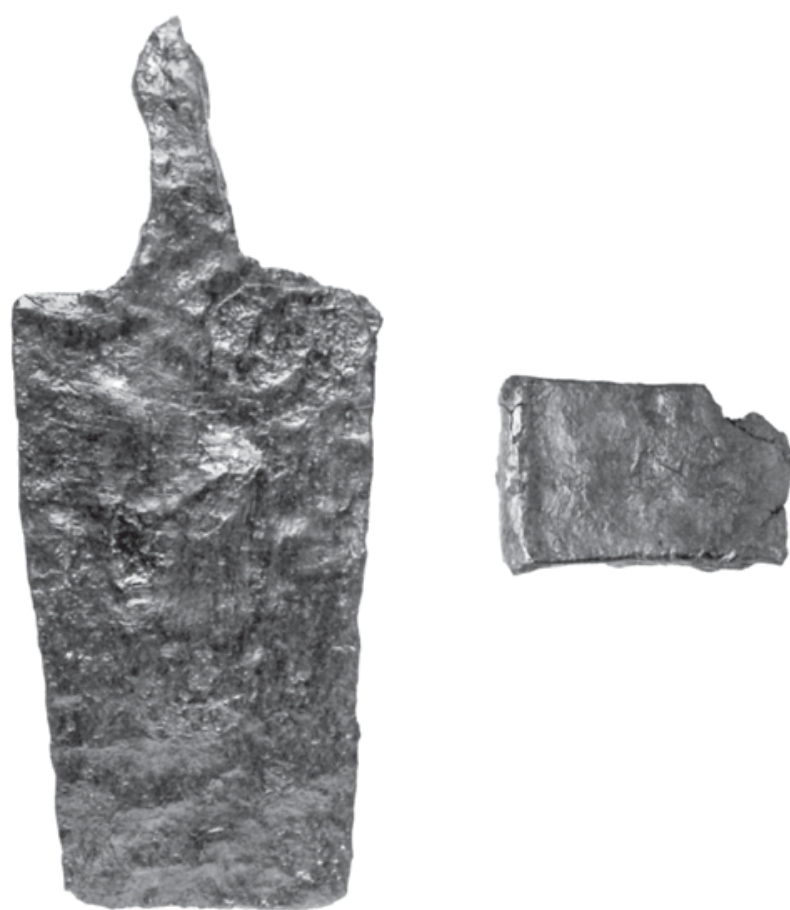

Abb. 53: Augst/BL, Augusta Raurica, Insula 22. Zwei Eisenobjekte aus den Schmiedebefunden von Bauzustand 1. Links Schmiedehalbfabrikat(?), rechts Fragment eines schmalen Barrens(?). M. 1:2.

(Abb.51,6); Spitze mit hellbeiger lehmiger Erde gefüllt. Querschnitt aussen oval, innen verrundet D-förmig. Masse: L.noch $180 \mathrm{~mm}$, Wanddicke 11-12 mm. Dm. max. $51 \times 77 \mathrm{~mm}$, innen max. $57 \times 30 \mathrm{~mm}$. Analyse: Probe 1963_09770_a (innen: Tabelle 2); Literatur: Laur-Belart 1964, LVIIIf. (Grabung generell); Fundkomplex V04690, Grabung 1963.054, Grabungsname: Steinler Insula 31, Region: Insula 31. Fundkomplexdatierung: nicht möglich (keine Begleitfunde)

7 Inv. 1964.1211. Zylindersegment (nicht konisch). Ein Ende ist alt abgeschnitten und stumpf, das andere gebrochen. Konzentrische Strukturen von zwei Lehmschichten. Oberfläche aussen ockerfarben und «narbig»; innen grau und uneben. Querschnitt aussen und innen unregelmässig rund. Masse: L. noch $124 \mathrm{~mm}$, Wanddicke 9-11 mm. Dm. $45 \times 47$ mm, innen $24 \times 25$ mm; Literatur: LaurBelart 1965, LXf. (Grabung generell); Fundkomplex Y01506 («aus Feuergrube»), Grabung 1964.054, Grabungsname: Steinler Insula 31, Region: Insula 31. Sondierschnitt S59/S47 (Schicht 6/9 nach Profil 60a); Abtragsdicke 0,14 m. Fundkomplexdatierung: um 20 bis 50; Datierungsgüte: wenig Material, 1 Münze (As, 16 v.-22 n. Chr.).

8 Inv. 1978.24301. Ende einer Lehmumhüllung? Poröses, lehmiges Material, dunkelgrau. Das erhaltene Ende endet eiförmig-spitz. Im Bruch ist gerade noch das dünne Ende eines Längshohlraums zu erkennen. Querschnitt aussen rund. Masse: L. noch $30 \mathrm{~mm}$, Dm. aussen 25 mm. Analyse: Probe 1978_24301_a (aussen: Tabelle 2); Literatur: Tomasevic-Buck 1984, 7-20 (Grabung generell); Fundkomplex B01611 (darin auch Eisenbrocken Abb.54, oben), Grabung 1978.052, Grabungsname: Giebenacherstrasse (Strassenverbreiterung), Region: Insula 31. Fundkomplexdatierung: um 190 bis 250; keine Angaben zur Datierungsgüte.

9 Inv. 1978.10498. Zylindersegment, konisch zulaufend. Ein Ende ist evtl. alt gebrochen und stumpf, das andere schräg gebrochen. Oberfläche aussen ockerfarben und relativ glatt; innen mit braunen Flecken (Abb. 51,9). Querschnitt aussen unregelmässig rund, 
innen sechseckig mit z. T. scharfen Kanten. Masse: L. noch 93 mm, Wanddicke 8-9 mm. Dm. 50-60 mm, innen 30-42 mm; Literatur: wie Kat.-Nr.8; Fundkomplex B01835, Grabung 1978.052, Grabungsname: Giebenacherstrasse, Region: Insula 31. Abtragsdicke 0,76 m. Fundkomplexdatierung: um 20 bis 50; Datierungsgüte: wenig Material.

10 Inv. 1983.24188. Wandbruchstück einer Lehmummantelung (oder «Hüttenlehmfragment»?). Ton aussen rötlich-hellgrau, innen blassrot. Oberfläche aussen glatt, innen streifige Längsabdrücke. Querschnitt aussen rundlich, innen unbestimmbar. Masse: Fragmentgrösse noch $40 \times 46 \mathrm{~mm}$, Wanddicke $11-14 \mathrm{~mm}$. Dm. geschätzt: aussen ca. $60 \mathrm{~mm}$, innen ca. $35 \mathrm{~mm}$; Literatur: kurzer Fundbericht in: Jahrbuch der Schweizerischen Gesellschaft für Ur- und Frühgeschichte 67, 1984, 210 Abb. 48 (Grabung generell); Schatzmann 2013, 202f. (jüngster Raumbefund); 206 (Befunddatierung Steinbau-Raum 9), Abb. 141 (Grundriss [jüngste Phase!]) und 143 (Münzen); Fundkomplex C00017, Grabung 1983.052 (s. auch Eisenstange Abb. 54, unten), Region: Insula 35, südwestliche Gebäudeeinheit, Raum 9. Abtragsdicke 0,48 m. Fundkomplexdatierung: um 100 bis 200; Befunddatierung: frühes 3.Jh.; Datierungsgüte: gut, viel Material, mit wenigen frühen Ausreissern; 3 Münzen, 161-207 n. Chr.

11 Inv. 1983.30827. Mittelteil einer Lehmumhüllung, bestehend aus einem umlaufenden Teilstück. Querschnitt aussen oval, innen fünfkantig (hausdachförmig), innere Breite sich von 36 auf $32 \mathrm{~mm}$ leicht verjüngend. Tonaufbau in zwei Schichten. Ton ockergelb, weich; innen ohne Belag. Masse: L. noch $91 \mathrm{~mm}$, Wanddicke 9-13 mm. Dm. max. $48 \times 59 \mathrm{~mm}$, innen $21 \times 32$ bis $22 \times 36 \mathrm{~mm}$; Literatur: wie Kat.-Nr. 10; Fundkomplex C00296, aus einer braunbeigen Werkstattschicht mit Holzkohlen (Abb. 56, links), Grabung 1983.052, Region: Insula 35. Abtragsdicke 0,26 m. Fundkomplexdatierung: nicht möglich (keine Begleitfunde).

12 Inv. 1983.30828. Endstück einer Lehmumhüllung, bestehend aus einem umlaufenden Teilstück. Querschnitt aussen rundlich, innen fünfkantig-verrundet (etwa hausdachförmig). Tonaufbau vermutlich mehrschichtig. Ton ockergelb, weich (Abb. 51,12); innen schwache Spuren eines ockerbraunen Belags. Masse: L. noch $80 \mathrm{~mm}$, Wanddicke 6-10 mm. Dm. max. $47 \times 50 \mathrm{~mm}$, innen bis 24-29 mm. Analyse: Probe 1983_30828_a (aussen); Probe 1983_30828_b (innen; Tabelle 2); Literatur: wie Kat.-Nr. 10; Fundkomplex C00296 (wie Kat.-Nr. 11); Grabung 1983.052, Region: Insula 35. Abtragsdicke $0,26 \mathrm{~m}$. Fundkomplexdatierung: nicht möglich (keine Begleitfunde).

13 Inv. 1983.30829. Endstück einer Lehmumhüllung, längs gebrochen. Querschnitt aussen rundlich, innen kantig (ein leicht spitzer Winkel erhalten). Ton zweischichtig, ockergelb, weich; innen keine Spuren eines Belags. Masse: L. noch $76 \mathrm{~mm}$, Wanddicke $8-10 \mathrm{~mm}$. Dm. ca. $45 \mathrm{~mm}$, innen bis ca. $26 \mathrm{~mm}$; Literatur: wie Kat.-Nr. 10; Fundkomplex C00296 (wie Kat.-Nr. 11); Grabung 1983.052, Region: Insula 35. Abtragsdicke 0,26 m. Fundkomplexdatierung: nicht möglich (keine Begleitfunde).

14 Inv. 1983.30830. Wandbruchstück einer Lehmummantelung. Ton aussen und innen ockerfarben, sehr weich, Originaloberfläche innen abgewittert. Querschnitt aussen rundlich, innen unbestimmbar. Masse: Fragmentgrösse noch $68 \times 88 \mathrm{~mm}$, Wanddicke $11 \mathrm{~mm}$. Dm. geschätzt: aussen ca. $80 \mathrm{~mm}$, innen ca. $60 \mathrm{~mm}$; Literatur: wie Kat.-Nr. 10; Fundkomplex C00296 (wie Kat.-Nr. 11); Grabung 1983.052, Region: Insula 35. Abtragsdicke 0,26 m. Fundkomplexdatierung: nicht möglich (keine Begleitfunde).

15 Inv. 1983.30831. Endbruchstück einer grossen Lehmummantelung. Ton aussen und innen ockerfarben. Oberfläche aussen und innen «narbig»-uneben. Querschnitt aussen rundlich, innen un-
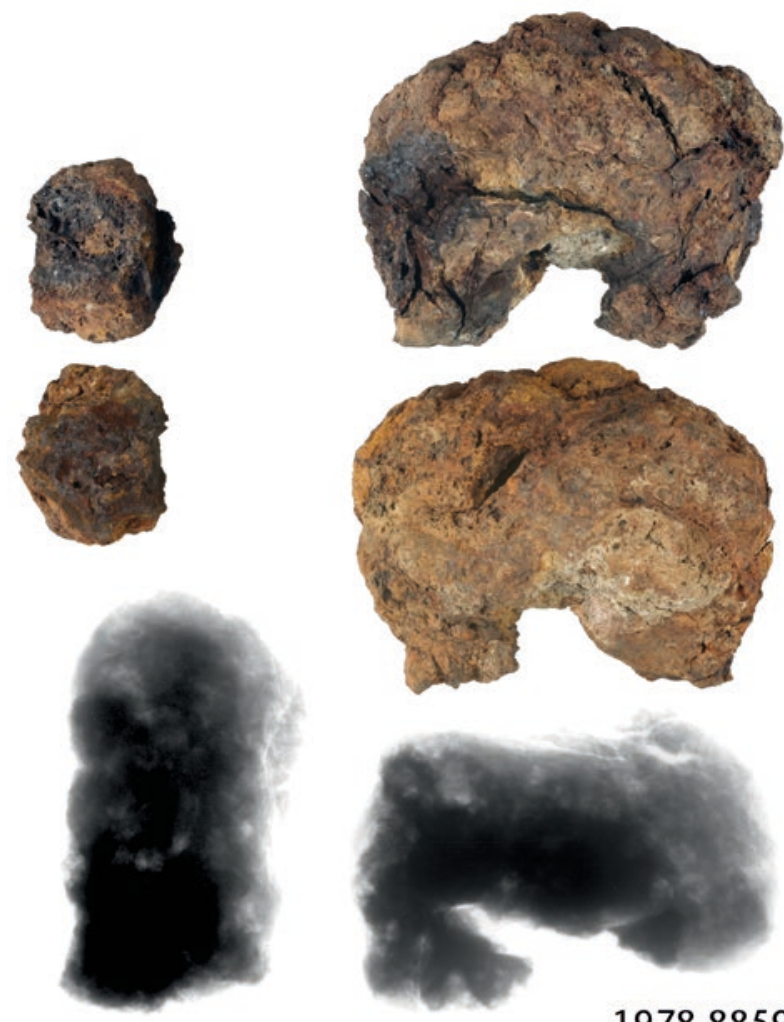

1978.8859
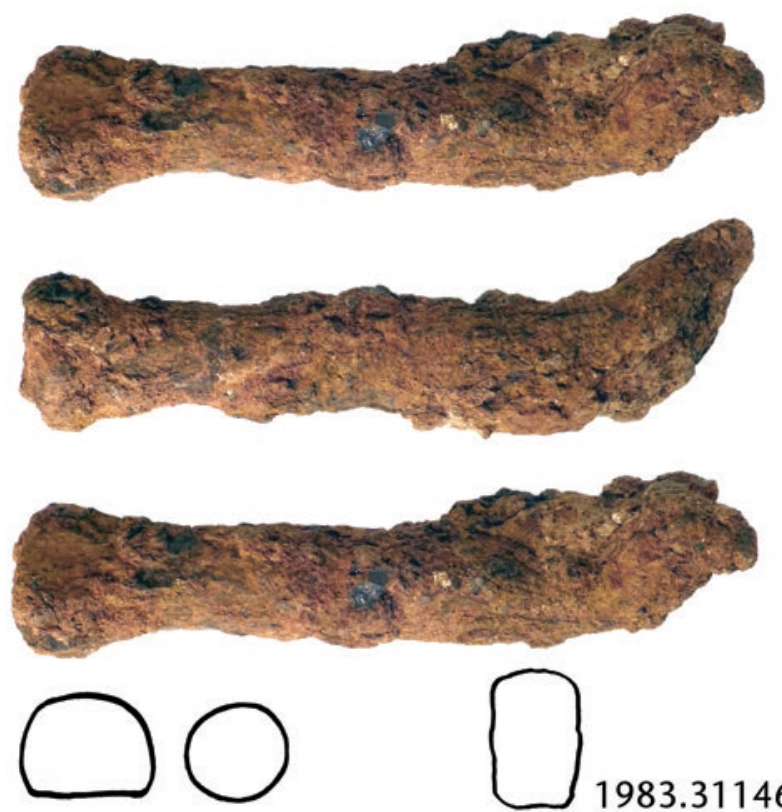

Abb. 54: Augst/BL, Augusta Raurica. Zwei massive Eisenstücke aus Grabungen mit Fragmenten von Lehmumhüllungen (Abb. 50): 1978.8859 aus Insula 31, FK B01611 (aus demselben Fundkomplex wie Abb. 50,8); 1983.31146 aus Insula 35 (aus derselben Grabung wie Abb. 50,10-25c), FK C00315. Nicht konserviert und analysiert. M. 1:2 
bestimmbar. Masse: Fragmentgrösse noch $44 \times 57 \mathrm{~mm}$, Wanddicke $13 \mathrm{~mm}$. Dm. geschätzt: aussen mind. $58 \mathrm{~mm}$, innen unbestimmbar; Literatur: wie Kat.-Nr. 10; Fundkomplex C00296 (wie Kat.-Nr. 11); Grabung 1983.052, Region: Insula 35. Abtragsdicke $0,26 \mathrm{~m}$. Fundkomplexdatierung: nicht möglich (keine Begleitfunde).

16 Inv. 1983.30832. Endstück einer relativ dünnwandigen Lehmumhüllung, längs gebrochen. Querschnitt aussen rundlich, innen oval. Ton offenbar einschichtig, ockergelb (Abb.51,16); innen keine Spuren eines Belags (Abb.51,16). Masse: Fragmentgrösse noch $40 \times 92 \mathrm{~mm}$, Wanddicke 6-7 mm. Dm. geschätzt: aussen ca. $42 \mathrm{~mm}$, innen mind. $30 \mathrm{~mm}$; Literatur: wie Kat.-Nr. 10; Fundkomplex C00296 (wie Kat.-Nr. 11); Grabung 1983.052, Region: Insula 35. Abtragsdicke 0,26 m. Fundkomplexdatierung: nicht möglich (keine Begleitfunde).

17 Inv. 1983.30833. Wandbruchstück einer Lehmummantelung. Ton sehr weich, aussen und innen ockerfarben. Oberfläche aussen und innen abgewittert. Querschnitt aussen rundlich, innen unbestimmbar. Masse: Fragmentgrösse noch $49 \times 56 \mathrm{~mm}$, Wanddicke 15-19 mm. Dm. mind. 110 mm; Literatur: wie Kat.-Nr. 10; Fundkomplex C00296 (wie Kat.-Nr. 11); Grabung 1983.052, Region: Insula 35. Abtragsdicke 0,26 m. Fundkomplexdatierung: nicht möglich (keine Begleitfunde).

18a-18f Inv. 1983.30834a-f. 25 grosse und kleine Bruchstücke von 2-3 Lehmummantelungen (mind. eine grosse und eine kleine). Ton sehr weich, Oberflächen meist verwittert. Tonfarbe ockergelb, innen in wenigen Fällen Spuren eines brauen Belags. 1 Fragment (1983.30834a) mit kleinem runden Loch von $4 \mathrm{~mm}$ Dm. (verkohltes Ästchen?); 1 Fragment (1983.30834b) mit grossem Innendurchmesser und darin sich kreuzenden Schnur(?)-Abdrücken (Abb. 51,18b); 1 Fragment (1983.30834c) mit sich kreuzenden Schnur- und Knotenabdrücken auf der Innenseite (Abb. 51,18c). Masse: Fragmentgrössen sehr unterschiedlich (13-88 mm). Wanddicken 6-21 mm. Dm. ca. 30 resp. max. ca. $110 \mathrm{~mm}$, innen schwer bestimmbar; Literatur: wie Kat.-Nr. 10; Fundkomplex C00296 (wie Kat.-Nr. 11); Grabung 1983.052, Region: Insula 35. Abtragsdicke 0,26 m. Fundkomplexdatierung: nicht möglich (keine Begleitfunde).

19 Inv. 1983.30927. 6 Fragmente einer(?) Lehmumhüllung, 2 davon Endstücke (nicht anpassend). Ton bräunlich-ockerfarben, im Innern z. T. rostbraune resp. graubraune Krusten. Querschnitt aussen rundlich, innen nicht bestimmbar. Masse: L. max. $49 \mathrm{~mm}$, Wanddicke 4-8 mm. Dm. mind. $40 \mathrm{~mm}$, innen unbestimmbar; Literatur: wie Kat.-Nr. 10; Fundkomplex C00308, aus einer graubraun-beigen Werkstattschicht (Schicht 21 nach Profil 28), sandig, mit Holzkohlen (Abb.56, links); Grabung 1983.052, Region: Insula 35. Abtragsdicke 0,30 m. Fundkomplexdatierung: um 20 bis 50; Datierungsgüte: einheitliches Material.

20 Inv. 1983.30927a. Unförmige Lehmumhüllung mit kleinem dünnen Längsloch (nicht einsehbar). Ein Ende wahrscheinlich Original, eines abgebrochen. Ton braun, relativ hart (Abb. 51,20). Befund der Röntgen-Tomographie (Abb. 51,20*): Das Loch verläuft in unregelmässiger Linie (leicht gewellt) durch die Mitte des Lehmobjekts und ist konstant gleich weit (ca. $3 \mathrm{~mm}$ ). Masse: L.noch $93 \mathrm{~mm}$, Wanddicke um $5 \mathrm{~mm}$ an den Enden und bis $13 \mathrm{~mm}$ im verdickten Mittelteil. Dm. 13-24 mm, innen $3 \mathrm{~mm}$. Analyse: Probe 1983_30927a_b (aussen beim Loch) und Probe 1983_30927a_c (aussen; Tabelle 2); Literatur: wie Kat.-Nr. 10; Fundkomplex C00308 (wie Kat.-Nr. 19); Grabung 1983.052, Region: Insula 35 Abtragsdicke 0,30 m. Fundkomplexdatierung: um 20 bis 50; Datierungsgüte: einheitliches Material.
21 Inv. 1983.30927b. Drei Wandbruchstücke einer relativ dünnwandigen Lehmummantelung. Ton ockerbraun, einschichtig aufgebaut, im Bruch rötlich, relativ hart gebrannt. Oberfläche aussen grob geglättet, innen mit Längsstruktur und bräunlichem Belag. Querschnitt aussen oval, innen flachgedrückt-oval. Masse: L. noch 48 resp. $62 \mathrm{~mm}$, Wanddicke $6 \mathrm{~mm}$. Dm. aussen 36 bis mind. $60 \mathrm{~mm}$, innen 25 bis mind. $42 \mathrm{~mm}$. Analyse: Probe 1983_30927b_a (aussen) und Probe 1983_30927b_b (innen; Tabelle 2); Literatur: wie Kat.-Nr. 10; Fundkomplex C00308 (wie Kat.-Nr. 19); Grabung 1983.052, Region: Insula 35. Abtragsdicke 0,30 m. Fundkomplexdatierung: um 20 bis 50; Datierungsgüte: einheitliches Material.

22 (Nachbrand: Abb. 52,22) Inv. 1983.30928. Vier grosse und ca. zehn kleine Fragmente eines Endstückes einer sehr grossen Lehmummantelung. Ein deutlicher Aussenwulst zeugt von einem mehrstufigen Aufbau (erst Mittelstück umhüllt, dann Endstück darüber geformt). Ton ockerfarben und weich, aussen seitlich am Ende leicht brandgeschwärzt; innen grau-ocker (ohne Belag). Oberfläche aussen grob geglättet, innen leicht narbig. Querschnitt aussen rundlich, innen verrundet-trapezförmig. Masse: L. noch $160 \mathrm{~mm}$, Wanddicke 7-13 mm. Dm. bis $68 \times 81 \mathrm{~mm}$; Trapez innen (an weitester Stelle gemessen): Basisbreite $40 \mathrm{~mm}$, Scheitelbreite $28 \mathrm{~mm}$, Trapezhöhe $56 \mathrm{~mm}$. Analyse: Probe 1983_30928_a (aussen) und Probe 1983_30928_b (innen; Tabelle 2); Literatur: wie Kat.-Nr. 10; Fundkomplex C00308 (wie Kat.-Nr. 19); Grabung 1983.052, Region: Insula 35. Abtragsdicke 0,30 m. Fundkomplexdatierung: um 20 bis 50; Datierungsgüte: einheitliches Material.

23 Inv. 1983.30933. Enge zylindrische Lehmumhüllung mit fast spitz zulaufendem Ende. Innen braungraue Kruste (1-2 mm dick) im Endstück einige zusammengebackene helle Steinchen. Ton: braungrau, mittelhart und schwach gebrannt, handgemacht, in der Matrix eingebettet mehrere Steinchen (bis $8 \mathrm{~mm}$ Grösse) und Holzkohlestückchen; aussen naturbelassen, ohne Brand- oder Schlackenspuren. Querschnitt aussen und innen rundlich. Masse L. noch $135 \mathrm{~mm}$, Dm. aussen $46 \mathrm{~mm}$, innen $35 \times 38 \mathrm{~mm}$. Wanddicke $5 \mathrm{~mm}$. Analyse: Probe 1983_30933_a (innen: Tabelle 2); Literatur: wie Kat.-Nr. 10; Fundkomplex C00309, aus einer graubeige gefleckten Werkstattschicht (Schicht 39 nach Profil 28) mit Holzkohlen (Abb. 56, links); Grabung 1983.052, Grabungsname: Steinlerstrasse, Region: Insula 35. Fundkomplexdatierung: Tendenz «früh»; Datierungsgüte: kaum Material.

24, 24a (Nachbrand: Abb. 52,24) Inv. 1983.30934. 5 grössere und 7 kleine Bruchstücke von zwei Lehmummantelungen. Ton weich, offenbar einlagig. Oberflächen z.T. schuppig abgewittert. Tonfarbe ockergelb, innen in wenigen Fällen Spuren eines braunen Belags. Querschnitt aussen und innen rundlich. Innen auf einigen Fragmenten eine 1-2 mm dünne sekundäre Lehmschicht (ebenfalls ockerfarben). 1 Fragment ist ein dünnes zapfenförmiges Endstück (1983.30934A). Masse: Fragmentlängen 47-92 mm, Wanddicken 5-11 mm. Dm. aussen ca. $50 \mathrm{~mm}$ (z. T. grösser), innen ca. 33 mm. Analyse: Probe 1983_30934_a (aussen) und Probe 1983_30934_b (innen; Tabelle 2); Literatur: wie Kat.-Nr. 10; Fundkomplex C00309 (wie Kat.-Nr. 23); Grabung 1983.052, Region: Insula 35. Abtragsdicke 0,30 m. Fundkomplexdatierung: Tendenz «früh»; Datierungsgüte: kaum Material.

25a-25c Inv. 1983.31017. 9 Fragmente einer Lehmummantelung. Ton ockerfarben, in Innern z. T. graubraune Flecken. Querschnitt aussen und innen rundlich. Masse: L. $\max .57 \mathrm{~mm}$, Wanddicke 8-11 mm. Dm. aussen ca. $76 \mathrm{~mm}$, innen ca. $60 \mathrm{~mm}$; Literatur: wie Kat.-Nr. 10; Fundkomplex C00311, aus einer braunbeigen Werkstattschicht (Schicht 34 nach Profil 28) mit siltigem Material (Abb.56, links); Grabung 1983.052, Region: Insula 35. Abtragsdicke 0,25 m. Fundkomplexdatierung: nicht möglich (keine Begleitfunde). 
Inv. 1969.6311. Wandbruchstück einer Lehmumhüllung. Ton aussen ockerfarben, innen braun gefleckt (Abb.51,26). Oberfläche aussen und innen uneben. Querschnitt aussen rundlich, innen kantig, einst vermutlich sechseckig. Masse: Fragmentgrösse noch $53 \times 68 \mathrm{~mm}$, Wanddicke $9 \mathrm{~mm}$. Dm. geschätzt: aussen ca. $53 \mathrm{~mm}$, innen ca. 33 mm. Analyse: Probe 1969_06311_a (innen: Tabelle 2); Literatur: Laur-Belart 1970, 288f. (Grabung allgemein); Fundkomplex A00470, Grabung 1969.053, Grabungsname: Venusstrasse (Ost und West), Region: Insula 44/50. Abtragsdicke 1,06 m. Sediment: Schutt, Ziegel und Steine mit Humus vermischt; Fundkomplexdatierung: um 180 bis 230; Datierungsgüte: wenig Material.

Inv. 1967.15691. Spitz zulaufende Röhre, an beiden Enden gebrochen. Im Bruch Struktur von möglicherweise zwei Lehmschichten. Im Lehm einige grössere graue und weisse Steinchen (eines ausgebrochen [Loch]?). Oberfläche aussen graubraun und uneben, innen mit rotbrauner Kruste. Querschnitt aussen rundlich, innen verrundet D-förmig (am schmaleren Ende) bis rundlich. Masse: L. noch $108 \mathrm{~mm}$, Wanddicke 7-8 mm. Dm. 30-40 mm, innen $14 \times 18$ bis $26 \times 27 \mathrm{~mm}$; Literatur: Laur-Belart 1968, XXII-XXV (Grabung allgemein); Fundkomplex X08104, Grabung 1967.051, Grabungsname: Kurzenbettli N2, Region: Region 5. Abtragsdicke 1,54 m. Sediment: Humus, Alluvion, Steine. Fundkomplexdatierung: um 1 bis 50; keine Angaben zur Datierungsgüte.

Im Kontext der Lehmfragmente 8 und 10-25c fanden sich u. a. zwei massive Eisenstücke (Abb. 54), die beide nicht konserviert sind und deren Analyse auf (erhöhten?) Kohlenstoff leider nicht möglich war. Es sind keine Geräte, sondern möglicherweise Eisenbarren. Nur ihre Massivität und Dimension, nicht jedoch Form und Querschnitte könnten zu einer Stahlproduktion in der postulierten Art passen.

\section{Datierung}

Die Lehmumhüllungen stammen von sechs verschiedenen Regionen (Insulae usw.; Abb.55) in Augusta Raurica und aus 16 verschiedenen Fundkomplexen. Nur vier davon sind nicht datierbar, weil sie keine Mitfunde aus Geschirrkeramik oder in Form von Münzen geliefert haben. Von zwölf der Fundensembles ist jedoch eine FundkomplexDatierung möglich ${ }^{523}$.

Die oben im Fundkatalog festgehaltenen Befund- und vor allem die Mitfunde-Datierungen zeigen deutlich, dass die meisten Belege von Eisen-Aufkohlung in Augusta Raurica in die Frühzeit der Stadt, d. h. in die Zeit der Holzbauten fallen! In mehreren Fällen sind die Lehmumhüllungsfragmente mit Geschirrkeramik und teilweise auch mit Münzen des 1.Jahrhunderts n. Chr. vergesellschaftet, meist sogar aus der ersten Jahrhunderthälfte (Kat.-Nr. 1, 5, 7, 1922, 27). Die mittlere Kaiserzeit ist bislang für diese metallurgischen Prozesse in Augusta Raurica nicht belegt. Erst wieder im späteren 2. und in der ersten Hälfte des 3.Jahrhunderts «tauchen» einige weitere Belege, nun aus den Steinbauperioden, wieder auf (Kat.-Nr. 8, 10, 26).

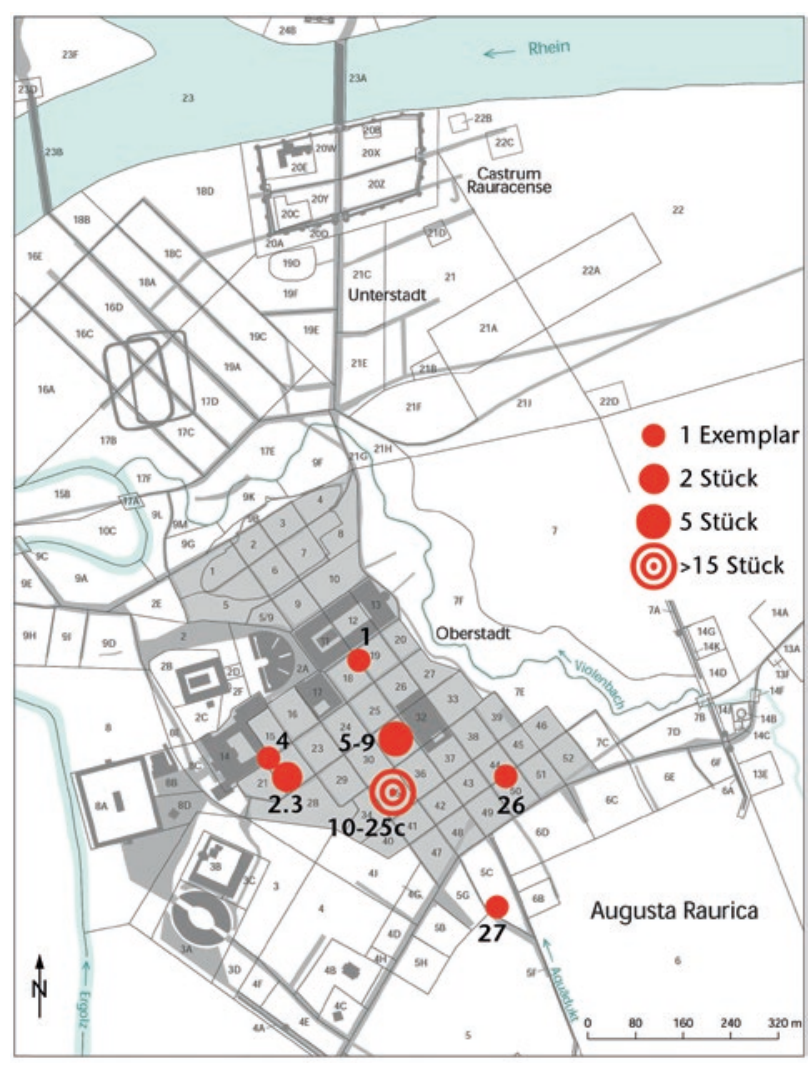

Abb. 55: Augst/BL, Augusta Raurica. Verbreitung der Lehmumhüllungen (Abb. 50) als Belege einer Stahlerzeugung, vor allem in der 1. Hälfte des 1. Jahrhunderts n. Chr. Fette Zahlen = Katalognummern. M. ca. 1:17000

\section{Verbreitung im Stadtareal und Befundkontext}

Die hier zusammengetragenen Lehmumhüllungsreste aus Augusta Raurica (Abb.50) stellen wohl nur einen verschwindend kleinen Bruchteil dieser unscheinbaren Fundgattung dar, die einst bei einem metallurgischen Prozess angefallen war. Es liegt in der Natur dieser Fragmente, dass sie schon beim Aufschlagen der Aufkohlungspakete stark fragmentiert worden, dann im Boden weiter zerfallen und schliesslich auf den Ausgrabungen gerne übersehen oder als «unwichtig» weggeworfen worden sind.

Die geborgenen und hier vorgelegten Stücke weisen zwei deutliche Konzentrationen auf: in Insula 31 und vor allem in der nur etwa $100 \mathrm{~m}$ südlich gelegenen Insula 35 (Abb. 55, grösste Symbole). Es scheint, dass an beiden Orten im 1.Jahrhundert n. Chr. Stahl aus Schmiedeeisen hergestellt worden ist (s. auch Abb. 56).

Die Einzelstücke stammen ebenfalls alle aus der Oberstadt und liegen in einem Umkreis von etwa $250 \mathrm{~m}$ um die

523 Ich danke an dieser Stelle Sylvia Fünfschilling für die Datierung von acht Fundkomplexen (die anderen vier FK-Datierungen sind schon früher ermittelt worden und der Inventar-Datenbank von Augusta Raurica entnommen). 

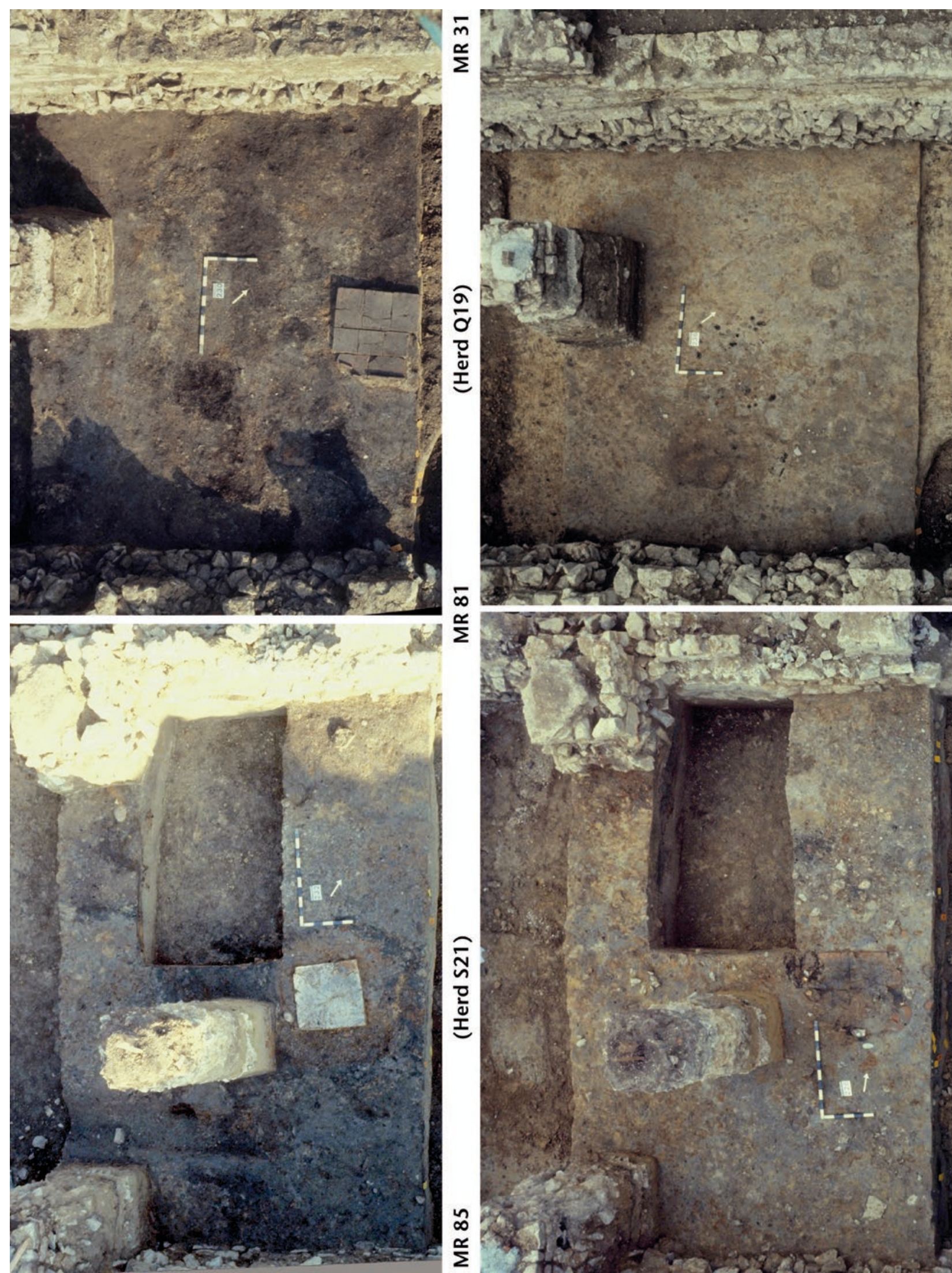

Abb. 56: Augst/BL, Augusta Raurica, Grabung von 1983 in der Insula 35. Aufsicht auf das frühe Planum mit den Lehmumhüllungen 10-25 (vor allem links aus dem Bereich um Feld S21). Die Bildpaare (oben, unten) sind standrichtig montiert. Die Mauern sind jünger und gehören nicht zum freigelegten Planum. Oben mit zwei Herden aus Ziegelplatten, unten sind diese bereits abgebaut. Die Plana zeigen Werkstattböden mit vielen Brandspuren, Aschekonzentrationen und Holzkohle, eine Verknüpfung im Detail mit den metallurgischen Prozessen in den Lehmumhüllungen (Abb. 50) ist allerdings nicht möglich. M. 1:60. 
beiden Kern-Insulae in allen Richtungen verstreut (Abb. 55, kleine Symbole). Ob sie tatsächlich sekundär verlagert sind oder Zeugen weiterer Produktionsstätten sind, bleibt im Einzelfall offen. Nur für Insula 22 mit ihren Schmiedewerkstätten ist ebenfalls eine Stahlerzeugung anzunehmen.

Leider lassen sich nur zu wenigen Fundstellen von Lehmumhüllungen aufschlussreiche Befunde anführen:

\section{Katalognummer 4 (und evtl. 2.3)}

Das Fragment $\mathbf{4}$ und wohl auch die Stücke $\mathbf{2}$ und $\mathbf{3}$ wurden in einem frühen Schmiedeareal in der Nordwestecke von Insula 22 gefunden (Abb. 55). Die drei Stücke stammen aus Grabungen, die unmittelbar nebeneinanderliegen (1980.051 und 1988.051). Zum Befund gehören Holzbauten mit verschiedenen Feuerstellen, Arbeitsgruben und Essen in stark kohligem Sediment (siehe auch Abb. 53) ${ }^{524}$. Hier wurde demzufolge nachweislich Eisen geschmiedet und vermutlich von denselben Spezialisten auch zu Stahl aufgekohlt.

\section{Katalognummer 7}

Von der regelmässig-röhrenförmigen Lehmumhüllung 7 aus Insula 31 (Abb.50,7) ist lediglich bekannt, dass sie aus einer «Feuergrube» mit wenigen datierenden Funden der 1. Hälfte des 1.Jahrhunderts stammt. Wahrscheinlich meinte Grabungsleiter Rudolf Laur-Belart damit den folgenden Befund: «In der Südwesthalle [von Insula 31], der wir die Hausnummer 5 gegeben haben, fand sich eine grosse, mit Backsteinen gefütterte Feuergrube, die Bruchstücke von Tonröhren und Bronzeschlacken enthielt $\ldots{ }^{525}$

\section{Katalognummern 10-25}

Das grösste Ensemble von Lehmumhüllungen stammt mit mehreren Dutzend Fragmenten (10-25) aus Insula 35 (Abb.55). Die Befunde und Funde sind noch nicht aufgearbeitet, weshalb es sich nicht sagen lässt, ob hier Schmiedehandwerk bezeugt ist. Alle gebrannten Lehmfragmente (ausser 10) konzentrieren sich auf eine Zone innerhalb der Holzbauten am Nordrand der Insula. Ein Streifen dieser holzkohlereichen siltigen Lehmschichten ist dokumentiert (Abb.56). Es sind typische dunkle Werkstattsedimente, wie sie in Schmieden und Giessereien vorgefunden werden. Die Funde 11-25 stammen aus den stratigraphisch untersten Schichten im Bereich der linken Fotos auf Abbildung 56. Die beiden sieben Meter auseinanderliegenden quadratischen Herdstellen in den Feldern S21 und Q19 sind Leistenziegel- und Tonplattenkonstruktionen. S21 ist sehr stark verbrannt: Das hellgrau verbrannte Ziegelmaterial und die um die quadratische Platte (ca. $67 \times 67 \mathrm{~cm}$ ) erkennbare kreisförmige Rot-Verfärbung mit kohligem äusserem Kranz ( $\varnothing$ ca. $135 \mathrm{~cm}$ ) lassen auf eine extreme Hitzeeinwirkung schliessen, während die Tonplatten von Q19 weit weniger verbrannt und auch eher als Herd konstruiert sind. Es könnte daher sein, dass unsere Lehmumhüllungen 11-25 auf dem «Herd S21» während langer Zeit ausgeglüht wurden, um die darin eingepackten Eisenbarren aufzukohlen (s. auch S. 123). Mit welchem Oberbau oder welcher Abdeckung die Hitze zusammengehalten worden ist, bleibt unbekannt. Die Verfärbungen (Abb.56, oben links) lassen jedenfalls auf eine kreisrunde Oberkonstruktion schliessen.

\section{Oberflächen-Röntgenfluoreszenzanalysen (pXRF)}

\section{Relevante Spuren im Innern der Lehmumhüllungen}

Zerstörungsfreie Oberflächenanalysen sollten allfällige generelle Unterschiede zwischen den Tonoberflächen aussen und den Negativen im Innern aufzeigen. Viele Elemente weisen leider keine stetigen Trends «von aussen nach innen» auf (Tabelle 2), was Hinweise auf die einst darin eingepackten Materialien und somit zur Funktion dieser Stücke geben würde.

Das Eisen scheint tendenziell innen angereichert $\mathrm{zu}$ sein $^{526}$. Aber auch das Gegenteil kann eintreten (z. B. bei 22 und die erste Messung von 24). Die zweite Messung von 24 zeigt hingegen das Gegenteil: innen mehr Eisen als aussen. Dies zeigt, dass an Originalfragmenten stets mehrere Messungen innen und aussen auszuführen wären, um Zufälligkeiten auszugleichen. Bei den rekonstruierten Lehmumhüllungen ist das Eisen nach dem Aufkohlungsprozess innen fast immer deutlich stärker ausgeprägt als aussen (Tabelle 2 , unten).

Weitere Stetigkeiten sind - immer mit Ausnahmen, «die die Regel bestätigen» - nur beim Kalium und Mangan (jeweils innen angereichert) resp. beim Strontium (aussen angereichert) festzustellen; für Kalzium lässt sich gar kein Trend ausmachen. Diese Beobachtungen bestätigen sich bei den Rekonstruktionen nur bei Eisen und Mangan (Tabelle 2, unten). Beim Schwefel ist ein genereller Unterschied festzustellen: Die bodengelagerten Originalproben weisen tendenziell innen weniger Schwefel auf als aussen, und bei den Rekonstruktionen ist es genau umgekehrt.

\footnotetext{
524 Dazu ausführlich Hänggi 1989, 50f. Abb. 2 (Holzbauten, mit Grabung 1980 [Kat.-Nr. 2 und 3]); Abb. 11 (Grabung 1980, Periode 2 [Kat.-Nr. 2 und 3]), Abb. 19 (Grabung 1988, Bauzustand 1 [Kat.Nr.4]); Abb. 22 (Bauzustand 2 [Kat.-Nr. 4]); Abb.32-34 (weitere Schmiede-Funde und -Befunde).

525 Laur-Belart 1965, V.

526 Diese Beobachtung machte als Erster Markus Helfert 2012 am Stück 6 (Abb. 50; generell: Tabelle 2).
} 


\begin{tabular}{|c|c|c|c|c|c|c|c|c|}
\hline Kat.-Nr. & Messmodus & Inv. & $\begin{array}{l}\text { Proben-Nr. } \\
\text { (Abb. \$12\$) }\end{array}$ & Messstelle & Wo? & $\mathrm{SiO}_{2}$ & $\mathrm{TiO}_{2}$ & $\mathrm{Al}_{2} \mathrm{O}_{3}$ \\
\hline \multicolumn{9}{|c|}{ Vergleichsmessungen innen-aussen: (am selben Stück; die «aussen»-Werte wurden auch für Tongruppenanalysen verwendet) } \\
\hline 1 & TestAll Geo & 1995.06002750 .7 & 1995_060_D02750_7_b & Oberfläche & aussen & 70,370 & 0,665 & 11,282 \\
\hline 1 & Mining Keramik & 1995.06002750 .7 & 1995_060_D02750_7_a & Oberfläche & innen 1 & 68,754 & 0,882 & 11,910 \\
\hline 1 & TestAll Geo & 1995.06002750 .7 & 1995_060_D02750_7_c & Oberfläche & innen 2 & 74,239 & 0,838 & 10,676 \\
\hline 1 & TestAll Geo & 1995.06002750 .7 & 1995.060.D02750.7_e_aussen & Oberfläche & aussen & 76,03 & 0,88 & 10,69 \\
\hline 1 & TestAll Geo & 1995.06002750 .7 & 1995.060.D02750.7_f_innen & Oberfläche & innen & 77,66 & 0,81 & 10,42 \\
\hline 2 & Mining Keramik & 1980,33753 & 1980_33753_a & Oberfläche & aussen & 75,804 & 1,169 & 12,622 \\
\hline 2 & Mining Keramik & 1980,33753 & 1980_33753_b & Oberfläche & innen & 75,570 & 1,023 & 8,596 \\
\hline 2 & TestAll Geo & 1980,33753 & 1980.33753_C_aussen & Oberfläche & aussen & 75,69 & 1,23 & 11,44 \\
\hline 2 & TestAll Geo & 1980,33753 & 1980.33753_d_innen & Oberfläche & innen & 59,78 & 1,28 & 7,89 \\
\hline 4 & TestAll Geo & 1988.05105038.18 & 1988_051_C05038_18_b & Oberfläche & aussen & 74,909 & 1,005 & 12,213 \\
\hline 4 & TestAll Geo & 1988.05105038 .18 & 1988_051_C05038_18_c & Oberfläche & innen 2 & 69,985 & 0,835 & 9,854 \\
\hline 13 & TestAll Geo & 1983,308 & 1983_30829_a & Oberfläche & aussen & 79,079 & 0,736 & 9,825 \\
\hline 13 & TestAll Geo & 1983,308 & 1983_30829_b & Oberfläche & innen & 82,203 & 0,757 & 9,441 \\
\hline 16 & TestAll Geo & 1983,308 & 1983_30832_a & Oberfläche & aussen & 81,197 & 0,799 & 9,427 \\
\hline 16 & TestAll Geo & 1983,308 & 1983_30832_b & Oberfläche & innen & 83,913 & 0,806 & 8,114 \\
\hline 16 & TestAll Geo & 1983,308 & 1983.30832_d_aussen & Oberfläche & aussen & 82,54 & 0,88 & 9,17 \\
\hline 16 & TestAll Geo & 1983,308 & 1983.30832_e_innen & Oberfläche & innen & 83,54 & 0,64 & 8,75 \\
\hline $18 \mathrm{~d}$ & TestAll Geo & $1983.30834 d$ & 1983_30834d_a & Oberfläche & aussen & 78,281 & 0,755 & 10,389 \\
\hline 18d & TestAll Geo & $1983.30834 d$ & 1983_30834d_b & Oberfläche & innen & 82,669 & 0,818 & 7,853 \\
\hline 21 & Mining Keramik & 1983.30927b & 1983_30927b_a & Oberfläche & aussen & 66,885 & 0,758 & 9,228 \\
\hline 21 & Mining Keramik & $1983.30927 \mathrm{~b}$ & 1983_30927b_b & Oberfläche & innen & 47,977 & 0,371 & 5,574 \\
\hline 22 & Mining Keramik & 1983,30928 & 1983_30928_a & Oberfläche & aussen & 77,210 & 0,832 & 9,551 \\
\hline 22 & Mining Keramik & 1983,30928 & 1983_30928_b & Oberfläche & innen & 83,189 & 0,874 & 10,065 \\
\hline 24 & Mining Keramik & 1984,30934 & 1984_30934_a & Oberfläche & aussen & 70,767 & 0,745 & 9,218 \\
\hline 24 & Mining Keramik & 1984,30934 & 1984_30934_b & Oberfläche & innen & 79,364 & 0,813 & 8,656 \\
\hline 24 & TestAll Geo & 1984,30934 & 1983.30934_C_aussen & Oberfläche & aussen & 75,03 & 0,94 & 9,16 \\
\hline 24 & TestAll Geo & 1984,30934 & 1983.30934_d_innen & Oberfläche & innen & 68,40 & 0,69 & 7,35 \\
\hline 26 & TestAll Geo & 1969,063 & 1969_06311_b & Oberfläche & aussen & 72,130 & 0,658 & 11,869 \\
\hline 26 & TestAll Geo & 1969,063 & 1969_06311_c & Oberfläche & innen 2 & 67,320 & 0,660 & 12,424 \\
\hline \multicolumn{9}{|c|}{ Messungen im Bruch (Tongruppenanalyse): } \\
\hline 1 & TestAll Geo & 1995.06002750 .7 & 1995_060_D02750_7_d & Oberfläche & Bruch & 65,939 & 0,687 & 9,774 \\
\hline 4 & TestAll Geo & 1988.05105038 .18 & 1988_051_C05038_18_d & Oberfläche & Bruch & 73,172 & 0,963 & 10,976 \\
\hline 13 & TestAll Geo & 1983,308 & 1983_30829_c & Oberfläche & Bruch & 79,104 & 0,741 & 10,067 \\
\hline 16 & TestAll Geo & 1983,308 & 1983_30832_c & Oberfläche & Bruch & 78,404 & 0,703 & 8,936 \\
\hline $18 \mathrm{~d}$ & TestAll Geo & $1983.30834 d$ & 1983_30834d_c & Oberfläche & Bruch & 78,331 & 0,766 & 9,660 \\
\hline 20 & Mining Keramik & $1983.30927 a$ & 1983_30927a_b & Bruch & Tongruppe 2 & 64,807 & 0,622 & 8,194 \\
\hline 26 & TestAll Geo & 1969,063 & 1969_06311_d & Oberfläche & Bruch aussen & 67,986 & 0,594 & 14,302 \\
\hline \multicolumn{9}{|c|}{ Einzelmesssungen alt (insbes. Messmodus «Soil»; keine Vergleichbarkeit aussen-innen): } \\
\hline 4 & Soil & 1988.051.C05038.18 & 1988_051_C05038_18_a & Oberfläche & innen 1 & & 0,551 & \\
\hline 6 & Soil & 1963.9770 & 1963_09770_a & Oberfläche & innen & & 0,195 & \\
\hline 8 & Mining Keramik & 1978,24301 & 1978_24301_a & Oberfläche & aussen & 67,824 & 0,609 & 13,882 \\
\hline 20 & Mining Keramik & 1983.30927a & 1983_30927a_c & Oberfläche & aussen & 78,097 & 0,748 & 8,495 \\
\hline 23 & Soil & 1983,309 & 1983_30933_a & Oberfläche & innen & & 0,226 & \\
\hline 26 & Soil & 1969,063 & 1969_06311_a & Oberfläche & innen 1 & & 0,586 & \\
\hline
\end{tabular}




\begin{tabular}{|c|c|c|c|c|c|c|c|c|c|c|c|c|}
\hline $\mathrm{Fe}_{2} \mathrm{O}_{3}$ & $\begin{array}{l}\text { Trend Fe: } \\
\text { (v. aussen } \\
\text { n. innen) }\end{array}$ & $\mathrm{MnO}$ & $\begin{array}{l}\text { Trend Mn: } \\
\text { (v. aussen } \\
\text { n. innen) }\end{array}$ & $\mathrm{MgO}$ & $\mathrm{CaO}$ & $\begin{array}{l}\text { Trend Ca: } \\
\text { (v. aussen } \\
\text { n. innen) }\end{array}$ & $\mathrm{K}_{2} \mathrm{O}$ & $\begin{array}{l}\text { Trend K: } \\
\text { (v. aussen } \\
\text { n. innen) }\end{array}$ & $\mathrm{P}_{2} \mathrm{O}_{5}$ & $\begin{array}{l}\text { Trend P: } \\
\text { (v. aussen } \\
\text { n. innen) }\end{array}$ & $S$ & $\begin{array}{l}\text { Trend S: } \\
\text { (v. aussen } \\
\text { n. innen) }\end{array}$ \\
\hline 9,264 & $\rightarrow$ & 0,035 & $\pi$ & 1,271 & 2,582 & ע & 2,102 & $\pi$ & 2,429 & y & 328 & y \\
\hline 9,456 & & 0,074 & & 1,948 & 2,307 & & 2,506 & & 1,758 & & 233 & \\
\hline 6,802 & & 0,049 & & 1,617 & 1,809 & & 2,533 & & 1,437 & & 63 & \\
\hline 6,32 & ע & 0,07 & ע & 0,66 & 1,72 & $y$ & 2,38 & $\rightarrow$ & 1,25 & ע & 138 & $\pi$ \\
\hline 5,74 & & 0,04 & & 0,94 & 1,15 & & 2,38 & & 0,85 & & 205 & \\
\hline 4,160 & $\pi$ & 0,067 & $\pi$ & 2,220 & 1,448 & $\pi$ & 2,444 & ע & 0,951 & $\pi$ & 177 & $y$ \\
\hline 5,334 & & 0,070 & & 0,920 & 1,469 & & 2,121 & & 1,237 & & 58 & \\
\hline 5,56 & $\pi$ & 0,05 & ע & 0,79 & 1,74 & $\pi$ & 2,47 & $\rightarrow$ & 1,04 & $\pi$ & 336 & ע \\
\hline 17,99 & & 0,42 & & 0,97 & 4,86 & & 2,24 & & 4,57 & & 117 & \\
\hline 5,723 & $\pi$ & 0,104 & $\pi$ & 1,242 & 1,371 & $\pi$ & 2,246 & $\pi$ & 1,186 & y & 31 & $\downarrow$ \\
\hline 7,199 & & 0,177 & & 1,034 & 6,813 & & 2,278 & & 1,826 & & & \\
\hline 6,208 & $y$ & 0,065 & $\pi$ & 0,462 & 1,053 & $y$ & 1,771 & $\pi$ & 0,802 & $y$ & 318 & $\downarrow$ \\
\hline 3,831 & & 0,131 & & 0,711 & 0,666 & & 1,821 & & 0,438 & & & \\
\hline 4,651 & y & 0,261 & y & & 0,968 & $y$ & 2,033 & $y$ & 0,665 & ע & 132 & $\downarrow$ \\
\hline 3,561 & & 0,078 & & 0,668 & 0,586 & & 1,902 & & 0,373 & & & \\
\hline 3,49 & $\pi$ & 0,08 & $\rightarrow$ & 0,78 & 0,72 & $\rightarrow$ & 1,94 & $\rightarrow$ & 0,40 & $\rightarrow$ & 130 & $\pi$ \\
\hline 3,78 & & 0,12 & & 0,00 & 0,76 & & 1,77 & & 0,63 & & 316 & \\
\hline 5,891 & y & 0,072 & $\pi$ & 1,053 & 0,966 & $y$ & 1,967 & $\pi$ & 0,628 & y & 43 & $\downarrow$ \\
\hline 4,881 & & 0,362 & & & 0,810 & & 2,098 & & 0,509 & & & \\
\hline 11,585 & $\pi$ & 0,018 & $\pi$ & 1,704 & 3,719 & $\pi$ & 1,872 & $y$ & 3,489 & $\pi$ & 257 & $y$ \\
\hline 15,246 & & 0,252 & & 1,551 & 6,378 & & 1,132 & & 6,329 & & 252 & \\
\hline 4,869 & $y$ & 0,332 & 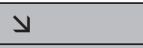 & 1,105 & 2,503 & $y$ & 1,983 & $\pi$ & 1,884 & ע & 233 & ע \\
\hline 2,449 & & 0,198 & & 1,104 & 0,956 & & 2,042 & & 0,415 & & 139 & \\
\hline 10,154 & $y$ & 0,086 & $\pi$ & 1,336 & 2,847 & $y$ & 1,907 & $\pi$ & 2,576 & $y$ & 289 & $y$ \\
\hline 3,527 & & 0,628 & & 1,182 & 1,194 & & 1,911 & & 0,940 & & 75 & \\
\hline 7,87 & $\pi$ & 0,05 & $\pi$ & 0,59 & 2,30 & $\pi$ & 1,90 & $\rightarrow$ & 2,17 & $\pi$ & 330 & $y$ \\
\hline 14,61 & & 0,64 & & 0,00 & 3,56 & & 1,70 & & 3,05 & & 11 & \\
\hline 7,117 & $\pi$ & 0,069 & $\pi$ & 1,806 & 2,130 & $y$ & 2,206 & $\pi$ & 2,016 & $y$ & 463 & $\pi$ \\
\hline 12,469 & & 0,423 & & 0,669 & 2,010 & & 2,562 & & 1,463 & & 665 & \\
\hline 14,577 & & 0,120 & & & 3,403 & & 2,359 & & 3,141 & & & \\
\hline 8,639 & & 0,199 & & 0,587 & 1,683 & & 2,184 & & 1,597 & & & \\
\hline 5,009 & & 0,103 & & 0,844 & 1,182 & & 1,899 & & 1,051 & & & \\
\hline 5,658 & & 0,069 & & 0,793 & 1,763 & & 1,747 & & 1,928 & & & \\
\hline 5,559 & & 0,160 & & & 1,360 & & 1,876 & & 2,288 & & 354 & \\
\hline 8,498 & & 4,137 & & 1,361 & 2,437 & & 1,536 & & 2,483 & & 171 & \\
\hline 9,739 & & 0,149 & & 1,105 & 2,028 & & 2,603 & & 1,493 & & & \\
\hline 5,569 & & 0,102 & & & 1,537 & & 1,122 & & & & 203 & \\
\hline 54,655 & (Fe hoch+) & 2,435 & $(\mathrm{Mn}$ hoch +$)$ & & 2,337 & & 0,568 & & & & 231 & \\
\hline 4,564 & & 0,155 & & 2,651 & 5,104 & $($ Ca hoch +$)$ & 2,214 & (K hoch) & 0,959 & & 3748 & (S hoch + ) \\
\hline 4,754 & & 0,720 & & 1,596 & 1,537 & & 1,779 & & 1,038 & & 108 & \\
\hline 6,858 & (Fe hoch) & 0,444 & & & 1,188 & & 0,547 & & & & 87 & \\
\hline 13,302 & & 0,155 & & & 2,052 & & 1,994 & & & & 583 & \\
\hline
\end{tabular}




\begin{tabular}{|c|c|c|c|c|c|c|c|c|}
\hline Kat.-Nr. & Messmodus & Inv. & $\begin{array}{l}\text { Proben-Nr. } \\
\text { (Abb. \$12\$) }\end{array}$ & Messstelle & Wo? & $\mathrm{SiO}_{2}$ & $\mathrm{TiO}_{2}$ & $\mathrm{Al}_{2} \mathrm{O}_{3}$ \\
\hline \multicolumn{9}{|c|}{ Rekonstruktionen: Vergleichsmessungen innen-aussen: } \\
\hline- & TestAll Geo & B05 & REK_B05_a_aussen & Oberfläche & aussen & 56,32 & 0,95 & 18,23 \\
\hline - & TestAll Geo & B05 & REK_B05_b_innen & Oberfläche & innen & 56,55 & 0,90 & 17,25 \\
\hline - & TestAll Geo & B07 & REK_B07_a_aussen & Oberfläche & aussen & 58,30 & 1,15 & 20,90 \\
\hline- & TestAll Geo & B07 & REK_B07_b_innen & Oberfläche & innen & 60,89 & 1,01 & 20,33 \\
\hline - & TestAll Geo & P07 & REK_P07_a_aussen & Oberfläche & aussen & 57,00 & 0,90 & 20,01 \\
\hline- & TestAll Geo & P07 & REK_P07_b_innen & Oberfläche & innen & 51,16 & 0,81 & 15,88 \\
\hline- & TestAll Geo & R05 & REK_R05_a_aussen & Oberfläche & aussen & 60,37 & 1,02 & 18,27 \\
\hline - & TestAll Geo & R05 & REK_R05_b_innen & Oberfläche & innen & 56,37 & 1,32 & 17,90 \\
\hline - & TestAll Geo & R07 & REK_R07_a_aussen & Oberfläche & aussen & 57,28 & 1,03 & 19,70 \\
\hline - & TestAll Geo & R07 & REK_R07_b_innen & Oberfläche & innen & 54,63 & 0,97 & 18,88 \\
\hline- & TestAll Geo & R08 & REK_R08_a_aussen & Oberfläche & aussen & 58,66 & 1,01 & 21,92 \\
\hline - & TestAll Geo & R08 & REK_R08_b_innen & Oberfläche & innen & 47,54 & 0,92 & 14,06 \\
\hline- & TestAll Geo & R11 & REK_R11_a_aussen & Oberfläche & aussen & 57,15 & 1,33 & 16,28 \\
\hline- & TestAll Geo & R11 & REK_R11_b_innen & Oberfläche & innen & 61,31 & 0,94 & 16,73 \\
\hline
\end{tabular}

Tabelle 2: Augusta Raurica (Augst/BL und Kaiseraugst/AG). pXRF-Oberflächenanalysen einiger Lehmummantelungen auf der Innen- und Aussenseite sowie an frischen Brüchen. Mit «Trend» sind für einige Elemente die Konzentrationsveränderungen - im Idealfall die Stetigkeit - von aussen nach innen mit Pfeilen dargestellt. Analysen Markus Helfert und Thomas Hahn. Die wenigen Negativwerte sind auf die Werkskalibration des Analysegeräts oder auf mangelnde Referenzproben oder auf röntgenspektrographische Effekte zurückzuführen; sie sind in unserem Zusammenhang aber irrelevant.

Download der Tabelle unter:

http://librum-publishers.com/antike-schmelztiegel/ oder via folgende DOI: 10.19218/9783906897387 


\begin{tabular}{|c|c|c|c|c|c|c|c|c|c|c|c|c|}
\hline $\mathrm{Fe}_{2} \mathrm{O}_{3}$ & $\begin{array}{l}\text { Trend Fe: } \\
\text { (v. aussen } \\
\text { n. innen) }\end{array}$ & $\mathrm{MnO}$ & $\begin{array}{l}\text { Trend } \mathrm{Mn} \text { : } \\
\text { (v. aussen } \\
\text { n. innen) }\end{array}$ & $\mathrm{MgO}$ & $\mathrm{CaO}$ & $\begin{array}{l}\text { Trend Ca: } \\
\text { (v. aussen } \\
\text { n. innen) }\end{array}$ & $\mathrm{K}_{2} \mathrm{O}$ & $\begin{array}{l}\text { Trend K: } \\
\text { (v. aussen } \\
\text { n. innen) }\end{array}$ & $\mathrm{P}_{2} \mathrm{O}_{5}$ & $\begin{array}{l}\text { Trend P: } \\
\text { (v. aussen } \\
\text { n. innen) }\end{array}$ & $S$ & $\begin{array}{l}\text { Trend S: } \\
\text { (v. aussen } \\
\text { n. innen) }\end{array}$ \\
\hline 8,19 & $\pi$ & 0,12 & $\pi$ & 2,08 & 6,76 & $y$ & 7,15 & $y$ & 0,20 & $\rightarrow$ & 143 & $\pi$ \\
\hline 12,62 & & 0,19 & & 2,78 & 5,38 & & 4,10 & & 0,24 & & 819 & \\
\hline 7,45 & ע & 0,13 & $\rightarrow$ & 2,62 & 4,57 & $\rightarrow$ & 4,66 & $y$ & 0,23 & $\rightarrow$ & 1268 & $\rightarrow$ \\
\hline 6,95 & & 0,11 & & 1,86 & 4,61 & & 3,97 & & 0,26 & & 1297 & \\
\hline 7,04 & $\pi$ & 0,28 & ע & 1,92 & 9,12 & $\pi$ & 3,50 & $\rightarrow$ & 0,22 & $\pi$ & 627 & $\pi$ \\
\hline 14,69 & & 0,22 & & 0,99 & 11,87 & & 3,51 & & 0,88 & & 1100 & \\
\hline 7,48 & $\pi$ & 0,12 & $\pi$ & 1,83 & 6,25 & $\pi$ & 4,45 & $\rightarrow$ & 0,22 & $\rightarrow$ & 308 & \\
\hline 8,00 & & 0,32 & & 2,33 & 9,05 & & 4,46 & & 0,25 & & -160 & \\
\hline 7,62 & $\pi$ & 0,15 & $\pi$ & 2,55 & 7,19 & $y$ & 4,28 & $\pi$ & 0,20 & $\rightarrow$ & 260 & $\pi$ \\
\hline 11,89 & & 0,20 & & 2,10 & 5,76 & & 5,31 & & 0,27 & & 2178 & \\
\hline 7,10 & $\pi$ & 0,10 & $\pi$ & 2,60 & 4,97 & $\pi$ & 3,35 & $y$ & 0,28 & $\pi$ & -56 & \\
\hline 15,26 & & 0,23 & & 3,31 & 15,47 & & 2,44 & & 0,77 & & 684 & \\
\hline 9,05 & y & 0,20 & ע & 2,78 & 7,97 & $y$ & 4,96 & $y$ & 0,27 & $\rightarrow$ & 418 & $\pi$ \\
\hline 7,61 & & 0,14 & & 1,75 & 6,87 & & 4,39 & & 0,26 & & 832 & \\
\hline
\end{tabular}




\begin{tabular}{|c|c|c|c|c|c|c|c|c|c|c|c|c|c|c|c|c|c|}
\hline Kat.-Nr. & v & $\mathrm{Cr}$ & $\mathrm{Ni}$ & $\mathrm{Cu}$ & $\mathrm{Zn}$ & As & $\mathrm{Se}$ & $\mathrm{Rb}$ & $\mathrm{Sr}$ & $\begin{array}{l}\text { Trend Sr: } \\
\text { (v. aussen } \\
\text { n. innen) }\end{array}$ & $\mathrm{Y}$ & $\mathrm{Zr}$ & $\mathrm{Nb}$ & $\mathrm{Ag}$ & Cd & Sn & $\mathrm{Ba}$ \\
\hline \multicolumn{18}{|c|}{ Vergleichsmessungen innen-aussen: (am selben Stück; die «aussen»-Werte wurden auch für Tongruppenanalysen verwendet) } \\
\hline 1 & 133 & 136 & 8 & 41 & 98 & 134 & & 73 & 168 & y & 40 & 335 & 17 & 6 & 10 & 10 & 350 \\
\hline 1 & 119 & 127 & & & 81 & 137 & & 79 & 137 & & 35 & 349 & 17 & 5 & & 7 & 406 \\
\hline 1 & 111 & 121 & 9 & 26 & 82 & 84 & & 89 & 137 & & 38 & 420 & 19 & 3 & 7 & & 318 \\
\hline 1 & 99 & 73 & 40 & 27 & 85 & 54 & 0 & 81 & 124 & ע & 40 & 420 & 19 & -3 & -8 & -4 & 305 \\
\hline 1 & 108 & 54 & 43 & 20 & 69 & 48 & 1 & 70 & 103 & & 32 & 380 & 17 & 0 & 1 & -1 & 199 \\
\hline 2 & 113 & 88 & & & 64 & 26 & & 94 & 120 & $y$ & 41 & 341 & 22 & & & & 301 \\
\hline 2 & 96 & 115 & & & 61 & 25 & & 95 & 112 & & 33 & 325 & 23 & & & & 285 \\
\hline 2 & 116 & 80 & 49 & 19 & 65 & 27 & -0 & 97 & 132 & $\rightarrow$ & 43 & 369 & 21 & 2 & 3 & 2 & 224 \\
\hline 2 & 205 & 148 & 66 & 16 & 61 & 36 & -1 & 91 & 128 & & 31 & 339 & 22 & 9 & 11 & 6 & 287 \\
\hline 4 & 148 & 99 & 44 & 22 & 217 & 37 & & 98 & 137 & $y$ & 40 & 352 & 23 & & & & 318 \\
\hline 4 & 119 & 124 & 58 & 21 & 57 & 31 & 2 & 70 & 125 & & 25 & 274 & 13 & & & & 445 \\
\hline 13 & 94 & 85 & 29 & 29 & 59 & 22 & & 70 & 93 & ע & 32 & 479 & 17 & & & & 321 \\
\hline 13 & 75 & 50 & 24 & 17 & 66 & 17 & & 70 & 87 & & 31 & 488 & 18 & & & & 243 \\
\hline 16 & 67 & 79 & 25 & 23 & 63 & 16 & 2 & 76 & 107 & $y$ & 30 & 492 & 17 & & & & 282 \\
\hline 16 & 65 & 76 & 22 & 21 & 57 & 17 & & 71 & 86 & & 31 & 497 & 19 & & & & 292 \\
\hline 16 & 86 & 63 & 29 & 17 & 56 & 16 & 1 & 76 & 97 & $\rightarrow$ & 29 & 502 & 17 & -3 & -5 & -1 & 169 \\
\hline 16 & 62 & 22 & 60 & 15 & 52 & 14 & -1 & 65 & 81 & & 33 & 464 & 14 & 4 & 8 & 5 & 211 \\
\hline $18 d$ & 97 & 92 & 23 & 32 & 73 & 22 & & 76 & 89 & ע & 35 & 482 & 18 & & & & 276 \\
\hline $18 \mathrm{~d}$ & 69 & 80 & 19 & 21 & 75 & 20 & & 69 & 86 & & 28 & 439 & 16 & & & & 224 \\
\hline 21 & 114 & 134 & & & 67 & 56 & & 54 & 145 & ע & 30 & 348 & 13 & & & & 465 \\
\hline 21 & 113 & 175 & & & 41 & 58 & & 42 & 140 & & 25 & 287 & 10 & & & & 349 \\
\hline 22 & 90 & 69 & & & 57 & 33 & & 70 & 118 & $y$ & 29 & 411 & 14 & & & & 511 \\
\hline 22 & 63 & 58 & & & 59 & 5 & & 82 & 79 & & 30 & 460 & 18 & & & & 305 \\
\hline 24 & 89 & 132 & & & 55 & 42 & & 59 & 140 & $y$ & 31 & 351 & 13 & & & & 579 \\
\hline 24 & 55 & 121 & & & 49 & 16 & & 69 & 83 & & 28 & 416 & 16 & & & & 323 \\
\hline 24 & 105 & 97 & 47 & 15 & 49 & 25 & 1 & 66 & 124 & ע & 34 & 474 & 15 & 1 & 6 & 3 & 323 \\
\hline 24 & 114 & 155 & 72 & 14 & 68 & 36 & 0 & 56 & 106 & & 27 & 409 & 14 & 8 & 12 & 3 & 362 \\
\hline 26 & 131 & 130 & 43 & 33 & 93 & 31 & 2 & 93 & 137 & ע & 57 & 382 & 16 & & & & 462 \\
\hline 26 & 142 & 174 & 47 & 23 & 86 & 20 & & 102 & 134 & & 22 & 346 & 14 & & & & 484 \\
\hline \multicolumn{18}{|c|}{ Messungen im Bruch (Tongruppenanalyse): } \\
\hline 1 & 137 & 125 & 94 & 26 & 92 & 175 & & 84 & 157 & & 35 & 342 & 17 & & & & 664 \\
\hline 4 & 140 & 108 & 73 & 23 & 70 & 48 & 2 & 104 & 149 & & 41 & 369 & 23 & 5 & & 10 & 254 \\
\hline 13 & 101 & 65 & 18 & 10 & 52 & 20 & & 74 & 90 & & 30 & 518 & 18 & & & 9 & 175 \\
\hline 16 & 99 & 75 & 48 & 12 & 40 & 28 & & 70 & 99 & & 29 & 479 & 17 & 5 & & 6 & 148 \\
\hline $18 \mathrm{~d}$ & 96 & 67 & 49 & 20 & 63 & 30 & 2 & 81 & 104 & & 35 & 520 & 19 & & & 9 & 191 \\
\hline 20 & 107 & 113 & & & 56 & 27 & & 61 & 114 & & 22 & 407 & 13 & & & & 596 \\
\hline 26 & 110 & 160 & 40 & 19 & 77 & 15 & & 108 & 133 & & 36 & 344 & 15 & & 4 & & 230 \\
\hline \multicolumn{18}{|c|}{ Einzelmesssungen alt (insbes. Messmodus «Soil»; keine Vergleichbarkeit aussen-innen): } \\
\hline 4 & 71 & 69 & 3 & & 47 & 41 & & 77 & 102 & & & 288 & & 14 & 17 & 115 & 496 \\
\hline 6 & 205 & 181 & 312 & 55 & & 100 & & 71 & 174 & (Sr hoch+) & & 184 & & & & 78 & \\
\hline 8 & 78 & 101 & 45 & 337 & 380 & 26 & & 93 & 104 & & 37 & 379 & 14 & & & 142 & 336 \\
\hline 20 & 86 & 79 & & & 46 & 12 & & 69 & 82 & & 27 & 432 & 15 & & & & 381 \\
\hline 23 & 29 & 30 & & 763 & 156 & 53 & & 67 & 104 & & & 390 & & 11 & 14 & 114 & 1480 \\
\hline 26 & 161 & 200 & 61 & 29 & 48 & 21 & & 84 & 112 & & & 313 & & 5 & 5 & 113 & 1204 \\
\hline
\end{tabular}




\begin{tabular}{|c|c|c|c|c|c|c|c|c|c|c|c|c|c|c|c|c|c|c|c|c|}
\hline La & $\mathrm{Ce}$ & $\mathrm{Hg}$ & $\mathrm{Pb}$ & $\mathrm{Bi}$ & Th & $\mathrm{Cl}$ & Co & Sc & Mo & $\mathrm{Pd}$ & $\mathrm{Sb}$ & $\mathrm{Te}$ & Cs & Hf & $\mathrm{Ta}$ & W & $\operatorname{Re}$ & $\mathrm{Au}$ & U & $\begin{array}{l}\text { Summe } \\
\text { (\%) }\end{array}$ \\
\hline & & & 104 & & 6 & 41 & 295 & & 3 & & & & & & & & & & & 100,0 \\
\hline & & 10 & 34 & & & & & & & & & & & & & & & & & 99,6 \\
\hline 42 & & 9 & 41 & & 13 & 112 & 159 & & 2 & & & & & & & & & 3 & & 100,0 \\
\hline 0 & -339 & 4 & 43 & 0 & 13 & 0 & 2 & 5 & 0 & -5 & -11 & -86 & -7 & 0 & 0 & 4 & 0 & 0 & 10 & 100 \\
\hline 47 & -274 & 7 & 37 & 0 & 13 & 0 & 45 & 3 & -0 & -1 & -1 & -24 & -1 & 0 & 0 & 4 & 0 & 2 & 8 & 100 \\
\hline 143 & 23 & & 31 & & & & & & & & & & & & & & & & & 100,9 \\
\hline 124 & & & 22 & & & & & & & & & & & & & & & & & 96,3 \\
\hline 145 & -128 & 1 & 46 & 0 & 16 & 0 & 41 & 9 & -2 & 1 & 4 & 38 & 8 & 0 & 0 & 8 & 0 & 5 & 9 & 100 \\
\hline 139 & -122 & 4 & 30 & 0 & 4 & 0 & -558 & 4 & -0 & 8 & 10 & 106 & 13 & 0 & 0 & -4 & 0 & 4 & 3 & 100 \\
\hline 172 & 4 & 4 & 25 & & 14 & 66 & 105 & & 3 & & & & & & & & & 4 & & 100,0 \\
\hline 286 & 242 & 2 & 26 & & 6 & 54 & & & 5 & & & & & & & & & 5 & & 100,0 \\
\hline 197 & 38 & 2 & 18 & & 12 & & 121 & & 4 & & & & & & & & & 4 & & 100,0 \\
\hline 128 & & 3 & 15 & & 15 & 32 & 62 & & 4 & & & & & & & & & 0 & & 100,0 \\
\hline 130 & & 3 & 16 & & 12 & 240 & 95 & & 4 & & & & & & & & & 3 & & 100,0 \\
\hline 191 & & & 50 & & 17 & 162 & 82 & & 4 & & & & & & & & & 2 & & 100,0 \\
\hline 42 & -285 & 2 & 18 & 0 & 14 & 0 & 28 & 3 & 1 & 1 & -4 & -31 & -2 & 0 & 0 & 13 & 0 & 2 & 7 & 100 \\
\hline 90 & -164 & 4 & 40 & 0 & 13 & 0 & -20 & 2 & 1 & 7 & 9 & 66 & 8 & 0 & 0 & -2 & 0 & 4 & 5 & 100 \\
\hline 170 & & 5 & 26 & & 15 & 0 & 74 & & 4 & & & & & & & & & 3 & & 100,0 \\
\hline & & 4 & 17 & & 13 & 271 & 73 & & 4 & & & & & & & & & & & 100,0 \\
\hline 182 & 121 & & 19 & & & & 213 & & & & & & & & & & & & & 99,3 \\
\hline & & & 15 & & & & & & & & & & & & & & & & & 84,8 \\
\hline 226 & 123 & & 20 & & & & & & & & & & & & & & & & & 100,3 \\
\hline 142 & 16 & & 20 & & & & & & & & & & & & & & & & & 101,3 \\
\hline 208 & 195 & 4 & 21 & & & & & & & & & & & & & & & & & 99,6 \\
\hline 64 & & & 16 & & & & & & & & & & & & & & & & & 98,2 \\
\hline 202 & 11 & 3 & 24 & 0 & 11 & 0 & -14 & 6 & -2 & 5 & 9 & 58 & 12 & 0 & 0 & 9 & 0 & 4 & 9 & 100 \\
\hline 146 & -96 & 3 & 22 & 0 & 5 & 0 & -396 & 10 & 4 & 3 & 8 & 80 & 11 & 0 & 0 & 4 & 0 & 3 & 4 & 100 \\
\hline 220 & 107 & 3 & 41 & & 12 & 379 & 105 & & 3 & & & & & & & & & 1 & & 100,0 \\
\hline 211 & 47 & & 23 & & 9 & 172 & & & 11 & & & & & & & & & 4 & & 100,0 \\
\hline & & & & & & & & & & & & & & & & & & & & \\
\hline 191 & 31 & 8 & 73 & & 2 & & 67 & & & & & & & & & & & 3 & & 100,0 \\
\hline 96 & & 6 & 31 & & 17 & 24 & & & 4 & & & & & & & & & 2 & & 100,0 \\
\hline & & 1 & 21 & & 13 & 132 & 19 & & 3 & & & & & & & & & 2 & & 100,0 \\
\hline & & & 20 & & 9 & & 30 & & 2 & & & & & & & & & & & 100,0 \\
\hline & & 1 & 24 & & 13 & & & & 4 & & & & & & & & & & & 100,0 \\
\hline 268 & 270 & & 18 & & & & & & & & & & & & & & & & & 94,1 \\
\hline 50 & & 2 & 26 & & 10 & & 91 & & & & & & & & & & & 3 & & 100,0 \\
\hline & & & & & & & & & & & & & & & & & & & & \\
\hline & & & 23 & & 5 & & & & & 27 & 36 & 459 & 31 & & & & & 5 & & 8,9 \\
\hline & & 9 & 53 & & 11 & & & & & 8 & & 273 & & & & & & 8 & 6 & 60,2 \\
\hline 184 & 136 & & 698 & & & 964 & & & & & & & & & & & & & & 98,0 \\
\hline 197 & 90 & & 18 & & & & & & & & & & & & & & & & & 98,8 \\
\hline & & & 34 & & 4 & & & & & 37 & 30 & 481 & 32 & & & 3 & & 6 & 6 & 9,3 \\
\hline & & 3 & 34 & & 4 & & & & & 36 & 25 & 450 & 30 & & & & & 6 & 10 & 18,1 \\
\hline
\end{tabular}




\begin{tabular}{|c|c|c|c|c|c|c|c|c|c|c|c|c|c|c|c|c|c|}
\hline Kat.-Nr. & V & $\mathrm{Cr}$ & $\mathrm{Ni}$ & $\mathrm{Cu}$ & $\mathrm{Zn}$ & As & $\mathrm{Se}$ & $\mathrm{Rb}$ & $\mathrm{Sr}$ & $\begin{array}{l}\text { Trend Sr: } \\
\text { ( } v \text {. aussen } \\
\text { n. innen) }\end{array}$ & $Y$ & $\mathrm{Zr}$ & $\mathrm{Nb}$ & $\mathrm{Ag}$ & $\mathrm{Cd}$ & Sn & $\mathrm{Ba}$ \\
\hline \multicolumn{18}{|c|}{ Rekonstruktionen: Vergleichsmessungen innen-aussen: } \\
\hline- & 127 & 105 & 68 & 74 & 3476 & 17 & 1 & 151 & 138 & $\rightarrow$ & 34 & 208 & 18 & 14 & 19 & 8 & 264 \\
\hline- & 107 & 166 & 95 & 86 & 771 & 21 & 2 & 147 & 143 & & 39 & 234 & 19 & 16 & 22 & 11 & 323 \\
\hline - & 155 & 153 & 88 & 90 & 28116 & 43 & 4 & 126 & 131 & $\rightarrow$ & 32 & 196 & 16 & 12 & 19 & 8 & 284 \\
\hline- & 132 & 122 & 66 & 35 & 841 & 6 & 1 & 128 & 137 & & 33 & 201 & 17 & 4 & 9 & 7 & 251 \\
\hline - & 133 & 123 & 75 & 46 & 923 & 21 & 1 & 138 & 154 & $\rightarrow$ & 36 & 205 & 19 & 12 & 11 & 9 & 305 \\
\hline- & 111 & 173 & 89 & 80 & 185 & 6 & 1 & 129 & 152 & & 33 & 204 & 17 & 16 & 28 & 12 & 366 \\
\hline - & 121 & 116 & 69 & 75 & 7979 & 13 & 2 & 129 & 139 & $\rightarrow$ & 30 & 197 & 16 & 3 & 5 & 4 & 226 \\
\hline - & 121 & 85 & 74 & 69 & 3159 & 6 & 1 & 143 & 137 & & 37 & 225 & 16 & 9 & 11 & 8 & 290 \\
\hline - & 152 & 140 & 71 & 52 & 5049 & 11 & 2 & 147 & 152 & $\rightarrow$ & 37 & 214 & 19 & 4 & 3 & 3 & 196 \\
\hline - & 131 & 104 & 64 & 67 & 302 & 8 & -0 & 153 & 158 & & 38 & 235 & 21 & 6 & 5 & 3 & 110 \\
\hline - & 160 & 151 & 64 & 36 & 1126 & 15 & 0 & 141 & 152 & $\pi$ & 37 & 222 & 19 & 4 & 2 & 4 & 221 \\
\hline - & 92 & 121 & 10896 & 844 & 1314 & 5 & 6 & 148 & 169 & & 40 & 227 & 18 & 7 & 15 & 8 & 219 \\
\hline - & 139 & 148 & 76 & 89 & 19390 & 35 & 3 & 140 & 133 & ע & 31 & 205 & 17 & 8 & 10 & 8 & 328 \\
\hline - & 113 & 105 & 82 & 43 & 7596 & 43 & 3 & 122 & 119 & & 29 & 186 & 14 & 10 & 14 & 9 & 335 \\
\hline
\end{tabular}

Tabelle 2 (Fortsetzung): Augusta Raurica (Augst/BL und Kaiseraugst/AG). pXRF-Oberflächenanalysen einiger Lehmummantelungen auf der Innen- und Aussenseite sowie an frischen Brüchen. Mit «Trend» sind für einige Elemente die Konzentrationsveränderungen - im Idealfall die Stetigkeit - von aussen nach innen mit Pfeilen dargestellt. Analysen Markus Helfert und Thomas Hahn. Die wenigen Negativwerte sind auf die Werkskalibration des Analysegeräts oder auf mangelnde Referenzproben oder auf röntgenspektrographische Effekte zurückzuführen; sie sind in unserem Zusammenhang aber irrelevant.

Download der Tabelle unter:

http://librum-publishers.com/antike-schmelztiegel/ oder via folgende DOI: 10.19218/9783906897387 


\begin{tabular}{|c|c|c|c|c|c|c|c|c|c|c|c|c|c|c|c|c|c|c|c|c|}
\hline La & $\mathrm{Ce}$ & $\mathrm{Hg}$ & $\mathrm{Pb}$ & $\mathrm{Bi}$ & Th & $\mathrm{Cl}$ & Co & $\mathrm{Sc}$ & Mo & $\mathrm{Pd}$ & $\mathrm{Sb}$ & $\mathrm{Te}$ & Cs & $\mathrm{Hf}$ & $\mathrm{Ta}$ & W & $\operatorname{Re}$ & $\mathrm{Au}$ & $U$ & $\begin{array}{l}\text { Summe } \\
\text { (\%) }\end{array}$ \\
\hline 144 & -111 & 11 & 162 & 0 & 21 & 0 & -71 & 5 & -0 & 7 & 12 & 116 & 14 & 0 & 0 & -20 & 0 & 4 & 11 & 100 \\
\hline 131 & -70 & 5 & 97 & 0 & 21 & 0 & -91 & -5 & -2 & 15 & 17 & 168 & 19 & 0 & 0 & 9 & 0 & 6 & 13 & 100 \\
\hline 176 & 10 & 64 & 234 & 0 & 17 & 0 & -151 & 13 & -3 & 12 & 14 & 113 & 15 & 0 & 0 & -160 & 0 & 6 & 6 & 100 \\
\hline 162 & -40 & -3 & 27 & 0 & 18 & 0 & 69 & 13 & -1 & 3 & 12 & 91 & 13 & 0 & 0 & 22 & 0 & 6 & 12 & 100 \\
\hline 173 & -0 & 9 & 130 & 0 & 20 & 0 & 13 & 11 & -2 & 7 & 13 & 129 & 16 & 0 & 0 & 8 & 0 & 4 & 13 & 100 \\
\hline 163 & -15 & 13 & 20 & 0 & 10 & 0 & -256 & 7 & -1 & 11 & 21 & 183 & 21 & 0 & 0 & 2 & 0 & 2 & 11 & 100 \\
\hline 144 & -63 & 23 & 179 & 0 & 19 & 0 & -39 & 6 & -1 & 6 & 7 & 65 & 10 & 0 & 0 & -44 & 0 & 7 & 9 & 100 \\
\hline 152 & -42 & 11 & 49 & 0 & 22 & 0 & -18 & -1 & -3 & 5 & 13 & 123 & 16 & 0 & 0 & -10 & 0 & 5 & 10 & 100 \\
\hline 128 & -91 & 17 & 68 & 0 & 22 & 0 & -53 & 14 & -1 & 5 & 6 & 48 & 8 & 0 & 0 & -24 & 0 & 3 & 11 & 100 \\
\hline 34 & -273 & 2 & 16 & 0 & 14 & 0 & -313 & 7 & -0 & 4 & 0 & 6 & -0 & 0 & 0 & 8 & 0 & 3 & 12 & 100 \\
\hline 159 & -66 & 9 & 57 & 0 & 22 & 0 & -25 & 8 & -2 & 1 & 5 & 51 & 8 & 0 & 0 & 3 & 0 & 7 & 11 & 100 \\
\hline 108 & -155 & 72 & 27 & 0 & 16 & 0 & -53 & -4 & -1 & 16 & 10 & 84 & 9 & 0 & 0 & -239 & 0 & 5 & 6 & 100 \\
\hline 198 & 36 & 35 & 272 & 0 & 19 & 17 & 19 & 8 & -4 & 9 & 14 & 143 & 18 & 0 & 0 & -84 & 0 & 6 & 10 & 100 \\
\hline 224 & 113 & 15 & 309 & 0 & 24 & 0 & -77 & 2 & -3 & 12 & 17 & 149 & 20 & 0 & 0 & -28 & 0 & 8 & 8 & 100 \\
\hline
\end{tabular}


Die These, Eisen sei mit Knochenkohle oder -asche aufgekohlt worden, um einen besonders guten, phosphorhaltigen Stahl zu erzeugen ${ }^{527}$, wird durch die Spuren in unseren Lehmfragmenten nicht erhärtet (Tabelle 2), denn weder Phosphor noch Strontium noch Barium, die für Knochensubstanzen typisch wären ${ }^{528}$, sind im Innern der Lehmumhüllungen tendenziell angereichert.

\section{Herkunft des Lehms}

Die Analysen auf frischen Bruchflächen der Lehmumhüllungen durch Markus Helfert hatten zum Ziel, anhand der Spurenelementanalysen die Tonzusammensetzung zu charakterisieren und wenn immer möglich mit bekannten Referenzgruppen ${ }^{529}$ zu korrelieren, um die Herkunft des verwendeten Tones zu bestimmen.

M. Helfert schreibt dazu ${ }^{530}$ : «Ich habe mir ... die Daten zu den Tonummantelungen / Stahltiegeln angeschaut und mit den Tonen verglichen. Das Tonmaterial ist sicher aus Augst, auch wenn es zwei Gruppen gibt, wovon eine nicht unmittelbar mit einer Referenzgruppe übereinstimmt. Die andere Gruppe ist exakt aus dem Zelglihof-Ton hergestellt [TON 060-064] ${ }^{531}$. Wenn man nun rund 5 Prozent Kalk hinzumischt, gelangt man genau bei der ersten besagten Gruppe. Ob das Beimischen von Kalk bewusst geschah oder hier ein anderer Ton zugrunde liegt, lässt sich mit unseren Analysen nicht entscheiden. Ich würde jedoch vermuten, dass dem Zelglihof-Ton in Form einer Rezeptur etwas Kalk bewusst hinzugefügt wurde.» Aus diesen Gründen wurde für die Experimente Zelglihof-Ton mit 5\% Kalk verwendet (s. unten).

\section{Beurteilung der Keramikstruktur}

Von neun originalen Lehmumhüllungen und acht rekonstruierten Packungen wurde je ein Fragment im Bruch unter dem Binokular näher betrachtet (je vier Beispiele sind abgebildet auf Abb. 57 und 58).

\section{Natürliche Magerung}

Die Lehmumhüllungen der Originale (Abb. 50 und 51) sind bekanntlich die Ausgangsmaterialien für die rekonstruierten Stücke (Abb. 76) gewesen (s. Anm. 530 sowie unten mit Anm. 548 und 556). Der für die Originale mit grosser Wahrscheinlichkeit ermittelte Ton aus Kaiseraugst/BL-Zelglihof enthält sehr viele kleine Quarzkörnchen (Abb. 57532). Dafür spricht auch der relativ hohe Si-Anteil in den antiken Lehmumhüllungen (Tabelle 5) ${ }^{533}$. Die Quarzkörner sind so klein und auch deutlich verrundet, dass sie als natürliche Bestandteile des Lehmes und nicht als absichtlich zugefügte Magerung angesehen werden müssen ${ }^{534}$. Die natürlichen Quarzkörnchen im Lehm der Rekonstruktionen sind nur geringfügig grösser (Abb. 58) als jene in der Matrix der Originale. Bei der Probe 1983.30928 (Abb. 57,22) könnte es sich allenfalls um einen andernorts gegrabenen Lehm handeln, da dieser etwas grobsandiger ist.

\section{Lehm der römischen Originale}

Der erwähnte hohe Siliziumgehalt der Lehmumhüllungen entspricht etwa den Werten von auch heute noch genutzten Feuerfesttonen. Die kleinen, natürlich im Lehm vorhandenen Quarzkörnchen fallen mit Korngrössen von 0,03-0,15 mm in den Bereich von Grobsilt (Grobschluff) zu Feinsand.

Im Bruch zeigen die Lehmumhüllungen eine heterogene Struktur mit vielen Schlieren, was auf einen nicht gut aufbereiteten, kaum durchgekneteten Ton schliessen lässt (Abb. 57)

Die römischen Scherben der Lehmumhüllungen weisen - genauso wie die Rekonstruktionen - im Innern keine grossen Poren auf. Bei der näheren Betrachtung erweist sich die Tonmatrix in beiden Fällen als dicht versintert. Dies muss auf die Brandbedingungen zurückzuführen sein. Die Beobachtungen lassen vermuten, dass die Umhüllungen - auch die antiken - lange Zeit bei hohen Temperaturen gebrannt wurden. Die entsprechenden Sinterspuren sind bei den Rekonstruktionen (Abb. 58,P07) etwas deutlicher ausgeprägt als bei den Originalen (Abb. 57,24). Ob dies auf etwas niedrigere Temperaturen als die $1000^{\circ} \mathrm{C}$ bei den rekonstruierenden Zementationsbränden zurückzuführen ist, ist schwer zu beurteilen.

527 Gansum 2004

528 Furger 2018, Tabellen 5 (Experiment 12) und 7 (Knochen roh, entfettet und geglüht)

529 Zusammenfassend zur Augster Geschirrkeramik: Jornet/Maggetti 2003 (mit älterer Lit.); zu den Augster Schmelztiegeln: Helfert/Furger 2017, 176-179 Abb.4-5; M. Helfert in: Furger 2018, 127 f. und $149 \mathrm{ff}$. Abb. 72 und 74, Ton 060-064.

530 E-Mail vom 19.10.2015. Ich danke an dieser Stelle Markus Helfert für die Analysen und die Tongruppenzuweisung.

531 Furger 2018, 127 Abb. 74, Fundstelle 3; Tab. 3.

532 Die Aufnahmen für die Abbildungen 57 und 58 erfolgten mit einem Binokular mit elektronischem Kameraaufsatz Leitz Z16 APO; die Bruchflächen wurden in der Vergrösserung 12,5 $\times$ und $63 \times$ mit Weissabgleich im Modus «Multifocus» aufgenommen.

533 Analog des Tones 060-064 Kaiseraugst / BL-Zelglihof: Furger 2018, 130 Abb. 74 (Fundstelle 3) und Tabelle 3 (https:/ / edoc.unibas. ch /57097/3/Tiegel_Tabelle3.xls).

534 Bei den hier aufgeführten Beobachtungen an den originalen und rekonstruierten Lehmumhüllungen stütze ich mich auf die Beurteilungen von Markus Helfert (Universität Frankfurt), dem ich für seinen fachlichen Rat sehr dankbar bin. 


\section{Lehm der Rekonstruktionen}

Mit Ausnahme der auffallend roten Farbe der neu gebrannten Rekonstruktions-Umhüllungen weisen diese kaum strukturelle Unterschiede zu den Originalen auf (Abb. 57 und 58). Im Vergleich zu den Originalen enthalten die Rekonstruktionen jedoch etliche grössere Steinchen.

Die abweichende Aufbereitung der Umhüllung von Probebarren P06 (s. S. 130) zur Verringerung der Trockenrissbildung ist im Bruchbild (Abb. 58,P06) sofort zu erkennen: P06 weist keine Feinrisse und Klüfte mehr auf. Der extra aufbereitete Ton von Probe P06 sticht zudem durch die kräftigen Farben hervor. Das teilweise Fehlen der schwarzreduzierten Innenseite an den anderen Rekonstruktionen ist allerdings nur sekundär auf die unterschiedliche Tonaufbereitung zurückzuführen, da Rissbildung auch im Innern zu rot oxidierender Atmosphäre führen konnte.

Für künftige Experimente mit möglichst geringer Schwundrissbildung beim Trocknen würde sich aus den Beobachtungen am Originalmaterial und Erfahrungen mit den Rekonstruktionen etwa folgende Lehmaufbereitung aufdrängen:

1. Den Ton «mager machen»: Die feinste Fraktion aus dem Ausgangsmaterial durch Schlämmen entfernen (wie auf S. 130 beschrieben), eventuell noch konsequenter als bei P06.

2. Um die Feinkörnigkeit der Originale zu erreichen, müssen die gröberen Sandteile aus dem Ton konsequent herausgesiebt werden.

3. Der Ton müsste zuerst in dünne Platten geformt und bis knapp Lederhärte vorgetrocknet werden, bevor die Eisenbarren damit eingehüllt und die Lehmfugen mit etwas Wasser sorgfältig verstrichen werden (s. auch Anm. 548).

Mit diesen Schritten liesse sich eine «ideale Matrix» erzielen, die den Originalen sehr nahe kommt. Eine derartige Zone ist in Abbildung 58,P06 oval eingetragen. 


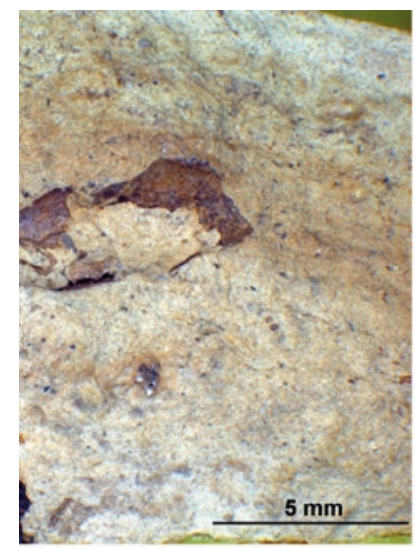

04 (1988.051.C05038.18)
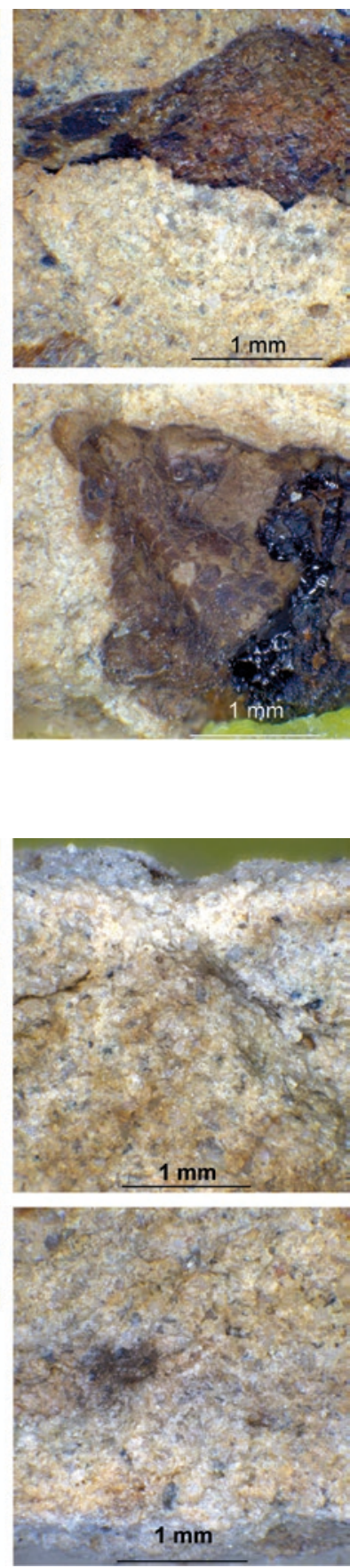

\section{$16(1983.30832)$}

$22(1983.3928)$
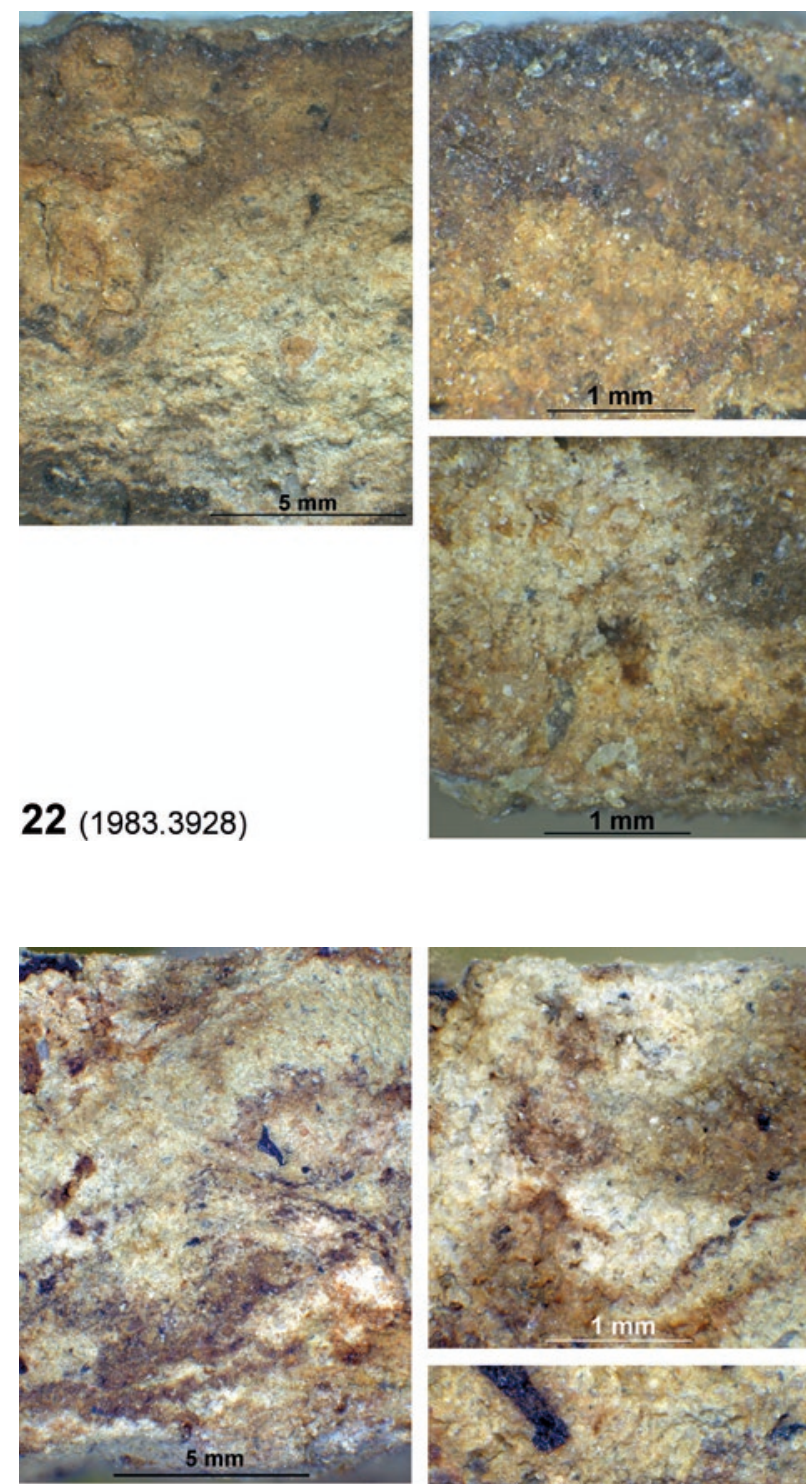

24 (1983.30934)
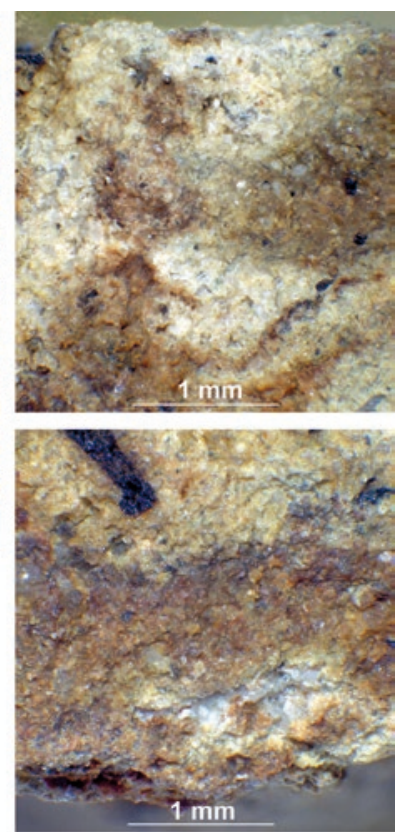

Abb. 57: Augst/BL, Augusta Raurica. Makroaufnahmen von Bruchkanten der vier Beispiele Kat.-Nr. 04, 16, 22 und 24 von römischen Lehmumhüllungen (wie Abb. 50). Jeweils links der ganze Querschnitt der Lehmumhüllung (aussen ist oben, Innenseite unten; M. 4:1), rechts je ein Ausschnitt vom Aussen- (oben) und Innenbereich (unten; M. 15:1). 


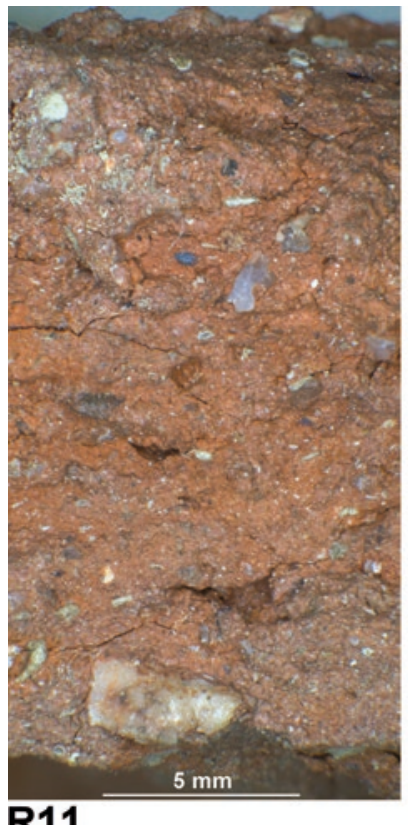

R11
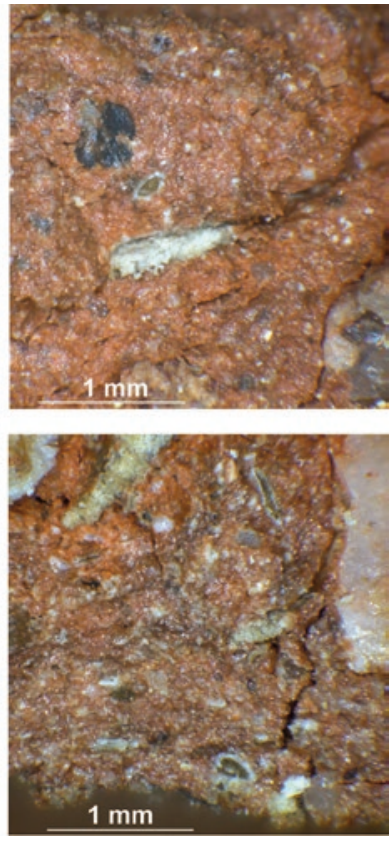

P06
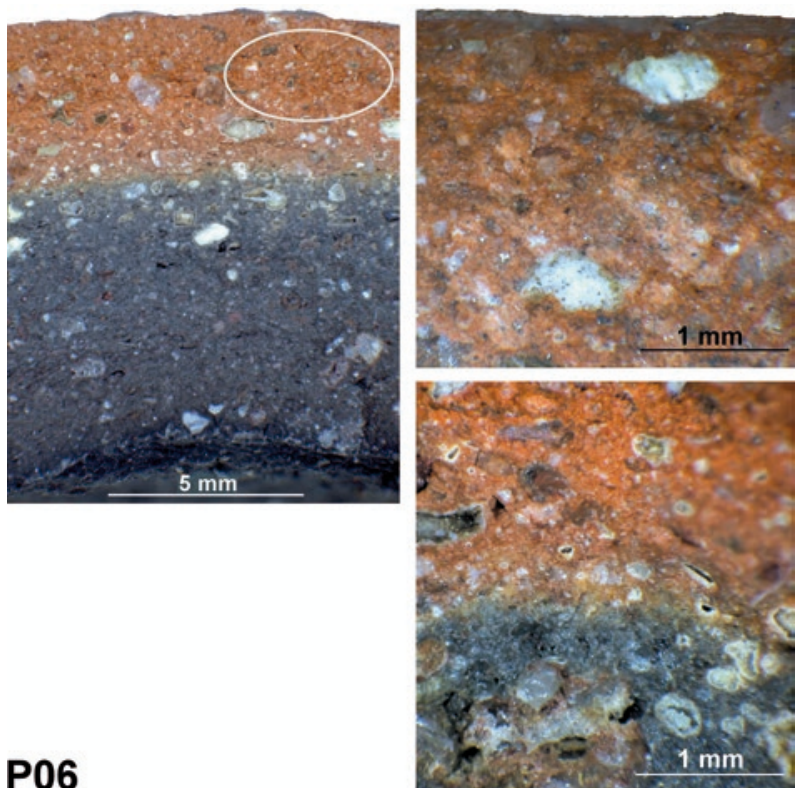

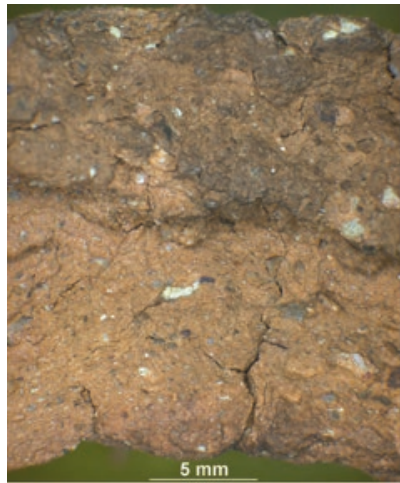

B07
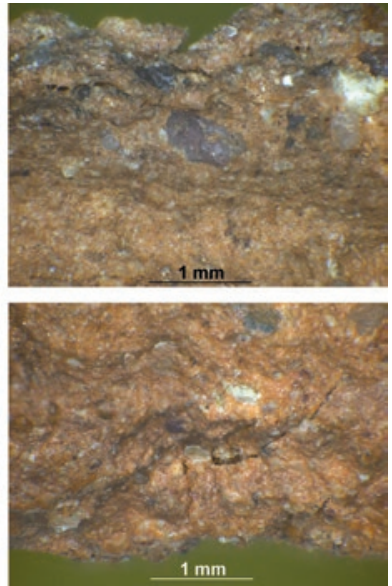

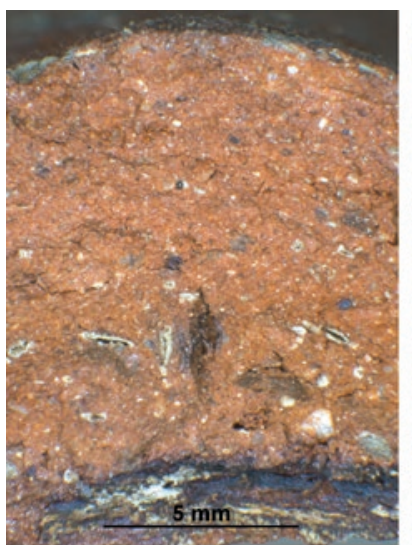

P07
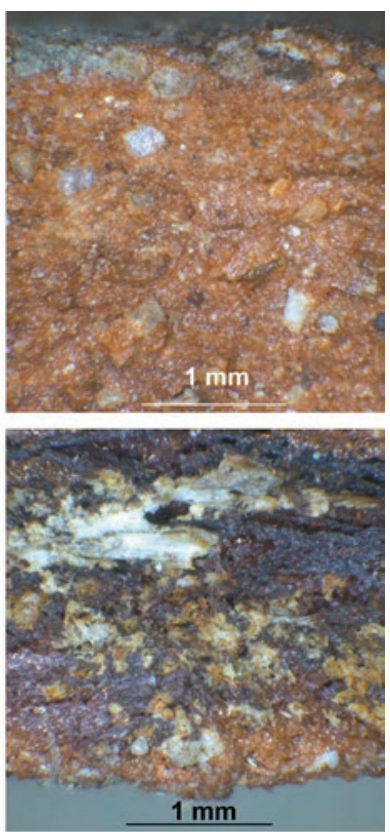

Abb. 58: Makroaufnahmen von Bruchkanten der vier rekonstruierten Lehmumhüllungen R11, B07, P06 und P07 (wie Abb. 76). Jeweils links der ganze Querschnitt der Lehmumhüllung (aussen ist oben, Innenseite unten; M. 4:1), rechts je ein Ausschnitt vom Aussen- (oben) und Innenbereich (unten; M. 15:1). Das weisse Oval bei P06 bezeichnet einen Ausschnitt mit sehr feiner, optimaler Matrix (siehe Text). 


\section{Grundlagen der Stahlerzeugung durch Aufkohlung}

\author{
Kohlenstoffträger: meist organische, \\ kohlenstoffhaltige Auflagen
}

Holzkohle: Als Kohlenstoffträger bietet sich in erster Linie Holzkohle an:Biringuccio 1540, 1. Buch, Kapitel 7 (zitiert nach Johannsen 1925, 77: «Kohlenstaub»); Réaumur 1722, 35; Kunckel 1732, 314f. (Weiden- und Buchenholzkohle, «klein gestossen und durchgesiebt ... fingersdick» aufgetragen); Perret 1780, 133; Halle 1783, 38 («Kohlengestübe»); Georgi 1785B, 308; 333; 336; 383-386 («zerpulverte Birkenkohlen»); Duhamel 1786, 421; 423; 429 («la cendre de différens bois»); 459f. (Aufbereitung von Holzkohlepulver); Rinman 1814, 465 f.; Rinman 1815, 602; 635 («Birkenkohlen»); de Fontenelle 1832, 209; Hartmann 1848, 732 («theils als Pulver, theils in kleinen Stückchen ... hauptsächlich ist es Eichenholz»); Reiser 1896, bes. 105; Leo 1902, 438; Ledebur 1903, 1079 («Laubholzkohle cementiert kräftiger als Nadelholzkohle»); Brearley 1914, 2 und 57; Bergmann 1920, 102 (in Härtungspulver für Feilen); Schiefer/Grün 1927, 189 f.; Krishnan 1954, 32f.; Schaaber 1963, 134 (industrielle Pulverkohlung); Rostoker / Bronson 1990, 123; Pleiner 2006, 67; Presslinger 2007, 64 .

Holzkohle - teils pulverisiert, teils als Granulat - wird in verschiedenen Zementationsverfahren sowohl zum Auftragen und heiss Einwirkenlassen auf der Eisenoberfläche als auch in den Glühkästen als «Zementationspulver» verwendet (box-hardening).

Aufkohlungsstoffe müssen in erster Linie viel Kohlenstoff enthalten und leicht zu beschaffen sein. In der Literatur sind - nebst Holzkohle - folgende Materialien als Kohlenstoffträger auf Eisen überliefert, die oft auch miteinander vermischt werden sollen ${ }^{535}$ :

Ochsenhorn: Kunckel 1732, 315; Perret 1780, 133; Georgi 1785B, 386; Cramer 1766, 555; Halle 1783, 38; Duhamel 1786, 421; Beck 1884, 836 («Hornfeilspäne»); Reiser 1896, 106 («Hornkohle»); 107 («Hornfeilspäne»); 108 («geröstetes Hornmehl»); Brearley 1914, 1; Bergmann 1920, 49 (auch «Kuhklauen»); 102 («Hornspäne», in Härtungspulver für Feilen); 98 («Verkohlung von Horn ...»); 246 («Hirschklauenpulver», für ein «HärteteigRezept»); Darmstädter 1927, 167 (Bockshorn); Schiefer/Grün 1927, 189 («Hornmehl»); Johannsen 1953, 153; Brepohl 1987, 80 (Theophilus Presbyter Buch 3, Kap. 18); Rostoker / Bronson 1990, 123; Pleiner 2006, 66; 200; Halleux 2007, 1313 (gebranntes und zerstossenes Ziegenhorn); 1315; Presslinger 2007, 64 («gemah- lenes Ochsenhorn mit Kochsalz»); Biringuccio, zitiert nach Craddock 2010, 152. - Gebranntes Ziegenhorn, nach einer Quelle des 11.Jh. n.Chr., zurückgehend wohl auf antike Quelle des 4. Jh. v. Chr.: Berthelot 1888, 328; Ploss 1957, 112.

Hufe: Halle 1783, 38 («Klauen»); Prechtl 1834, 12 («Ochsenklauen»); Beck 1884, 836 («tierische Abfälle, Tierklauen»); Reiser 1896, 106 («Klauenspäne»); 108 («Klauenmehl ... für Feilen»); Schiefer/Grün 1927, 190 («Hufmehl»); Rostoker/Bronson 1990, 123; Pleiner 2006, 66; 200; Biringuccio, zitiert nach Craddock 2010, 152 .

Tierhaare: Cramer 1766, 555; Perret 1780, 133; Halle 1783, 38; Duhamel 1786, 421 («les poils»).

Knochen: Cramer 1766, 555; Duhamel 1786, 421 («chaux d'os», Knochenasche); Prechtl 1834, 12; Leo 1902, 438 («Beim Zusatz von Knochenmehl verhält sich das Cementirungspulver während des Glühens compakt und schliesst den Zutritt der Luft besser ab als reine Holzkohle allein; die Kohlenstoffaufnahme vollzieht sich infolgedessen gleichmässiger.»); Ledebur 1903, 1079 und 1081; Bergmann 1920, 102 («Knopfabfälle» [von Knochenknöpfen], in Härtungspulver für Feilen); Schiefer/Grün 1927, 189 («Knochenmehl»); Pleiner 2006, 200; Wagner 2007, 293; 295 (China).

Schweineschmalz: Reiser 1896, 106 («animalische Fette»); Brepohl 1987, 81 (Theophilus Presbyter Buch 3, Kap. 19); Maddin et al. 1991, 19; Presslinger 2007, 64.

Leder: Cramer 1766, 555; Perret 1780, 133 («Häute, Lederabfälle»); Georgi 1785B, 383 («verkohlte Lederlappen»); Halle 1783, 38 («Lederabgängsel»); Rinman 1815, 677 («gebranntes und zerpulvertes Leder»); Prechtl 1834, 12 («Lederschnitzel»); Beck 1884, 836; Reiser 1896, 106; Ledebur 1903, 1081 (Lederabfälle); Bergmann 1920, 98 («Verkohlung von ... Ledermehl»); 123 («Lederkohle»); Schiefer/Grün 1927, 189f. («Lederkohle»); Johannsen 1953, 153; Biringuccio zit. nach Rostoker/Bronson 1990, 123; Brepohl 1987, 81 (Theophilus Presbyter Buch 3, Kap. 19: Eisen, mit Bocksleder-Riemchen umwickelt); Rostoker / Bronson 1990, 123; Pleiner 2006, 66; Presslinger 2007, 64; Söderberg 2008, 4 Abb. 12 (Abdrücke von Tierhaaren [Fell?] im Innern von Lehmumhüllungen).

Tierische Abfälle, Exkremente: Georgi 1785B, 383 («gebrannten Taubenkoth»); Rinman 1815, 677 («Kuhmist»); Beck 1884, 836 («... Exkremente, besonders von Vö-

535 So Kunckel 1732, 315 
geln»); Bergmann 1920, 102 («eingetrockneter Kuhoder Pferdeharn», in Härtungspulver für Feilen).

Holzschnipsel: Buchanan 1807, vol. I, 175 (Cassia auriculata = Senna auriculata = matura tea tree); vol. II, 20 (Stammholz von Cassia auriculata); Bersch 1899, 754; Kupuram 1989, 336 (nach Heyne) und 330; Juleff 1998, 117 (Madhuca longifolia, «rather than the ranawara [Cassia auriculata]»); Biswas 2001, 123 (Cassia auriculata); Wagner 2007, 295 (Sägemehl, China).

Holzasche: Duhamel 1786, 421 («cendres neuves»); 459 (ein Viertel bis ein Drittel des Kohlenstoffgemisches aus Holzasche); Rinman 1815, 635 («frischgebrannte Holzasche», «Asche von Birkenholz und von Birken- und Wacholderholz zusammen, ist am besten»); de Fontenelle 1832, 209; Brearley 1914, 2.

Pflanzenblätter und -ranken, Spelzen und Mehl: Buchanan 1807, vol. II, 20; Reiser 1896, 108 («Roggenmehl»); 109 («Kornmehl»); Bergmann 1920, 98 («Roggenmehl»); 102 («Roggenmehl», in Härtungspulver für Feilen); 246 («Chinarinde», für ein «Härteteig-Rezept»); Kupuram 1989, 336 (Convolvulus laurifolia = eine Windenart; nach Heyne) und 330 (Ipomea [Prunkwinde] oder Convolvulus [Winde]); Biswas 2001, 123.

Schilf: Söderberg 2008, 4 Abb. 14 (Abdrücke von schilfähnlichem faserigem Material im Innern von wikingerzeitlichen Lehmumhüllungen; hier: Abb. 29,1.9.14).

Gras: Söderberg 2008, 4 Abb. 11 (Abdrücke von grasähnlichem faserigem Material im Innern von Lehmumhüllungen).

Russ: Kunckel 1732, 315 («Russ aus Schornsteinen»); Perret 1780, 133; Halle 1783, 38; Georgi 1785B, 336; 383 («harten Schornsteinruss»); Rinman 1815, 677 («Russ mit Bierhefen»); Bréant 1823, 225; de Fontenelle 1832, 209; Reiser 1896, 107; Brearley 1914, 1 («a small quantity of lampblack»); Schiefer/ Grün 1927, 190.

Koks: Brunhuber 1991, 75.

Graphit: Bréant 1823, 225; Beck 1884, 245 (Graphit als Kohlenstoffträger im asiatischen Tiegelstahl); Brunhuber 1991, 75.

Gemisch aus Hühnerfeder-Asche und zerquetschten Sauerkleeblättern: Höfer 1972, 56.

\section{Und als Zusätze:}

- Salz: Perret 1780, 133 («Salze von allen Arten, Meersalz»); Georgi 1785B, 336 («Koch- oder Seesalz»); 337 (Salz «soll die völlige Brennung beschleunigen; zu viel aber, den Stahl unter dem Schmieden berstend machen»); Duhamel 1786, 421; 459; de Fontenelle 1832, 209; Berthelot 1888, 328; Rinman 1815, 677 («... Kochsalz ... die Eigenschaft besitzt, die Verwandlung des Eisens in Stahl zu beschleunigen, und dieselbe bei einem geringeren Hitzgrad möglich zu machen ...»); Reiser 1896, 106 f. (Blutlaugensalz); 108 («Das Kochsalz wird früher geröstet, um ein Zerknistern desselben beim Gebrauche zu verhüten»); Brearley 1914, 1 f.; Bergmann
1920, 49 («Blutlaugensalz», «Chlornatrium» [Kochsalz]); 98 («Kochsalz, Blutlaugensalz»); 246 («Kochsalz», für ein «Härteteig-Rezept»); Schiefer / Grün 1927, 189f. («Soda»); 190 («Kochsalz»); Hils 1985, 68 Anm. 31 (Blutlaugensalz); Halleux 2007, 1315; Wagner 2007, 295 (China).

- Salpeter: Georgi 1785B, 383; Reiser 1896, 106 f.; Bergmann 1920, 98 («Kalisalpeter», auch Pottasche, Leim usw.); 246 («blausaures Kali, ... Salpeter» [sowie «schwarze Seife»], für ein «Härteteig-Rezept»).

- Branntkalk: Réaumur 1722, 37; Bergmann 1920, 49; Schiefer/Grün 1927, 189f. («Schlämmkreide»); 190 («Bariumkarbonat»).

- Glaspulver: Georgi 1785B, 385 f. («... Härtepulver mit fein zerpulvertem Kristallglase gemischt ...», ferner Tischlerleim, Borax, Pottasche, Kieselmehl, Salmiak, Bierhefen usw.); Reiser 1896, 106; 108; Bergmann 1920, 102 (in Härtungspulver für Feilen).

- Kolophonium: Bergmann 1920, 102 (in Härtungspulver für Feilen). - Vereinzelt auch andere Harze und Ähnliches: Reiser 1896, 106 (Harze); Schiefer / Grün 1927, 190 («Gummi arabicum»).

- sogar kohlenstoffreiche «feine Dreh- und Feilspäne von grauem Roheisen»: Prechtl 1834, 12.

- U.v.a.m. (so etwa Kalk, Salmiak, Urin, Borax [Perret 1780, 133; Reiser 1896, 106 ff.])

Die tierischen Substanzen (Horn, Knochen[asche], Leder usw.) in dieser Aufzählung enthalten auch Stickstoff, was durch «Nitridierung» zu noch besseren Stählen führt als Holzkohle (s. oben mit Anm. 336 und 339).

Aufgrund der Analysen an den inneren und äusseren Oberflächen der Lehmumhüllungsreste aus Augusta Raurica allein lassen sich keine direkten Rückschlüsse auf spezielle Kohlenstoffträger ziehen:

Hätte man Knochenasche (statt Holzkohle) als Aufkohlungsmittel zur bewussten Erzeugung eines Phosphorstahls eingesetzt, so müsste im Umhüllungsinneren tendenziell mehr Phosphor, aber auch Calzium, Strontium und Barium festgestellt werden, da diese für Knochensubstanzen typisch wären ${ }^{536}$. Dies ist jedoch nicht der Fall (Tabelle 2). Im Experiment wurde die Eisenprobe $\mathbf{R 0 6}$ mit einem Knochen-/Holzkohle-Gemisch aufgekohlt (Abb.71,R06; siehe S. 119 und 126).

Hätte man - aus welchem Grund auch immer - Leder oder Tierhaut um die Eisenbarren gewickelt, müssten leicht erhöhte Schwefel-, Chlor- und Strontium-Werte erkennbar sein ${ }^{537}$. Auch dies ist nicht der Fall (Tabelle 2).

536 Furger 2018, Tabelle 7. - Siehe auch oben mit Anm. 528. 537 Furger 2018, Tabelle 7. 


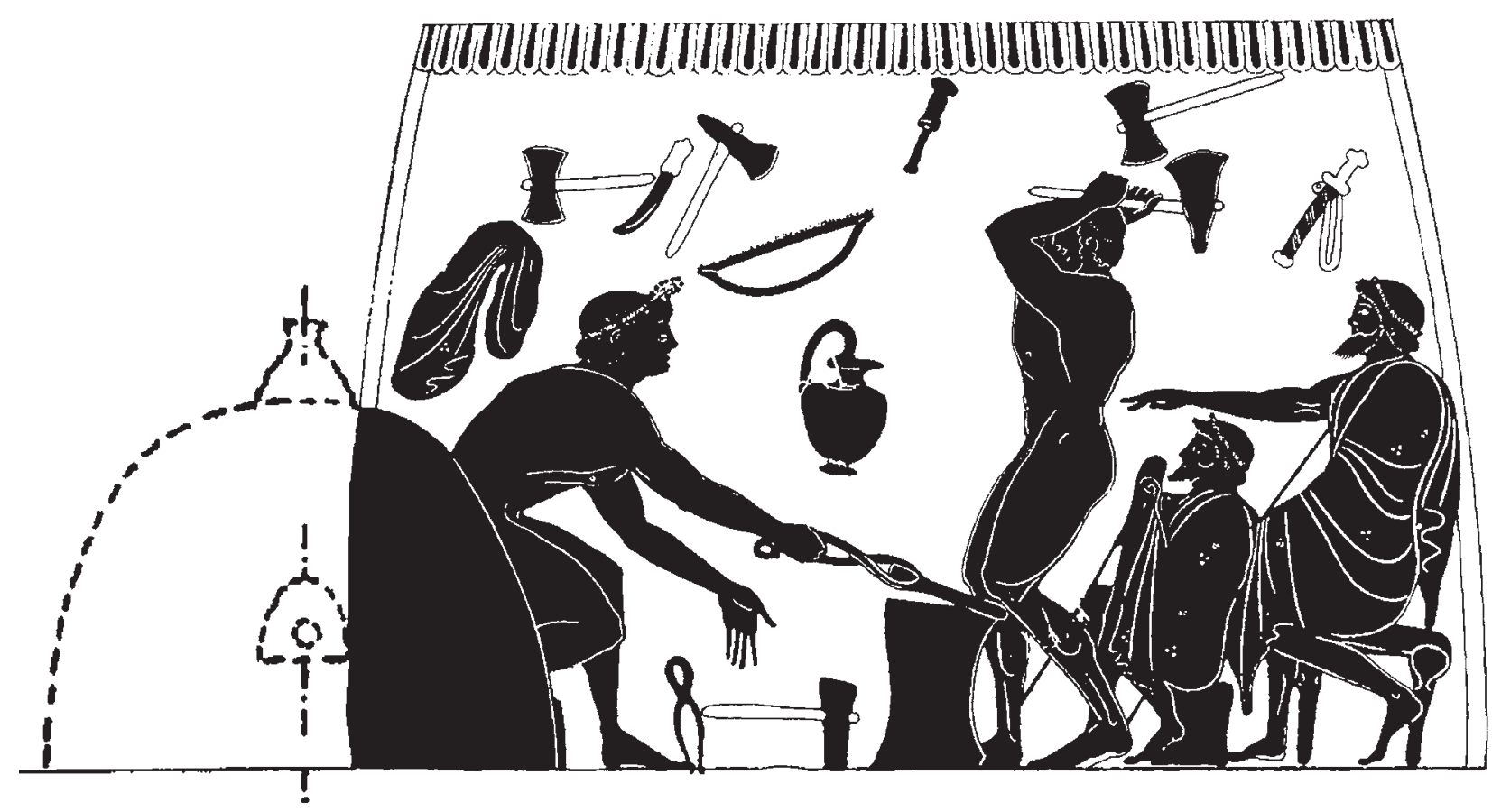

Abb. 59: Orvieto / I, attisches Vasenbild um 510-500 v. Chr. Dargestellt ist eine Schmiedewerkstatt, in deren Zentrum ein Amboss steht mit dem hammerführenden Schmied rechts daneben und einem Gehilfen links, der das Werkstück mit einer Zange hält. Der nur teilweise dargestellte, gestrichelt ergänzte Ofen links ist nach Conophagos / Papadimitriou 1986, 136, möglicherweise ein Zementationsofen, in dem nach Bedarf Eisenstücke zu Stahl aufgekohlt werden konnten.

Auch Tierhaut kam in zwei der Experimente zum Einsatz (Abb. 71,P07.R07). Just diese beiden Proben wurden jedoch nicht auf Schwefel hin analysiert (Tabelle 6).

\section{Antike Herde und Öfen zur Aufkohlung?}

Die Anforderungen an eine Wärmequelle, an der Eisen mit Holzkohle oder anderem kohlenstoffhaltigem Material zu Stahl «aufgekohlt» resp. zementiert werden konnte, waren relativ simpel: Es musste eine genügend hohe Temperatur von etwa $800-1000^{\circ} \mathrm{C}$ erreicht werden, die durch fortwährendes Befeuern während vieler Stunden auch gehalten werden konnte (S. 29, Tabelle 1).

Die Lehmumhüllungen aus Augusta Raurica sind oxidierend gebrannt und aussen nicht versintert (Abb. 50), wie etwa Schmelztiegel, welche direkt in den glühenden Holzkohlen erhitzt worden sind. Dies spricht dafür, dass die Lehmpakete zur Stahlerzeugung in einer separaten Brennkammer, d.h. von der Glut resp. den Flammen getrennt, erhitzt worden sind. Alle diese Voraussetzungen erfüllt ein normaler Töpferofen ${ }^{538}$ ! Auf der Suche nach antiken Zementationsöfen für Stahl ist also auf eine ähnliche Konstruktion zu achten.

Dass solche Zementationsöfen direkt in einer Schmiede gestanden haben könnten, schlagen Constantin Conophagos und George Papadimitriou vor ${ }^{539}$. Sie machen auf ein Vasenbild aus Orvieto/I aus dem Ende des
6.Jahrhunderts v.Chr. aufmerksam, auf welchem eine Schmiedewerkstatt in vollem Betrieb dargestellt ist. In deren Zentrum steht ein Amboss mit dem hammerführenden Schmied rechts daneben und einem Gehilfen links, der das Werkstück mit einer Zange hält (Abb. 59). Der nur teilweise erhaltene, in der Umzeichnung gestrichelt ergänzte Ofen links ist nach Conophagos / Papadimitriou möglicherweise ein Zementationsofen, in welchem nach Bedarf direkt in der Schmiedewerkstatt Eisenstücke zu Stahl aufgekohlt werden konnten.

Eine früh ausgegrabene, aber gut dokumentierte Ofenkonstruktion kam 1932 in Colsterworth, Lincolnshire/GB, ans Tageslicht ${ }^{540}$. Die kleine, runde Konstruktion wies eine Lochtenne mit Öffnungen für mehrere Blasebälge auf (Abb.60); der Lehm war in der Heizkammer völlig durchgebrannt wie brüchige Ziegel. Stratigraphie und Streufunde datieren ihn ins 1./2.Jahrhundert n. Chr. Für die primäre Verhüttung hat der Ofen wohl nicht gedient, denn dazu wäre er wohl mit seiner bemerkenswerten Lochtenne nicht mehr so gut erhalten gewesen. Darin aufgefundene Eisenreste mit immerhin $0,2-0,5 \%$ Kohlenstoff lassen vermuten,

538 Conophagos / Papadimitriou 1986, 136

539 Conophagos / Papadimitriou 1986, 136 Abb. 11 (= unsere Abb. 59).

540 Hannah 1932; Schrüfer-Kolb 2004, 30 f. Abb. 16 («Alternatively, it [the furnance] could be interpreted as a carburisation hearth .... No explicit carburization hearths have come to my knowledge (..»). 
dass hier in während langer Zeit geschürter Glut Stahl aufgekohlt worden ist: «The higher carbon percentage shows that ... some of the pieces may have lain for some considerable time in contact with red-hot charcoal and become carburized.» ${ }^{541}$ Von allfälligen Abfällen wie Lehmumhüllungen ist allerdings nicht die Rede, so dass offenbleiben muss, ob mit Ton ummantelte Eisenstangen wie jene aus Augusta Raurica in solchen Öfen oder in anderen Feuern behandelt worden sind. Immerhin geht die Interpretation von Henry F. Cleere ebenfalls in diese Richtung: «Small fragments of bloomery iron, cut up on an anvil to increase their surface area for diffusion of carbon, were mixed up with some carbonaceous material - leaves or cow dung would be suitable - and sealed into rough balls or packs made of puddled clay... These packs were placed inside the chamber with a great deal of charcoal around them, and the charcoal was then ignited and raised to a high temperature by the use of bellows through the holes in the sides [of the furnance; Abb.60]. Once the desired temperature had been reached, it is conceivable that the gaps between the walls of the structure and the sides of the pit were filled in, to increase the blanket of fuel all round.... When the charcoal had all been consumed, the clay lumps would be broken open, to reveal small lumps of iron that had been completely carburized by combustion of the carbonaceous material in the reducing conditions inside the clay packs.» ${ }^{542}$

Trotz der über mehrere Quartiere in Augusta Raurica verstreuten Lehmumhüllungen (Abb.55) sind nur in Insula 35 Spuren eines möglichen Aufkohlungsofens beobachtet worden (Abb.56, «Herd S21»). Rings um ein zweilagiges Ziegelplattenfundament zeichnet sich eine kreisrunde verbrannte Struktur von $135 \mathrm{~m}$ Durchmesser ab. Da nichts von der aufgehenden Konstruktion - vielleicht einst eine Kuppel - erhalten war, muss offenbleiben, ob hier Lehmpakete mit eingeschlossenen Eisenbarren und kohlenstoffhaltigen Zuschlägen während vieler Stunden bei $800-1000^{\circ} \mathrm{C}$ in einem geschlossenen Brennraum erhitzt und dabei die Barren zu Stahl zementiert worden sind.

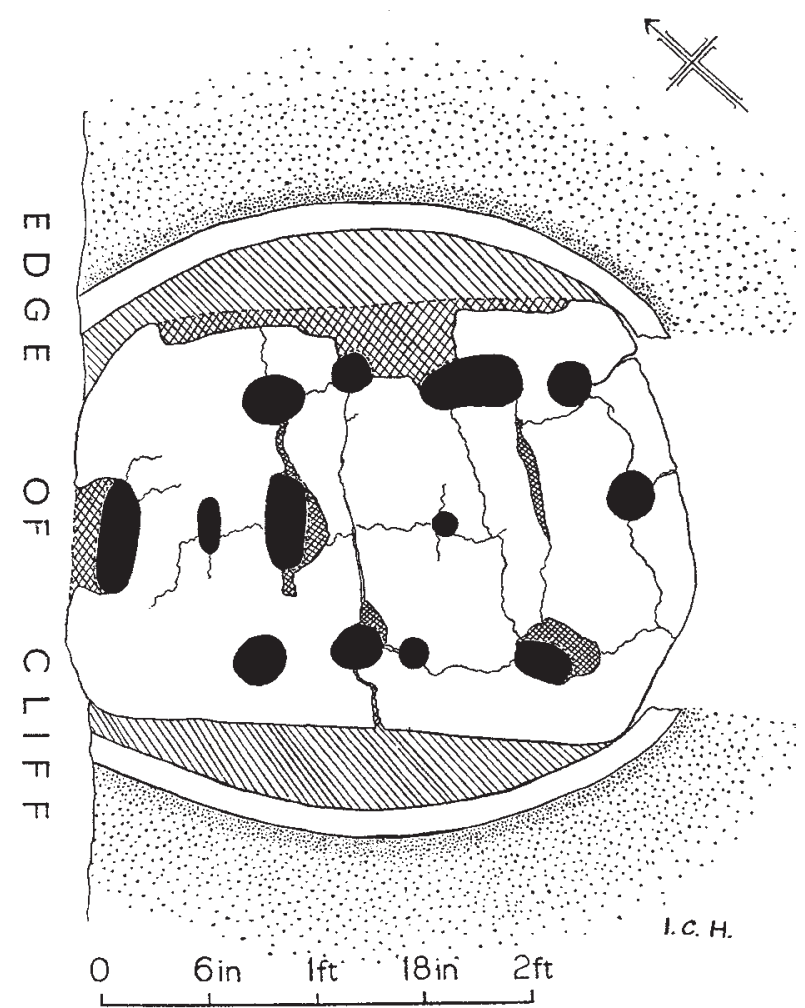

Abb. 60: Lincolnshire/GB. Grundriss eines als «blast furnace» (Rennofen) interpretierten römischen Ofens für die Eisenverarbeitung. Die Konstruktion mit Lochtenne und sehr starken Brandspuren war vermutlich als Ofen zum «Aufkohlen» (carburisation) resp. für die Einsatzhärtung von Eisen bestimmt. Denkbar wäre, dass auch in Augusta Raurica in ähnlichen Öfen die in organischen Materialien und Lehm verpackten Eisenstangen während langer Zeit im Holzkohlefeuer geglüht worden sind. 


\section{Experimenteller Nachvollzug der Eisen-Aufkohlung im Lehmmantel}

\section{Ausgangsmaterial: kohlenstoffarmes "Weicheisen»}

Im archäologischen Experiment wurden folgende drei «Weicheisen»-Sorten verwendet (Abb. 61):

R Reineisen der Firma Angele ${ }^{543}$ (Werkangabe: max. 0,01\% C), Flachstäbe $30 \times 20 \mathrm{~mm}$

B Buttereisen der Firma Angele (Werkangabe: ca. 0,03\% C), Quadratstäbe $30 \times 30 \mathrm{~mm}$

P Weicheisen unbekannter Herkunft aus der Kunstschmiede B. Pivot, Basel, Quadratstab $30 \times 30 \mathrm{~mm}$, enthält bloss 0,006\% C (Tabelle 6, P01/P03).

Die Rohstäbe wurden alsdann in stabförmige Barren geschmiedet (Abb. 61) ${ }^{544}$, die in Dimension und Querschnitt etwa den Negativabdrücken in den römischen Lehmumhüllungen aus Augusta Raurica entsprechen (Abb. 50). Die Dimensionen und Gewichte der einzelnen Eisenstücke gehen aus Tabelle 3 hervor. Alle Barren wurden langsam an der Luft abgekühlt und zur Entfernung des Zunders mit der rotierenden Stahlbürste gebürstet. Alle Stücke erhielten ihre Barrennummer (R01 ff.; B01 ff.; P01 ff.) je zweimal eingepunzt (Abb. 61).

Alle diese kohlenstoffarmen Eisen sind sehr homogen in ihrer Struktur (Abb. 62-70). Das «Reineisen» ist sehr feinkörnig, das «Buttereisen» leicht grober und das kohlenstoffärmste Weicheisen «Pivot» sehr grosskörnig (Abb. 68). Die Vickers-Härten der unaufgekohlten Weicheisen sind erwartungsgemäss sehr gering. Erstaunlicherweise aber sind dennoch signifikante, vom minimen C-Gehalt abhängige Härteunterschiede erkennbar. Entsprechend gering fielen auch die Kohlenstoff- und Schwefelanalysen aus (Abb. 64; 67; 70).

\begin{tabular}{|c|c|c|c|c|c|c|}
\hline $\begin{array}{l}\text { Probe- } \\
\text { Nr. }\end{array}$ & Länge & Breite & Dicke & $\begin{array}{l}\text { Gewicht } \\
\text { (g) }\end{array}$ & $\begin{array}{l}\text { Summe } \\
\text { (g) }\end{array}$ & $\varnothing(\mathrm{g})$ \\
\hline \multicolumn{7}{|c|}{$\mathrm{B}=$ Buttereisen (ca. 0,03\% C): } \\
\hline B05 & 235 & 27 & 28 & 1122,8 & \multirow{3}{*}{3102,2} & \multirow{3}{*}{1034,1} \\
\hline B06 & 252 & 25 & 25 & 884,1 & & \\
\hline B07 & 233 & 27 & 27 & 1095,3 & & \\
\hline B13 & \multirow{6}{*}{$\begin{array}{r}85- \\
96 \mathrm{~mm}\end{array}$} & \multirow{6}{*}{$30-40 \mathrm{~mm}$} & \multirow{6}{*}{$5-6 m m$} & 98,4 & \multirow{6}{*}{710,0} & \multirow{6}{*}{118,3} \\
\hline B14 & & & & 116,7 & & \\
\hline B15 & & & & 124,3 & & \\
\hline B16 & & & & 139,1 & & \\
\hline B17 & & & & 125,1 & & \\
\hline B18 & & & & 106,4 & & \\
\hline \multicolumn{7}{|c|}{$\mathrm{R}=$ Reineisen (ca. 0,01\% C): } \\
\hline R05 & 183 & \multirow{8}{*}{$\begin{array}{r}18-20 \times \\
18 \mathrm{~mm}, \\
\text { rechteckig }\end{array}$} & & 472,0 & \multirow{8}{*}{3403,1} & \multirow{8}{*}{425,4} \\
\hline R06 & 180 & & & 382,2 & & \\
\hline R07 & 187 & & & 411,4 & & \\
\hline R08 & 190 & & & 502,6 & & \\
\hline R09 & 180 & & & 386,8 & & \\
\hline R10 & 190 & & & 456,0 & & \\
\hline R11 & 185 & & & 390,9 & & \\
\hline R12 & 191 & & & 401,2 & & \\
\hline R13 & \multirow{6}{*}{$\begin{array}{r}78- \\
92 \mathrm{~mm}\end{array}$} & \multirow{6}{*}{$36-40 \mathrm{~mm}$} & \multirow{6}{*}{$4-7 \mathrm{~mm}$} & 134,4 & \multirow{6}{*}{720,7} & \multirow{6}{*}{120,1} \\
\hline R14 & & & & 108,1 & & \\
\hline $\mathrm{R} 15$ & & & & 96,7 & & \\
\hline $\mathrm{R} 16$ & & & & 124,2 & & \\
\hline R17 & & & & 133,1 & & \\
\hline R18 & & & & 124,2 & & \\
\hline \multicolumn{7}{|c|}{$P=$ Weicheisen Pivot $(0,006 \%$ C): } \\
\hline P05 & 105 & \multirow{4}{*}{$\begin{array}{r}26-27 \times \\
24 \mathrm{~mm}, \\
\text { trapezförmig }\end{array}$} & & 451,6 & \multirow{4}{*}{1739,3} & \multirow{4}{*}{434,8} \\
\hline P06 & 92 & & & 406,9 & & \\
\hline P07 & 101 & & & 456,1 & & \\
\hline P08 & 95 & & & 424,7 & & \\
\hline
\end{tabular}

Tabelle 3: Dimensionen und Gewicht der vorbereiteten Weicheisen-Barren für die Aufkohlungsexperimente (Abb. 61).

543 Angele Schmiedetechnik, D-88416 Ochsenhausen, www.angeleshop.com.

544 Ich danke an dieser Stelle Bernard Pivot für eine Musterstange «Weicheisen» («P») und dass ich am 23.02.2016 alle Stücke in seiner gut eingerichteten Schmiede herstellen durfte (Abb. 61, rechts unten). 

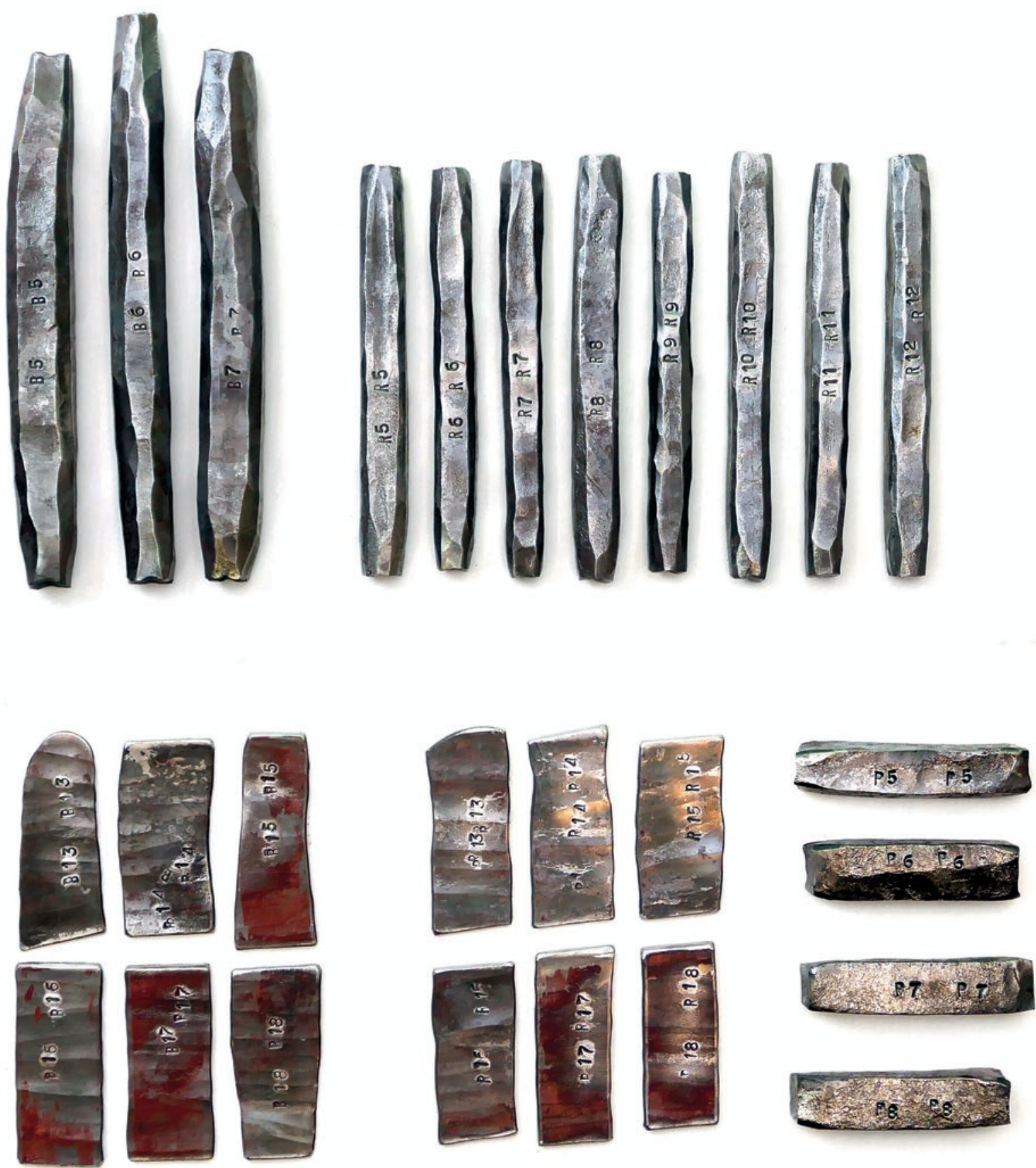

Abb. 61: Aufkohlungsexperimente in Lehmumhüllungen: Die 27 Barren aus Weicheisen, die in den Experimenten Verwendung fanden (Dimensionen: Tabelle 3). Oben links: Barren B05-B07 aus «Buttereisen» (s. Text); oben rechts: Barren R05-R12 aus «Reineisen» (s. Text); unten links: B13-B18 kleine Platten für Tiegel-Experiment aus «Buttereisen» (Abb. 115); unten Mitte: R13-R18 kleine Platten für Tiegel-Experiment aus «Reineisen»; unten rechts: Barren P05-P08 aus weichem, sehr kohlenstoffarmem Schmiedeeisen «Pivot». M. 1:3. 

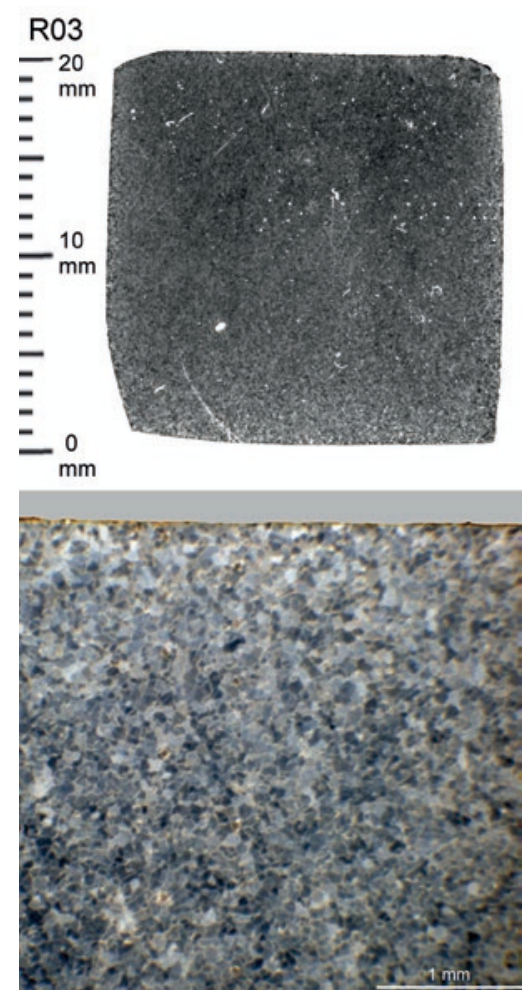

Abb. 62: Barrenquerschnitt R03 («Reineisen", nicht aufgekohlt). Scan M. 2:1 resp.

Binokularaufnahme M. 15:1.
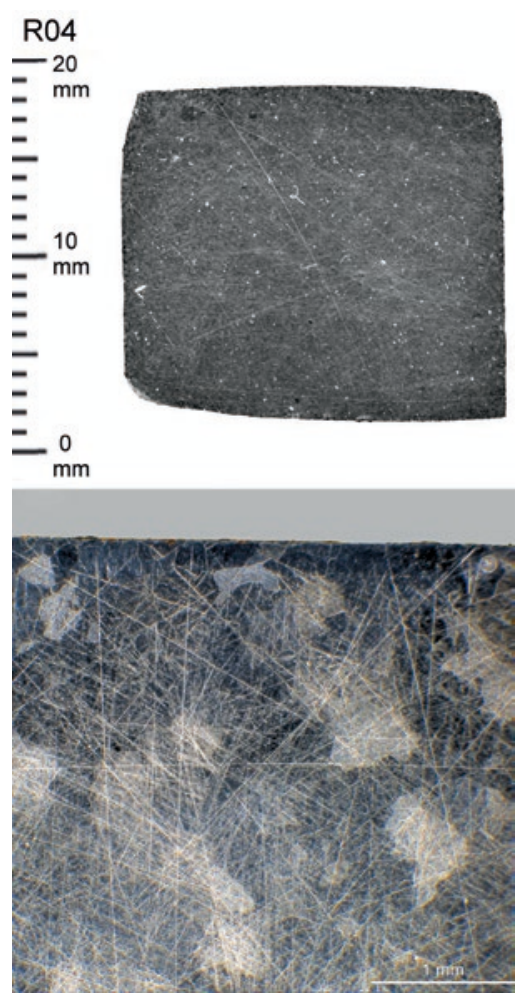

Abb. 63: Barrenquerschnitt R04 ( Reineisen», nicht aufgekohlt). Scan M. 2:1 resp.

Binokularaufnahme M. 15:1.
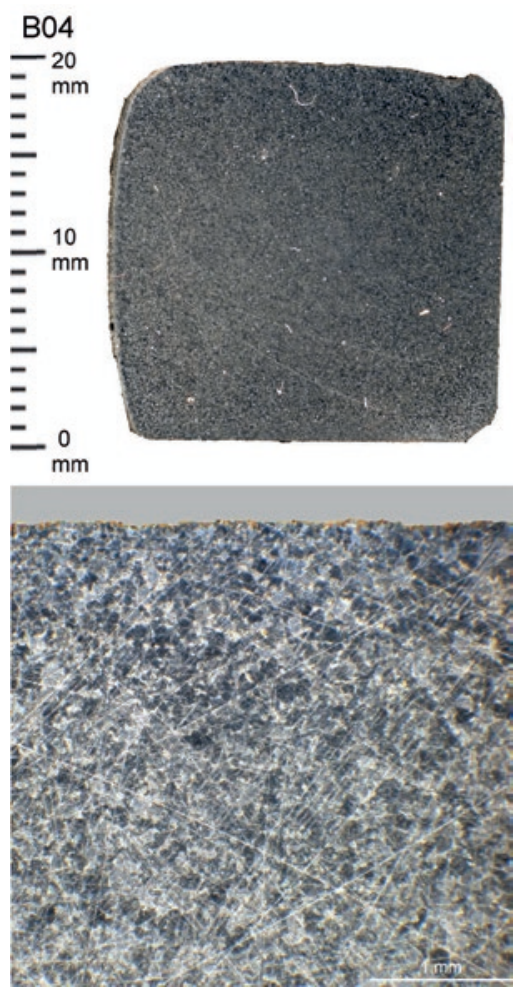

Abb. 66: Barrenquerschnitt B04 («Buttereisen», nicht aufgekohlt). Scan M. 2:1 resp. Binokularaufnahme M. 15:1.
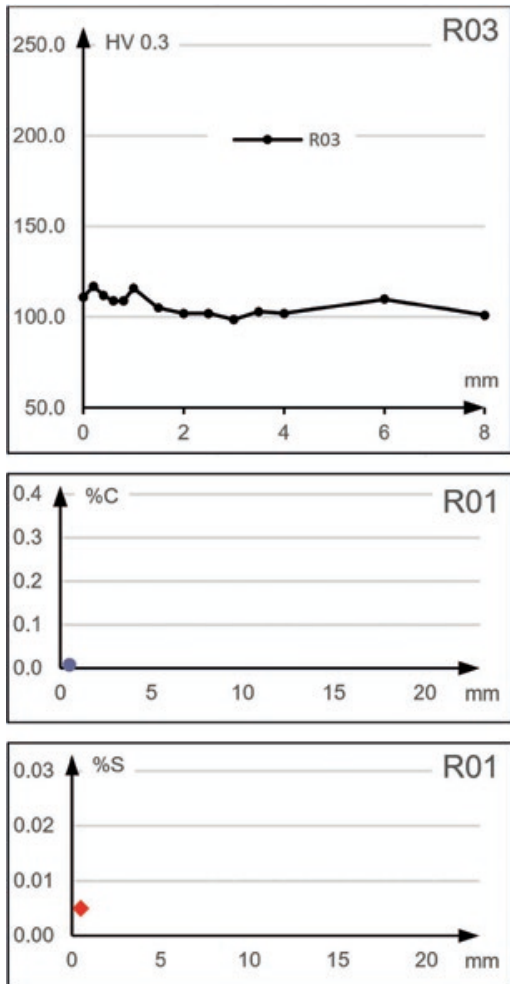

Abb. 64: Barrenquerschnitte R03 («Reineisen», nicht aufgekohlt). Diagramme (v. o. n. u.) Vickers-Härte 0,3, Kohlenstoff- und Schwefelanalysen.
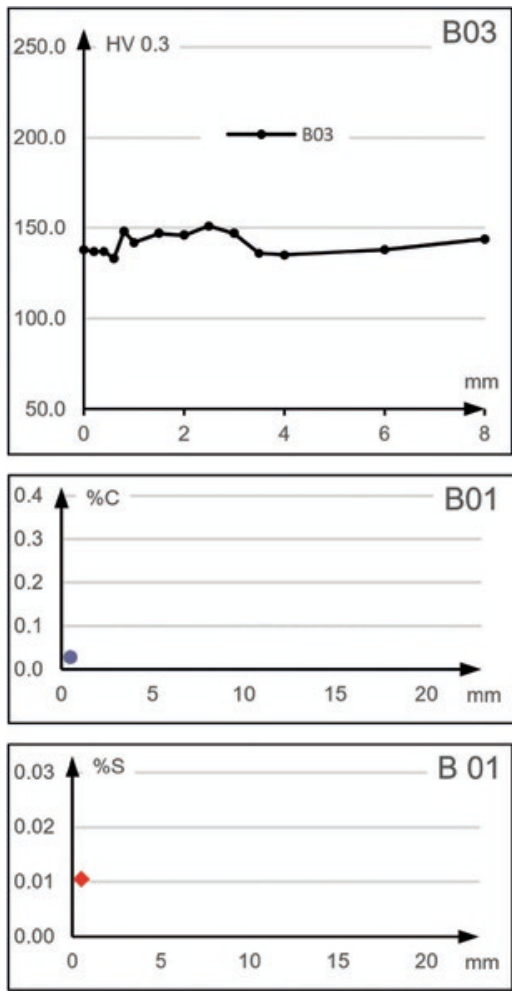

Abb. 67: Barrenquerschnitte B03

(«Buttereisen»). Diagramme (v. o. n. u.)

Vickers-Härte 0,3, Kohlenstoff- und Schwefelanalysen. 


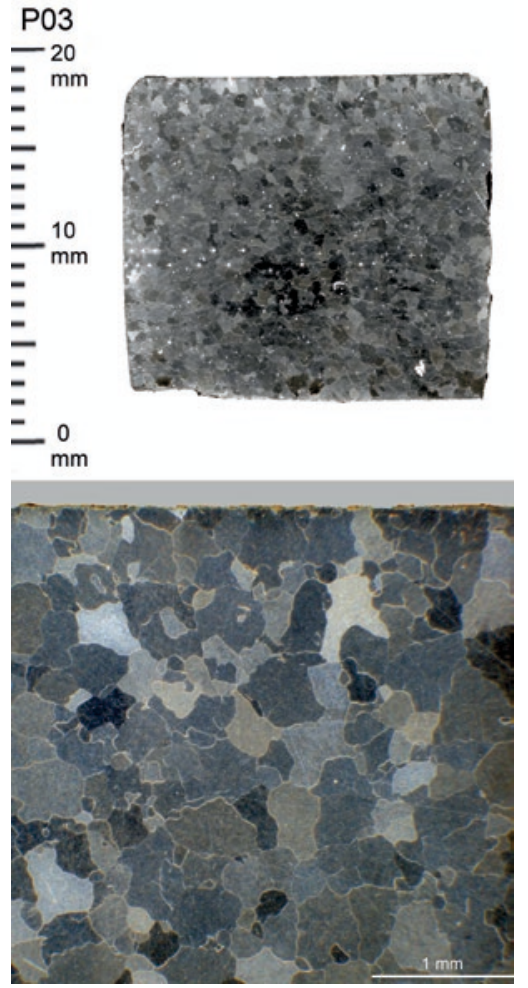

Abb. 68: Barrenquerschnitt P03 (Weicheisen «Pivot», nicht aufgekohlt). Scan M. 2:1 resp. Binokularaufnahme M. 15:1.
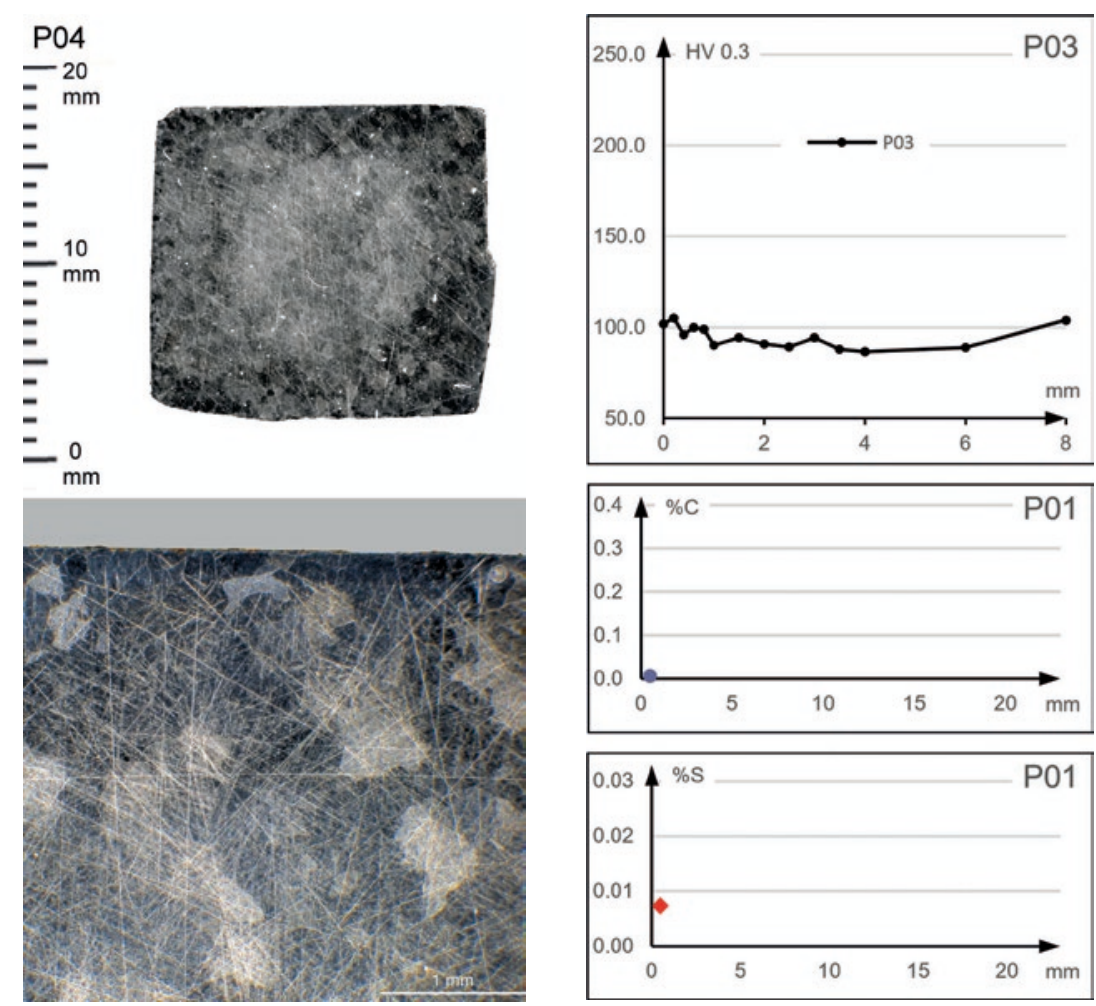

Abb. 69: Barrenquerschnitt P04 (Weicheisen "Pivot», nicht aufgekohlt). Scan M. 2:1 resp. Binokularaufnahme M. 15:1.
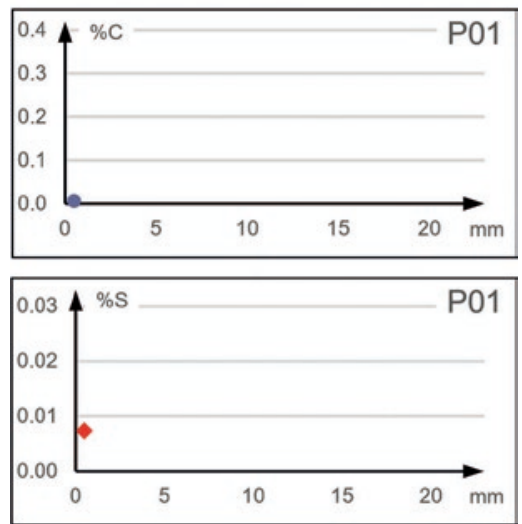

Abb. 70: Barrenquerschnitte P03 (Weicheisen «Pivot»). Diagramme (v. o. n. u.) Vickershärte 0,3, Kohlenstoff- und Schwefelanalysen.

\section{Die verwendeten Kohlenstoffträger}

Aus der Literatur ist ein gutes Dutzend - meist organische - Materialien bekannt, die zur Kohlenstoffanreicherung bei der traditionellen Stahlerzeugung verwendet wurden (s. oben S. 112f.). Wir haben mit folgenden acht Stoffen experimentiert (Zusammenstellung in Tabelle 5):

1. Holzkohle (Gemisch aus feinem Grus und Pulver; Abb. 71,B05)

2. Holz: Sägemehl, relativ grob (P08, nicht abgebildet)

3. Gräser: Getreidedrusch resp. Spelzen, trocken (Abb. 71,R11)

4. Schilf: grüne Stängel, geschnitten im April (Abb. 71,R10)

5. Tierhorn: Rinderhornspäne (vermischt 1:1 mit Holzkohle; Abb. 71,R08)

6. Tierhaut: Schweineschwarte (Abb. 71,P07.R07)

7. Kochenasche: gebrannt aus Rinder-Röhrenknochen, gemörsert und grob gesiebt ${ }^{545}$ (vermischt 1:1 mit Holzkohlegrus; Abb. 71,R06)

8. Graphit: sog. «Graphit-Silberpuder» der Firma Kremer ${ }^{546}$, enthaltend 94-96\% Kohlenstoff (Abb. 71,B06).

Die Kohlenstoffträger 1-4 sind also pflanzlichen Ursprungs, 5-7 tierisch und 8 mineralisch. Alle wären den antiken Metallhandwerkern zur Verfügung gestanden.

\section{Die Lehmumhüllungen}

Für die in den Experimenten angebrachten Lehmumhüllungen wurde derselbe Lehm verwendet, der aufgrund der Spurenelement-Zusammensetzung in den Originalen (Abb.50) mit hoher Wahrscheinlichkeit nachgewiesen werden konnte (s. oben mit Anm.530). Es handelt sich um Lehm von Kaiseraugst/AG-Zelglihof, der zwar nicht für Geschirrkeramik, aber nachweislich in römischen Bronzegiessereien in Augusta Raurica für Schmelztiegel, Lutum (äussere Verschleissschicht auf Tiegeln) und Gussformen verwendet worden ist ${ }^{547}$.

Um das Risiko von Trockenrissbildungen (Abb. 71,B05, unteres Bild) zu mindern, wurde dem fetten Lehm 2-3\% Quarzmagerung von 0,1-1,0 mm Korngrösse beigemischt (im Extremfall 10\% Magerung bei B06, R06 und R10). Der Lehm muss theoretisch auch gut vorgeknetet sein, damit er beim Umwickeln der Eisenbarren nicht allzu brüchig wird (was sich an den Originalen jedoch nicht bestätigt:

545 Furger 2018, 233-238 Abb. 155-162 (Experiment 12).

546 Kremer Pigmente GmbH \& KG, D-88317 Aichstetten, http: / / www. kremer-pigmente.com / media / files_public / 47700-47710.pdf (18.04.2016).

547 M. Helfert in: Furger 2018, 127-149 Abb. 72, insbes. 127 f. Abb. 74, Ton 060-064. 

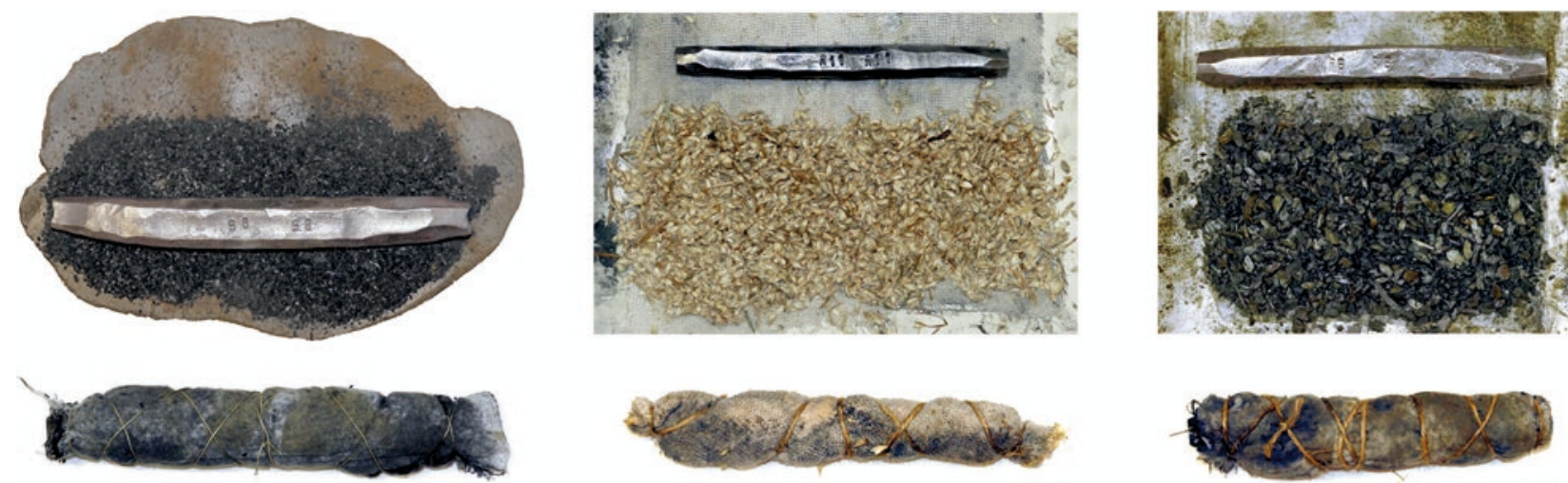

R11
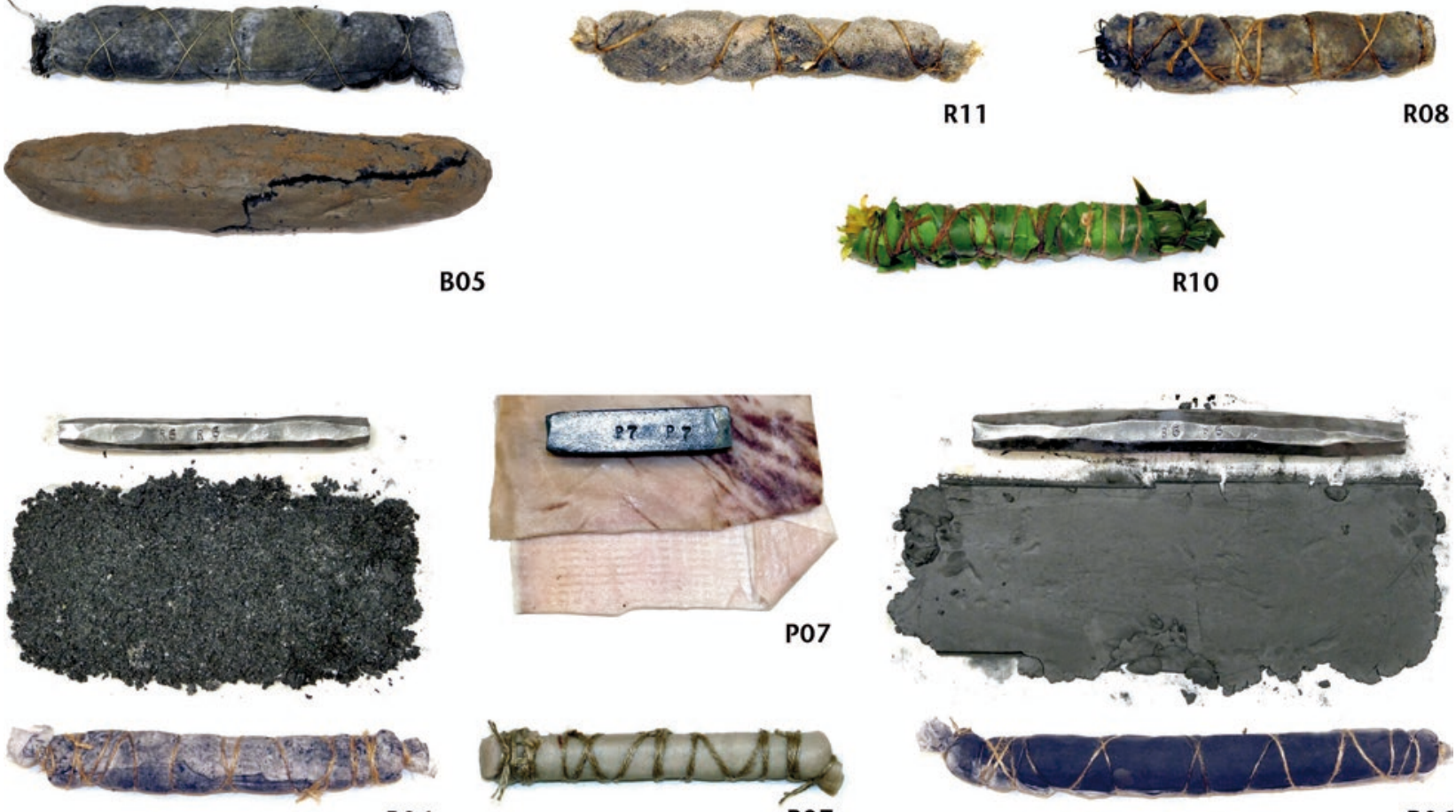

R06

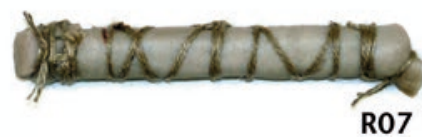

B06

Abb. 71: Aufkohlungsexperimente in Lehmumhüllungen: Auftragen kohlenstoffhaltiger Materialien auf die Barren aus Weicheisen (Abb. 61): B05, Bild oben: Direktauftrag von Holzkohle auf Eisen schlägt fehl; B05 Bild unten: Die Lehmumhüllungen bilden beim Trocknen Risse, die laufend mit feuchtem Lehm ausgebessert werden, bis die Pakete trocken sind (Abb. 72). - Teilweise umwickelt mit Gewebe: B05 (Holzkohle), R11 (Getreidedrusch), R08 (Hornspäne), R10 (Schilf), R06 (Knochenasche mit Holzkohle), P07 und R07 (Tierhaut), B06 (Graphit). M. 1:5.

oben mit Abb. 57). Dann ist das Auswallen in 3-6 mm dicke Lehmplatten gut zu bewerkstelligen. Als Trennmittel auf der Unterlage wurde trockenes Lehmpulver verwendet ${ }^{548}$.

Ein direktes Einrollen der Barren auf HolzkohleGrus in einen Lehmmantel (Abb. 71,B05, Bild oben) hat sich als äusserst riskant erwiesen: Kaum treten Trockenrisse auf, platzt das Bündel auf, die Holzkohle rieselt heraus und ein erneutes Zusammenkneten des Lehms wird durch die vielen Kohlenteilchen fast unmöglich. Die Erfahrung zeigte, dass es einfacher geht, wenn zuerst das organische, kohlenstoffreiche Material in einen Stoffstreifen aus Baumwolle oder Leinen eingewickelt (Abb. 71,R11. R08), das entstandene Bündel zur Sicherheit verschnürt (Abb. 71, alle Beispiele) und erst dann mit Lehm umhüllt wird (Abb.71,B05, Bild unten; 72). Anstelle eines Textils liessen sich genauso gut dünne Tierhaut oder grosse Pflanzenblätter zum Umwickeln verwenden. Von solchen Verschnürungen und Verknotungen haben sich anscheinend wenige Abdrücke in gebrannten römischen Lehmhüllen erhalten (Abb. 50,18b.18c). Solche Textilpäckchen waren bei der Tierhaut- und Schilfbeschichtung der Barren nicht nötig (Abb.71,R07.R10). Die pulverigen Stoffe wie Holzkohle, Knochenasche oder Graphit wurden vor dem Umwickeln mit Wasser und etwas Seife gut angefeuchtet, um sie als Paste besser verteilen zu können.

Während des Trocknungsprozesses ist weiterhin grosse Aufmerksamkeit gefordert. Die mit Lehm umhüllten Eisenstangen sollten an einem feuchten Ort oder abgedeckt nur ganz langsam getrocknet werden. Dennoch bildeten sich über die ersten Tage immer wieder Trockenrisse (Abb.71,B05, Bild unten), die laufend mit frischem nassem Lehm verschlossen wurden. Weil die Auflage auf den Barren unter der Lehmhülle weich ist (Grus, Pulver,

548 Kurz nach Abschluss der Vorbereitungen empfahl mir Johannes Weiss (Aeugst/ZH), den ausgewallten Ton antrocknen zu lassen, dann erst das Paket mit dem Eisenbarren darin einzuwickeln (und an der Fuge mit Wasser gut zu verstreichen), damit der Lehm weniger Risse bekommt. 

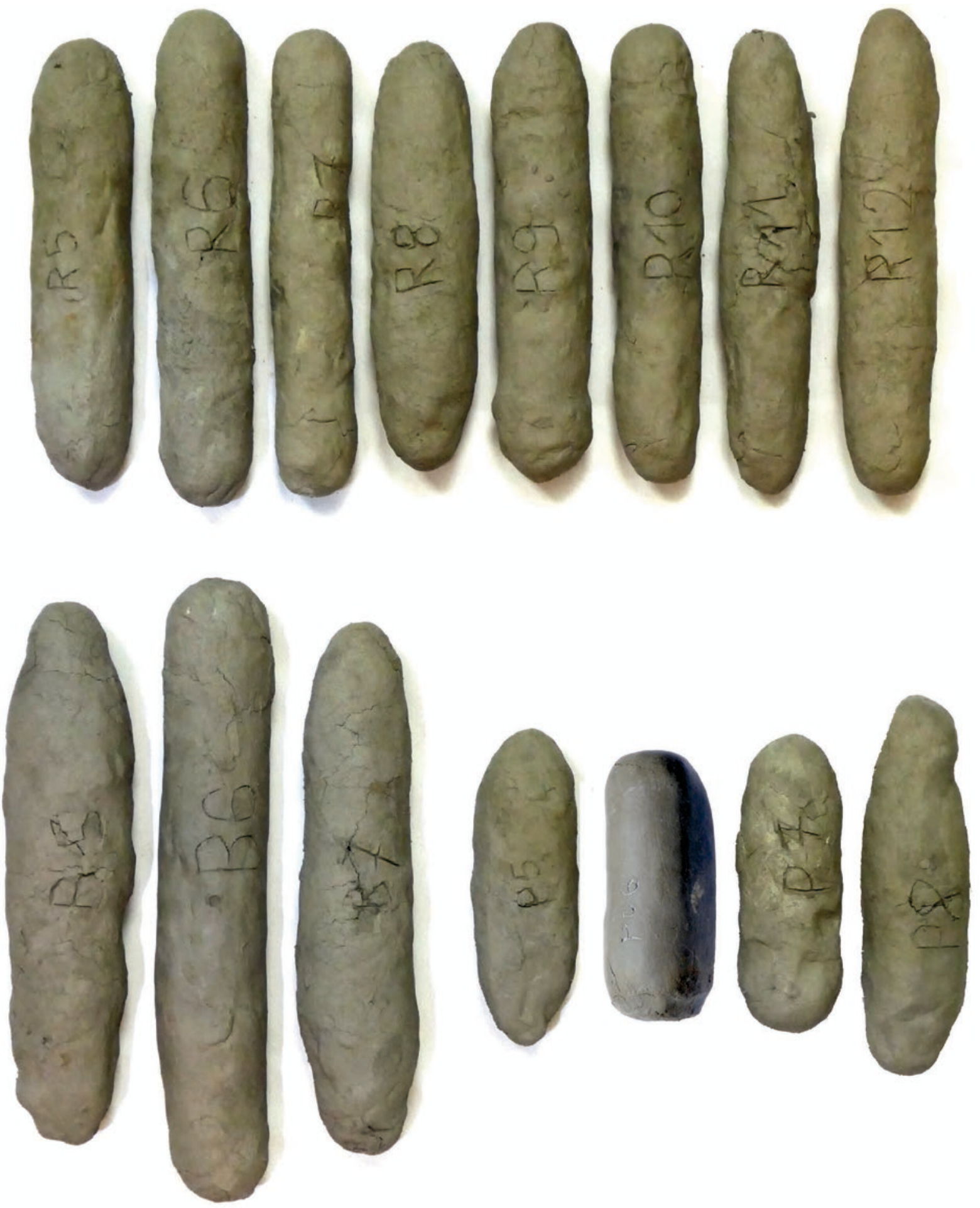

Abb. 72: Aufkohlungsexperimente in Lehmumhüllungen: Die fertigen, getrockneten Lehmpakete vor dem Einsatz im Feuer (Barreninhalt: Abb. 61). Obere Reihe: R05-R12; untere Reihe: R05-R07 und P05-P08 (P06: Versuch mit abweichender Lehmaufbereitung). - Dieselben Objekte nach dem Brand: Abb. 76. - M. 1:3 


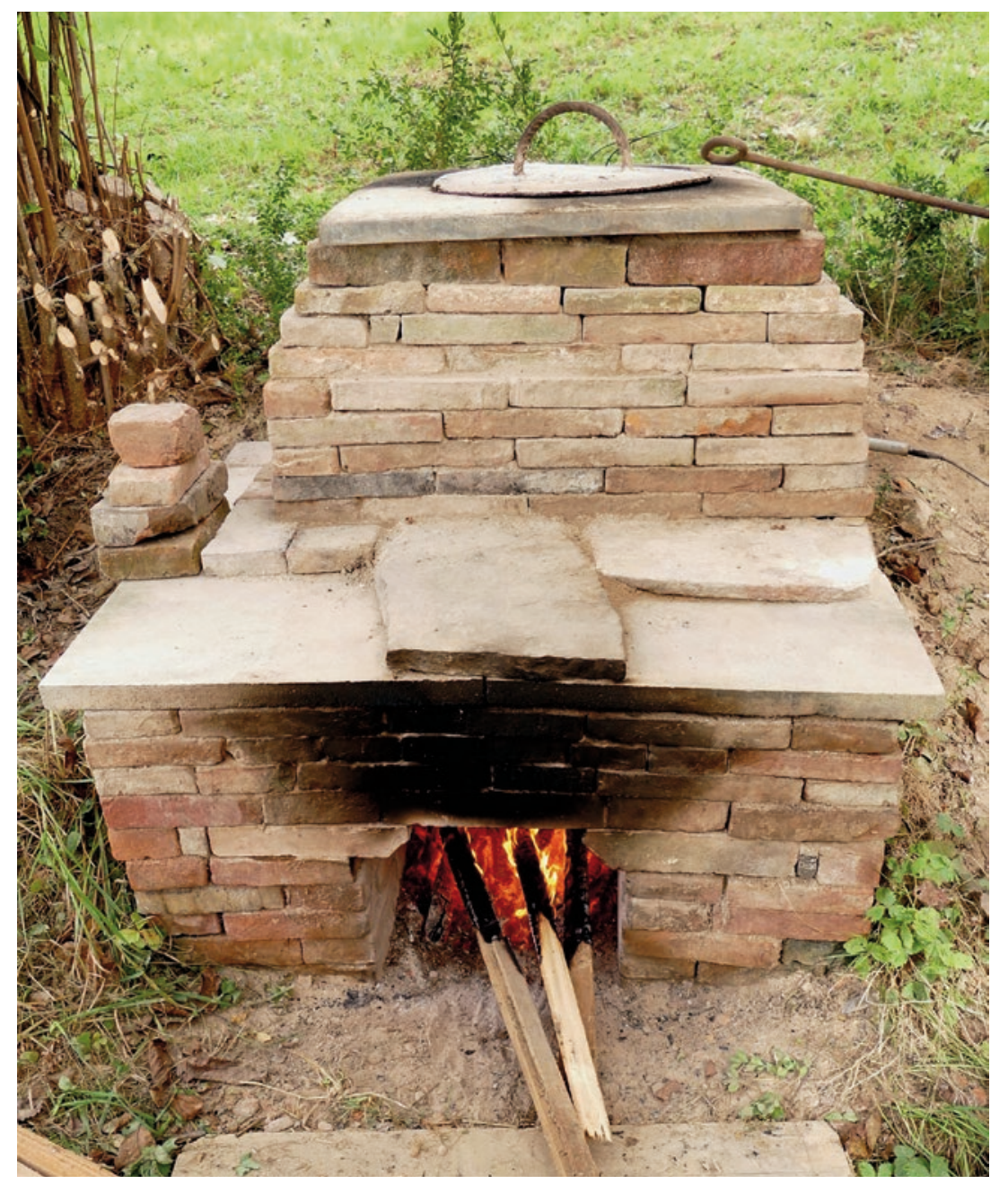

Abb.73: Aufkohlungsexperimente in Lehmumhüllungen: Der zur Zementation (der mit organischen Materialien und Lehm umhüllten Eisenbarren) verwendete Brennofen. Er ist aus Ziegelsteinen und wenigen Schamottesteinen (an strategisch heiklen Stellen) trocken gemauert (ohne Lehm); die Hohlräume zwischen den Bausteinen sind zur Isolation mit Asche zugestopft. Den Brennraum selbst bildet ein eingebauter Eisenblechzylinder von $40 \mathrm{~cm}$ Durchmesser (Abb. 74). Gefeuert wurde mit dünn gespaltenem Tannenholz.
Späne, Drusch usw.), kann Kneten und Reparieren zu erneuter Rissbildung führen. Ein sanftes Zusammendrücken der Lehmschichten mit beiden Händen führt zu einer Verdichtung der Umhüllung und kann bis zur Lederhärte fortgesetzt werden. Dann ist auch der Moment ideal, in die einzelnen Lehmstangen die Probennummer einzuritzen (Abb. 72). Die handlichen Eisen-Lehm-Pakete dürfen erst dann ins Feuer gebracht werden, wenn sie vollständig durchgetrocknet sind. Am Schluss dieser Vorbereitungen waren 14 Barren mit organischem Material beschichtet und in einem Lehmmantel eingepackt (Abb. 72; Tabelle 5).

$\mathrm{Zu}$ einer modifizierten Lehmvorbereitung für den Barren P06 siehe unten S. 130.

\section{Der experimentelle Prozess der Aufkohlung im Brand}

\section{Experiment-Konzeption}

Wie an den originalen Lehmumhüllungen aus Augusta Raurica beobachtet (oben S.93 und Abb.50), sollten die Eisen-Lehm-Pakete zwar bei grosser Hitze und während möglichst langer Zeit geglüht werden, aber nicht direkt in der Holzkohleglut, sondern in einem Ofen im Luftstrom und von der Glut getrennt ${ }^{549}$. Die Wahl fiel schliesslich auf einen kleinen Brennofen des Experimentalarchäologen Johannes Weiss in Aeugst/ZH (Abb. 73). Wegen verschiedener, bei vorherigen Bränden entstandener Defekte haben wir den aus Ziegelsteinen errichteten und innerhalb der Konstruktion mit Asche isolierten Ofen abgebaut und mit einem neuen Eisenzylinder (Höhe $60 \mathrm{~cm}, \varnothing 40 \mathrm{~cm}$ ) im Brennraum (Abb. 74) wiederaufgebaut. Unser Experimentier-Brennofen ist etwa halb so gross im Durchmesser wie der oben vorgestellte, (vermutlich) römische Zementationsofen von Lincolnshire/GB (Abb. 60) und weist eine ganz ähnliche Lochtenne auf.

549 Ich danke an dieser Stelle den Experimentalarchäologen Christoph Jäggi (Metallurgie) und Johannes Weiss (Töpfereitechnik) für anregende Diskussionen zu diesem Thema. 

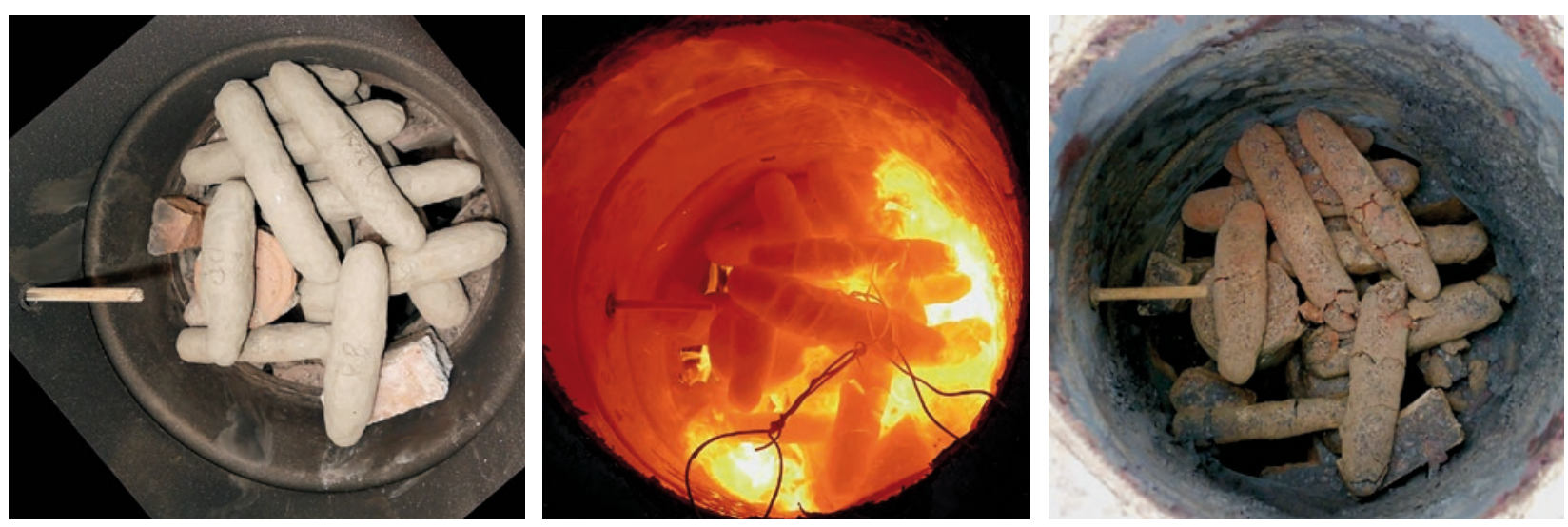

Abb. 74: Aufkohlungsexperimente in Lehmumhüllungen: Blick in den mit einem Blechzylinder ausgeschlagenen Feuerungsraum des Brennofens (Abb. 73): links Beschickung mit den «Lehmstangen» (Abb. 72) auf der Lochtenne, Mitte Vollbrand bei rund $1000{ }^{\circ} \mathrm{C}$; rechts die teils gesprungenen Lehmumhüllungen nach dem Brand (Abb. 76). - Die Drähte im mittleren Bild dienen zum vorzeitigen Herausnehmen der Barren R12 und B07. - Das dünne Eisenrohr links in der Ofenwand enthält das Temperatur-Messelement. - Jeweils links ist zuunterst der runde, mit einem Deckel verschlossene Tiegel zu sehen, in welchem ebenfalls Eisenstücke in Holzkohlepulver zementiert wurden (Abb. 115).

\section{Feuerung}

Der Ofen wurde mit den vorbereiteten Lehmstangen beschickt (Abb. 74, links), mit einem Deckel zu etwa zwei Dritteln verschlossen (Abb. 73, oben) und mit trockenem, fein gespaltenem Tannenholz befeuert. Die Aufwärmphase zur Erreichung der angestrebten Zementationstemperatur im Ofeninnern von rund $1000^{\circ} \mathrm{C}$ dauerte $6 \frac{1}{2}$ Stunden, wobei bei $200^{\circ}$ gebremst wurde, damit die Tonumhüllungen und die organischen Stoffe darin nicht durch Wasserdampfexplosionen bersten («Kristallwasser»; Abb. 75).

Dass in einem mit Holz und nicht mit Holzkohle befeuerten Ofen Temperaturen von bis zu über $1000^{\circ} \mathrm{C}$ erreicht werden können, erstaunt zunächst. Der Trick ist, ganz fein gespaltene und trockene Scheite zu verwenden, die blitzschnell in starken Flammen verbrennen und zu Asche zerfallen ${ }^{550}$. Entsprechend hoch ist der manuelle Aufwand, um genügend feinst gespaltenes Brennholz für einen Langversuch zur Hand zu haben.

Da wir zunächst mit zu grobem Holz gefeuert haben, füllte sich der Schürhals des Ofens mit so viel Holzkohle und Glut, dass Teile davon mit einer Schaufel entfernt werden mussten (siehe Kommentare zum Feuerungsprotokoll Abb. 75). Mit feinerem Holz wäre das nicht passiert, wie die Feuerführung in der Folge zeigt.

Mit ganz klein gespaltenen, daumendünnen Scheiten lodern die Flammen so stark auf, dass die Hitze im Ofen sprunghaft ansteigt. Genau so werden immer wieder 1000 bis maximal $1080^{\circ} \mathrm{C}$ erreicht!

Das Feuerungsrezept müsste lauten: Nur wenig, dafür äusserst fein gespaltenes Holz aufs Mal einfeuern und dafür alle paar Minuten neue Brennholzspäne nachschieben ein permanenter Prozess über viele Stunden bis zum Ende des Experiments!

\section{Dauer des Zementationsbrandes}

Ursprünglich war - auf der Basis historischer Feldbeobachtungen und alter Zementationsrezepte - geplant, eine kleine Serie von zwei Eisenbarren während 12 Stunden und den ganzen Rest während insgesamt 24 Stunden auf Zementationstemperatur von $\pm 1000^{\circ} \mathrm{C}$ zu halten (Abb. 74, Mitte). Wegen der erwähnten Probleme mit dem Glutanfall im Schürhals und aus Mangel an gut spaltbarem Tannenholz mussten diese Zeiten reduziert werden.

Unser Experiment dauerte:

- $\quad$ für die Barren R12 und B07 (= Phase 1; beide mit Holzkohle als Kohlenstoffträger) $4 \frac{1}{2}$ Stunden bei durchschnittlich $945^{\circ} \mathrm{C}$ und

- für alle übrigen Barren (Phasen 1 und 2) insgesamt 71⁄2 Stunden bei durchschnittlich $985^{\circ} \mathrm{C}$ (Abb. 75).

Es zeigte sich nach dem Brand, dass einige der Lehmumhüllungen, die mit einem Ende zuunterst im heissesten Teil des Ofens lagen, offenbar knapp über $1200^{\circ} \mathrm{C}^{551}$ abbekommen hatten und stellenweise angeschmolzen und etwas deformiert worden waren (Abb. 76,R07.B05.B06; 79,B05).

550 Auch diesen Hinweis verdanke ich Johannes Weiss, der beim Brennen von Keramik diese Erfahrung gemacht hat und auf dieselbe Feuerungsart bei japanischen Schmieden verweist.

551 Zum Hitzeverhalten des betreffenden Tones: Furger 2018, 127 Abb. 74 (TON 060-064). 


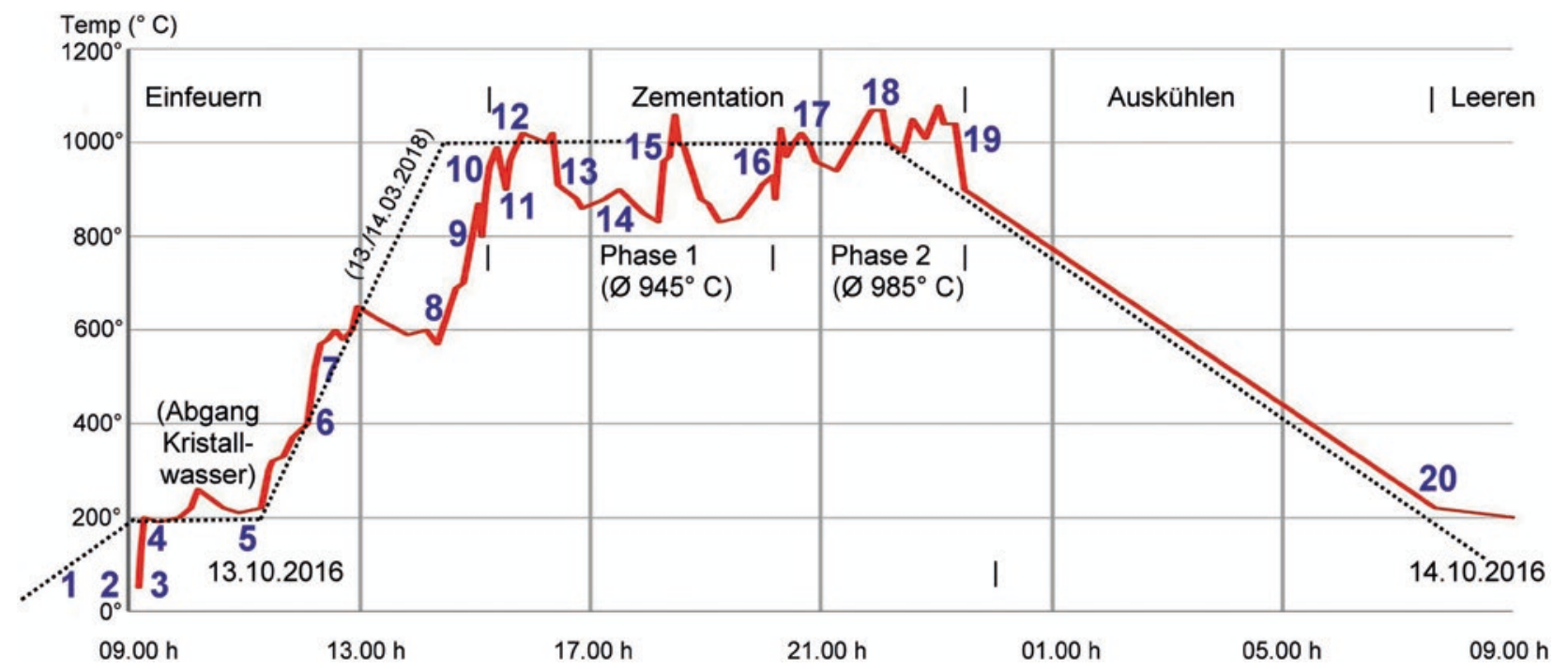

Abb. 75: Aufkohlungsexperimente in Lehmumhüllungen: Temperaturkurve des Zementationsprozesses auf der Zeitachse (aus dem Feuerungsprotokoll), durchgeführt in einem mit Holz befeuerten Ofen (Abb. 73). - Schwarze Punktlinie: Nachtrag P06 (Elektroofen). - Blaue Nummern:

1. Ofen am Vorabend des Experiments leicht vorgeheizt zur Erzeugung eines besseren Sogs

2. Beschicken mit den lehmumhüllten Eisenstangen und dem Tiegel; Ofenschacht oben zudecken

3. Anfeuern mit trockenem Tannenholz

4. Einheizen mit gespaltenen Holzscheiten $(\varnothing 6-12 \mathrm{~cm})$ und hochfahren auf ca. $200^{\circ} \mathrm{C}$, dann Temperatur halten (volle Austrocknung und Abgang des Kristallwassers)

5. Nach ca. 2 Stunden bei gut $200^{\circ} \mathrm{C}$ schärfer einfeuern (Abb. 73)

6. Brennholz breit verteilen auf die ganze Fläche des Schürhalses

7. Kurzzeitig schwerer Geruch und schwarzer Rauch (von der Tierhaut in R07 und P07?)

8. Volles Feuer mit noch dünner gespaltenen Holzscheiten $(\varnothing 5-8 \mathrm{~cm})$

9. Die Flammen werden länger und lodern ab dieser Temperatur fortan oben aus der zu etwa 2/3 abgedeckten Ofenmündung heraus

10. Deckel etwas mehr verschliessen (Abdeckung ca. $3 / 4$ ), so dass noch einige rote Flammen oben emporschiessen

11. Deckel wieder etwas weniger verschliessen (ca. 2/3 der Ofenöffnung sind zugedeckt)

12. Ab dieser Temperatur um die $1000^{\circ} \mathrm{C}$ wird der effektive

Zementationsprozess definiert (Abb.74, Mitte) und seine Dauer gemessen
13. Temperaturabfall infolge zu dicker Holzscheite $(\varnothing 5-8 \mathrm{~cm})$, die zu langsam brennen; Befeuerung fortan mit noch dünner gespaltenem Tannenholz $(\varnothing 2-6 \mathrm{~cm})$

14. Im Schürhals haben sich zu viel Glut und Asche angesammelt; fünf grosse Schaufeln voll werden entfernt. - Ein Konstruktionsstein hat sich unter der Lochtenne gelöst und verstellt den Weg der Flammen in den Brennraum; er wird ebenfalls via Schürhals entfernt

15. Erneut besondere Sorgfalt auf sehr dünne lange Holzspäne

16. Die beiden mit Holzkohle und Lehm umhüllten Barren R12 und BO7 (Tabelle 5) werden mit Hilfe zuvor daran befestigter Eisendrähte aus dem Ofen genommen. Die Lehmumhüllungen haben im Feuer einige Risse bekommen (Abb. 74, rechts; 76). Die beiden Barren darin dienen als Muster eines kurzen Zementationsprozesses (41/2 Stunden)

17. Es wird nach wie vor intensiv mit sehr feinen Holzspänen gefeuert $(\varnothing$ $2-6 \mathrm{~cm}$ ), die Temperatur im Ofen kann bei angestrebten $1000^{\circ} \mathrm{C}$ gehalten werden

18. Die Aussentemperatur steigt trotz Einnachten wegen aufkommenden Föhnwetters leicht an

19. Ende des Einfeuerns und des dokumentierten Zementationsprozesses (71/2 Stunden); der Ofen wird vor dem Schürhals und auf der oberen Öffnung mit Blechen geschlossen

20. Am folgenden Morgen ist der Ofen im Innern noch über $200^{\circ} \mathrm{C}$ warm. Er bleibt bis zum vollständigen Abkühlen und zur Entnahme des Brenngutes (Abb. 74, rechts) verschlossen.

\section{Ergebnis des Brandes, Veränderungen und Rückstände}

Je nach Lage im Ofen (Tabelle 5) waren die Lehmumhüllungen unterschiedlichen Temperaturen ausgesetzt. Die Werte in Abbildung 75 entsprechen dem mittleren Ofenbereich (Messsonde: Abb. 74, Rohr links); darüber war es etwas weniger heiss und zuunterst wurden zeitweise Temperaturen bis zu ca. $1250^{\circ} \mathrm{C}$ erreicht ${ }^{552}$. Die Grade der Rissbildung, das Vorkommen von Überbränden und allfällige Rückstände in den Lehmumhüllungen gehen aus Tabelle 4 hervor.

552 Der verwendete Ton wird bei Testbränden um $1240^{\circ} \mathrm{C}$ dunkelbraun und verschlackt feinblasig (Furger 2018, 127 Abb. 74, Lagerstätte 3, TON060-064). 

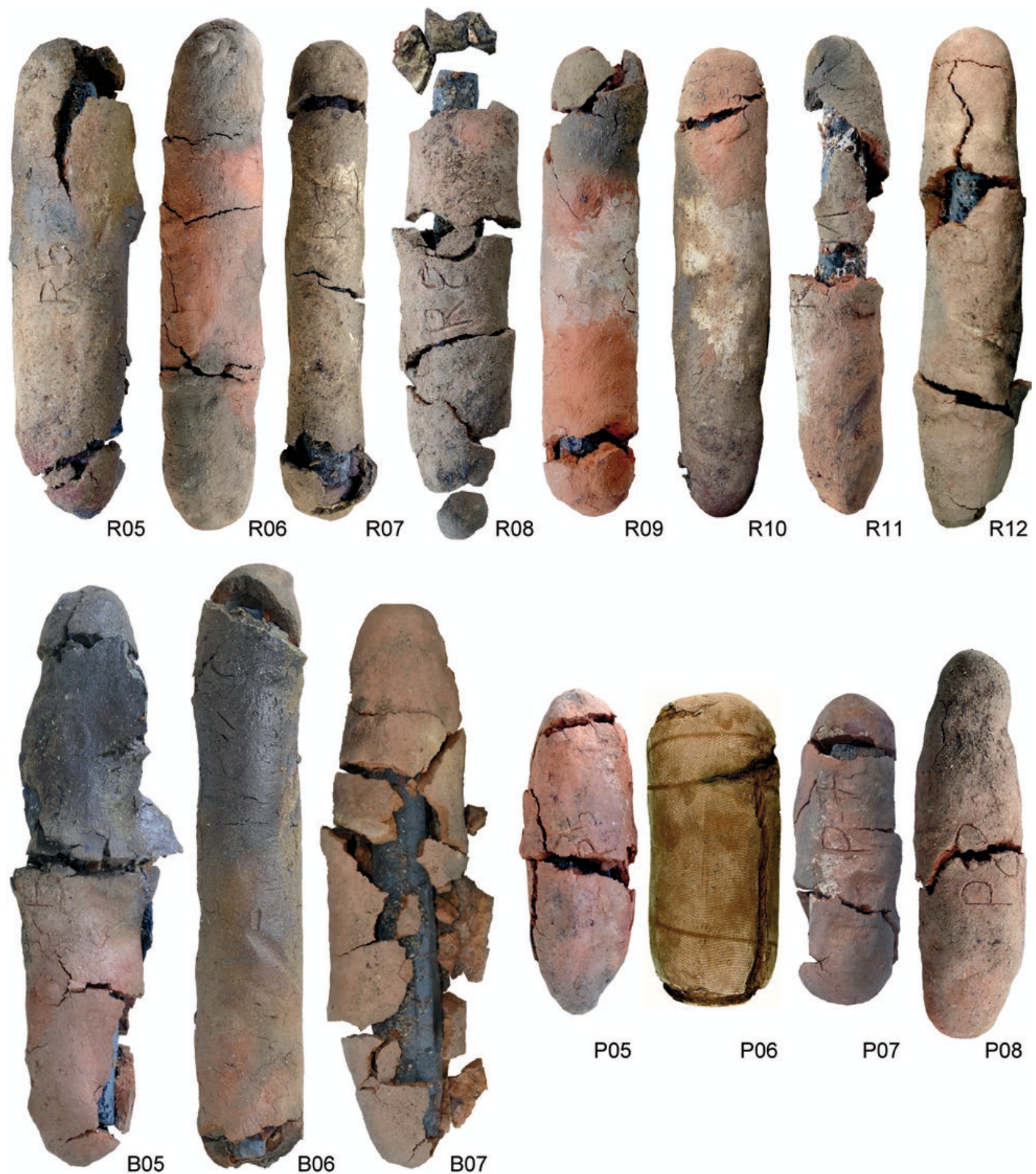

Abb. 76: Aufkohlungsexperimente in Lehmumhüllungen: Die Lehmpakete nach dem Einsatz im Zementationsfeuer (Barreninhalt: Abb. 61). Obere Reihe: R05R12; untere Reihe: R05-R07 und P05-P08. - P06 ist separat im Elektroofen gebrannt worden. - Dieselben Objekte vor dem Brand: Abb. 72 . - M. 1:3. 


\begin{tabular}{|c|c|c|c|}
\hline Nr. & Beschichtung & Erhaltung der Lehmumhüllung & Rückstände im Innern \\
\hline R05 & Holzkohle & Endkappen aufgebrochen und z.T. stark deformiert & Keine \\
\hline R06 & Knochenasche & Wenige Risse & 32,0 g weisslich-beiges Pulver, spezifisch eher leicht \\
\hline R07 & Tierhaut & $\begin{array}{l}\text { Endkappen aufgebrochen, Mittelteil mit einem Riss, } \\
\text { kompakt gebrannt }\end{array}$ & 6,1 g Eisenoxyd-Schuppen \\
\hline R08 & Tierhorn & Stark aufgebrochen & Keine \\
\hline R09 & Sägemehl & Endkappen aufgebrochen, Mittelteil intakt & 0,5 g weisse «Fasern» und feinste Tonpartikel \\
\hline R10 & Schilf & Eine Endkappe aufgebrochen, Mittelteil intakt & Keine \\
\hline R11 & Drusch & Eine Hälfte stark aufgebrochen, die andere intakt & $0,3 \mathrm{~g}$ weisse bis braune «Fasern» \\
\hline R12 & Holzkohle & Mehrere Risse, ein Ende intakt & 1,6 g Holzkohlepulver \\
\hline B05 & Holzkohle & Aufgebrochen und stark deformiert & 15,0 g Eisenoxyd-Schuppen \\
\hline B06 & Graphit & Endkappen aufgebrochen, Mittelteil intakt & 45,0 g schwarzes, feines Pulver, spezifisch eher schwer \\
\hline B07 & Holzkohle & Stark aufgebrochen & $\begin{array}{l}\text { 4,8 g «sandiges» braunes Material mit kleinsten } \\
\text { Tonpartikeln, holzkohlehaltig }\end{array}$ \\
\hline P05 & Holzkohle & Wenige Risse & Keine \\
\hline P06 & Holzkohle & Intakt, nur wenige Haarrisse & 8,8 g Holzkohlegrus, verkohlte Textilfetzchen \\
\hline P07 & Tierhaut & Wenige Risse & 1,2 g Eisenoxyd-Schuppen \\
\hline P08 & Sägemehl & Ein Riss durch die Mitte & $0,6 \mathrm{~g}$ weisse bis beige «Fasern» und feinste Tonpartikel. \\
\hline
\end{tabular}

Tabelle 4: Aufkohlungsexperimente in Lehmumhüllungen: Erhaltung der Lehmumhüllungen (als Folge der Lehmbeschaffenheit, Verarbeitung und Feuerführung) und Rückstände im Innern (als Folge der eingebauten, meist organischen Kohlenstoffträger-Beschichtungen).

Im Vergleich mit den römischen Originalen (Abb. 50) sind die im archäologischen Experiment gewonnenen Lehmumhüllungen (Abb. 76) respektive die Fragmente nach Entnahme der Eisenbarren (Abb. 77) zum Teil etwas zu stark gebrannt (aus dem unteren Ofenbereich), vor allem aber oft infolge ungeeigneter Lehmkonsistenz eingerissen. Der Scherben der Originale ist meist beigegrau und weicher als jener aus dem Experiment. Den Originalfunden am nächsten bezüglich Brandfarbe und Tonkonsistenz kommen die Experimentier-Umhüllungen R06, R09 und R10 sowie P05P08 (Abb. 76).

Die Schwundrisse beim Trocknen und erneut beim Brennen liessen sich durch eine Quarzsand-Magerung nicht verhindern, und eine Magerung ist an den Originalen makroskopisch auch nicht auszumachen (Abb. 57). Das Geheimnis liegt wahrscheinlich an der Tonaufbereitung, der wir uns mit dem Nachtrag P06 annähern wollten (s. die «Korrektur der Lehmrezeptur» unten; P06 auf Abb. 58, 72 und 76).

Die Proben mit - leider aufgetretenen - starken Rissen enthielten in der Regel keine Rückstände, da die extra eingebrachten organischen Stoffe oxidiert sind und sich verflüchtigen konnten. Die Knochenasche, mit welcher der Barren R06 umgeben war, hinterliess ein weissliches Pulver kalzinierter Knochensubstanz (Tabelle 4). Auch Sägemehl (R09, P08) und Getreide-Drusch (R11) haben helle, jedoch faserige Rückstände hinterlassen (Tabelle 4). Das als Kohlenstoffträger verwendete Tierhorn hat in Probe R08 zu einem schmutziggelben, fast weissen Innenbelag geführt (Abb.77,R08). Andere Rückstände betreffen schuppenar- tige Eisenoxidplättchen, die sich auf allen Barrenoberseiten bildeten (R07, B05, P05, P07; vgl. auch Abb. 79).

\section{Abdrücke im Innern}

Bei unserer experimentellen Aufkohlung von Eisenbarren interessierten nicht nur der «Erfolg» antiker Stahlerzeugung durch eine messbare Erhöhung des Kohlenstoffgehaltes im Eisen (Tabelle 6) und eine damit einhergehende höhere Materialhärte, sondern auch die Spuren an den Werkstattabfällen, die im Fall von Augusta Raurica die einzigen Zeugnisse sind (Abb. 50 und 51). Einige aufgebrochene Fragmente der gebrannten Lehmumhüllungen seien deshalb hier gezeigt (Abb. 77):

R07: Die dicke, um den Eisenbarren gewickelte Tierhaut (Schweineschwarte) hat einen schwarzen Belag im Lehmnegativ hinterlassen; die diagonal umwickelte Fixierschnur ist deutlich zu erkennen. Trotz des dicken Auftrags zeichnet sich der viereckige Querschnitt des Barrens in der Lehmumhüllung noch sehr gut ab.

R08: Die Tierhorn-Splitter erzeugten eine auffallend gelblich-weisse Schicht im Innern, in welcher die Schnur über dem Stoffstück sich ebenfalls deutlich abzeichnet. Im einen Endstück hat sich Eisenoxid vom Barren im Lehm festgesetzt.

R09: Die Beschichtung des Vierkant-Barrens mit Sägemehl war offenbar so dick, dass sich der Barrenquerschnitt nicht mehr erkennen lässt und rund erscheint. Vom Sägemehl erhielten sich weisse «Fasern» (Tabelle 4).

R10: Die um den Barren gewickelten Schilfblätter und die Fixierschnur haben sich in faserigen Abdrücken sehr deutlich in der Lehmumhüllung erhalten. In den Endstücken haben sich Eisenoxidteile vom Barren im Lehm festgesetzt. 

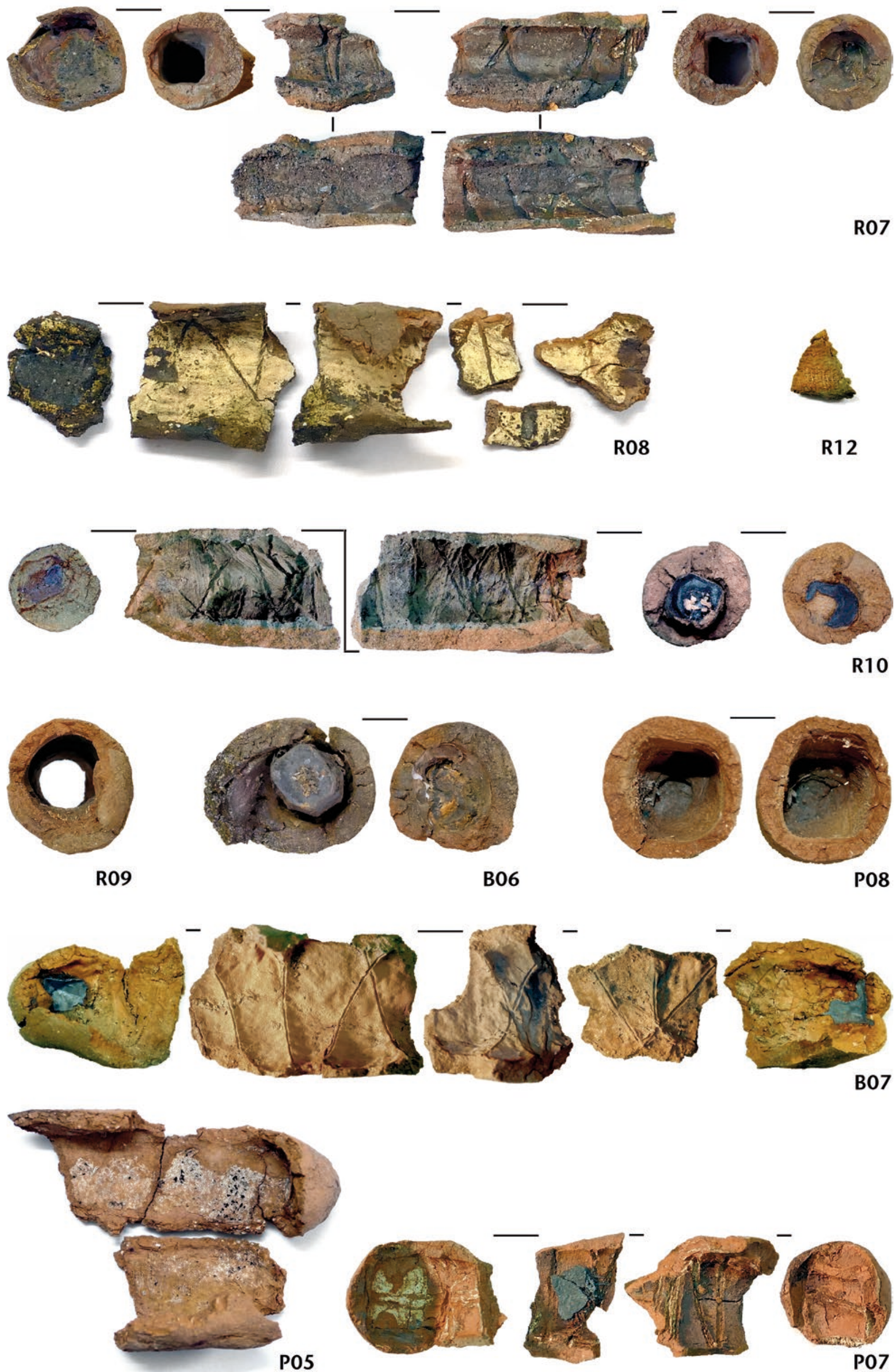

Abb. 77: Aufkohlungsexperimente in Lehmumhüllungen: Details einiger Lehmumhüllungen nach dem Brand und dem Öffnen zur Herausnahme der zementierten Eisenbarren (Übersicht und Barrennummern: Abb. 76; Tabellen 4 und 5). Originalfunde im Vergleich: Abb.50. M. 1:2. 


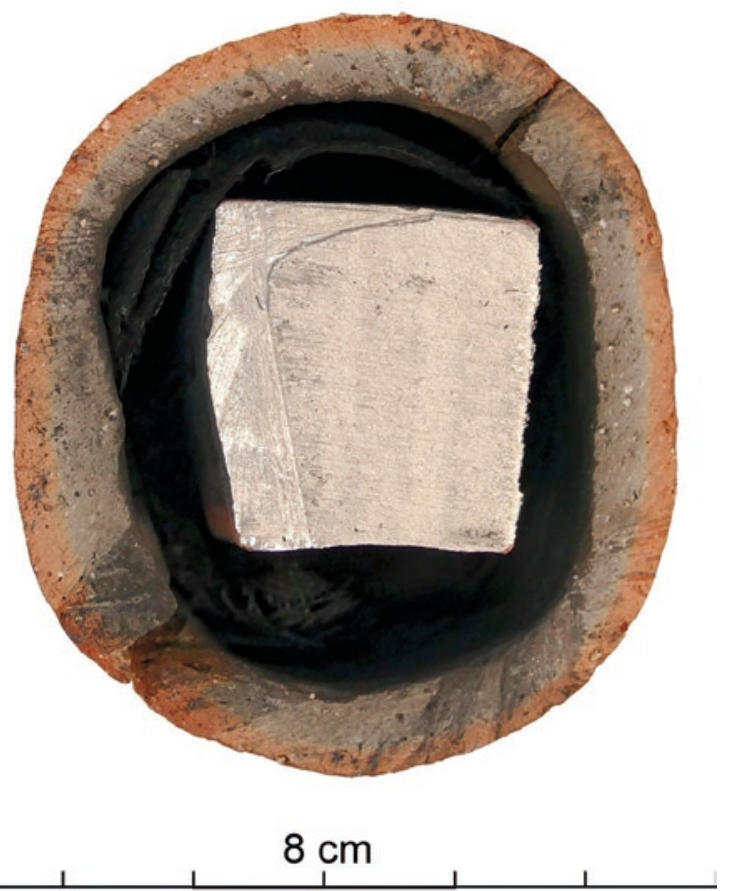

Abb. 78: Die aufgeschnittene Lehmumhüllung mit dem Barren P06 nach dem geglückten Brand. Man beachte den rot reduzierenden Brand aussen und den schwarz reduzierenden innen. M. 1:1.

R12: Das Gewebe, mit welchem das Holzkohlegrus auf dem Barren mit einer Schnur fixiert worden ist, hat sich in weissen feinen Fasern erhalten.

B06: Von der Graphitbeschichtung, der einzigen nicht-organischen im Test, ist zwar viel schwarzes Pulver in der Lehmumhüllung verblieben (Tabelle 4), die Innenfläche lässt jedoch keinerlei Rückschlüsse auf die Beschichtung zu.

B07: Das Holzkohlegrus ist hier mit Hilfe eines feinen Baumwollgewebes um den Eisenbarren herum gerollt und mit einer diagonal gewickelten Schnur fixiert worden. Beides hat sich äusserst scharf im Lehm der Umhüllung abgezeichnet (vgl. Abb. 51,18a.18c). In den Endstücken haben sich Eisenoxidteile vom Barren im Lehm festgesetzt.

P05: Auf der Innenseite der Lehmumhüllung hat sich das Baumwollgewebe in feinsten weissen Faserresten erhalten, auf welchen sich stellenweise Holzkohlepartikel von der Barrenbeschichtung festgesetzt haben.

P06: Da diese Lehmumhüllung mit modifiziertem Lehm um den Eisenbarren P06 geformt und nachträglich in einem Elektroofen gebrannt wurde, blieb die Umhüllung - mit Ausnahme weniger Haarrisse - intakt. Sie konnte aufgesägt werden (Abb. 78). Abdrücke an den Innenwänden zeigen das Negativ des mit Holzkohle umhüllten und einem Stück Stoff verschnürten Barrens.

P07: Die um den Barren gewickelte Tierhaut hat, ganz anders als bei R07, hier zu keinem schwarzen Belag geführt; im einen Endstück und bei den Schnurabdrücken von der Umwicklung ist sogar ein weisser Belag entstanden. Ein vom Barren abgeplatztes kleines Eisenoxidplättchen hat sich auf dem Lehm festgesetzt. In den Endstücken ist der kantige Barrenquerschnitt noch schwach zu erkennen.

P08: Hier ist der Eisenbarren wie in R09 mit Sägemehl beschichtet worden, sein Querschnitt ist als verrundet-quadratisches Negativ jedoch noch gut zu erkennen. Wenige weisse «Fasern» lagen im Innern (Tabelle 4) resp. haften noch am Lehm.
Dass die Abdrücke in den experimentell erzeugten Umhüllungs-Bruchstücken viel präziser die Barren-Umwicklungen mit organischem Material abbilden und deutlicher erhalten sind als die Originale (Abb. 51, unten), ist naheliegend. Der Grund liegt einerseits bei der langen Lagerung der römischen Stücke im Boden und andererseits im sehr weich erhaltenen Ton der Originalfunde. Die dunkle Kruste auf den Innenflächen mancher Originale ist jedoch auch beim Experiment entstanden. Sie ist bei den Originalen naheliegenderweise verwittert (Abb. 51, unten), bei den Experimentobjekten - aber nicht bei allen! - sehr deutlich als dichter Belag vorhanden (Abb. 77).

Die mehrfach an den Originalen beobachteten braunen, «gescheckten» Innenbeläge sind nach Ausweis der Oberflächenanalysen (Tabelle 2) wohl nicht direkt auf das Eisen der Barren zurückzuführen.

Die Barren-Querschnitte sind - wie es scheint - nicht so oft eindeutig aufgrund der Lehmbruchstücke zu erkennen wie bei den Originalen. Der Querschnitt der Lehmumhüllung um den viereckigen Barren R09 ist kreisrund, jene von R07, R09, P07 und P08 zeigen jedoch noch deutlich die kantigen Formen der beschichteten und umhüllten Eisenbarren.

\section{Die Eisenbarren nach dem Brand}

Mit Ausnahme des «Nachzüglers» P06 sind alle Eisenbarren durch den Zementationsprozess geringfügig schwerer geworden (Tabelle 5). Die Gewichtszunahme beträgt 0,32,2\% und könnte einerseits auf anhaftende Verkrustungen zurückzuführen sein. Andererseits hat das lange Glühen - trotz der theoretisch schützenden Lehmumhüllung - die Bildung einer dicken, kompakten Oxidschicht auf dem Barren bewirkt, die stellenweise blasig erscheint oder sich gar aufgewölbt hat (Abb. 79) ${ }^{553}$ und vermutlich für die Gewichtszunahme verantwortlich ist. Diese fast schwarze Schicht ist bis zu 1,5 mm dick, extrem hart und spröde. Sie lässt sich mit dem Hammer leicht wegschlagen. Teilchen der schwarzen Eisenoxidschicht sind in den Lehmbruchstücken haften geblieben (Abb. 77,R10.B07.P07).

Dieses Phänomen ist auch den frühindustriellen Zementier-Spezialisten aufgefallen: «Die ursprünglichste und älteste Form des Einsatzhärtens fand bei der Herstellung des Zementstahles Anwendung, den man wegen der eigentümlichen auf der Oberfläche auftretenden Blasen auch Blasenstahl nannte und der heute das Ausgangsprodukt erstklassigen Tiegelstahles ist.»554

553 Ledebur 1903, 1085 (Blasenbildungen, «welche dem rohen Cementstahle eigenthümlich sind und ihm in England den Namen blister-steel [Blasenstahl] verschafft haben»); Rostoker/Bronson 1990, 124 («... to deform the steel and to force bubbles above its surface»).

554 Schiefer/Grün 1927, 184 f. 


\begin{tabular}{|c|c|c|c|c|c|c|c|c|c|c|}
\hline $\begin{array}{l}\text { Barren- } \\
\text { nummer }\end{array}$ & $\begin{array}{l}\text { Eisen } \\
\text { (Abb. 61) }\end{array}$ & Beschichtung & $\begin{array}{l}\text { Abb. } \\
72 ; 76\end{array}$ & Umhüllung & $\begin{array}{l}\text { Gewicht } \\
\text { vorher }\end{array}$ & $\begin{array}{l}\text { Gewicht } \\
\text { nachher }\end{array}$ & $\begin{array}{l}\text { Gewichts- } \\
\text { zunahme }\end{array}$ & $\begin{array}{l}\text { Lage im } \\
\text { Ofen }\end{array}$ & $\begin{array}{l}\text { Brenn- } \\
\text { dauer } \\
\text { (h) }\end{array}$ & $C$ max. \\
\hline R05 & \multirow{8}{*}{ «Reineisen» } & Holzkohle & R05 & \multirow{15}{*}{$\begin{array}{l}\text { Lehm Kaiser- } \\
\text { augst-Zelglihof } \\
\text { (TON061), } \\
\text { mit 2-10\% } \\
\text { Quarzmagerung } \\
\text { 0-1 mm }\end{array}$} & $472,0 \mathrm{~g}$ & $492,0 \mathrm{~g}$ & $+4,24 \%$ & unten & $71 / 2$ & $0,031 \%$ \\
\hline R06 & & Knochenasche & R06 & & $382,2 \mathrm{~g}$ & $394,6 \mathrm{~g}$ & $+3,24 \%$ & oben & $71 / 2$ & $0,016 \%$ \\
\hline R07 & & Tierhaut & R07 & & $411,4 g$ & $420,5 \mathrm{~g}$ & $+2,21 \%$ & unten & $71 / 2$ & - \\
\hline R08 & & Tierhorn & R08 & & $502,6 \mathrm{~g}$ & $522,9 \mathrm{~g}$ & $+4,04 \%$ & oben & $71 / 2$ & - \\
\hline R09 & & Sägemehl & R09 & & $386,8 \mathrm{~g}$ & $397,2 \mathrm{~g}$ & $+2,69 \%$ & oben & $71 / 2$ & - \\
\hline R10 & & Schilf & R10 & & $456,0 \mathrm{~g}$ & $466,7 \mathrm{~g}$ & $+2,35 \%$ & unten & $71 / 2$ & - \\
\hline R11 & & Drusch & R11 & & $390,9 \mathrm{~g}$ & $403,2 \mathrm{~g}$ & $+3,15 \%$ & Mitte & $71 / 2$ & - \\
\hline R12 & & Holzkohle & R12 & & $401,2 \mathrm{~g}$ & $405,3 \mathrm{~g}$ & $+1,02 \%$ & zuoberst & $41 / 2$ & $0,013 \%$ \\
\hline B05 & \multirow{3}{*}{ «Buttereisen» } & Holzkohle & B05 & & $1122,8 \mathrm{~g}$ & $1147,5 \mathrm{~g}$ & $+2,20 \%$ & zuunterst & $71 / 2$ & - \\
\hline B06 & & Graphit & B06 & & $884,1 \mathrm{~g}$ & $886,7 \mathrm{~g}$ & $+0,29 \%$ & unten & $71 / 2$ & $0,356 \%$ \\
\hline B07 & & Holzkohle & B07 & & $1095,3 \mathrm{~g}$ & $1101,1 \mathrm{~g}$ & $+0,53 \%$ & zuoberst & $41 / 2$ & - \\
\hline P05 & \multirow{4}{*}{$\begin{array}{l}\text { Weicheisen } \\
\text { «Pivot» }\end{array}$} & Holzkohle & P05 & & $451,6 \mathrm{~g}$ & $460,6 \mathrm{~g}$ & $+1,99 \%$ & oben & $71 / 2$ & $0,008 \%$ \\
\hline $\mathrm{P} 06^{*}$ & & Holzkohle & P06 & & $406,9 \mathrm{~g}$ & $405,1 \mathrm{~g}$ & $-0,44 \%$ & (E-Ofen) & $71 / 2$ & $0,387 \%$ \\
\hline P07 & & Tierhaut & P07 & & $456,1 \mathrm{~g}$ & $462,2 \mathrm{~g}$ & $+1,34 \%$ & oben & $71 / 2$ & - \\
\hline P08 & & Sägemehl & P08 & & $424,7 g$ & $433,0 \mathrm{~g}$ & $+1,95 \%$ & oben & $71 / 2$ & - \\
\hline
\end{tabular}

Tabelle 5: Aufkohlungsexperimente in Lehmumhüllungen: Übersicht über die vorbereiteten Eisenbarren, beschichtet und umhüllt. - Brenndauer: in Phase 1 mit $\varnothing 945^{\circ} \mathrm{C}$ : viereinhalb Stunden; in Phase 2 mit $\varnothing 985^{\circ} \mathrm{C}$ : drei Stunden (siehe Details Abb. 77 und 79 ). . * = mit optimierter Lehmaufbereitung umhüllt und als Nachtrag in Elektroofen gebrannt.

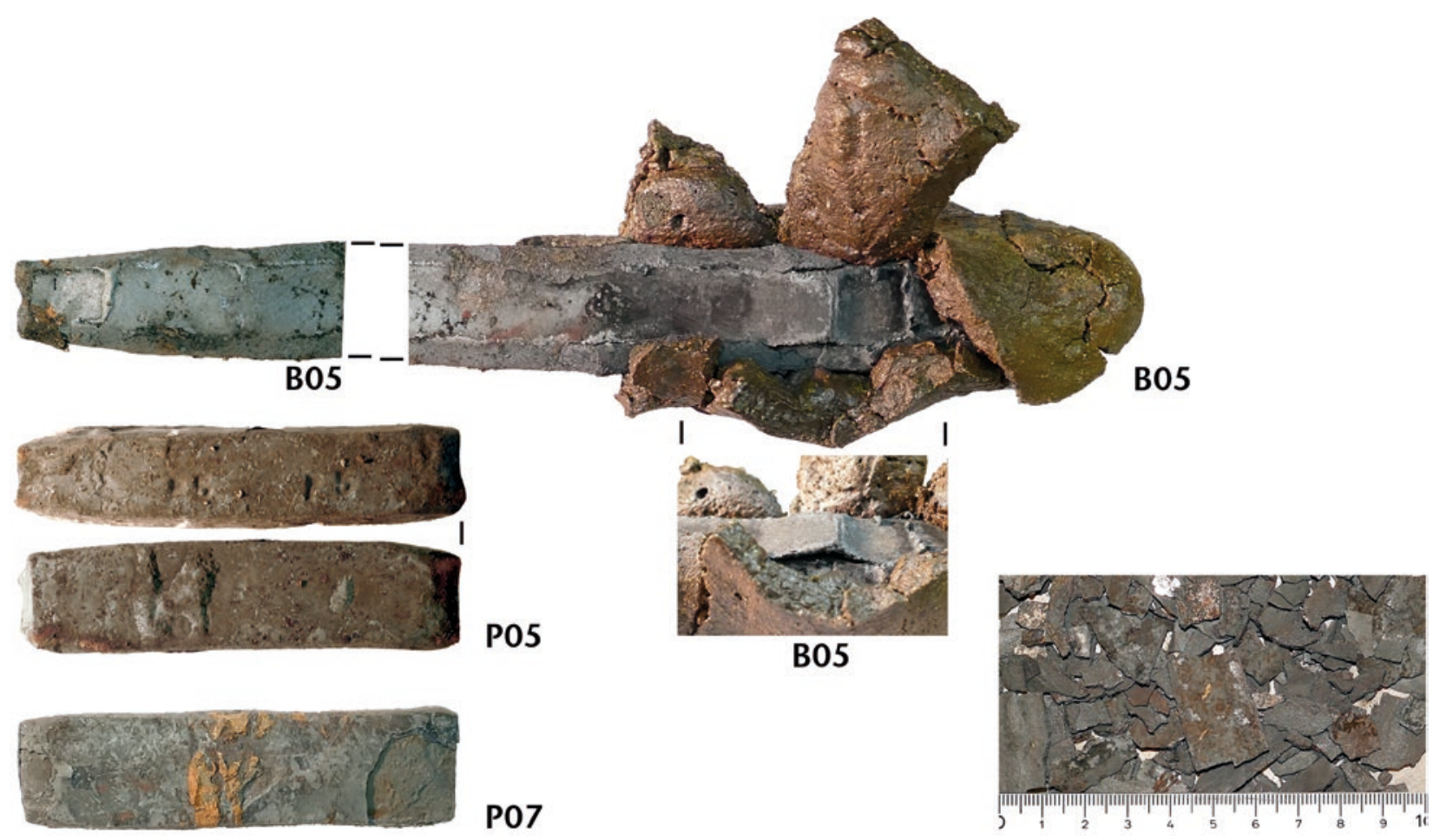

Abb. 79: Aufkohlungsexperimente in Lehmumhüllungen: Oxidschicht-Oberflächen einiger zementierter Eisenbarren nach dem Brand und nach dem Entfernen der Lehmumhüllung. Die Stange B05 lag mit ihrer Lehmumhüllung zuunterst im Feuerraum und ist wie ein Fehlbrand geschmolzen, die Eisenoxidschicht darunter hat sich partiell aufgewölbt und vom Barren gelöst. Rechts unten Teile der Eisenoxidbeläge, die mit dem Hammer von den Barren abgeklopft werden können. M. 1:2. 
Der mit einer verbesserten Lehmaufbereitung umhüllte Barren P06 ist als einziger 0,44\% leichter geworden (Tabelle 5: *); er wies jedoch keine Oxidschicht auf.

Es ist naheliegend, dass Risse in der Umhüllung den Eintritt von etwas Sauerstoff während des Zementierens bei grosser Hitze erlauben, was dann zu den beobachteten dicken Oxidschichten führt. Andererseits konnte beim gut verschlossenen Stück P06 kein Sauerstoff eindringen und sich kein Hammerschlag bilden. Infolgedessen ist wohl auch die geringfügige Gewichtabnahme (statt -zunahme) erfolgt.

\section{Korrektur der Lehmrezeptur}

Aufgrund des oben zu Schwundrissen und Magerung Gesagten entspricht der für die Umhüllungen verwendete Ton zwar der antik genutzten Lagerstätte von KaiseraugstZelglihof, aber zum Abgleich mit den Ergebnissen der Tonanalysen sollten ca. $5 \%$ Kalk beigemischt werden ${ }^{555}$. Es soll auf eine Magerung verzichtet werden, da auch keine an den Originalen makroskopisch erkennbar ist. Ein nach dem Brand relativ weicher Lehm, der den Originalen entspricht und auch kaum schwindet beim Trocknen, lässt sich durch Entfernen des «Klebers» im Lehm aufbereiten. Ein solches Gemisch ist auch recht hitzebeständig und formstabil.

Daher wurde für die Umhüllung des als Reserve zurückbehaltenen Barrens P06 (Abb.61) Lehm von Kaiseraugst-Zelglihof folgendermassen aufbereitet ${ }^{556}$ : Trocknen des Lehms, Pulverisieren (1453g Trockengewicht), Sieben und in Regenwasser auflösen, durch ein feines Sieb lassen zur Entfernung kleinster Steinchen, aufrühren und stehen lassen. Nach einem Tag oben abschöpfen, und das etwa drei bis neun Mal wiederholen. Mit einer Probe von der Basis der Lehmmasse kann geprüft werden, wann sie «mager» genug ist, d.h., ob sie noch genug Kleber zum plastischen Formen enthält und noch nicht zu siltig geworden ist. Am Schluss durch Trocknen eindicken und mit 5\% Kalksteinpulver vermischen.

Unsere Lehmbereitung wurde durch viermaliges $\mathrm{Ab}$ schöpfen des Wassers nach jeweils einem Tag Setzenlassen «entfettet». Die vier Filterrückstände der abgeschöpften Wasser-Lehm-Emulsion ergaben ein Trockengewicht von insgesamt $1011 \mathrm{~g}$ feinstem Tonschluff. Somit wurden dem Ursprungslehm 30\% Feinstpartikel entzogen und zum Schluss 5\% Kalksteinpulver zugegeben. Hierzu diente gemörserter Tuffstein aus dem französischen Jura.

Die Lehmumhüllung des mit Holzkohleschrot und einem Stoffstück umwickelten Eisenbarrens verdanke ich den erfahrenen Händen von Johannes Weiss. Um Schwundrisse in der Ummantelung beim Trocknen möglichst zu verhindern, wurde in einer Plastiktüte extrem langsam getrocknet. Nach drei Monaten traten im immer noch etwas lederharten Material dennoch feine Risse auf (Abb. 72,P06). Sie wurden nicht mit neuem Lehm gefüllt, sondern durch sorgfältiges Zudrücken mit einem massiven Spatel wieder geschlossen. Zwei Wochen später wurde die Lehmstange mit Stoffstreifen sehr satt - längs und rundum - eingewickelt und an der Luft endgültig trocknen gelassen.

Diese letzte Probe ist der Einfachheit halber in einem Elektroofen während zwei Stunden bei $200^{\circ} \mathrm{C}$ vorgewärmt (zur Entfernung des Kristallwassers; vgl. Abb. 75,4-5) und anschliessend bei $1000^{\circ} \mathrm{C}$ ebenfalls während $71 / 2$ Stunden geglüht worden (Abb. 75, schwarze Punktlinie).

Die Lehmumhüllung mit dem Barren P06 wurde nach dem Brand aufgesägt (Abb. 78). Die Undurchlässigkeit für Luftsauerstoff führte dazu, dass die Umhüllung aussen oxidierend-rot, innen aber reduzierend-schwarz geworden ist (Abb. 78). Dieser Befund war an den anderen Experimentierscherben und den Originalen zwar nicht zu beobachten (dazu siehe S. 126), ist aber erklärbar: Es scheint, dass die Handwerker die Eisen-Lehm-Pakete relativ früh und noch heiss aus dem Feuer nahmen und aufbrachen. So konnte der Sauerstoff die Keramikbruchstücke auch an den Innenseiten noch beige bis rot oxidieren, was nach Auskunft von Praktikern sehr rasch erfolgt. Auch diese nachträglich präparierte und behandelte Probe P06 findet sich auf unserer Abbildung 76.

\section{Probenaufbereitung für die Analysen}

Die Probenvorbereitung, die Kohlenstoffanalysen und die Vickers-Härtebestimmungen ${ }^{557}$ konnten entgegenkommenderweise im Labor der Georg Fischer AG in Schaffhausen durchgeführt werden ${ }^{558}$.

Zur Bestimmung der Härte (und zur späteren Kohlenstoffanalyse) wurden aus allen Barren drei Scheiben von je etwa $1 \mathrm{~cm}$ Dicke herausgesägt (Abb. 80). Die Probeentnahme erfolgte konsequent in jenem Barrenabschnitt, der nach dem Zementationsfeuer von der Lehmumhüllung am besten bedeckt war (Abb. 76), wo also der Kohlenstoff am wenigsten verbrennen konnte. Zusätzlich wurden für die Kohlenstoffanalyse 2-3 weitere Scheibchen von nur ca. 2-3 mm Dicke herausgesägt. Die drei dickeren Proben jedes Barrens sind jeweils

555 Siehe oben mit Anm. 530-531.

556 All diese Hinweise und Rezepturen empfahl mir freundlicherweise Johannes Weiss in Aeugst/ZH. Ich danke ihm für die tatkräftige Unterstützung und Beratung während der vier Tage Feldexperimente im Oktober 2016

557 Zur Methode: Smithells 1949, 509 ff.; Brunhuber 1991, $470 \mathrm{f}$.; $1147 \mathrm{f}$.

558 Ich danke an dieser Stelle der Georg Fischer AG in Schaffhausen für die grosszügige Unterstützung bei den Laboranalysen, insbesondere Dirk Lindemann (Leiter Business Unit Europe Automotive AG) für die Bewilligung, Rudolf Kubiz (Chemiker im Metallographielabor) für die Analysen und Instruktionen bei der Probenvorbereitung sowie Urs Werner (Senior Partner) für die Vermittlung des Kontakts. 


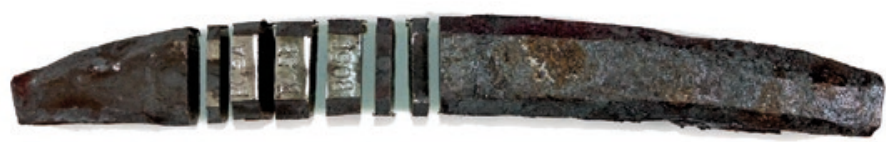

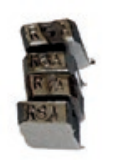
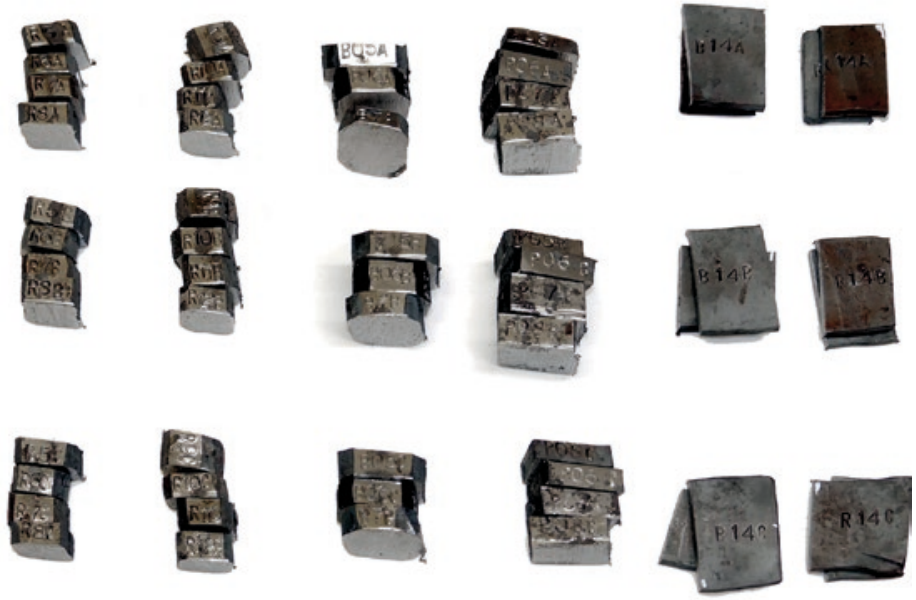

Abb. 80: Aufsägen der aufgekohlten Barren zur Probengewinnung. Oben: Beispiel: Probe B05: Drei dickere Probensegmente zu ca. $11 \mathrm{~mm}$ wurden unterschiedlich gehärtet und dienten den Härtemessungen; drei dünnere Proben zu ca. $5 \mathrm{~mm}$ wurden mit dem Mikrotom zerlegt für die Kohlenstoff- und Schwefelanalysen. M. 1:3. - Unten: Alle Härtemessungs-Proben vor dem Einbetten, Polieren und Analysieren.

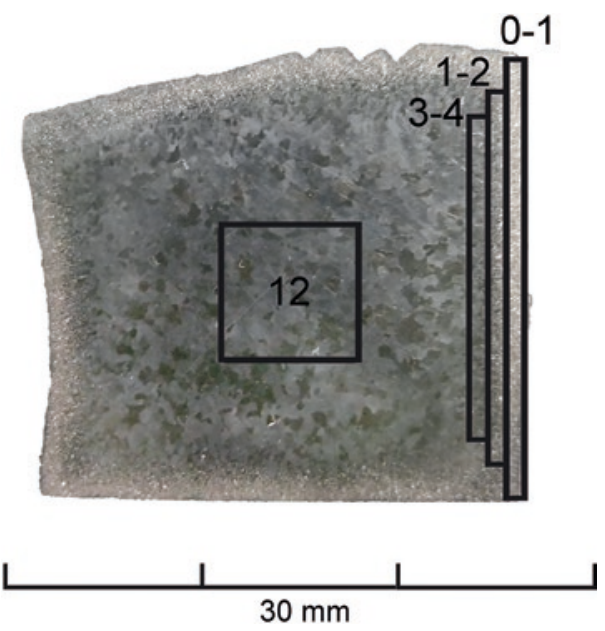

Abb. 81: Schematische Darstellung der Präparation kleiner Proben mit Hilfe eines Mikrotoms (Schneidegerät für dünne Schnittpräparate), am Beispiel von P06B. Pro Kohlenstoff-/Schwefelanalyse werden etwa $1 \mathrm{~g}$ Metall benötigt. Ergebnisse siehe Tabelle 6. M.2:1.
A nach dem Zementationsprozess unverändert gelassen (Serie A),

B bei $640-660^{\circ} \mathrm{C}$ geglüht (Abb.9, links) und in Wasser abgeschreckt (Serie B)

C resp. geglüht, abgeschreckt, bei $340-355^{\circ} \mathrm{C}$ angelassen (Abb. 9, rechts) und erneut in Wasser abgeschreckt worden (Serie C).

Die Proben wurden zuerst den Härtetests unterzogen. Hierfür haben wir die aus den Barren herausgesägten 1-cmScheiben mit einer Heizpresse in Phenolharz eingebettet ${ }^{559}$. Anschliessend wurden die Presslinge in drei Durchgängen maschinell geschliffen und poliert ${ }^{560}$. Die polierten Barrenquerschnitte wurden mit Nital ${ }^{561}$ angeätzt, um den Grad der erzielten Aufkohlung mit einem hochauflösenden Scanner ${ }^{562}$ und unter dem Auflichtmikroskop ${ }^{563}$ beurteilen zu können (Abb.62-120). Erst aufgrund dieser optischen Befunde konnte eine Teilserie mit den am deutlichsten aufgekohlten Proben bestimmt werden, die einerseits für die Vickers-Härtenbestimmung und andererseits für die Präparierung der Kohlenstoff- und Schwefelproben verwendet wurden. Zuerst sollte der Härteverlauf von aussen nach innen bestimmt werden (s. unten, Abb. 82-110 und Tabelle 9).

Erst nachdem eine gewisse Aufnahme von Kohlenstoff an der Barrenoberfläche anhand der polierten Anschliffe im Mikroskop nachgewiesen werden konnte (Abb.62120), sind die entsprechenden Barren auch für die Analyse des Kohlenstoff- und Schwefelgehaltes präpariert worden (Abb. 34, unten): Aus den erwähnten dünnen Barrenscheibchen wurde mit dem Mikrotom 564
1. eine möglichst oberflächennahe Schicht von $1 \mathrm{~mm}$ Dicke herausgesägt (Abb. 81, Bezeichnung «0-1» mm),

2. direkt anschliessend eine zweite Schicht (Bezeichnung «1-2» $\mathrm{mm})$,

559 Zum Fixieren der Proben wurden die Warmeinbettpressen «Opal 450» und «Opal 460» der Firma «ATM GmbH» verwendet (https: / / www.atm-m.de / de / produkte / einbettpressen / warmeinbettpressen/opal-460/ [17.03.2018]); als Vulkanisiermasse diente das Phenolharz «MultiFast PRESI» der Firma «Struers» (https: / / e-shop.struers.com/ [17.03.2018]).

560 Als Schleif- und Poliermotor wurde ein «SAPHIR 550» der Firma «ATM GmbH» verwendet (https: / / www.atm-m.de [17.03.2018]).

561 Nital ist eine alkoholische Salpetersäure.

562 Zur Anwendung kam ein Flachbettscanner Epson Perfection V700Photo (Dual Lens System); die polierten Oberflächen wurden mit 4800 dpi Auflösung gescannt (jeweils oberes Bild auf Abb. $62 \mathrm{ff}$. und $68 \mathrm{ff}$.)

563 Im Einsatz stand ein Binokular mit elektronischem Kameraaufsatz Leitz Z16 APO; die polierten Oberflächen wurden in der Vergrösserung 12,5 × mit Weissabgleich aufgenommen (jeweils unteres Bild auf Abb. $62 \mathrm{ff}$. und $68 \mathrm{ff}$.). - Ich danke an dieser Stelle Philippe Rentzel von der Forschungsgruppe «Integrative Prähistorische und Naturwissenschaftliche Archäologie» (IPNA) der Universität Basel für die Benutzung von Scanner und Binokular im IPNA-Labor und Christine Pümpin für die Anleitungen an den Geräten.

564 Zum Auftrennen der dünnen Proben wurde das Mikrotom «Mecatome T180» der Firma «PRESI GmbH» verwendet (https: / www. presi.com / gmbh / trennmaschinen / 1-mecatome-t180.html [17.03.2018]) 


\begin{tabular}{|c|c|c|c|c|c|c|}
\hline Probe & Lehm* & C-Träger & Aufkohlung* & HV max. & C & s \\
\hline \multicolumn{7}{|c|}{ Stangenbarren aus Lehmumhüllungen, «Reineisen»: } \\
\hline R01/R03 & ohne & ohne & - & $(99-117)$ & 0.00829 & 0.00500 \\
\hline R05.00-01 & \multirow{4}{*}{ C } & \multirow{4}{*}{ Holzkohle } & \multirow{4}{*}{$1,2 \mathrm{~mm}$} & $186 \mathrm{HV} \mathrm{0,3}$ & 0.0310 & 0.00496 \\
\hline R05.01-02 & & & & $173 \mathrm{HV} 0,3$ & 0.0156 & 0.00280 \\
\hline R05.03-04 & & & & $122 \mathrm{HV} 0,3$ & 0.0103 & 0.00307 \\
\hline R05.09 & & & & $110 \mathrm{HV} \mathrm{0,3}$ & 0.00643 & 0.00323 \\
\hline R06.00-01 & \multirow{3}{*}{ C } & \multirow{3}{*}{ Knochenasche } & \multirow{3}{*}{$0,5 \mathrm{~mm}, \mathrm{Z}$} & $139 \mathrm{HV} 0,3$ & 0.0162 & 0.0120 \\
\hline R06.01-02 & & & & $128 \mathrm{HV} 0,3$ & 0.00993 & 0.00303 \\
\hline R06.09 & & & & $101 \mathrm{HV} 0,3$ & 0.0106 & 0.00297 \\
\hline R07 & $\mathrm{C}$ & Tierhaut & $\mathrm{K}$ & - & & \\
\hline R08 & $\mathrm{D}$ & Tierhorn & $K$ & - & & \\
\hline R09 & $\mathrm{B}$ & Sägemehl & $\mathrm{Z}, \mathrm{K}$ & - & & \\
\hline R10 & $\mathrm{B}$ & Schilf & $\mathrm{Z}, \mathrm{K}$ & - & & \\
\hline R11 & C & Getreidedrusch & $\mathrm{Z}, \mathrm{K}$ & - & & \\
\hline R12 & \multirow{4}{*}{ C } & \multirow{4}{*}{ Holzkohle } & \multirow{4}{*}{$0,4-1,0 \mathrm{~mm}$} & - & & \\
\hline R12.00-01 & & & & $138 \mathrm{HV} 0,3$ & 0.0112 & 0.0123 \\
\hline R12.01-02 & & & & $120 \mathrm{HV} 0,3$ & 0.0131 & 0.00426 \\
\hline R12.09 & & & & $112 \mathrm{HV} 0,3$ & 0.00732 & 0.00324 \\
\hline \multicolumn{7}{|c|}{ Stangenbarren aus Lehmumhüllungen, «Buttereisen»: } \\
\hline B01/B3 & ohne & ohne & - & $(135-151)$ & 0.0281 & 0.0105 \\
\hline B05 & C & Holzkohle & $\mathrm{Z}, \mathrm{K}$ & & & \\
\hline B06.00-01 & \multirow{4}{*}{ C } & \multirow{4}{*}{ Graphit } & \multirow{4}{*}{$1,6 \mathrm{~mm}$} & $210 \mathrm{HV} \mathrm{0,3}$ & 0,355 & 0.0293 \\
\hline B06.01-02 & & & & $139 \mathrm{HV} 0,3$ & 0.0889 & 0.0114 \\
\hline B06.03-04 & & & & $133 \mathrm{HV} \mathrm{0,3}$ & 0.0417 & 0.00979 \\
\hline B06.11 & & & & $131 \mathrm{HV} 0,3$ & 0.0285 & 0.0105 \\
\hline B07 & $\mathrm{D}$ & Holzkohle & K & & & \\
\hline \multicolumn{7}{|c|}{ Stangenbarren aus Lehmumhüllungen, "Eisen Pivot»: } \\
\hline $\mathrm{P} 01 / \mathrm{P} 03$ & ohne & ohne & - & $(88-105)$ & 0.00601 & 0.00731 \\
\hline P05.00-01 & \multirow{4}{*}{ C } & \multirow{4}{*}{ Holzkohle } & \multirow{4}{*}{$0,8 \mathrm{~mm}, \mathrm{Z}, \mathrm{K}$} & $125 \mathrm{HV} 0,3$ & 0.00760 & 0.0204 \\
\hline P05.01-02 & & & & $103 \mathrm{HV} 0,3$ & 0.00577 & 0.00630 \\
\hline P05.03-04 & & & & $94 \mathrm{HV} 0,3$ & 0.00525 & 0.00777 \\
\hline P05.13 & & & & $93 \mathrm{HV} 0,3$ & 0.00375 & 0.00703 \\
\hline P06.00-01 & \multirow{5}{*}{ A } & \multirow{5}{*}{ Holzkohle } & & $210 \mathrm{HV} 0,3$ & 0.387 & 0.0113 \\
\hline P06.01-02 & & & & $133 \mathrm{HV} 0,3$ & 0.0810 & 0.00925 \\
\hline P06.03-04 & & & $1,4 \mathrm{~mm}$ & $117 \mathrm{HV} 0,3$ & 0.0460 & 0.00856 \\
\hline P06.09 & & & & $106 \mathrm{HV} 0,3$ & 0.00641 & 0.00864 \\
\hline P06.12 & & & & $96 \mathrm{HV} 0,3$ & 0.00407 & 0.00786 \\
\hline P07 & C & Tierhaut & $\mathrm{Z}, \mathrm{K}$ & & & \\
\hline P08 & $\mathrm{B}$ & Sägemehl & $\mathrm{Z}, \mathrm{K}$ & & & \\
\hline Flachbarren & s Tiegel (Abb. & ), «Reineisen» (R & uttereisen» (B) & & & \\
\hline $\mathrm{R} 13$ & & & $?$ & & & \\
\hline R14R & & & & & 0.0222 & 0.00506 \\
\hline R14Z & & & $?$ & & 0.0261 & 0.00524 \\
\hline R15R & A & & $12 \mathrm{~mm}$ & 260 HV 03 & 0.0335 & 0.00521 \\
\hline R15Z & (aus Tiegel) & Holzkohle & $1,2 \mathrm{~mm}$ & 260 HV 0,3 & 0.0471 & 0.00531 \\
\hline $\mathrm{B} 13$ & & & $?$ & & & \\
\hline B14R & & & $?$ & & 0.0329 & 0.0104 \\
\hline B14Z & & & $?$ & & 0.0519 & 0.0107 \\
\hline B15R & & & $1,3 \mathrm{~mm}$ & $196 \mathrm{HV} \mathrm{0,3}$ & 0.303 & 0.0105 \\
\hline B15Z & & & & & 0.198 & 0.0102 \\
\hline
\end{tabular}

Tabelle 6: Aufkohlungsexperimente in Lehmumhüllungen: In den Spalten rechts die Analysenergebnisse der Kohlenstoff- und Schwefelgehalte (Abb. 111) an verschiedenen Stellen (Abb. 81) ausgesuchter Barren. In den Spalten links die Befunde an den Lehmumhüllungen und in den äussersten Zonen der aufgekohlten Eisenbarren. Siehe auch Abb. $85 \mathrm{ff}$.

Fette Probennummern: Stahlerzeugung erfolgreich ( $\geq 0,1 \%$ C); Lehm ${ }^{*}=$ Rissbildung an den Lehmumhüllungen nach dem Brand (Abb. 76): $A=$ Lehmumhüllung nach Brand \pm intakt; $B=$ nur randständige Risse; $C=$ mehrere Risse; $D=$ Lehmumhüllung völlig zerbrochen. - Aufkohlung * $=$ Befund gemäss Anschliff, im Mikroskop: $R=$ Aufkohlung in der Randzone erkennbar; $K=$ keine Aufkohlung in der Randzone erkennbar; $Z=$ Verzunderung an der Probenoberfläche (keine Aufkohlung); (Zahl) = Aufkohlungstiefe in mm. 


\begin{tabular}{|c|c|c|c|}
\hline Probe & C-Träger & C & S \\
\hline B06.00-01 & Graphit & 0,355 & 0.0293 \\
\hline P05.00-01 & Holzkohle & 0.00760 & 0.0204 \\
\hline R12.00-01 & Holzkohle & 0.0112 & 0.0123 \\
\hline R06.00-01 & Knochenasche & 0.0162 & 0.0120 \\
\hline B06.01-02 & Graphit & 0.0889 & 0.0114 \\
\hline P06.00-01 & Holzkohle & 0.387 & 0.0113 \\
\hline B14Z & Holzkohle & 0.0519 & 0.0107 \\
\hline B15R & Holzkohle & 0.303 & 0.0105 \\
\hline B06.11 & Graphit & 0.0285 & 0.0105 \\
\hline B01 / B3 & (ohne) & 0.0281 & 0.0105 \\
\hline B14R & Holzkohle & 0.0329 & 0.0104 \\
\hline B15Z & Holzkohle & 0.198 & 0.0102 \\
\hline B06.03-04 & Graphit & 0.0417 & 0.00979 \\
\hline P06.01-02 & Holzkohle & 0.0810 & 0.00925 \\
\hline P06.09 & Holzkohle & 0.00641 & 0.00864 \\
\hline P06.03-04 & Holzkohle & 0.0460 & 0.00856 \\
\hline P06.12 & Holzkohle & 0.00407 & 0.00786 \\
\hline P05.03-04 & Holzkohle & 0.00525 & 0.00777 \\
\hline P01/P03 & (ohne) & 0.00601 & 0.00731 \\
\hline P05.13 & Holzkohle & 0.00375 & 0.00703 \\
\hline P05.01-02 & Holzkohle & 0.00577 & 0.00630 \\
\hline R15Z & Holzkohle & 0.0471 & 0.00531 \\
\hline R14Z & Holzkohle & 0.0261 & 0.00524 \\
\hline R15R & Holzkohle & 0.0335 & 0.00521 \\
\hline R14R & Holzkohle & 0.0222 & 0.00506 \\
\hline R01/R03 & (ohne) & 0.00829 & 0.00500 \\
\hline R05.00-01 & Holzkohle & 0.0310 & 0.00496 \\
\hline R12.01-02 & Holzkohle & 0.0131 & 0.00426 \\
\hline R12.09 & Holzkohle & 0.00732 & 0.00324 \\
\hline R05.09 & Holzkohle & 0.00643 & 0.00323 \\
\hline R05.03-04 & Holzkohle & 0.0103 & 0.00307 \\
\hline R06.01-02 & Knochenasche & 0.00993 & 0.00303 \\
\hline R06.09 & Knochenasche & 0.0106 & 0.00297 \\
\hline R05.01-02 & Holzkohle & 0.0156 & 0.00280 \\
\hline
\end{tabular}

Tabelle 7: Aufkohlungsexperimente in Lehmumhüllungen:

Schwefelanalysen, hier absteigend sortiert (Auszug aus Tabelle 6).

braun $=$ «Reineisen $»$, hellbraun $=«$ Buttereisen $»$, hellgrau $=$ Weicheisen «Pivot». 
3. dort, wo eine tiefere Aufkohlung erkennbar war, auch eine dritte Schicht (Bezeichnung «3-4» $\mathrm{mm}$; Zwischenbereich $=$ Sägeverlust) und

4. aus der Barrenmitte (Bezeichnung in mm entsprechend dem Barrenradius) herauspräpariert.

\section{Aufkohlungsbefund im Mikroskop}

Für die Betrachtung unter dem Auflichtmikroskop standen die polierten Anschliffe der Barrenquerschnitte zur Verfügung, die primär für die Vickers-Härtemessungen präpariert worden sind (Abb.112,4). Eine noch intensivere, feinere Politur, wie sie für perfekte Miroskopaufnahmen erforderlich wäre, war aus betrieblichen Gründen leider nicht möglich. Daher weisen etliche unserer Aufnahmen deutliche Krater (z. B. Abb. 63) oder Schlieren (Abb. 82) auf. In zwei Fällen war es aus unerfindlichen Gründen nicht möglich, eine Nital-Ätzung zu erreichen (z. B. Abb. 104).

Wie zu erwarten, erweisen sich die unbehandelten Rohmaterialien in der Mikrostruktur und Härte sowie in ihrem Chemismus als sehr homogen (Abb.62-70). Wie oben schon erwähnt, ist das «Reineisen» sehr feinkörnig, das «Buttereisen» leicht grober und das kohlenstoffärmste Weicheisen «Pivot» sehr grosskörnig (Abb. 68).

Die unter verbesserten Bedingungen aufgekohlten Proben P06A, P06B und P06C weisen im polierten Anschliff und nach der Nital-Ätzung (s. Anm. 561) spontan und von Auge gut erkennbar eine hellere äussere Schicht mit feinerem Korn auf (Abb. 107-109). Auf dieser Basis konnte die Tiefe, in welche der Kohlenstoff während unserer Zementation in die Eisenbarren eingedrungen ist, ermittelt werden (Abb.110; Tabelle 6). Mit einer dichteren Lehmumhüllung wäre eine Aufkohlung sicher bei allen anderen Proben ebenfalls geglückt. Der Luftzutritt durch während des Brandes in den Lehmumhüllungen entstandene Risse hatte leider bewirkt, dass das Aufkohlungsexperiment mit den meisten Barren gescheitert ist, d.h., die meisten Proben zeigten im Mikroskop keinerlei Aufkohlung an der Metalloberfläche (Abb. 82-109).

Die Fragestellung an die Proben R12 und B07, inwieweit sich eine verkürzte Zementationsdauer von nur 41/2 (statt 71/2) Stunden auf die Aufkohlungstiefe bemerkbar macht, konnte daher nicht abgeklärt werden (Abb. 93-95 resp. 101). Einzig in Probe B07A veränderten sich die oberflächennahen Zonen etwas (Abb. 101).

Die mehr oder weniger geglückten Experimente sind in Tabelle 10 zusammengestellt; ihre Schnitte sind in den Abbildungen 82 bis 110 (siehe auch das Tiegel-Experiment: Abb.116-121) $2 \times$ und $15 \times$ vergrössert wiedergegeben. Eine in den Makro-Schnittbildern sichtbare Aufkohlung war nur bis maximal 1,6 mm Tiefe zu erkennen (Beispiel Abb.99). Mit Ausnahme der im Tiegel zementierten Eisen- platte R15 (Abb. 116-118) geht die optisch erkennbare Aufkohlung parallel mit dem effektiven Kohlenstoffgehalt einher (Tabelle 10). Es sind dies ${ }^{565}$ :

B06: 1,6 mm tief aufgekohlt. Stangenbarren, mit Graphit beschichtet, in Lehmumhüllung zementiert (Abb. 71; 98-99): tiefste Eindringtiefe des Kohlenstoffs im Experiment (Tabelle 10), trotz Rissen im Lehmmantel an beiden Enden des Barrens (Abb. 76). Die präparierten und analysierten Proben wurden aus dem Mittelteil des Barrens genommen, wo der Kohlenstoff vom Graphit anscheinend ungehindert in das Eisen diffundieren konnte.

P06: 1,4 mm tief aufgekohlt. Stangenbarren, mit Holzkohle beschichtet, in Lehmumhüllung zementiert (Abb. 107-110). Diese Probe ist dank optimierter Lehmzubereitung der Hülle (S. 130 und Abb. 76) ebenfalls gut aufgekohlt worden, weil die Umhüllung intakt blieb und so der Kohlenstoff optimal in das Eisen diffundieren konnte (Nachtrag, gebrannt in einem Elektroofen).

R05: 1,2 mm tief aufgekohlt. Stangenbarren, mit Holzkohle beschichtet, in Lehmumhüllung zementiert (Abb. 82-85). Trotz langer Risse in der Lehmumhüllung (Abb.76) wurde das Eisen etwas aufgekohlt. In den Makro-Bildern des Barrenquerschnitts fällt jedoch auf, dass die Aufkohlung nur beim langsam abgekühlten Stück deutlich sichtbar ist (Abb. 82), bei den abgeschreckten resp. angelassenen Teilproben jedoch nur durch eine geringfügige Kornverkleinerung (Abb.83 und 84).

P05: 0,8 mm tief aufgekohlt. Stangenbarren, mit Holzkohle beschichtet, in Lehmumhüllung zementiert (Abb.103-106). Es sind hier dieselben Unterschiede zwischen den drei Härtungsstufen zu beobachten wie bei R05.

R12: $0,4-1,0 \mathrm{~mm}$ tief aufgekohlt. Stangenbarren, mit Holzkohle beschichtet, in Lehmumhüllung zementiert (Abb.93-96). Die minimale Aufkohlung ist nur an einer Barrenoberfläche zu erkennen (Abb. 93 und 95, obere Ansicht, Kante rechts unten).

R06: $0,5 \mathrm{~mm}$ tief aufgekohlt. Stangenbarren, mit Knochenasche beschichtet, in Lehmumhüllung zementiert (Abb. 86-88). Trotz relativ intakter Lehmumhüllung (Abb. 76) sind nur ganz geringe Ansätze einer Aufkohlung erkennbar.

B15: 1,3 mm tief aufgekohlt. Plattenbarren, mit Holzkohle beschichtet, in Tiegel zementiert (Abb.115; 119-121). Die guten Aufkohlungsbedingungen am «Buttereisen» im hermetisch abgedichteten Tiegel

565 Die Beurteilung und Ausmessung der Aufkohlungstiefen verdanke ich Rudolf Kubiz von der Georg Fischer AG in Schaffhausen. 
(Abb. 115,6.7) haben in 711/2 Stunden Glühzeit bei rund $1000^{\circ} \mathrm{C}$ zu einem guten Resultat geführt.

R15: 1,2 mm tief aufgekohlt. Plattenbarren, mit Holzkohle beschichtet, in Tiegel zementiert (Abb. 115; 116118). Was für B15 zutrifft, ist auch für das «Reineisen» von R15 der Fall.

Alle übrigen Barren aus Weicheisen zeigten nach dem Experiment optisch keine Spuren einer geglückten Aufkohlung (Beispiele Abb.89-92), was wohl an den schadhaften Lehmumhüllungen liegt (Abb. 76), durch deren Risse der Kohlenstoff entweichen statt auf das Eisen einwirken konnte. Bezüglich Härteverlauf zeigten einige der Proben ohne sichtbare Aufkohlungszone dennoch einen leichten Härteanstieg nahe der Oberfläche (s. unten; z. B. Abb. 88).

Die Aufkohlung ist bei unseren Experimenten bis zu einer maximalen Eindringtiefe von 1,6 mm (makroskopisch ca. $2,5 \mathrm{~mm}$ ) erfolgt. Dies konnte vom ungeübten Experimentator wenigstens bei einigen Proben auf Anhieb erzielt werden. Grosse, jahrelange Erfahrung, eine optimale Lehmaufbereitung, ein Trocknungsprozess ohne Rissbildung und noch längere Glühzeiten (über 71/2 Stunden) würden sicherlich zu viel besseren, kohlenstoffreicheren Stählen führen, wie wir sie ja von manchem Fundobjekt resp. seiner archäometrischen Untersuchung kennen (Beispiele in Anm. 155-167).

\section{Kohlenstoffanalysen der Experimentierbarren}

Von einer Auswahl der zementierten Eisenbarren sind Kohlenstoff- und Schwefelanalysen durchgeführt worden ${ }^{566}$. Um die Eindringtiefe des Kohlenstoffs zu ermitteln, habe ich dünne Scheibchen in 1, 2 und $4 \mathrm{~mm}$ Tiefe sowie im Zentrum der Barren präpariert (Abb. 81 und 111,3). Die Ergebnisse sind in Tabelle 6 zusammengestellt.

Von den nicht zementierten drei Eisensorten wurde die Härte ebenfalls gemessen (Kohlenstoffgehalt nach Tabelle 6, «ohne»).

\begin{tabular}{|l|l|l|}
\hline $\begin{array}{l}\text { «Reineisen» } \\
\text { (R01/R03): }\end{array}$ & $99-117$ HV 0,3 & $0,0083 \%$ C \\
\hline $\begin{array}{l}\text { «Buttereisen» } \\
\text { (B01/B03): }\end{array}$ & $135-151$ HV 0,3 & $0,0281 \%$ C \\
\hline $\begin{array}{l}\text { Weicheisen «Pivot» } \\
\text { (P01/P03): }\end{array}$ & $88-105$ HV 0,3 & $0,0060 \%$ C \\
\hline
\end{tabular}

Die Härten sind demzufolge vom Kohlenstoff - bereits in diesen geringen Mengen! - abhängig, auch wenn diese Proben noch gar nicht sekundär aufgekohlt worden sind.

Bereits im mikroskopischen Befund (Abb.82-120) zeigte es sich, dass infolge der zum Teil starken Rissbildung in den Lehmumhüllungen (Abb. 76) in vielen Proben zu viel Kohlenstoff verbrennen konnte, anstatt in das Eisen zu dringen. Dadurch fand in den meisten Proben nur eine sehr geringe Aufkohlung statt. Die Kohlenstoffanalysen zeigen das sehr deutlich (Tabelle 6): Nur gerade die Proben B06, P06 und B15 haben in den äusseren Bereichen genug Kohlenstoff aufgenommen, um als «low carbon steel» bezeichnet werden zu können (s. oben Anm. 58):

\begin{tabular}{|l|l|l|}
\hline B06: & $0,355 \%$ C & dank Graphit? \\
\hline P06: & $0,387 \%$ C & dank verbesserter Tonaufbereitung \\
\hline B15: & $0,303 \%$ C & aus dem Tiegel Abb. 115 \\
\hline
\end{tabular}

Die Mehrzahl der Proben scheint auf den ersten Blick gar keine Aufkohlung erfahren zu haben, denn die Analysenwerte liegen meist unter 0,05\% C (Gewichtsprozent). Unsere Messungen der Vickers-Härten lassen jedoch durchaus eine gewisse Härtungseigenschaft durch Abschrecken resp. Anlassen erkennen (Abb. 85 ff.). Es erstaunt daher ein wenig, dass bei manchen Proben trotz sehr geringen Kohlenstoffwerten einerseits im Mikroskop eine Aufkohlung in den oberflächennahen Zonen zu beobachten ist (Abb. 82; 101; 103-105) und andererseits die Härteverläufe indirekt eine leichte - in den C-Analysen nicht erkannte Aufkohlung mit Härtungsmöglichkeit zu erkennen geben (Abb. 86-88; 93-96; 103-106; 116-118).

\section{Schwefelanalysen der Experimentierbarren}

Die Schwefelwerte (Gewichtsprozent) in unseren Proben sind durch mehrere Faktoren beeinflusst, wenn wir die Ergebnisse sortieren und die Eisenqualität farbig auseinanderhalten (Tabelle 7):

1. Die Eisenqualitäten unterscheiden sich deutlich in den Schwefelgehalten. Das «Reineisen» (braun) enthält am wenigsten Schwefel, ausser im obersten Millimeter der aufgekohlten Proben («00-01»). Das «Buttereisen» (hellbraun) ist am schwefelreichsten.

2. Die allerhöchsten Schwefelgehalte sind in den äussersten Bereichen, nahe der Barrenoberflächen, zu finden («00-01»). Der Schwefel wird demzufolge auch durch den Zementationsprozess oberflächlich etwas angereichert.

566 Die C- und S-Analysen (Verbrennungs-Infrarot-Analysen im Induktionsofen) erfolgten mithilfe des Analyseautomaten «CS230» der Firma «LECO Corporation» (http://leco-europe.com [17.03.2018]). - Siehe auch Anm. 558. 

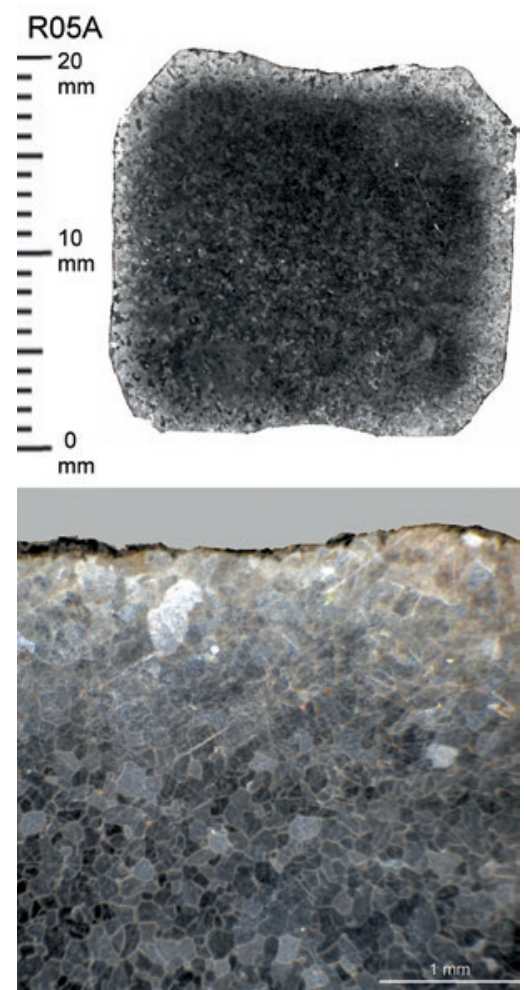

Abb. 82: Barrenquerschnitt R05A («Reineisen», aufgekohlt mit Holzkohle, langsam erkaltet). Scan M. 2:1 resp. Binokularaufnahme M. 15:1.
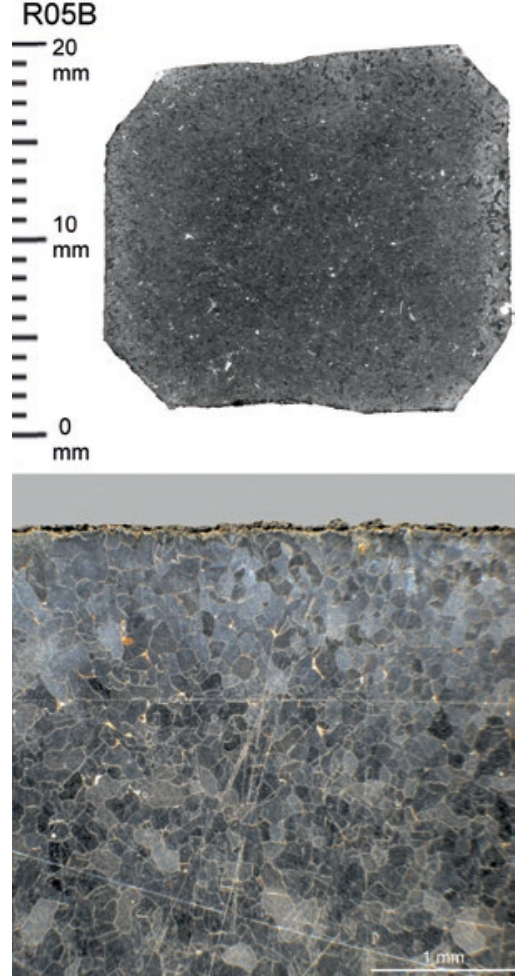

Abb. 83: Barrenquerschnitt R05B ( Reineisen», Holzkohle, geglüht und abgeschreckt). Scan M. 2:1 resp. Binokularaufnahme M. 15:1.
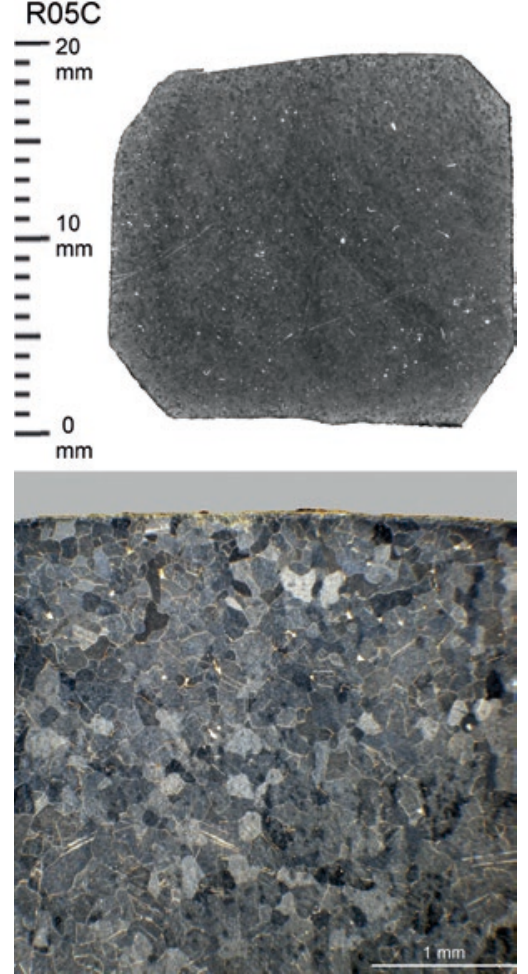

Abb. 84: Barrenquerschnitt R05C («Reineisen», Holzkohle, abgeschreckt und angelassen). Scan M. 2:1 resp. Binokularaufnahme M. 15:1.

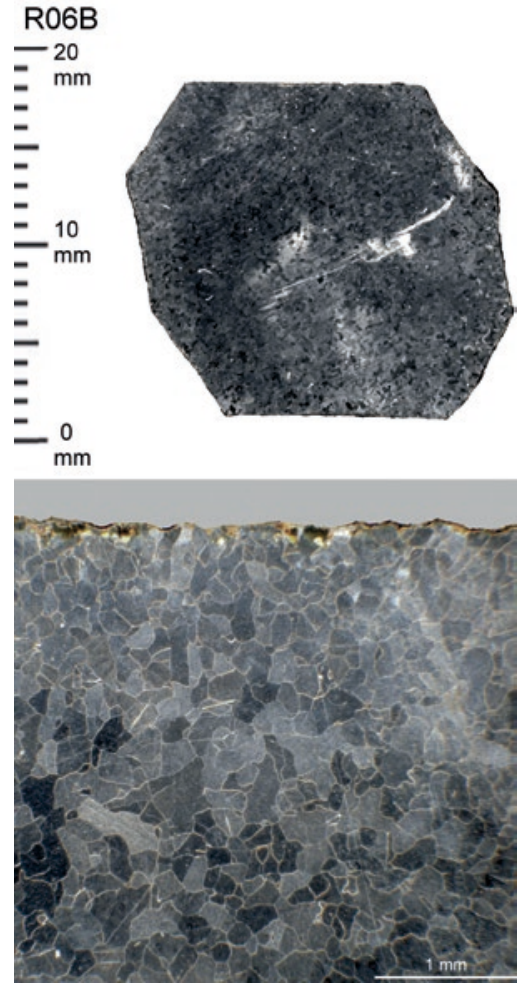

Abb. 86: Barrenquerschnitt R06B ( RReineisen», Knochenasche, geglüht und abgeschreckt). Scan M. 2:1 resp. Binokularaufnahme M. 15:1.
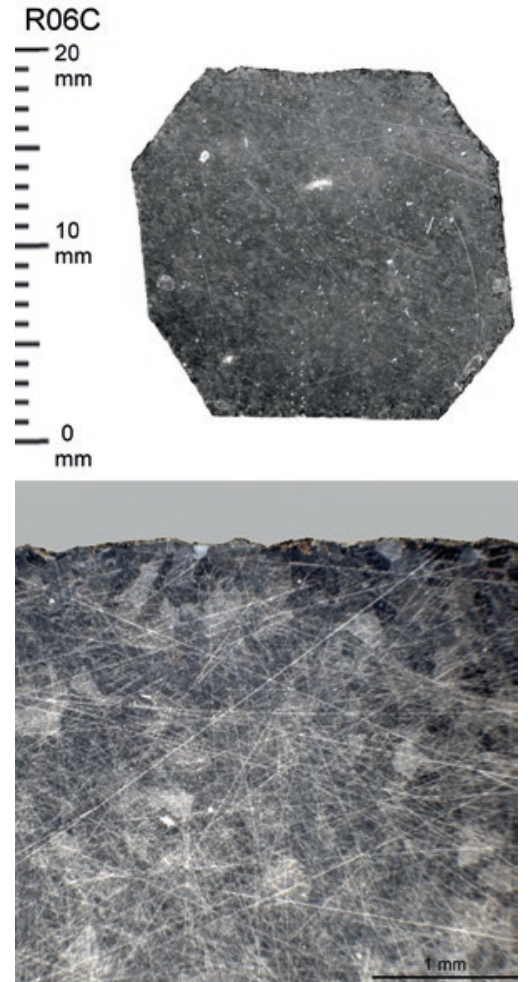

Abb. 87: Barrenquerschnitt R06C («Reineisen», Knochenasche, abgeschreckt und angelassen). Scan M.2:1 resp. Binokularaufnahme M. 15:1. 

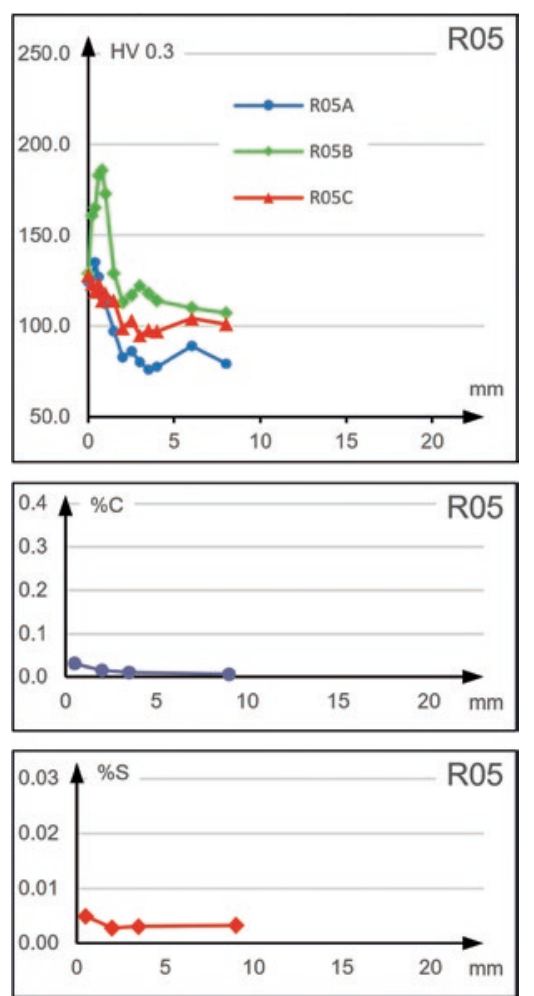

Abb. 85: Barrenquerschnitte R05A-R05C («Reineisen»). Diagramme (v.o.n.u.) VickersHärte 0,3, Kohlenstoff- und Schwefelanalysen.
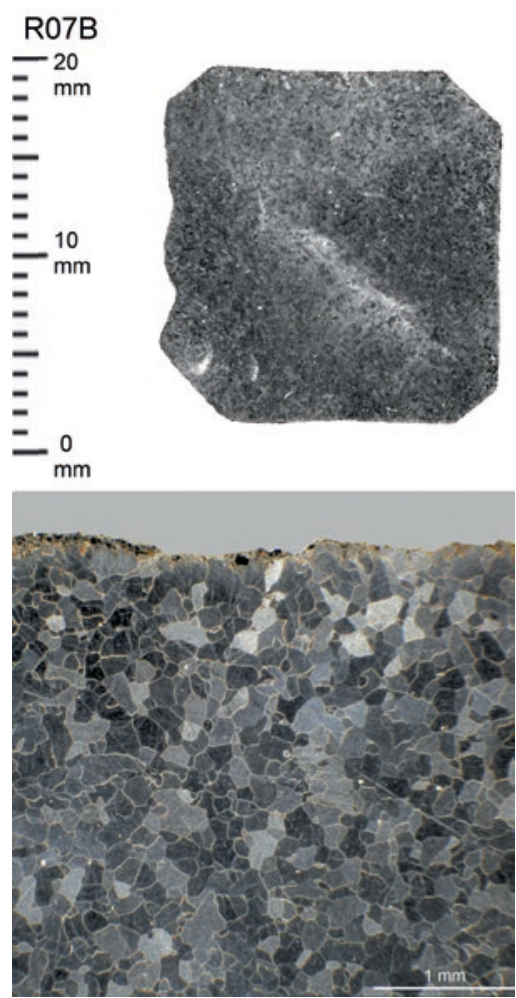

Abb. 89: Barrenquerschnitt R07B («Reineisen», Tierhaut, geglüht und abgeschreckt). Scan M.2:1 resp. Binokularaufnahme M. 15:1.
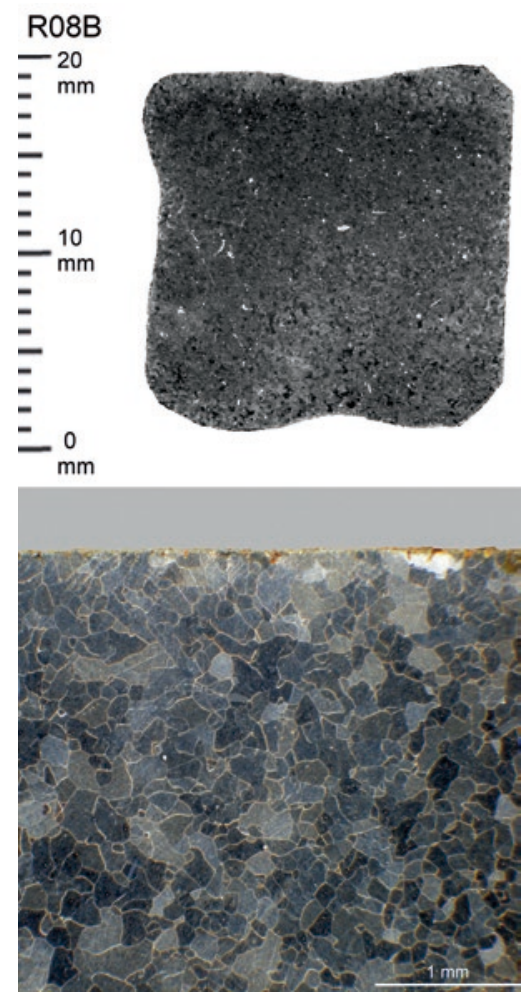

Abb. 90: Barrenquerschnitt R08B ("Reineisen», Tierhorn, geglüht und abgeschreckt). Scan M. 2:1 resp. Binokularaufnahme M. 15:1.

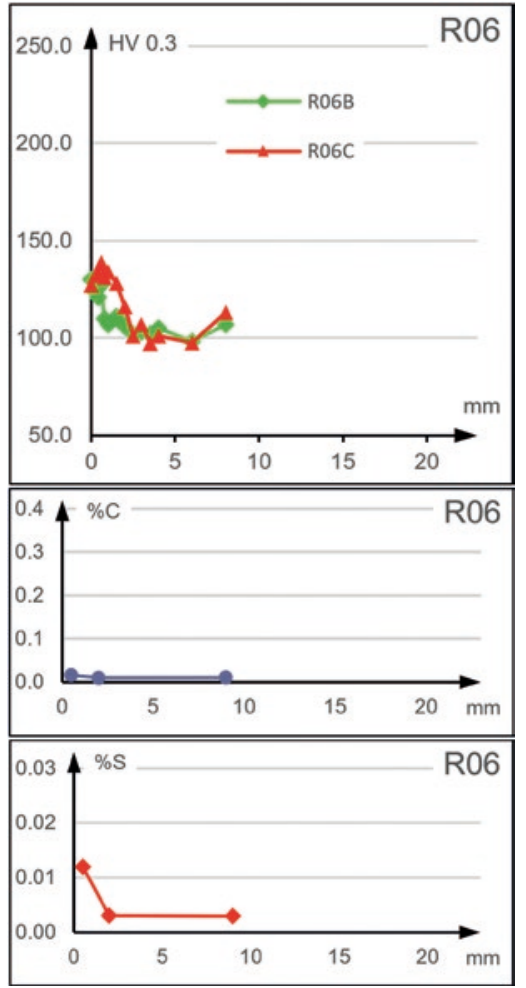

Abb. 88: Barrenquerschnitte R06B-R06C («Reineisen»). Diagramme (v. o.n.u.) VickersHärte 0,3, Kohlenstoff- und Schwefelanalysen.

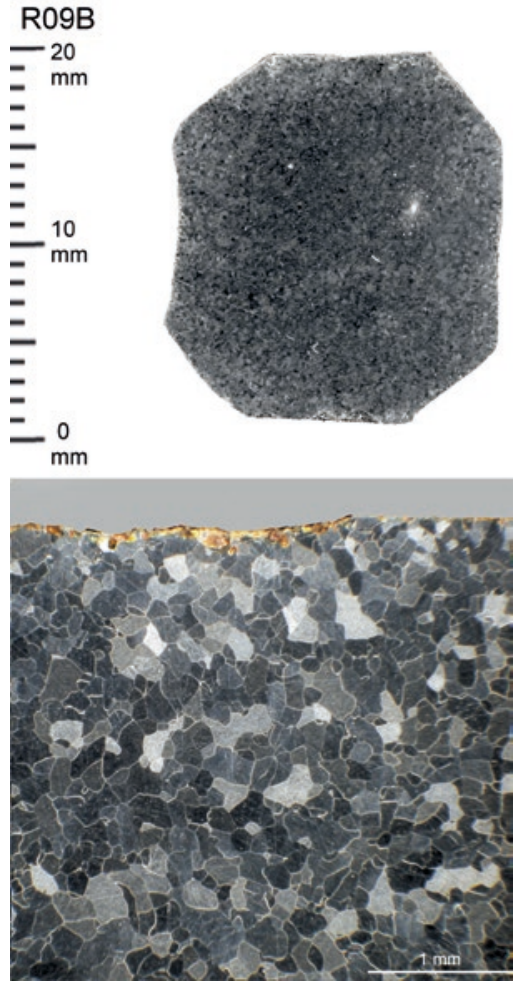

Abb.91: Barrenquerschnitt R09B ( Reineisen», Sägemehl, geglüht und abgeschreckt). Scan M. 2:1 resp. Binokularaufnahme M. 15:1.
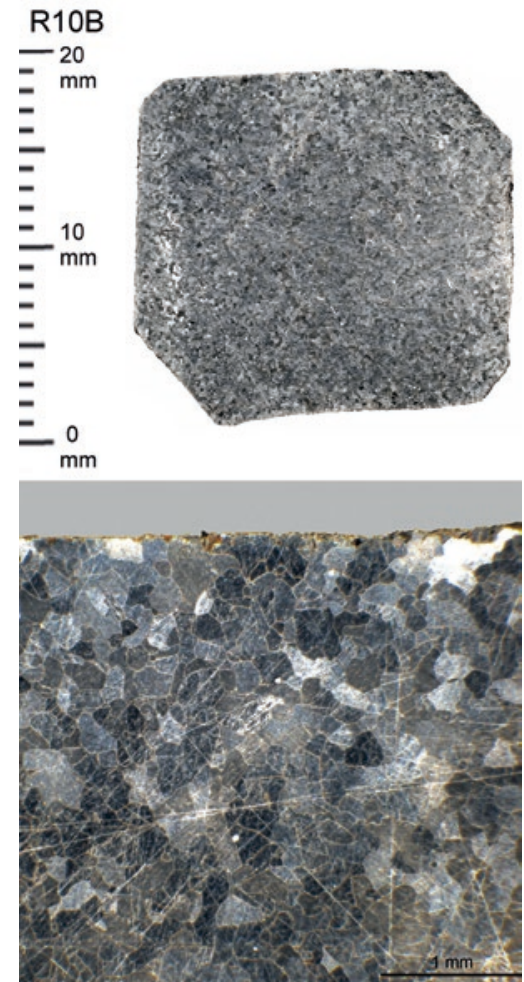

Abb. 92: Barrenquerschnitt R10B («Reineisen», Schilf, geglüht und abgeschreckt). Scan M.2:1 resp. Binokularaufnahme M. 15:1. 

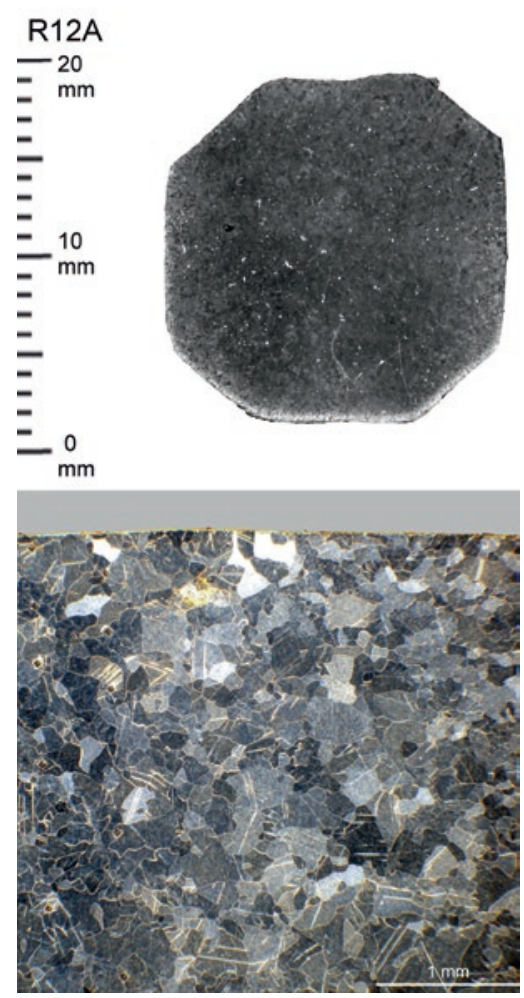

Abb. 93: Barrenquerschnitt R12A («Reineisen», aufgekohlt mit Holzkohle, langsam erkaltet). Scan M.2:1 resp. Binokularaufnahme M. 15:1.
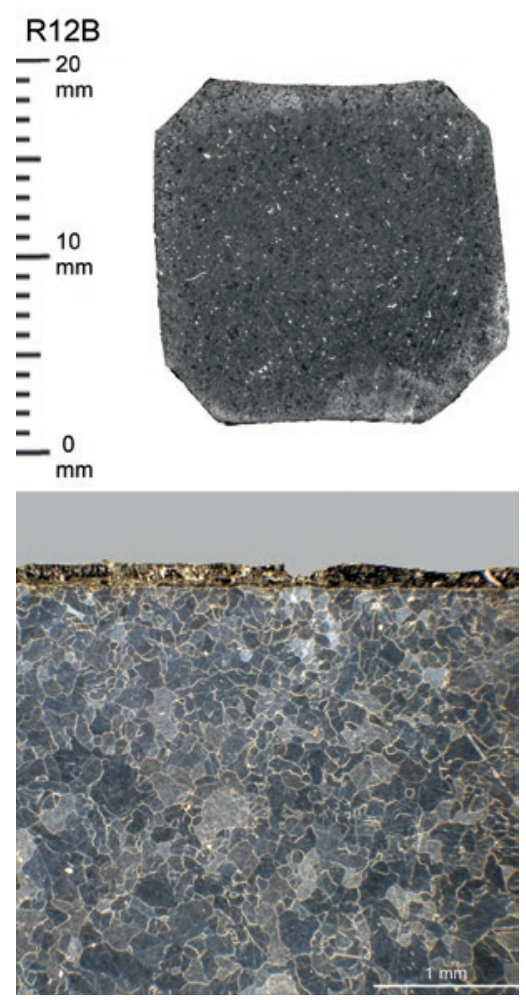

Abb. 94: Barrenquerschnitt R12B («Reineisen», Holzkohle, geglüht und abgeschreckt). Scan M. 2:1 resp. Binokularaufnahme M. 15:1.
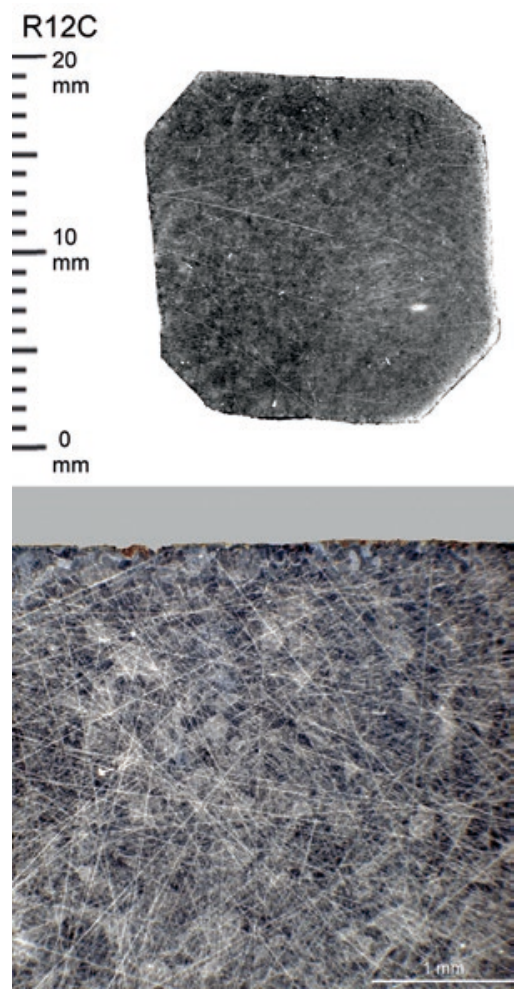

Abb. 95: Barrenquerschnitt R12C («Reineisen», Holzkohle, abgeschreckt und angelassen). Scan M. 2:1 resp. Binokularaufnahme M. 15:1.
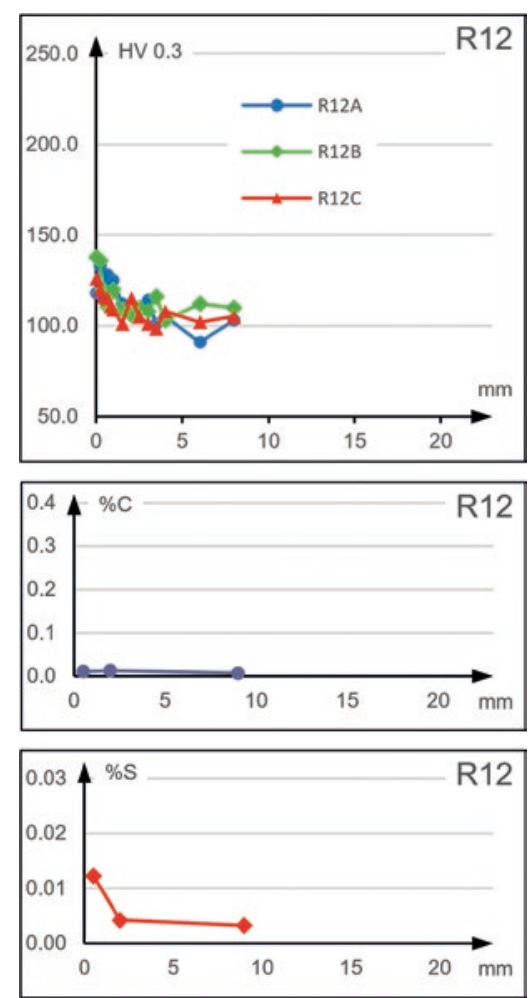

Abb. 96: Barrenquerschnitte R12A-R12C («Reineisen»). Diagramme (v. o. n. u.) VickersHärte 0,3, Kohlenstoff- und Schwefelanalysen.
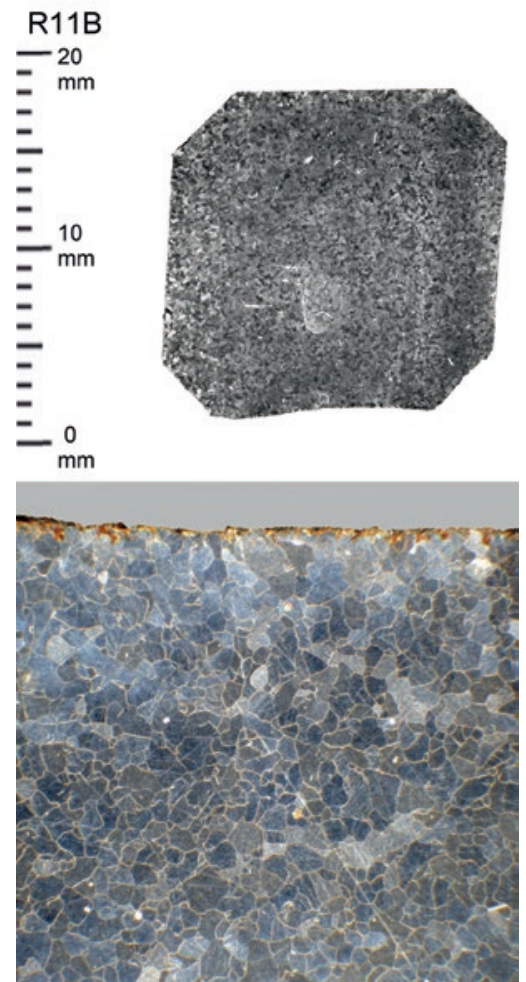

Abb. 97: Barrenquerschnitt R11B («Reineisen», Getreidedrusch, geglüht und abgeschreckt). Scan M. 2:1 resp. Binokularaufnahme M. 15:1. 

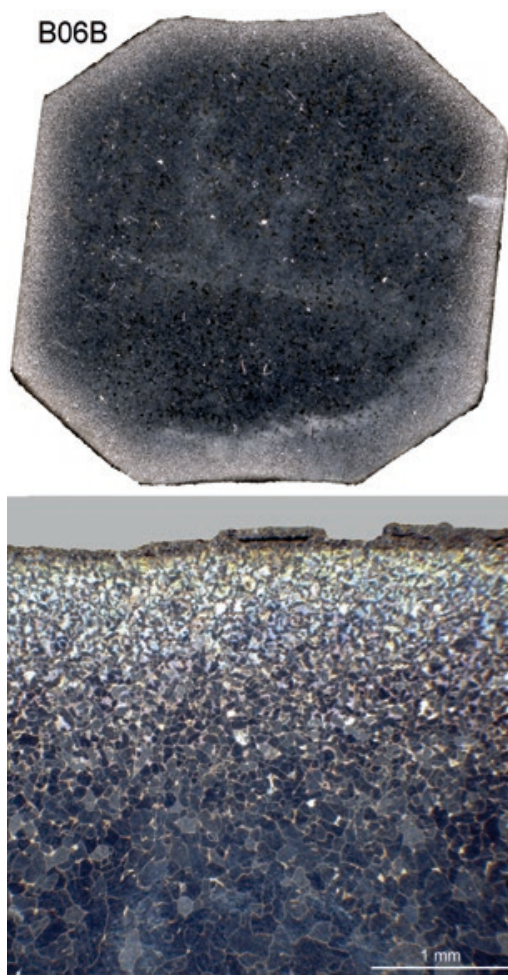

Abb. 98: Barrenquerschnitt B06B («Buttereisen», Graphit, geglüht und abgeschreckt). Scan M. 2:1 resp. Binokularaufnahme M. 15:1.

B07A
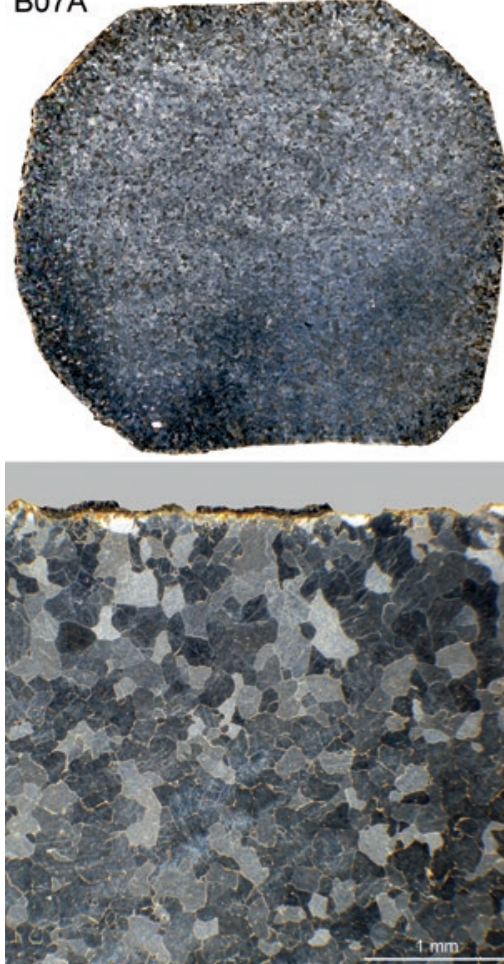

Abb. 101: Barrenquerschnitt B07A («Reineisen», aufgekohlt mit Holzkohle, langsam erkaltet). Scan M. 2:1 resp. Binokularaufnahme M. 15:1.
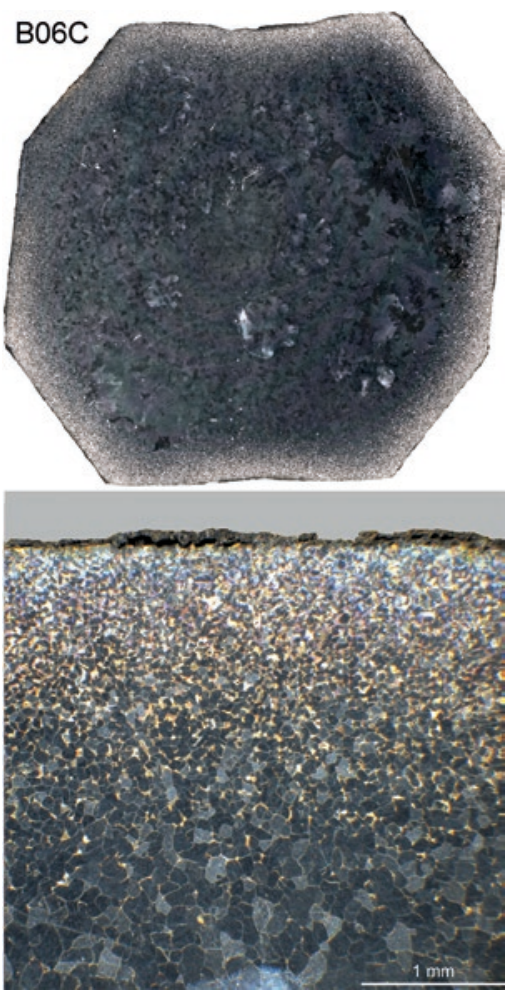

Abb. 99: Barrenquerschnitt B06C ( «Reineisen», Graphit, abgeschreckt und angelassen). Scan M. 2:1 resp. Binokularaufnahme M. 15:1.
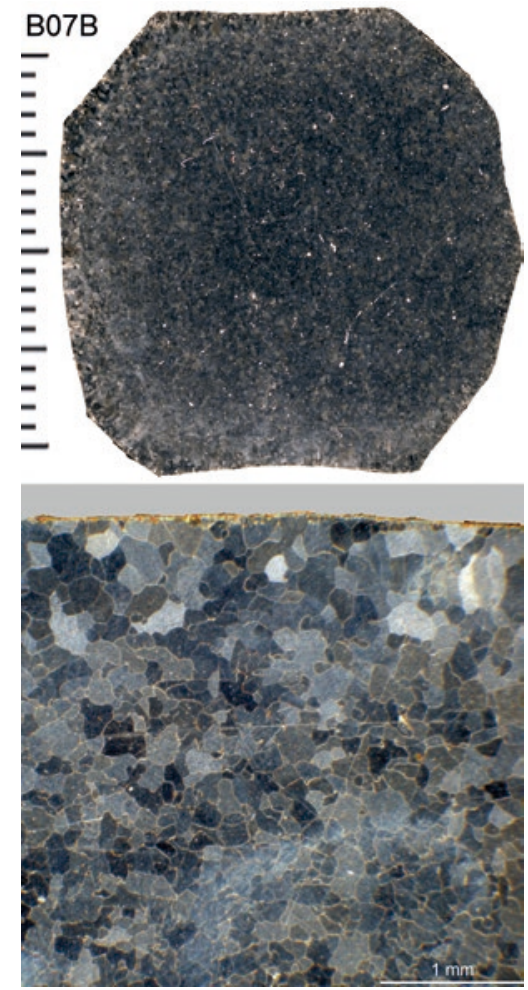

Abb. 102: Barrenquerschnitt B07B («Reineisen», Holzkohle, geglüht und abgeschreckt). Scan M. 2:1 resp. Binokularaufnahme M. 15:1.

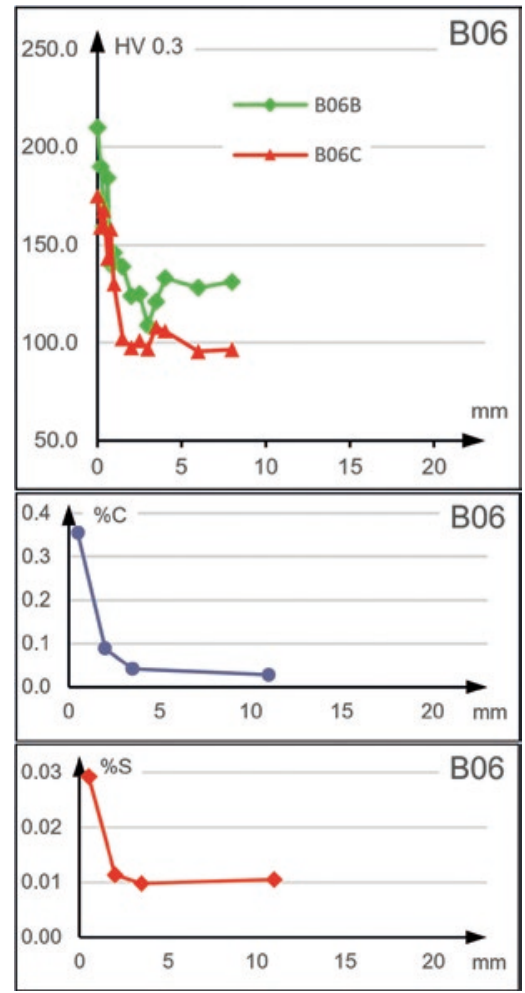

Abb. 100: Barrenquerschnitte B06B-B06C («Reineisen»). Diagramme (v. o. n. u.) VickersHärte 0,3, Kohlenstoff- und Schwefelanalysen. 

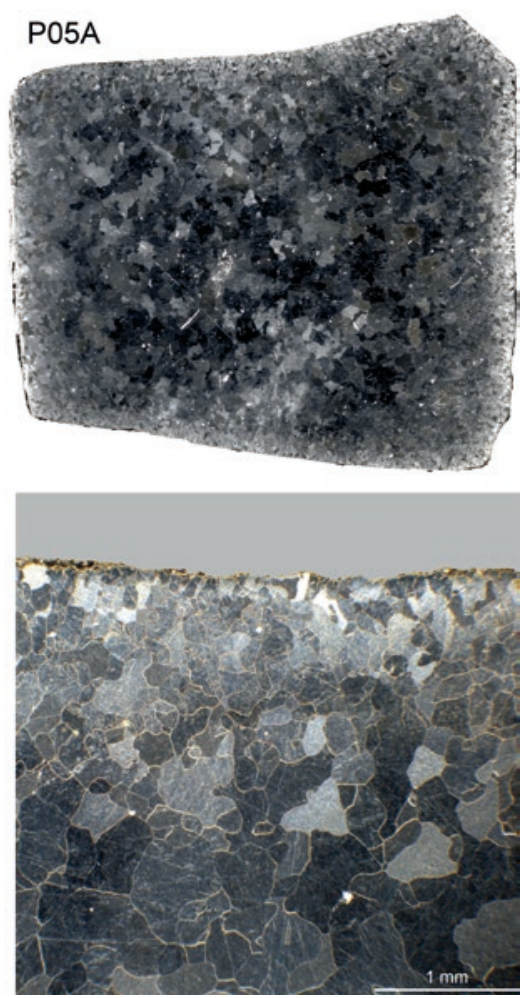

Abb. 103: Barrenquerschnitt P05A («Reineisen», aufgekohlt mit Holzkohle, langsam erkaltet). Scan M. 2:1 resp. Binokularaufnahme M. 15:1.
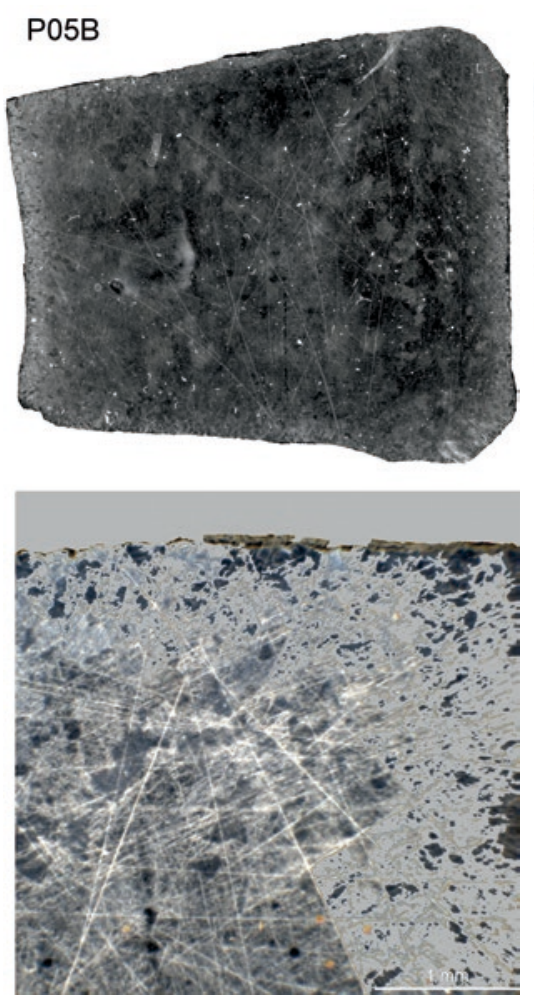

Abb. 104: Barrenquerschnitt P05B («Reineisen», Holzkohle, geglüht und abgeschreckt). Scan M. 2:1 resp. Binokularaufnahme M. 15:1.

\section{P05C}
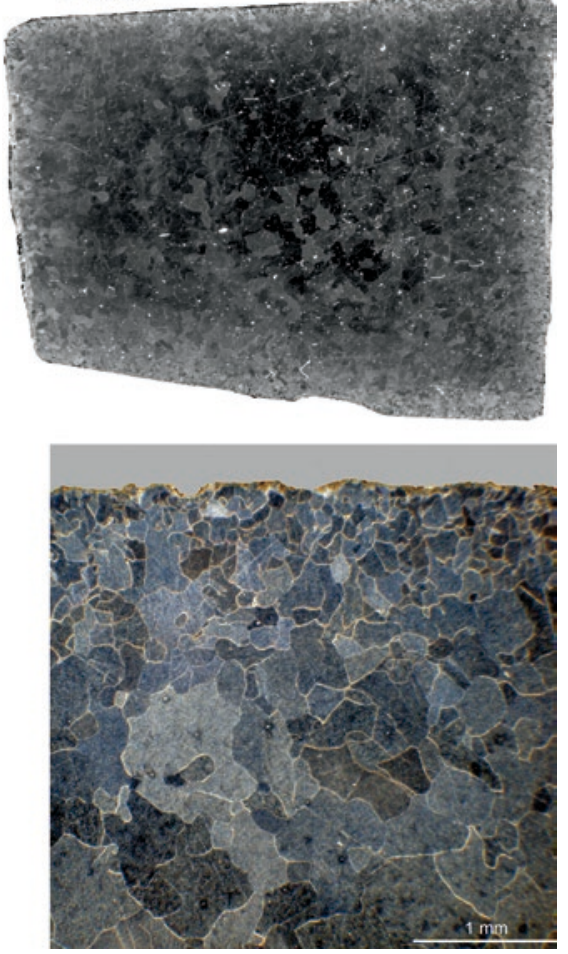

Abb. 105: Barrenquerschnitt P05C («Reineisen», Holzkohle, abgeschreckt und angelassen). Scan M. 2:1 resp. Binokularaufnahme M. 15:1.
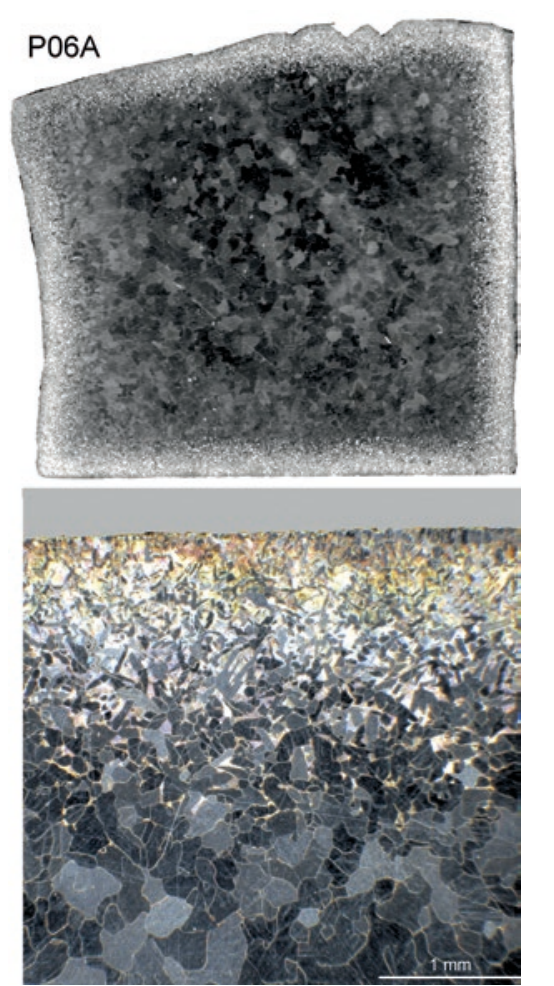

Abb. 107: Barrenquerschnitt P06A («Reineisen», aufgekohlt mit Holzkohle, langsam erkaltet). Scan M.2:1 resp. Binokularaufnahme M. 15:1.
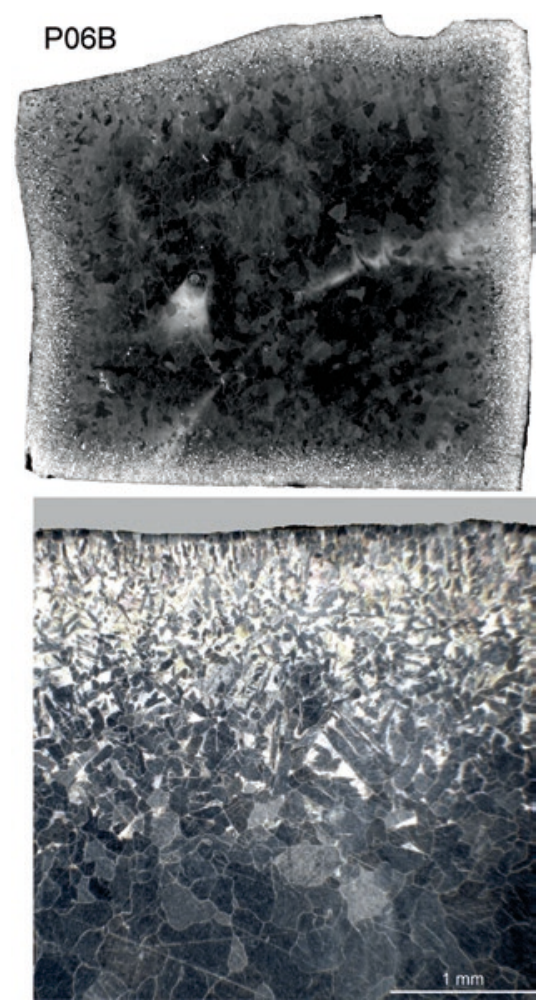

Abb. 108: Barrenquerschnitt P06B («Reineisen», Holzkohle, geglüht und abgeschreckt). Scan M. 2:1 resp. Binokularaufnahme M. 15:1.
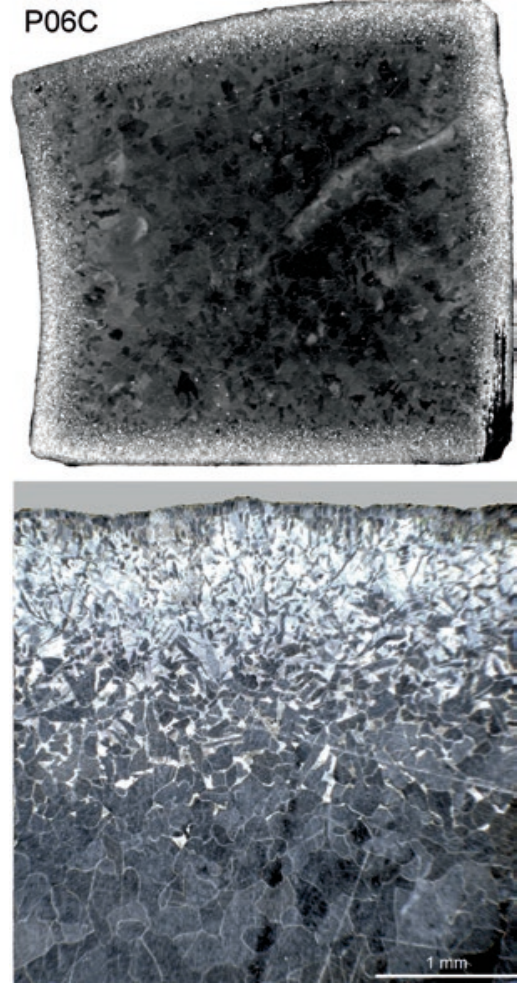

Abb. 109: Barrenquerschnitt P06C («Reineisen», Holzkohle, abgeschreckt und angelassen). Scan M. 2:1 resp. Binokularaufnahme M. 15:1. 

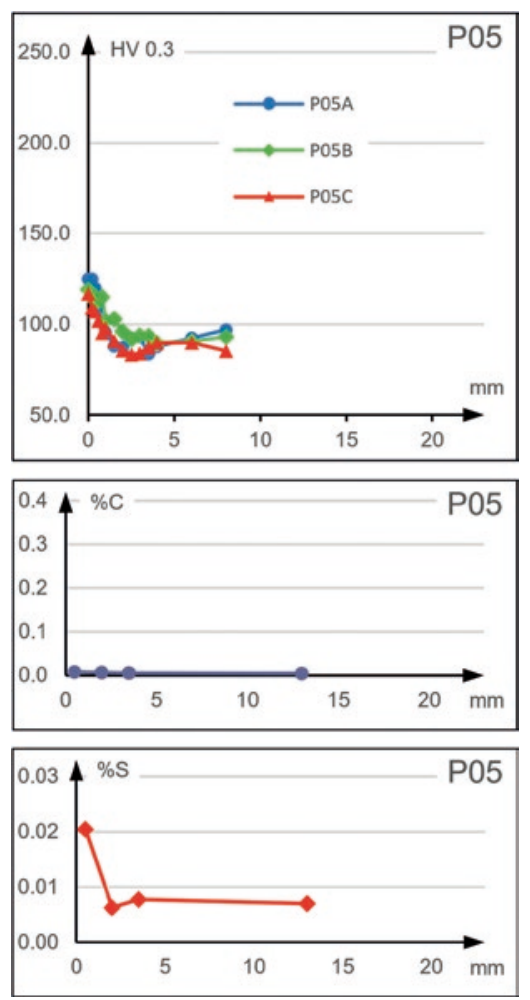

Abb. 106: Barrenquerschnitte P05A-P05C

(«Reineisen»). Diagramme (v.o.n.u.) VickersHärte 0,3, Kohlenstoff- und Schwefelanalysen.
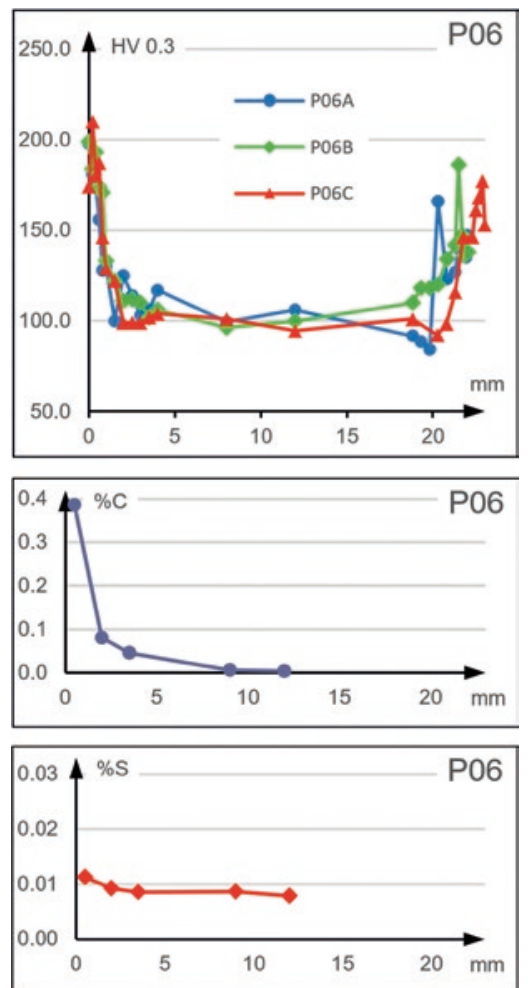

Abb. 110: Barrenquerschnitte P06A-P06C («Reineisen»). Diagramme (v.o.n.u.) VickersHärte 0,3, Kohlenstoff- und Schwefelanalysen. 

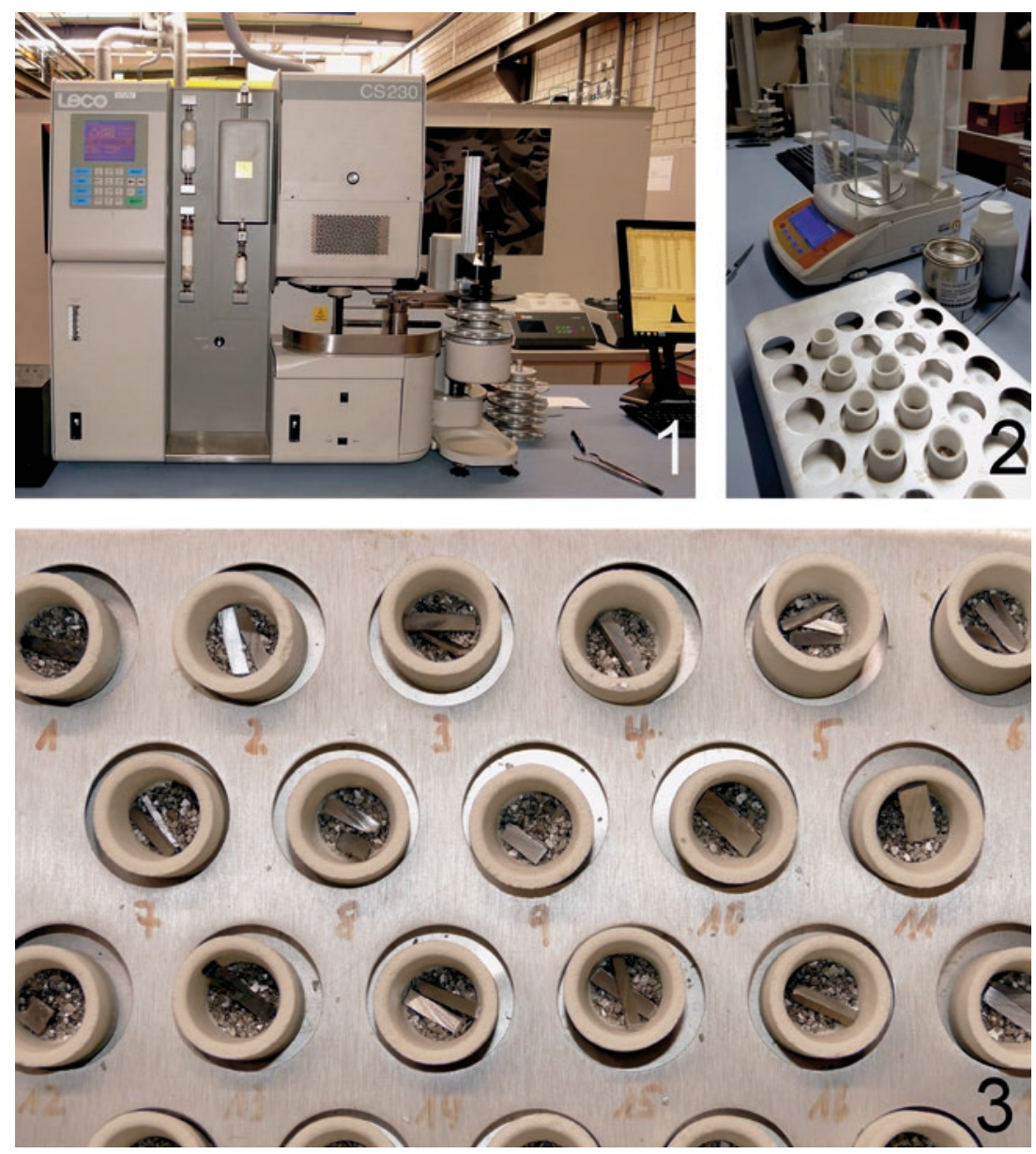

Abb. 111: Analyse der Kohlenstoff- und Schwefelgehalte. $1=$ Analyseautomat $~ « L E C O$, CS230", 2 = hoch hitzebeständige Probentiegelchen vor der Feinwaage (1/1000 Gramm), bereit zum Einwägen der individuellen Probengewichte ( 0,6 bis $1,5 \mathrm{~g}), 3=$ kleine Proben- $«$ Streifchen», aus den Barren (Abb. 81) mit dem Mikrotom aus verschiedenen Positionen im Barrenquerschnitt herausgeschnitten.

3. Die bei der Zementation verwendeten Kohlenstoffträger in den Lehmumhüllungen können sich offenbar ebenfalls auf die Schwefelgehalte im Eisen auswirken:

a. Knochenasche enthält nur wenig Schwefel, weil er verglüht ist ${ }^{567}$. Im Barreninnern scheint Schwefel sogar abgereichert (deutlich unterhalb R01/R03). Dass die Probe R06.00-01 an der Barrenoberfläche mit Schwefel angereichert ist, muss auf andere Ursachen zurückzuführen sein.

b. Graphit bewirkt nicht nur hohe Kohlenstoffanteile im Oberflächenbereich der Eisenbarren (s. oben), sondern führt dort auch zu den höchsten von uns gemessenen Schwefelwerten. Von uns untersuchter Graphit enthielt immerhin 0,69-1,12\% $S^{568}$ und kann daher den Spitzenwert in Tabelle 7 erklären.

Die alternativ eingesetzten Kohleträger wie Tierhaut, Sägemehl, Tierhorn usw. können leider nicht beurteilt werden, obwohl sie einen z. T. hohen Schwefelanteil besitzen (Knochen, Horn) ${ }^{569}$, denn die mit ihnen durchgeführten Zementationsversuche sind wegen $\mathrm{zu}$ grosser Luftzufuhr (Risse in den Lehmumhüllungen) gescheitert.

4. Innerhalb der einzelnen Eisenqualitäten weisen die aufgekohlten Proben aus den Lehmumhüllungen tendenziell etwas weniger Schwefel auf als jene aus dem versiegelten Tiegel (Probenserien 14 und 15; Tabelle 7). Eindeutig ist dieser Trend allerdings nicht, und es sei dahingestellt, ob sich in einem Tiegel mehr Schwefel (z. B. aus der Holzkohle) im Zementationsfeuer löst und in das Eisen übergeht als in den Lehmumhüllungen.

Um Rückschlüsse auf die bei der historischen Stahlerzeugung verwendeten Kohlenstoffträger ziehen zu können, müssten weitere Experimente in diesem Sinne durchgeführt und auch mehr - für die Zuschlagstoffe signifikante - Spurenelemente in die Vergleiche einbezogen werden.
567 Furger 2018, Tabelle 7 («Knochen geglüht»).

568 Furger 2018, Tabelle 3 (Fundort [FO] 59 Hauzenberg-Kropfmühl / D).

569 Furger 2018, Tabelle 7. 
Mangan- und weitere Analysen der Experimentierbarren

\section{Methodik}

Im Gegensatz zu den oben beschriebenen Kohlenstoff- und Schwefelanalysen anhand herauspräparierter Kleinproben in 1, 2 und $4 \mathrm{~mm}$ Tiefe konnten die polierten Querschnitte unserer Barrenproben auch integral mit pXRF570 analysiert werden, und zwar mit Blick auf weitere metallische Elemente, die für die Beurteilung von Stahl von Interesse sind. Der Nachteil allerdings ist, dass - gerätebedingt - nur die polierten Barrenquerschnitte als Ganzes, und nicht kleine Segmente wie bei den C- und S-Analysen (Abb. 81), gemessen werden konnten.

Da durch die Zementation des Eisens seine Oberfläche sich anders respektive mehr veränderte als sein Inneres, haben wir uns behelfsmässig entschlossen, mit dem 8-mm- $\varnothing$-Messfenster des pXRF-Spektrometers nicht nur die Mitte der Barrenquerschnitte, sondern zusätzlich auch den Randbereich an der Barrenaussenseite zu messen (Tabelle 8, «Rand»).

Es interessierten vor allem die Spuren anderer Metalle in den zementierten Eisenbarren. Daher wurde im Modus «alloy» gemessen. Es sollte vor allem herausgefunden werden, ob

1. durch das Aufkohlen auch andere Elemente als Kohlenstoff und Schwefel sich oberflächennah an den Barren anreicherten.

2. Eine zweite Frage war, wie sich die Schwefelbestimmung durch die Infrarot-Verbrennungsanalyse im Induktionsofen von der portablen energiedispersiven Röntgenfluoreszenzanalyse (pXRF) allenfalls unterscheidet.

3. Es interessierte zudem, ob durch die Aufkohlung mit gezielt eingesetzten, unterschiedlichen Kohlenstoffträgern auch andere die Stahlqualität beeinflussende Elemente (wie Mn, P, Si) in das Eisen gelangt sind.

4. Und schliesslich könnten sich weitere Spurenelemente ergeben, welche sich in den drei verwendeten «Weich»-Eisen in signifikant unterschiedlicher Form nachweisen lassen.

\section{Begleitelemente des Aufkohlungsprozesses}

Die beim Aufkohlen experimentell verwendeten Kohlenstoffträger können von Natur aus Elemente enthalten, die in anderen organischen Substanzen kaum vorhanden sind. Zum Beispiel enthalten bei den von uns verwendeten CTrägern Tierhaut und Schilf relativ viel Silizium; während für Graphit und Schilf die Kaliumgehalte typisch sind ${ }^{571}$. Leider sind die hier interessierenden Elemente nahe der Nachweisgrenze des pXRF-Spektrometers.

So zeigt sich beim Arsen, dass - wenn überhaupt nachweisbar - nur Spuren davon in den Randzonen der Barren- querschnitte, d.h. in Oberflächennähe der aufgekohlten Eisenstücke, nachweisbar sind (Tabelle 8). Bezeichnenderweise stammen die Arsen-Nachweise ausschliesslich von Proben, die mit Holzkohle zementiert worden sind, was bedeutet, dass das Arsen aus der Holzkohle zu stammen scheint.

Ganz ähnlich verhält es sich beim Schwefel (Tabelle 8, «Rand»-Proben), was sich noch deutlicher bei der Mikroproben-Verbrennungsanalyse im Induktionsofen abzeichnet (z. B.Abb.100, unten). Die Schwefel-Nachweise sind mit Holzkohle und bezeichenderweise mit Graphit als Zementiermaterial assoziiert, die ziemlich sicher hier als Quellen des Schwefels zu gelten haben.

Die wenigen Proben mit Zirkonium-Spuren sind alle mit Holzkohle zementiert und weisen diese Spuren nahe der Nachweisgrenze immer nur im «Rand»-Bereich auf (Tabelle 8). Woher das Zirkonium stammt, muss offenbleiben; aus der Holzkohle dürfte es nicht kommen.

Auch Wolfram ist lediglich an den zementierten Oberflächen überhaupt nachweisbar, wenn auch weniger stetig als etwa Silizium (Tabelle 8). Auch dieses Element scheint nicht aus dem Zementationsmittel zu stammen.

Silizium ist in fast allen Proben nachweisbar. In den oberflächennahen «Rand»-Zonen ist es aber 3- bis 10mal stärker vertreten und folglich ebenfalls beim Zementationsprozess angereichert worden (Tabelle 8). Silizium kommt in Holzkohle kaum vor und in Graphit nur mässig (Anm. 571). Seine Quelle könnte eher der Lehm der Barrenumhüllungen sein.

Die übrigen Elemente sind kaum in den Eisenproben nachweisbar (zum Mangan siehe unten).

\section{Methodenvergleich Schwefelanalysen}

Die Schwefelgehalte der kreisförmigen, durch den pXRFSpektrometer abgedeckten Flächen von $50 \mathrm{~mm}^{2}$ (Tabelle 8) lassen sich nur schwer vergleichen mit den herauspräparierten Mikroproben aus unterschiedlichen Objekttiefen (Abb.81). Immerhin waren erhöhte Schwefelgehalte bei beiden Methoden nur in Oberflächennähe der Eisenbarren zu finden (Tabellen 6 und 8) und somit wie der Kohlenstoff dem Zementationsprozess geschuldet. Die höchsten analysierten Schwefelgehalte liegen bei 0,005-0,029\% bei der Infrarot-Verbrennungsanalyse im Induktionsofen und 0,012-0,060\% bei der Spektralanalyse pXRF. Weil die zweite Methode wenig gezielt misst und Schwefel nur nahe seiner Nachweisgrenze vorhanden ist, sind die Messserien nicht vergleichbar.

570 Zu Gerät und Methode: M. Helfert, in Furger 2018, 17-20 Abb. 1.

571 Viele der Stoffe sind für andere Vergleiche analysiert worden in: Furger 2018, Tabellen 3 (Holzkohle, Knochenasche, Leder, Pflanzenblätter und Holz) und 7 (Graphit). 


\begin{tabular}{|c|c|c|c|c|c|c|c|c|c|}
\hline Probe & C-Träger & As & Al & $\mathrm{Ti}$ & V & $\mathrm{Cr}$ & $\mathrm{Mn}$ & $\mathrm{Fe}$ & $\mathrm{Ni}$ \\
\hline \multicolumn{10}{|l|}{ «Reineisen» } \\
\hline R03 & ohne & 0,000 & 0,000 & 0,000 & 0,000 & 0,000 & 0,155 & 99,697 & 0,000 \\
\hline R04 & ohne & 0,000 & 0,000 & 0,000 & 0,000 & 0,000 & 0,157 & 99,639 & 0,028 \\
\hline R05A & Holzkohle & 0,000 & 0,000 & 0,000 & 0,000 & 0,000 & 0,138 & 99,649 & 0,029 \\
\hline R05A Rand & Holzkohle & 0,000 & 0,000 & 0,000 & 0,000 & 0,000 & 0,145 & 99,584 & 0,027 \\
\hline R05B & Holzkohle & 0,000 & 0,000 & 0,000 & 0,000 & 0,000 & 0,147 & 99,738 & 0,025 \\
\hline R05B Rand & Holzkohle & 0,000 & 0,000 & 0,000 & 0,000 & 0,000 & 0,160 & 99,459 & 0,000 \\
\hline R05C & Holzkohle & 0,000 & 0,000 & 0,000 & 0,000 & 0,000 & 0,145 & 99,754 & 0,000 \\
\hline R05C Rand & Holzkohle & 0,041 & 0,000 & 0,000 & 0,000 & 0,000 & 0,136 & 99,248 & 0,000 \\
\hline R06B & Knochenasche & 0,000 & 0,000 & 0,000 & 0,000 & 0,000 & 0,134 & 99,776 & 0,000 \\
\hline $\mathrm{R} 06 \mathrm{C}$ & Knochenasche & 0,000 & 0,000 & 0,000 & 0,000 & 0,000 & 0,146 & 99,735 & 0,026 \\
\hline R07B & Tierhaut & 0,000 & 0,000 & 0,000 & 0,000 & 0,000 & 0,146 & 99,720 & 0,000 \\
\hline R08B & Tierhorn & 0,000 & 0,000 & 0,000 & 0,000 & 0,000 & 0,156 & 99,842 & 0,000 \\
\hline $\mathrm{R} 10 \mathrm{~B}$ & Schilf & 0,000 & 0,000 & 0,000 & 0,000 & 0,000 & 0,162 & 99,662 & 0,000 \\
\hline $\mathrm{R} 12 \mathrm{~A}$ & Holzkohle & 0,000 & 0,000 & 0,000 & 0,000 & 0,000 & 0,137 & 99,706 & 0,027 \\
\hline $\mathrm{R} 12 \mathrm{~B}$ & Holzkohle & 0,000 & 0,000 & 0,000 & 0,000 & 0,000 & 0,139 & 99,652 & 0,000 \\
\hline \multirow[t]{2}{*}{$\mathrm{R} 12 \mathrm{C}$} & Holzkohle & 0,000 & 0,000 & 0,000 & 0,000 & 0,000 & 0,136 & 99,713 & 0,000 \\
\hline & & & & & & $\emptyset:$ & 0,146 & & \\
\hline \multicolumn{10}{|l|}{ «Buttereisen» } \\
\hline B03 & ohne & 0,000 & 0,000 & 0,000 & 0,000 & 0,014 & 0,110 & 99,832 & 0,000 \\
\hline B04 & ohne & 0,000 & 0,000 & 0,003 & 0,000 & 0,019 & 0,121 & 99,688 & 0,000 \\
\hline B05 & Holzkohle & 0,000 & 0,000 & 0,000 & 0,000 & 0,005 & 0,115 & 99,752 & 0,000 \\
\hline B06B & Graphit & 0,000 & 0,000 & 0,000 & 0,000 & 0,000 & 0,108 & 99,715 & 0,000 \\
\hline B06B Rand & Graphit & 0,000 & 0,000 & 0,000 & 0,000 & 0,012 & 0,107 & 99,447 & 0,000 \\
\hline B06C & Graphit & 0,000 & 0,464 & 0,000 & 0,000 & 0,025 & 0,120 & 99,242 & 0,000 \\
\hline B06C Rand & Graphit & 0,000 & 0,305 & 0,000 & 0,000 & 0,007 & 0,108 & 99,122 & 0,000 \\
\hline B07A & Holzkohle & 0,000 & 0,000 & 0,000 & 0,000 & 0,022 & 0,121 & 99,734 & 0,000 \\
\hline \multirow[t]{2}{*}{ B07B } & Holzkohle & 0,000 & 0,000 & 0,000 & 0,000 & 0,012 & 0,124 & 99,650 & 0,000 \\
\hline & & & & & & $\varnothing:$ & 0,115 & & \\
\hline \multicolumn{10}{|l|}{ "Eisen Pivot» } \\
\hline P03 & ohne & 0,000 & 0,000 & 0,000 & 0,000 & 0,000 & 0,191 & 99,577 & 0,024 \\
\hline P04 & ohne & 0,000 & 0,000 & 0,000 & 0,000 & 0,006 & 0,199 & 99,607 & 0,025 \\
\hline P05A & Holzkohle & 0,000 & 0,267 & 0,000 & 0,024 & 0,019 & 0,198 & 99,474 & 0,000 \\
\hline P05B & Holzkohle & 0,000 & 0,000 & 0,000 & 0,000 & 0,000 & 0,205 & 99,670 & 0,022 \\
\hline $\mathrm{P} 05 \mathrm{C}$ & Holzkohle & 0,000 & 0,000 & 0,000 & 0,000 & 0,000 & 0,195 & 99,718 & 0,000 \\
\hline P06A & Holzkohle & 0,000 & 0,307 & 0,000 & 0,000 & 0,013 & 0,213 & 99,307 & 0,022 \\
\hline P06A Rand & Holzkohle & 0,088 & 0,000 & 0,000 & 0,000 & 0,000 & 0,162 & 98,717 & 0,000 \\
\hline P06B & & 0,000 & 0,224 & 0,000 & 0,000 & 0,000 & 0,191 & 99,478 & 0,000 \\
\hline P06B Rand a & Holzkohle & 0,000 & 0,000 & 0,000 & 0,000 & 0,000 & 0,186 & 99,419 & 0,000 \\
\hline P06B Rand b & Holzkohle & 0,000 & 0,000 & 0,000 & 0,000 & 0,000 & 0,208 & 99,533 & 0,000 \\
\hline P06C & Holzkohle & 0,000 & 0,265 & 0,000 & 0,000 & 0,000 & 0,213 & 99,375 & 0,000 \\
\hline P06C Rand & Holzkohle & 0,086 & 0,000 & 0,000 & 0,000 & 0,000 & 0,147 & 98,705 & 0,000 \\
\hline P07B & Tierhaut & 0,000 & 0,320 & 0,000 & 0,000 & 0,000 & 0,202 & 99,260 & 0,026 \\
\hline \multirow[t]{2}{*}{ P08B } & Sägemehl & 0,000 & 0,000 & 0,000 & 0,000 & 0,000 & 0,215 & 99,624 & 0,028 \\
\hline & & & & & & $\varnothing:$ & 0,195 & & \\
\hline \multicolumn{10}{|c|}{ Aus Tiegel: «Reineisen» resp. «Buttereisen» } \\
\hline R15B Rand & Holzkohle & 0,085 & 0,000 & 0,000 & 0,000 & 0,000 & 0,138 & 98,776 & 0,000 \\
\hline R15C Rand & Holzkohle & 0,059 & 0,000 & 0,000 & 0,000 & 0,000 & 0,133 & 98,840 & 0,000 \\
\hline B15B Rand & Holzkohle & 0,000 & 0,000 & 0,000 & 0,000 & 0,016 & 0,106 & 99,509 & 0,000 \\
\hline B15C Rand & Holzkohle & 0,033 & 0,000 & 0,000 & 0,000 & 0,014 & 0,115 & 99,142 & 0,033 \\
\hline \multicolumn{10}{|c|}{ Zum Vergleich: Phenolharz (Labor-Einbettungsmasse) } \\
\hline $\mathrm{PhH}(\mathrm{t}-\mathrm{a}-\mathrm{g})$ & - & 0,000 & 0,059 & 0,006 & n.g. & n.g. & n.g. & 0,043 & n.g. \\
\hline
\end{tabular}

Tabelle 8: Aufkohlungsexperimente in Lehmumhüllungen: Oberflächen-pXRF-Analysen an den zementierten Eisenbarren, gemessen an den Querschnitten (Auswahl der im «Alloy-Modus» analysierten Elemente). In der Regel wurde eine runde Fläche von 8 mm Durchmesser im Zentrum gemessen. Die mit «Rand» bezeichneten Analysen erfassen auch den Rand- resp. den Oberflächenbereich der Eisenbarren, wo die Zementiermittel (Kohlenstoff-C-Träger) am ehesten eingewirkt haben. Die bei den «Rand»-Messungen mitanalysierte Einbettmasse aus Phenolharz hat die hier interessierenden Elemente kaum beeinträchtigt (unterste Zeile, gemessen im Modus «test all geo»). Die mit $\varnothing$ bezeichneten Werte sind die durchschnittlichen Mangangehalte in den drei verschiedenen im Experiment verwendeten Eisenqualitäten. 


\begin{tabular}{|c|c|c|c|c|c|c|c|c|c|c|c|c|}
\hline $\mathrm{Zr}$ & $\mathrm{Nb}$ & Mo & W & $\mathrm{Mg}$ & $\mathrm{Si}$ & $P$ & S & $\mathrm{Ca}$ & K & $\mathrm{Cl}$ & $\mathrm{Sr}$ & Bal \\
\hline 0,000 & 0,000 & 0,000 & 0,000 & 0,000 & 0,130 & 0,000 & 0,000 & & & & & 99,982 \\
\hline 0,000 & 0,000 & 0,000 & 0,016 & 0,000 & 0,138 & 0,000 & 0,000 & & & & & 99,978 \\
\hline 0,000 & 0,000 & 0,001 & 0,000 & 0,000 & 0,164 & 0,000 & 0,000 & & & & & 99,981 \\
\hline 0,000 & 0,000 & 0,000 & 0,000 & 0,000 & 0,229 & 0,000 & 0,000 & & & & & 99,985 \\
\hline 0,000 & 0,000 & 0,000 & 0,000 & 0,000 & 0,077 & 0,000 & 0,000 & & & & & 99,987 \\
\hline 0,000 & 0,000 & 0,000 & 0,029 & 0,000 & 0,326 & 0,000 & 0,000 & & & & & 99,974 \\
\hline 0,000 & 0,000 & 0,001 & 0,000 & 0,000 & 0,097 & 0,000 & 0,000 & & & & & 99,997 \\
\hline 0,006 & 0,000 & 0,000 & 0,000 & 0,000 & 0,538 & 0,000 & 0,000 & & & & & 99,969 \\
\hline 0,000 & 0,000 & 0,002 & 0,000 & 0,000 & 0,086 & 0,000 & 0,000 & & & & & 99,998 \\
\hline 0,000 & 0,000 & 0,000 & 0,000 & 0,000 & 0,073 & 0,000 & 0,000 & & & & & 99,980 \\
\hline 0,000 & 0,000 & 0,000 & 0,000 & 0,000 & 0,117 & 0,000 & 0,000 & & & & & 99,983 \\
\hline 0,000 & 0,000 & 0,000 & 0,000 & 0,000 & 0,000 & 0,000 & 0,000 & & & & & 99,998 \\
\hline 0,000 & 0,000 & 0,000 & 0,000 & 0,000 & 0,174 & 0,000 & 0,000 & & & & & 99,998 \\
\hline 0,000 & 0,000 & 0,000 & 0,000 & 0,000 & 0,105 & 0,000 & 0,000 & & & & & 99,975 \\
\hline 0,000 & 0,000 & 0,000 & 0,000 & 0,000 & 0,207 & 0,000 & 0,000 & & & & & 99,998 \\
\hline 0,000 & 0,000 & 0,000 & 0,000 & 0,000 & 0,136 & 0,000 & 0,000 & & & & & 99,985 \\
\hline
\end{tabular}

\begin{tabular}{|r|r|r|r|r|r|r|r|r|r|r|r|r|}
\hline \multicolumn{10}{|l|}{} \\
\hline 0,000 & 0,000 & 0,004 & 0,000 & 0,000 & 0,000 & 0,000 & 0,000 & & & & & 99,960 \\
\hline 0,000 & 0,000 & 0,003 & 0,000 & 0,000 & 0,123 & 0,000 & 0,000 & & & & & 99,957 \\
\hline 0,000 & 0,000 & 0,005 & 0,000 & 0,000 & 0,081 & 0,000 & 0,000 & & & & & 99,958 \\
\hline 0,000 & 0,000 & 0,004 & 0,000 & 0,000 & 0,128 & 0,000 & 0,000 & & & & & 99,955 \\
\hline 0,000 & 0,000 & 0,004 & 0,033 & 0,000 & 0,339 & 0,000 & 0,012 & & & & 9 & 99,954 \\
\hline 0,000 & 0,000 & 0,004 & 0,000 & 0,000 & 0,096 & 0,000 & 0,000 & & & & 9,951 \\
\hline 0,000 & 0,000 & 0,004 & 0,000 & 0,000 & 0,373 & 0,000 & 0,037 & & & & 99,956 \\
\hline 0,000 & 0,000 & 0,004 & 0,000 & 0,000 & 0,068 & 0,000 & 0,000 & & & & 99,949 \\
\hline 0,000 & 0,000 & 0,004 & 0,017 & 0,000 & 0,138 & 0,000 & 0,000 & & & & & 99,945 \\
\hline & & & & & & & & & & & & \\
\hline
\end{tabular}

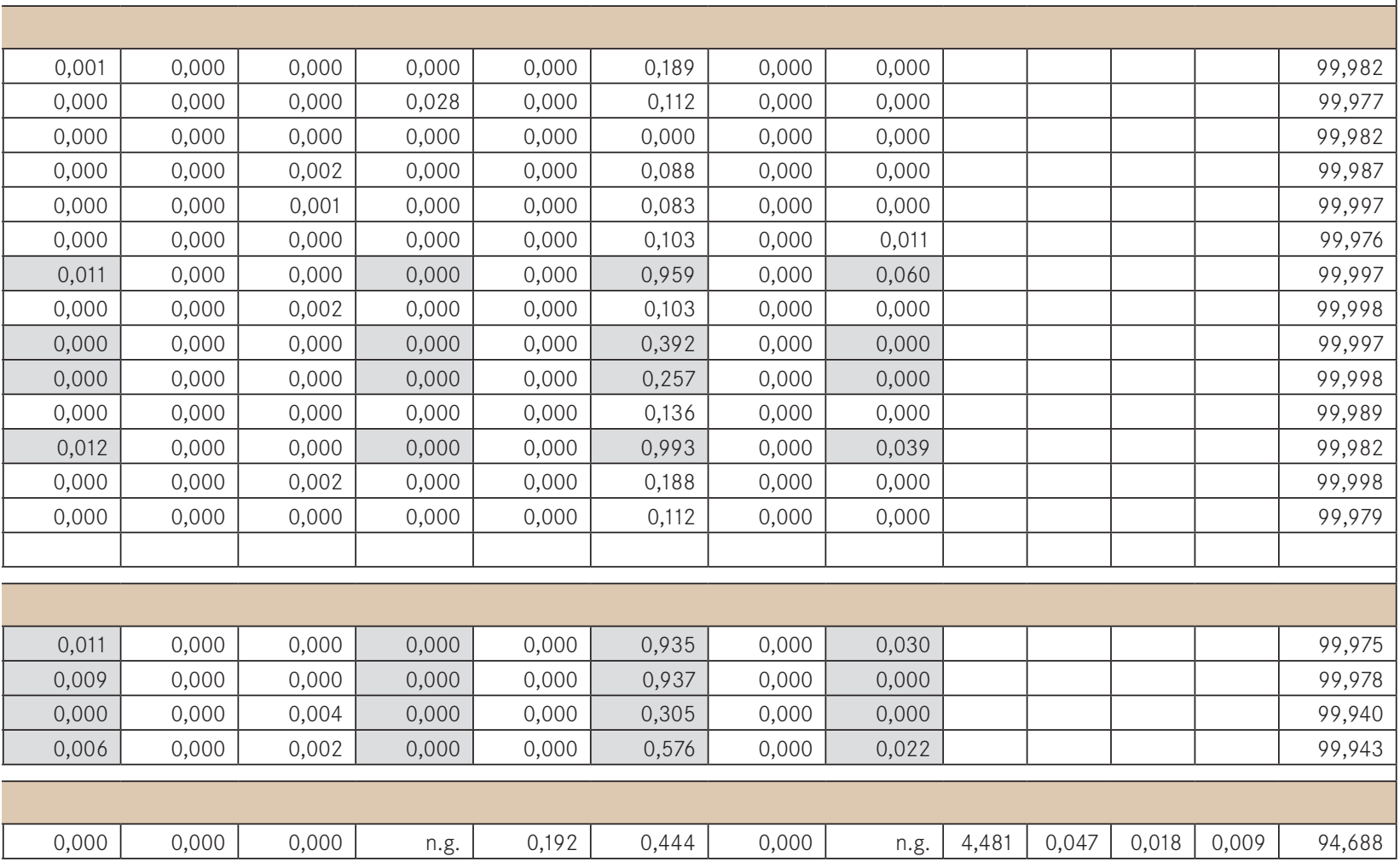



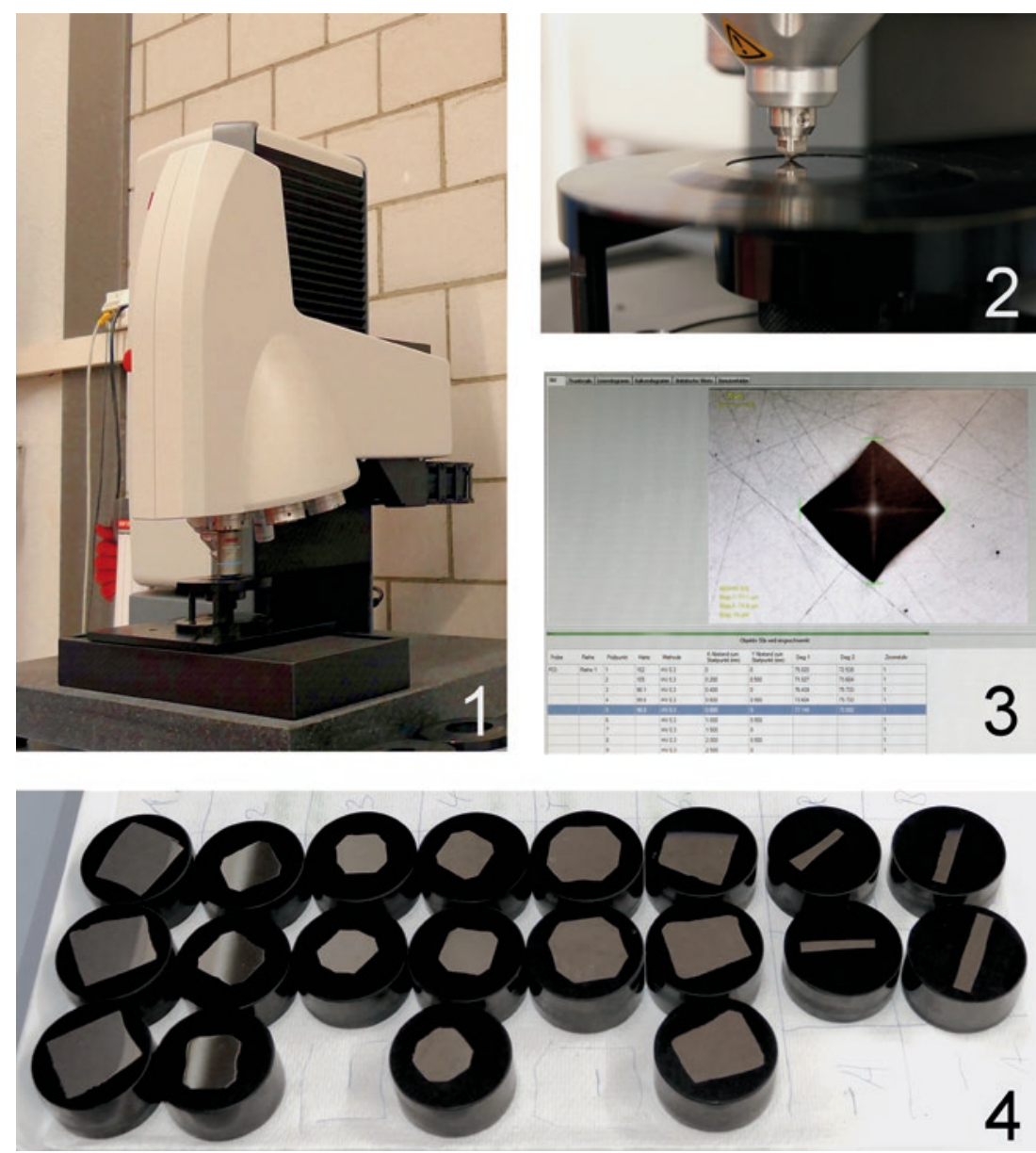

Abb. 112: Bestimmung der Vickers-Härten. 1 = Messgerät «Struers, DuraScan», 2 = Detail mit der Diamant-Pyramide, die von oben auf die polierte Eisenoberfläche gepresst wird, $3=$ Bildanalyse (Grösse) des Diamant-Eindrucks (schwarzer Rhombus) mit Umrechnung auf den Härtegrad (Print-Screen), 4 = die aufgekohlten, polierten Barrenproben, bereit für Härtebestimmungen am Mikroskop.

\section{Unterschiede in den drei verwendeten \\ Weicheisenqualitäten}

Ermittelt man für die drei im Experiment verwendeten «Weicheisen» die Mangan-Durchschnittswerte (Tabelle 8: $\varnothing)$, so zeigt sich, dass dieses Element charakteristisch für das Ausgangsmaterial ist - unbeeinflusst von den Zementationsversuchen. Das «Buttereisen» enthält demzufolge rund 0,115\% Mn, das «Reineisen» 0,146\% Mn und das «Eisen Pivot» mit 0,195\% am meisten Mangan. Dass die letztere Qualität zu besonders guten Aufkohlungsergebnissen geführt hat, könnte allenfalls durch das Mangan begünstigt worden sein (siehe oben mit Anm. 103).

\section{Härtemessungen an den Experimentierbarren}

\section{Methodik}

Für die Messungen wurde die Methode nach Vickers angewendet und dabei ein neues, programmierbares Gerät «DuraScan» der Firma «Struers/Emco-Test» verwendet $\left(\right.$ Abb. 112) ${ }^{572}$. Die Belastung erfolgte bei allen Messungen mit 300 Gramm (HV 0,3). Gemessen wurde auf den polierten Querschnitten (Abb. 112,4). Die Messreihen (gut sicht- bar auf Abb. 119, oben) starteten jeweils 0,09 mm vom Rand entfernt - einerseits so nahe an der Barrenoberfläche wie möglich (höchste Aufkohlung), andererseits nicht allzu nahe, um zu gewährleisten, dass die Messeindrücke nicht abgleiten konnten. Dennoch sind die äussersten Messungen ganz nahe der Barrenoberfläche oft etwas «weicher» ausgefallen als die nächstgelegenen Werte aus der aufgekohlten Randzone (Beispiele Abb. 85; 121). Das liegt nach Aussage von Laborleiter Rudolf Kubiz daran, dass die Diamantspitze des Messgeräts - immer noch sehr nahe am Objektrand - etwas abdriften konnte und dadurch eine $z u$ geringe Härte ermittelte.

\section{Die Härten des unbehandelten Experimentier-} Rohmaterials

Der Kohlenstoffgehalt und das gewählte Härtungsverfahren stehen in einem direkten Verhältnis zueinander. Die Härteunterschiede in unserer kleinen Versuchsserie zwischen «abgeschreckt» und «angelassen» sind allerdings geringer ausgefallen als erwartet (Abb. 85 ff.). Bei höheren Kohlenstoffgehalten würden die Härtedifferenzen viel deutlicher ausfallen (s. unten und z. B. Abb. 100 und 110).

572 https:/ / www.struers.com (17.03.2018). 
Die Überschreitung eines gewissen Härtegrades gibt an, ob wir es mit einem Stahl zu tun haben. Wurde dieser gehärtet, so wird die Härtemessung höher ausfallen als bei geglühtem Stahl. Das Glühen und das Härten führten zu Härtegraden, in denen sich der Kohlenstoffgehalt widerspiegelt ${ }^{573}$. Dieser Umstand ermöglichte es in verschiedenen Materialuntersuchungen, relativ einfach mit Vickersoder Brinell-Härtemessungen zwischen weichem Eisen der Schäfte und Griffe und hartem Stahl an den Schneiden und Spitzen derselben Objekte zu unterscheiden - also indirekt ein Zusammenschweissen dieser beiden Eisenwerkstoffe und einen darauffolgenden Härtungsprozess nachzuwei$\operatorname{sen}^{574}$.

Die drei kohlenstoffarmen, in den Experimenten benutzten Eisenqualitäten sind erwartungsgemäss relativ weich. Sie zeigen im Lieferzustand folgende Härtegrade:

\begin{tabular}{|l|l|}
\hline $\begin{array}{l}\text { R-Serie = Reineisen Angele, 0,0083\% C } \\
\text { (Werkangabe: <0,01\% C; Abb. 113, } \\
\text { 3. Kolonne): }\end{array}$ & $99-117$ HV 0,3575 \\
\hline $\begin{array}{l}\text { B-Serie = Buttereisen Angele } 576,0,028 \% ~ C \\
\text { (Werkangabe: <0,03\% C); Abb. 113, } \\
\text { 2. Kolonne): }\end{array}$ & 135-151 HV 0,3 \\
\hline $\begin{array}{l}\text { P-Serie = Weicheisen «Pivot», 0,006\% C, } \\
\text { Messung 2018 (Abb. 113, 1. Kolonne): }\end{array}$ & $88-105$ HV 0,3 \\
\hline $\begin{array}{l}\text { P-Serie = Weicheisen «Pivot», 0,006\% C, } \\
\text { Messung 2015: }\end{array}$ & $81-104$ HBW577 \\
\hline
\end{tabular}

\section{Die Härten des geglühten und abgeschreckten Experimentier-Rohmaterials}

Obwohl solche Reineisen praktisch keinen Kohlenstoff enthalten und demzufolge nur wenig härtbar sind, wurden Proben dieser drei Eisenqualitäten geglüht (bei $640-660^{\circ} \mathrm{C}$ ) und langsam abgekühlt, respektive rasch abgeschreckt respektive auch abgeschreckt und gelbbraun angelassen (bei $340-355^{\circ} \mathrm{C}$ ). Die darauf erfolgten Härtemessungen zeigten, dass die Roheisen-Proben (R01/R03, B01/B03 und P01/P03) an ihren Aussenseiten durchaus leicht gehärtet werden konnten, wenngleich die aufgekohlten Proben viel höhere Härtegrade erreichten (Tabelle 6; siehe auch oben).

\section{Vergleichende Härtemessungen}

Um dieses Ausgangsmaterial und die experimentellen Aufkohlungsergebnisse (s. unten) untereinander und mit «normalen» Eisen- und Stahlobjekten vergleichen zu können, wurde aus der Literatur die zu erwartende Härte-Bandbreite ermittelt.

Archäometrische Härteuntersuchungen an römischen Eisengeräten ergaben ein Gefälle zwischen weichen (schmiedeeisernen) und harten (stählernen) Zonen von maximal 110 bis 900 Vickers-Härte (HV ${ }^{578}$ resp. 105 bis 855 Brinell-Härte (HBW). Die Obergrenze 900 HV entspricht sehr gut gehärtetem, qualitätsvollem Stahl, wie er nur sel-
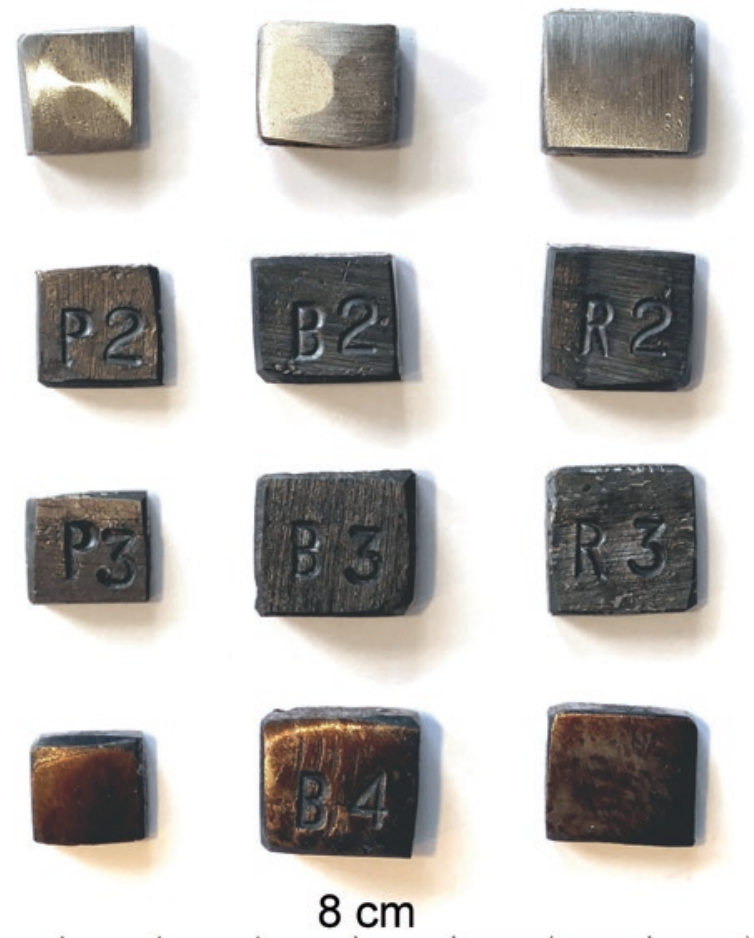

$8 \mathrm{~cm}$

Abb. 113: Die drei für die Aufkohlungsexperimente verwendeten kohlenstoffarmen Weicheisen (P. B.R), noch nicht aufgekohlt, im Härtetest: Kolonnen von links nach rechts: $P=$ Weicheisen Pivot» $(0,006 \% C)$; $B=$ Buttereisen Angele $(C<0,03 \%) ; R=$ Reineisen Angele $(C<0,01)$. Zeilen von oben nach unten: $1=$ Rohzustand, angeschliffen; $2=$ geglüht und langsam im Sand abgekühlt; $3=$ geglüht und im Wasser abgeschreckt; $4=$ geglüht, in Wasser abgeschreckt und angelassen bis gelbbraun (ca. $\left.240^{\circ} \mathrm{C}\right)$. Ergebnisse der Vickers-Härtemessungen und C-/S-Gehalte siehe Tabelle 6. M. 1:1.

573 Oberhoffer 1920, 105 Abb. 104 (Tabelle mit Brinell-Härte in Relation zum Kohlenstoffgehalt); Schaaber 1976/77, 90f. Abb. 1a (Grafik der Vickers-Härte-Streubänder von geglühten und gehärteten Eisenwerkstoffen mit 0,1 bis 0,8\% C). - Vickers-Härten (HV) können zur (vereinfachten) Umrechung zu Brinell-Härten (HBW) mit dem Faktor 0,95 multipliziert werden.

574 Beispiele u.a. bei: Livadefs 1956, 52 ff. Tab. 2 und 112; Schaaber 1977, 230-266 Tab. 2 Abb. 57.

575 Unaufgekohlt, aber dennoch geglüht und abgeschreckt (Werte: Tabelle 6).

576 Fa. Angele Maschinenbau und Schmiedebedarf, D-88416 Ochsenhausen; www.angele-shop.com.

577 Brinell-Härte HBW 2,5/62,5, Mittelwert von jeweils drei gemessenen Einzelstellen. Durchgeführt 2015 in der Georg-Fischer AG in Schaffhausen.

578 Nachgewiesen in verschiedenen Härtemessungen an antiken Originalen, zum Beispiel: Vetters 1966, 174 (250-850 HK [ HV]); Schaaber 1977, 237 Tab. 2; 257 Abb. 57 (104-900 HV 0,5); Epprecht/Schaller 1981, 33 Abb. 1; 2; 4; 7; 17; 18 (127-800 HV); Epprecht/Schaller 1986, 186 (römisches Schmiedeeisen: [70]100-200 MHV); Wagner 1993, 281 (ungehärtet 100-150 HV bei 0,25\% C, kalt gehämmert bis 250 HV); Presslinger et al. 2007, 233 Tab. 4 (92-858 HV). 
ten im Fundgut vorliegt, so zum Beispiel in Form eines quaderförmigen, $80 \times 58 \times 20 \mathrm{~mm}$ messenden Barrens aus Chur/GR-Welschdörfli (Abb.33,46) ${ }^{579}$. Die Untergrenze zeigt sich im Härtebereich von etwa 110-180 HV. In diesem Feld liegen zum Beispiel die zahlreichen Härtemessungen an römischen Schiffsnägeln aus Zwammerdam/NL, die meist zwischen 140 und 250 HV schwanken ${ }^{580}$. Die 13 geprüften Eisen- und Stahlklumpen aus der antiken Verhüttungsstätte in Semlach/A-Eisner in Noricum ergaben Härten zwischen 97 und 408 HV $^{581}$.

Nicht gehärteter Stahl weist nur etwa 86-140 HV 0,3 (105 HBW) auf, wie auch unsere Untersuchungen zeigten. Durchschnittliche, gehärtete antike Werkzeuge ergeben normalerweise Vickers-Härten an Stahl-Arbeitskanten von etwa 220 bis $500 \mathrm{HV}^{582}$. Mit unseren - allerdings teilweise missglückten (Rissbildung) - Rekonstruktionen konnte der untere Wert von 200 HV 0,3 knapp erreicht werden (Tabelle 6).

\section{Härtemessungen an experimentell hergestelltem «Römerstahl»}

Wie erwähnt, erfolgten die Härtemessungen auf polierten Querschnitten der beprobten aufgekohlten Barren mit einem computergesteuerten, programmierbaren VickersMikroskop (Abb. 112). Damit sich die zum Teil sehr nahe beieinanderliegenden Messpunkte nicht gegenseitig beeinträchtigten, wurde in Zickzacklinien gemessen (Tabelle 9: T. resp. Abw.).

Wie zu erwarten war, erwiesen sich die nicht aufgekohlten «Blindproben» R01/R03, B01/B03 und P01/P03 als kaum härtbar (Abb.62-70), wie es für kohlenstoffarme Weicheisen ja auch typisch ist. Die ganz geringen Spuren von Kohlenstoff, die nach Werksangaben und eigenen Analysen im «Weicheisen» enthalten sind, führen dennoch zu signifikanten Härteunterschieden in Relation zu den Kohlenstoffgehalten (Tabellen 6 und 9):

- B01/B03: 0,0281\% C mit $\varnothing 141 \mathrm{HV}$ (relativ viel C)

- R01/R03: 0,0083\% C mit $\varnothing 107 \mathrm{HV}$

- P01/P03: 0,0060\% C mit $\varnothing 95$ HV (relativ wenig C).

Mit anderen Worten: Gibt man einem sehr kohlenstoffarmen Eisen nur 0,03\% Kohlenstoff zu, so erhöht sich seine Vickers-Härte um über 40 Härtegrade - ohne Abschrecken oder dergleichen.

Auch die nicht geglückten Aufkohlungen (R06, R12, P05) wiesen nach dem Abschrecken und dem Anlassen gering erhöhte Härtewerte auf. Dass sich die entsprechenden Eisenoberflächen im Zementationsfeuer trotz eines gewissen Luftzutritts geringfügig verändert haben, zeigen die wenig erhöhten Schwefelwerte und die aussen geringfügig höheren Härtewerte (Abb. 88; 96; 106).

Von den erfolgreich aufgekohlten Eisenproben (R05, B06, B12) sind Härtemessungen möglich, die den Erwar- tungen entsprechen: In nicht geglühtem und nicht abgeschrecktem Zustand ist eine geringe Oberflächenverhärtung festzustellen, die nach innen rasch abnimmt (Abb. 85; 100; 121: blaue Linien). Mit dem Abschrecken allein werden kohlenstoffreiche Stähle zu hart und spröde, um als Werkzeug oder Waffe bestehen zu können. Deshalb werden diese Werkstoffe anschliessend «angelassen», d. h. auf gelbe bis braune Wärme gebracht und erneut in Wasser abgeschreckt, damit sie eine optimale Härte und Elastizität gleichermassen erhalten. Das Abschrecken unserer auf 640-660 ${ }^{\circ} \mathrm{C}$ erhitzten Proben in Wasser führte logischerweise zu stärkeren Härten der Proben (grüne Linien) als die nach dem Abschrecken zusätzlich bei $340-355^{\circ} \mathrm{C}$ angelassenen Stücke (rote Linien).

Wieso Probe R15 dieses typische Muster nicht zeigt (Abb. 118), ist nicht klar. Das Abschrecken führte wie üblich zu einer deutlichen Erhärtung der Metalloberflächen (grüne Linie). Das Anlassen bewirkte jedoch keine erhöhte Elastizität bei leicht verringerter Oberflächenhärte, sondern führte zu einer «Rück-Homogenisierung» auf rund 130-150 HV im ganzen Plattenquerschnitt (rote Linie).

In unseren Experimenten konnten auch einige folgende Relationen zwischen natürlichen Kohlenstoffträgern und erzeugbaren Härten aufgezeigt werden: Mineralischer Graphit als Kohlenstoffträger (Probe B06) führte zu einer praktisch identischen Aufkohlung und Härtbarkeit wie bei den Proben, die mit Holzkohlegranulat zementiert wurden (Probe P06; Tabelle 10). Mit beiden Zuschlägen wurde dieselbe grösste Härte von 210 HV 0,3 erzielt. Auch wenn das Zementationsfeuer von Probe R06 nicht optimal verlief, zeigen die Analysen resp. Härtemessungen, dass auch Knochenasche ein taugliches Aufkohlungsmittel ist.

\section{Fazit der Aufkohlungsexperimente}

Wir lernen aus den Experimenten zur Aufkohlung von Eisen in Lehmumhüllungen Folgendes:

1. Die Lehmumhüllungen müssen aus einem feuerfesten Ton gemacht werden, der das stundenlange Glühen bei rund $1000^{\circ} \mathrm{C}$ aushält.

2. Noch anspruchsvoller ist eine Lehmmischung, die gewissenhaft aufzubereiten ist und die beim Trocknen und beim Glühen keine Risse bildet. Risse waren in unserer Testserie die Hauptursache, dass aus mehreren Proben beim Glühen (Abb. 74; 76) der Kohlenstoff ver-

579 Epprecht/Schaller 1986, 186 (0,9\% C; Martensit durchschnittlich MHV 1000, feinstlammelarer Perlit um MHV 700).

580 Mauri 2012, 54-64 (Ausnahme in einem «Stahlnest»: 356 HV).

581 Birch 2017, Tab. 1.

582 Epprecht/Schaller 1981,32f. Abb. 1; 4; 7; 18; Presslinger/Mayr 2001, 289 Tab. 5. 


\begin{tabular}{|c|c|c|c|c|c|c|c|c|c|}
\hline Probe & M'pt. & HV 0,3 & T. $(\mathrm{mm})$ & $\begin{array}{l}\text { Abw. } \\
(\mathrm{mm})\end{array}$ & Probe & M'pt. & HV 0,3 & T. $(\mathrm{mm})$ & $\begin{array}{l}\text { Abw. } \\
(\mathrm{mm})\end{array}$ \\
\hline R05A & 1 & 124,0 & 0,0 & 0,0 & $\mathrm{R} 06 \mathrm{C}$ & 1 & 127,0 & 0,0 & 0,0 \\
\hline R05A & 2 & 128,0 & 0,2 & 0,5 & R06C & 2 & 132,0 & 0,2 & 0,5 \\
\hline R05A & 3 & 135,0 & 0,4 & 0,0 & $\mathrm{R} 06 \mathrm{C}$ & 3 & 133,0 & 0,4 & 0,0 \\
\hline R05A & 4 & 127,0 & 0,6 & 0,5 & R06C & 4 & 139,0 & 0,6 & 0,5 \\
\hline R05A & 5 & 116,0 & 0,8 & 0,0 & $\mathrm{R} 06 \mathrm{C}$ & 5 & 131,0 & 0,8 & 0,0 \\
\hline R05A & 6 & 112,0 & 1,0 & 0,5 & R06C & 6 & 134,0 & 1,0 & 0,5 \\
\hline R05A & 7 & 97,2 & 1,5 & 0,0 & R06C & 7 & 128,0 & 1,5 & 0,0 \\
\hline R05A & 8 & 82,7 & 2,0 & 0,5 & R06C & 8 & 116,0 & 2,0 & 0,5 \\
\hline R05A & 9 & 86,0 & 2,5 & 0,0 & R06C & 9 & 101,0 & 2,5 & 0,0 \\
\hline R05A & 10 & 80,2 & 3,0 & 0,5 & $\mathrm{R} 06 \mathrm{C}$ & 10 & 107,0 & 3,0 & 0,5 \\
\hline R05A & 11 & 76,0 & 3,5 & 0,0 & R06C & 11 & 97,2 & 3,5 & 0,0 \\
\hline R05A & 12 & 77,4 & 4,0 & 0,5 & $\mathrm{R} 06 \mathrm{C}$ & 12 & 101,0 & 4,0 & 0,5 \\
\hline R05A & 13 & 88,9 & 6,0 & 0,0 & R06C & 13 & 97,4 & 6,0 & 0,0 \\
\hline R05A & 14 & 79,2 & 8,0 & 0,0 & $\mathrm{R} 06 \mathrm{C}$ & 14 & 113,0 & 8,0 & 0,0 \\
\hline R05B & 1 & 129,0 & 0,0 & 0,0 & R12A & 1 & 118,0 & 0,0 & 0,0 \\
\hline R05B & 2 & 161,0 & 0,2 & 0,5 & R12A & 2 & 133,0 & 0,2 & 0,5 \\
\hline R05B & 3 & 165,0 & 0,4 & 0,0 & R12A & 3 & 115,0 & 0,4 & 0,0 \\
\hline R05B & 4 & 183,0 & 0,6 & 0,5 & R12A & 4 & 128,0 & 0,6 & 0,5 \\
\hline R05B & 5 & 186,0 & 0,8 & 0,0 & R12A & 5 & 121,0 & 0,8 & 0,0 \\
\hline R05B & 6 & 173,0 & 1,0 & 0,5 & R12A & 6 & 125,0 & 1,0 & 0,5 \\
\hline R05B & 7 & 129,0 & 1,5 & 0,0 & R12A & 7 & 112,0 & 1,5 & 0,0 \\
\hline R05B & 8 & 113,0 & 2,0 & 0,5 & R12A & 8 & 107,0 & 2,0 & 0,5 \\
\hline R05B & 9 & 117,0 & 2,5 & 0,0 & R12A & 9 & 109,0 & 2,5 & 0,0 \\
\hline R05B & 10 & 122,0 & 3,0 & 0,5 & R12A & 10 & 114,0 & 3,0 & 0,5 \\
\hline R05B & 11 & 118,0 & 3,5 & 0,0 & R12A & 11 & 101,0 & 3,5 & 0,0 \\
\hline R05B & 12 & 114,0 & 4,0 & 0,5 & R12A & 12 & 105,0 & 4,0 & 0,5 \\
\hline R05B & 13 & 110,0 & 6,0 & 0,0 & R12A & 13 & 91,1 & 6,0 & 0,0 \\
\hline R05B & 14 & 107,0 & 8,0 & 0,0 & R12A & 14 & 103,0 & 8,0 & 0,0 \\
\hline R05C & 1 & 128,0 & 0,0 & 0,0 & R12B & 1 & 138,0 & 0,0 & 0,0 \\
\hline R05C & 2 & 123,0 & 0,2 & 0,5 & R12B & 2 & 136,0 & 0,2 & 0,5 \\
\hline R05C & 3 & 119,0 & 0,4 & 0,0 & R12B & 3 & 120,0 & 0,4 & 0,0 \\
\hline R05C & 4 & 123,0 & 0,6 & 0,5 & R12B & 4 & 111,0 & 0,6 & 0,5 \\
\hline R05C & 5 & 114,0 & 0,8 & 0,0 & R12B & 5 & 118,0 & 0,8 & 0,0 \\
\hline R05C & 6 & 118,0 & 1,0 & 0,5 & R12B & 6 & 120,0 & 1,0 & 0,5 \\
\hline R05C & 7 & 114,0 & 1,5 & 0,0 & R12B & 7 & 109,0 & 1,5 & 0,0 \\
\hline R05C & 8 & 98,8 & 2,0 & 0,5 & R12B & 8 & 106,0 & 2,0 & 0,5 \\
\hline R05C & 9 & 103,0 & 2,5 & 0,0 & R12B & 9 & 110,0 & 2,5 & 0,0 \\
\hline R05C & 10 & 94,8 & 3,0 & 0,5 & R12B & 10 & 108,0 & 3,0 & 0,5 \\
\hline R05C & 11 & 97,7 & 3,5 & 0,0 & R12B & 11 & 116,0 & 3,5 & 0,0 \\
\hline R05C & 12 & 97,0 & 4,0 & 0,5 & R12B & 12 & 103,0 & 4,0 & 0,5 \\
\hline R05C & 13 & 104,0 & 6,0 & 0,0 & $\mathrm{R} 12 \mathrm{~B}$ & 13 & 112,0 & 6,0 & 0,0 \\
\hline R05C & 14 & 101,0 & 8,0 & 0,0 & R12B & 14 & 110,0 & 8,0 & 0,0 \\
\hline R06B & 1 & 130,0 & 0,0 & 0,0 & R12C & 1 & 126,0 & 0,0 & 0,0 \\
\hline R06B & 2 & 124,0 & 0,2 & 0,5 & R12C & 2 & 120,0 & 0,2 & 0,5 \\
\hline R06B & 3 & 121,0 & 0,4 & 0,0 & R12C & 3 & 116,0 & 0,4 & 0,0 \\
\hline R06B & 4 & 127,0 & 0,6 & 0,5 & $\mathrm{R} 12 \mathrm{C}$ & 4 & 115,0 & 0,6 & 0,5 \\
\hline R06B & 5 & 110,0 & 0,8 & 0,0 & R12C & 5 & 111,0 & 0,8 & 0,0 \\
\hline R06B & 6 & 107,0 & 1,0 & 0,5 & R12C & 6 & 109,0 & 1,0 & 0,5 \\
\hline R06B & 7 & 111,0 & 1,5 & 0,0 & R12C & 7 & 101,0 & 1,5 & 0,0 \\
\hline R06B & 8 & 106,0 & 2,0 & 0,5 & $\mathrm{R} 12 \mathrm{C}$ & 8 & 115,0 & 2,0 & 0,5 \\
\hline R06B & 9 & 102,0 & 2,5 & 0,0 & R12C & 9 & 105,0 & 2,5 & 0,0 \\
\hline R06B & 10 & 103,0 & 3,0 & 0,5 & R12C & 10 & 101,0 & 3,0 & 0,5 \\
\hline R06B & 11 & 102,0 & 3,5 & 0,0 & $\mathrm{R} 12 \mathrm{C}$ & 11 & 98,4 & 3,5 & 0,0 \\
\hline R06B & 12 & 105,0 & 4,0 & 0,5 & R12C & 12 & 108,0 & 4,0 & 0,5 \\
\hline R06B & 13 & 98,1 & 6,0 & 0,0 & R12C & 13 & 102,0 & 6,0 & 0,0 \\
\hline R06B & 14 & 107,0 & 8,0 & 0,0 & $\mathrm{R} 12 \mathrm{C}$ & 14 & 105,0 & 8,0 & 0,0 \\
\hline
\end{tabular}

\begin{tabular}{|c|c|c|c|c|}
\hline Probe & M'pt. & HV 0,3 & T. $(\mathrm{mm})$ & $\begin{array}{l}\text { Abw. } \\
(\mathrm{mm})\end{array}$ \\
\hline B06B & 1 & 210,0 & 0,0 & 0,0 \\
\hline $\mathrm{B} 06 \mathrm{~B}$ & 2 & 190,0 & 0,2 & 0,5 \\
\hline B06B & 3 & 159,0 & 0,4 & 0,0 \\
\hline B06B & 4 & 184,0 & 0,6 & 0,5 \\
\hline B06B & 5 & 140,0 & 0,8 & 0,0 \\
\hline B06B & 6 & 146,0 & 1,0 & 0,5 \\
\hline B06B & 7 & 139,0 & 1,5 & 0,0 \\
\hline B06B & 8 & 124,0 & 2,0 & 0,5 \\
\hline B06B & 9 & 125,0 & 2,5 & 0,0 \\
\hline B06B & 10 & 109,0 & 3,0 & 0,5 \\
\hline B06B & 11 & 121,0 & 3,5 & 0,0 \\
\hline B06B & 12 & 133,0 & 4,0 & 0,5 \\
\hline B06B & 13 & 128,0 & 6,0 & 0,0 \\
\hline B06B & 14 & 131,0 & 8,0 & 0,0 \\
\hline B06C & 1 & 175,0 & 0,0 & 0,0 \\
\hline $\mathrm{B} 06 \mathrm{C}$ & 2 & 159,0 & 0,2 & 0,5 \\
\hline $\mathrm{B} 06 \mathrm{C}$ & 3 & 168,0 & 0,4 & 0,0 \\
\hline $\mathrm{B} 06 \mathrm{C}$ & 4 & 143,0 & 0,6 & 0,5 \\
\hline $\mathrm{B} 06 \mathrm{C}$ & 5 & 158,0 & 0,8 & 0,0 \\
\hline $\mathrm{B} 06 \mathrm{C}$ & 6 & 130,0 & 1,0 & 0,5 \\
\hline $\mathrm{B} 06 \mathrm{C}$ & 7 & 102,0 & 1,5 & 0,0 \\
\hline B06C & 8 & 97,5 & 2,0 & 0,5 \\
\hline $\mathrm{B} 06 \mathrm{C}$ & 9 & 101,0 & 2,5 & 0,0 \\
\hline $\mathrm{B} 06 \mathrm{C}$ & 10 & 96,8 & 3,0 & 0,5 \\
\hline $\mathrm{B} 06 \mathrm{C}$ & 11 & 108,0 & 3,5 & 0,0 \\
\hline $\mathrm{B} 06 \mathrm{C}$ & 12 & 106,0 & 4,0 & 0,5 \\
\hline $\mathrm{B} 06 \mathrm{C}$ & 13 & 95,7 & 6,0 & 0,0 \\
\hline $\mathrm{B} 06 \mathrm{C}$ & 14 & 96,5 & 8,0 & 0,0 \\
\hline P05A & 1 & 125,0 & 0,0 & 0,0 \\
\hline P05A & 2 & 125,0 & 0,2 & 0,5 \\
\hline P05A & 3 & 120,0 & 0,4 & 0,0 \\
\hline P05A & 4 & 109,0 & 0,6 & 0,5 \\
\hline P05A & 5 & 101,0 & 0,8 & 0,0 \\
\hline P05A & 6 & 95,6 & 1,0 & 0,5 \\
\hline P05A & 7 & 87,9 & 1,5 & 0,0 \\
\hline P05A & 8 & 87,3 & 2,0 & 0,5 \\
\hline P05A & 9 & 92,0 & 2,5 & 0,0 \\
\hline P05A & 10 & 93,0 & 3,0 & 0,5 \\
\hline P05A & 11 & 83,7 & 3,5 & 0,0 \\
\hline P05A & 12 & 87,7 & 4,0 & 0,5 \\
\hline P05A & 13 & 92,6 & 6,0 & 0,0 \\
\hline P05A & 14 & 97,0 & 8,0 & 0,0 \\
\hline P05B & 1 & 119,0 & 0,0 & 0,0 \\
\hline P05B & 2 & 117,0 & 0,2 & 0,5 \\
\hline Р05B & 3 & 113,0 & 0,4 & 0,0 \\
\hline Р05B & 4 & 113,0 & 0,6 & 0,5 \\
\hline P05B & 5 & 115,0 & 0,8 & 0,0 \\
\hline P05B & 6 & 102,0 & 1,0 & 0,5 \\
\hline P05B & 7 & 103,0 & 1,5 & 0,0 \\
\hline P05B & 8 & 95,9 & 2,0 & 0,5 \\
\hline P05B & 9 & 91,8 & 2,5 & 0,0 \\
\hline Р05B & 10 & 93,9 & 3,0 & 0,5 \\
\hline P05B & 11 & 93,3 & 3,5 & 0,0 \\
\hline P05B & 12 & 89,5 & 4,0 & 0,5 \\
\hline P05B & 13 & 90,5 & 6,0 & 0,0 \\
\hline Р05B & 14 & 93,0 & 8,0 & 0,0 \\
\hline
\end{tabular}

Tabelle 9: Aufkohlungsexperimente in Lehmumhüllungen: Vickers-Härten auf den Barrenquerschnitten (Abb. 62-70; 82-121). M'Pt. = Messpunkt;

$T .=$ Tiefe der Messpunkte ab Oberfläche; Abw. = seitliche Abweichung zum ersten Messpunkt (Messpunkte in Zickzacklinie). 


\begin{tabular}{|c|c|c|c|c|c|c|c|c|c|}
\hline Probe & M'pt. & HV 0,3 & T. $(\mathrm{mm})$ & $\begin{array}{l}\text { Abw. } \\
(\mathrm{mm})\end{array}$ & Probe & M'pt. & HV 0,3 & T. $(\mathrm{mm})$ & $\begin{array}{l}\text { Abw. } \\
(\mathrm{mm})\end{array}$ \\
\hline P05C & 1 & 117 & 0 & 0 & P06B & 19 & 134,0 & 20,8 & 0,0 \\
\hline P05C & 2 & 109 & 0,2 & 0,5 & P06B & 20 & 142,0 & 21,3 & 0,5 \\
\hline P05C & 3 & 107 & 0,4 & 0 & P06B & 21 & 186,0 & 21,5 & 0,0 \\
\hline P05C & 4 & 102 & 0,6 & 0,5 & P06B & 22 & 147,0 & 21,7 & 0,5 \\
\hline P05C & 5 & 95 & 0,8 & 0 & P06B & 23 & 136,0 & 21,8 & 0,0 \\
\hline P05C & 6 & 97,9 & 1 & 0,5 & P06B & 24 & 138,0 & 22,1 & 0,5 \\
\hline P05C & 7 & 90,9 & 1,5 & 0 & P06C & 1 & 174,0 & 0,0 & 0,0 \\
\hline P05C & 8 & 85,6 & 2 & 0,5 & P06C & 2 & 210,0 & 0,2 & 0,5 \\
\hline $\mathrm{P} 05 \mathrm{C}$ & 9 & 83,4 & 2,5 & 0 & P06C & 3 & 180,0 & 0,4 & 0,0 \\
\hline P05C & 10 & 83,9 & 3 & 0,5 & $\mathrm{P} 06 \mathrm{C}$ & 4 & 187,0 & 0,6 & 0,5 \\
\hline P05C & 11 & 87,3 & 3,5 & 0 & P06C & 5 & 146,0 & 0,8 & 0,0 \\
\hline P05C & 12 & 89,7 & 4 & 0,5 & P06C & 6 & 129,0 & 1,0 & 0,5 \\
\hline P05C & 13 & 89,9 & 6 & 0 & $\mathrm{P} 06 \mathrm{C}$ & 7 & 122,0 & 1,5 & 0,0 \\
\hline P05C & 14 & 85,2 & 8 & 0 & $\mathrm{P} 06 \mathrm{C}$ & 8 & 99,1 & 2,0 & 0,5 \\
\hline P06A & 1 & 198,0 & 0,0 & 0,0 & $\mathrm{P} 06 \mathrm{C}$ & 9 & 98,8 & 2,5 & 0,0 \\
\hline P06A & 2 & 181,0 & 0,2 & 0,5 & P06C & 10 & 98,8 & 3,0 & 0,5 \\
\hline P06A & 3 & 174,0 & 0,4 & 0,0 & P06C & 11 & 102,0 & 3,5 & 0,0 \\
\hline P06A & 4 & 156,0 & 0,6 & 0,5 & $\mathrm{P} 06 \mathrm{C}$ & 12 & 104,0 & 4,0 & 0,5 \\
\hline P06A & 5 & 128,0 & 0,8 & 0,0 & $\mathrm{P} 06 \mathrm{C}$ & 13 & 101,0 & 8,0 & 0,0 \\
\hline P06A & 6 & 130,0 & 1,0 & 0,5 & P06C & 14 & 94,5 & 12,0 & 0,6 \\
\hline P06A & 7 & 100,0 & 1,5 & 0,0 & P06C & 15 & 101,0 & 18,8 & 0,0 \\
\hline P06A & 8 & 125,0 & 2,0 & 0,5 & $\mathrm{P} 06 \mathrm{C}$ & 16 & 92,0 & 20,3 & 0,6 \\
\hline P06A & 9 & 114,0 & 2,5 & 0,0 & P06C & 17 & 98,4 & 20,8 & 0,1 \\
\hline P06A & 10 & 103,0 & 3,0 & 0,5 & P06C & 18 & 116,0 & 21,3 & 0,6 \\
\hline P06A & 11 & 106,0 & 3,5 & 0,0 & P06C & 19 & 146,0 & 21,8 & 0,1 \\
\hline P06A & 12 & 117,0 & 4,0 & 0,5 & $\mathrm{P} 06 \mathrm{C}$ & 20 & 146,0 & 22,3 & 0,6 \\
\hline P06A & 13 & 99,3 & 8,0 & 0,0 & P06C & 21 & 161,0 & 22,5 & 0,1 \\
\hline P06A & 14 & 106,0 & 12,0 & 0,6 & $\mathrm{P} 06 \mathrm{C}$ & 22 & 168,0 & 22,7 & 0,6 \\
\hline P06A & 15 & 91,8 & 18,8 & 0,0 & P06C & 23 & 177,0 & 22,9 & 0,1 \\
\hline P06A & 16 & 88,5 & 19,3 & 0,5 & $\mathrm{P} 06 \mathrm{C}$ & 24 & 153,0 & 23,0 & 0,6 \\
\hline P06A & 17 & 84,3 & 19,8 & 0,0 & R15B & 1 & 233,0 & 0,0 & 0,0 \\
\hline P06A & 18 & 166,0 & 20,3 & 0,5 & R15B & 2 & 260,0 & 0,2 & 0,5 \\
\hline P06A & 19 & 123,0 & 20,8 & 0,0 & R15B & 3 & 226,0 & 0,4 & 0,0 \\
\hline P06A & 20 & 127,0 & 21,3 & 0,5 & R15B & 4 & 231,0 & 0,6 & 0,5 \\
\hline P06A & 21 & 140,0 & 21,5 & 0,0 & R15B & 5 & 187,0 & 0,8 & 0,0 \\
\hline P06A & 22 & 139,0 & 21,7 & 0,5 & R15B & 6 & 168,0 & 1,0 & 0,5 \\
\hline P06A & 23 & 135,0 & 21,9 & 0,0 & R15B & 7 & 141,0 & 1,2 & 0,0 \\
\hline P06A & 24 & 147,0 & 22,0 & 0,5 & R15B & 8 & 134,0 & 1,4 & 0,5 \\
\hline P06B & 1 & 199,0 & 0,0 & 0,0 & R15B & 9 & 144,0 & 1,6 & 0,0 \\
\hline P06B & 2 & 184,0 & 0,2 & 0,5 & R15B & 10 & 120,0 & 1,8 & 0,5 \\
\hline P06B & 3 & 193,0 & 0,4 & 0,0 & R15B & 11 & 133,0 & 2,0 & 0,0 \\
\hline P06B & 4 & 174,0 & 0,6 & 0,5 & R15B & 12 & 142,0 & 2,2 & 0,5 \\
\hline P06B & 5 & 171,0 & 0,8 & 0,0 & R15B & 13 & 126,0 & 2,4 & 0,0 \\
\hline P06B & 6 & 133,0 & 1,0 & 0,5 & R15B & 14 & 198,0 & 2,6 & 0,5 \\
\hline P06B & 7 & 122,0 & 1,5 & 0,0 & R15B & 15 & 144,0 & 2,8 & 0,0 \\
\hline P06B & 8 & 111,0 & 2,0 & 0,5 & R15B & 16 & 168,0 & 3,0 & 0,5 \\
\hline P06B & 9 & 112,0 & 2,5 & 0,0 & R15B & 17 & 165,0 & 3,2 & 0,0 \\
\hline P06B & 10 & 110,0 & 3,0 & 0,5 & R15B & 18 & 168,0 & 3,4 & 0,5 \\
\hline P06B & 11 & 102,0 & 3,5 & 0,0 & R15B & 19 & 206,0 & 3,5 & 0,0 \\
\hline P06B & 12 & 106,0 & 4,0 & 0,5 & R15C & 1 & 106,0 & 0,0 & 0,0 \\
\hline P06B & 13 & 96,5 & 8,0 & 0,0 & R15C & 2 & 143,0 & 0,2 & 0,5 \\
\hline P06B & 14 & 99,8 & 12,0 & 0,6 & R15C & 3 & 153,0 & 0,4 & 0,0 \\
\hline P06B & 15 & 110,0 & 18,8 & 0,0 & R15C & 4 & 160,0 & 0,6 & 0,5 \\
\hline P06B & 16 & 118,0 & 19,3 & 0,5 & R15C & 5 & 148,0 & 0,8 & 0,0 \\
\hline P06B & 17 & 118,0 & 19,8 & 0,0 & R15C & 6 & 140,0 & 1,0 & 0,5 \\
\hline P06B & 18 & 120,0 & 20,3 & 0,5 & R15C & 7 & 128,0 & 1,2 & 0,0 \\
\hline
\end{tabular}

\begin{tabular}{|c|c|c|c|c|}
\hline Probe & M'pt. & HV 0,3 & T. $(\mathrm{mm})$ & $\begin{array}{l}\text { Abw. } \\
(\mathrm{mm})\end{array}$ \\
\hline R15C & 8 & 126,0 & 1,4 & 0,5 \\
\hline $\mathrm{R} 15 \mathrm{C}$ & 9 & 131,0 & 1,6 & 0,0 \\
\hline R15C & 10 & 120,0 & 1,8 & 0,5 \\
\hline R15C & 11 & 133,0 & 2,0 & 0,0 \\
\hline $\mathrm{R} 15 \mathrm{C}$ & 12 & 174,0 & 2,2 & 0,5 \\
\hline R15C & 13 & 130,0 & 2,4 & 0,0 \\
\hline R15C & 14 & 131,0 & 2,6 & 0,5 \\
\hline $\mathrm{R} 15 \mathrm{C}$ & 15 & 150,0 & 2,8 & 0,0 \\
\hline $\mathrm{R} 15 \mathrm{C}$ & 16 & 127,0 & 3,0 & 0,5 \\
\hline R15C & 17 & 152,0 & 3,2 & 0,0 \\
\hline R15C & 18 & 138,0 & 3,4 & 0,5 \\
\hline $\mathrm{R} 15 \mathrm{C}$ & 19 & 146,0 & 3,5 & 0,0 \\
\hline $\mathrm{R} 15 \mathrm{C}$ & 20 & 115,0 & 3,8 & 0,5 \\
\hline B15B & 1 & 195 & 0 & 0 \\
\hline B15B & 2 & 196 & 0,2 & 0,5 \\
\hline B15B & 3 & 178 & 0,4 & 0 \\
\hline B15B & 4 & 176 & 0,6 & 0,5 \\
\hline B15B & 5 & 169 & 0,8 & 0 \\
\hline B15B & 6 & 137 & 1 & 0,5 \\
\hline B15B & 7 & 112 & 1,2 & 0 \\
\hline B15B & 8 & 145 & 1,4 & 0,5 \\
\hline B15B & 9 & 125 & 1,6 & 0 \\
\hline B15B & 10 & 110 & 1,8 & 0,5 \\
\hline B15B & 11 & 106 & 2 & 0 \\
\hline B15B & 12 & 105 & 2,2 & 0,5 \\
\hline B15B & 13 & 102 & 2,4 & 0 \\
\hline B15B & 14 & 112 & 2,6 & 0,5 \\
\hline B15B & 15 & 106 & 2,8 & 0 \\
\hline B15B & 16 & 108 & 3 & 0,5 \\
\hline B15B & 17 & 106 & 3,2 & 0 \\
\hline B15B & 18 & 103 & 3,4 & 0,5 \\
\hline B15B & 19 & 97,2 & 3,546 & 0 \\
\hline B15B & 20 & 110 & 3,8 & 0,5 \\
\hline B15B & 21 & 108 & 4 & 0 \\
\hline B15B & 22 & 105 & 4,2 & 0,5 \\
\hline B15B & 23 & 109 & 4,4 & 0 \\
\hline B15B & 24 & 109 & 4,6 & 0,5 \\
\hline B15B & 25 & 121 & 4,8 & 0 \\
\hline B15B & 26 & 114 & 5 & 0,5 \\
\hline B15B & 27 & 126 & 5,2 & 0 \\
\hline B15B & 28 & 121 & 5,4 & 0,5 \\
\hline B15B & 29 & 121 & 5,6 & 0 \\
\hline B15B & 30 & 129 & 5,8 & 0,5 \\
\hline B15B & 31 & 84,1 & 6 & 0 \\
\hline B15C & 1 & 148,0 & 0,0 & 0,0 \\
\hline B15C & 2 & 168,0 & 0,2 & 0,5 \\
\hline B15C & 3 & 182,0 & 0,4 & 0,0 \\
\hline B15C & 4 & 158,0 & 0,6 & 0,5 \\
\hline B15C & 5 & 138,0 & 0,8 & 0,0 \\
\hline B15C & 6 & 121,0 & 1,0 & 0,5 \\
\hline B15C & 7 & 105,0 & 1,2 & 0,0 \\
\hline $\mathrm{B} 15 \mathrm{C}$ & 8 & 99,3 & 1,4 & 0,5 \\
\hline B15C & 9 & 93,9 & 1,6 & 0,0 \\
\hline B15C & 10 & 95,4 & 1,8 & 0,5 \\
\hline B15C & 11 & 92,8 & 2,0 & 0,0 \\
\hline B15C & 12 & 87,0 & 2,2 & 0,5 \\
\hline
\end{tabular}

Tabelle 9: Vickers-Härten auf den Barrenquerschnitten, Fortsetzung. 


\begin{tabular}{|c|c|c|c|c|}
\hline Probe & M'pt. & HV 0,3 & T. (mm) & $\begin{array}{l}\text { Abw. } \\
(\mathrm{mm})\end{array}$ \\
\hline B15C & 13 & 88,1 & 2,4 & 0,0 \\
\hline B15C & 14 & 90,5 & 2,6 & 0,5 \\
\hline B15C & 15 & 95,7 & 2,8 & 0,0 \\
\hline B15C & 16 & 94,6 & 3,0 & 0,5 \\
\hline B15C & 17 & 112,0 & 3,2 & 0,0 \\
\hline B15C & 18 & 105,0 & 3,4 & 0,5 \\
\hline B15C & 19 & 114,0 & 3,5 & 0,0 \\
\hline B15C & 20 & 126,0 & 3,8 & 0,5 \\
\hline B15C & 21 & 151,0 & 4,0 & 0,0 \\
\hline B15C & 22 & 158,0 & 4,2 & 0,5 \\
\hline B15C & 23 & 173,0 & 4,4 & 0,0 \\
\hline B15C & 24 & 184,0 & 4,6 & 0,5 \\
\hline B15C & 25 & 179,0 & 4,7 & $-0,0$ \\
\hline B15C & 26 & 130,0 & 4,9 & 0,6 \\
\hline R03 & 1 & 111,0 & 0,0 & 0,0 \\
\hline R03 & 2 & 117,0 & 0,2 & 0,5 \\
\hline R03 & 3 & 112,0 & 0,4 & 0,0 \\
\hline R03 & 4 & 109,0 & 0,6 & 0,5 \\
\hline R03 & 5 & 109,0 & 0,8 & 0,0 \\
\hline R03 & 6 & 116,0 & 1,0 & 0,5 \\
\hline R03 & 7 & 105,0 & 1,5 & 0,0 \\
\hline R03 & 8 & 102,0 & 2,0 & 0,5 \\
\hline R03 & 9 & 102,0 & 2,5 & 0,0 \\
\hline R03 & 10 & 98,6 & 3,0 & 0,5 \\
\hline R03 & 11 & 103,0 & 3,5 & 0,0 \\
\hline R03 & 12 & 102,0 & 4,0 & 0,5 \\
\hline R03 & 13 & 110,0 & 6,0 & 0,0 \\
\hline R03 & 14 & 101,0 & 8,0 & 0,0 \\
\hline B03 & 1 & 138,0 & 0,0 & 0,0 \\
\hline B03 & 2 & 137,0 & 0,2 & 0,5 \\
\hline B03 & 3 & 137,0 & 0,4 & 0,0 \\
\hline B03 & 4 & 133,0 & 0,6 & 0,5 \\
\hline B03 & 5 & 148,0 & 0,8 & 0,0 \\
\hline B03 & 6 & 142,0 & 1,0 & 0,5 \\
\hline B03 & 7 & 147,0 & 1,5 & 0,0 \\
\hline B03 & 8 & 146,0 & 2,0 & 0,5 \\
\hline B03 & 9 & 151,0 & 2,5 & 0,0 \\
\hline $\mathrm{B} 03$ & 10 & 147,0 & 3,0 & 0,5 \\
\hline B03 & 11 & 136,0 & 3,5 & 0,0 \\
\hline B03 & 12 & 135,0 & 4,0 & 0,5 \\
\hline B03 & 13 & 138,0 & 6,0 & 0,0 \\
\hline B03 & 14 & 144,0 & 8,0 & 0,0 \\
\hline P03 & 1 & 102,0 & 0,0 & 0,0 \\
\hline P03 & 2 & 105,0 & 0,2 & 0,5 \\
\hline P03 & 3 & 96,1 & 0,4 & 0,0 \\
\hline P03 & 4 & 99,8 & 0,6 & 0,5 \\
\hline P03 & 5 & 98,8 & 0,8 & 0,0 \\
\hline P03 & 6 & 90,1 & 1,0 & 0,5 \\
\hline P03 & 7 & 94,3 & 1,5 & 0,0 \\
\hline P03 & 8 & 90,9 & 2,0 & 0,5 \\
\hline P03 & 9 & 89,3 & 2,5 & 0,0 \\
\hline P03 & 10 & 94,3 & 3,0 & 0,5 \\
\hline P03 & 11 & 87,9 & 3,5 & 0,0 \\
\hline P03 & 12 & 86,6 & 4,0 & 0,5 \\
\hline P03 & 13 & 88,9 & 6,0 & 0,0 \\
\hline P03 & 14 & 104,0 & 8,0 & 0,0 \\
\hline
\end{tabular}

\begin{tabular}{|c|c|c|c|c|}
\hline Probe & C-Träger & Aufkohlung* & HV max. & C \\
\hline B06.00-01 & \multirow{4}{*}{ Graphit } & \multirow{4}{*}{$1,6 \mathrm{~mm}$} & $210 \mathrm{HV} 0,3$ & 0.35500 \\
\hline B06.01-02 & & & 139 HV 0,3 & 0.0889 \\
\hline B06.03-04 & & & $133 \mathrm{HV} 0,3$ & 0.0417 \\
\hline B06.11 & & & $131 \mathrm{HV} 0,3$ & 0.0285 \\
\hline P06.00-01 & \multirow{5}{*}{ Holzkohle } & \multirow{5}{*}{$1,4 \mathrm{~mm}$} & $210 \mathrm{HV} 0,3$ & 0.387 \\
\hline P06.01-02 & & & $133 \mathrm{HV} 0,3$ & 0.0810 \\
\hline P06.03-04 & & & 117 HV 0,3 & 0.0460 \\
\hline P06.09 & & & $106 \mathrm{HV} 0,3$ & 0.00641 \\
\hline P06.12 & & & $96 \mathrm{HV} 0,3$ & 0.00407 \\
\hline R05.00-01 & \multirow{4}{*}{ Holzkohle } & \multirow{4}{*}{$1,2 \mathrm{~mm}$} & $186 \mathrm{HV} 0,3$ & 0.0310 \\
\hline R05.01-02 & & & 173 HV 0,3 & 0.0156 \\
\hline R05.03-04 & & & $122 \mathrm{HV} 0,3$ & 0.0103 \\
\hline R05.09 & & & 110 HV 0,3 & 0.00643 \\
\hline P05.00-01 & \multirow{3}{*}{ Holzkohle } & \multirow{3}{*}{$0,8 \mathrm{~mm}$} & $125 \mathrm{HV} 0,3$ & 0.00760 \\
\hline P05.01-02 & & & $103 \mathrm{HV} 0,3$ & 0.00577 \\
\hline P05.03-04 & & & $94 \mathrm{HV} 0,3$ & 0.00525 \\
\hline R12.00-01 & \multirow{3}{*}{ Holzkohle } & \multirow{3}{*}{$0,4-1,0 \mathrm{~mm}$} & $138 \mathrm{HV} 0,3$ & 0.0112 \\
\hline R12.01-02 & & & $120 \mathrm{HV} 0,3$ & 0.0131 \\
\hline R12.09 & & & 112 HV 0,3 & 0.00732 \\
\hline R06.00-01 & \multirow{3}{*}{$\begin{array}{l}\text { Knochen- } \\
\text { asche }\end{array}$} & \multirow{3}{*}{$0,5 \mathrm{~mm}, \mathrm{Z}$} & 139 HV 0,3 & 0.0162 \\
\hline R06.01-02 & & & $128 \mathrm{HV} 0,3$ & 0.00993 \\
\hline R06.09 & & & $101 \mathrm{HV} 0,3$ & 0.0106 \\
\hline B 15R & \multirow{2}{*}{ Holzkohle } & \multirow{2}{*}{$1,3 \mathrm{~mm}$} & $196 \mathrm{HV} 0,3$ & 0.303 \\
\hline B $15 Z$ & & & $91 \mathrm{HV} 0,3$ & 0.198 \\
\hline R15R & \multirow{2}{*}{ Holzkohle } & \multirow{2}{*}{$1,2 \mathrm{~mm}$} & $260 \mathrm{HV} \mathrm{0,3}$ & 0.0335 \\
\hline R15Z & & & 115 HV 0,3 & 0.0471 \\
\hline
\end{tabular}

Tabelle 10: Aufkohlungsexperimente in Lehmumhüllungen: Relation zwischen Kohlenstoffart und Stahlhärten (Auszug aus Tabelle 6). Infolge mehrerer gescheiterter Aufkohlungsversuche - Rissbildung (Abb. 76) und Sauerstoffzutritt - lässt sich lediglich aussagen, dass sich Holzkohle und Knochenasche als Kohlenstoffträger eignen und dass der schwerer zu beschaffende Graphit ein noch vorzüglicherer Wirkstoff wäre.

${ }^{*}$ mikroskopischer Befund.

Tabelle 9: Vickers-Härten auf den Barrenquerschnitten, Fortsetzung. 
brennen und entweichen konnte und die darin eingebetteten Eisenbarren keine Aufkohlung erfuhren.

3. Die erforderliche Glühdauer darf nicht unterschätzt werden. Die in unserem Experiment realisierte Glühdauer von $7 \frac{1}{2}$ Stunden (bei $\pm 1000^{\circ} \mathrm{C}$ ) führte im Idealfall (Probe P06, Abb.72) zu einer Eindringtiefe des Kohlenstoffs von maximal 1-3 mm (Abb. 82-85; 98100; 107-110). Das genügt für eine Oberflächenhärtung, zum Beispiel für ein fertig geschmiedetes Werkzeug (Beispiel Abb. 114). Will man relativ homogenen Stahl, müsste man dünnere Platten während rund zwei Tagen zementieren, die dann fast durchgehend Kohlenstoff aufnehmen könnten.

4. Die kürzere Glühdauer von nur $4 \frac{1}{2}$ Stunden (statt 71/2) unserer Proben R12 und B07 lässt sich - wegen Sauerstoffzutritt in den gerissenen Lehmumhüllungen nicht abschliessend mit der restlichen Serie vergleichen: Während der Eisenbarren B07 optisch eine geringfügige Aufkohlung erkennen lässt (Abb.101), zeigt Barren R12 weder optisch noch chemisch eine oberflächliche Kohlenstoffanreicherung. Er ist aber dennoch aussen leicht härter als innen geworden (Abb.93-96). Beide «Halbzeit-Barren» R12 und B07 waren mit Holzkohlepulver beschichtet und zementiert worden.

5. Die Wahl des Kohlenstoffträgers erscheint sekundär. Holzkohle gilt sicher als das verlässlichste Material erster Wahl und wird nicht zuletzt deshalb auch in den meisten Rezepten angegeben (siehe oben Seiten 112 113). Weil einige unserer Experimente infolge Rissbildung missraten sind, kann nicht jeder kohlenstoffhaltige Zuschlagstoff auf seine Eignung beurteilt werden. Immerhin erwies sich auch Graphit als sehr zuverlässiges und wirksames Aufkohlungsmittel, in weniger deutlichem Masse auch Knochenasche (Tabelle 10).

6. Möglicherweise wären unsere Experimente erfolgreicher verlaufen, wenn wir den erwähnten Kohlenstoffträgern auch Salz beigemischt hätten (siehe oben nach Anm.535). Salz «accélère la réaction et qui est encore présent aujourd'hui dans les céments commerciaux»583.

7. Wegen «Anfängerfehlern» des Experimentators verliefen viele Experimente mit Lehmumhüllungen unbefriedigend. Es ist daher kein Wunder, dass im kompakt verschlossenen Tiegel bessere Aufkohlungsergebnisse erzielt worden sind (Abb.116-121). Optimierte Umhüllungen würden jedoch zu gleich guten Ergebnissen führen und wären erst noch flexibler bezüglich Barrenform und -grösse. Würden unsere im Tiegel aufgestählten Platten R15 oder B15 lagenweise aufeinander geschweisst und zu Werkzeugen oder Waffen geschmiedet, hätte man einen damastähnlichen Lagenstahl von guter Qualität!

8. Im Vergleich der originalen, beige bis braun gebrannten Lehmumhüllungen (Abb.50; 51) sind die rekon- struierten gebrannten Stücke (Abb.76; 77) bisweilen dunkel reduziert, vor allem wenn die Umhüllung beim Brand intakt und dicht blieb (Abb. 78). Dass die Originale auch innen beige-braun sind, könnte darauf zurückzuführen sein, dass sie noch sehr heiss aufgeschlagen wurden und danach auch inwendig etwas oxidierten.

Die Erfahrungen und Schlussfolgerungen machen bewusst, dass in der Experimentellen Archäologie, vor allem wenn «ausgestorbene» Technologien erkundet werden sollen, die mangelnde Erfahrung und Routine der Experimentatorinnen und Experimentatoren nur ansatzweise repräsentative Angaben zu Zeitaufwand, Energiebedarf, Qualität usw. der Endprodukte erlauben im Hinblick auf das (in der Antike) Machbare. Bei noch nicht ganz «ausgestorbenen» handwerklichen Arbeiten können wir immerhin noch alte Meister ${ }^{584}$ oder «Traditionalisten» in der Dritten Welt ${ }^{585}$ befragen, «wie es früher war». Mit anderen Worten: Auf der Basis langer Erfahrung und optimierter Produktionsbedingungen (Lehmumhüllungen, Zementationsdauer etc.) sind in Augusta Raurica sicher bessere Stähle - mit höherem Kohlenstoffgehalt in grösserer Tiefe der Eisenbarren - gelungen. Als heutige Experimentatoren müssen wir akzeptieren, dass wir beim Rekonstruieren alter, ausgestorbener Handwerkstechniken wie Lehrlinge wieder «bei null» beginnen müssen.

583 Halleux 2007, 1315 Anm. 51

584 So in der von Paul Hugger (1930-2016) begründeten Reihe «Sterbendes Handwerk» (ab 1972 «Altes Handwerk») der Schweizerischen Gesellschaft für Volkskunde (Abteilung Film). In ihr sind zwischen 1963 und 2003 - viele Hefte (und meist auch darauf abgestimmte Dokumentarfilme) über 67 verschiedene Handwerke erschienen. Die Reihe ist leider eingestellt worden 585 Zum Beispiel: Gardi 1969; Knöpfli 1997; Furger 2017. 


\section{«Experiment Theophilus»}

Das oben (mit Anm.335) zitierte Rezept von Theophilus Presbyter ist wohl zwischen 1100 und 1130 niedergeschrieben worden. Es beschreibt die Aufkohlung von kleinen, fertig hergestellten Feilen aus weichem Eisen: Zur Vorbereitung sind sie mit «altem Schweineschmalz» einzuschmieren und anschliessend mit «Bockleder-Streifchen» zu umwickeln und ebenso mit Leinenfaden. Um jede so eingewickelte Feile ist eine Hülle aus «durchgeknetetem Ton» zu formen. Nach dem Trocknen wird in einem kräftig belüfteten Feuer gebrannt, «bis das Leder verbrennt». Dass das Eisenstück nach dem Abschrecken in Wasser einfach «herausgenommen» werden soll, wird dadurch ermöglicht, dass die Angel nicht mit Ton bedeckt sein soll und die Lehmhülle oben offen belassen wurde.

Die Möglichkeit, hier ein genau nach der Presbyter'schen Anleitung aufgekohltes Eisenstück vorstellen zu dürfen und am Endprodukt die Härte zu testen, verdanke ich Markus Binggeli ${ }^{586}$. Er schmiedete einen römischen Nagelschaft mit quadratischem Querschnitt zu einem Meisselchen resp. einer Schrotpunze (Abb.114, rechts), umhüllte es mit Schweineschmalz und Lederstreifchen, umwickelte alles dicht mit einer Schnur und umhüllte das Paket mit einem hitzebeständigen Ton, so dass das MeisselOberteil etwas oben herausragte. Das Ganze wurde dann im offenen Holzkohlefeuer während einer halben Stunde rotglühend gehalten, bis die Oberfläche der Lehmumhüllung ganz leicht versinterte. Das kleine Werkzeug wurde noch hellrot glühend herausgezogen und im Wasser abgeschreckt. Danach wurde es im Feuer gelbbraun angelassen $^{587}$. Auch die verkohlten Lederreste liessen sich aus der Lehmhülle herausklopfen (Abb. 114).

Vom mir überlassenen Material konnte im Labor leider nicht die Brinell- oder Vickers-Härte ermittelt werden. Als simplen Test habe ich jedoch die Oberfläche des Meisselchens (Abb. 114, rechts) mit einer Reissnadel, einem Stichel und einem Diamanten geritzt: einerseits oben am Schaft und andererseits unten nahe der gehärteten Schneide. Der Unterschied ist deutlich: der wenig aufgekohlte Schaft lässt sich gut sichtbar ritzen, im gehärteten Schneidebereich sind die Spuren makroskopisch jedoch nicht erkennbar.

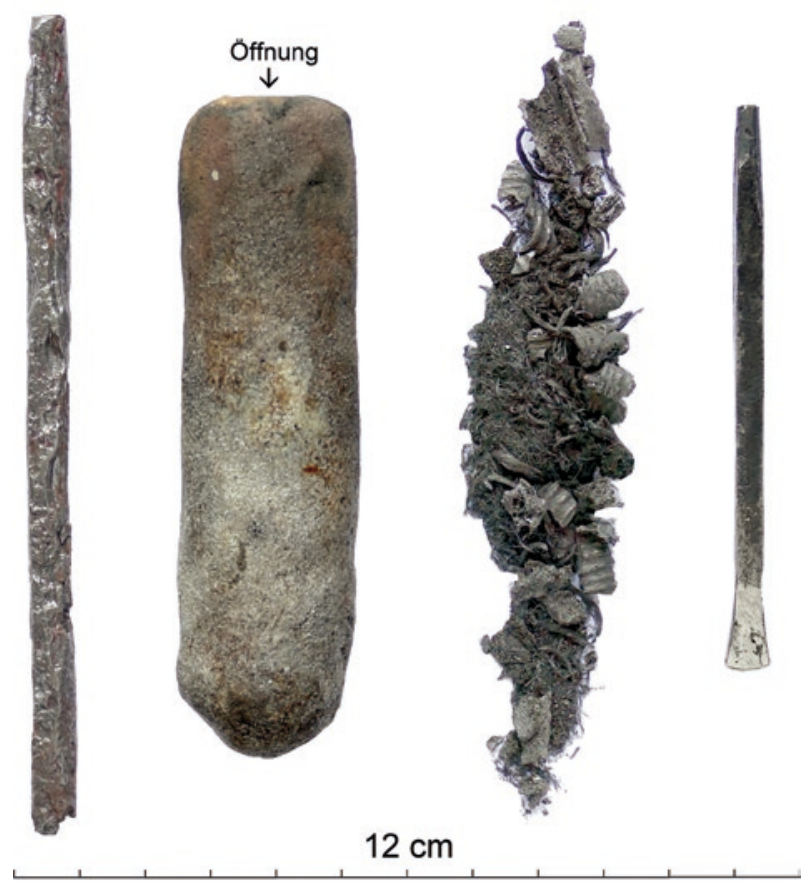

Abb. 114: Aufkohlungsexperiment nach Theophilus Presbyter (historisches Rezept siehe Seite 56), durchgeführt durch Markus Binggeli. V. l.n.r.: römischer Eisennagel als Ausgangsmaterial für einen kleinen geschmiedeten Meissel (ganz rechts), Lehmumhüllung nach einer halben Stunde bei Rotglut (Öffnung oben, nicht sichtbar), verkohlte Rückstände der Umhüllung mit Schweinefett, Leder und Schnur, der aufgekohlte Meissel (Härtetest siehe Text). M.2:3
586 Gold- und Bronzeschmied, Spezialist für frühe Metalltechnik. Gaselstrasse 30, CH-3098 Schliern bei Köniz, E-Mail: binggelim@ sunrise.ch.

587 Theophilus gibt im Buch 3, Kap. 18, dieses Verfahren für kleine Feilen, die nach dem Härten nicht angelassen werden, nur im Feuer getrocknet, wobei ein Trocknen bei höherer Temperatur auch einen Anlasseffekt haben kann (Brepohl 1987, 80). 


\section{Aufkohlung in Tiegeln}

Aus historischen Quellen wissen wir, dass oft auch in Tiegeln oder sonstigen Keramikgefässen - statt mit direkt aufgebrachten Lehmumhüllungen - aufgekohlt wurde ${ }^{588}$. Ich habe auch diese Methode in einem kleinen «Neben-Experiment» nachvollzogen. Zwei interessante Befunde von Gefässen, gefüllt mit Hunderten von römischen Schuhnägeln aus Augusta Raurica (Abb.122, oben), sollen anschliessend als mögliche Zeugnisse eines Massenhärtungsprozesses zur Diskussion gestellt werden.

\section{Experiment}

\section{Durchführung}

Als kleines, parallel zu den obigen Experimenten vollzogenes Projekt wurden einige Weicheisen-Platten (Abb. 61, unten links; 115,1) mit Holzkohle umhüllt (Abb. 115,3.4). Verwendet wurden die Platten B13-B15 («Buttereisen» mit ca. 0,03\% C) und R13-R15 («Reineisen» mit max. 0,01\% C). Statt diese in einer Lehmumhüllung abzudichten, wurden sechs mit Hilfe kleiner Stoffstücke in Holzkohle eingepackte Platten dicht aufeinandergeschichtet vertikal in einen Tiegel gepackt (Abb. 115,6). Der Tiegel misst $110 \mathrm{~mm}$ im Durchmesser und ist $132 \mathrm{~mm}$ hoch. Die Freiräume zwischen den Platten und über der ganzen Tiegelcharge wurden ebenfalls mit Holzkohle bis zum Rand gefüllt (Abb. 115,5). Als Deckel diente eine gebrannte runde Tonscheibe, die mit Lutum auf dem Tiegelrand «aufgeklebt» wurde ${ }^{589}$.

Der leere Tiegel wog $637 \mathrm{~g}$, voll beschickt und verschlossen $1634 \mathrm{~g}$ (feucht) resp. $1548 \mathrm{~g}$ (trocken); die Netto-Charge (6 Eisenplatten) total 679 g. Nach dem Befeuern (Abb. 115,7) wog der volle verschlossene Tiegel $1475 \mathrm{~g}(-4,7 \%)$, die darin aufgekohlten sechs Platten zusammen $680 \mathrm{~g}$. Dies entspricht einer durchschnittlichen Gewichtszunahme von $+0,2 \%$, deutlich geringer als bei den einzeln in Lehmumhüllungen gebrannten Eisenstangen (vgl. Tabelle 5). Die Proben zeigten nach dem Zementationsfeuer daher eine schwarze Oberfläche direkt auf dem Eisen; d. h., es bildeten sich keine dicken Oxidschichten wie auf den Barren aus den Lehmumhüllungen (z.B.Abb.79,B05.P05). Das wird daran liegen, dass eine optimale Zementation ohne Luftzutritt erfolgte und zu einem ähnlichen Befund führte wie der Barrennachtrag P06.

\section{Ergebnisse}

Obwohl die Eisenplatten alle im selben Tiegel zementiert worden sind, weisen sie nach dem Brand unterschiedliche Aufstählungen auf (Tabelle 6), die ich nicht erklären kann:

- Probe R15, ursprünglich aus «Reineisen» aufgekohlt, weist mit «nur» rund 0,04\% Kohlenstoff die höchste gemessene Vickers-Härte in unserer ganzen Versuchsserie von 260 HV 0,3 auf (Abb. 118).

- Ganz anders hat die Platte B15, ursprünglich aus «Buttereisen», mit rund 0,25\% C viel mehr Kohlenstoff aufgenommen, erbrachte nahe der Metalloberfläche aber «nur» eine Härte von 196 HV (Abb. 121).

Beide Proben erlangten beim Zementationsprozess also ähnliche Härtungseigenschaften und wären für die Herstellung von Werkzeugen gleichermassen geeignet gewesen. Was frappiert, sind hingegen die so unterschiedlichen Kohlenstoffgehalte. Sie müssen dennoch als repräsentativ für die Proben gelten, da beide Platten je zweimal analysiert worden sind.

Beim «box-hardening» im gut verschlossenen Tiegel (Abb. 115) waren - gesamthaft gesehen - die Aufkohlungsresultate einheitlicher und besser (Abb. 116-121) als bei den Einzelbarren, die separat mit je einem Lehmmantel umhüllt waren, welcher jedoch in manchen Fällen geborsten ist (Abb. 76). Dass der antike «Stahlbrenner» - wie auch seine wikingerzeitlichen Nachfolger (Abb.29) - die Umhüllungsmethode anwendete und nicht die Zementation in Tiegeln mit separaten Deckeln, lässt vermuten, dass er die Tiegelmethode entweder noch nicht kannte oder nur in Sonderfällen anwendete (z.B. mit fertig geschmiedeten Produkten: Abb. 122).

588 Siehe die Angaben für Indien sowie die Rezepte von J. Kunckel (1732), W.W.Woodward (1775) und L.B.Guyton de Morveau (1785) oben S. 54 ff. Das Rezept von Johann Andreas Cramer von 1766, zitiert oben Seite 57, kommt unserer Versuchsanordnung am nächsten.

589 Verwendet wurde die Lehmmischung «Lutum 3», die aufgrund von römischen Tiegelfunden aus Augusta Raurica rekonstruiert und im Experiment nachvollzogen wurde: Furger 2018, $197 \mathrm{f}$. Abb. 115 und 119,3, Experimente 3 und 4. - Der Tiegel (Abb. 115,4) ist zuvor in Experiment 12/2 verwendet worden (Furger 2018, 237 Abb. 161). 

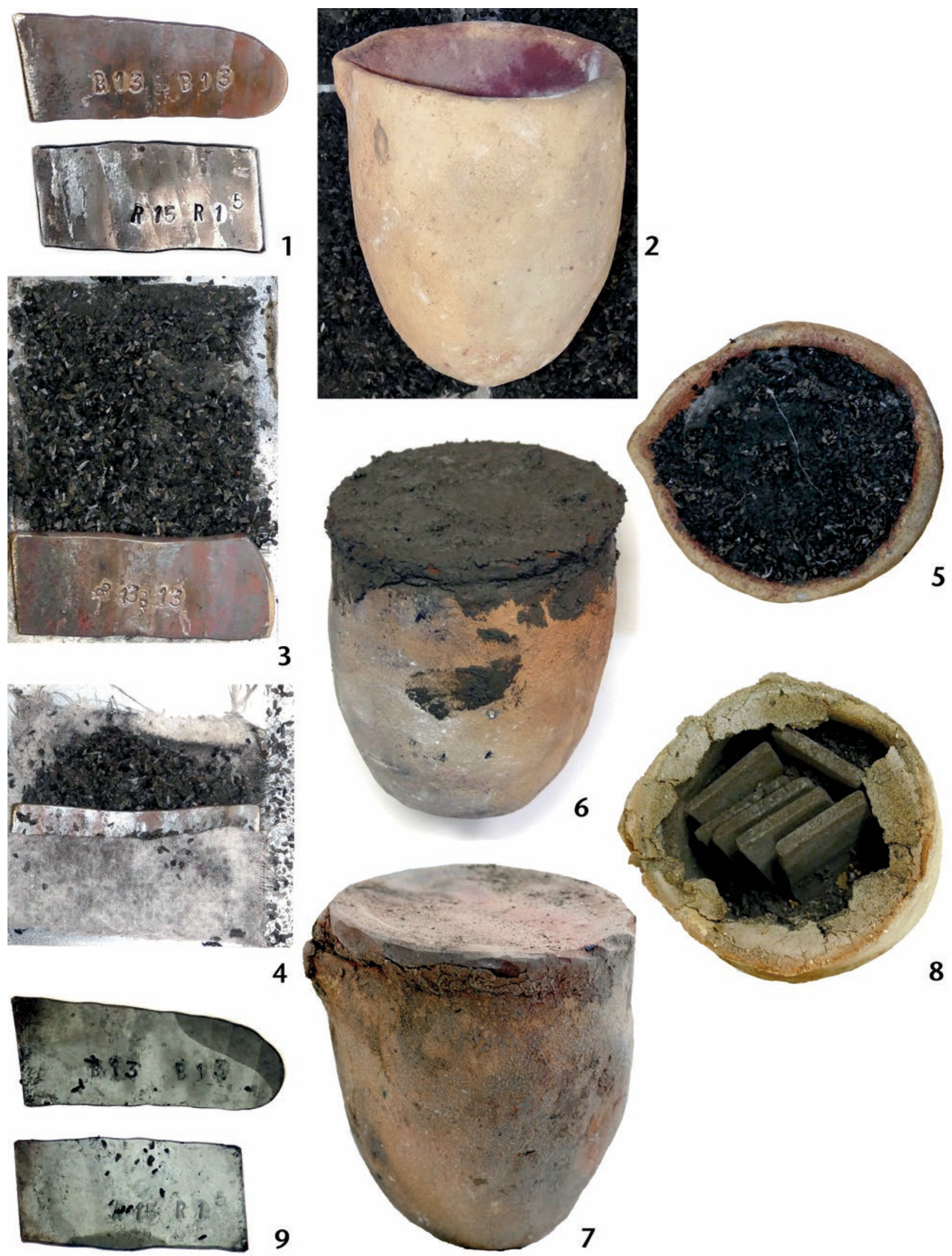

9

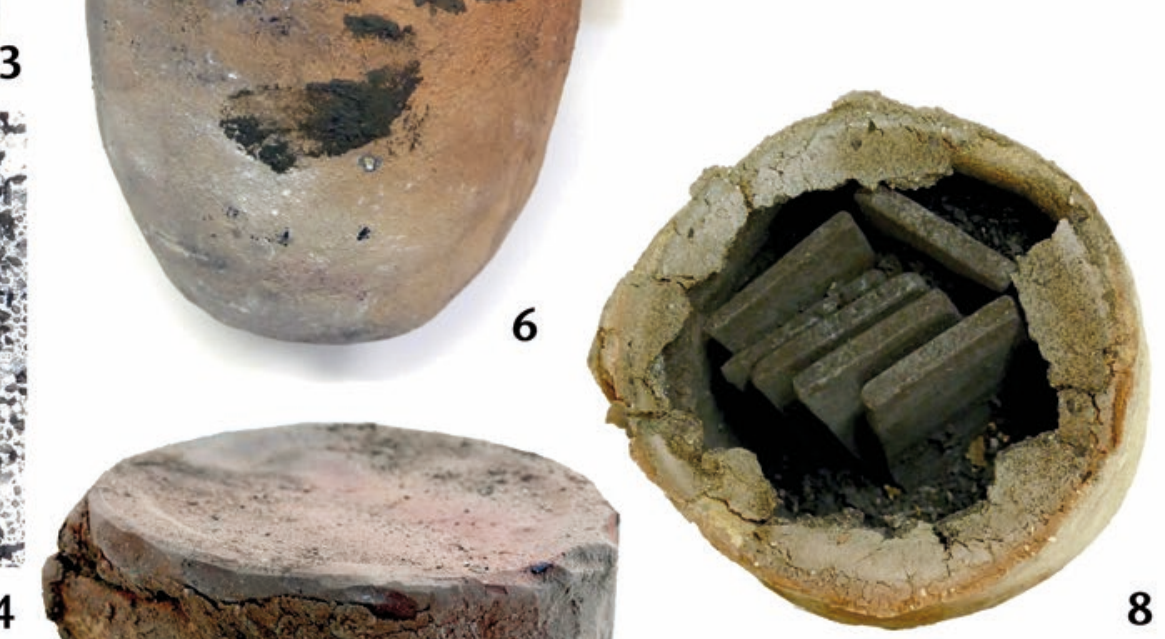

Abb. 115: Aufkohlungsexperiment in Tiegel: 1 zwei der sechs kleinen Weicheisen-Platten (Abb. 61, unten links); 2 leerer Tiegel (Höhe 132 mm); 3 Stoffstück mit Holzkohle und Eisenplatte; 4 halb eingewickelt; 5.6 Tiegel gefüllt mit sechs mit Holzkohle umwickelten Eisenplatten, Holzkohle auch in den Zwischenräumen, bis zum Rand; 7 Tiegel mit lutiertem Deckel verschlossen; 8 Tiegel nach 71/2 Stunden in der Holzkohleglut, nach dem Öffnen (s. Abb. 74, runde Scheibe); 9 fertig aufgekohlte Platten. M. 1:2. 

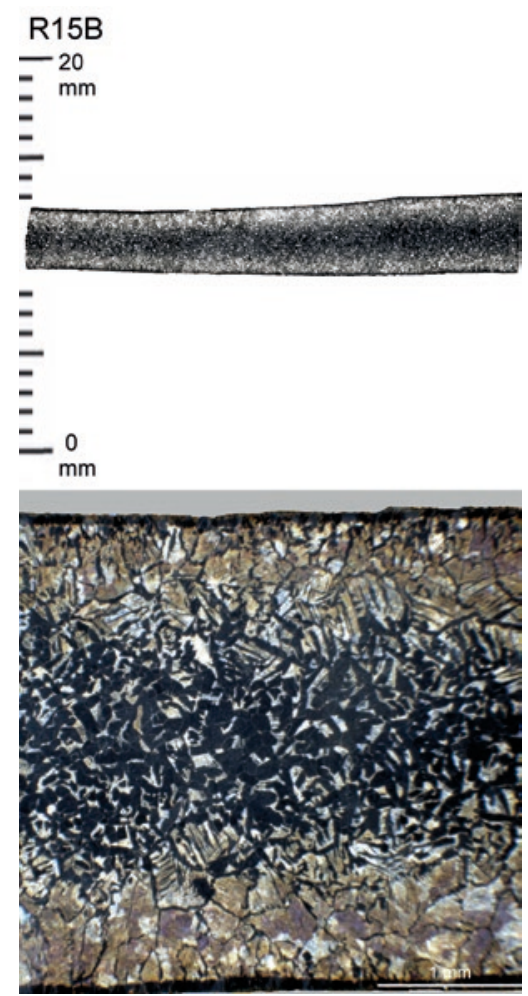

Abb. 116: Barrenquerschnitt R15B («Reineisen», Holzkohle in Tiegel, geglüht und abgeschreckt). Scan M.2:1 resp. Binokularaufnahme M. 15:1.
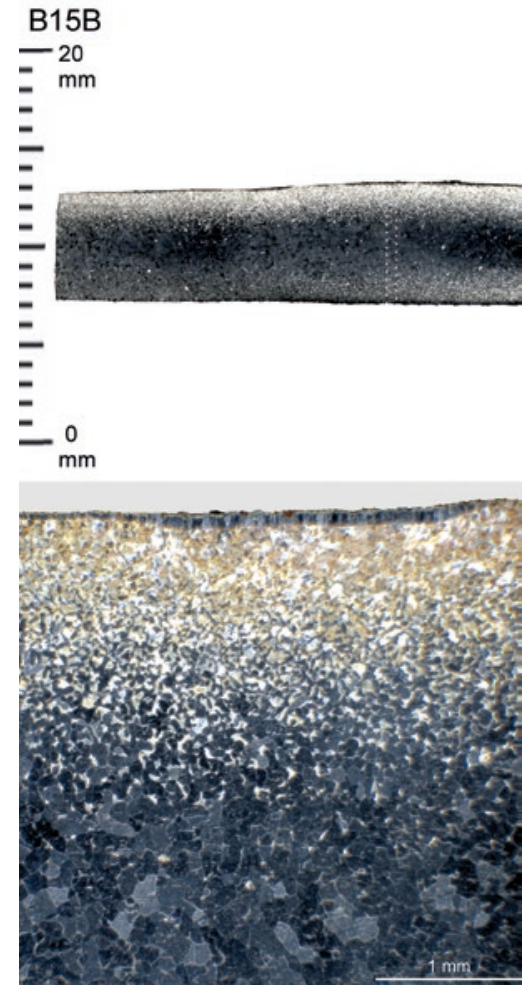

Abb. 119: Barrenquerschnitt B15B («Reineisen», Holzkohle in Tiegel, geglüht und abgeschreckt). Scan M. 2:1 resp. Binokularaufnahme M. 15:1.
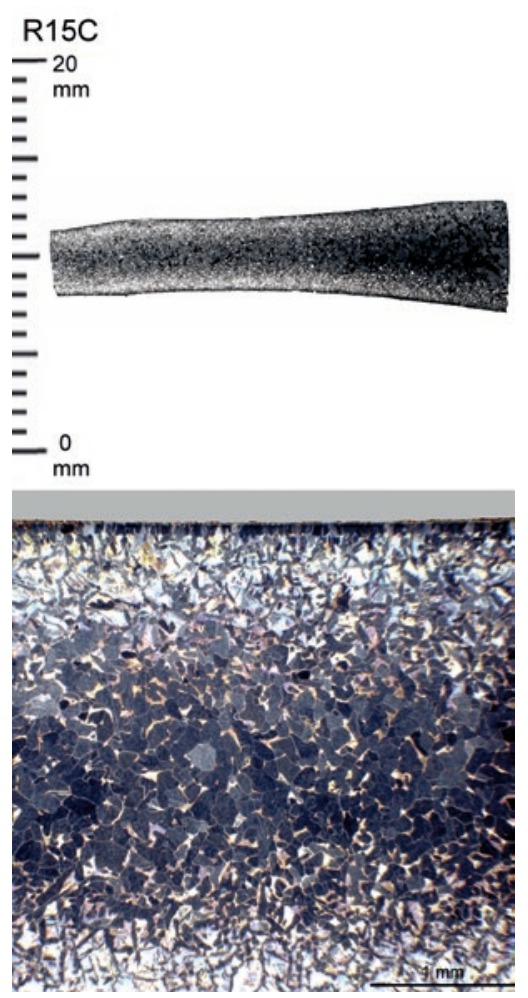

Abb. 117: Barrenquerschnitt R15C («Reineisen», Holzkohle in Tiegel, abgeschreckt und angelassen). Scan M.2:1 resp. Binokularaufnahme M. 15:1
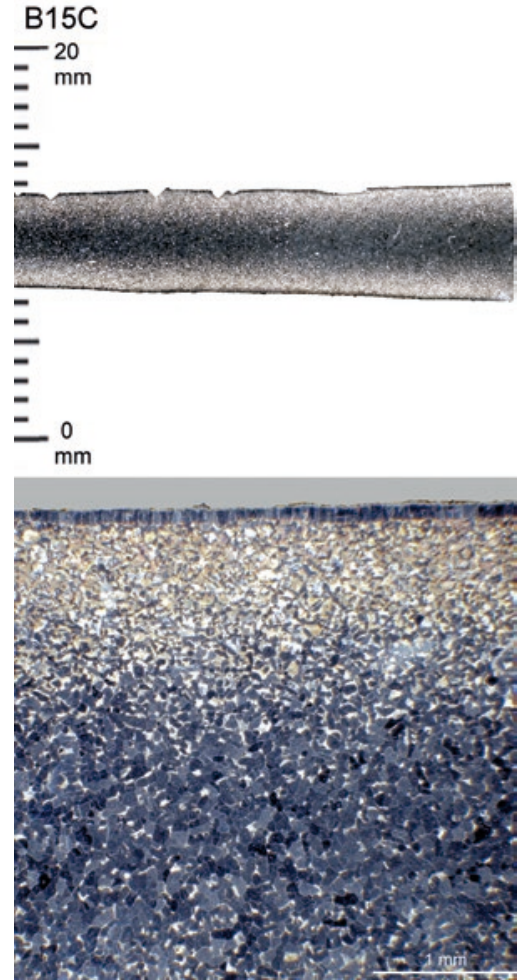

Abb. 120: Barrenquerschnitt B15C («Reineisen», Holzkohle in Tiegel, abgeschreckt und angelassen). Scan M.2:1 resp. Binokularaufnahme M. 15:1.

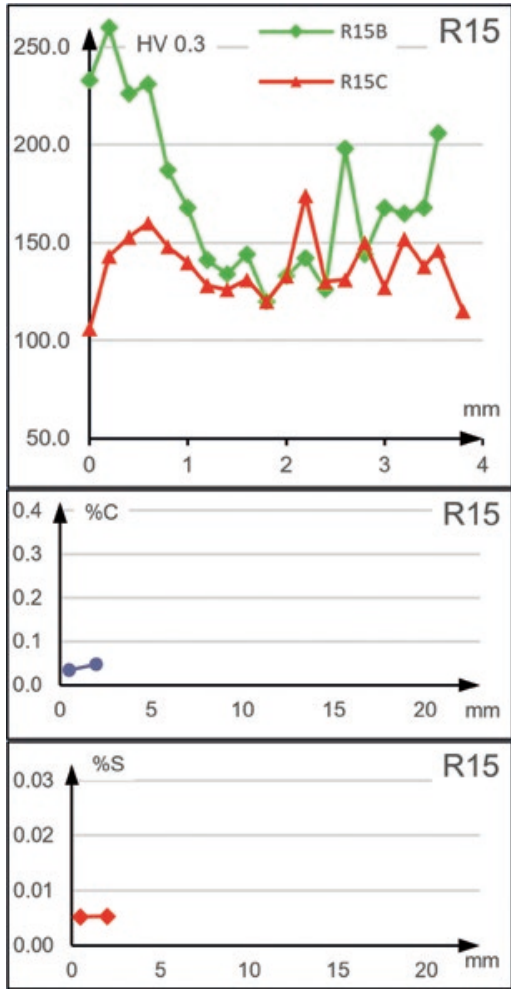

Abb. 118: Barrenquerschnitte R15B-R15C («Reineisen»). Diagramme (v. o.n. u.) VickersHärte 0,3, Kohlenstoff- und Schwefelanalysen.

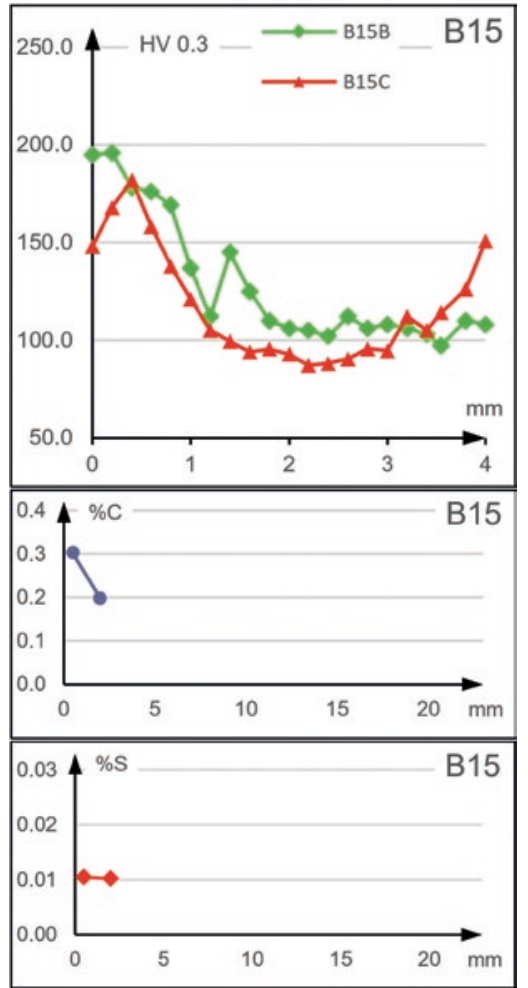

Abb. 121: Barrenquerschnitte B15B-B15C («Reineisen»). Diagramme (v. o.n.u.) VickerHhärte 0,3, Kohlenstoff- und Schwefelanalysen. 
Im Tiegel aufgekohlte römische Schuhnägel?

Im reichen Tiegelmaterial von Augusta Raurica werden auch zwei keramische Gefässteile aufbewahrt, die mit Hunderten von kleinen, gleichförmigen Eisenstückchen gefüllt sind (Abb. 122). Die Korrosion hat die Objekte fast zur Unkenntlichkeit entstellt und innig mit dem Gefässboden verbunden:

\section{Inv. 1961.12028}

Flacher Gefässboden von $125 \mathrm{~mm}$ Durchmesser, mit dunkelbraunen verbackenen, uniformen Eisenteilen gefüllt, darüber angebackener Keramikring mit $140 \mathrm{~mm}$ Aussen- und $50 \mathrm{~mm}$ Innendurchmesser (Abb.122, oben). Die Keramik ist rot gebrannt und weist aussen keine Spuren von Überhitzung oder Versinterung auf. Die Eisenteile im Innern sind einheitlich gross und stark verrostet, lassen sich aber als typische Schuhnägel identifizieren ${ }^{590}$. Augst/ BL, Insula 30, FK X01136 (mit Keramik des 1. und 2.Jh.). Oberflächenanalyse der Eisenteile ${ }^{591}: 96,4 \%$ Fe, $0,2 \% \mathrm{Cu}, 2,0 \% \mathrm{~Pb}, 0,03 \% \mathrm{Zn}, 0,2 \% \mathrm{Mn}, 0,7 \%$ Co.

\section{Inv. 1977.7955}

Flacher Boden eines Topfes. Standfläche mit $93 \mathrm{~mm}$ Durchmesser, mit rotbrauner verbackener «Schlackenmasse» gefüllt (Abb. 122, unten). Keramik ähnlich wie bei 1961.12028. Die kleinen Eisenteile sind zu stark korrodiert, um deren ursprüngliche Form erkennen zu können; von der Grösse her wären ebenfalls Schuhnägel möglich. Aus Augst/BL, Insula 25 (mit Keramik der Mitte des 1.Jh. n. Chr. [um 30-70], u. a. ein gestempelter Terra-sigillata-Teller des Aquitanus, um 40-55). Oberflächenanalyse der Eisenteile (Analysestelle: weisser Kreis in Abb. 122): 98,9\% Fe, 0,2\% Cu, 2,0\% Pb, 0,3\% Zn, 0,3\% Mn, 0,2\% Co.

Der Keramikring auf dem Gefäss 1961.12028 war vermutlich als Deckel mit Lehm (Lutum) aufgeklebt, und die kleine Öffnung im Zentrum konnte separat verschlossen resp. reguliert werden. Die metallischen Elemente in der eisernen Charge der beiden Tongefässe konnten analysiert werden, nicht jedoch die leichten Elemente wie z. B. Kohlenstoff.

Ob die Schuhnägel im Gefäss 1961.12028 neu und ungebraucht oder gebraucht und abgetragen sind, lässt sich wegen der starken Korrosion und ohne Präparation oder Röntgenaufnahmen nicht ermitteln. Nur im ersten Fall wäre an einen Zementationsprozess in den Gefässen zu denken, bei dem neue Schuhnägel aufgekohlt worden wären, um sie anschliessend härten und widerstandsfähiger machen zu können ${ }^{592}$. Immerhin berichtet Plinius, dass ein besonderes Eisen «nur in kurzen Stücken verwendbar» (kohlenstoffreiche Stahlstückchen aus dem Rennofen?) und daher für Schuhnägel besonders geeignet $\operatorname{sei}^{593}$.

Die einzige mir bekannte archäometrische Untersuchung eines römischen Schuhnagels erbrachte Spuren eines hypereutektoiden Stahls, aber es konnte am untersuchten Stück wegen starker Korrosion nicht beurteilt werden, ob der Kohlenstoff im Rennofen oder erst durch Aufkohlung in das Schuhnageleisen eingebracht wurde ${ }^{594}$.

Dass Nägel aus Stahl besser sind als aus weichem Eisen, ist eine triviale Erkenntnis. Charles Frémont schreibt in seinem grossen Werk «Le clou» von 1912 über Nägel ganz generell: «Les clous faits avec ces aciers très ductiles au- ront plus de raideur, ils seront beaucoup plus résistants \& la flexion, flamberont moins, et cependant pourront se plier sans se rompre quand tes conditions du travail t'exigeront.»595 Und für Marquita Volkens, die eine ausführliche Studie über römische Schuhnägel vorgelegt hat, war klar: «Les clous [de chaussures] nécessistent en éffet l'utilisation d'un fer riche en carbone.»596

Die beiden Schuhnagel-Sets aus Augusta Raurica scheinen beide aus dem 1. Jahrhundert zu stammen, also etwa derselben Zeit wie die für Augusta Raurica postulierte Stahlproduktion in Lehmumhüllungen.

Es ist nicht abschliessend klar, ob römische Nägel und insbesondere die kleinen Schuhnägel bewusst aus Stahl hergestellt worden sind oder nicht. Römische Nägel waren bisher nur punktuell Gegenstand metallurgischer Untersuchungen. Das riesige Nageldepot mit 875000 Nägeln aus dem Legionslager von Inchtuthil/GB war Gegenstand mehrerer Untersuchungen ${ }^{597}$. Diese haben ergeben, dass die Nägel aus uneinheitlichem Eisen zusammengeschmiedet worden sind. Die Tatsache, dass kohlenstoffhaltiger Stahl eher im Nagelinnern zu finden ist und aussen weiches Eisen vorliegt, spricht gegen eine sekundäre Aufkohlung (der Oberfläche), sondern für die Verwendung heterogener, z. T. auch kohlenstoffreicher Rennofen-Luppen ${ }^{598}$. Solange die Objekte in den Keramikgefässen aus Augusta Raurica (Abb.122) nicht analysiert sind und deren Kohlenstoffgehalt bekannt ist, bleibt die Frage offen: Hat man Schuhnägel in einem einfachen Zementationsprozess aufgekohlt, um sie widerstandsfähiger gegen Abnutzung zu machen?

590 Die Deutung verdanke ich Markus Helfert.

591 Die beiden pXRF-Analysen (Röntgenfluoreszenzanalyse mit portablem Messgerät NITON) verdanke ich Markus Helfert, Universität Frankfurt/M.

592 Ich danke an dieser Stelle der Schuhspezialistin Marquita Volken für wertvolle Hinweise. Sie schreibt in einer E-Mail vom 25.04.2016 u. a.: «To make the nails a weak/soft iron is necessary but I do wonder if the hobnails weren't hardened afterwards - some hobnails show quite resistance to wear while others show that they wore down quickly - also the hobnail shafts on used shoes sometimes show curling and riveting resistance (possibly hardened) indications of being struck several times to make the point of the shaft enter and turn over - while others show a single blow was sufficient.»

593 Plin. nat. 34,143; Rottländer 2000, 39 und 53 Anm.25; Volken 2011, 316.

594 C.Degrigny/V. Boissonnas, Hypoeutectoid steel - Roman Times (2013). Nur online: https: / / micorr.org/artefacts / 215/ (22.03.2018).

595 Frémont 1912, 38 f.; 44; 122 (Zitat).

596 Volken 2011 (S. 316: Zitat).

597 Angus et al. 1962; Sim 2012, 122-127 Abb. 77 Farbtaf. 29-30 (mit äterer Lit.).

598 Straube 1996, 31; Sim 2012, 127. - Gegenteiliger Ansicht: Mapelli et al. 2009, 55 («the nail has been obtained by the carburation during the forging process of mild low carbon steel»). 

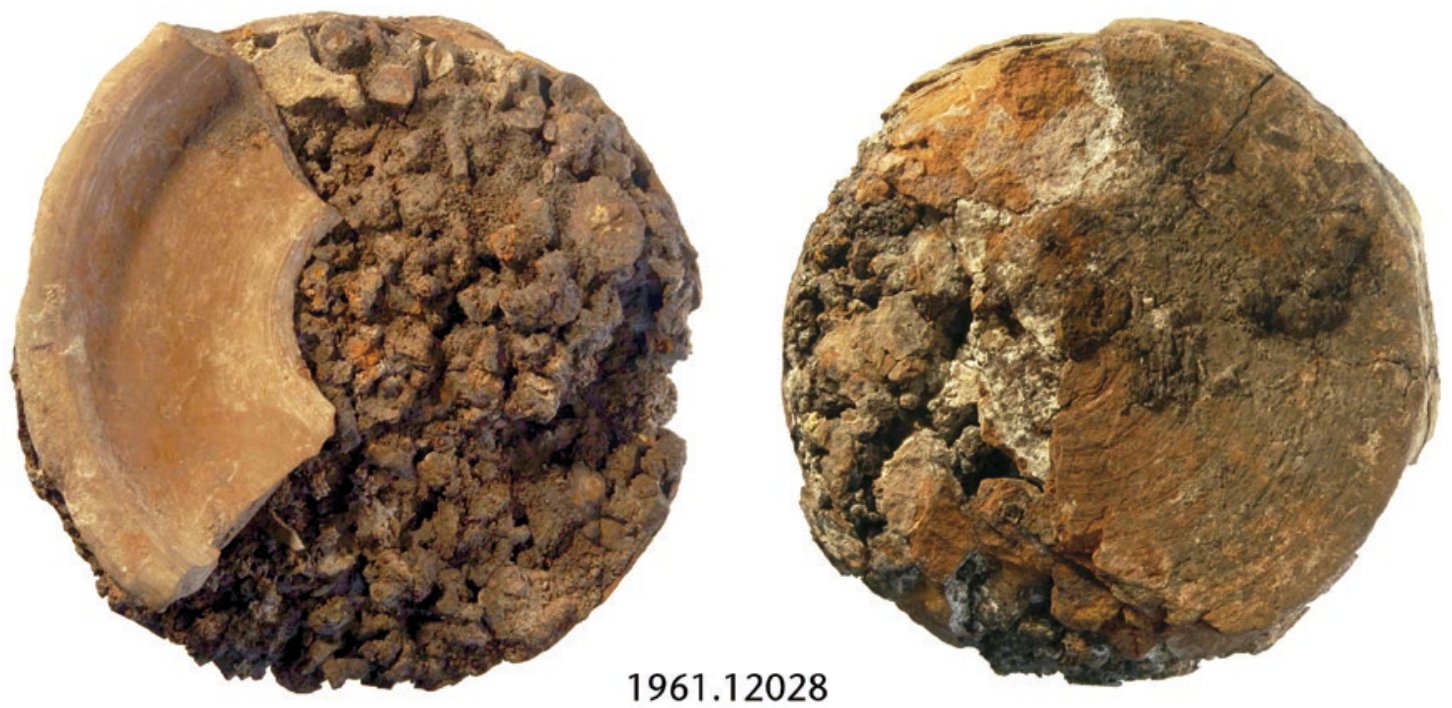

0

$10 \mathrm{~cm}$

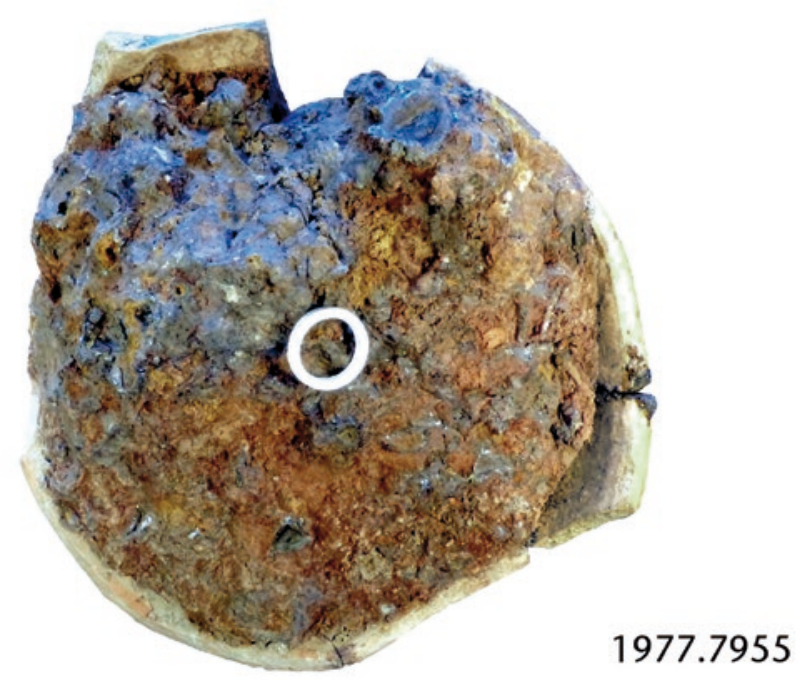

Abb. 122: Augst/BL, Augusta Raurica. Zwei flachbodige Tontöpfe, gefüllt mit gleichförmigen, kleinen Eisenstückchen, die stark zusammenkorrodiert sind (bei 1961.12028 als Schuhnägel erkennbar). Es ist möglich, dass die Stücke zur Härtung mit Holzkohlepulver vermischt und im geschlossenen Gefäss während mehrerer Stunden bei hoher Hitze aufgekohlt worden sind. Der weisse Kreis unten gibt die Analysestelle an. M. 1:2. 


\section{Fazit zur antiken Stahlerzeugung und Zusammenfassung}

Der hier beschriebene archäologische Befund in Augusta Raurica und unsere rekonstruierenden Experimente führten - so wie vermutlich auch in römischer Zeit - zu handlichen Stahlbarren, die vor Ort problemlos zu verarbeiten, aber auch leicht $\mathrm{zu}$ verhandeln und transportieren waren 599 .

Der hier dokumentierte erste Nachweis römerzeitlicher Stahlerzeugung in den Nord- und Nordwestprovinzen lässt vermuten, dass noch einige weitere dezentrale «Aufkohlungsbetriebe» in Betrieb waren und erst noch zu erkennen resp. zu entdecken sind. Der Eindruck, dass «the Romans are in fact more likely to have been consumers rather than producers of high quality iron», ist zwar angesichts von historisch überlieferten Stahlimporten aus dem Land der Seres ${ }^{600}$ (Asien) entstanden ${ }^{601}$, heute aber nicht mehr haltbar. Die nachgewiesenen Produktionsorte in Noricum und der Colonia Raurica zeigen uns die beiden unterschiedlichen Technologien, mit denen innerhalb des Imperiums Stahl erzeugt wurde.

Es darf zusammengefasst werden, dass die ältesten Eisenund Stahlfunde äusserst selten sind und das Material in der Frühzeit seiner technischen Nutzung sehr wertvoll und exklusiv war. Ob zuerst sogar ausschliesslich Meteoreisen («Himmelseisen», mit deutlichen Nickelgehalten) genutzt und verarbeitet wurde, wäre immerhin denkbar, solange nicht auch das Verhütten von Eisenerzen in so früher Zeit nachgewiesen ist. In Sumer und Ägypten war Meteoreisen seit mindestens 3000 v. Chr. bekannt und als wertvolle «Rarität» verarbeitet worden.

Die eigentliche Eisenverhüttung in Rennöfen und anschliessende Verarbeitung zu Gebrauchsgerät setzt im Irak frühestens um 3000 v. Chr. ein, im 2. Jahrtausend bei den Hethitern und um 2000 v. Chr. in Griechenland. Der eigentliche Übergang von der Bronze- in die Eisenzeit erfolgte im Nahen Osten spätestens um 1200 v. Chr., in Mitteleuropa um 800 v. Chr.

Von härtbarem Stahl erfahren wir erwartungsgemäss später: zuerst aus literarischen Quellen des 12.Jahrhunderts v. Chr. Archäometrische Nachweise aus der Frühzeit des Stahls mögen in Zukunft folgen. Spätestens aus dem 6. Jahrhundert v. Chr. stammen die bisher ältesten Funde, die archäo-metallurgisch als Kohlenstoffstahl beschrieben werden können, und etwa gleichzeitig erwähnen die antiken Autoren vermehrt den Stahl und die Härtungsprozesse. Überhaupt mag es erstaunen, dass Eisen und Stahl in den antiken Schriftquellen relativ häufig erwähnt sind.

Die Stahlerzeugung, d.h. die Anreicherung des Eisens mit Kohlenstoff, erfolgte schon in der Antike auf zwei We- gen: erstens durch direktes Verhütten unter ganz bestimmten Bedingungen und zweitens mit Aufkohlung durch langes Glühen in einer Kohlenstoffathmosphäre. Das eine wird «Direktverfahren» genannt, das andere «Zementation»; für das erste steht das ferrum Noricum (S. 44 ff.), für das zweite die Befunde aus Augusta Raurica (S. 88 ff.). Die beiden Themen nehmen denn auch einen besonders grossen Platz in diesem Buch ein. Ein archäometrischer Nachweis von ferrum Noricum in Fundobjekten steckt heute noch in den Kinderschuhen und muss durch noch ausgeklügeltere Isotopenanalysen oder Spurenelementsuche in kleinsten Schlackeneinschlüssen verfeinert werden ${ }^{602}$.

Die je länger je häufiger unternommenen archäometrischen Untersuchungen von antiken Eisen- und Stahlobjekten sind enorm wichtig. Homogene Stähle aus vorindustrieller Zeit sind extrem selten (z.B. Tiegelstahl aus Asien). Wenn kohlenstoffreicher Stahl (d.h. mit etwa 0,2 bis $1,5 \%$ C) nachgewiesen werden kann, so ist er immer heterogen über die Objekte verteilt und mit Zonen von weicherem Eisen durchzogen. Die Homogenisierung der unterschiedlichen Eisenwerkstoffe durch Aus- und Umschmieden der Stahlluppen ist langwierig, energieraubend und nie vollkommen. Auffallend oft lassen sich an den polierten Querschnitten feine Schlackenstreifen erkennen, die vom Zusammenschweissen einzelner Eisen- und Stahlstücke zeugen. Das Feuerschweissen wurde demzufolge sehr oft angewendet, einerseits zur Durchmischung von Stählen unterschiedlicher Kohlenstoffgehalte und andererseits zur bewussten Erzielung bestimmter physikalischer Eigenschaften von Werkzeug, Gerät oder Waffe. Dazu gehören sowohl Einsatzwerkzeuge mit lokal eingeschweissten Stahlstreifen im Schneidenbereich als auch Verbundstoffe mit optimaler, oft auch ornamental gestalteter Durchmischung von hartem und sprödem Stahl mit weichem und elastischem Eisen (Damaszenerstahl). Der metallurgische Nachweis von Aufkohlung durch Zementation, wie er für die römische Zeit erstmals aus den Funden von Augusta Raurica erschlossen werden kann, ist mangels Laboruntersuchungen bis heute selten geblieben. Die Me-

599 Presslinger 2008, 241 («Stahlbarren mit hohem Kohlenstoffgehalt waren daher in der Latène- und Römerzeit eine Handelsware»).

600 Entweder das «Land, aus dem die Seide stammt» oder das Gebiet der «Seidenhändler» (Karawanenrouten): Schoff 1915.

601 So etwa bei Godfrey / van Nie 2004, 1124 (Zitat).

602 Starley 1999; Schwab et al. 2006; Brauns et al. 2017; Dillmann et al. 2017; Desai 2018 (Methodenübersicht); Rose et al. 2018 (114: Methodenübersicht). 
thode konnte sowohl an Rohstangen und dünnen Barren angewendet werden (Beispiel Augusta Raurica) als auch an fertig geschmiedeten Objekten, deren Oberflächen man in einem letzten Arbeitsschritt härten wollte (Beispiel Waffen).

Weitere Themen, die in diesem Buch behandelt werden, sind: die traditionellen Methoden der Materialprüfung (S.15f.), die unterschiedlichen Kohlenstoffgehalte von Eisen und Stählen im Verhältnis zu ihren technischen Eigenschaften (S. 19f.), die verschiedenen Verfahren zur Aufkohlung von Eisen (Zementation, «case-hardening»; S. $28 \mathrm{ff}$.), der Stahl beim römischen Schriftsteller Plinius (S. 38), die speziellen antiken bis neuzeitlichen Tiegelstahlverfahren in Mittelasien (S.39ff.), die Barrenformen für Weicheisen und Stahl von der Antike bis ins frühe Mittelalter (S. $62 \mathrm{ff}$.) sowie einige wenige ethnographische Beispiele der Stahlbearbeitung (S. 54f.). Wann immer möglich, werden einerseits antike Autoren zur Ergänzung der archäologischen und metallurgischen Befunde beigezogen, was $\mathrm{zu}$ einer intensiven interdisziplinären «Verwebung» der Themen in einigen Kapiteln geführt hat. Andererseits wird wiederholt anhand von historischem Know-how der letzten 1500 Jahre der Bogen von der Antike zum Beginn der Industrialisierung in Europa gespannt. 


\section{Conclusions to antique steelmaking, and summary}

From archaeological evidence and modern experimentation, it is demonstrated that steel ingots were produced in Roman Augusta Raurica (near Basel, Switzerland), processed locally without problem and were easily transported and traded $^{603}$. The presented evidence of Roman steel production in the Northern and North Western provinces suggest - documented here for the first time - that further decentralized cementation works may subsequently be discovered. That «Romans are in fact more likely to have been consumers rather than producers of high-quality iron, ${ }^{604}$, suggested by records of steel imports from the land of the Seres ${ }^{605}$ (India or China), is no longer tenable. Proven production sites in Noricum (Southern Austria) and the Colonia Raurica (Switzerland) clearly demonstrate that there were in fact two steel making technologies used inside the Empire.

It can be said that older iron and steel findings are extremely rare and during these early periods steel usage was valuable and exclusive, perhaps there is not even enough evidence to prove that meteoric iron (iron from the heavens; ; with a clear nickel content) was not the exclusive source. It is known that meteoric iron was used at least from 3000 BC in Sumer and Egypt and was an extremely valuable rarity.

Iron smelting in bloomery furnances, and its subsequent processing to basic commodities, started at the earliest about $3000 \mathrm{BC}$ in Iraq, in the second millennium with the Hittites, and by 2000 BC appeared in Greece. The transition from the Bronze Age to the Iron Age is deemed to have taken place in the Near East about $1200 \mathrm{BC}$ at the latest and in central Europe by about 800 BC.

The hardening of steel appears first in literary sources from the $12^{\text {th }}$ Century BC, but archeometric evidence has yet to be discovered. The oldest finds that archeo-metallurgists describe as carbon steel date only from the $6^{\text {th }}$ century $\mathrm{BC}$ whilst, in the same period, contemporary authors also mention steel and steel hardening processes. It is surprising how frequently iron and steel is in fact mentioned in ancient literary sources.

Steelmaking, i. e. the enrichment of iron with carbon, was already carried out in antiquity in two different ways, firstly, by direct smelting under very specific conditions and secondly via the carburisation of iron by lengthy heating in a carburizing atmosphere. The first, the «direct process, produced the so-called ‘ferrum Noricum〉 (pp. $44 \mathrm{ff}$.), the second is evidenced in Augusta Raurica (pp. $88 \mathrm{ff}$.). Both processes are extensively dealt with in this book. Archeometric proof of the production of ferrum Noricum is still lacking and requires more sophisticated investigation of trace elements in the minute slag inclusions ${ }^{606}$.
It is extremely important that there should be more archeometric investigations of iron and steel objects in this area. Homogeneous steels from pre-industrial times, such as those made from Asian crucible steel, are extremely rare. When carbon rich steel (eg containing between 0.2 and $1.5 \% \mathrm{C}$ ) is discovered, the carbon is always heterogeneously distributed throughout the object, interspersed with zones of soft iron. The homogenising of components by forging and beating out the bloomery iron is time consuming, energy intensive and never perfect. Fine streaks of slag can remarkably frequently be recognized on polished surfaces, evidencing the welding together of different iron and steel pieces. Forge welding was frequently used on one hand in an attempt to mix steels of different carbon contents and on the other for deliberately achieving specific physical properties for tools, other implements and weapons. In this second category belong tools with steel strips locally on-welded to provide cutting edges, as well as composite materials with an optimal combination of hard and brittle steel with soft and elastic iron, often with ornamentally designed patterns (such as with Damascus steel). Metallurgical proof of carburisation by cementation in objects dating from Roman times found in Augusta Raurica is scarce even today, because of a paucity of laboratory investigation. This method could be used to treat both crude bars and thin rods as well as forged and finished objects, such as weapons, the surfaces of which needed to be hardened in a final processing step.

Further topics covered in the book include traditional methods of material testing (pp. $15 \mathrm{f}$.), differences in the carbon content of irons and steels in relation to their technical properties (pp. $19 \mathrm{ff}$.), different methods of carburising iron (cementation, case hardening; pp. $28 \mathrm{ff}$.), mentions of steel by the Roman author Pliny (p. 38), the form of the bars and ingots for soft iron and steel from antiquity to the Early Middle Ages (pp. $62 \mathrm{ff}$.) and the special crucible steel processes of Central Asia from antiquity to the present (pp. $39 \mathrm{ff}$.) as well as some ethnographic examples of steel processing (pp. $54 \mathrm{f}$.). Whenever possible, ancient writers have been consulted for further information on archeological and metallurgical discoveries, resulting in an intensive,

603 Presslinger 2008, 241 («Ingots with a high carbon content were therefore a trading good in the Latène- and Roman times»).

604 As suggested by Godfrey / van Nie 2004, 1124 (quotation).

605 Either the «land where the silk is coming from» or the area of the «silk traders» (caravan routes): Schoff 1915.

606 Starley 1999; Schwab et al. 2006. 
interdisciplinary intertwining > of methodology in several chapters and by drawing this together with the established know-how of the last 1500 years, a continuum from antiquity to the beginning of the industrial revolution in Europe is presented.

(translation Urs Werner and Richard Williams) 


\section{Glossar}

$\mathrm{Zu}$ Begriffsdefinitionen in der Stahl-Metallographie siehe auch die ausführlichen Glossare bei Senn Bischofberger 2005, 104-106, und Kastowsky et al. 2011, 512-516.

Abschrecken: Glühen des Eisens (Stahls) auf Dunkelrot- bis Weissglut (Abb. 9, links) und möglichst zügiges Eintauchen in ein kaltes Medium (Wasser, Öl, evtl. Luft). Das Abschrecken bewirkt eine markante Veränderung des Kristallgefüges und macht einen Stahl extrem hart (unelastisch und brüchig)

Anlassen: Leichtes (Wieder-)Erhitzen des Stahls, jedoch nur bis zu gelber oder brauner «Anlassfarbe» (Abb.9, rechts) und nochmaliges Abschrecken in Wasser. Damit wird die Abschreckstruktur nochmals verändert: Der Stahl ist weniger spröde als abgeschreckt und dafür etwas elastischer.

Aufkohlen: Einbringen von Kohlenstoff in das Eisen bei möglichst heisser Glut. Je kompakter und konzentrierter Kohlenstoff auf der Metalloberfläche liegt, desto weniger kann er verbrennen (z. B. dank Lehmumhüllungen), und je länger er bei Hitze einwirken kann, desto tiefgreifender ist die Kohlenstoffaufnahme im Eisen.

Austenit: Gefügebestandteil, $\gamma$-Mischkristalle des Eisen-KohlenstoffSystems in Eisen und Stahl, bildet sich ab $723^{\circ} \mathrm{C}$ und ist stabil zwischen $911^{\circ}$ und $1392^{\circ} \mathrm{C}$.

Box-hardening: (Früh-)industrieller Begriff analog dem $\rightarrow$ Aufkohlen, jedoch stets in Zementationskisten aus Eisenblech (Abb. 18; 19), Gusseisen, Stein oder gemauerten Kammern. Entscheidend für den Erfolg sind genügend Abstand zwischen den Eisenteilen, eine dichte Holzkohle- resp. Zementationspulver-Packung dazwischen und ein dicht verschliessender Deckel.

Damaszenerstahl: Mehrlagiger, sehr arbeitsaufwendiger Verbundstoff aus zusammengeschweissten «weichen» Eisen- und «harten» Stahlstreifen. Durch vielfaches Falten und erneutes Feuerverschweissen entstehen viellagige Barren, die dünn zu Schwertern, Messern und anderen Qualitätsprodukten ausgeschmiedet werden (Abb. 8). Diese Lamellenstruktur vereinigt Härte und Elastizität gleichermassen. Je nach Falttechnik können die unterschiedlichsten Muster erzeugt werden (Anordnung der dünnen Lagen). Diese typische Struktur des Damaszenerstahls wird durch Ätzen in Säure und Polieren sichtbar gemacht.

Eutektischer Stahl: Eisen-Kohlenstoff-Legierung im Mischverhältnis mit niedrigster Schmelztemperatur. Eutektische Zusammensetzung: $4.3 \% \mathrm{C}$.

Eutektoider Stahl: Stahl mit etwa 0,8\% C, der im wärmebehandelten Zustand ausschliesslich $\rightarrow$ perlitisches Gefüge besitzt.

Ferrit: Gefügebestandteil, $\alpha$-Mischkristalle des Eisen-Kohlenstoff-Systems, unter $911^{\circ} \mathrm{C}$ vorliegend. Hauptbestandteil von weichem Schmiedeeisen $(<0,1 \% \mathrm{C})$, gut verformbar, aber korrosionsanfällig.

Feuerschweissen: Zusammenfügen mehrerer Eisen- oder Stahlteile bei sehr grosser Hitze (Hochweissglut). Die Verbindungsflächen müssen zuvor gut anpassend, blank und zunderfrei gemacht werden. Auf sie wird als Oxidationsschutz «Schweisspulver» (Borax, Quarzsand usw.) gestreut, und die Eisenteile werden sofort mit sanften, aber bestimmten Schlägen aufeinandergehämmert. Da das Eisen auf Hitze knapp vor dem «Verbrennen» gebracht wurde, kann es unter Druck und ohne Oxidation miteinander verschmelzen.

Frischen: Verringerung des Kohlenstoffgehaltes («Entkohlen») an der Oberfläche durch langdauerndes resp. mehrfaches Erhitzen. Einerseits ist dies von Nachteil beim Schmieden von Stahl, andererseits ist Frischen nötig, um stark kohlenstoffhaltigen Stahl (z. B. $\rightarrow$ Roheisen / Gusseisen) in schmiedbaren Werkzeugstahl um- zuwandeln. Gefrischt wurde früher durch «Abkohlen» (langsames Glühen) im Schmiedefeuer ${ }^{607}$.

Gerbstahl, Gärbstahl: Stahl wird aus zusammengeschweissten, zuvor zementierten Teilen und durch Umschmieden zu einem möglichst homogenen Werkstoff gebracht.

Gusseisen: Siehe $\rightarrow$ Roheisen

Härten: Siehe $\rightarrow$ Abschrecken und $\rightarrow$ Anlassen 608 .

Hypereutektoider Stahl: Eisen-Kohlenstoff-Legierung im Mischverhältnis optimaler Härte und Festigkeit (>0,8\% C), bildet vor allem $\rightarrow$ Martensit mit etwas Restaustenit beim Abschrecken.

Kohlenstoff(-stahl): Wichtigster Stahl-Legierungsstoff. Schon etwa $0,3 \%$ Kohlenstoffanteil macht Eisen härtbar (siehe $\rightarrow$ Abschrecken und $\rightarrow$ Anlassen; oben mit Anm. 54-71). Kohlenstoff kann entweder durch spezielle Feuer-, Luft- und Schlackenführung im Rennofen oder nachträglich durch $\rightarrow$ Aufkohlen des Eisens legiert werden.

Martensit: $\quad$ Ein Gefüge, das beim Glühen und anschliessenden schnellen Abschrecken (Härten) von Stahl entsteht.

Perlit: $\quad$ Ein $\rightarrow$ eutektoides Gefüge des Stahls, lamelliert resp. schichtförmig aufgebaut. Ein Gemisch aus $\rightarrow$ Ferrit und $\rightarrow$ Zementit. Feinkörniger Perlit entsteht beim langsamen Abkühlen von Stahl (ab mindestens $723^{\circ} \mathrm{C}$ ), grobkörniger beim $\rightarrow$ Anlassen.

Rennofen: Einfacher Verhüttungsofen (Abb. 10; 11; 28) für kleinere Mengen Eisenerz, betrieben mit Blasebälgen oder natürlichem Luftzug. Das aus dem Prozess resultierende Produkt wird Ofenschwamm oder Luppe genannt und enthält noch zahlreiche Gasblasen sowie viele Schlacken- und Holzkohleeinschlüsse, die in einem separaten Arbeitsgang ausgeschmiedet werden müssen.

Roheisen: Gusseisen mit hohem Kohlenstoffgehalt (>2\% C), sehr spröde und nicht schmiedbar.

Schweissen: Siehe $\rightarrow$ Feuerschweissen.

Tempern: Hitzebehandlung in der Metallurgie. Langes Tempern erfolgt z. B. beim Härten von Stahl (siehe $\rightarrow$ Abschrecken, $\rightarrow$ Anlassen) oder beim Entkohlen von Roheisen (siehe $\rightarrow$ Frischen).

Troostit: Gefüge von sehr feinlammeliertem («feinstreifigem») $\rightarrow$ Perlit. Entsteht beim kontrollierten und etwas verzögerten Abschrecken von geglühtem Stahl in einem Ölbad, wenn der $\rightarrow$ Austenit nicht mehr vollständig in die Perlitstufe umgewandelt wird.

Widmannstätten-Gefüge: Typisches, nadelförmiges Mikrogefüge im Stahl, das sich bei raschem Abkühlen nach dem Glühen bildet.

Zementation, Zementieren: Metallurgischer Umwandlungsprozess in einem geschlossenen System (z. B. einem verschlossenen Tiegel) in einer bestimmten Atmosphäre (z. B. reduzierend, mit Holzkohle). So ist von Zementation die Rede, wenn Grundmetalle in einem geschlossenen System entweder angereichert werden, zum Beispiel Eisen mit Kohlenstoff ( $\rightarrow$ Stahl) oder Kupfer mit Zinkerz ( $\rightarrow$ Messing), oder zu reinigen sind (Altgold, Reingold).

Zementierpulver: Gemisch, meist mit dem Hauptbestandteil Holzkohlepulver, das zum Aufkohlen resp. $\rightarrow$ Zementieren von Eisen bei grosser Hitze und über einen längeren Zeitraum unter Luftabschluss verwendet wird. Z. enthält vor allem pflanzlichen und / oder tierischen Kohlenstoff.

Zementit: Eisencarbid $\mathrm{Fe}_{3} \mathrm{C}$, hart und sehr spröde. Entsteht nach dem Härten des Stahls und dem abschliessenden $\rightarrow$ Anlassen.

607 Johannsen 1953, 154f.; Presslinger 2007, 64; Lang 2017, 6, Absatz 3.

608 Halle 1783; Reiser 1896; Presslinger 2007, 64. 


\section{Quelleneditionen und Übersetzungen}

Amm.: Edition und Übersetzung: Ammianus Marcellinus. Römische Geschichte, lateinisch und deutsch und mit einem Kommentar von W. Seyfarth (Berlin 1970).

Aristot. meteor.: Übersetzung: Aristoteles Werke in deutscher Übersetzung, herausgegeben von E. Grumach, fortgeführt von H. Flashar (Berlin 1970).

Caes. Gall.: Edition und Übersetzung: C.Iulius Caesar. Der Gallische Krieg. De bello Gallico. Lateinisch-deutsch. Herausgegeben und übersetzt von O. Schönberger (Düsseldorf / Zürich 1998).

Cassiod. var.: Edition und Übersetzung: Briefe des Ostgotenkönigs Theoderich der Grosse und seiner Nachfolger. Aus den «Variae» des Cassiodor, herausgegeben von L.Janus, eingeleitet und übersetzt von P. Dinzelbacher (Heidelberg 2010).

Clem. Al. strom.: Übersetzung: Titus Flavius Klemens von Alexandria Die Teppiche (Stromateis). Deutscher Text nach der Übersetzung von F. Overbeck, herausgegeben und eingeleitet von C.A.Bernoulli und L. Früchtel (Basel 1936).

Curt.: Edition und Übersetzung: Quintus Curtius Rufus. Historiae Alexandri Magni. Geschichte Alexanders des Grossen, übersetzt von F. Olef-Kraft (Stuttgart 2014).

Diod.: Übersetzung: Diodoros. Griechische Geschichte Buch I-X, zweiter Teil, übersetzt von G. Wirth und O.Veh (Stuttgart 1993) resp. Diodoros Historische Bibliothek, in der Übersetzung von J. F. Wurm, herausgegeben von G. Klawes (Wiesbaden 2014).

Eur. Alc.: Edition und Übersetzung: Euripides. Alkestis, herausgegeben, übersetzt und kommentiert von G. A. Seeck (Berlin 2008)

Gal. de anatomicis administrationibus: Übersetzung: Galen on anatomical procedures. De Anatomicis Administrationibus. Translation of the surviving books, with introduction and notes by C.Singer (Oxford 1956).

Hesychius, Lexicon: Hesychii Alexandrini lexicon. editionem post Kurt Latte continuantes recensuerunt et emendaverunt Peter Allan Hansen et al. (Berlin 1953-2009).

Hom. Od.: Übersetzung: Homer. Odyssee. Übersetzung, Nachwort und Register von R. Hampe (Stuttgart 2009).

Hor. carm.: Edition und Übersetzung: Die Gedichte des Horaz, lateinisch und deutsch, nach Kayser, Nordenflycht und Burger, herausgegeben von H. Färber (München 1954).

Hor. epod.: Edition und Übersetzung: Horaz. Oden und Epoden. Lateinisch und deutsch, nach der Übersetzung von W. Richter, überarbeitet und mit Anmerkungen versehen von F. Weitz (Darmstadt 2010).

Itin. Ant.: Edition: Itineraria Romana. Volumen prius. Antonini Augusti et Burdigalense, edidit Otto Cuntz, accedit tabula geographica (Stuttgart 1929).

Lykophr.: Edition und Übersetzung: Lykophron's Alexandra. Griechisch und deutsch mit Anmerkungen von C.von Holzinger (Leipzig 1895).

Mart. und Mart. Spect.: $\quad$ Edition und Übersetzung: M. Valerius Martialis, Epigramme. Lateinisch-deutsch; hrsg. und übers. von Paul Barié und Winfried Schindler (Düsseldorf 2013).

Ov. met.: Edition und Übersetzung: P. Ovidius Naso. Metamorphosen. Lateinisch / Deutsch, übersetzt und herausgegeben von M. von Albrecht (Stuttgart 2010).

Petron.: Edition und Übersetzung: Petronius. Das Gastmahl des Trimalchio, lateinisch und deutsch, herausgegeben und übersetzt von C. Hoffmann (München 1937).

Philon, Belopoiika: Edition und Übersetzung: Griechische Kriegsschriftsteller. Aeneias. Von Vertheidigung der Städte. Heron und Philon. Vom Gerüstbau, nebst einem Anhange zu den Schriften Heron's und Philon's ... Griechisch und Deutsch mit kritischen und erklärenden Anmerkungen von H. Köchly und W. Rüstow (Leipzig 1853) 185-317; 240-317.

Plin. nat.: Edition und Übersetzung: C.Plinius Secundus d. Ä. Naturkunde XXXI. Metallurgie, herausgegeben und übersetzt von R. König in Zusammenarbeit mit K. Bayer (Darmstadt 2008), resp. Plinius Secundus d. Ä. Über Glas und Metalle. Übersetzt und kommentiert von der Projektgruppe Plinius, herausgegeben von R. C. A. Rottländer (St. Katharinen 2000).

Plut. Crassus: Übersetzung: Plutarchs vergleichende Lebensbeschreibungen, übersetzt von J.F.S. Kaltwasser, neu herausgegeben von O. Güthling, 7. Band (Leipzig ca. 1890)

Plut. De primo frigido: Übersetzung: Plutarch's Morals, translated from the Greek by several hands, corrected and revised by W. W. Goodwin (Cambridge 1874) [Zitat in Anm.21 ins Deutsche übersetz vom Verfasser, da die deutsche Ausgabe von J. C. F. Bähr, Stuttgart 1861, 2813, hier technisch unkorrekt ist].

Rut. Nam.: Edition und Übersetzung: Rutilius Claudius Namatianus. De reditu suo sive Iter Gallicum. Herausgegeben, eingeleitet und erklärt von E. Doblhofer (Heidelberg 1972).

Steph. Byz.: $\quad$ Edition und Übersetzung: Stephani Byzantii. Ethnica, recensuit Germanice vertit adnotationibus indicibusque instruxit M. Billerbeck (Berlin 2014).

Strab.: Edition und Übersetzung: Strabons Geographika, Band 2, Buch V-VIII, mit Übersetzung und Kommentar, herausgegeben von S. Radt (Göttingen 2003).

Xen. an.: Edition und Übersetzung: Anabasis. Der Zug der Zehntausend: Cyri Anabasis. Xenophon, Übersetzung, Einleitung und Anmerkungen von H. Vretska (Stuttgart 1958'; 2009). 


\section{Literatur}

Agricola 1557: Georg Agricola, Zwölf Bücher vom Berg- und Hüttenwesen. Sowie sein Buch von den Lebewesen unter Tage (Originalausgaben Basel 1556: «De re metallica». Basel 1557: «Vom Bergkwerck»), zitiert nach W. Fries/W. Treue (Hrsg.), Georg Agricola. Vom Berg- und Hüttenwesen (München 1980²).

Alföldy 1969: G. Alföldy, Epigraphica Norica. Epigraphische Studien 8 (Düsseldorf 1969) 1-34.

Alföldy 1970: G. Alföldy, Patrimonium Regni Norici. Ein Beitrag zur Territorialgeschichte der römischen Provinz Noricum. Bonner Jahrbücher 170, 1970, 163-177.

Alföldy 1974: G. Alföldy, Noricum (London 1974).

Al Hassan/Hill 1986: A. Y.al Hassan/D. R. Hill, Islamic technology (Cambridge / Paris 1986).

Alipour/Rehren 2014: R. Alipour/T. Rehren, Persian Pūlād Production: Chāhak Tradition. Journal of Islamic Archaeology 1/2, 2014, 231-261.

Allen 1967: D. Allen, Iron currency bars in Britain. Proceedings of the Prehistoric Society 33, 1967, 307-335.

Amborn 1976: H.Amborn, Die Bedeutung der Kulturen des Niltals für die Eisenproduktion im subsaharischen Afrika. Studien zur Kulturkunde 39 (Wiesbaden 1976).

Andrews et al. 2017: P. Andrews/R. MacKenzie/P. S. Quinn, Crucible steel production at Derwentcote Forge, County Durham. Historical Metallurgy. The Journal of the Historical Metallurgy Society 50/1, 2017, 53-66.

Angus et al. 1962: N. S. Angus / G. T. Brown/H. F. Cleere, The iron nails from the roman legionary fortress at Inchtuthil, Pertshire. Journal of The Iron and Steel Institute 200, January 1962, 956-968.

Anonymus 1900: (ohne Autor) Die Eisenerzeugung bei den Naturvölkern Afrikas mit besonderer Berücksichtigung der Eisenindustrie in Togo. Stahl und Eisen 20/6, 1900, 347-351.

Armbruster 1995: B. Armbruster, Traditionelles Goldschmiedehandwerk in Westafrika und bronzezeitliche Metallverarbeitung in Europa. Beiträge zur Allgemeinen und Vergleichenden Archäologie 15 (Mainz 1995) 111-201.

Balasubramaniam 2007: R. Balasubramaniam, Wootz Steel received by Alexander. Indian Journal of History of Science 43/3, 2007, 511-516.

Balasubramaniam 2008: R. Balasubramaniam, Marvels of Indian Iron through the Ages (New Delhi 2008).

Barraclough 1981: K.C.Barraclough, The development of the early steelmaking processes - an essay in the history of technology (Diss. Sheffield 1981)

Bauvais 2008: S. Bauvais, Prolégomènes à une histoire de la métallurgie du fer au Levant Sud. Bulletin du Centre de recherche français de Jérusalem 19, 2008,

Bauvais et al. 2018: S. Bauvais et al., «Guard the good deposit»: Technology, Provenance and Dating of Bipyramidal Iron Semi-Products of the Durrenentzen Deposit (Haut-Rhin, France). Archaeometry 60/2, 2018, 290-307.

Beck 1884: $\quad$ L. Beck, Die Geschichte des Eisens in technischer und kulturgeschichtlicher Beziehung 1. Von der ältesten Zeit bis um das Jahr 1500 n. Chr. (Braunschweig 1884).

Becker 1973: A. Becker, Franks Casket. Zu den Bildern und Inschriften des Runenkästchens von Auzon. Sprache und Literatur 5 (Regensburg 1973).

Belfort/Ross 2007: P. Belford/R.A. Ross, English steelmaking in the seventeenth century: the excavation of two cementation furnances at Coalbrookdale. Historical Metallurgy. The Journal of the Historical Metallurgy Society 41, 2007, 105-123.
Bergmann 1920: H.Bergmann, Chemisch-technisches Rezeptbuch für die gesamte Metallindustrie $\left(1920^{3}\right)$.

Berranger 2014: M. Berranger, Le fer, entre matière première et moyen d'échange, en France, du vII ${ }^{\mathrm{e}}$ au $\mathrm{I}^{\mathrm{er}}$ siècle avant J.-C. Approches interdisciplinaires (Dijon 2014).

Berranger et al. 2014: M. Berranger et al., L'artisanat du fer dans la villa de Touffréville (Calvados) à l'époque augusto-claudienne: approches archéométallurgique et archéométrique. ArchéoSciences. Revue d'archéométrie 38, 2014, 183-203.

Berranger et al. 2017A: M. Berranger et al., Analyse technologique, étude de provenance et datation par le radiocarbone du dépôt de demiproduits ferreux de Durrenentzen (Haut-Rhin, France): une vision renouvelée de l'économie du fer au premier âge du Fer. ArchéoSciences. Revue d'archéométrie 41/1, 2017, 45-67.

Berranger et al. 2017B: M. Berranger et al., Organisation des productions sidérurgiques en Gaule (VII ${ }^{\mathrm{e}} \mathrm{I}^{\mathrm{er}} \mathrm{s}$. a. J.-C.): de la réduction du métal à l'élaboration des demi-produits. In: S. Marion et al. (Hrsg.), Production et proto-industrialisation aux âges du Fer. Perspectives sociales et environnementales. Actes du $39^{\mathrm{e}}$ colloque international de l'AFEAF (Nancy, 14-17 mai 2015) (Bordeaux 2017) 301-333.

Berranger/Fluzin 2007: M. Berranger/P. Fluzin, Organisation de la chaîne opératoire en métallurgie du fer aux $\mathrm{II}^{\mathrm{e}}-\mathrm{I}^{\mathrm{er}}$ siècle av. J.C., sur l'oppidum d'Entremont (Aix-en-Provence, Bouches-duRhône): la circulation de métal. Revue d'Archéométrie 31, 2007, 7-22.

Berranger/Fluzin 2012: M. Berranger/P. Fluzin, From raw iron to semi-product: quality and circulation of materials during the Iron Age in France. Archaeometry 54/4, 2012, 664-684.

Bersch 1899: J. Bersch, Lexikon der Metall-Technik. Handbuch für alle Gewerbetreibenden und Künstler auf metallurgischem Gebiete (Leipzig o. J. [1899]).

Berthelot 1888: M.Berthelot, Collection des anciens alchimistes grecs. Troisième livraison, comprenant: Les vieux auteurs, les traités techniques et les commentateurs. Texte grec et traduction française (Paris 1888).

Bhardway/Sharma 1997: H.C. Bhardway/V.L.Sharma, Technology, Tools \& Appliances (Allahabad 1997).

Bialeková 2000: D. Bialeková, Eisenbarren. In: A. Wieczorek/H.M. Hinz (Hrsg.), Europas Mitte um 1000 (Stuttgart 2000) 201-202.

Bianchi 1997: U.Bianchi, I.O.M.D.ubi ferrum nascitur. In: G. M. Bellelli / U. Bianchi (Hrsg.), Orientalia sacra urbis Romae Dolichena et Heliopolitana. Recueil d'études archéologiques et historico-religieuses sur les cultes cosmopolites d'origine commagénienne et syrienne. Studia Archaeologica 84 (Roma 1986) 591-597.

Biborski et al. 1982: M. Biborski / P. Kaczanowski / Z. Kędziereki / J.Stępiński, Metallographische Untersuchungen als Kriterium einer Identifikation römischer Schwerter. In: J. Piaskowski (Hrsg.), Ancient iron manufacture centres in Northern Central Europe (Krakow 1982) 65-98.

Biborski et al. 1986: M. Biborski / P. Kaczanowski / Z. Kędziereki / J.Stępiński, Ergebnisse der metallographischen Untersuchungen von römischen Schwertern aus dem Vindonissa-Museum Brugg und dem Römermuseum Augst. Gesellschaft Pro Vindonissa. Jahresbericht 1985 (1986) 45-80.

Birch 2017: T. Birch, Abandoned or unused? Ultra-high carbon steel and cast iron lumps from Semlach / Eisner. Weggeworfen oder ungenutzt? Hoch aufgekohlter Stahl und Gusseisenklumpen von der Fundstelle Semlach / Eisner. In: Cech et al. 2017, 131-149.

Biringuccio 1540: Vannuccio Biringuccio, De la Pirotechnia (Venedig 1540), zitiert nach Johannsen 1925 
Biswas 2001: A. K. Biswas, Minerals and Metals in Pre-Modern India (New Delhi 2001).

BMCRE: H. Mattingly, Coins of the Roman Empire in the British Museum, Vol. 3 (London 1936, reprint 1976).

Bofinger/Schmid 2012: J. Bofinger/D. Schmid, Quer durch die Landschaft. Archäologische Untersuchungen auf der Trasse der EPSPipeline in Baden-Württemberg. Denkmalpflege in Baden-Württemberg, Nachrichtenblatt der Landesdenkmalpflege 41/3, 2012, 131-137.

Bossert-Radtke 1992: C. Bossert-Radtke, Die figürlichen Rundskulpturen und Reliefs aus Augst und Kaiseraugst. Forschungen in Augst 16 = CSIR Schweiz III. Germania superior. Augusta Rauricorum (Augst 1992).

Brady/Clauser 1991: G.S. Brady/H. R. Clauser, Materials Handbook. An Encyclopedia for Managers, Technical Professionals, Purchasing and Production Managers, Technicians, Supervisors, and Foremen (New York 1991 12).

Brauns et al. 2017: M. Brauns et al., Möglichkeiten und Grenzen von Osmium-Isotopenverhältnissen zur Herkunftsbestimmung von archäologischen Eisenobjekten - Eine Modellstudie an Verhüttungsresten aus Hüttenberg (Österreich). In: Cech et al. 2017, 151165

Bréant 1823: J. R. Bréant, Description d'un procédé à l'aide duquel on obtient une espèce d'acier fondu, semblable a celui des lames damassées orientales. Bulletin de la Société d'Encouragement pour l'Industrie Nationale 22, 1823, 222-227 (erweiterte Fassung in: Annales de Mines 9, 1824, 519-528). - English version: J.R. Bréant, On a Process, by which is obtained a Species of Cast-steel, similar to that of which the Damascus Sword-blades are made. The Technical Repository 6, 1824, 49-55.

Brearley 1914: H. Brearley, The Case Hardening of Steel (London 1914). Brepohl 1987: E. Brepohl, Theophilus Presbyter und die mittelalterliche Goldschmiedekunst (Leipzig 1987).

Briard 1976: J. Briard, La métallurgie. In: J. Guilaine (Hrsg.), La préhistoire française 2 (Paris 1976) 236-245.

Brunhuber 1991: E. Brunhuber, Giesserei-Lexikon (Berlin 19915),

Brusin 1991: J. B. Brusin, Inscriptiones Aquileiae. Pubblicazioni della Deputazione di storia patria per il Friuli 20. Pars prima (Udine 1991).

Buchanan 1807: F.Buchanan, Journey from Madras through the countries of Mysore, Canara, and Malabar. 3 vols. (London 1807).

Buxbaum 1932: B. Buxbaum, Feilen. Werkstattbücher für Betriebsbeamte, Vor- und Facharbeiter 46 (Berlin 1932).

Cabboi et al. 2007: S. Cabboi et al., Les systèmes de production sidérurgique chez les Celtes du Nord de la France. In: P.-Y. Milcent (Hrsg.) L'économie du Fer protohistorique: de la production à la consommation du métal. XXVIII ${ }^{\mathrm{e}}$ colloque de l'Afeaf, Toulouse, 20-23 mai 2004. Aquitania Supplément 14/2 (Bordeaux 2007) 35-62.

Cech 2008A: B. Cech (Hrsg.), Die Produktion von Ferrum Noricum am Hüttenberger Erzberg. Die Ergebnisse der interdisziplinären Forschungen auf der Fundstelle Semlach / Eisner in den Jahren 20032005. Austria Antiqua 2 (Wien 2008)

Cech 2008B: B. Cech, 400 years of Roman iron production in Hüttenberg, Carinthia, Austria. In: B. Cech (Hrsg.), Early Iron In Europe. Prehistoric, Roman and Medieval Iron Production. International Conference Hüttenberg, Carinthia, Austria $8^{\text {th }}-12^{\text {th }}$ September 2008, 8-9.

Cech 2010: B. Cech, Technik in der Antike (Darmstadt 2010).

Cech 2012: B. Cech, The production of ferrum Noricum. Largescale Roman iron production in Hüttenberg (Austria). Notizie Archeologiche Bergomensi 20, 2012, 79-94.

Cech et al. 2017: B. Cech (Hrsg.), Die Produktion von Ferrum Noricum am Hüttenberger Erzberg. Die Ergebnisse der interdisziplinären Forschungen auf der Fundstelle Semlach/Eisner in den Jahren 2006-2009. Austria Antiqua 6 (Graz 2017).

Celis 1991: G. R. Celis, Eisenhütten in Afrika. Beschreibung eines traditionellen Handwerks. Museum für Völkerkunde Frankfurt am Main, Sammlung 7: Afrika (Frankfurt 1991).
CIL III: T. Mommsen (Hrsg.), Corpus Inscriptionum Latinarum 3. Inscriptiones Asiae, provinciarum Europae Graecarum, Illyrici Latinae (Berlin 1873).

Clar/Meixner 1953: E.Clar/H. Meixner, Das Manganvorkommen von Dürnstein (Stmk.) bei Friesach. Carinthia II, 143/63, 1953, 145-148.

Cleere 1981: H.F.Cleere, The iron industry of Roman Britain (unpublished PhD thesis. University College London; http: / www. wealdeniron.org.uk/HCleereThesis.pdf [07.11.2015]).

Coleman 2006: K. M. Coleman, M. Valerii Martialis Liber spectaculorum. Edited with introduction, translation and commentary (Oxford 2006).

Comenius 1843: J.A.Comenius, Neuer Orbis Pictus für die Jugend oder Schauplatz der Natur, der Kunst und des Menschenlebens, nach der früheren Anlage des Comenius bearbeitet und dem jetzigen Zeitbedürfnisse gemäss eingerichtet von J.E. Gailer (Reutlingen 1842).

Congdon 1971: L.O.K.Congdon, Steel in Antiquity: A Problem in Terminology. In: D.G. Mitten et al. (Hrsg.), Studies presented to George M. A. Hanfmann (Mainz 1971) 17-27.

Conophagos/Papadimitriou 1986: C. Conophagos/G. Papadimitriou, La métallurgie du fer et de l'acier en Grèce, pendant la période classique (Rom 1986).

Coustures et al. 2006: M.-P. Coustures et al., La provenance des barres de fer romaines des Saintes-Maries-de-la-Mer (Bouches-duRhône). Gallia, 63, 2006, 243-261.

Corretti / Benvenuti 2001: A. Corretti / M. Benvenuti, The beginning of iron metallurgy in Tuscany, with special reference to Etruria Min eraria. Mediterranean Archaeology. Australian and New Zealand Journal for Mediterranean Archaeology 14, 2001, 127-145.

Craddock 1998: P. T. Craddock, New Light on the Production of Crucible Steel in Asia. Bulletin of the Metals Museum of the Japan Institute of Metal 29, 1998, 41-66.

Craddock 2003: P. T. Craddock, Cast Iron, Fined Iron, Crucible Steel: Liquid Iron in the Ancient World. In: P. Craddock/J. Lang (Hrsg.), Mining and Metal Production Through The Ages (London 2003) 231-257.

Craddock 2010: P.T.Craddock, Early Metal Mining and Production (Edinburgh 1995'; London 2010²)

Craddock 2013: P. T. Craddock, Refractories: Ceramics with a Purpose. The Old Potter's Almanack 18/2, 2013, 9-20.

Craddock et al. 2017: P.Craddock/P. Andrews/M. Spataro, «Not even if we had offered him $£ 50$ ): Early crucible steel production and the history of the Huntsman process. Historical Metallurgy. The Journal of the Historical Metallurgy Society 50/1, 2016 (2017) 28-42.

Cramer 1766: J. A. Cramer, Anfangsgründe der Probierkunst, in zweien Theilen abgefasset ... Teil 2: Der Probierkunst anderer praktischer Teil (Stockholm 1746' Leipzig 1766²).

Cranstone 1997: D. Cranstone, Derwentcote Steel Furnace. An Industrial monument in County Durham. Oxford Archaeology, Lancaster Imprints 6 (Oxford 1997).

Crew 1991: P. Crew, The Experimental Production of Prehistoric Bar Iron. Historical Metallurgy 25/1, 1991, 21-36.

Crew 1994: P.Crew, Currency Bars in Great Britain. Typology and Function. In: M. Mangin (Hrsg.), La sidérurgie ancienne de l'Est de la France dans son contexte européen. Archéologie et archéometrie. Annales Littéraires de l'Université de Besançon 536 (Besançon 1994) 345-350.

Crew 1995: P. Crew, Aspects of the iron supply. In: B. Cunliffe (Hrsg.) Danebury 6. A hillfort community in perspective (London 1995).

Crew/Salter 1993: P.Crew/C. Salter, Currency bars with welded tips. In: A. Espelund (Hrsg.), Bloomery Ironmaking during 2000 years 3 (Trondheim 1993) 11-25.

Cunliffe 2005: B. Cunliffe, Iron Age Communities in Britain. An account of England, Scotland and Wales from the seventh century BC until the Roman Conquest (London 20054). 
Curle 1982: C. L. Curle, Pictish and Norse finds from the Brough of Birsay 1934-74. Society of Antiquaries of Scotland. Monograph Series 1 (Edinburgh 1982).

Da 1965: L. Da, Die uralte Technik der Eisenherstellung in China. In: W. U. Guyan (Hrsg.), Vita Pro Ferro. Festschrift für Robert Durrer zum 75. Geburtstag (Schaffhausen 1965) 63-70 (chinesisch und deutsch).

Daicoviciu et al. 1953: C. Caicoviciu et al., Şantierul Grădiştea Muncelului. Studii şi cercetări de istorie veche (SCIV) 4, 1953, 1-2, 153219.

Daim et al. 2005: F. Daim/M.Mehofer/B. Tobias, Die langobardischen Schmiedegräber aus Poysdorf und Brno. Fragen, Methoden, erste Ergebnisse. In: W. Pohl/P. Erhart (Hrsg.), Die Langobarden. Herrschaft und Identität. Forschungen zur Geschichte des Mittelalters 9 (Wien 2005) 201-224.

Darmstädter 1927: E.Darmstädter, Eisenhärtung mit Pflanzen. Geschichtsblätter für Technik, Industrie und Gewerbe 11/3, 1927, 163-169.

David et al. 1989: N. Navid et al., Between bloomery and blast furnace: Mafa iron-smelting technology in North Cameroon. The African Archaeological Review 7, 1989, 183-208.

de Fontenelle 1832: J. de Fontenelle, Manuel complet du bijoutier, du joaillier, de l'orfèvre, du graveur sur métaux et du changeur. Tome premier (Paris 1832).

Delmare et al. 1982: F. Delmare/G. Nicolas/E. Mencarelli, Etude du forgeage d'un lingot de fer protohistorique. Mémoires et Etudes Scientifiques de Métallurgie, Février 1982, 97-104.

Dembski 1983: G. Dembski, MET.NOR. - Zwei Quadrantes des Hadrianus aus Lauriacum. Mitteilungen der Österreichischen Numismatischen Gesellschaft 23/1, 1983, 80-83.

Desai 2018: M. N. Desai, An Overview of Iron Provenance and Its Possible Extension to Crucible Steel Archaeometallurgy. Journal of Multidisciplinary Studies in Archaeology 6, 2018, 926-944

Dexheimer 1998: D. Dexheimer, Oberitalische Grabaltäre. Ein Beitrag Zur Sepulkralkunst der römischen Kaiserzeit. British Archaeological Reports BAR, International Series 741 (Oxford 1998).

Diels / Schramm 1919: H. Diels / E. Schramm, Philons Belopoiika (Viertes Buch der Mechanik). Griechisch und Deutsch. Abhandlungen der Preussischen Akademie der Wissenschaften 1918. Philosophisch-Historische Klasse 16 (Berlin 1919).

Dieudonné-Glad et al. 2001: N. Dieudonné-Glad et al., Metallographic examination of five flat iron bars with socket from the river Saône (France), Historical Metallurgy. The Journal of the Historical Metallurgy Society 35/2, 2001, 67-73.

Dillmann et al. 2017: P. Dillmann, Circulation of iron products in the North-Alpine area during the end of the first Iron Age $\left(6^{\text {th }}-5^{\text {th }} c\right.$. $\mathrm{BC})$ : A combination of chemical and isotopic approaches. Journal of Archaeological Science 87, 2017, 108-124.

Dinnez 2001: M. K. Dinnez, Literary Evidence for Crucible Steel in Medieval Spain. Historical Metallography. The Journal of the Historical Metallurgy Society 35/2, 2001, 74-80.

Dobesch 2000: G. Dobesch, Urgeschichtliches Eisen in der Sicht des Althistorikers. In: H. Friesinger/K. Pieta/J. Rajtàr (Hrsg.), Metallgewinnung und -verarbeitung in der Antike (Schwerpunkt Eisen). Archaeologica Slovaca Monographiae 3 (Nitra 2000) 11-25

Dolenz 1998: H. Dolenz, Eisenfunde aus der Stadt auf dem Magdalensberg. Kärntner Museumsschriften 75 = Archäologische Forschungen zu den Grabungen auf dem Magdalensberg 13 (Klagenfurt 1998).

Dostál 1983: B. Dostál, Železné Sekerovité Hřivny z Břeclavi-Pohanská. Sborník Prací Filozofické Fakulty Brněnské Univerzity. Studia Minora Facultatts Philosophicae Universitatis Brunensis E28 (Brünn 1983) 174-201.

Doswald 1994A: C. Doswald, Les lingots de fer protohistoriques en Europe occidentale: problématique générale. In: M. Mangin (Hrsg.), La sidérurgie ancienne de l'Est de la France dans son contexte européen. Archéologie et archéométrie. Annales Littéraires de l'Université de Besançon 536 (Besançon 1994) 333-343.
Doswald 1994B: C.Doswald, Die Eisenfunde und Werkstätten des Vicus. In: R. Hänggi/C. Doswald/K. Roth-Rubi, Die frühen römischen Kastelle und der Kastell-Vicus von Tenedo-Zurzach. Veröffentlichungen der Gesellschaft Pro Vindonissa 11 (Brugg 1994) 257-319.

Drescher 1976: H. Drescher, Barren. In: Reallexikon der Germanischen Altertumskunde 2 (Berlin / New York 1976) 67 s. v. Barren.

Drescher 1983: Metallhandwerk des 8.-11.Jahrhunderts in Haithabu auf Grund der Werkstattabfälle. In: H.Jankuhn et al. (Hrsg.), Das Handwerk in vor- und frühgeschichtlicher Zeit 2. Archäologische und philologische Beiträge (Göttingen 1983) 174-192.

Duhamel 1786: J.P.F.G.Duhamel, Acier. In: C.-J.Panckoucke (Verleger), Encyclopédie méthodique. Chymie, pharmacie et métallurgie 1 (Paris 1786) 420-463.

Dunbabin 1978: K.M.D. Dunbabin, The Mosaics of Roman North Africa. Studies in Iconography and Patronage (Oxford 1978).

Dungworth 2011: D.Dungworth, The Metalworking debris. In: J. A. Nowakowski / H. Quinnell (Hrsg.), Trevelgue Head, Cornwall: the importance of C. K. Croft Andrew's 1939 excavations for prehistoric and Roman Cornwall (London 2011) 220-244.

Durman 2002: A. Durman, Iron resources and production for the Roman frontier in Pannonia. Historical Metallurgy. The Journal of the Historical Metallurgy Society 36, 2002, 24-32.

Egger 1961: R. Egger, Die Stadt auf dem Magdalensberg, ein Grosshandelsplatz. Die ältesten Aufzeichnungen des Metallwarenhandels auf dem Boden Österreichs. Denkschriften der Österreichischen Akademie der Wissenschaften, Phil.-Hist. Klasse 79 (Wien 1961).

Ehrenreich 1985: R.Ehrenreich, Technology and the Ironworking Community in the Iron Age of Southern Britain. British Archaeological Reports BAR, British series 144 (Oxford 1985).

Eichert/Mehofer 2014: S. Eichert/M. Mehofer, Neue Analysen an alten Waffen. Zur Archäologie und Archäometallurgie frühmittelalterlicher Waffen aus dem Museum der Stadt Villach. Neues aus Alt-Villach 51, 2014, 7-35.

Epprecht/Schaller 1981: W. Epprecht/ E. Schaller, Eisen und Stahl aus Vindonissa. Gesellschaft Pro Vindonissa. Jahresbericht 1981, 2953.

Epprecht/Schaller 1986: W. Epprecht/E. Schaller, Metallkundliche Untersuchung des römischen Stahlblockes. In: A. Hochuli-Gysel et al. 1986, 186-188 Abb. 65-68 Taf. 60,16 (gefolgt von einem Beitrag von A.Mutz, «Technologische Auswertung des römischen Stahlblockes», 188-189 Abb. 69-70).

Erichsen 1924: F.Erichsen (Übers.), Die Geschichte Thidreks von Bern. Thule. Altnordische Dichtung und Prosa, 2. Reihe, Bd.22 (Jena 1924).

Espelund 1996: A. Espelund, Archäo-Metallurgie, von Norwegen aus betrachtet. Ferrum 68, 1996, 43-53.

Evans 2008: C. Evans, Crucible steel as an enlightened material. Historical Metallurgy. The Journal of the Historical Metallurgy Society $42 / 2,2008,79-88$.

Evenstad 1790: O. Evenstad, Afhandling om Jern-Malm, som findes i Myrer og Moradser i Norge, og Omgangsmaaden med at forvandle den til Jern og Staal. Et Priisskrift, som vandt det Kongelige Landhuusholdnings-Selskabs 2den Guldmedaille, i Aaret 1782. Det Kongelige Danske Landhuusholdnings-selskabs Skrifter D3 (København 1790; reprint København 1960) 387-449; zitiert nach der gekürzten Englischübersetzung von N. L. Jensen: A treatise on iron ore as found in the bogs and swamps of Norway and the process of turning it into iron and steel. Bulletin of the Historical Metallurgy Group 2/2, 1968, 61-65.

Evenstad 1801: O. Evenstad, Gekrönte Preisschrift oder praktische Abhandlung von den Sumpf- und Morast-Eisensteinen in Norwegen (Göttingen 1801).

Facella 2013: $\quad$ M. Facella, Ubi ferrum nascitur «... wo das Eisen geboren wird». In: C. Hattler (Red.), Imperium der Götter. Isis · Mithras . Christus. Kulte und Religionen im Römischen Reich (Karlsruhe 2013) 284 .

Fantar 1994: M. H. Fantar, La mosaïque en Tunisie (Paris 1994) 
Fedele 2016: F.G.Fedele, Prähistorische Mobilität am Splügenpass / Mobilità umana preistorica intorno allo Spluga. In: G.Jäger (Hrsg.), Der Splügenpass. Zur langen Geschichte einer kurzen Transitroute / La lunga storia di una breve via di transito (Chur 2016) 19-46.

Fell 2003: V.Fell, Metallographic Examination of Two Iron Age Hooked Blocks from England. In: L. C. Nørbach (Hrsg.), Prehistoric and Medieval Direct Iron Smelting in Scandinavia and Europe. Aspects of Technology and Science (Aarhus 3003) 129-133.

Fell/Salter 1998: V.Fell/C.J.Salter, Metallographic examination of seven Iron Age ferrous axeheads from England, Historical Metallurgy. The Journal of the Historical Metallurgy Society 32/1, 1998, $1-6$.

Feuerbach 2006: A. Feuerbach, Crucible steel: Production and identification. In: R. D. Smith (Hrsg.), Make all sure. The conservation and restoration of arms and armour (Leeds 2006), 12-17.

Feuerbach 2007: A. Feuerbach, Production and trade of crucible steel in Central Asia. Indian Journal of History of Science 42/3, 2007, 319-336.

Feuerbach et al. 2003: A.M. Feuerbach/D. R. Griffiths/J.F. Merkel, Early Islamic Crucible Steel Production at Merv, Turkmenistan. In: P.Craddock/J.Lang (Hrsg.), Mining and Metal Production Through The Ages (London 2003) 258-266.

Feugère 2000: M. Feugère, Un nouveau dépôt de lingots de fer de La Tène finale: Bretteville-sur-Odon (Calvados). Instrumentum 11, 2000, 15.

Feugère/Serneels 1998: M. Feugère/V.Serneels, Production, commerce et utilisation du fer entre l'Ebre et le Rhône: premiers éléments de réflexion. In: M. Feugère/V. Serneels (Hrsg.), Recherches sur l'économie du fer en Méditerranée nord-occidentale. Monographies Instrumentum 4 (Montagnac 1998) 251-262.

Fischer 1990: U. Fischer (Hrsg.), Fachkunde Metall. Europa-Fachbuchreihe für Metallberufe (Haan-Gruiten 199050).

Fluzin 2002: P. Fluzin, La chaîne opératoire en sidérurgie: matériaux archéologies et procédés. Apport des études métallographiques. In: H. Bocoun (Hrsg.), Aux origines de la métallurgie du fer en Afrique. Une ancienneté méconnue. Afrique de l'Ouest et Afrique centrale (Paris 2002) 59-91.

Fluzin et al. 2012A: P. Fluzin et al., An archaeological and archaeometrical approach of ferrous semi-product: typology, quality and circulation. In: C. Cucini (Hrsg.), Acta Mineraria et Metallurgica. Studi in onore di Marco Tizzoni. Notizie Archeologiche Bergomensi 20 (Bergamo 2012) 195-204.

Fluzin et al. 2012B: P. Fluzin et al., The multidisciplinary approach (archaeology and archaeometry) to bloomsmithing activities in France: examples of results from the last twenty years. In: J. Hošek et al. (Hrsg.), The archaeometallurgy of Iron. Recent Developments in Archaeological and Scientifc Research (Prag 2011) 223-236.

Forbes 1950: R.J.Forbes, Metallurgy in Antiquity. A notebook for archaeologists and technologists (Leiden 1950)

Forbes 1964: J.R. Forbes, Studies in Ancient Technology, vol. 9 (Leiden 1964).

Forrer 1932: R. Forrer, Zur Altersfrage der rhomboïden Eisenluppen. Germania 16, 1932, 102-104.

France-Lanord 1963: A. France-Lanord, Les lingots de fer protohistoriques. Revue d'Histoire de la sidérurgie 4, 1963, 167-178.

Frémont 1912: C.Frémont, Le clou. Études expérimentales de technique industrielle (Paris 1912).

Friedland 2013: S. N. Friedland, Die Olsborg und ihr Umfeld. Entstehung, Entwicklung und Bedeutung einer slawenzeitlichen Region in Wagrien (Diss. Kiel 2013).

Fry 1952: A. Fry, Untersuchung eines keltischen Spitzbarrens aus dem Fund von Sauggart (Kr. Ehringen). Fundberichte aus Schwaben N.F. 12/2, 1938-1951 (1952), 49-50.

Fulford et al. 2004: M. Fulford / D. Sim/A. Doig, The production of Roman ferrous armour: a metallographic survey of material from Britain, Denmark and Germany, and its implications. Journal of Roman Archaeology 17, 2004, 197-220.
Furger 1995: A.R. Furger/J. Riederer, Aes und aurichalcum. Empirische Beurteilungskriterien für Kupferlegierungen und metallanalytische Untersuchungen an Halbfabrikaten und Abfällen aus metallverarbeitenden Werkstätten in Augusta Raurica. Jahresberichte aus Augst und Kaiseraugst 16, 1995, 115-180.

Furger 2017: A. R. Furger (mit einem Beitrag von R.J.Shakya), Der vergoldete Buddha. Traditionelles Kunsthandwerk der Newar-Giesser in Nepal (Basel 2017). - English version: A. R. Furger (with a contribution by R.J. Shakya), The gilded Buddha. The traditional art of the Newar metal casters in Nepal (Basel 2017).

Furger 2018: A. R. Furger, Antike Schmelztiegel. Archäologie und Archäometrie der Funde aus Augusta Raurica. Beiträge zur Technikgeschichte 1 (Basel 2018).

Gaitzsch 1978: W. Gaitzsch, Römische Werkzeuge. Limesmuseum Aalen, Kleine Schriften zur Kenntnis der römischen Besetzungsgeschichte Südwestdeutschlands 19 (Stuttgart 1978).

Galik et al. 2003: A. Galik/C. Gugl/G. Sperl, Feldkirchen in Kärnten. Ein Zentrum norischer Eisenverhüttung. Archäologische Forschungen 9 (Wien 2003).

Galili et al. 2015: E. Galili et al., Cargoes of iron semi-products recovered from shipwrecks of the Carmel coast, Israel. Archaeometry $57,2015,505-535$.

Gansum 2004: T. Gansum, Role the Bones - from Iron to Steel. Norwegian Archaeological Review 37/1, 2004, 41-56.

Gardi 1954: R. Gardi, Der schwarze Hephaistos (Bern 1954).

Gardi 1969: R.Gardi, Unter afrikanischen Handwerkern. Begegnungen und Erlebnisse in Westafrika (Bern 1969). - English version: R. Gardi, African crafts and craftsmen (New York 1970).

Gebers 1981: W. Gebers, Bosau. Untersuchungen einer Siedlungskammer in Ostholstein 5. Der slawische Burgwall auf dem Bischofswarder. Teil 1, Katalog und Beilagen. Offa-Bücher 45 (Neumünster 1981).

Georgi 1785A: J.G.Georgi, Versuch einer Geschichte des Eisens mit Anwendung für Gewerbe und Handwerker. Erster Band (Berlin 1785).

Georgi 1785B: J.G.Georgi, Versuch einer Geschichte des Eisens mit Anwendung für Gewerbe und Handwerker. Zweiter Band (Berlin 1785)

Gilmour 2015: B. Gilmour, New evidence for the early making and heat-treating of crucible steel: Kindi's iron treatise. In: S.Srinivasan/S. Ranganathan / A. Giumlia-Mair (Hrsg.), Metals and Civilisation. Proceedings of the Seventh International Conference on the Beginnings of the Use of Metals and Alloys (BUMA VII) (Bangalore 2015) 193-197.

Giolitti 1915: F. Giolitti, The cementation of iron and steel (New York 1915).

Giot 1964: P.-R. Giot, Les lingots de fer bipyramidaux de Bretagne. Annales de Bretagne 71/1, 1964, 51-60.

Giumlia-Mair 2015: A. Giumlia-Mair, Metallurgische Analysen. In: P. Gamper (Hrsg.), Gurina. Die römische Stadt aus der Zeit der Eroberung Noricums. Teil 2 (Klagenfurt am Wörthersee 2015) 440522.

Glaser 1995: F.Glaser, Norische Rennöfen im Görtschitztal. In: G. Guntsche-Liessmann / F.W.Leitner (Red.), Grubenhunt \& Ofensau. Vom Reichtum der Erde 2. Beiträge. Landesausstellung Hüttenberg/Kärnten 29. April - 29. Oktober 1995 (Klagenfurt 1995) 273-276.

Glaser 2000: F. Glaser, Antike Eisengewinnung in Noricum. In: H. Friesinger / K. Pieta / J. Rajtár (Hrsg.), Metallgewinnung und -verarbeitung in der Antike (Schwerpunkt Eisen). Archaelogica Slovaca Monographiae, Communicationes 3 (Nitra 2000) 49-62.

Glaser 2005: F. Glaser, Abteilung für Provinzialrömische Archäologie und Antike Numismatik mit der Aussenstelle Römermuseum Teurnia [2005]. Rudolfinum. Jahrbuch des Landesmuseums Kärnten 2005 (2007) 65-77.

Glodariu 1968: I. Glodariu, Importuri romane în cetăţile dacice din munţii Orăştiei (Römische Importware in den dakischen Burgen von Orăştie). Apulum 7/1, 1968, 353-367. 
Godfrey/van Nie 2004: E. Godfrey/M.van Nie, A Germanic ultrahigh carbon steel punch of the Late Roman-Iron Age. Journal of Archaeological Science 31, 2004, 1117-1125.

Golfomitsou et al. 2017: S. Golfomitsou / T. Rehren / C. Eckmann, Conservation and Archaeological Science for the Protection and Understanding of Ancient Craftsmanship in Cultural Heritage. In: A. Tsuneki/Sh. Yamada/K-i. Hisada (Hrsg.), Ancient West Asian Civilization (Singapore 2017) 199-217.

Gömöri 1988: J.Gömöri, The Earliest Use of Metals in Hungary. In: R. Maddin (Hrsg.), The Beginning of the Use of Metals and Alloys (Cambridge Mass. 1988) 80-91.

Gömöri 2000: J.Gömöri, Az avar kori ès Árpád-kori vaskohászat régészeti emlékei Pannoniában (Magyarorság iparregészeti lelőhelykatasztere I. Vasmüvesség). Archaeometallurgical sites in Pannonia in the Avar and early Arpad periods (Register of industrial archaeological sites in Hungary I. Ironworking). (Sopron 2000).

Gostenčnik 2005: K. Gostenčnik, Schriftquellen zu Rohstoffgewinnung und handwerklicher Produktion in Noricum. In: M. Polver (Hrsg.), Artisanat et économie romaine: Italie et provinces occidentales de l'Empire. Monographies instrumentum 32 (Montagnac 2005) 97-109.

Gostenčnik 2010: K. Gostenčnik, Le fer, des alliages cuivreux et l'or: l'artisanat du métal sur le Magdalensberg. In: P. Chardron-Picault (Hrsg.), Aspects de l'artisanat en milieu urbain: Gaule et Occident romain. Revue Archéologique de l'Est, $28^{\mathrm{e}}$ supplément (Dijon 2010) 289-303.

Grassl 1988: H. Grassl, Norisches Eisen aus dem Burgenland? Historische Bemerkungen zur rezenten Forschung. Römisches Österreich 15/16, 1987-1988, 83-88.

Gruber et al. 2011: C. Gruber/B.Bahrig/A. R. Furger, Aktuelle Korrosionsgefahr? Nachweis von Düngerresten im Boden von Augusta Raurica. Jahresberichte aus Augst und Kaiseraugst 32, 2011, 201222.

Güder et al. 2017: Ü. Güder/M.-H. Gates/Ü. Yalçın, Early Iron from Kinet Höyük, Turkey: Analysis of Objects and Evidence for Smithing. Metalla 23/2, 2017, 51-65.

Gustafsson/Söderberg 2005: B.Gustafsson/A.Söderberg, The tidy metalworkers of Fröjel. Viking Heritage Magazine 2005, Nr. 3, 1417.

Guyton de Morveau 1785: L. B. Guyton de Morveau, Examen des faits qui doivent servir de base à la théorie de la conversion du fer en acier. Nouveaux Mémoires de l'Académie de Dijon, Premier semestre 1785 (Dijon 1785) 406-434.

Guyton de Morveau 1786: L.B.Guyton de Morveau, dasselbe in: L. B. Guyton de Morveau / H. Maret / J. P. F. G. Duhamel (Hrsg.), Encyclopédie Méthodique. Chymie, pharmacie et métallurgie 1 (Paris 1786) 422-432.

Haberfelner et al. 1928: H. Haberfelner/F. Sellner/K. A. Redlich, Die Eisenerzlagerstätten im Zuge Lölling-Hüttenberg-Friesach in Kärnten. Berg- und Hüttenmännisches Jahrbuch 76, 1928, 87-114; $117-126$.

Haglund 1978: K. Haglund, Rod-shaped and scythe-shaped currency bars. In: K. Lamm / A. Lundström (Hrsg.), Excavations at Helgö V / 1 (Stockholm 1978) 38-45.

Hahn 1993: H.P.Hahn, Eisentechniken in Nord-Togo. Kulturanthroposophische Studien 21 (Münster / Hamburg 1993).

Halle 1783: J.S.Halle, Praktische Anweisung alle Stahlarten zu kennen, zu härten, anzulassen und zu bearbeiten. Zum Gebrauch der mechanischen Künstler, sonderlich der Künstler in Stahl (Berlin 1783).

Halleux 2007: R. Halleux, Sur la fabrication de l'acier dans l'Antiquité et au Moyen Âge. Comptes rendus des séances de l'Académie des Inscriptions et Belle-Lettres 151/3, 2007, 1301-1318.

Hallinder 1978: P. Hallinder, Currency bars of Mastermyr type. In: K. Lamm / A. Lundström (Hrsg.), Excavations at Helgö V / 1. Workshop, Part II (Stockholm 1978) 45 f.
Hallinder/Haglund 1978: P. Hallinder/K. Haglund, Iron Currency Bars in Sweden. In: K. Lamm / A. Lundström (Hrsg.), Excavations at Helgö V / 1 (Stockholm 1978) 30-37.

Hallinder/Tomtlund 1978: P. Hallinder/J.-E. Tomtlund, Rod-shaped blanks from Helgö. In: K.Lamm/A.Lundström (Hrsg.), Excavations at Helgö V / 1. Workshop, Part II (Stockholm 1978) 59-80.

Hanemann 1930: H. Hanemann, Untersuchung eines eisernen Spitzbarrens aus der vorrömischen Zeit. Prähistorische Zeitschrift 21, 1930, 271-274.

Hänggi 1989: R.Hänggi, Augusta Rauricorum. Insula 22: Grabungsund Dokumentationsstand 1988. Mit Exkursen zur Dokumentationstechnik in Augst seit 1923 und zu Parasiteneiern in «Kotsteinen» und Erdproben. Jahresberichte aus Augst und Kaiseraugst 10, 1989, 29-72.

Hannah 1932: I. C. Hannah, Roman Blast Furnance in Lincolnshire. The Antiquaries Journal 12/3, 1932, 262-268.

Hartmann 1848: C.Hartmann, Der wohlunterrichtete Hochofenund Hammermeister oder gemeinfassliche Darstellung der Roheisenerzeugung, der Stabeisenfabrication und Stahlbereitung (Weimar 1848).

Healy 1978: J.F. Healy, Mining and Metallurgy in the Greek and Roman World (London 1978).

Heath 1839: J.M. Heath, On Indian Iron and Steel. The Journal of the Royal Asiatic Society of Great Britain and Ireland 5/2, 1839, 390-397.

Hedges/Salter 1979: R. E. M. Hedges/C.J. Salter, Source determination of iron currency bars through the analysis of slag inclusions. Archaeometry 21, 1979, 615-675.

Helfert/Furger 2017: M. Helfert/ A. R. Furger, Archäometrische Untersuchungen in Augusta Raurica: Schmelztiegel, Schmelzgrube in situ und Gusskerne von Grossbronzen. In: M. Kemkes/S. Matesic (Hrsg.), Römische Grossbronzen am UNESCO-Welterbe Limes. Beiträge zum Welterbe Limes 9 (Darmstadt 2017) 174-185.

Henseling 1981: K. O.Henseling, Bronze, Eisen, Stahl. Bedeutung der Metalle in der Geschichte (Reinbeck 1981).

Hils 1985: H.-P.Hils, Von dem herten. Reflexionen zu einem mittelalterlichen Eisenhärtungsrezept. Sudhoffs Archiv. Zeitschrift für Wissenschaftsgeschichte 69, 1985, 62-75.

Hingley 1990: R. Hingley, Iron Age «currency bars»: the archaeological and social context. Archaeological Journal 147, 1990, 91-117.

Hirt 2010: A.M.Hirt, Imperial Mines and Quarries in the Roman World. Organizational Aspects 27 BC - AD 236 (Oxford 2010).

Hochuli-Gysel et al. 1986: A. Hochuli-Gysel et al., Chur in römischer Zeit 1. Ausgrabungen Areal Dosch. Antiqua 12 (Basel 1986).

Hodgkin 1886: T. Hodgkin, The letters of Cassiodorus. Being a condensed translation of the Variae Epistolae of magnus Aurelius Cassiodorus Senator (London 1886). - Online-Version: http: / / www. gutenberg.org / files / 18590/18590-h / 18590-h.htm\#BOOK_IV (20.01.2017)

Hofeneder 2017: A.Hofeneder, Die antiken literarischen Zeugnisse zum Ferrum Noricum. In: Cech et al. 2017, 1-25.

Höfer 1972: A.Höfer, Eine Siedlung und Werkstatt der Dorfschmiede (Kāmi) in Nepal. Archiv für Völkerkunde 26, 1972, 29-57. - English version: A. Höfer, A settlement and smithy of the blacksmiths (Kāmi) in Nepal. Kailash 4, 1976, 349-396.

Holland 1892: T. H. Holland, Preliminary Report on the Iron-ores and Iron-Industries of the Salem District. Records of the Geological Survey of India 25/3, 1892, 135-159.

Hollemann/Wiberg 2007: A. F. Hollemann/ N. Wiberg, Lehrbuch der Anorganischen Chemie (Berlin 2007 102).

Hope 2001: V.M. Hope, Constructing Identity: The Roman Funerary Monuments of Aquileia, Mainz and Nimes. British Archaeological Reports BAR, International series 960 (Oxford 2001).

Hoyland/Gilmour 2006: G. Hoyland/B. Gilmour, Medieval Islamic Swords and Swordmaking: Kindi's treatise «On swords and their kinds» (edition, translation, and commentary) (Cambridge $2006^{1}$ [2012ㄹ). 
Humphrey et al. 1998: J.W.Humphrey/J. P. Oleson/A. N. Sherwood, Greek and Roman Technology: A Sourcebook. Annotated Translations of Greek and Latin Texts and Documents (London/New York 1998).

Huntingford 1980: G.W.B.Huntingford, The Periplus of the Erythraean Sea by an unknown author. With some extracts from Agatharkhidēs «On the Erythraean sea` (London 1980).

Izquierdo 1980: A.F. Izquierdo, Estudio de los restos arqueológicos submarinos en las Costas de Castellón. Cuadernos de prehistoria y arqueología castellonenses 1980, no. 7, 135-195.

Jacobi 1974: G.Jacobi, Werkzeug und Gerät aus dem Oppidum von Manching. Die Ausgrabungen in Manching 5 (Wiesbaden 1974).

Jahn 1861: O.Jahn, Darstellungen antiker Reliefs, welche sich auf Handwerk und Handelsverkehr beziehen (Leipzig 1861).

Johannsen 1925: O.Johannsen, Biringuccios Pirotechnia. Ein Lehrbuch der chemisch-metallurgischen Technologie und des Artilleriewesens aus dem 16. Jahrhundert (Braunschweig 1925).

Johannsen 1953: O.Johannsen, Geschichte des Eisens (Düsseldorf $\left.1925^{1} ; 1953^{3}\right)$.

Jornet/Maggetti 2003: A. Jornet/M. Maggetti, Analyse chimique, minéralogique et technique de la céramique de vaisselle de Liebrüti. In: T. Tomasevic Buck (mit einem Beitr. v. A. Jornet/M. Maggetti), Augusta Raurica. Probleme, Anregungen und Neufunde. Schriften des Vorarlberger Landesmuseums A / 7 (Bregenz 2003) 55-79.

Juleff 1996: G.Juleff, An ancient wind-powered iron smelting technology in Sri Lanka. Nature 379/January 1996, 60-63.

Juleff 1998: G.Juleff, Early Iron and Steel in Sri Lanka. A Study of the Samanalawewa Area. Materialien zur Allgemeinen und Vergleichenden Archäologie 54 (Mainz 1998).

Juleff 2015: G.Juleff, Crucible Steel at Hattota Amune, Sri Lanka, in the first millennium AD: archaeology and contextualisation. In: S. Srinivasan/S. Ranganathan/A. Giumlia-Mair (Hrsg.), Metals and Civilizations. Proceedings of the Seventh International Conference on the Beginnings of the Use of Metals and Alloys (BUMA VII) (Bangalore 2015) 78-86.

Karsten 1821: C.J. B. Karsten, Metallurgische Reise durch einen Theil von Baiern und durch die süddeutschen Provinzen Oesterreichs (Halle 1821).

Kastowsky et al. 2011: K. Kastowsky/M.Mehofer/P.Peter Spindler, Metallurgische Untersuchung an ausgewählten Stücken aus dem Gräberfeld Mannersdorf am Leithagebirge, NÖ. In: P.C. Ramsl (Hrsg.), Das latènezeitliche Gräberfeld von Mannersdorf am Leithagebirge, Flur Reinthal Süd, Niederösterreich. Studien zu Phänomenen der latènezeitlichen Kulturausprägungen (Wien 2011) 508-585.

Kaus 1981: K. Kaus, Lagerstätten und Produktionszentren des Ferrum Noricum. In: G.Sperl (Red.), Eisengewinnung und -verarbeitung in der Frühzeit, gehalten anlässlich der Tagung des Fachausschusses für Montangeschichte des Bergmännischen Verbandes Österreichs in Reichenau an der Rax, Niederösterreich, 22. bis 24. September 1977. Leobener grüne Hefte, Neue Folge 2 (Wien 1981) 74-92.

Kleemann 1961: O. Kleemann, Stand der archäologischen Forschung über die eisernen Doppelpyramiden-(Spitz-)Barren. Archiv für das Eisenhüttenwesen 32, 1961, 581-585.

Kleemann 1966: O. Kleemann, Der erste Fund vorgeschichtlicher Eisenbarren in Franken. Mainfränkisches Jahrbuch für Geschichte und Kunst 18, 1966, 121-134.

Klein 1760: J.G.F.Klein, Ausführliche Beschreibung der Metalllothe und Löthungen, darin sowohl alle Schlag-, Schnell-, Hart-, WeichMetall und andere Lothe zu machen; als auch alle Metalle selbst zu löthen angewiesen werden (Berlin 1760).

Kleinschmidt 1944: B. Kleinschmidt, Das Schleifen in der Metallverarbeitung (Berlin 1944).

Knoll et al. 1980: H. Knoll et al., Plinius der Ältere über das Eisen. Bericht Nr. 81 des Geschichtsausschusses des Vereins Deutscher Eisenhüttenleute. Archiv für das Eisenhüttenwesen 51/12, 1980, 487-492.
Knöpfli 1997: H. Knöpfli, Lost-wax casting. In: H. Knöpfli, Crafts and technologies: Some traditional craftsmen of the Western Grasslands of Cameroon. British Mus. occasional papers 107 (London 1997) 31-52.

Kolling 1993: A.Kolling, Die Römerstadt in Homburg-Schwarzenacker (Homburg-Saarpfalz 1993).

Kossmat 1910: F. Kossmat, Eisenerzlagerstätten der Ostalpen. Mitteilungen der Geologischen Gesellschaft in Wien 3, 1910, 455-457.

Kostoglou 2003: M. Kostoglou, Iron and steel currency bars in ancient Greece. Mediterranean Archaeology and Archaeometry 3, 2003, 63-68.

Kostoglou 2008: M. Kostoglou, Iron and steel in ancient Greece. Artefacts, Technology and Social Change in Aegean Thrace from Classical to Roman Times. British Archaeological Reports BAR, International series 1883 (Oxford 2008).

Krishnan 1954: M.S. Krishnan, Iron-ore. Iron and Steel. Bulletins of the Geological Survey of India, Ser. A, No. 9 (Calcutta 1954).

Kucypera / Hošek 2014: P. Kucypera /J. Hošek, Hypereutectoid steel in early medieval sword production in Europe. Fasciculi Archaeologiae Historicae 27, 2014, 31-39.

Kunckel 1732: J. Kunckel, Der curieusen Kunst- und Werck-Schul erster Theil (Nürnberg 1732).

Kuppuram 1989: G.Kuppuram, Ancient Indian mining, metallurgy and metal industries, Vol. 2 (Delhi 1989).

Landrin 1835: H.Landrin, Manuel du coutelier, ou traité théorique et pratique de l'art de faire tous les ouvrages de coutellerie (Paris 1835).

Lang 2017: J. Lang, Paper for special issue on «Aspects of Ancient Metallurgy». Roman iron and steel: A review. Materials and Manufacturing Processes 2017, DOI:10 10801104269142017 1279326, 1-10.

Laur-Belart 1964: R. Laur-Belart, 28. Jahresbericht der Stiftung Pro Augusta Raurica [1963]. Basler Zeitschrift für Geschichte und Altertumskunde 64, 1964, XLV-LVI.

Laur-Belart 1965: R. Laur-Belart, 29.Jahresber. Stiftung Pro Augusta Raurica [1964]. Basler Zeitschrift für Geschichte und Altertumskunde 65, 1965, XLVII-LXII.

Laur-Belart 1968: R.Laur-Belart, 32.Jahresber. Stiftung Pro Augusta Raurica [1967]. Basler Zeitschrift für Geschichte und Altertumskunde 68, 1968, XVII-XXXIV.

Laur-Belart 1970: R. Laur-Belart, 34.Jahresber. Stiftung Pro Augusta Raurica [1969]. Basler Zeitschrift für Geschichte und Altertumskunde 70, 1970, 287-306.

Leber 1967: P.Leber, Aus dem römischen Kärnten. Carinthia I, 157, 1967, 517-529.

Le Coze 2012: J. Le Coze, L'acier fondu au creuset en France au $19^{e}$ siècle: héritage de l'Orient et naissance des aciers spéciaux. I: Description des outils et de procédés de fusion en creuset depuis le $9^{\mathrm{e}}$ jusqu'au $20^{\text {e }}$ siècle. Matériaux \& Techniques 100, 2012, 343-366.

Ledebur 1903: A. Ledebur, Handbuch der Eisenhüttenkunde für den Gebrauch im Betriebe wie zur Benutzung beim Unterricht bearbeitet. Abteilung 3: Das schmiedbare Eisen und seine Darstellung (Leipzig 19034).

Leo 1902: F. Leo, Cementirung von Schmiedeisen. Stahl und Eisen 22/1, 1902, 438-440.

Leroy et al. 2012: S. Leroy et al., Datation radiocarbone des alliages ferreux anciens. Radiocarbon dating of ancient iron alloys. In: Actes du colloque Sciences des matériaux du patrimoine culturel. 20 et 21 novembre 2012, Paris, Institut national d'histoire de l'art (Paris 2012), 57-63.

Leroy et al. 2014: S. Leroy et al., Provenance et circulation des alliages ferreux. In: P. Dillmann/L. Bellot-Gurlet (Hrsg.), Circulation des matériaux et des objets dans les sociétés anciennes (Paris 2014) 73-101.

Lettich 2003: G. Lettich, Itinerari epigrafici aquileiesi. Guida alle epigrafi esposte nel Museo archeologico nazionale di Aquileia (Trieste 2003). 
Lindeberg 2010: M.Lindeberg, Forging history. Spade-shaped currency bars, history and identity in central Norrland. Current Swedish Archaeology 18, 2010, 203-221.

Livadefs 1956: C.J.Livadefs, The Structural Iron of the Parthenon. Journal of the Iron and Steel Institute 182/1, 1956, 49-66.

Long et al. 2002: L. Long/C. Rico/C. Domergue, Les épaves antiques de Camargue et le commerce maritime du fer en Méditerranée nord-occidentale (I ${ }^{\text {er }}$ siècle avant J.-C. - I er après J.-C.). In: M. Khanoussi et al. (Hrsg.), L'Africa romana. Lo sapazio marittimo del Mediterraneo occidentale: geographia storica ed economia (Roma 2002) 165-188.

Lowe et al. 1991： T. L. Lowe / N. Merk/G. Thomas, An historical mullite fibre-reinforced ceramic composite: Characterization of the ‘wootz crucible refractory. In: P. B. Vandiver/J. Druzik/G. S. Wheeler (Hrsg.), Materials Issues in Art and Archaeoloy 2 (Pittsburgh 1991) 627-632.

Lyaya et al. 2012: E.C.Lyaya/B.B.Bertram/T. Rehren, The Bloom Refining Technology in Ufipa, Tanzania (1850-1950). In: C. Robion-Brunner / B. Martinelli (Hrsg.), Métallurgie du fer et Sociétés africaines. Bilans et nouveaux paradigmes dans la recherche anthropologique et archéologique. Cambridge Monographs in African Archaeology 81 (Oxford 2012) 195-207.

Mack et al. 2000: I. Mack et al., Liquid steel in Anglo-Saxon England. Historical Metallurgy. The Journal of the Historical Metallurgy Society $34 / 2,2000,87-96$.

Maddin et al. 1991: R. Maddin/A. Hauptmann/D. Baatz, A metallographic examination of some iron tools from the Saalburgmuseum. Saalburg-Jahrbuch 46, 1991, 5-23.

Mäder 2003: S. Mäder, Stähle, Steine und Schlangen. Zur Kultur- und Technikgeschichte von Schwertklingen des frühen Mittelalters (Diss. Berlin 2003)

Malzacher 1963: H.Malzacher, Der Magdalensberg und seine Beziehung zum norischen Eisenwesen. Berg- und hüttenmännische Monatshefte 108/3, 1963, 49-59.

Mangin / Fluzin 2006: M. Mangin / P. Fluzin, L'organisation de la production métallurgique dans une ville gallo-romaine: le travail du fer à Alésia. Revue archéologique de l'Est 55, 2006, 129-150.

Mapelli et al. 2009: C. Mapelli et al., Nails of the Roman legionary at Inchtuthil. La Metallurgia Italiana. Gennaio 2009, 51-58.

Maréchal 2002: J.-F. Maréchal, À propos de nouveaux lingots de fer d'époque romaine découverts sur la côte de Narbonnaise. Bulletin de la Société Nationale des Antiquaires de France 1998 (2002) 239_ 254.

Martin / Ruffat 1998: T. Martin / H. Ruffat, Un dépôt de lingots de fer du début de La Tène III à Montans (Tarn). In: M. Feugère/V. Serneels (Hrsg.), Recherches sur l'économie du fer en Méditerranée nord-occidentale. Monographies Instrumentum 4 (Montagnac 1998) 110-115.

Massalski 1841: $\quad$ E.T. (?) Massalski, Préparation de l'acier damassé en Perse. Annuaire du Journal des mines de Russie 1841, 297-308.

Mauri 2012: M. Mauri, The roman nails of Zwammerdam ships: a proposal for provenance, conservation and technological level (Diss. Bologna 2012).

Mehlis 1915: C. Mehlis (mit einem Nachtrag von G. Kossinna), Zu den vorgeschichtlichen Eisenbarren (Spitzbarren). Mannus 7, 1915, 117-120; 338-341.

Merluzzo et al. 2014: P.Merluzzo/M. Leroy/C. Grapin, Étude métallographique de deux masses de fer brut et de deux bandages de roues gallo-romains d'Alésia. Revue archéologique de l'Est 63, No. 186, 2014, 237-258.

Michel 2011: X. Michel, Etude archéologique des techniques d'acquisition et de transformation du métal dans le cadre de la production des lames de sabre au Japon (IXe-XVIe siècle) (Diss. Paris 2011).

Mitsche 1961: R. Mitsche, Untersuchungen an norischen Meisseln vom Magdalensberg / Kärnten. Berg- und hüttenmännische Monatshefte 106/11, 1961, 460-465.

Modin/Lagerquist 1978: S. Modin/ M. Lagerquist, The metallographic examinations of rod-shaped blanks. In: K. Lamm/A. Lundström
(Hrsg.), Excavations at Helgö V:1. Workshop, Part II (Stockholm 1978) 110-151.

Moesta 1983: H. Moesta, Erze und Metalle - ihre Kulturgeschichte im Experiment (Berlin / Heidelberg/New York 1983).

Monguilan/Tivolle 1987: L. Monguilan, Une épave Romaine chargée de fer et de plomb dans le Golfe de Fos-Saint-Gervais I (mit metallurgischem Analysenbericht von A. Tivolle S.178f.). In: Actes du Colloque Mines et Métallurgie en Gaule dans les provinces voisines. Caesarodunum 22 (Paris 1987) 171-179.

Müller 1985: U.Müller, Die römischen Gebäude in KaiseraugstSchmidmatt. Archäologie der Schweiz 8/1, 1985, 15-29.

Müller 1990: F. Müller, Der Massenfund von der Tiefenau bei Bern. Zur Deutung latènezeitlicher Sammelfunde mit Waffen. Antiqua 20 (Basel 1990).

Müller-Karpe 1994: A. Müller-Karpe, Altanatolisches Metalhandwerk. Offa-Bücher 75 (Neumünster 1994).

Mushet 1840: D. Mushet, Papers in iron and steel, Practical and Experimental (London 1840).

Mutz 1976: A. Mutz, Römisches Schmiedehandwerk. Augster Museumshefte 1 (Augst 1976).

Mutz 1981: A. Mutz, Einige Bermerkungen zum Depotfund von 16 Eisenbarren in Schwadernau BE. In: von Kaenel 1981, 128-129.

Naumann 1964: F.K.Naumann, Untersuchungen alter Fundstücke von den Ausgrabungen am Magdalensberg in Kärnten. Archiv für das Eisenhüttenwesen 35/6, 1964, 405-502.

Navasaitis/Selskienè 2007A: J. Navasaitis/A. Selskienè, Iron smelting techniques in the Virbaliūnai ancient settlement. Archaeologia Baltica 8 (Łódź 2007) 387-394.

Navasaitis/Selskienè 2007B: J.Navasaitis/A.Selskiené, Metallographic Examination of Cast Iron Lump Produced in the Bloomery Iron Making Process. Materials Science (Medžiagotyra) 13/2, 2007, 167-173.

Needham 1958: J. Needham, The Development of Iron and Steel Technology in China (London 1958).

Needham 1980: J. Needham, The Evolution of Iron and Steel Technology in East and Southeast Asia. In: T. A. Wertime/J. D. Muhly (Hrsg.), The Coming of the Age of Iron (New Haven 1980) 507-541.

Nellmann 2005: E.Nellmann, Das Annolied. Mittelhochdeutsch / Neuhochdeutsch (Stuttgart $1975^{1} ; 2005^{6}$ ).

Neumann/Wilsdorf 1954: B. Neumann/H. Wilsdorf, Die ältesten Verfahren der Erzeugung technischen Eisens durch direkte Reduktion von Erzen mit Holzkohle in Rennfeuern und Stücköfen und die Stahlerzeugung unmittelbar aus dem Eisenerz. Freiberger Forschungshefte D6 (Berlin 1954).

Oberhoffer 1920: P. Oberhoffer, Das schmiedbare Eisen. Konstitution und Eigenschaften (Berlin 1920).

Ohlhaver 1939: H. Ohlhaver, Frühmittelalterliche Eisenbarren aus Staré Město in Mähren. Germania 23, 1939, 119-122.

Orengo 2003: L. Orengo, Forges et forgerons dans les habitats laténiens de la Grande Limagne d'Auvergne. Monographies Instrumentum 26 (Montagnac 2003).

Pagès 2010: G. Pagès, Artisanat et économie du fer en France méditerranéenne de l'Antiquité au début du Moyen-Age: une approche interdisciplinaire (Montagnac 2010).

Pagès at al. 2006: G. Pagès/L. Schneider/P. Fluzin, Le travail du fer dans l'établissement perché tardo-antique du Roc de Pampelune (Argelliers, Hérault): l'apport des analyses métallographiques. ArchéoSciences. Revue d'Archéométrie 29, 2005, 107-116.

Pagès et al. 2011A: G. Pagès et al., A study of the Roman iron bars of Saintes-Maries-de-la-Mer (Bouches-du-Rhône, France). A proposal for a comprehensive metallographic approach. Journal of Archaeological Science 38, 2011, 1234-1252.

Pagès et al. 2011B: G. Pagès/F. Fluzin/L. Long, L'acier, une variété de fer parmi d'autres? Approches méthodologiques des demi-produits des épaves romaines des Saintes-Maries-de-la-Mer (Bouchesdu-Rhône, France). In: P. Dillmann et al. (Hrsg.), L'acier en Europe avant Bessemer. Collection Méridiennes, Série «Histoire et Technique» (Toulouse 2011) 83-110. 
Pagès 2014: G. Pagès, Productions, commerces et consommation du fer dans le Sud de la Gaule de la Protohistoire à la domination romaine. Gallia 71/2, 2014, 47-67.

Paret 1935: O.Paret, Der grosse Eisenbarrenfund von Sauggart OA. Riedlingen. Fundberichte aus Schwaben N.F.8, 1933-1935 (1935), 91-92

Paynter 2002: S. Paynter, Analysis of Objects from Stanway, Colchester. Centre for Archaeology Report 72 (Swindon 2002).

Paynter 2007: S. Paynter, Romano-British workshops for iron smelting. Historical Metallurgy. The Journal of the Historical Metallurgy Society 41/1, 2007 15-31.

Papakhristou/Rehren 2001: O.Papakhristou/T. Rehren, Iron and steelproduction in old Termez (Research Prospects). In: P. Leriche et al. (Hrsg.), La Bactriane au carrefour des routes et des civilisations de l'Asie centrale. Termez et les villes de Bactriane-Tokharestan. Actes du colloque de Termez 1997 (Paris 2001) 145-159.

Papachristou/Rehren 2008: O.Papachristou/T.Rehren, A Tentative Comparison of Steelmaking Crucibles from Central Asia and the Indian Subcontinent. In: Y. Facorellis/N.Zacharias/K. Polikreti (Hrsg.), Proceedings of the 4th Symposium of the Hellenic Society for Archaeometry. National Hellenic Research Foundation, Athens 28-31 May 2003. British Archaeological Reports BAR, International Series 1746 (Oxford 2008) 519-528

Perret 1780: J.J.Perret, Herrn Perret's Abhandlung vom Stahl, dessen Beschaffenheit, Verarbeitung und Gebrauch (Dresden 1780) - Übersetzung der französischen Originalausgabe: J.J.Perret, Mémoire sur l'acier, dans lequel on traite des différentes qualités de ce métal, de la forge, du bon emploi \& de la trempe (Paris 1779).

Pfeiffer 1861: F.Pfeiffer, Das Buch der Natur von Konrad von Megenberg. Die erste Naturgeschichte in deutscher Sprache (Stuttgart 1861)

Piaskowski 1961: J.Piaskowski, Metallographic investigations of ancient iron objects from the territory between the Oder and the Basin of the Vistula river. Journal of The Iron and Steel Institute, July 1961, 263-282.

Piccottini 1981: G.Piccottini, Antike Zeugnisse für das «ferrum Noricum». In: F. H. Ucik (red.), 2500 Jahre Eisen aus Hüttenberg. Eine montanhistorische Monografie. Kärntner Museumsschriften 68, 1981, 70-75.

Piccottoni 1985: G.Piccottoni, Ein römerzeitlicher Votivaltar aus Kärnten. In: E. Weber / G. Dobesch (Hrsg.), Römische Geschichte, Altertumskunde und Epigraphik. Festschrift für Arthur Betz zur Vollendung seines 80. Lebensjahres (Wien 1985) 465-470 Taf. 7.

Piccottini 2002: G. Piccottini (m. Beitr. V.H. Dolenz/F. Glaser/R. Jernej), Virunum. In: M.Šašel Kos/P. Scherrer (Hrsg.), The Autonomous Towns in Noricum and Pannonia - Die autonomen Städte in Noricum und Pannonien. Situla 40 (Ljubljana 2002) 103-134.

Pleiner 1968: R. Pleiner, Problem of Direct Steel Production in Early Ferrous Metallurgy. Steel Times 33, 1968, 312-318.

Pleiner 1969A: R. Pleiner, Experimental smelting of steel in early medieval furnaces. Památky Archeologické 60/2, 1969, 458-487.

Pleiner 1969B: R. Pleiner, Iron working in ancient Greece (Praha 1969).

Pleiner 1970: R. Pleiner, Zur Schmiedetechnik im römerzeitlichen Bayern. Bayerische Vorgeschichtsblätter 35, 1970, 113-141 Taf. 8-20.

Pleiner 1980: R. Pleiner, Early Iron Metallurgy in Europe. In: T. A. Wertime/J. D. Muhly (Hrsg.), The Coming of the Age of Iron (New Haven / London 1980) 375-415

Pleiner 1996: R. Pleiner, Metallographische Untersuchung des gestempelten römischen Eisenbarrens E1170. In: Schaltenbrand Obrecht 1996, 221-226 Abb. 219-226.

Pleiner 1997: R. Pleiner, Vom Rennfeuer zum Hochofen. Die Entwicklung der Eisenverhüttung, 9.-14.Jahrhundert. In: U.Lindgren (Hrsg.), Europäische Technik im Mittelalter 800-1200. Tradition und Innovation (Berlin 1996) 249-256.

Pleiner 2003: R.Pleiner, European Iron Blooms. In: L.C. Nørbach (Hrsg.), Prehistoric and Medieval Direct Iron Smelting in Scandinavia and Europe. Aspects of Technology and Science (Aarhus 3003) 183-189.
Pleiner 2006: R. Pleiner, Iron in Archaeology. Early European Blacksmiths (Praha 2006).

Pleiner/Bjorkman 1974: R.Pleiner/J.Bjorkman, The Assyrian Iron Age. The History of Iron in the Assyrian Civilisation. Proceedings of the American Philosophical Society 118/3, 1974, 283-313.

Pleiner et al. 2003: R. Pleiner et al. (2003), Lingots et couteaux en fer d'Alésia: études archéométriques de pièces inédites. Revue Archéologique de l'Est 52, 2003, 91-130.

Ploss 1957: E. Ploss, Wielands Schwert Mimung und die alte Stahlhärtung. Beiträge zur Geschichte der deutschen Sprache und Literatur 79, 1957, 110-128.

Poppe 1820: J.H.M. Poppe, Technologisches Lexicon 5. Sta-Z (Stuttgart/Tübingen 1820).

Prakash 2011: B. Prakash, Ancient Indian iron and steel. An archaeometallurgical study. Indian Journal of History of Science $46 / 3$ 2011, 381-410.

Prechtl 1834: J.J. R. von Prechtl (Hrsg.), Technologische Encyklopädie oder alphabetisches Handbuch der Technologie, der technischen Chemie und des Maschinenwesens. Zum Gebrauche für Kameralisten, Ökonomen, Künstler, Fabrikanten und Gewerbetreibende jeder Art. Fünfter Band Eisen-Feuerschwamm (Stuttgart 1834).

Presslinger 2007: H.Presslinger, Der Mythos über das Härten von Stahl. Res Montanarum. Zeitschrift des Montanhistorischen Vereins Österreich 41, 2007, 60-64.

Presslinger 2008: H. Presslinger, Ferrum Noricum - Archäometallurgische Untersuchungsergebnisse von Schlacken und Stahlprodukten. In: Cech 2008A, 232-250.

Presslinger et al. 2007: H. Presslinger / E. M. Rupprechtsberger / O. H Urban, Stahlwerkstoffe der Kelten- und Römerzeit. Berg- und hüttenmännische Monatshefte 152, 2007, Heft 5, 146-150 (Teil 1) und Heft 7, 232-234 (Teil 2).

Presslinger et al. 2016: H. Presslinger / F. Glaser / C. Commenda / K.-M Kröpfl, Roheisen - eine Handelsware zur Stahlerzeugung in den römerzeitlichen Schmieden. Berg- und hüttenmännische Monatshefte 161/3, 2016, 137-142.

Presslinger/Köstler 1991: H.Presslinger/H.J. Köstler, Der Werkstoff Stahl im Altertum. Ferrum. Nachrichten aus der Eisenbibliothek 63, 1991, 18-26.

Presslinger / Mayr 2001: H. Presslinger/M. Mayr, Celtic steel - an evaluation of depot finds. Steel research international 72/8, 2001, 283-290.

Presslinger / Rupprechtsberger 2016: H. Presslinger/E. M. Rupprechtsberger, Der frühlatènezeitliche Gürtelhaken aus Linz-St. Peter metallurgische Untersuchung. Jahrbuch der Gesellschaft für Landeskunde und Denkmalpflege Oberösterreich 161, 2016, 21-32.

Rädeker/Naumann 1961: W. Rädeker/F. K. Naumann, Untersuchung vor- oder frühgeschichtlicher Spitzbarren. Archiv für das Eisenhüttenwesen 32, 1961, 587-595.

Ramos et al. 1984: J.E. Ramos/J. Wagner/A. Fernández-Izquiero, El yaccimiento arqueológico submarino de Ben-Afelí. Estudio de los materiales (Almazora, Castellón). Cuadernos de Prehistoria y Arqueología 10, 1984, 121-158.

Read 1934: T.T. Read, Metallurgical fallacies in archaeological literature. American Journal of Archaeology 38, 1934, 382-389.

Réaumur 1722: R. A. F. de Réaumur, Art de convertir le fer forgé en acier et l'art d'adoucir le fer fondu, ou de faire des ouvrages de fer fondu aussi finis que de fer forgé (Paris 1722).

Rehder 1989: J.E. Rehder, Ancient Carburization of Iron to Steel. Archaeomaterials 3, 1989, 27-37.

Rehren / Papakhristou 2000: T. Rehren/O. Papakhristou, Cutting Edge Technology - The Ferghana Process of medieval crucible steel making. Metalla 7/2, 2000, 55-69.

Rehren/Papachristou 2003: T. Rehren/O. Papachristou, Similar like White and Black: a Comparison of Steel-making Crucibles from Central Asia and the Indian Subcontinent. In: Th. Stöllner et al (Hrsg.), Man and Mining. Studies in honour of Gerd Weisgerber on occasion of his $65^{\text {th }}$ birthday (Bochum 2003) 393-404. 
Reisborg 1996: S. Reisborg, Gropar med rester av metallbearbetning. In: J. Wikborg (Red.), Bastubacken ett gravfält från äldre romersk järnålder Raä 73. Tortuna sn, Västmanland, Tryckta rapporter från Arkeologikonsult AB, Nr. 15 (Uppsala 1996) 240-242.

Reiser 1896: F. Reiser, Das Härten des Stahles in Theorie und Praxis (Leipzig 18912).

Renoux 2004: G. Renoux, La métallurgie des anciens: cuire ou recuire, les recettes du forgeron. Revue des Études Latines 82, 2004, 19-24.

RIC: H.Mattingly/E.A.Sydenham, The Roman Imperial Coinage, Vol. 2 (London 1926).

Riha 1986: E. Riha, Römisches Toilettgerät und medizinische Instrumente aus Augst und Kaiseraugst. Forschungen in Augst 6 (Augst 1986).

Riley 2011: D. Riley, Anglo-Saxon Iron and Steelmaking (Sheffield 2011).

Rinman 1814: S. Rinman, Geschichte des Eisens mit Anwendung für Künstler und Handwerker. Erster Band (Liegnitz 1814).

Rinman 1815: S. Rinman, Geschichte des Eisens mit Anwendung für Künstler und Handwerker. Zweiter Band (Liegnitz 1815).

Roesch 1975: K. Roesch, Kommagene - das Land «ubi ferrum nascitur». In: F. K. Dörner (Hrsg.), Kommagene. Geschichte und Kultur einer antiken Landschaft. Antike Welt 6, 1975, Sondernummer, 15-17.

Roesch / Kühn 1976: K. Roesch / H. M. Kühn, Synthetische Herstellung von Rennfeuereisen und dessen handwerkliche Verarbeitung. Archiv für das Eisenhüttenwesen 47, 1976, 5-8.

Rommel 1929: H. Rommel, Stahl. In: G. Wissowa (Bearb.), Paulys Realencyclopädie der classischen Altertumswissenschaft 2. Reihe, 6. Band (Stuttgart 1929) Sp. 2126-2133.

Rose et al. 2018: T. Rose et al., Die Bedeutung von Raseneisenerzen für die Herkunftsrekonstruktion mittels Eisenisotopen. Archäometrie und Denkmalpflege 2018, 114-117.

Rostoker / Bronson 1990: W. Rostoker / B. Bronson, Pre-Industrial Iron. Its Technology and Ethnology (Philadelphia 1990).

Rottländer 2000: R. C. A. Rottländer (Hrsg.), Plinius Secundus d. Ä. Über Glas und Metalle. Übersetzt und kommentiert von der Projektgruppe Plinius (St. Katharinen 2000).

Sachse 1989: M. Machse, Damaszener Stahl. Mythos, Geschichte, Technik, Anwendung (Bremerhaven 1989).

Said 1989: H. M. Said, Al-Beruni's Book on Mineralogy. The Book Most Comprehensive In Knowledge On Precious Stones (Islamabad 1989).

Salin 1957: E. Salin, La civilisation Mérovingienne d'après les sépultures, les textes et le laboratoire 3. Les techniques (Paris 1957).

Salter 1997: C.Salter, Bloomery Steel - an Overlooked Material. In: P. Crew/S. Crew (Hrsg.), Early Ironworking in Europe. Archaeology and Experiment. Plas Tan y Bwlch occasional paper 3 (Gwynedd 1997)102-103.

Sanidas et al. 2016: G. M. Sanidas et al., Polykmetos Sideros : à propos du fer en Grèce antique. Revue archéologique 2016/2, 279-301.

Sauder 2013: L. Sauder, Making steel in the «Aristotle furnance. In: D.Dungworth/R.C.P.Doonan (Hrsg.), Accidental and Experimental Archaeometallurgy. The Historical Metallurgy Society. Occasional publication 7 (London 2013) 107-110.

Schaaber 1963: O.Schaaber, Beiträge zur Frage des norischen Eisens. Metallkundliche Grundlagen und Untersuchungen an Funden vom Magdalensberg. Carinthia I / 153, 1963, 129-206 Taf. 1-36.

Schaaber 1964: O.Schaaber, Metallkundliche Untersuchung an Fundstücken aus Schweissstahl vom Magdalensberg. Archiv für das Eisenhüttenwesen 35/6, 1964, 502-506.

Schaaber 1976/77: O.Schaaber, Überlegungen zur Deutung der Plinius-Angaben über das Eisen aufgrund metallkundlicher Funduntersuchungen. Jahreshefte des Österreichischen Archäologischen Institituts 51, 1976/77, Hauptblatt. 85-105. (Praktisch identische Fassung: O.Schaaber, Diskussion der Plinius-Angaben über das Eisen anhand metallkundlicher Funduntersuchungen. Jahrbuch der Wittheit zu Bremen 18, 1974, 215-245)
Schaaber 1977: O.Schaaber, Metallkundliche Untersuchungen zur Frühgeschichte der Metallurgie. Archäologie und Naturwissenschaften 1, 1977, 221-268.

Schäfer 2002: A.Schäfer, Manching - Kelheim - Berching-Pollanten. Eisen als Wirtschaftsfaktor. In: C.Dobiat/S. Sievers/T. Stöllner (Hrsg.), Dürrnberg und Manching. Wirtschaftsarchäologie im ostkeltischen Raum. Kolloquien zur Vor- und Frühgeschichte 7 (Bonn 2002) 219-241.

Schaltenbrand Obrecht 1996: V.Schaltenbrand Obrecht, Die Eisenfunde. In: E. Deschler-Erb et al., Vitudurum 7. Ausgrabungen im Unteren Bühl. Die Funde aus Metall. Ein Schrank mit Lararium des 3.Jahrhunderts. Monogr. Kantonsarchäologie Zürich 27 (Zürich / Egg 1996) 141-228.

Schatzmann 2013: R. Schatzmann, Die Spätzeit der Oberstadt von Augusta Raurica. Untersuchungen zur Stadtentwicklung im 3. Jahrhundert. Forschungen in Augst 48 (Augst 2013).

Schiefer/Grün 1927: J.Schiefer/E. Grün, Lehrgang der Härtetechnik (Berlin 1927).

Schmid 1932: W.Schmid, Norisches Eisen. Beiträge zur Geschichte des österreichischen Eisenwesens, Abt. 1, Heft 2 (Wien/Berlin/ Düsseldorf 1932).

Schmidt / Avery 1978: P. Schmidt / D. H. Avery, Complex Iron Smelting and Prehistoric Culture in Tanzania. Science 201, 1978, Nr. 4361, 1085-1089.

Schmidt / Avery 1983: P. R. Schmidt / D. H. Avery, More Evidence for an Advanced Prehistoric Iron Technology in Africa. Journal of Field Archaeology 10/4, 1983, 421-434.

Schoff 1912: W.H.Schoff, The periplus of the Erythraean Sea. Travel and trade in the Indian Ocean by a merchant of the first century (London 1912).

Schoff 1915: W.H.Schoff, The Eastern Iron Trade of The Roman Empire. Journal of the American Oriental Society 35, 1915, 224-239.

Schrüfer-Kolb 2004: I. Schrüfer-Kolb, Roman iron production in Britain. Technological and socio-economic landscape development along the Jurassic Ridge. British Archaeological Reports BAR, British series 380 (Oxford 2004).

Schwab 2002: R.Schwab, Evidence for carburized steel and quench-hardening in the «Celtic oppidum of Manching. Historical Metallurgy. The Journal of the Historical Metallurgy Society 36/1, 2001, 6-16.

Schwab et al. 2006: R.Schwab et al., The provenance of iron artefacts from Manching: a multi-technique approach. Archaeometry 48/3, 2006, 433-452.

Schwarzlose 1886: F. W. Schwarzlose, Die Waffen der alten Araber aus ihren Dichtern dargestellt. Ein Beitrag zur arabischen Alterthumskunde, Synonymik und Lexicographie (Leipzig 1886).

Senn Bischofberger 2005: M. Senn Bischofberger, Das Schmiedehandwerk im nordalpinen Raum von der Eisenzeit bis ins frühe Mittelalter. Internationale Archäologie. Naturwissenschaft und Technologie 5 (Rahden 2005).

Sherby/Wadsworth 2001: O.D.Sherby/J.Wadsworth, Ancient Blacksmiths, the Iron Age, Damascus steels, and modern metallurgy. Journal of Materials Processing Technology 117, 2001, 347353.

Shore 1986: D. Shore, Steel-making in ancient Africa. In: I. V.Sertima (Hrsg.), Blacks in Science: Ancient and Modern (New Brunswick 1986) 157-162.

Siegelová 1984: J.Siegelová, Gewinnung und Verarbeitung von Eisen im Hethitischen Reich im 2.Jahrtausend v. u.Z. Annals of the Náprstek Museum 12, 1984, 71-168.

Sim 2012: D. Sim, The Roman Iron Industry in Britain (Stroud 20021; $\left.2012^{2}\right)$.

Smithells 1949: C.J. Smithells, Metals reference book (London 19491).

Snodgrass 1980: A. M. Snodgrass, Iron an Early Metallurgy in the Mediterranean. In: T. A. Wertime/J. D. Muhly (Hrsg.), The Coming of the Age of Iron (New Haven 1980) 335-374. 
Söderberg 2008: A.Söderberg, Metallurgical clay packages. In H. Clarke/K. Lamm (Hrsg.), Excavations at Helgö 17. Workshop, Part 3 (Stockholm 2008) 1-11.

Söderberg / Gustafsson 2007: A. Söderberg/ B. Gustafsson, Från prestigevarugjutning till myntning. Tidigmedeltida metallurgi i kvarteret Trädgårdsmästaren, Sigtuna. In: S. Tesch/R. Edberg/A. Wikström (Hrsg.), Situne Dei. Årsskrift för Sigtunaforskning 2007, 17 40.

Solier 1981: Y.Solier (Hrsg.), Les épaves de Gruissan. Archaeonautica, 3, 1981, 7-264.

Soulignac 2017: R.Soulignac, Les Scories de forge du Pays dogon (Mali). Entre ethnoarchéologie, archéologie expérimentale et archéométrie (Hochwald / Basel 2017).

Sperl 2002A: G. Sperl, FERRUM NORICUM - Stand der Forschung über eine frühe Stahlqualität. Berg- und Hüttenmännische Monatshefte $147 / 3,2002,61-65$.

Sperl 2002B: G.Sperl, Frühestes Werkstoff-Prüfzentrum am Magdalensberg. Rudolfinum. Jahrbuch des Landesmuseums für Kärnten 2001/2002 (2002), 151-156.

Sperl 2004: G.Sperl, Zum Stand der Erforschung des Ferrum Noricum. In: H. Heftner/K. Tomaschitz (Hrsg.), Ad Fontes! Festschrift für Gerhard Dobesch zum fünfundsechzigsten Geburtstag am 15. September 2004 dargebracht von Kollegen, Schülern und Freunden (Wien 2004) 961-976.

Srinivasan 2007: S. Srinivasan, On higher Carbon and Crucible Steels in Southern India: further Insights from Mel-Siruvalur, Kodumanal and Pattinam. Indian Journal of History of Science 42/2, 2007, 673-695.

Srinivasan 2017: S. Srinivasan, Ultrahigh-carbon «wootz» from crucible carburization of molten iron: Hypereutectoid steel from «Tamil Nadu Process» at Mel-siruvalur. Materials and Manufacturing Processes 32/7-8, 2017, 909-915

Starley 1999: D.Starley, Determining the Technological Origins of Iron and Steel. Journal of Archaeological Science 26, 1999, 1127 1133.

Steiger et al. 1977: R. Rteiger et al., Augst. Insula 31. Ausgrabungen und Funde 1960/61. Forschungen in Augst 1 (Augst 1977).

Steinbrings 1928: D.W.Steinbrings, Praktische Natur- und Werkstoffkunde für metallverarbeitende Berufe als Grundlage für die Werkstattkunde und das fachliche Rechnen (Stuttgart 1928).

Stephens 1884: G.Stephens, Handbook of the old-northern runic monuments of Scandinavia and England (London 1884).

Straube 1973: H.Straube, Beitrag zur antiken Stahlerzeugung im Raume Kärnten. Radex-Rundschau 1973, Nr. 2, 479-498.

Straube 1986: H. Straube, Kritische Gegenüberstellung der Theorien über die Metallurgie des Rennfeuers. Ferrum 57, 1986, 20-28.

Straube 1996: H.Straube (mit Beitr. v. H.Dolenz/G. Piccottini), Ferrum Noricum und die Stadt auf dem Magdalensberg (Wien 1996).

Straube et al. 1964: H. Straube/B. Tarmann/E. Plöckinger, Erzreduktionsversuche in Rennöfen norischer Bauart. Kärntner Museumsschriften 35 (Klagenfurt 1964).

Sütterlin 1996: H.Sütterlin, Miliaria in Augusta Raurica. Bemerkungen zu den Meilensteinfunden im Bereich der Hohwartstrasse (Grabung 1995.60). Jahresberichte aus Augst und Kaiseraugst 17, 1996, 71-87.

Szmoniewski 2010: B.S. Szmoniewski, Axe-like iron bars in the early Middle Ages from Central and Northern Europe. Some comments. In: A. Măgureanu / E. Gáll (Hrsg.), Între stepă şi Imperiu. Zwischen der Steppe und dem Reich. Archäologische Studien für Radu Harhoiu zum 65. Geburtstag (Bukarest 2010) 289-295.

Tholander 1971: $\quad$ E. Tholander, Evidence of the Use of Carburized Steel and Quench Hardening in Late Bronze Age Cyprus. Opuscula Atheniensa 10, 1971, 15-22.

Thouvenin 1984: A. Thouvenin, Lingots de fer gaulois et techniques de forge. Revue archéologique de l'Est et du Centre-Est 35/3-4 $1984,368-372$.
Tomasevic-Buck 1984: T.Tomasevic-Buck, Ausgrabungen in Augst und Kaiseraugst im Jahre 1978. Jahresberichte aus Augst und Kaiseraugst 4, 1984, 7-54

Tomasevic-Buck 1985: T.Tomasevic-Buck, Ausgrabungen in Augst und Kaiseraugst im Jahre 1980. Jahresberichte aus Augst und Kaiseraugst 5, 1985, 239-295.

Trebsche 2012: P. Trebsche, Grösse und Wirtschaftsstruktur latènezeitlicher Flachlandsiedlungen im österreichischen Donauraum. Zborník Slovenského Národného Múzea 106. Archeológia 22 (Ročník 2012) 131-153.

Truffaut 2008: E. Truffaut, Ferrum Noricum am Hüttenberger Erzberg - besonderes Erz oder besonderes Know-how? In: Cech 2008A, 251-271.

Truffaut 2014: E. Truffaut, Steelmaking in a bloomery furnace: behaviour of manganese. In: B. Cech/T. Rehren (Hrsg.), Early Iron in Europe. Monographies Instrumentum 50 (Montagnac 2014) 285-298.

Tylecote 1987: R. F. Tylecote, The early history of metallurgy in Europe (London 1987).

Ulbert 1984: G. Ulbert, Cáceres el Viejo. Ein spätrepublikanisches Legionslager in Spanisch-Extremadura. Madrider Beiträge 11 (Mainz 1984).

Validi 1936: A.-Z.Validi, Die Schwerter der Germanen, nach arabischen Berichten des 9.-10.Jahrhunderts. Zeitschrift der Deutschen Morgenländischen Gesellschaft 1936, 19-37.

van der Merve 1980: N. van de Merve, The Advent of Iron in Africa. In: T. A. Wertime/J. D. Muhly (Hrsg.), The Coming of the Age of Iron (New Haven 1980) 463-506

Vega et al. 2003: E. Vega et al., Forging of phosphoric iron. An analytical and experimental approach. Archaeometallurgy in Europe (Milan 2003) 337-346.

Vetters 1966: H. Vetters, Ferrum Noricum. Anzeiger der Österreichischen Akademie der Wissenschaften, Phil.-Hist. Klasse 103, Nr. 25 (Wien 1966) 167-186

Volken 2011: M. Volken, Les clous de chaussures du site de Pfyngut: les bases d'une typo-chronologie. In: O. Paccolat (Hrsg.), Pfyn / Finges. Evolution d'un terroir de la plaine du Rhône. Le site archéologique de «Pfyngut» (Valais, Suisse). Cahiers d'Archéologie Romande 121 (Lausanne 2011) 315-388.

von Kaenel 1981: H.-M.von Kaenel, Ein Depotfund von 16 doppelpyramidenförmigen Eisenbarren in Schwadernau BE. Archäologie der Schweiz 4/1, 1981, 15-21.

Voysey 1832: H.W. Voysey, Description of the Native Manufacture of Steel in Southern India. The Journal of the Asiatic Society of Bengal 1, 1832, 245-247.

Wagner 1990: D. B. Wagner, Ancient Carburization of Iron to Steel: A Comment. Archaeomaterials 4, 1990, 111-117.

Wagner 1993: D. B. Wagner, Iron and Steel in Ancient China. Handbuch der Orientalistik/Handbook of Oriental Studies, 4. Abteilung, Band 9 (Leiden / New York / Köln 1993).

Wagner 2007: D. B. Wagner, Chinese steel making techniques with a note on Indian wootz steel in China. Indian Journal of History of Science 42/3, 2007, 289-318.

Wagner 2008: D.B.Wagner, Ferrous Metallurgy. In: J. Needham (Hrsg.), Science and Civilisation in China 5. Chemistry and Chemical Technology 11, Ferrous Metallurgy (Cambridge 2008).

Walach et al. 2017: G. Walach/R. Scholger/B. Cech, Geomagnetic and Geoelectric Prospection on a Roman Iron Production Facility in Hüttenberg, Austria (Ferrum Noricum). Archaeological Prospection 18, 2011, 149-158

Weidmann 1991: T.Weidmann, Metallverarbeitende Werkstätten. In: I. Bauer et al., Üetliberg, Uto-Kulm. Ausgrabungen 1980-1989. Berichte der Zürcher Denkmalpflege. Archäologische Monographien 9 (Zürich 1991) 232-251.

Westphalen 2004: P.Westphalen, Das Grobschmiedehandwerk in Haithabu. In: W. Melzer (Hrsg.), Schmiedehandwerk in Mittelalter und Neuzeit. Beiträge des 6. Kolloquiums des Arbeitskreises ar- 
chäologische Erforschung des mittelalterlichen Handwerks. Soester Beiträge zur Archäologie 5 (Soest 2004) 25-32.

Williams 2012: A. R. Williams, The Sword and the Crucible. A History of the Metallurgy of European Swords up to the 16th Century. History of Warfare 77 (Leiden / Boston 2012).

Winkler 1969: G. Winkler, Die Reichsbeamten von Noricum und ihr Personal bis zum Ende der römischen Herrschaft. Österreichische Akademie der Wissenschaften, Phil.-hist. Klasse, Sitzungsberichte 261/2 (Wien 1969).

Woodward 1795: William Wallis Woodward, One Thousand valuable Secrets, in the elegant and useful Arts, Collected from the Practice of the best Artists, and containing an Account of the Various Methods... (Philadelphia 1795).

Woytek 2004: B. Woytek, Die Metalla-Prägungen des Kaisers Traian und seiner Nachfolger. Numismatische Zeitschrift 111/112, 2004, 35-68 (sowie Nachtrag: B. Woytek, Die Metalla-Prägungen des Kaisers Traian und seiner Nachfolger: Supplementum. Mitteilungen der Österreichischen Numismatischen Gesellschaft 44/4, 2004, 134-139.)

Wrona 2013: A. Wrona, The Production of High Carbon Steel Directly in Bloomery Process: Theoretical Bases and Metallographic Analyses of the Experiments Results. EXARC Journal 2013/2.

Yalçın 1999: Ü. Yalçın, Early iron metallurgy in Anatolia. Anatolian Studies 48, 1998 (1999), 177-187.

Zagórska-Telega/Bochnak 2001: J.Zagórska-Telega/T. Bochnak, Ein Depot mit frühmittelalterlichen axtförmigen Eisenbarren aus Kostowice, Fst. 2, Gde. Kroczyce, Woiw. Ślaskie. Acta Archaeologica Carpathica 36, 2001, 39-47.

Zaitz 1988: E.Zaitz, Frühmittelalterliche axtförmige Eisenbarren aus Kleinpolen. Slovenská archeológia 36/2, 1988, 261-275.

Zwicker 1967: U.Zwicker, Untersuchungen an einem Eisenbarren aus dem Depotfund von Renningen (Kr. Leonberg). Fundberichte aus Schwaben N.F. 18, 1967, 282-283.

Zwicker 1996: U.Zwicker, Ein Werkzeugstahl des Saturninus. Bayerische Vorgeschichtsblätter 61, 1996, 245-246.

\section{Abbildungsnachweis}

Abb. 1: $\quad$ Nach Jahn 1861, Taf. 9,9.

Abb.2: $\quad$ Nach Feuerbach 2002, Map 7 und Fig. 26.

Abb. 3: $\quad$ Nach Craddock 1998, Abb. 9 und 10.

Abb. 4: Nach Mäder 2003, Abb. 45.

Abb. 5: Nach Kleemann 1966, Abb. 3.

Abb. 6: Nach Kleinschmidt 1944, Abb. 302.

Abb. 7: Nach Zwicker 1996, Taf. 8,2.

Abb. 8: 1-2 Privatsammlung; 3-4 nach Sachse 1989, Seite 6 und Abb. 110.

Abb. 9: Nach Fischer 1990.

Abb. 10: Nach Glaser 1995, Abb. 2 .

Abb.11: Nach Glaser 1995, Abb. 1.

Abb. 12: Nach Glaser 2000, Abb. 7.

Abb.13: Nach Brearley 1914, Abb. 1.

Abb. 14: Nach Kostoglou 2008, Abb. 30.

Abb. 15: Nach Berranger/Fluzin 2007, Abb. 5.

Abb. 16: Nach Berranger et al. 2014, Abb.9.

Abb. 17: Fotos und Copyright Historic England Archive, Swindon / GB, 30.01.2019 (siehe auch http: / / www. english-heritage.org.uk/visit / places / derwentcote-steelfurnace/ history / (19.05.2018).

Abb. 18: Nach Schiefer/Grün 1927, Abb. 156 und 157.

Abb. 19: Nach http://www.nabertherm.de/produkte/ thermprozesstechnik/1-schutzgassysteme/Large/ Gluehkasten_fmt.jpg (09.11.2016). Der Hinweis wird Hansjörg Kilchenmann, Messerschmied in Basel, verdankt.

Abb.20: Nach Stephens 1884, Abb. S. 145.

Abb.21: Nach Kuppuram 1989, Abb. P. 329 (in Anlehnung an Buchanan 1807).

Abb.22: 1 nach Alipour / Rehren 2014, Abb. 11; 2 nach Feuerbach et al. 2003, Abb. 17.6; 3 und 4 nach Rehren / Papachristou 2003, Abb. 3 und 2; 5 nach Craddock 2003, Abb. 16,11.22; 6 nach Kuppuram 1989, Abb. S. 331 (nach K. N.P. Rao); 7 und 11 nach Juleff 2015, Abb. 2 und 10; 8-10 nach Rehren / Papachristou 2003, Abb. 4-6.

Abb.23: Nach Srinivasan 2017, Abb. 1.

Abb.24: Umzeichnungen nach CIL III und Alföldy 1969, Nr. 33 Abb. 4.

Abb. 25: Nach Brusin 1991, Kat.-Nr. 703.

Abb. 26: 1 nach RIC II, Taf. 16,330; 2-4 nach BMCRE III, Taf. 98,3-5; 5 nach Dembski 1983, Abb. 4.

Abb.27: Zusammenstellung und Kartierung Alex R. Furger (nach Anm. 276-278). Kartengrundlage: «Noricum \& Pannonia in the Fifth Century» von 1895 (nach T. Hodgkin).

Abb.28: Nach Cech 2008B, Abb. Seite 8 (ausführlich: Cech 2012, 90 f. Abb. 13-14).

Abb.29: Reproduziert nach den in Anm. 312-323 zitierten Quellen.

Abb.30: Nach Comenius 1842, Taf. 315

Abb.31: Links nach Biborski et al. 1982, Abb. 7.a; rechts nach Presslinger 2007, Abb. 3.

Abb.32: 1-4 nach Cabboi et al. 2007, Abb. 5; 5 nach Doswald 1994B, Abb. 205; 6 nach Gömöri 2000, Abb. 112,3; 7 nach Merluzzo et al. 2014, Abb. 6; 8 nach Paynter 2007, Abb. 14; 9 nach Berranger et al. 2017, Abb. 4-5; 10 nach Epprecht/Schaller 1986, Abb. S. 188.

Abb. 33: 1.2 nach Pleiner / Bjorkman 1974, Abb. 8,1.5; 3 nach Fedele 2016, Abb. 3; 4 nach Briard 1976, Abb. 2,2; 5 nach Kolling 1993, Taf. 64, oben; 6 nach Delamare et al. 1982, Abb. 1 7.9.14.18 nach Müller 1990, Taf.27-29; 8.13.19.20 nach Jacobi 1974, Taf. 76-77; 10.11 nach Pagès 2014, Abb. 8; 12.16 nach Fluzin et al. 2012B, Abb. 99,d.e; 15 nach Berranger et 
al. 2014, Taf.13_Ca74; 17 nach Fluzin et al. 2012A, Abb. 5; 21 nach Ehrenreich 1985, Abb. 2,7; 22 nach Fell 2003, Abb. 22-1, links; 23 nach Pagès 2014, Abb. 7,2; 24 nach Mutz 1976, Abb. 19; 25 nach Müller 1985, Abb. 15,3; 26 nach Gaitzsch 1978, Abb. 14; 27-32 nach Coustures et al. 2006, Abb. 4; 33 nach Gömöri 1988, Abb. 8.2,b (= Gömöri 2000, Abb. 43); 34.44 nach Pleiner 2006, Abb. 17,6.10; 35.38.45 nach Durman 2002, Abb. 7,1-3; 36 nach Durman 2002, Abb. 3,17; 37 nach Durman 2002, Abb. 6,2; 39.40 nach Ulbert 1984, Taf. 29,264.265; 41-43 nach Solier 1981, Abb. 81; 46 nach Hochuli-Gysel et al. 1986, Taf. 60,16; 47 nach Schaltenbrand Obrecht 1996, Taf. 69,1170; 48 nach Senn Bischofberger 2005, 128f. Kat.-Nr. 15; 49.50 nach Pleiner 2006, Abb. 18,1.2; 51 nach Pleiner 2006, Abb. 19,7; 52 nach Pleiner 2006, Abb.18,4; 53.54.61 nach Lindeberg 2010, Abb. 4,1-3; 55-58.62.65-68 nach Zaitz 1988, Abb. 1-8; 59.60 nach Dostál 1983, Abb. 3,3.5; 63.64 nach Dostál 1983, Abb. 4,3.4; 67 nach Pleiner 2006, Abb. 20,5; 69 nach Ohlhaver 1939, Abb. 2; 70.71.73.74.75.76.77.78.79.84.86.87 nach Westphalen 2002, Taf.33-39; 72 nach Pleiner 2006,

Abb. 19,19; 80-83 nach Hallinder / Tomtlund 1978, Abb. 2-3; 85 nach Pleiner 2006, Abb. 21,1; 88 nach Friedland 2013, Abb. 24,1; 89 nach Pleiner 2006, Abb. 18,5.

Abb.34: Foto Friederike und Ortolf Harl, freigestellt von Ursi Schild (Museum Augusta Raurica, Inv. 1894.477).

Abb. 35: Nach Fantar 1994, Farbtafel Seiten 115-118.

Abb. 36: Nach Bofinger/Schmid 2012, Abb. 3 resp. Umschlagbild.

Abb.37: Nach Berranger et al. 2017A, Abb.4-6.

Abb.38: Nach France-Lanord 1963, Abb. 3, 4 und 9; Montage Alex R. Furger.

Abb. 39: Nach Delmare et al. 1982, Abb.2-4.

Abb. 40: Nach Berranger / Fluzin 2012, Abb. 8.

$A b b .41$ : Nach Fluzin et al. 2012A, Abb. 5.

Abb. 42: 1: nach Orengo 2003, Taf. 36,10; 2-8: nach Doswald 1994B, Abb. 212m, E439.e441-445.e449; 9-13 nach Schäfer 2002, Abb. 13,2-8.

Abb. 43: Nach Berranger / Fluzin 2012, Abb. 9.

$A b b .44$ : Nach Pagès 2014, Abb. 10; Objektzeichungen nach Coustures et al. 2006, Abb. 4

Abb. 45: Nach Pagès et al. 2011A, Abb. 2,4C.5C.6C; 4; 9 .

Abb. 46: Nach Pagès et al. 2011A, Abb.2,1L.1M.2M.4L.

Abb. 47: Nach Lang 2017, Abb. 4.

Abb. 48: Nach den in Anm. 481-496 genannten Quellen.

Abb. 49: Nach Berranger / Fluzin 2012, Abb. 2 und 7 (Umgestaltung Alex R. Furger).

Abb. 50: Zeichnungen Felicitas Prescher; Fotos und Montage Alex R. Furger.

Abb. 51: Fotos Alex R. Furger; Computer-Tomographie von Kat.-Nr. 20* Paul Scherrer Institut, Villingen/CH, David Mannes.

Abb. 52: Nachbrände und Fotos Alex R. Furger.

Abb. 53: Nach Hänggi 1989, 51 Abb. 32.

Abb. 54: 1978.8859: Fotos und Röntgenaufnahme Ronald Simke; 1983.31146: Fotos Alex R. Furger.

Abb. 55: Plangrundlage Ausgrabungen Augst / Kaiseraugst; Kartierung Alex R. Furger.

Abb. 56: Fotos Ausgrabungen Augst / Kaiseraugst (Grabung 1983.052, Fotos 232, 230, 226, 236), Entzerrung und Layout Alex R. Furger.

Abb. 57; 58: Aufnahmen Alex R. Furger (siehe Anm. 532).

Abb. 59: Nach Monumenti inediti 11 (Rom 1879-1883) Taf. 29, unten, resp. Conophagos / Papadimitriou 1986, Abb. 11.

Abb.60: Nach Hannah 1932, Abb.1.

Abb. 61: Schmiedearbeit und Foto Alex R. Furger.

Abb. 62-69; 82-109 und 116-120: Mikroskopaufnahmen Alex R. Furger, unter Anleitung von Christine Pümpin (s. Anm.563).
Abb. 64; 67; 70; 85; 88; 96; 100; 106; 110; 118; 121: Probenaufbereitung Alex R. Furger; Härtemessungen und Analysen Rudolf Kubiz (Georg Fischer AG, Schaffhausen); Grafik Dieter Denger (Basel).

Abb.71: Fotos Alex R. Furger.

Abb. 72: Foto Alex R. Furger.

Abb. 73: Ofenbau Johannes Weiss; Foto Alex R. Furger.

Abb. 74: Fotos Alex R. Furger.

Abb.75: Temperaturmessung mit Chromel-/Alumel-Thermolement, platziert im Zentrum des zylindrischen Brennraums (Abb. 74: Rohr links). Feldprotokoll und Messungen Hannes Weiss und Alex R. Furger.

Abb. 76: Fotos und Montage Alex R. Furger.

$A b b .77:$ Fotos Alex R. Furger.

Abb. 78: Präparation und Foto Alex. R. Furger.

Abb. 79: Fotos Alex R. Furger.

Abb. 80: Foto Alex R. Furger.

Abb. 81: Foto und Zeichnung Alex R. Furger.

Abb. 111: Fotos Alex R. Furger.

Abb. 112: Fotos Alex R. Furger.

$A b b .113:$ Präparation und Foto Alex. R. Furger.

$A b b$. 114: Foto Alex R. Furger.

$A b b$. 115: Fotos Alex R. Furger.

$A b b .122$ : Fotos Alex R. Furger. 
Die römische Stadt Augusta Raurica bei Basel erbrachte u. a. zahlreiche archäologische Zeugnisse der frühen Metallverarbeitung, insbesondere Grabungsbefunde von Bronzegiesserwerkstätten und Hunderte von mobilen Zeugnissen ihrer Tätigkeit: Fehlgüsse, Halbfabrikate, Schmelztiegel, Gussformen usw. Die 893 Schmelztiegel bilden den bisher umfangreichsten archäologischen Fundbestand im antiken Europa. Ihnen ist die aktuelle archäologische und naturwissenschaftliche Studie gewidmet. Es handelt sich hierbei um eine einzigartige Untersuchung mit einem originellen und innovativen Forschungsansatz. Sie bildet eine wichtige Grundlage für weitere wirtschaftsgeschichtliche, archäologische und archäometrische Untersuchungen sowie für die Experimentelle Archäologie und ist so verständlich geschrieben, dass sie auch für ein nicht-naturwissenschaftliches Publikum geeignet ist.

Die vielseitigen, interdisziplinären Untersuchungen verfolgen zwei Schwerpunkte: Einerseits werden die römischen Schmelztiegel von Augusta Raurica archäologisch dokumentiert und bezüglich der Tonherkunft sowie der Metallspuren erfolgreich analysiert. Andererseits werden mit Experimenteller Archäologie neue Wege beschritten, indem das Töpfern von Tiegeln, die Herstellung der äusseren Verschleissschicht «Lutum», das Zementieren von Messing sowie weitere Phänomene der TiegelMetallurgie erprobt und rekonstruiert werden.
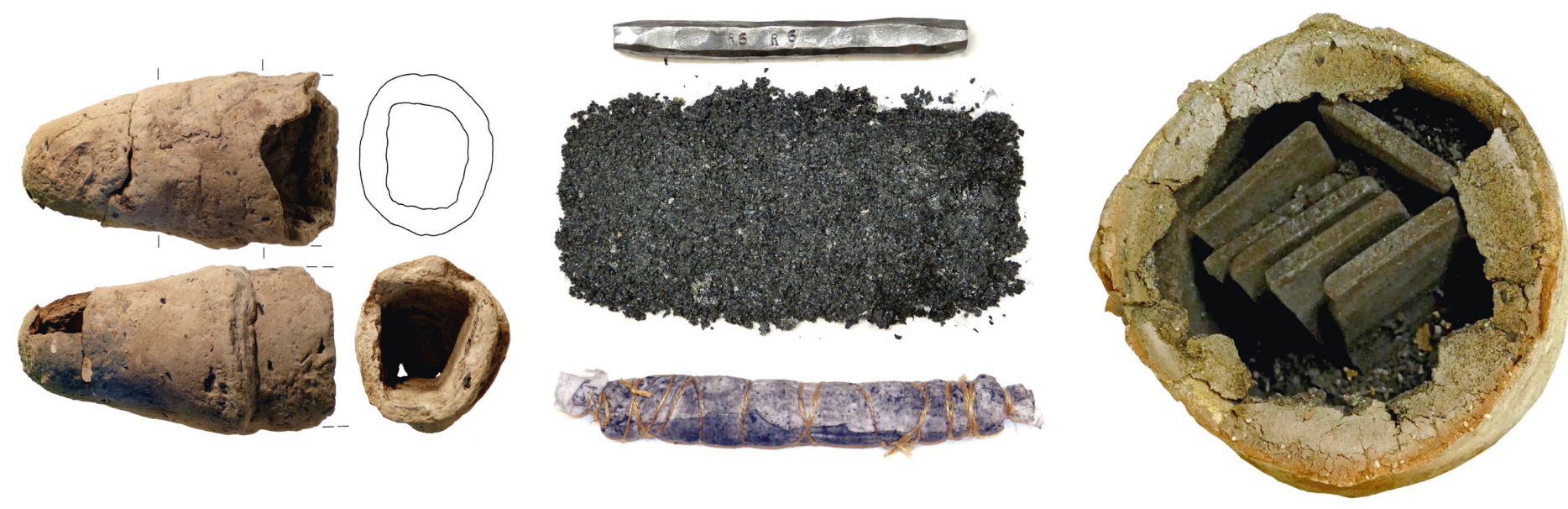